\title{
An Analysis of the Results of Federal Incentives Used to Stimulate Energy Production
}

June 1980

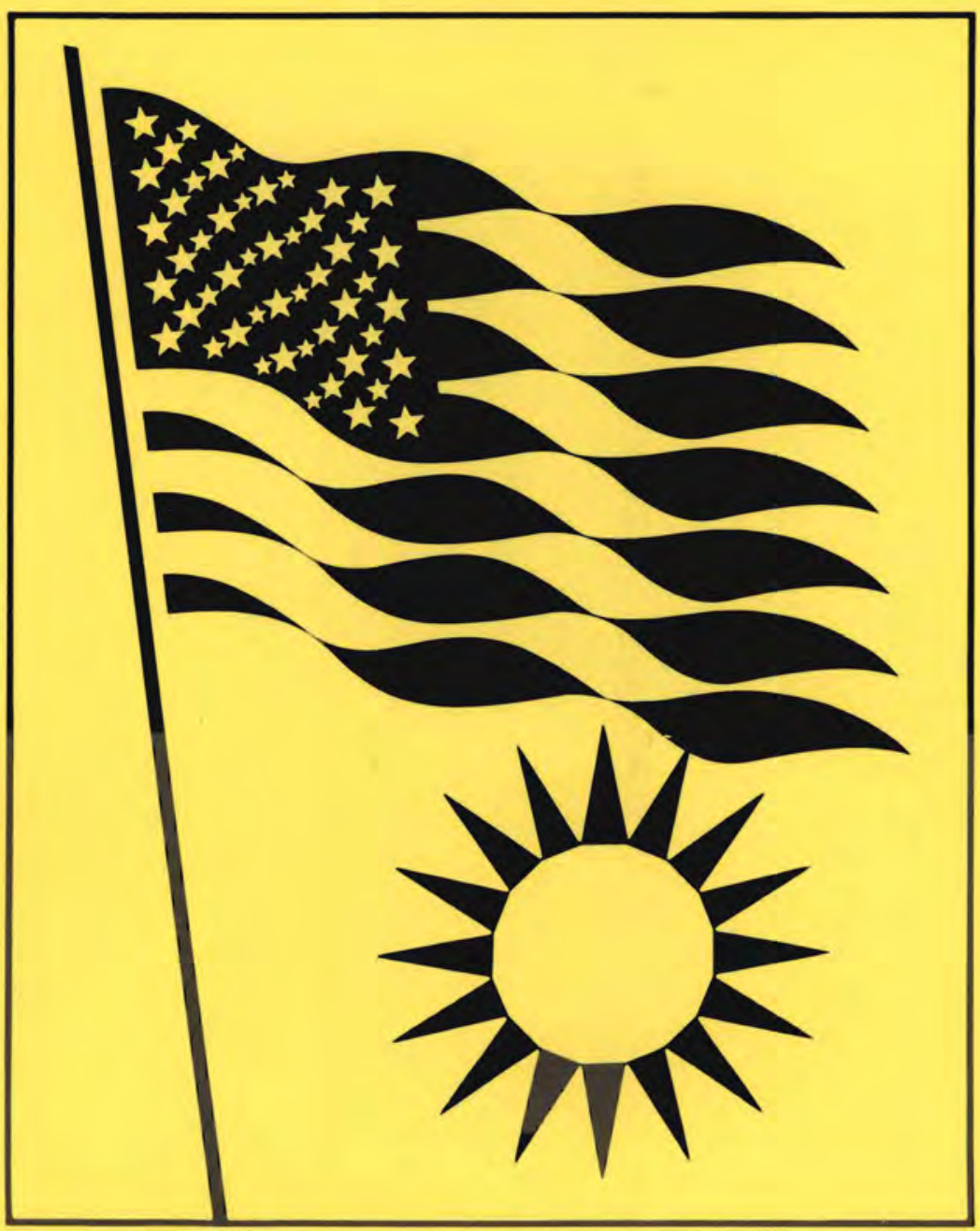

Prepared for the U.S. Department of Energy Under Contract DE-AC06-76RLO 1830

Pacific Northwest Laboratory Operated for the U.S. Department of Energy by Battelle Memorial Institute 


\title{
NOTICE
}

This report was prepared as an account of work sponsored by the United States Government. Neither the United States nor the Department of Energy, nor any of their employees, nor any of their contractors, subcontractors, or their employees, makes any warranty, express or implied, or assumes any legal liability or responsibility for the accuracy. completeness or usefulness of any information, apparatus, product or process disclosed, or represents that its use would not infringe privately owned rights.

The views, opinions and conclusions contained in this report are those of the contractor and do not necessarily represent those of the United States Government or the United States Department of Energy.

\author{
PACIFIC NORTHWEST LABORATORY \\ operated by \\ BATTELLE \\ for the \\ UNITED STATES DEPARTMENT OF ENERGY \\ Under Contract DE-AC06-76RLO 1830
}
Printed in the United States of America
Available from
National Technical Information Service
United States Department of Commerce
5285 Port Royal Road
Springfield, Virginia 22151

Price: Printed Copy \$

$\because$ Microfiche $\$ 3.00$

\begin{tabular}{cr} 
•Pages & \multicolumn{1}{c}{$\begin{array}{c}\text { NTIS } \\
\text { Selling Price }\end{array}$} \\
$001-025$ & $\$ 4.00$ \\
$026-050$ & $\$ 4.50$ \\
$051-075$ & $\$ 5.25$ \\
$076-100$ & $\$ 6.00$ \\
$101-125$ & $\$ 6.50$ \\
$126-150$ & $\$ 7.25$ \\
$151-175$ & $\$ 8.00$ \\
$176-200$ & $\$ 9.00$ \\
$201-225$ & $\$ 9.25$ \\
$226-250$ & $\$ 9.50$ \\
$251-275$ & $\$ 10.75$ \\
$276-300$ & $\$ 11.00$
\end{tabular}


Pacific Northwest Laboratory

B. W. Cone

H. Harty

J. C. Emery

P. D. Cohn

A. G. Fassbender

R. P. Mazzucchi

Battelle Memorial Institute - Columbus, Ohio
W. J. Sheppard
D. E. Lenerz

Human Affairs Research Center - Seattle, WA.

R. J. Cole

J. H. Maxwe 11

P. E. Sommers

A. R. Maurizi

A. A. Marcus

Cox, Langford \& Brown - Washington, D.C.

J. N. Nassikas

June 1980

Prepared for

the U.S. Department of Energy

under Contract DE-AC06-76RL0 1830

Pacific Northwest Laboratory

Richland, Washington 99352 


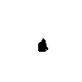

$\bullet$

$\checkmark$ 


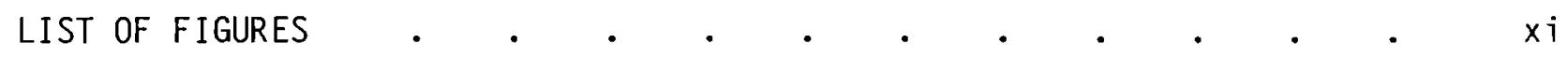

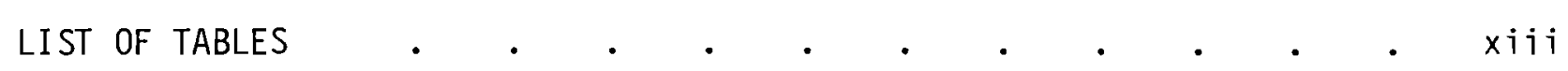

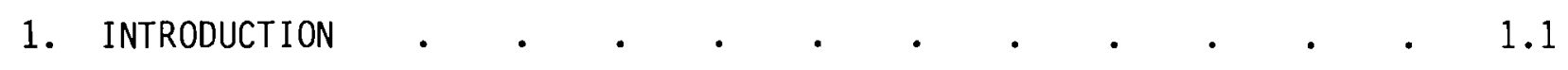

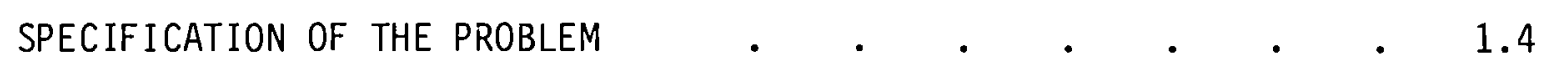

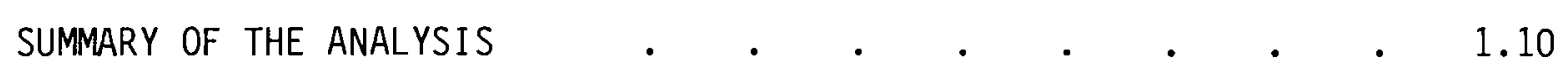

2. A THEORETICAL POLICY ANALYSIS APPROACH TO EFFECTS ESTIMATION $\quad 2.1$

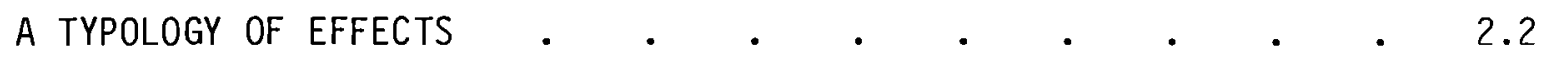

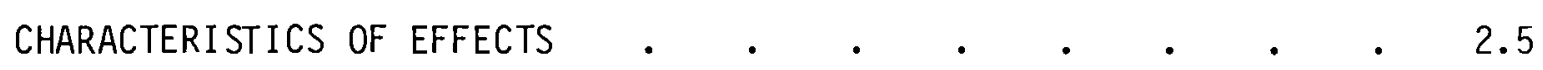

METHODS FOR ESTIMATING EFFECTS $\quad$ •

Estimation by the Inspection Method . . . . . 2.6

Estimation by the Engineering Approach . • • • . 2.8

Estimation by the Analogy Approach $\quad$. $\quad$. 2.9

Estimation by the Modeling Approach . . . . 2.10

Estimation by the Quantified Expert-Opinion Approach . . 2.26

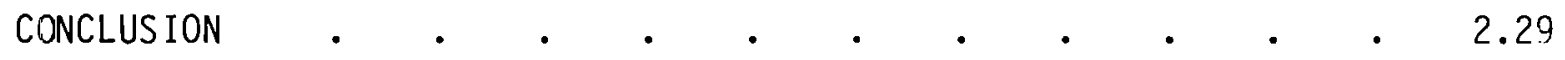

3. GENERIC ANALYSIS OF THE RESULTS OF INCENTIVES $\quad$ • $\quad$ • $\quad$ • $\quad 3.1$

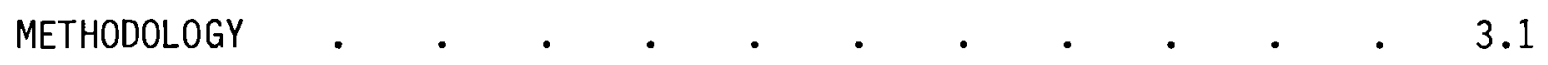

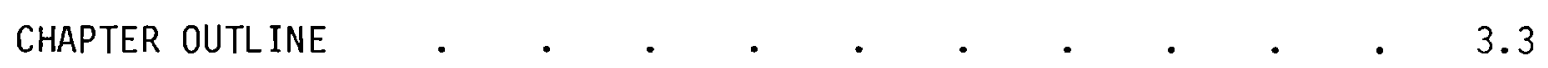

THEORETICAL DISCUSSION

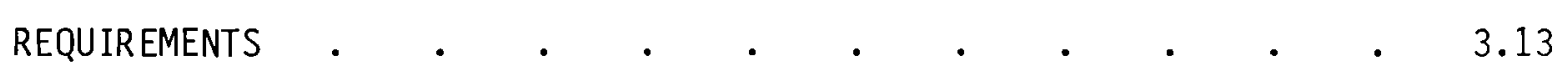

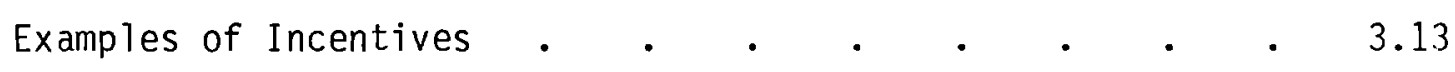

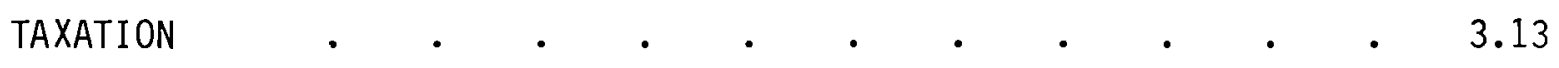

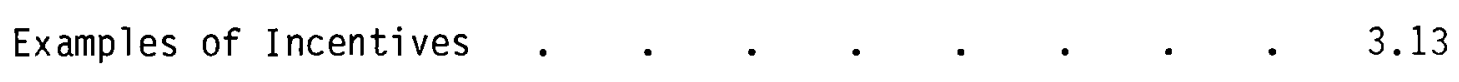

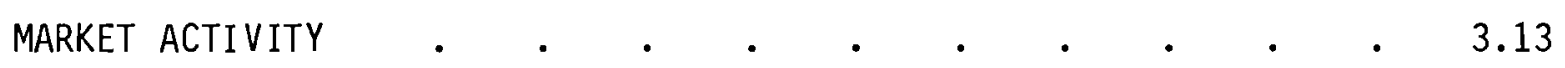

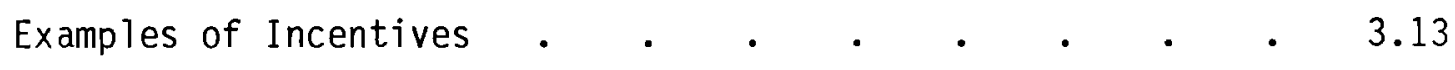




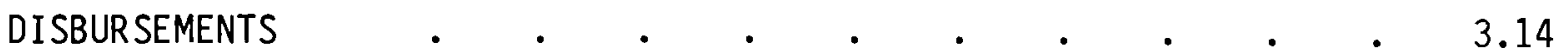

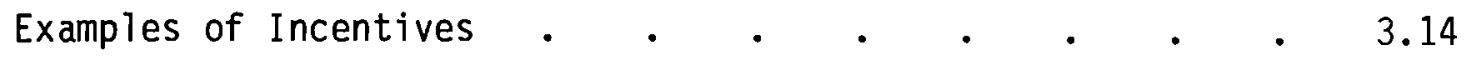

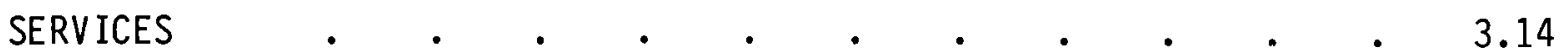

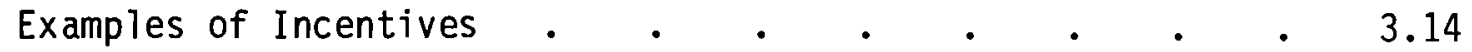

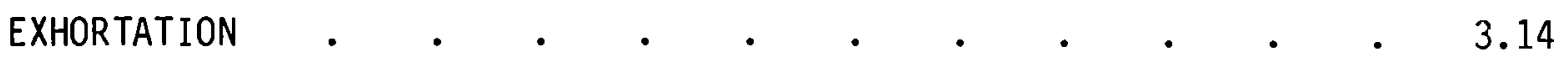

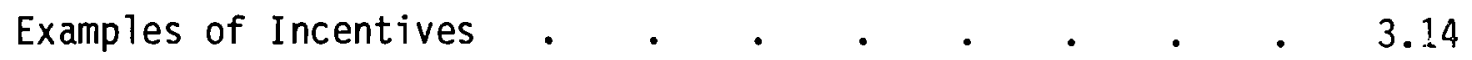

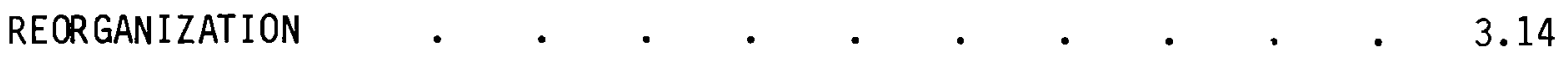

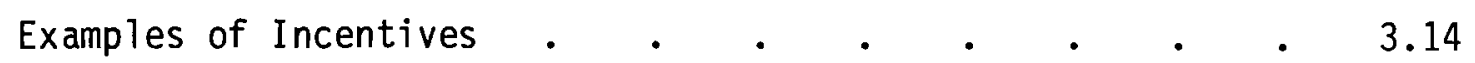

RESULTS OTHER THAN THE QUANTITY AND PRICE OF ENERGY • • • • 3.15

CONCLUSIONS ABOUT THE CHARACTERISTICS OF INCENTIVES $\quad$ • $\quad 3.20$

Size of Energy Results . . . . . . . . . 3.22

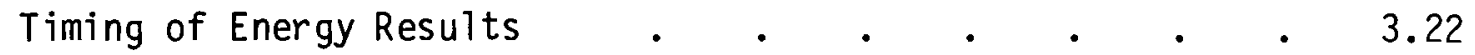

Predictability of Energy Results . . . . . . . 3.23

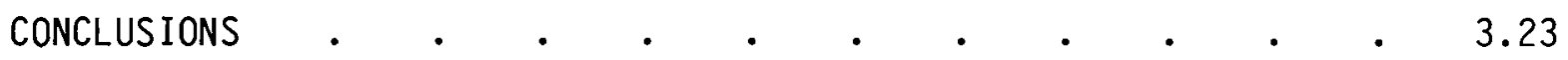

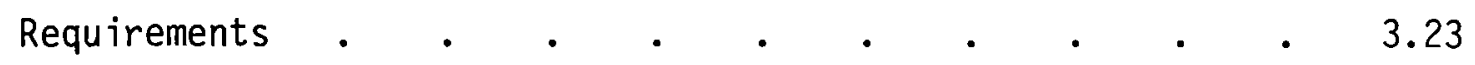

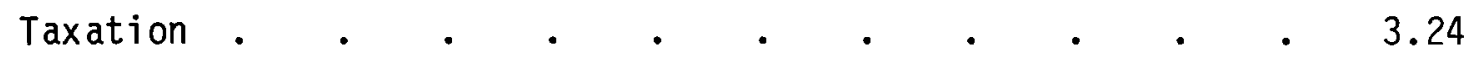

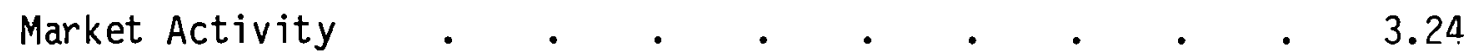

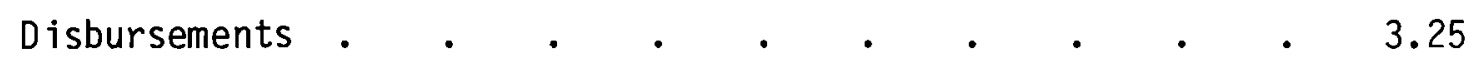

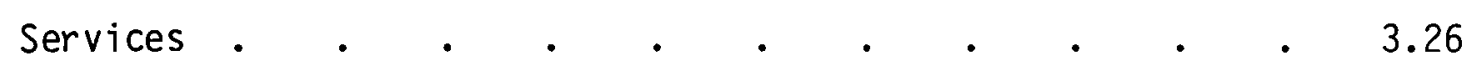

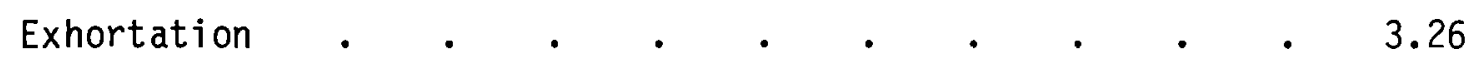

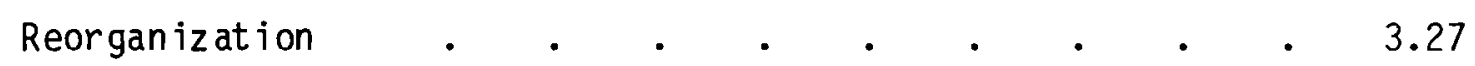

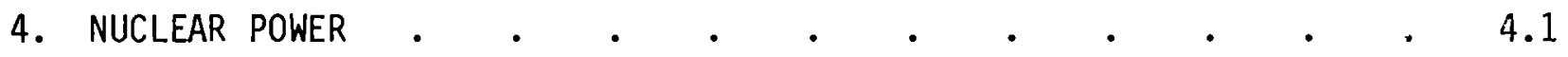

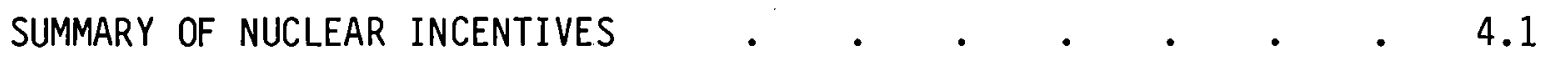

NUCLEAR ENERGY PRODUCTION AND FEDERAL INCENTIVES • • • • • 4.2

NUCLEAR ENERGY PRODUCTION COSTS AND FEDERAL INCENTIVES • • • 4.5 
EVALUATING THE EFFECTS OF FEDERAL INCENTIVES

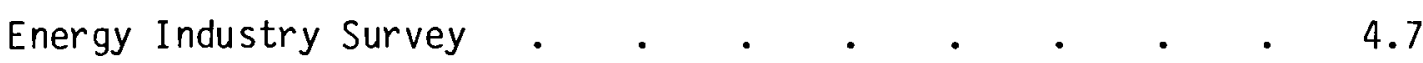

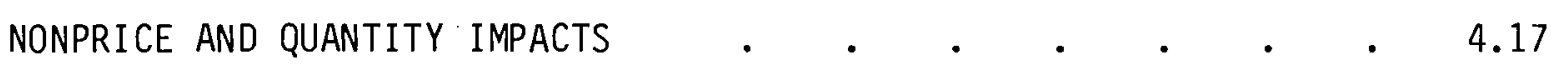

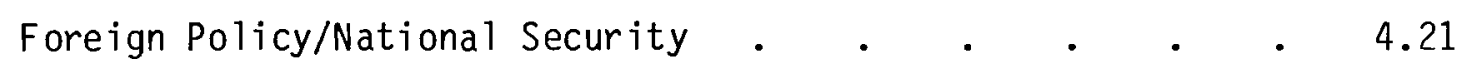

THE IMPACT OF FEDERAL INCENTIVES ON THE PRICE AND OUTPUT OF

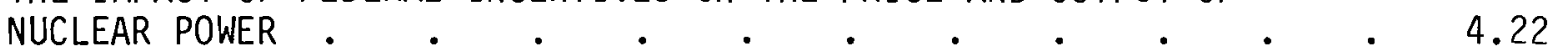

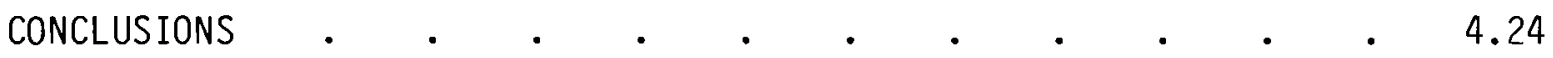

RECOMMENDATIONS FOR SOLAR POLICY • • . . . . . . . 4.26

5. HYDROELECTRICITY $. \quad . \quad$.

INTRODUCTION

FEDERAL INVOLVEMENT IN HYDROELECTRIC PRODUCTION.$\quad \cdot \quad \cdot \quad \cdot 5.2$

Army Corps of Engineers . • . . . . . . 5.4

Bureau of Reclamation . . . . . . . . . . 5.6

The Tennessee Valley Authority (TVA) • $\quad$. $\quad$ • 5.7

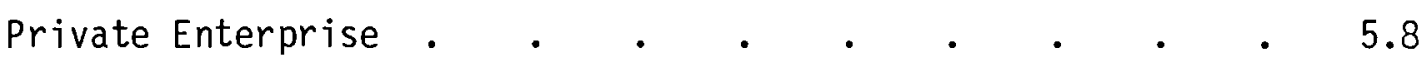

Municipa1, State, District, and Cooperative Systems . $\quad 5.9$

Bonneville Power Administration . $\quad$. $\quad$. $\quad$. 5.9

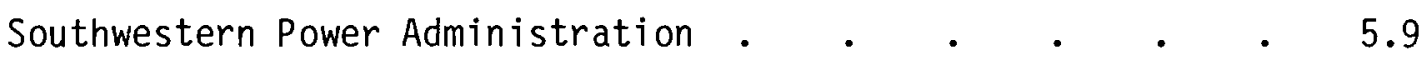

Southeastern Power Administration . . . . . 5.10

The Western Area Power Administration . . . . 5.10

Alaska Power Administration . . . . . . . 5.10

Federal Energy Regulatory Commission . . . . . 5.10

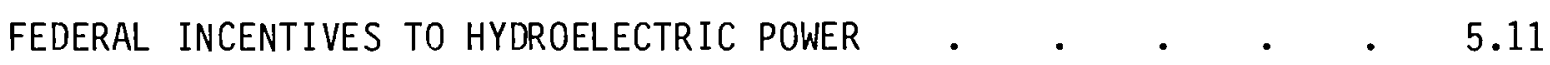

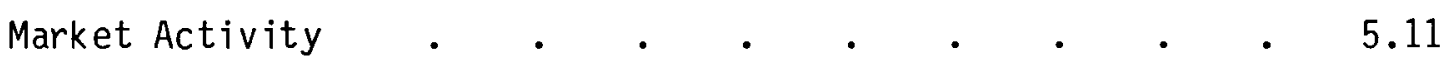

Requirements . . $. \quad . \quad$. . . . . 5.15

Taxation . . . . . . . . . . . . . 5.15 
HYDROELECTRICITY PRODUCTION AND FEDERAL INCENTIVES • • $\quad$ • 5.16

HYDROELECTRICITY PRICE AND FEDERAL INCENTIVES $\quad$ • . • • 5.21

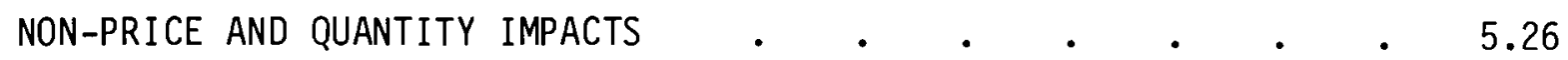

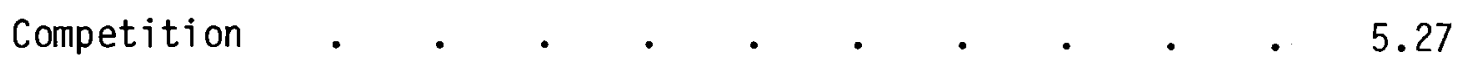

Sectoral Impacts . . . . . . . . . 5.28

Sectoral Subsidies . . . . . . . . . 5.31

Capital Formation . . . . . . . . . 5.33

Employment/Productivity . . . . . . . . . 5.33

Balance of Payments . . . . . . . . . 5.34

Public/Private Relations . . . . . . . 5.34

Regulatory Burden . . . . . . . . . 5.34

Quality of Life . . . . . . . . . . 5.35

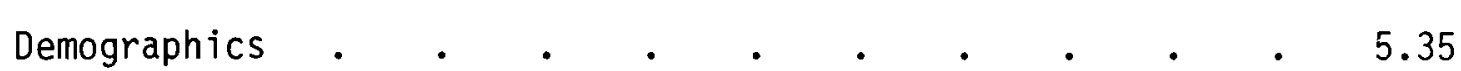

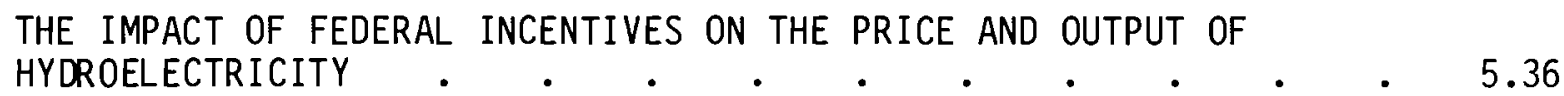

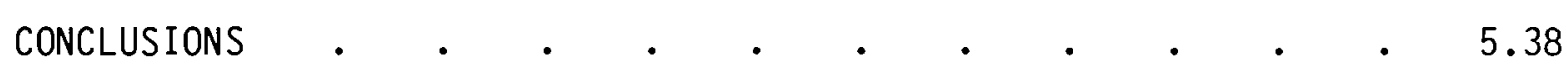

RECOMMENDATIONS FOR SOLAR POLICY . . . . . . . . . 5.39

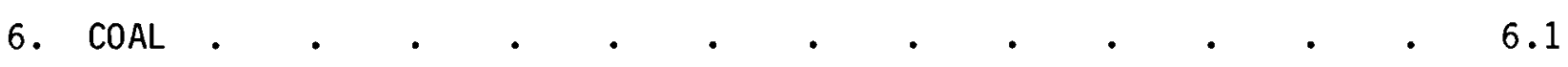

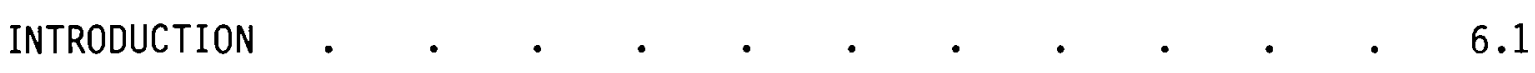

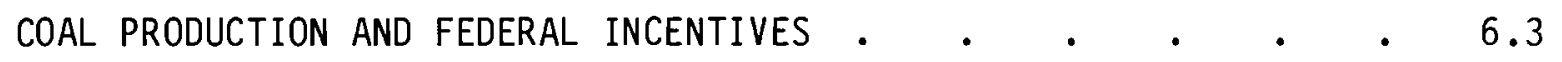

COAL PRICE AND FEDERAL INCENTIVES • • • • • • • • $\quad . \quad 6.7$

EVALUATING THE EFFECTS OF FEDERAL INCENTIVES $• . \quad \cdot \quad \cdot 6.10$

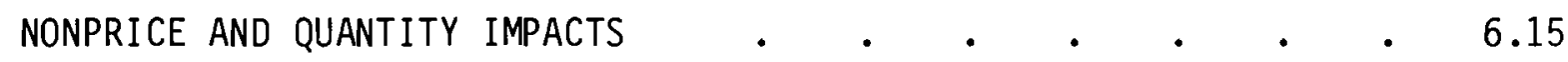

Competition . . . . . . . . . . . 6.15

Balance of Payments $. \quad . \quad . \quad . \quad . \quad . \quad 6.16$

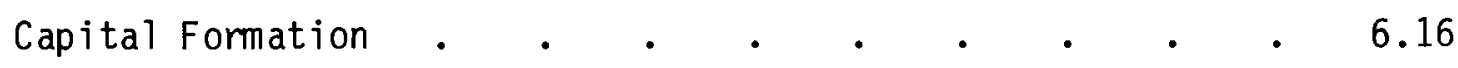




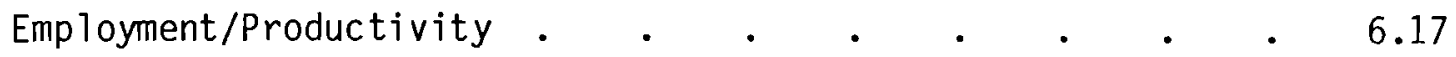

Income Class $\quad . \quad+\quad . \quad . \quad . \quad . \quad . \quad . \quad . \quad .6 .18$

Regulatory Burden . $\quad$ • . . . . . . . . 6.18

Quality of Life . $\quad . \quad \ldots \quad . \quad . \quad . \quad . \quad 6.18$

THE IMPACT OF FEDERAL INCENTIVES ON THE PRICE AND OUTPUT OF COAL $\quad 6.19$

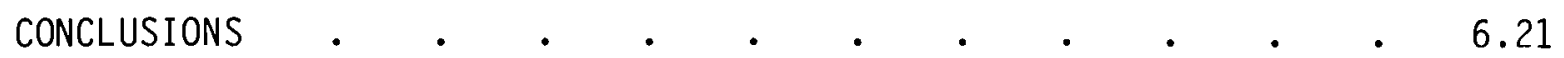

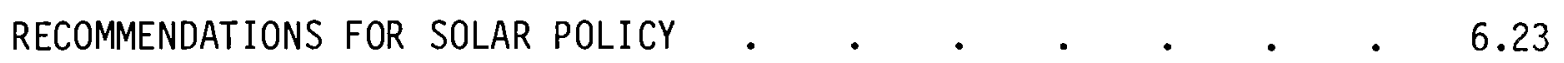

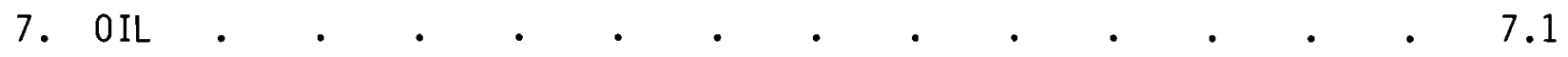

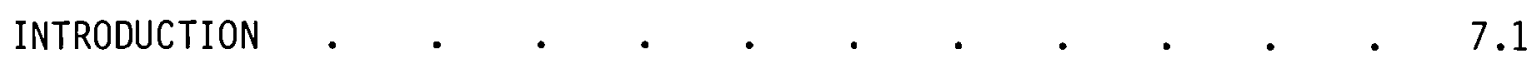

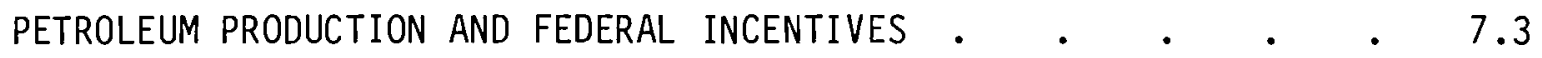

PETROLEUM PRICE AND FEDERAL INCENTIVES • • • • • • • • • 7.6

EVALUATING THE EFFECTS OF FEDERAL INCENTIVES $\quad \cdot \quad \cdot \quad \cdot \quad \cdot \quad 7.8$

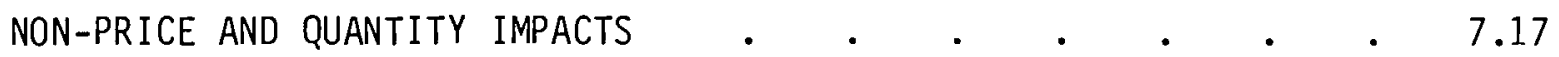

Competition $\quad . \quad$. $\quad . \quad$. $\quad$. $\quad$. 7.18

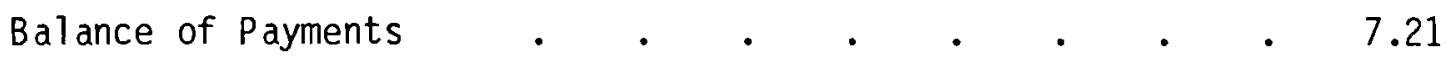

Capital Formation . $\quad$. $\quad$. $\quad$. $\quad$. 7.22

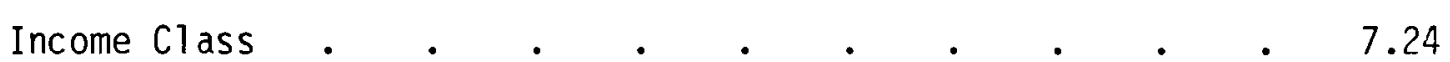

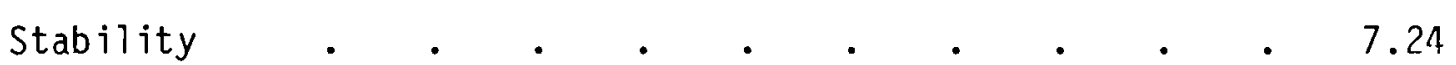

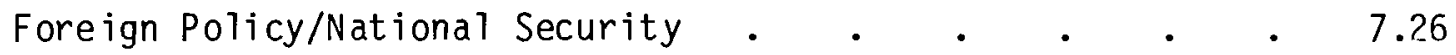

State/Federal Relations . . . . . . . . . 7.27

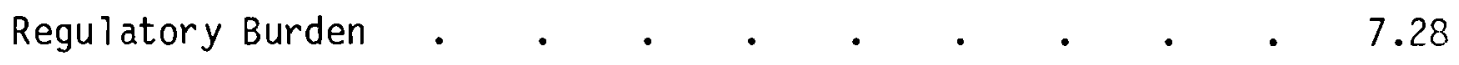

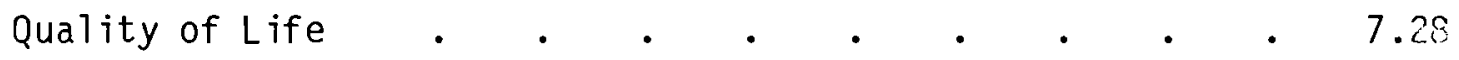

IMPACT OF FEDERAL INCENTIVES ON THE PRICE AND OUTPUT OF OIL $\quad 7.29$

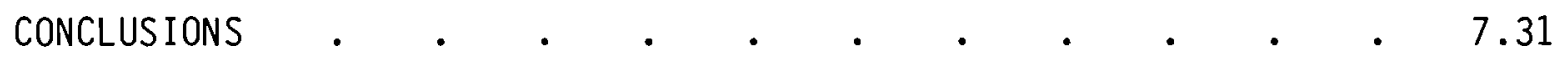

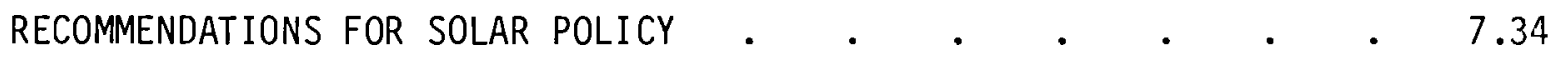




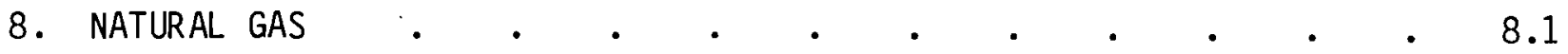

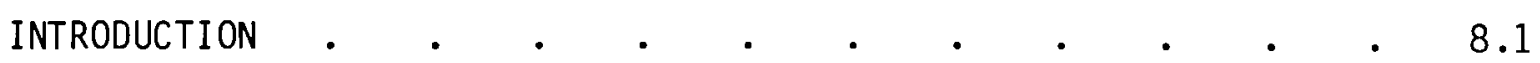

NATURAL GAS PRODUCTION AND FEDERAL INCENTIVES $\quad . \quad \ldots \quad$ e $\quad . \quad 8.3$

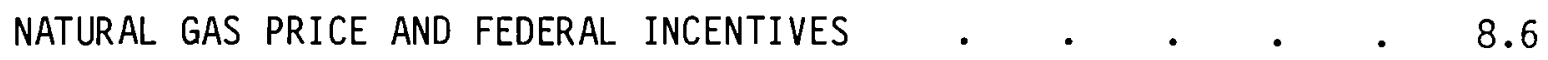

EVALUATING THE EFFECTS OF FEDERAL INCENTIVES $\quad$ • $\quad$ • $\quad$ • 8.12

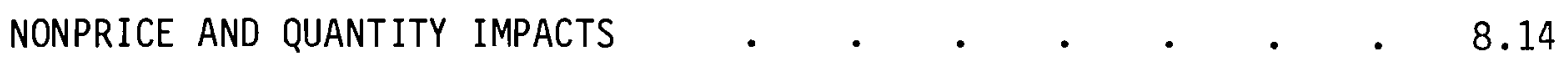

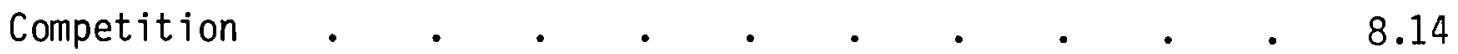

Balance of Payments $\quad$. $\quad . \quad$. $\quad$. $\quad$. 8.15

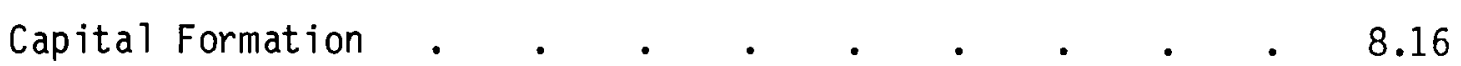

Sectoral Impacts . . . . . . . . . . . 8.16

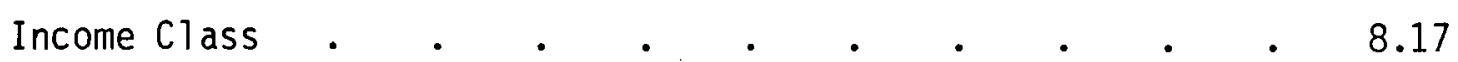

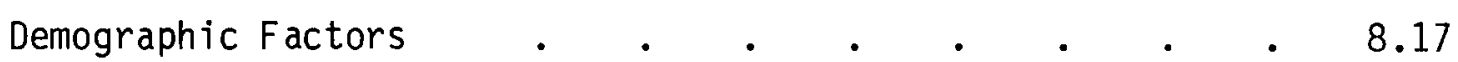

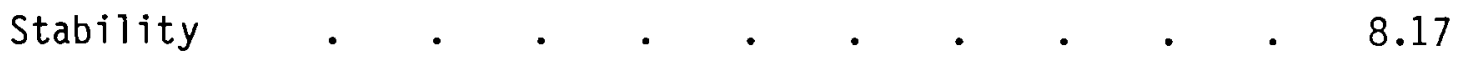

Foreign Policy/National Security $\quad$. $\quad$. $\quad$. $\quad$. 8.18

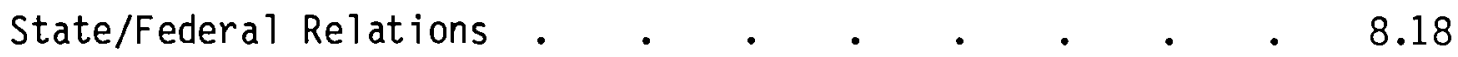

Regulatory Burden . $\quad . \quad$. $\quad . \quad$. $\quad . \quad$. 8.18

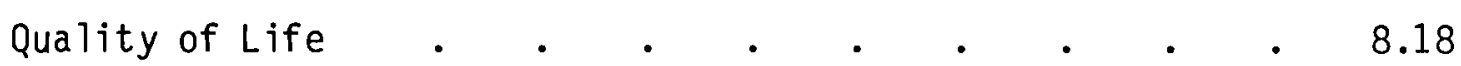

THE IMPACT OF FEDERAL INCENTIVES ON THE PRICE AND OUTPUT OF

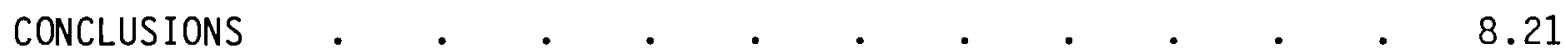

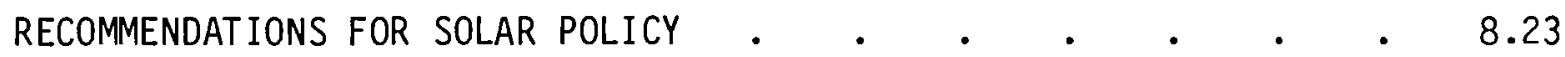

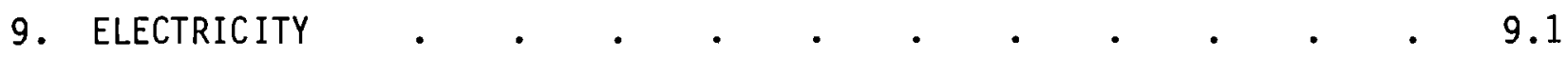

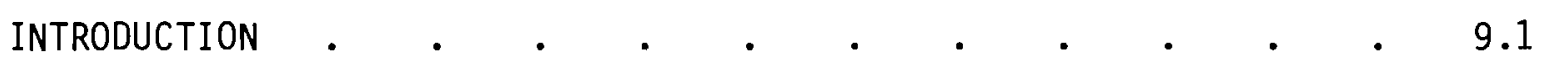

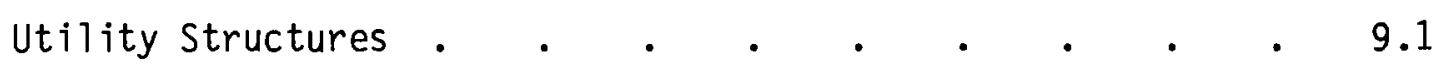

FEDERAL INCENTIVES TO ELECTRICITY PRODUCTION $\quad . \quad \cdots \quad . \quad \cdot \quad 9.2$ 
ELECTRICITY PRODUCTION AND FEDERAL INCENTIVES $\quad$ • $\quad$ • $\quad$ • $\quad 9.10$

ELECTRICITY PRICE AND FEDERAL INCENTIVES $\quad . \quad$ • $\quad . \quad$ • $\quad$ • 9.14

FEDERAL INCENTIVES AND ELECTRIC UTILITIES $\quad \cdot \quad \cdot \quad \cdot \quad \cdot \quad \cdot \quad 9.18$

Investor-Owned Electric Utilities . $\quad . \quad$. $\quad . \quad$. 9.19

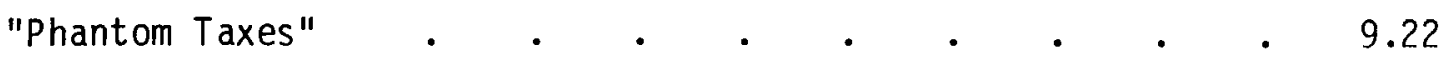

Government-Owned Electric Utilities . $\quad$ • . $\quad$. $\quad 9.25$

REA-Financed, Cooperatively-Owned Electric Utilities . . $\quad 9.28$

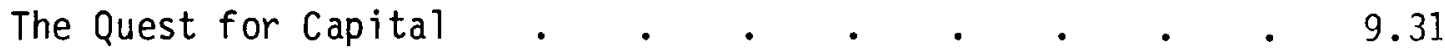

Financing and Interest Cost Comparisons for JOAs and IOUS . 9.34

The Current Trends of Private Power $\quad . \quad$. $\quad . \quad$. 9.35

THE IMPACT OF FEDERAL INCENTIVES ON THE PRICE AND OUTPUT OF

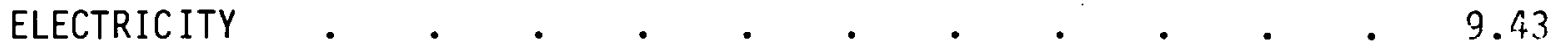

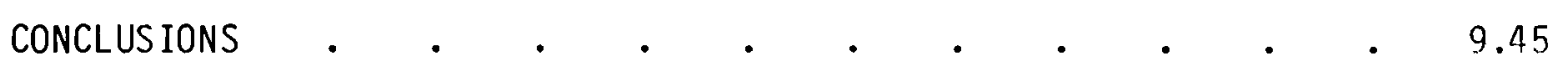

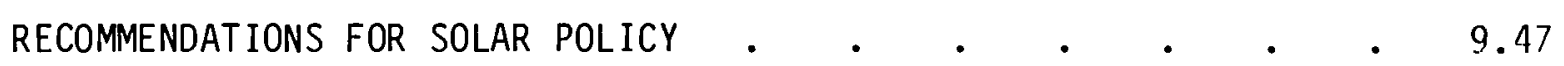

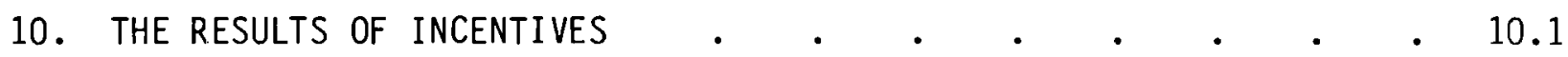

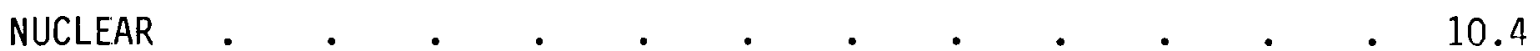

HYDRO $\quad$ • $\quad$ •

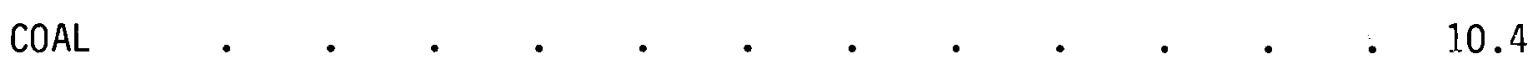

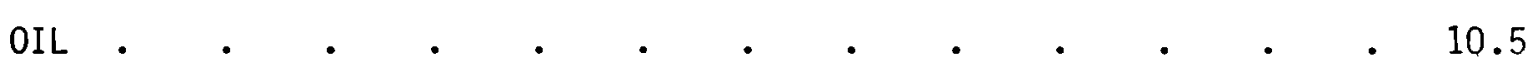

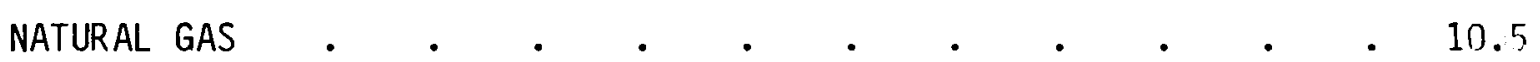

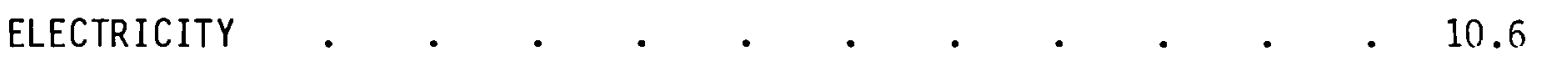

INCENTIVE COST PER UNIT OF INDUCED PRODUCTION $\quad . \quad \cdots \quad . \quad 10.6$

11. PARITY BETWEEN SOLAR ENERGY AND TRADITIONAL ENERGY SOURCES • • 11.1

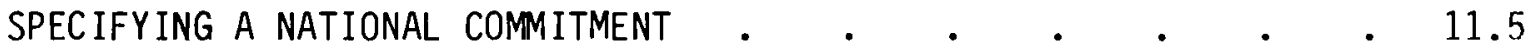

\begin{tabular}{l} 
12. THE HISTORY OF TRADITIONAL ENERGY INCENTIVES AS A GUIDE TO \\
SOLAR ENERGY INCENTIVES \\
\hline
\end{tabular} 


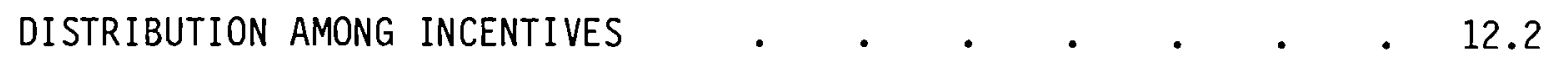

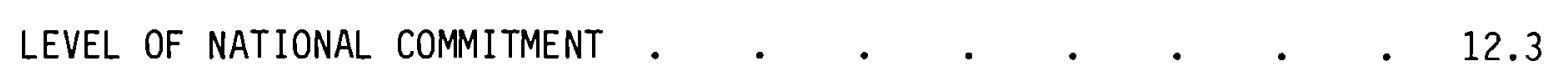

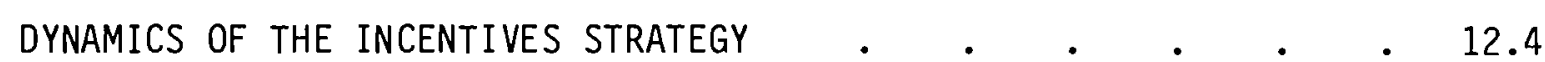

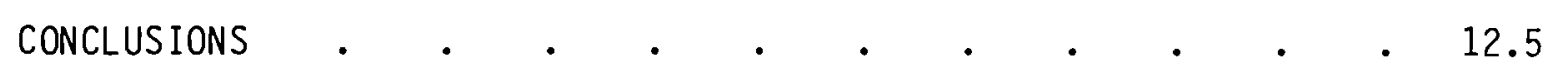

APPENDIX A -- MACROECONOMIC MODELS OF THE U.S. • • • • • • $\quad$ A.1

APPENDIX B -- STATEMENTS ON THE RESULTS OF FEDERAL ENERGY ACTIONS \& B.1

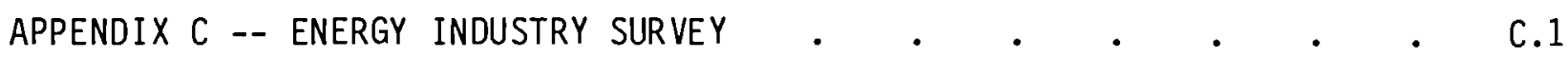

APPENDIX D - - FUEL CONVERSION FACTORS

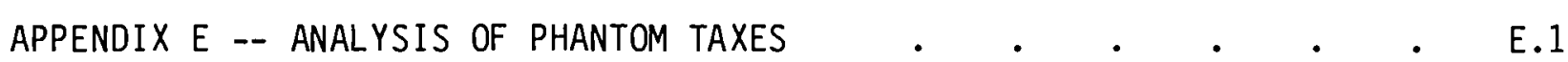

APPENDIX F -- FINANCING AND INTEREST COST COMPARISONS FOR A JOINT OPERATING AGENCY AND AN INVESTOR-OWNED UTILITY $\quad \cdot \quad \cdot \quad \cdot \quad \cdot \quad \cdot \quad \cdot \quad F .1$ APPENDIX G -- SUBSIDY VALUE OF TWO SOLAR ENERGY INCENTIVES • • • • $\quad$ G.1

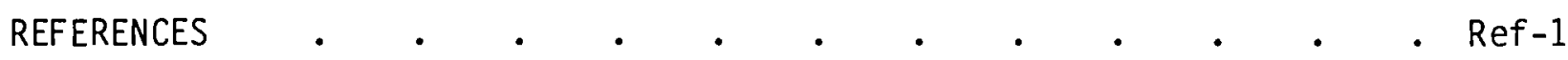

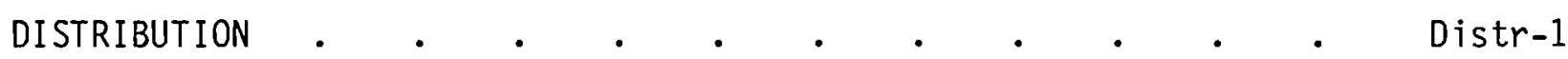




\section{FIGURES}

1.1 The Real and Apparent Market for Energy . . . . . 1.9

2.1 The Interactive Process of Policy Actions . . . . . . 2.2

3.1 Cost of Requirements Incentives by Year . . . . . 3.10

3.2 Cost of Taxation Incentives by Year . . . . . . $\quad$. 3.11

3.3 Cost of Market Activity Incentives by Year . . . . . . 3.11

3.4 Cost of Disbursement Incentive by Year . . . . . . 3.12

3.5 Cost of Services Incentives by Year . . . . . . 3.12

4.1 Nuclear: Cumulative Production and Incentives . . . . 4.3

4.2 Nuclear: Annual Production and Incentives . . . . . . 4.5

4.3 Annual Production Cost and Annual Incentives . . . . . 4.6

4.4 Annual Production Cost and Cumulative Incentives . . . . 4.6

4.5 Tabulation of Responses Estimating Effectiveness of Federal

4.6 Monetary Effects of Nuclear Power as a Replacement to 0i1-Electric Production . . . . . . . . . . 4.18

4.7 Value of Nuclear Fuel Sold Per Year From 1970 to 2000 . . . 4.20

5.1 Annual Production of Hydroelectric Power and Annual Amount 5.14

5.2 Cumulative Production of Hydroelectric Power and Cumulative Federal Incentives Since 1933.0 .5 .14

5.3 Generating Capacity of Federal and Non-Federal Facilities . $\quad 5.19$

5.4 Annual Production of Hydroelectricity by Federal and

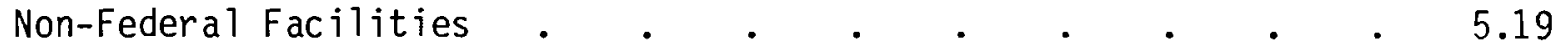

5.5 BPA Hydroelectric Power Price and Annual Amount of Federal

6.1 Coal: Annual Production and Incentives . $\quad . \quad$. $\quad . \quad$. 6.4 
6.2 Coal: Cumulative Production and Incentives . . . . 6.6

6.3 Coal Prices and Annual Incentives . . . . . . . 6.9

6.4 Coal Prices and Cumulative Incentives . . . . . 6.11

7.1 Annual Production and Incentives for $0 i 1$. $\quad . \quad$. . 7.4

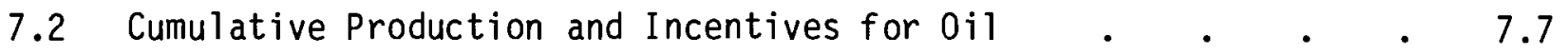

7.30 0il Prices and Annual Incentives . . . . . . . . 7.9

$7.40 i 1$ Prices and Cumulative Incentives . $\quad . \quad$. $\quad . \quad$. 7.11

7.5 The Effects of Price Controls . . . . . . . . 7.16

8.1 Natural Gas: Annual Production and Incentives . . . . 8.4

8.2 Natural Gas: Cumulative Production and Incentives . . $\quad . \quad 8.7$

8.3 Natural Gas Prices and Annual Incentives . . . . . 8.9

8.4 Natural Gas Prices and Cumulative Incentives . . . 8.10

9.1 Annual Electricity Production and Incentives . . . $\quad$. 9.9

9.2 Cumulative Electricity Incentives and Production . . . $\quad . \quad 9.9$

9.3 Annual Electricity Prices and Incentives . . . . . 9.15

9.4 Bonneville Power Administration Base Alternative Electric
Energy Prices

11.1 The S-Shaped Industrial Growth Curve . . . . . . 11.6

C.1 U.S. Energy Production versus Year, 1950 to 2000 •.$\quad$ C.2 
$\underline{\text { TABLES }}$

1.1 An Estimate of the Cost of Incentives Used to Stimulate Energy Production

2.1 Typology of Effects

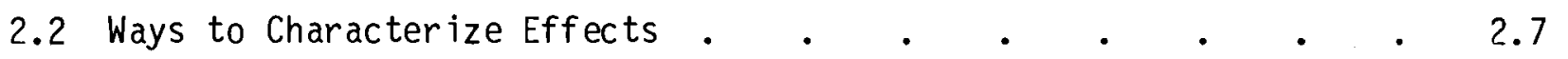

2.3 Profitability and Production in the U.S. $0 i 1$ and Gas Industry:

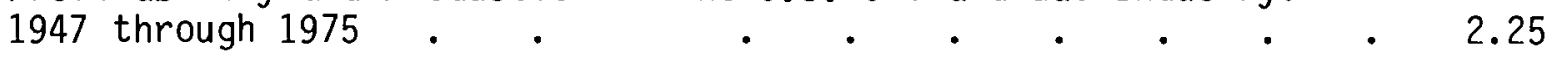

3.1 General Tendencies of Incentive Impacts . . . . . . 3.8

3.2 General Characteristics of Incentives . . . . . . 3.17

4.1 A Sumary of the Cost of Incentives to Stimulate Civilian Nuclear Power Production .

4.2 Annual and Cumulative Nuclear Production and Federal Incentives . 4.4

4.3 Response of Those Who Believed that Federal R\&D Was of Significant Benefit in the Development of Nuclear Power . . 4.9

4.4 Response of Those Who Believed that Federal R\&D Was Not of Significant Benefit in the Development of Nuclear Power . . 4.11

4.5 Economic Effects of Nuclear Electric Market Penetrations . $\quad 4.19$

4.6 A Summary of Incentive Effects on Civilian Nuclear Power Production 4.23

4.7 A Summary of Incentive Effects on Nuclear Electric Power Price - 4.23

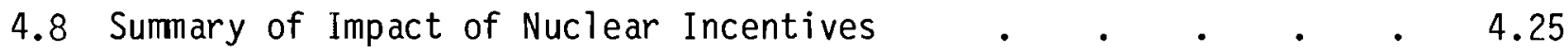

5.1 Federal Incentives Used to Stimulate the Development of Hydro-Energy and Electricity Transmission . . . . . . . . . 5.2

5.2 Electric Utility Hydroelectric Plants in the United States . 5.3

5.3 Marketing of Federal Hydroelectric Production in 1976 . . $\quad 5.5$

5.4 Annual Hydroelectric Incentives . . . . . . . . 5.12

5.5 Cumulative Federal Incentives to Stimulate Hydroelectricity • $\quad 5.13$

5.6 Generating Capacity of Hydroelectric Facilities . • • • 5.17

5.7 Production of Hydroelectricity . . . . . . . . 5.18 
5.8 Bonneville Power Administration Prices for Hydroelectric Power . $\quad 5.23$

5.9 Private Production Expenses -- 1971 to 1976 . . . . . . 5.27

5.10 Economic Activity Resulting from the Reclamation Program,

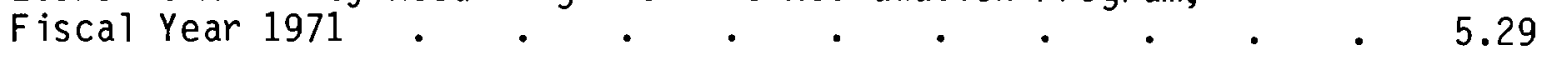

5.11 Growth in Value Added by Manufacturing in Industries with

Electricity-Intensive Production Techniques $\quad$. $\quad . \quad$. 5.31

5.12 An Estimate of the Results of Incentives Used to Stimulate

Hydroenergy Production . . . . . . . . . 5.38

5.13 An Estimate of the Results of Incentives Used to Stimulate

Hydroenergy Production in Terms of Price . . . . . 5.38

5.14 Summary of Impact of Hydroelectricity Incentives . . . $\quad 5.40$

6.1 Sumary of Incentives to Coal by Type . . . . . . 6.2

6.2 Annual Coal Production and Federal Incentives . . . . 6.5

6.3 Cumulative Coal Production and Federal Incentives ..$\quad$. 6.7

6.4 Coal Prices and Federal Incentives . . . . . . 6.8

6.5 An Estimate of the Results of Incentives Used to Stimulate
Coal Production . . . . . . . . . 6.20

6.6 An Estimate of the Results of Incentives Used to Stimulate
Coal Production in Terms of Price. . . . . . . 6.20

6.7 Summary of Impact of Coal Incentives • • • • • • 6.22

7.1 Surmary of 0 il Incentives by Type . • • • • • • • 7.2

7.2 Annual 011 Production and Federal Incentives . • • • • 7.5

7.3 Cumulative $0 i 1$ Production and Federal Incentives . . . . 7.8

$7.40 i 1$ Prices and Federal Incentives . • • • • • • • 7.10

7.5 $0 i 1$ and Gas Extraction (SIC 13) Number of Employees and 7.18

7.6 An Estimate of the Results of Incentives Used to Stimulate
0il Production

7.7 An Estimate of the Results of Incentives Used to Stimulate
0il Production in Terms of Price. . . . . . . . . . . 


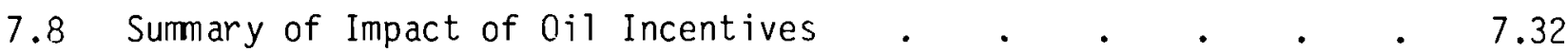

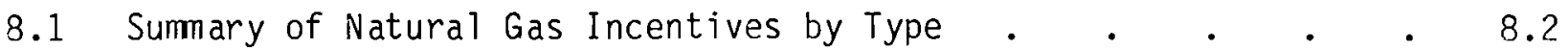

8.2 Annual Natural Gas Production and Federal Incentives . . $\quad 8.5$

8.3 Cumulative Natural Gas Production and Federal Incentives . $\quad$ - 8.8

8.4 Natural Gas Price and Federal Incentives . . . . . . 8.11

8.5 An Estimate of the Results of Incentives Used to Stimulate Natural Gas Production . . . . . . . . . . . 8.19

8.6 An Estimate of the Results of Incentives Used to Stimulate Natural Gas Production in Terms of Price . . . . . . . . . 8.19

8.7 Summary of Impacts of Natural Gas Incentives $\quad . \quad$. $\quad$. $\quad 8.22$

9.1 Electric Utility Net Generation, United States 1967 to 1976. $\quad 9.3$

9.2 Percent Breakdown of Investment in Total Electric Plant for
Investor-Owned and Cooperatively-Owned Utilities . . . . 9.4

9.3 Federal Incentives Used to Stimulate the Development of

Electric Energy . $\quad . \quad$. $\quad . \quad$. $\quad . \quad$. 9.5

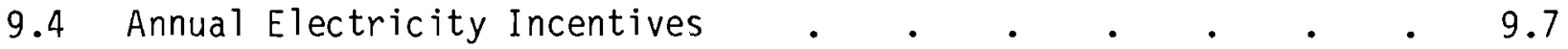

9.5 Cumulative Electricity Incentives . . . . . . . . 9.8

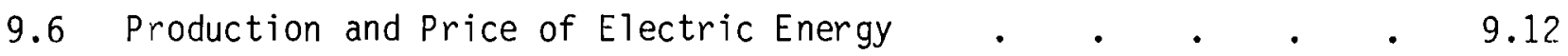

9.7 Electricity Production by Utility Type During the Period the
Quantified Federal Incentives Were in Effect $. \quad . \quad . \quad . \quad 9.13$

9.8 Disposition of One Revenue Dollar by Investor-Owned Electric
Utilities

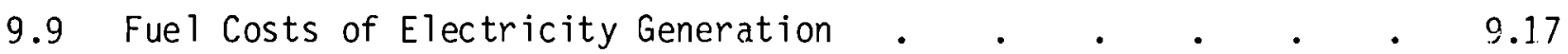

9.10 Cost of Additional Generating Capacity $\quad . \quad$. . . . . 9.18

\begin{tabular}{l}
9.11 Investment Tax Credits Provided to Investor-Owned Electric \\
Utilities \\
\hline
\end{tabular}

9.12 Representative Investor-Owned Electric Utilities Distributing $\quad 9.23$

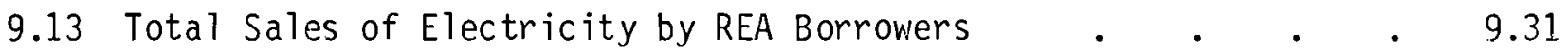


9.14 Projected Capital Expenditures of Electric Utilities . . $\quad 9.32$

9.15 Capital Raising Mechanisms of Different Electric Utility Types • 9.33

9.16 Selected Income Relationships of Investor-Owned Class A \& B

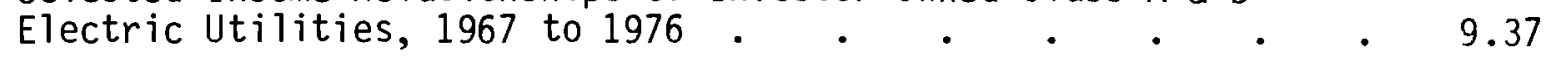

9.17 An Estimate of the Results of Incentives Used to Stimulate Electricity Production . . . . . . . . . . 9.44

9.18 An Estimate of the Results of Incentives Used to Stimulate Electricity Production in Terms of Price . . . . . 9.44

9.19 Sumbary of Impact of Electricity Incentives . . . . $\quad 9.46$

10.1 An Estimate of the Production Results of Incentives Used to Stimulate Energy Production. . . . . . . . 10.2

10.2 An Estimate of the Price Impacts of Incentives Used to Stimulate

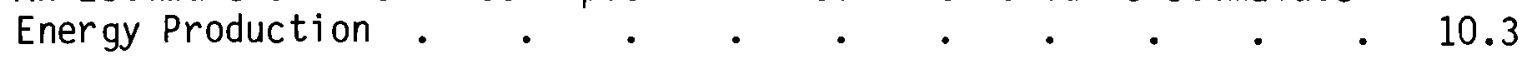

10.3 The Cost of Federal Energy Incentives Per Unit of Induced

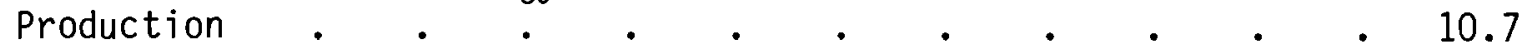

11.1 Energy Production and Incentives by Energy Form . • . . 11.3

11.2 Energy Production and Incentives by Energy Form During 1977 • 11.3

11.3 Parity Index for Energy Form and Total . • • . . 11.5

12.1 A Point of Departure for Federal Incentives to Solar Energy Based on Historic Incentives to Traditional Sources of Energy . . 12.5

B.1 Reports on Energy Actions by Policy Makers and Activists . . B.3

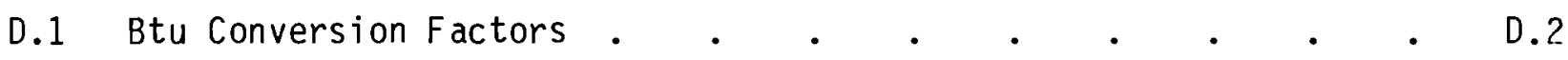

E.1 Present Value of Accelerated Depreciation Schedules • . . E.3

F.1 Construction Phase: JOA Estimated Financing Costs • • . F.3

F.2 Operation Phase: JOA Estimated Financing and Interest Costs . F.4

F.3 Decommissioning Phase: JOA Estimated Financing and Interest Costs F.5

F.4 Estimated Financing and Interest Costs if JOA Bonds are Sold at

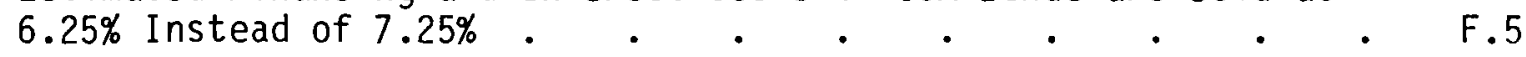

F.5 Construction Phase: IOU Estimated Financing and Interest costs . F.7 
F.6 Investor-Owned Utility - Financing Costs . . . . . . F.8

F.7 IOU Estimated Financing Schedule - Preferred Stock Sales • • F.7

F.8 IOU Estimated Financing Schedule - First Mortgage Bond Sales . F.8

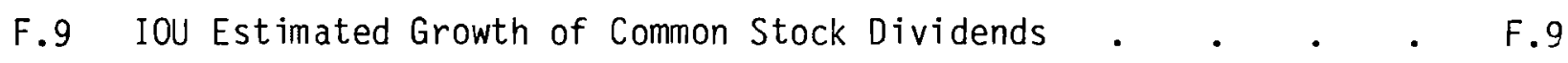

F.10 Investor-Owned Utility - Estimated Flow of Funds . • . . F.10

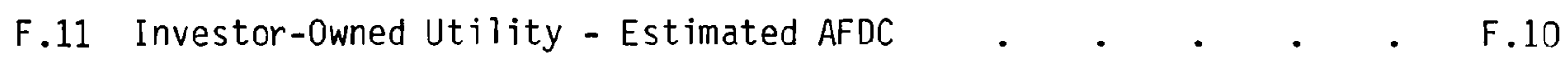

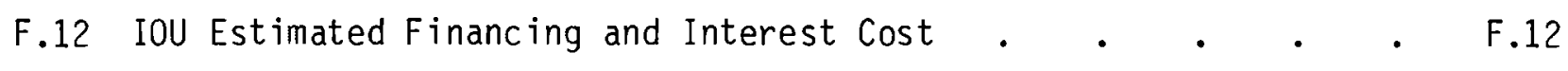


. 
CHAPTER 1

INTRODUCTION

by

Bruce W. Cone, Economist 


\section{INTRODUCTION}

It is estimated that the production of coal, gas, and $0 i 1$ has been stimulated by federal incentives that amount to $\$ 127$ billion (Cone et al. December 1978, p. 276). The future availability of sufficient quantities of these traditional energy forms, however, is in question. The amount of solar energy that reaches the earth's surface every two weeks, on the other hand, is equivalent to all of the known reserves of coal, gas, and oil. Yet, solar energy has an insignificant share of the national energy budget. What should be the level of federal incentives to solar energy? How should these incentives be al located?

In October 1976 Pacific Northwest Laboratory (PNL) (a) began a research program entitled "An Analys is of Federal Incentives Used to Stimulate Energy Production" at the request of the Energy Research and Development Administration, now the Department of Energy (DOE). The purpose of the research program conducted by PNL is to analyze the federal incentives used to stimulate nuclear, hydro, coal, gas, oil, and electricity production in order to apply what is learned to the selection of an incentives strategy to induce new energy production from renewable resources. The first report of the program furnished input to the Domestic Policy Review of Solar Energy during the summer of 1978 (Cone et al. March 1978). The Great Adventure, a Report of the 10 Regional Public Hearings on Solar Energy for the Domestic Policy Review (Franklin Institute for Local Self-Reliance October 1978) stated that, "In almost every region people cited the Battelle Memorial Institute report (Cone et al. March 1978) on the amount of subsidies given in the past to fossil fuel and nuclear industries." (Franklin Institute for Local Self-Reliance October 1978, p. 10).

The analys is of the results of $\$ 217$ billion of federal incentives related to the production of nuclear, hydro, gas, coal, 0il, and electricity -- some of which were initiated as long as 60 years ago -- is complex. Theoretically, these incentives begin with decisions on fiscal policy. They are buried within initiatives intended to direct government spending and taxation to

(a) Operated for the Department of Energy by Battelle Memorial Institute. 
increase the stability of the total economic activity. Legislators fashioned the initial concepts into law by applying the goals of achieving social utility and equitable distribution. Federal administrations promulgated rules and regulations to implement the intent of Congress as expressed in the law. Judges canonized the law by applying standards of consistency, equivalence, and predictability. The resulting effort was an exploitation of the opportunity for pecuniary profit and for effective participation in decision making. The resulting product could have been more energy marketed.

Theoretically, it all sounds so neat and orderly. Practically, the measurement of intent and, therefore the results of incentives, is less precise.

The late Senator Hubert Humphrey (March 1975, p. 22) said: "We don't have any economic impact statement for government decisions. The government goes around willy-nilly making decisions of consequence... The manner in which we are presently utilizing government resources and government agencies is a haphazard, helter skelter enterprise."

William E. Simon (1978, p. 3), first administrator of the Federal Energy Administration (now part of the Department of Energy) believed that: "...The government in general and Congress in particular were responsible for both the economic and energy crisis and for the dangers associated with them." The process of allocating incentives to various forms of energy was constrained by political considerations. Simon (1978, p. 47) observes: "No sooner did the rumor get out that I was to chair the 0il Policy Committee, than I was deluged by advice, demands, and warnings from an incredible number of interested parties, ranging from the 55 federal agencies which had been regulating the oil industry to the industry itself -- the major companies and the independents, marketers, producers, refiners, and jobbers. The assault was dizzying."

Some forms of energy were systematically favored. "0i1," writes B. Oppenheimer $(1974$, p. 15) "doesn't have any enemies on Capitol Hill...Stories are well known in the corridors of Congress about Senator Russell Long and before him, Senator Robert Kerr, finding campaign contributions for colleagues faced with tough re-election campaigns." J. Ray McDermott and Company and Brown and Root, Inc., two world giants in the offshore construction and pipeline 
industry, were given high marks by oil industry officials for effective lobbying efforts with President Johnson and the Longs of Louisiana. In an industry with "logistics almost equivalent to going to the moon," where speed and ability to get the job done are often more important than costs, results were closely dependent on the timely distribution of incentives at the federal level (Huey July 7, 1978). Such perceived influence and carefully planned actions on the part of the members of the private sector were taken into account by Dechesneau (1975). In $h$ is extensive analys is of competition in the U.S. energy industry, he concludes: "Government improvised restrictions on free markets are responsible for many of the energy problems facing the U.S."

Atomic energy also has been systematically supported by the federal government. For example, following the Atomic Energy Act of 1954 which allowed for private ownership and operation of nuclear reactors, the question of liability was raised. Members of the nuclear industry went to Washington and lobbied for a policy to protect the ir investment. William Gale (U.S. Congress, Joint Committee on Atomic Energy, 1956 Hearings, p. 240), Chairman, Commonwealth Edison Company, said: "At this time we do not see any sound bas is on which we can risk solvency on the possibility, remote as it may be, of a major nuclear catastrophe." Charles H. Weaver (U.S. Congress, Joint Committee on Atomic Energy, 1956 Hearings), Vice President of the Westinghouse Electric Company argued: "Obviously we cannot risk the financial stability of our company...we cannot exclude the possibility that a great enough fool aided by a great enough conspiracy of circumstances would bring about an accident exceeding available insurance." Francis K. McCune (U.S. Congress, Joint Committee on Atomic Energy, 1957 Hearings, p. 148), Vice-President of the General Electric Company, threatened closure of a planned facility unless Congress agreed to sought-after support: "At present, I see no alternative but to recommend that work on the Dresden Station be halted as soon as practicable after the end of this session of Congress in case appropriate legislation has not been passed by that time." In response, Congress passed the Price Anderson Act which put limits on the liability of the industry in case of accident.

This brief review of the politics of allocating incentives suggests that government involvement in the energy market has occurred for many reasons. 
Small groups with large interests have counted more than large dispersed groups with small interests. Some energy incentives were born in the accounting offices of the energy producers and possibly in places like the Petroleum Club of Morgan City. But these incentives often were also formulated with the intent of protecting consumer welfare and the stability of overall economic activity. They, were justified as efforts to aid the nation's economic development.

These cases indicate that there were no long-range energy goals. As a nation of short-term pragmatists, we dealt with the future only when it became the present. We focused on immediate crises and accomplished necessary actions that produced immediately visable outcomes.

The previous research indicated that government action did promote rapid energy production. What were the results of historic government action? Did the government stimulate energy production through the use of incentives? Did the actual result of energy incentives vary from the original intent in such a manner that energy production was either stifled or not affected? Answers to these questions could aid in the productive allocation of federal monies to achieve national energy goals.

\section{SPECIFICATION OF THE PROBLEM}

The point of departure for this analysis is the categorization and quantification of past incentives to increase energy production. Table 1.1 indicates, by energy source and incentive type, how the $\$ 217$ billion of federal expenditure has been allocated. $0 i 1$ received the largest share of incentive funds, and electricity received the second largest share. Incentives for gas, nuclear, and hydro power have received intermediate amounts of funding and coal has received the smallest percentage of incentives. Nearly $50 \%$ of the costs of incentives were tax levies or the exemption or reduction of existing taxes. Requirements, such as price controls, accounted for $20.1 \%$ of the incentives. Almost $19 \%$ of the total expenditure involved government market activities, such as the Tennessee Valley Authority (TVA). The federal government allocated 9.0\% of incentives through non-traditional services such as exploration, research, development, and demonstration. The incentives provided through traditional 
TABLE 1.1. An Estimate of the Cost of Incentives Used to Stimulate Energy Production (in Billions of $1977 \$$ ) (reprinted from Cone et al. December 1978, p. 276)

\begin{tabular}{|c|c|c|c|c|c|c|c|c|}
\hline & Nuc lear & Hydro & Coal & $0 i 1$ & Gas & Electricity & Total & $\begin{array}{l}\% \text { of Total } \\
\text { Incentives }\end{array}$ \\
\hline Taxation & & 1.8 & 4.03 & 50.4 & 16.04 & 31.37 & 103.54 & 47.7 \\
\hline Disbursements & & & & 1.1 & & & 1.10 & 0.5 \\
\hline Requirements & 1.1 & 0.03 & 0.67 & 41.9 & 0.06 & & 43.76 & 20.1 \\
\hline $\begin{array}{l}\text { Traditional Ser- } \\
\quad \text { vices }\end{array}$ & & & 2.31 & 6.0 & & 0.48 & 8.79 & 4.0 \\
\hline $\begin{array}{l}\text { Nontraditional } \\
\text { Services }\end{array}$ & 15.1 & & 2.68 & 1.5 & 0.3 & & 19.58 & 9.0 \\
\hline Market Activity & 1.8 & 13.5 & $\underline{0.02}$ & 0.4 & 0.1 & 24.73 & 40.55 & 18.7 \\
\hline Totals & 18.0 & 15.33 & 9.71 & 101.3 & 10.50 & 50.58 & 217.42 & 100.0 \\
\hline $\begin{array}{l}\% \text { of Total } \\
\text { Incentives }\end{array}$ & 3.3 & 7.0 & 4.5 & 46.6 & 7.6 & 26.0 & 100 & \\
\hline
\end{tabular}


government services accounted for $4.0 \%$ of the total. Approximately $0.5 \%$ of the cost of incentives was in the form of disbursements, for which the federal government demanded no direct good or service in return.

The six categories of incentives can be disaggregated as follows:

1. Taxation exemption, or reduction of existing taxes.

- 0 il and gas

- Expensing of drilling costs

- Percentage depletion allowance

- Hydro

- Tax exempt power revenues

- Coal

- Depletion allowance

- Electricity

- Investment tax credits

- Liberalized depreciation

- Tax-exempt power revenues

- Tax free bonds.

2. Disbursements in which the federal government distributes money without requiring anything in return.

- $0 \mathrm{il}$ and gas

- Tanker subsidies

- Nuclear

- Liability insurance.

3. Nontraditional services such as exploration, research, development, and demonstration of new technologies.

- $0 i 1$, gas, and coal

- Research and development

- Geological Survey data collection

- Bureau of Mines data collection

- Nuclear

- Research and development. 
4. Market activity under conditions similar to those faced by non-governmental producers and consumers.

- $0 i 1$, gas, and coal

- Bureau of Land Management Leasing

- Nuclear

- Uranium purchasing

- Enrichment plant construction and operation

- Hydro

- Construction and operation of dams

- Rurar Electrifization Administration (REA) loans.

5. Traditional government services provided through a non-governmental entity, without diraci charge.

- $0 i 1$ and coal

- Maintenance of ports and waterways

- Electricity

- REA Administration.

6. Requirements backed by the threat of criminal or civil action.

- 0 il

- Federal Energy Administration price regulations

- Stripper well price incentives

- New oil incentives

- High yield on pipelines

- Gas

- Federal Power Commission

- Wellhead price controls

- Coal

- Mine health and safety

- Hydro

- Regulation of non-federal dams

- Nuclear

- Atomic Energy Commission and Nuclear Regulatory Commission safety regulations. 
Each of the six categories of incentives are represented by one to five sources of energy. We have counted 33 distinct types of incentives. Each of the 33 has had an impact on the quantity and price of energy.

On an aggregate level, economic theory can, a priori, aid in the specification of impacts. Figure 1.1 shows supply and demand curves depicting the real and apparent market for energy in the U.S. Curve $S_{e}$ represents a secular supply curve for U.S. energy; that is, it represents the supply schedule for all of the energy that exists in known forms over time. The curve represents in an approximate way the range of energy quantities that would be marketed at various prices in the absence of federal production incentives. The shape of the curve is primarily determined by the existence and location of known energy resources and the rate at which a stream of technology can transform these resources into fuel and power. As more energy resources are used, the supply becomes more inelastic. This is so because it costs more to dig or drill deeper or to utilize lower grade resources.

The market for energy exists at the intersection of Curve $S_{e}$ and the demand for energy, Curve $D_{e}$, that is, at Point $A$. Federal production incentives transfer some of the costs of energy production to the public sector. This results in an apparent supply curve, $S_{e}$, that is different from the real supply curve, $\mathrm{S}_{\mathrm{e}}$. The results of incentives can therefore be measured in terms of: 1) a change in the quantity of energy produced at the same price, represented by $Q_{3}$, or 2 ) a change in the price of a given quantity of energy, represented by $P_{3}$, or 3 ) a change in the price and quantity of energy, represented by Point $C$. Given the market demand, Curve $D_{e}$, the result of incentives to energy production would be Point $C$, with a lower market price and an increased quantity of energy relative to the initial equilibrium, Point $A$.

The preceding analysis neglects certain issues. First, it does not allow the determination of how much each specific or categorical type of incentive affected price and/or quantity, if at all. It is one thing to say that, in the aggregate, energy price and/or supply changed because of production incentives, and yet, quite another to indicate how much of the supply and/or price change was due to incentives like percentage depletion allowances. Second, the analys is begs the question of the results of federal expenditures directed to 


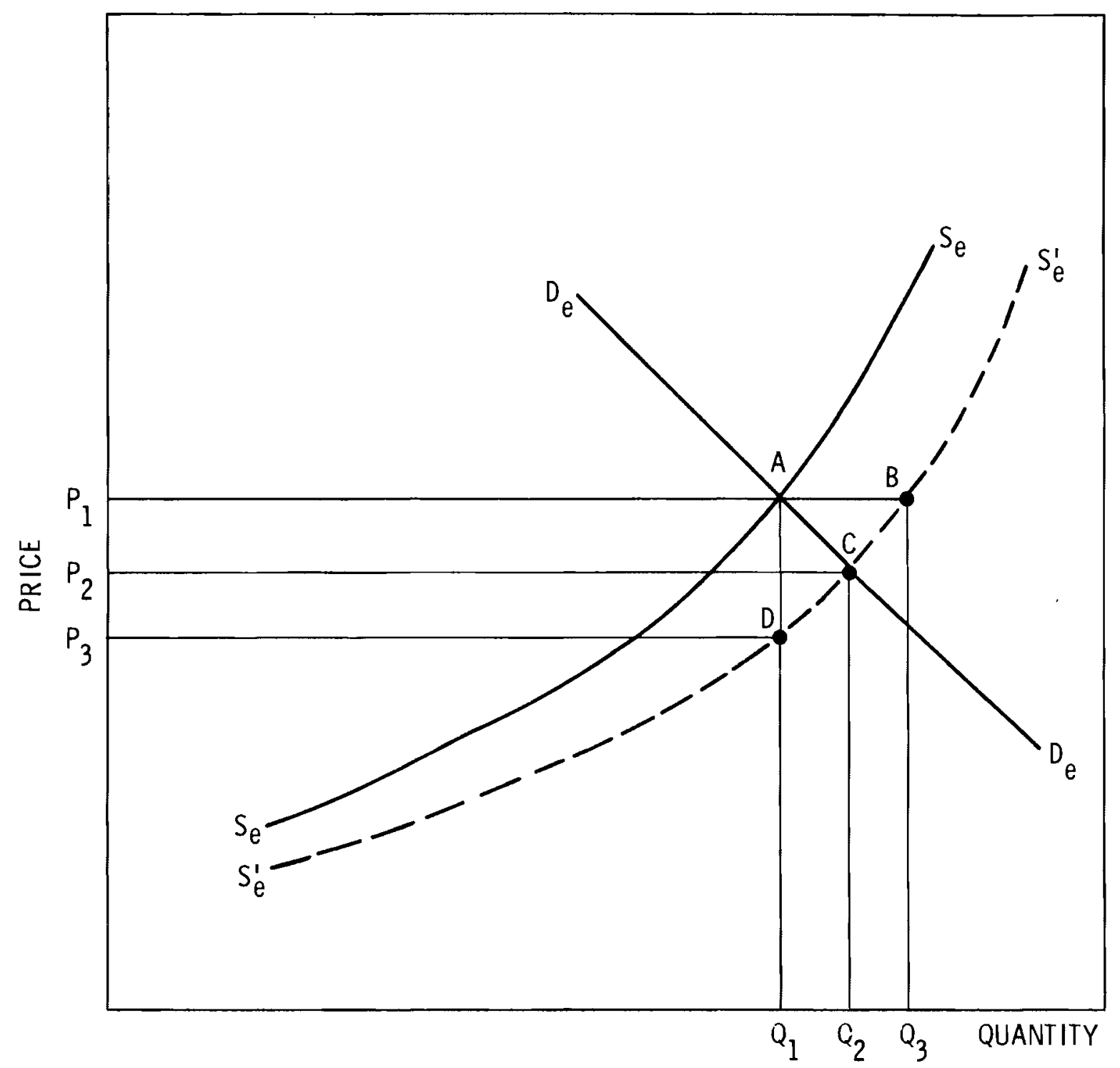

FIGURE 1.1. The Real and Apparent Market for Energy

various energy sources through alternative procedures, i.e., the opportunity costs. What would have been the results if the incentives applied to oil production had been spent on coal production instead? Would the U.S. have produced more or less energy if emphasis had been placed on disbursement instead of taxation?

Theoretically, measuring the results of incentives to increase energy production is a problem of measuring the shift in costs from the production sector to the public, or consuming, sector and the resultant impact on energy 
prices and quantity. Empirically, the determination of intent and the measurement of results are not precise, particularly when two actions have opposing impacts, for example, establishing oil quotas and giving foreign oil production special tax rules. The simultaneous result of the initiation of 33 incentives in a dynamic economy is not likely to be measured with precision. In fact, it may not be measurable at a11. But if lessons are to be learned from the investment of $\$ 217$ billion, the task of measurement must be undertaken. The findings must be reported, and the dialog must continue if the distribution of incentives to solar energy production are to incorporate even the vaguest lessons from past incentives to the production of traditional energy sources. Thus, the problem at hand is to:

1. define alternative strategies to measure the results of incentives,

2. choose a strategy thought appropriate for an energy form,

3. collect and analyze the available data

4. record the findings, and

5. present the findings for discussion.

\section{SUMMARY OF THE ANALYSIS}

The analytical portion of the report is divided into twelve chapters. The first chapter is theoretical; the rest are empirical. The purpose of Chapter 2 is to examine the problem of estimating effects from a theoretical perspective. Methods of quantifying and identifying the many interactive effects of government actions are discussed. In Chapter 3, a generic analysis of the results of federal incentives is presented. This chapter assesses the results of the major categories of government action. Primary emphasis is on FY-1976 and FY-1977 incentive expenditures.

Chapters 4 through 9 deal with incentives to energy forms -- nuclear, hydro, coal, 0il, gas, and electricity. Each chapter contains seven sections. In the first section, a brief discussion of the historic incentive types and their dollar values is presented; the second section presents graphical analysis depicting the value of incentives relative to the quantity of energy produced; the third section, a graphical analysis relating incentive value to the 
production price of the energy form under consideration. Both graphical presentations are considered for a designated time period of stability for the energy form and analyzed on an annual and cumulative basis. The fourth section presents a discussion of current thought, possible analytical techniques or models, or an analysis of expert opinion concerning the impacts of energy incentives. The fifth section contains an analysis of the possible nonquantifiable economic, social, and political impacts of the various energy incentives. The sixth section draws conclusions about incentive results and the final section identifies possible applications to solar policy.

Chapter 10 sumarizes the preceeding six chapters. The estimated results of the incentives for the various energy forms are presented in terms of their quantity and price impacts. The incentive cost per million Btu of induced energy production is also discussed.

Chapter 11 discusses the parity issue, that is an equivalence between federal incentives to renewable resources and federal incentives to traditional energy resources. The parity value is derived on a basis that gives greater weight to recent years. Any analysis of incentives for solar needs will profit from an analysis of the costs of solar incentives per miliion Btu compared with those for traditional energy forms.

Chapter 12 concludes the analysis. The results of incentives used to stimulate energy production are tabulated and conclusions are drawn that are applicable to solar energy policy. 


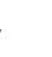


CHAPTER 2

A THEORETICAL POLICY ANALYSIS

APPROACH TO EFFECTS ESTIMATION

by

Roland J. Cole, Policy Analyst and Lawyer James H. Maxwell, Political Scientist Paul E. Sommers, Economist

Alex R. Maurizi, Economist

Alfred A. Marcus, Political Scientist 
A THEORETICAL POLICY ANALYSIS APPROACH TO EFFECTS ESTIMATION

In this analysis we are interested in identifying and quantifying the results of actions in the energy policy area. To do so, we pay attention to the effects of individual actions and how these effects interact to produce results. We develop a typology of effects and list ways to characterize these effects. We also examine five procedures for estimating the characteristics of effects. These procedures are: 1) inspection, 2) engineering, 3) analogy, 4) modeling, and 5) quantified expert opinion (QEO).

Careful and explicit attention to identifying and quantifying effects is important when evaluating the results of federal actions toward energy. Care is needed because actions can interact with each other, making the identification and quantification of effects difficult. The energy policy area (where federal actions have addressed every energy source at every stage of production and consumption) requires careful attention to unraveling these interactive effects. Chapter 1 has already listed the incentives whose results we are trying to identify.

Figure 2.1 diagrams the interactive process. In Column $I$, there is the policy area, the subject matter under discussion, in this case energy policy; in Column II, the actions identified as part of the policy area; in Column III, the effects of these actions; in Column IV, the interactions of the various effects; and in Column $V$, the results of these actions after the various effects have interacted.

Previous studies that we have examined have analyzed the results of government action and have given careful and explicit attention to methodology.(a)

(a) These studies included: Altman (1976); Cain and Hollister (1972); Cho (1972); Clawson (February 1959); Council on Environmental Quality (December 1975); Curry et al. (January 1977); Def ina (November 1977); Dun lop (1975); EPA (September 1973, December 1973, October 1974, February 1975); Glennan (1972); General Accounting Office (June 3, 1977); Haveman and We isbrod (1970); Houston (1972); Kamrany (1974); Klarman (1965); Kuburski (1974); Kvasha (1975); Lehne and Fisk (1974); MacAvoy (1970); Mack and Myers (1965); Margol is (1970); Mintz (1973); Nash, Pearce and Stanley (1975); National Research Council (1977); Peltzman (1973); Rossi (1972); Rothenburg (1965); Shields (1975); Smith (September 1976); Sorensen and Grove (1977); Weisbrod (1965); and Whelan (1976). 


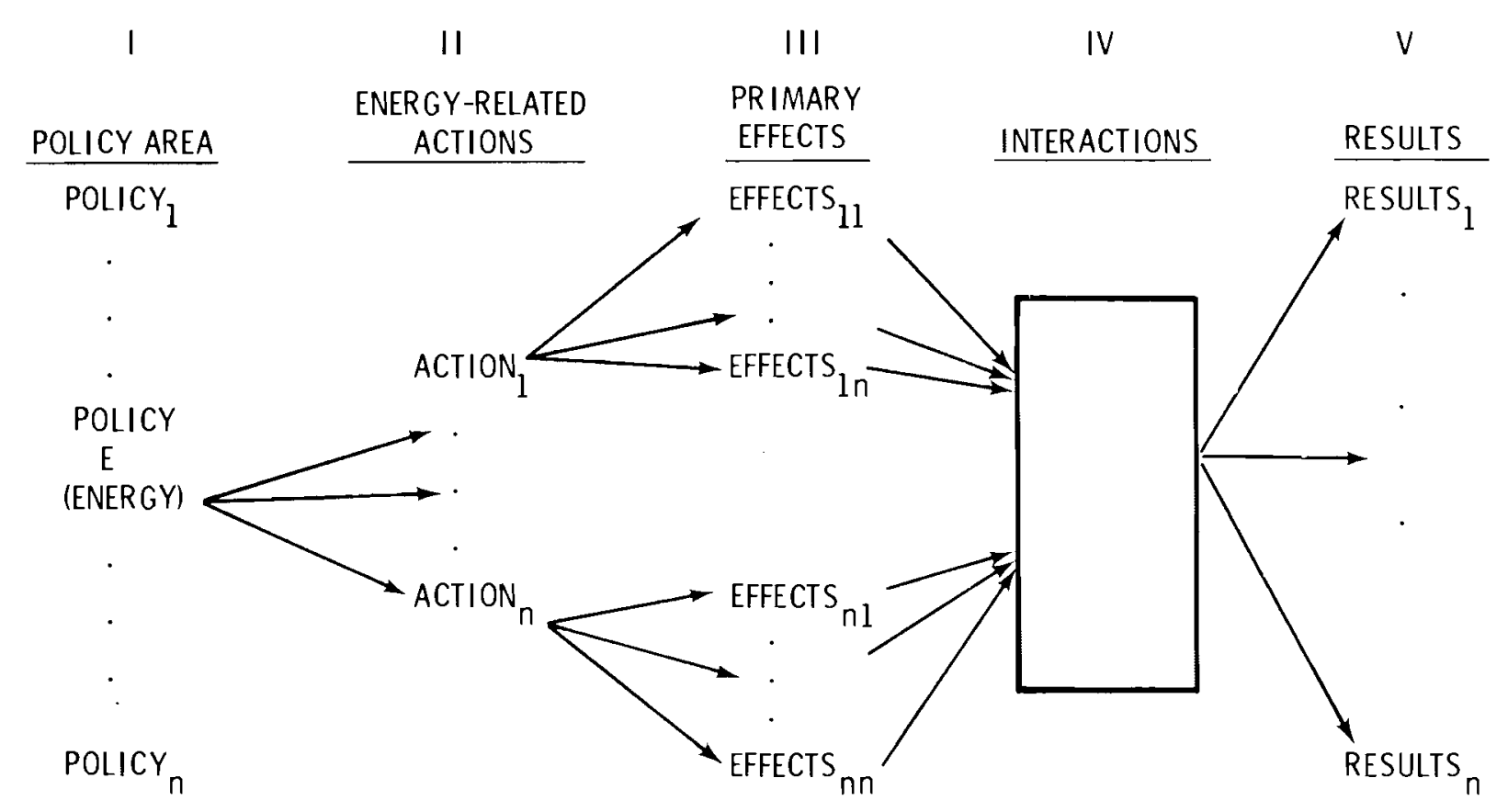

FIGURE 2.1. The Interactive Process of Policy Actions (Cone et al. March 1978)

actions (discussed in Cone et al. March 1978, pp. 35-44); 2) to develop perspectives on assigning effects to actions (also discussed in Cone et al. March 1978, pp. 21-35); 3) to develop a typology of the effects of government actions; and 4) to list ways to characterize these effects. The 1 ist in particular helps quantify effects, unravel their interactions, and thereby identify and quantify results. With the list in hand, procedures can be examined for estimating effects.

\section{A TYPOLOGY OF EFFECTS}

A typology of effects identifies effects stemming from an action and helps ensure that the identification is complete. A typology should meet the following criteria:

1. Universality. A typology should be useable with all types of government action in all policy area. Universality ensures uniformity among the types of energy actions and between analyses of energy actions and analyses of other policy areas. 
2. Completeness. A typology should include all the effects that have been ident ified. Completeness is necessary for the same reason as un iversality.

3. Exclusiveness. Each effect should fit into one, and only one, category in the typology. Although this criterion can never be met completely, the closer the typology approaches this goal the easier it is to identify all effects, to avoid double-counting, and to unravel interactions.

4. Concreteness. Categories should correspond to phenomena that are at least observable, if not measurable. Phenomena should be changes in the world, not kinds of causation or degrees of change. Consequently, many 1 ists offered by others as typologies of effects we have treated as typologies of the characteristics of effects.

At least 25 attempts to develop a typology of effects have been made. (a) Many of the typologies are fairly good, but none meet all the criteria. The typologies, nonetheless, identify individual items, and suggest categories into which to put these items.

Our typology, which appears in Table 2.1, relies heavily on previous attempts and on four viewpoints of government action (economic, political, organizational, and legal) that are discussed in Cone et al. (March 1978, pp. 21-35). Our categories cover all of the items we identified, plus others that previous studies identified. The specific items within these categories are not designed to be exhaustive, but to list the items we covered in this research.

(a) In developing our typography of effects, we looked at the following studies: Nash, Pearce, and Stanley (1975); Jones (1977); Cook and Scioli (1972); Shields (1975); Bishop (1972); Dickinson (1975); Schwartz (1975); Harrar and Bawden (1972); Wholey (1972); Acar (1976); Kraenzel (1957); Williams (1969); Wolf (1974, pp. 1-44); Haveman and Weisbrod (1970); Council on Environmental Quality (December 1975, pp. 681-683); Curry et al. (January 1972); Defina (November 1977); Ca in and Hollister (1972); Houston (1972); Klarman (1965); MacAvoy (1970); Weisbrod (1965); Ross i (1972); and Rothenburg (1965). 
TABLE 2.1. Typology of Effects

I. Economic
A. Competition versus Monopoly
B. Sectoral Impacts (Input-Output Model)
C. Sectoral Subsidies
D. Income - Class (Who pays? Who gets?)
E. Capital Formation
F. Change in Price/Change in Quantity
G. Inflation
H. Employment/Productivity
I. Balance of Payment

II. Political
A. Foreign Policy/National Security
B. (Societal) Stability

III. Organizational/Legal
A. State/Federal Relations
B. Public/Private Boundaries
C. Regulatory Burden

IV. Environmental/Quality of Life

V. Demographic
A. Urban versus Rural
B. Regional

The major concern in this report is with changes in the quantity of energy produced and changes in the price at which it is sold (Item I.F in the typology). Other effects are important because they contribute to an understanding of price and quantity effects. In some cases, price and quantity effects may stem from other kinds of effects. In other cases, price and quantity may be 
overshadowed in public debate by other effects. Other effects are apt to be especially crucial when comparing solar incentives with incentives for other forms of energy.

\section{CHARACTERISTICS OF EFFECTS}

The typology we developed identifies effects, but it does not quantify effects. An effect's $\underline{k \text { ind }}$ is only one characteristic of an effect, and a nonquantitative one at that. Therefore, a list that characterizes effects as well as categorizes also has to be developed.

Our list was developed in the same way as the typology. A list of characteristics, however, is meant to help with quantification and perhaps even unraveling of interactions, not with identification per se. Criteria of evaluation, therefore, are somewhat different. Criteria such as completeness and concreteness no longer apply, although universality and exclusivity do. The criteria used in assessing characteristics are the following:

1. Universality. Characteristics should apply to all effects and types of actions.

2. Exclusivity. Characteristics should fit into one, and only one, category in order to avoid more than a single measure of the same thing.

3. Importance. Although the list need not contain all characteristics, it should contain important characteristics, grouped into categories that are themselves important.

4. Relevance. Every category of the typology should relate to one or more of the following:

a. Causation. Characteristics should help describe how effects are related to individual governmental actions.

b. Change. Characteristics should help describe how or how much the effects are related to changes in the world.

c. Interaction. Characteristics should help describe how or how much effects of one action interact with the effects of another action to produce results. 
Once again, previous efforts are fairly good, but none of them conforms with all of the criteria. (a) Nevertheless, previous attempts have suggested terms and categories for our list. Our typology, which appears as Table 2.2, relies heavily on the previous attempts and on the four viewpoints of governmental action we previously developed.

\section{METHODS FOR ESTIMATING EFFECTS}

A typology of effects and a list of ways to characterize effects are not all that an analyst needs in order to identify and quantify results. In addition to these typologies, the analyst needs a procedure for estimating (by measurement, calculation, or otherwise) the values to assign to the relevant characteristics of the identified effects.

Procedures for performing such estimations do exist, although none of them are completely satisfactory. Descriptions of some of these procedures appear in Mosteller (1977, pp. 164-185), Singer (1971), Pill (1971), Luft (1976), Lucas (1974), Suchman (1967), Yin (1975), Guttenberg (1971), Dalky (1969), and Dorfman (1968).

A complete description and evaluation of effects-estimation techniques is a complex task which is beyond the scope of this project. However, some of the more commonly employed general approaches to effects estimation are identified and comments are made on their strengths and limitations.

\section{Estimation by the Inspection Method}

If the action has already occurred, the effects or results may have already occurred as well. In those cases, a comparison of the world before and after the action took place may yield a reasonable estimate of the action's results. However, such a comparison will only be reasonable where other

(a) We found the following studies to be particularly useful in developing our typology of effect characteristics: Sorensen and Grove (1977), Jacob (1972), Rigby (1976), Acharya (1972), Kuburski (1974), Prill (1975), Mitchell (1977), Strom (1975), and Goldfarb (1975). 
TABLE 2.2. Ways to Characterize Effects

I. Measures
A. Timing
1. Completed
2. Continuing
3. Future

B. Duration

C. Size

D. Probability of occurrence

II. Relationship to the Government Action
A. Caused totally by the action
B. Caused partially by the action
1. Requires simultaneous other actions
2. Requires intervening other actions (indirect)
C. Not caused by the action

III. Relationship to the Action's Sponsors
A. Prediction
1. Predicted by sponsors
2. Not predicted
B. Motivation
1. Was a reason for sponsorship
2. Was neutral
3. Was a reason for opposition

IV. Parties Involved
A. Producers
B. Consumers

V. Energy Variables
A. Form
B. Stage of production and consumption 
elements of the context remain reasonably consistent, and where there is no reason to believe that the changes observed would have occurred without the action. (a)

The literature on policy analys is offers a number of examples of this approach. (b) Kenneth Dolbeare and Phillip E. Hammond in School Prayer Decisions: From Court Policy to Local Practice (1971) describe the often nebulous results of the Supreme Court's prayer decision on local school practices. In another case study, Implementation: How Great Expectations in Washington are Dashed in Oakland, Jeffrey Pressman and Aaron Wildavasky (1973) describe the failures and unsuccessful implementation of an economic development program in 0akland. Many of these studies examine a law in a straightforward fashion and determine whether its major provisions have been enacted.

Unfortunately, such simple before-and-after comparisons are rarely adequate, particularly in the energy area. The government has been taking a number of new actions each year for a number of years, and the energy market is dynamic enough for there to be change over time even without government actions. Therefore, the use of this method is limited. When the world is changing so rapidly as to preclude using simple observation to assign effects and results to actions, some other method is necessary to perform this assignment.

\section{Estimation by the Engineering Approach}

The engineering, or "grass roots," method utilizes a Work Breakdown Structure (WBS)--a hierarchical tree of work elements which comprise the item to be estimated. The procedure is to estimate, from various sources, the specific items associated with each part of an action and to sum these to yield a total effects estimate.

The engineering method is predicated on a detailed categorical breakdown of effects. Hence, it is particularly suited for estimates of economic and environmental effects which are amenable to a systems analys is approach and

(a) For an illuminating discussion of this method see Tufte (1970).

(b) For examples of this method in the policy analys is literature, see Bardach (1977); Derthrick (1972); Freeman and Haveman (1972); and Murphy (1971). 
for which standard causal relationships are available. This method is not appropriate in the absence of sufficient definition regarding causal relationships between actions and effects.

An advantage of the engineering technique is that it provides a detailed itemization of effects by type of effect which is useful for determining which effects have the most profound impact and thus warrant the focus of attempts at change. A detailed itemization also facilitates an ex post facto, elementby-element, analys is of the accuracy of estimation, thereby focusing attention on specific areas for which estimating procedures could be improved or modified.

Shortcomings of the engineering approach are three:

- Its cost is relatively high.

- Considerable time is required in preparation of an estimate.

- Many effects are not amenable to an engineering estimate based on standard assumptions about causal relationships.

As with any method of estimation, a decision to use the engineering approach should be made only after consideration of the features of the action and its effects, the cost of estimation, the accuracy desired, and the time element.

Estimation by the Analogy Approach

Estimation by analogy compares the effects of a new action to the effects of a similar action that has already been studied and for which effects data are available. The previously developed action becomes the baseline against which analogies are drawn and judgments regarding effects extrapolated. The similarities needed for analogous comparison include such aspects as type, risk, impact, and scale.

One potential shortcoming of this method is the obvious requirement for the existence of a "similar" previously studied action complete with effects data. Because government actions often take place at the threshold of the state of knowledge and experience in an area or technology, they often preclude the existence of a past action with a sufficient degree of similarity. As a 
result, the analogy approach may not be applicable to many actions. In any event, this method requires a subjective determination that the action of interest with the context in which it takes place and the previously studied action with the context in which it took place are similar enough that one can confidently judge how estimated effects should differ from those of the baseline action. The potential accuracy of this method hinges largely on the degree of similarity between the two actions and the two contexts.

A commonly cited example of the analogy approach is Duncan Newhauser's study of hernias (1971). He wanted to know the strangulation or incarceration rate, in order to do a cost-benefit analys is of hernia operations in the elderly; he had no such data for the United States in modern times. However, he discovered data from a Parisian physician who ran a truss clinic in 1880 to 1884 when elective operations for hernias were not done. Strangulation or incarceration complications are called "accidents," and 1.43\% of 10,000 patients recalled accidents. Adjusting these data to account for those who would have died before appearing at the clinic, Newhauser (1971) calculated a probability of accident per hernia year of 0.0037 .

The primary advantages of this method are its relatively low cost and the speed with which an estimate of effects can be derived. Although the analogy approach does not require a categorical breakdown of effects, some categorization scheme would certainly be helpful in conceptualizing and assessing the degree of similarity between projects.

Estimation by the Modeling Approach

Effects modeling, or parametric estimation, is a statistical procedure requiring a large data base of similar actions. Effects are defined as being dependent on the technical characteristics (the independent explanatory variables) of the action to be estimated.

Modeling the effects of federal energy incentives is subject to all of the same pitfalls common to modeling the economy and the role of energy in the economy, as in the large-scale macroeconomic models of the U.S. economy that have been in existence for some time. For a further discussion, see Appen$\operatorname{dix} A$. Of course modeling can help estimate non-economic effects and results in addition to economic ones. 
Each of the existing models is fitted in some way to a body of historical data. The models, however, differ widely in the way they specify interrelationships in the economy or another context. They all have to deal with the simultaneous interaction of these relationships. Identifying the separate impact of each exogenous variable on all the endogenous variables in the system is essential and requires examining each behavioral equation in the system to be sure it is identified and not underidentified; in an underidentified system there is no way to tell which changes in the endogenous variables resulted from which changes in the exogenous variables. However, there are standard techniques employed to guarantee the identifiability of these large models and to handle the statistical estimation problems which occur with simultaneous equations.

The identification problem $(a)$ is important to keep in mind in connection with any kind of consumers' surplus approach. Federal incentives to reduce energy prices and stimulate production may be accompanied by other events which shift the demand for energy and result, at a later date, in higher rather than lower prices being associated with increased production. Without identifying the separate factors responsible for the demand shift, it is not possible to accurately assess the extent to which the federal incentive actually lowered energy prices.

The nature of the historical data available often affects the specification of the model. Dynamic adjustment mechanisms that use lagged responses are limited by the length of historical time series data. A lag of 10 years, for example, in a 25-yr data series effectively reduces the number of observations for fitting the model to 15 years. The lack of historical data often compels the combination of time-series with cross-section data. (This is certainly the case with the federal energy incentives table presented in Cone et al. March 1978, p. 109, where even two more years of data besides the one presented would require the cross-section data to be combined with the time-series data to enlarge the data base.)

(a) For discussions of the identification problem in simultaneous equation systems and the associated statistical techniques for dealing with estimation problems, see: Johnston (1972, pp. 341-408), Wonnacott and Wonnacott (1970, pp. 172-190 and 343-400), and Thiel (1971, pp. 429-540). 
The alternative models, with their differing specification and data bases, typically yield a range of predicted values for endogenous variables given the same values for key exogenous variables. Sometimes quite different specifications will yield almost identical predicted outcomes. One good example of this is the first California Energy Commission staff forecast of California electric energy demand, which used an econometric approach, and the first adopted forecast of California electric energy demand, which used an end-use engineering approach; the 10-yr forecasts from these two different modeling approaches were virtually identical. This is undoubtedly due to the fact that the different independent variables used in the two approaches were both very highly correlated with the movement of the same key economic variables over time, a problem common to the modeling approach since time-series data are frequently so heavily dominated by strong-trend elements. This means that frequently a number of alternative specifications will be equally suitable to the data; they can, of course, yield different, rather than identical, results.

All modeling using historical data to predict future outcomes (i.e., to forecast) faces the problem that the future may be unlike the past in ways which prevent accurate forecasting. For example, the price of electricity has been declining in real terms in the U.S. for most of this century (as has the price of $0 i 1$ and other energy sources). Past behavior is therefore the result of declining real prices and may not be an accurate guide to predicting behavior in the future when the real price of electricity is expected to cont inue to $r$ ise as it has since the early 1970s. Yang (October 1976) has shown that the elasticity of demand has been considerably lower since 1973 than it was before 1973. Since our electricity-using capital stock is the result of a long period of real price declines, we are unable to instantaneously adjust to rising prices by cutting back on electricity use to the same extent that we adjusted to real price declines in the past by increasing electricity use. This asymmetry of response means that we will overstate the anticipated reduction in future electricity use as a result of rising prices if we base our forecasts primarily upon historical data prior to 1973. As time passes we will be able to observe behavior under the new situation and make more accurate forecasts. In 1974, of course, there was absolutely no way to incorporate this 
important element in electricity demand forecasts since there was no historical data other than those for which prices were falling in real terms. Therefore, the estimating relationships are only as good as the data base from which they are drawn. In many situations the uniqueness and dynamics of the kinds of change rapidly render historical data obsolete and of little estimative value. This is particularly evident in areas with rapidly changing technologies.

The major shortcoming of modeling is its dependence on a large data base of similar actions. In the case of many actions, such a collection of data may not be available. In addition, the cost and time required to formulate a model and compile a data base are considerable and justified only if the model is projected to be applicable well into the future.

The modeling of individual energy sectors has, of course, become very important since the oil embargo and consequent four-fold increase in the nominal price of oil from abroad. (a) The modeling of the oil, natural gas, and electricity industries has become very complex. A large number of models for each industry have been developed. Each sector has its own associated technology and data base; it requires a sizeable resource commitment to develop one or more models for that sector. This means it may be very difficult, indeed, to arrive at estimates of energy price and quantity changes resulting from federal energy incentives; other, cruder methods may have to be utilized in the absence of resources to do the requisite modeling or make the necessary alterations to existing models.

We surveyed both the major macroeconomic models and the major energy models in order to determine if they would be suitable for our purposes. These models included:

(a) For a discussion of oil, natural gas and electricity modeling, see: Eckbo, Jacoby, and Smith (1978); Kennedy (1974); EPRI (February 1977); Khazzoom (1971); Erickson and Spann (1971); Helms (1974); Joskow and Baughman (1976); Taylor (1975); Griffin (1974); Mathematical Sciences Northwest, Inc. (1977); Mount, Chapman, and Turell (June 1973); J. W. Wilson and Associates (February 1977); Williams (March 1976); California Energy Commission Staff (November 1976); Economic Sciences Corporation (October 1975); and California Energy Commission Staff (September 1975). 
The Gulf Energy Model: Gulf $0 i 1$ Corporation (January 1977) and Gulf $0 i 1$ Corporation (Apri1 13, 1977);

The Hudson-Jorgenson Model: Ford Foundation Energy Policy Project (1975), Hudson and Jorgenson (1974; 1976, pp. 7-94), and Hoffman and Jorgenson (1977);

The Manne Energy Technology Assessment Model: Manne (1976; December 1977);

Zimmerman's Coal Model: Zimmerman (1977);

The Baughman-Joskow Regional Electricity Model: Baughman, Joskow, and Kamat (September 1977) and Joskow and Baughman (1976);

The MacAvoy-Pindyk Natural Gas Model: MacAvoy and Pindyck (1975) and Pindyck (1978);

The National Coal Model: ICF, Inc. (October 1976) and the Energy Information Administration (February 1978, p. 82);

The PIES Model: Federal Energy Administration (November 1974, pp. 195-282), the Department of Energy's many modeling efforts, and the Energy Information Administration (February 1978, pp. 79-91).

In reviewing these models, we used a number of criteria. The first set of criteria dealt with the substance of the model. That is, we wanted to know whether it could be manipulated to give us the estimates we wanted. The answer to that question depended both on the characteristics of the model and the data it already contained. The second set of criteria related to the costs (in time, money, and trouble) involved in using the models for our purposes.

Backcasting with Models

The models we reviewed were constructed for the purpose of forecasting the likely or possible future state of the economy given various assumptions (e.g., assumptions about government tax policy or about the quantity of oil that will be discovered in the next 15 years). However, for present purposes, we require a model or models which can backcast. Backcasting can be defined as simulating the effects of alternative policies or states of the world which could have, 
but did not, obtain in a historical time period. The question is, what if the depletion allowance had been set at 22\% in 1958 instead of the actual policy of $27.5 \%$, or what if the government had not spent several billions of dollars on nuclear research resulting in the construction of full-scale commercial reactors starting in 1963? In essence, by backcasting we seek to create counterfactual history so as to get quantitative estimates of the effects previous policies have had on the economy. We want to find out what the world would have been like without a specific level of funding for a type of incentive as applied to a form of energy production.

Conceptually, backcasting would appear to be a simple matter. One would need to select a model containing the sector of interest (coal, oil, electricity, etc.) which models the policy variable of interest (e.g., oil depletion allowance). Then, the time parameters for a historical time period of interest would have to be set and the computer would simulate the model under variations in actual policy (e.g., depletion allowances $10 \%$ and $50 \%$ above and below actual levels).

In fact, it is not that easy to carry out this task for practical, operational reasons resulting from the fact that models are built to forecast, not to backcast. Models are not good at backcasting for the following reasons: 1) lagged real data series are not available for many of the models; 2) simulated data series are not available; 3 ) a significantly different economic structure was present in earlier years; and 4) model behavior has simply not been explored in the historical period. Correcting these problems for the large-scale models we reviewed would be a large-scale, expensive undertaking even in cases where such corrections were feasible.

The problem of the missing data, real or simulated, could be, in many cases, fixed by gathering additional data and constructing the necessary data files. In some cases, however, the data were just not collected by a government agency or private organization in the past and there would be no hope of obtaining the data now. Where data collection or data construction is feasible, major resources are typically required. It is not a matter of inputing 5 or 10 data points, but of inputting hundreds or thousands of data points. 
If the data can be obtained and if it is appropriate to assume the model's representation of the economies structure applies to the historical period under study, then the remaining problem is one of running and evaluating the model in new and unexplored territory. The models we reviewed are large-scale, very complex, and usually non-linear mathematical systems. Initial validation runs of such models have to be undertaken with great care to avoid mathematical explosions or the calculation of extremely improbable results. In short, considerable judgment must be exercised in setting parameters and in interpreting results. This requirement for judgment is one of the reasons that use of large-scale models seldom goes beyond use by the original authors. In this case the problem of "technology transfer" is very significant.

Only limited attempts to run models in historical time periods have been undertaken. The Baughman-Joskow Regional Electricity Model has been run to a limited extent in such a mode. The MacAvoy-Pindyck Natural Gas Model has also been simulated in a limited historical time period. In both cases the results are not particularly useful.

\section{Models and the Analogy Approach}

The technical limitations on the backcasting capabilities of most energy and economy models do not totally preclude their use for estimating the effects of federal government incentives on the energy sector. Earlier in this chapter we have suggested that impacts can be estimated by making analogies to similar programs and their impacts. Models which can forecast policy impacts of interest can be used in this spirit to establish the analogy required. No comparable tool exists which can handle great complexities and numerous interactions among variables in an explicit fashion, and which can analyze policies with no close historical antecedents. Models of an appropriate nature are uniquely powerful tools in such situations.

This approach, which we call analogy-by-model, has definite limitations. First, the economic structure of the model may not be similar to that of the historical period of interest. Technological change may have introduced new technologies and driven older technologies out of the market place. Such changes modify the coefficients representing the efficiency at which primary 
energy inputs are converted into secondary forms of energy or into useful work. Thus, any use of the analogy-by-model approach should be for a time period close to that for which the model is designed to forecast. Second, the historical period under study may call for data inputs or parameter values which are outside the range used in estimating the model. In this case, it would be difficult to assess the validity of the results.

A third limitation of this approach has to do with a possible bias in the results. Typically, a model would be used to assess the magnitude of change of some outcome variable (e.g., quantity of $0 i 1$ produced) in response to some input policy (e.g., a tax program). This quantity would be calculated for some future year since the model only operates in a forecast mode. Then the quantity change would be attributed to some earlier period in which we want to assess the policy effect. Many other variables would not be the same in the forecast and historical years; hence, it is possible that the estimate of policy impact could be biased. A partial solution is to set variables affected by the policy at levels approximating the historical period, to the extent that this is possible. This tactic may, of course, lead to some of the previous problems we have mentioned.

The list of shortcomings of this approach needs to be balanced by one argument in its favor. The parameters of most models are estimated using some form of historical data. This is by definition true of econometric models and is to some extent true of process models which may use historical experience of engineers to formulate coefficients. A model based on historical data ought to be good at assessing policy impacts in that same time frame. In fact, if a model can be manipulated to assess historical policies, it may be more valid for this purpose than for forecasting. Operated in a forecast mode, a mode] is always open to the objection that unanticipated technological changes will modify the coefficients in the model or that demanders' preferences for various forms of energy and for other uses of income will change. These objections are not available in a historical analysis.

In conclusion, the analogy-by-model approach has admitted shortcomings, but may be useful in two situations: 1) when no other analytical tool can adequately handle complex and interactive effects of policies, and 2) when an 
analogy approach is indicated but no historical analogy is available. In the detailed model capabilities sections that follow, attention should be paid to the policy variables available in each model even if the discussion indicates that the model cannot be run in a backcast mode. In some cases, an analogy-bymodel approach may be feasible and desirable.

\section{Summary of Model Capabilities}

As an illustration of the capabilities and limitations of the modeling approach, consider the list of policies in Chapter 1. Most of the policies can be evaluated using four of the energy-economic models discussed below. However, considerable preparatory work and several strong assumptions would be required.

The Gulf Energy Model could be used in an analogy-by-model approach to evaluate the effects of coal, oil, and natural gas depletion allowances, oil and gas expensing of intangible drilling expenses, health and safety standards in the coal industry, oil pricing schemes, and federal income tax exemptions for public power entities. To incorporate these policies into the Gulf Model (or to take them out if they are assumed to be an effect in Gulf Base Case simulations) would require translation of policy effects into implications for the long-run marginal cost curve for a particular technology. These implications might be developed from the inspection method or the engineering approach. The total costs involved are apt to be quite high, however.

Evaluation of coal health and safety standards would require the assumption that observed declines in mining productivity are due entirely to the Coal Mine Health and Safety Act of 1969. This is a very strong assumption that would be challenged by many observers of the coal industry.

Coal leasing policies could be evaluated using the Zimmerman Coal Supply Model, assuming that the effects of leasing policy on the stock of minable coal reserves can be specified. The reserve data base in the Zimmerman Model is based on Eastern reserves, however, whereas the leasing policy of interest mainly affects Western coal lands. Thus, the "analogy" in this case would be a bit tenuous. It should be noted that $Z$ immerman himself assumes that the Eastern data are typical of national conditions, and that his model produces a valid long-run supply curve for the nation's coal industry. 
An alternative to using the Zimmerman Model for coal leasing policy would be to use the Gulf Model, which separates the Eastern and Western regions for purposes of constructing long-run marginal cost curves. To use the Gulf Model, the effects of leasing policy on Western region marginal cost curves would have to be specified. This would be a non-trivial research task.

The National Coal Model could be used to explore the effects of the Coal Mine Health and Safety Act of 1969 on the coal industry on the assumption that post-1969 underground mining productivity declines are due to the Act alone (a very strong assumption which would provide an upper-bound estimate of policy impact). Alternative productivity assumptions would have to be linked to coal supply cost at the mine mouth for underground mines. The effects of depletion allowances could also be assessed if the impact of this policy on coal cost at the mine mouth can be specified. Unless there are differential effects of depletion allowances by region or mining technique there is no reason to use this very detailed model to assess this policy. The Gulf Model might be more appropriate for assessing this policy.

The MacAvoy-Pindyck Natural Gas Model is ideally suited to examine wellhead price setting and offshore leasing policies for the natural gas sector in the 1968 to 1985 time frame. Wellhead prices are exogenous inputs to MacAvoyPindyck, making analys is of this policy very easy to conduct. Offshore leasing policies would have to be evaluated for their effects on reserve availability, and on discovery and development costs. Considerable work might be needed to produce the required cost and quantity inputs for the model in order to simulate leasing policies.

Two nuclear power policies could be evaluated using the Baughman-Joskow Regional Electricity Model in the time frame of 1947 to $1990 .{ }^{(a)}$ One could work through the assumptions about policy impacts. For example, if the impact of the Price-Anderson Act can be conceptualized as permitting the development

(a) Availability of the model is not an issue per se since it is a DOE model. This model is a more detailed model, in terms of regional, technological, and economic factors, than the Gulf model. Finer resolution of policy impacts is therefore possible. 
of the nuclear power industry, i.e., an assumption that, in the absence of the Act, no nuclear power industry would have developed, then one could impose a moratorium on nuclear technologies in the model and simulate the supply side using only fossil fuel and hydroelectric technologies. If nuclear R\&D can be conceptualized as making nuclear technology available earlier than otherwise, then these effects can be simulated using a moratorium on nuclear technologies in particular time frames. If nuclear $R \& D$ is thought of as affecting the costs of constructing or operating nuclear reactors, then these cost effects can be simulated in the Baughman-Joskow Model once they are concretely specified as so many dollars in certain years.

Four policies listed in Chapter 1 cannot be handled by the models surveyed in this report in either the backcast or analogy-by-model mode. Coal R\&D conducted by the Bureau of Mines has had an effect on mining technology and on information about reserves. But until the effects of these efforts on marginal cost curves are specified, or the effects on reserve stocks of minable coal are delineated, the policy impacts cannot be simulated. Leasing policies for oil reserves cannot be handled unless the impact of such policies on marginal cost curves for particular producing regions is specified. The federal government's activities in constructing and operating dams cannot be adequately handled unless estimates of the costs of building and operating these facilities by investor-owned utilities can be provided. Government provision of nuclear fuel enrichment would appear to have no effect, since studies by Tybout (1958) indicate that these services were provided at about the same cost as private entrepreneurs would have charged had the government left the business to the private sector. Thus, simulation of the impacts of three of these policies would require major preparatory research. Several of the other policies for which modeling capabilities have been indicated also require some preparatory work, but for coal R\&D, oil leasing, and federal hydro-power activities, the magnitude of preparatory research required is much larger. Uranium enrichment policies do not seem to require any modeling effort.

Only two models have been found which have explicit backcasting capabilities. Both of these are single-sector models and their backcasting 
capabilities are severely limited. The MacAvoy-Pindyck Natural Gas Model can backcast in the 1968 to 1974 time period, although little expertise in using the model in this way seems to exist. The Baughman-Joskow Regional Electricity Model begins investment simulation in 1947, but uses exogenous demand levels until 1972. Policies which impact these two sectors can accordingly be evaluated by the models in an explicit backcast mode for these years, but with the limitations mentioned.

The remaining models we surveyed offer a great variety of policy modeling capabilities. However, none of them operate in a backcast mode. All operate in a forecast mode, with time horizons extending forward from the present to several months in the future and all the way out to 75 years in the future. Use of any of these models for this project would entail simulating the effects of a policy in a future time frame rather than simulating its effects in a historical period. Thus, they could be used to create analogies, or simply the future projected effects of imposing or removing a policy which was previously utilized in some historical time period. Such use of models lacks the concreteness and veracity of a good understanding of the actual effects of actual historical policies. This limitation of the analogy-by-model strategy must be kept in mind in evaluating the strategy.

In addition, the models suffer from their very large scale and complicated structure. This makes them expensive to use and difficult to access. Accordingly, any serious consideration of the analogy-by-model strategy should be restricted to models available on a commercial basis, such as the Gulf Energy Model and the Data Resources Model, and to studies with ample budgets.

The primary advantages of these models lie in their ability to take into account the complexities and interdependencies of energy economics in an explicit fashion. Tax policies affect investments; $0 i 1$ prices affect the use of natural gas; and environmental policies affect the choice of generating plants by electric utilities. The many feedbacks and the many independent variables in the energy sector can be handled explicitly only by large scale models. However, the cost effectiveness of using models to evaluate historical 
policies may not be high relative to more traditional analytical techniques when the models are restricted to the analogy-by-model mode, or when substantial preparatory analyses are necessary to prepare needed model inputs. Therefore, they have not been used in the generic analysis, and have been minimally employed for specific energy forms.

\section{A Possible New Model}

We also investigated an analytical tool designed to determine the effects of past incentives and for use to determine the effects of future incentives for new energy technologies. The analytical approach we investigated is based upon the relation between the profitability of investment in an energy industry and the amount of energy produced by that energy industry. It is appropriate for analyzing the effects of financial incentives upon energy production in industries dominated by private enterprises motivated by a profit incentive. Since the expenditures on financial incentives in the oil, gas, and coal industries amount to over half of all energy incentives expenditures, this analytical tool can be helpful even if applied in only these three industries.

One important advantage of this new approach is that it allows the use of a single, consistent method for determining the effects of both past and future energy incentives. This is an advantage not shared by any available energyeconomic model, either large scale or small scale.

When the structure of the industry can be expected to change either independently of government policy or as a result of that policy, then the traditional kind of modeling is no longer appropriate for providing an accurate guide to the effects of that policy, since the historical period provides no experience with a changed industry structure; the past relations among factors of production can no longer serve as an accurate guide to their expected future relations. Such is the situation we may be faced with concerning energy incentives and their effects on the development of new energy technologies. The production relationships in the coal or oil industry will tell us little about how much more solar energy will be produced as a result of an incentive designed to stimulate solar production. 
The most likely event is that detailed production relations will be developed for the new energy sources as we gather actual production experience. These can then serve as a basis for formulating detailed energy-economic models (for the solar, wind, and geothermal industries) similar in design to some of the current, detailed models of existing energy industries. The major difficulty with this approach is that we may need to wait for 10 or 20 years for the historical data to be generated for these new industries and to allow sufficient time for the energy-economic modelers of these new industries to develop those new tables. A new approach is clearly needed which is based on our historical experience, yet which in some way can be relied upon to provide us with accurate information about the effects of stimulating these new technologies with various incentives. Insofar as financial incentives are concerned, the profitability-production relation we investigated provides just such a new approach.

\section{The Profitability-Production Relation}

The crux of this new approach is the assumption that private, profitoriented energy firms are interested in getting the greatest possible return on every dollar they invest in energy production. It is expected that they will invest more in those energy activities providing higher returns and less in those providing lower returns. It is expected that the higher its return relative to the return from other activities, the more they will invest in any given energy activity over time. Therefore, production should be greater from those energy activities yielding higher returns. For any given energy activity, production over time should be greater the higher the return from that activity. Since the ultimate outcome of energy firm behavior is energy production, and since the ultimate motivating element is the profitability from that energy production, we examined the relation between profitability and production directly.

An Example: The $0 i 1$ and Gas Industry

We chose the oil and gas industry to investigate the usefulness of this new approach. This choice was dictated by the fact that data is readily 
available on the two elements of this approach: the after-tax rate of return on invested capital in the industry and the number of British Thermal Units (Btu's) of 011 and gas produced. (a) See Table 2.3.

Four alternative specifications of the profitability-production relation were estimated over the historical period. The estimation results indicate that a statistically significant, positive relation between profitability and production has existed over this period for the oil and gas industry. Moreover, the results indicate rather surprisingly that the effects of profitability on production are felt with a time lag of one year or less. This analysis is set forth in detail by Maurizi (November 30, 1978).

Using the Profitability-Production Relation to Estimate the Impact of Past Energy Incentives

The profitability-production relation provides a way to estimate the impact of past energy incentives. The only additional ingredient that is needed is an indication of the extent to which past financial incentives have altered the profitability of investment in the industry. In other words, if a particular set of tax incentives had the result of increasing the rate of

(a) The Chase Manhattan Bank has annually calculated the after-tax rate of return on invested capital (defined as net income--which is total revenue less operating costs and other expenses, taxes and writeoffs--divided by average invested capital) for a group of 29 large petroleum companies since 1945. The rate of return is calculated both for worldwide operations and U.S. operations. The return from U.S. operations has been used for this example. It is believed that $60 \%$ to $70 \%$ of U.S. $0 i 1$ production and $60 \%$ to $70 \%$ of U.S. natural gas production results from the group of petroleum companies included in the Chase series. This rate of return series has been compared with the Btu production of $0 i 1$ and natural gas in the U.S., an annual series prepared by the U.S. Bureau of Mines beginning in 1947 . The Btu's of oil have been added to the Btu's of natural gas to provide the combined production of Btu's of oil and gas because the rate of return series has been calculated for a group of firms which produce both oil and gas. The analysis could be performed for a single industry such as coal just as we11. The U.S. Bureau of Mines provides us with annual production of coal in Btu's. However, the rate of return to investment in the coal industry has not been calculated; this annual data would need to be calculated before analysis of the coal industry could be conducted in a manner similar to that done for $0 i 1$ and gas. 
TABLE 2.3. Profitability and Production in the U.S. $0 i 1$ and Gas Industry: 1947 through 1975

\begin{tabular}{lcc} 
Year & Rate of Return $(\%)(a)$ & $\begin{array}{c}\text { Production of } 0 i 1 \text { and Gas } \\
\text { (Quadri11ion Btu's) }(b)\end{array}$ \\
\cline { 2 - 2 } 1947 & 14.9 & 15.9 \\
1948 & 20.0 & 17.7 \\
1949 & 12.9 & 16.7 \\
1950 & 14.6 & 18.4 \\
1951 & 15.9 & 21.4 \\
1952 & 14.0 & 22.3 \\
1953 & 14.0 & 23.3 \\
1954 & 13.0 & 23.1 \\
1955 & 13.5 & 25.0 \\
1956 & 13.9 & 27.9 \\
1957 & 13.0 & 27.2 \\
1958 & 9.5 & 26.4 \\
1959 & 9.7 & 28.0 \\
1960 & 10.0 & 28.8 \\
1961 & 10.0 & 29.9 \\
1962 & 10.3 & 30.9 \\
1963 & 11.2 & 32.0 \\
1964 & 11.1 & 32.8 \\
1965 & 10.8 & 33.6 \\
1966 & 12.1 & 35.8 \\
1967 & 12.3 & 38.2 \\
1968 & 11.7 & 40.1 \\
1969 & 11.0 & 41.7 \\
1970 & 9.9 & 43.9 \\
1971 & 9.3 & 44.8 \\
1972 & 9.6 & 44.8 \\
1973 & 10.5 & 43.6 \\
1974 & 14.6 & 42.3 \\
1975 & 12.9 & 39.8 \\
& 19.9 &
\end{tabular}

(a) 1947 to 1969: U.S. Senate Commerce Committee, June 29, 1974, Hearings, p. 249.

1970 to 1975: Chase Manhattan Bank (October 1977).

(b) 1947 to 1975: Bureau of Mines (1968).

return in the $0 i 1$ and gas industry from say, $8 \%$ to say, $10 \%$, then the profitability production relation enables us to estimate the extent to which production increased as a result of the tax incentives.

Estimates of the impact of financial incentives on the rate of return could be obtained from other studies whenever they are available, or from a 
simulation of the effects of the incentive on the rate of return to the industry. The advantage of the latter simulation approach is that it will also be necessary for analyzing the impact of future energy incentives in new technology industries. In other words, one basic relation (the profitabilityproduction relation), together with the process of simulating the effects of financial incentives on the rate of return, can form the basis for analyzing the production impact of both past and future energy incentives--i.e., for both old and new technologies. This makes it possible to employ a common method for analyzing past and future energy incentive effects, which is not possible with any of the existing energy models. More technically, the same profitabilityproduction relation can be used for both backcasting and forecasting.

Using the Profitability-Production Relation to Estimate the Impact of Future Incentives

In order to estimate the production impact of financial incentives in the new energy technology industries, it will first be necessary to determine the impact of those financial incentives upon the rate of return to investment in those industries. Since even the latter is largely a speculative effort, this means that the estimate of the impact of the financial incentives on the rate of return will depend upon the set of assumptions which are the basis of the rate of return calculations. These include such things as the expected future price of energy sold (whether produced from solar, wind, or geothermal sources), the expected future cost of producing that energy, and the discount rate applied to future revenues and costs. This will probably require the construction of several different scenarios depicting the alternative combinations of these critical assumptions that bracket the expected rate-of-return levels. The impact of the financial incentives on production could then be determined for each of these scenarios. The critical qualification is that these future energy industries are operated by private enterprise motivated by a profit incentive.

Estimation by the Quantified Expert-Opinion (QEO) Approach

Although each of the foregoing techniques has certain advantages, they are inadequate for estimating effects in situations of unique actions or actions for which old ways of operation or technology no longer apply. It is in these 
situations that the (QEO) approach may be most applicable. The quantified expert-opinion approach is a combination of the analogy method and approaches like the Delphi process of polling expert opinion. The Delphi process, as the name implies, is a subjective expert-oracle approach to estimation: a group of "authorities," knowledgable and experienced in planning for implementing the action or actions similar, provide "expert" opinions as to what the effects will be. A typical Delphi process operates as follows. Each participant receives and completes a questionnaire. The identities of the other members are kept confidential or anonymous from individual members. The results of the questionnaires are analyzed and forwarded to the individual respondents so that they can compare their answers to those of others. The participants at the extremes are asked to write short explanations of their positions, and these are relayed back to the group unsigned, Each participant then has the opportunity to change his or her position. The process is repeated until opinion stabilizes. Finally, the responses are statistically analyzed and aggregated to yield a group response. For estimating, the expert opinions are made relative to an action which has been chosen to serve as a baseline.

Another less formal technique is to seek the opinions of those persons who have been actively involved in creating and operating the government actions of interest. Presumably these active participants have a special and valuable perspective on the actions. They know what their goals were when they helped create the action; they also pay close attention to whether those goals were achieved. Thus, interviewing these persons helps identify potential effects (using the participants' judgment about whether their goals were achieved). This report makes particular use of this technique in Chapter 3 , which generically analyzes the impact of energy-related actions on the price and quantity of energy.

The views of the participants are particularly valuable because the participants are apt to care about results in addition to effects. They are caught up in the context in which the action took place and are likely to have a holistic viewpoint.

Expert opinion is available from a number of sources. Some sources, however, are preferable to others. Formally expressed expert opinions (those 
opinions stated in writing) are preferred for their availability and the care given to preparing them. Examples of formally expressed opinion include: Congressional committee reports on bills introduced to Congress, published hearings on Congressional oversight and appropriation proceedings, published reports by federal agency officials on their energy-related actions, and reports issued by trade associations with energy interests. Second preference is given to expert opinions resulting from interviews with energy-related interest groups, Congressional staff members, and agency officials. Where reports of such interviews are not available, it is possible to conduct them.

Formally expressed expert opinions, however, are more available than generally thought. Since 1974, Congress has used a consistently applied method to analyze the impacts of government actions. This method, required by Section 301(c) of the Congressional Budget Act of 1974 (P.L. 94-344, 85 Stat. 431-461), has been developed through working agreements between standing committees and the Congressional Budget office. The Act requires each standing committee of Congress to prepare an evalution of the fiscal impact of federal action within their jurisdiction on annual budget outlays.

These impact evaluations, though, are limited in purpose. By emphasizing fiscal impacts, many other type of effects to federal actions remain outside the scope of these studies. Where additional types of effects are suggested by a review of actions for the purpose of making fiscal justifications, they are not explicitly stated. Yet by identifying each major federal action, these reports lay the groundwork for the consideration of additional types of effects such as a categorization of real returns associated with measures of program effectiveness, or a categorization of effects to population growth, high density urbanization, industrial expansion, resource exploitation, and new and expanding technological advances. The latter illustrate some impact formats which could be, but are not consistently, employed. These reports, nonetheless, are a good beginning to a systematic approach to assessing the impacts of government actions.

Outside of Congress, the Office of Management and Budget (OMB) does systematically evaluate federal actions. With the advent of the Planning Programming Budgeting System (PPBS), OMB has placed greater emphasis on the 
objectives of federal actions, and, to the extent that PPBS considers objectives, there is some identification of anticipated effects to government actions.

Although an attempt is made to describe federal actions by policy area in the Special Analys is volume of the President's budget message, these reports are limited to analyses of fiscal arrangements used to conduct various federal actions. For the most part, descriptions of effects to federal actions are peripheral to the discussion of fiscal policy.

The techniques described in this section are systematic efforts to use group judgment and expertise in areas where knowledge is incomplete--the basic premise being that "many heads are better than one" and that a group will be more objective if there is no direct confrontation.

The QEO method is particularly applicable to actions for which a significant portion of the effects are not tangible or "hard" effects. It also has the advantage of producing a relatively acceptable estimate at a moderate cost in a short time period.

\section{CONCLUSION}

The evaluation of a government action cannot stop with the identification and quantification of effects, because no government action takes place by itself. Instead, as Figure 2.1 depicted, the effects of individual actions interact to produce results in a given policy area. Therefore, a major problem for evaluation is to determine how actions interact with each other in the same policy area. Fortunately, many of the techniques used to identify and quantify effects can extend to identifying and quantifying results.

A theoretical framework for analyzing the results of federal actions toward energy involves four elements:

1. The idea that a policy area, like energy, contains actions that have effects that interact to produce results (Figure 2.1).

2. The idea that effects and results can be categorized in terms of economic, political, organizational, legal, environmental, demographic, and quality 
of 1 ife factors (Table 2.1). In this report we are concerned primarily with economic factors: the quantity of energy produced and the price at which it is sold.

3. The idea that effects can be further characterized by various measures to aid quanitification and the unraveling of interactions (Table 2.2).

4. The idea that effects can be estimated by using a variety of methods, and that some methods are more appropriate to particular situations than others.

The effects of government actions form "a seamless web." Each action influences everything, just as pulling on one spot of a web will move other parts. However, just as parts of the web are moved much more than others by pulling at a particular spot, a particular action will have some effects more than others. Attention, therefore, must be given to identifying major actions that have major impacts.

This concentration on items of major impact, however, requires a caveat. Minor effects may interact or accumulate to produce major results. Therefore, when analyzing actions at the effects stage, one needs to be sensitive to minor effects so as to preclude missing major items at the results stage. To heighten this sensitivity, we have developed a typology of effects that is as complete as we could make it. Throughout the rest of this report, we keep this typology and the wide range of potential effects in mind.

We have identified five general methods comonly employed for effects and results estimation: 1) inspection, 2) engineering, 3) analogy, 4) modeling, and 5) quantified expert-opinion. Even though categorization may not play a direct role in the estimation process, it nonetheless provides a useful conceptual framework for viewing effects, a rather detailed checklist of the types of effects that should be considered, and a guiding commentary on the mechanics for correct treatment of effects.

An estimate of effects can vary from a gross overview to a detailed estimate prepared from complete specifications. The cost, accuracy desired, and need for the estimate combine to influence the choice as to which approach or combination of methods to employ. In general, the time and effort required for 
preparation (the cost of the estimate) depends on the accuracy desired which, in turn, should correspond to the ultimate use of purpose of the estimate. Similarly the type, availability, and accuracy of inputs required by the various estimation methods should be considered when choosing an appropriate method. It would be inappropriate, for example, to apply the engineering approach in the assessment of effects resulting from many energy-related actions, since many types of actions have subjective effects that do not lend themselves to quantification or a breakdown into elemental quantities.

These considerations preclude a generalization identifying a "best" method. Instead, methods are of ten more effectively used in combination with one another. One approach may be applied as a "first pass" to indicate those effects or effects categories dominating the total estimate and deserving of attention since, if drastically misjudged, they can impact significantly on the total estimate. A second, and different, approach or approaches may then be applied to these dominant categories in an attempt to refine and improve the accuracy of the final estimate.

Most important is the fact that estimating approaches can be combined to get a comprehensive view of results. For example, the quantified expertopinion approach may be used to estimate the quality of life and organizational effects associated with an action; the more highly structured engineering approach can be used for aggregating economic and environmental effects; and the analogy approach can be used to estimate political effects or legal effects, each based on applicable data from a similar experience.

Recormendation of an appropriate method for estimating the effects of an action requires the consideration of a number of the characteristics of the action. The reliability of historical data for similar actions, the uniqueness or dissimilarity of the action to past actions, the degree of accuracy sought, and the cost of estimation are all determinants of the "best" estimating procedure to employ. Because government action includes so many types, no single estimating procedure can be recomended as being definitively most appropriate to all actions and all effects.

In this report, various techniques for estimating effects and results have been used. Chapter 3 and Chapter 4 use versions of the quantified expert 
opinion methodology. Chapter 5 relies on the engineering approach, but much of the data has been collected using inspection methods and with analogies in mind. Similarly, Chapter 6, Chapter 7, Chapter 8, and Chapter 9 do not use large-scale energy/economic models, but rely on a combination of the inspection, analogy, and quantified expert opinion methods. 
CHAPTER 3

GENERIC ANALYSIS OF THE RESULTS OF INCENTIVES

by

Roland J. Cole, Policy Analyst and Lawyer

Pau 1 E. Sommers, Economist

James H. Maxwe 11, Political Scientist 


\section{GENERIC ANALYSIS OF THE RESULTS OF INCENTIVES}

The purpose of this chapter is to analyze results of the six types of incentives used to stimulate energy production. Each of the other chapters analyzes the actions connected with a single energy form. The actions are traced over a number of years. In this chapter, we examine the results of incentives by incentive type rather than by energy form, and we focus on FY-1976 and FY-1977. Thus, in terms of the general questions asked in Chapter 1 , we are primarily concerned with determining how the impacts of incentives vary with the level of funding, and with examining the cummulative results of specific incentive types on the national energy budget.

In this chapter, we report on the effects of federal energy actions predicted by economic theory and observed by policy makers and policy activists. By drawing upon rich empirical and theoretical literature on types of government action or federal energy policy, we discover important insights that might otherwise be missed in the chapters dealing with single energy forms.

\section{METHODOLOGY}

In this chapter, we use the quantified expert opinion methodology described in Chapter 2. That is, we are using what we identify as the "center of gravity" among expert opinions in order to propose estimates of results of federal energy actions. First, we outline what economic theory predicts as the expected effects of the major incentive types on the price and quantity of energy produced. (The major incentive types--requirements, taxation, market activity, services, disbursements, and exhortation--were defined in Cone et al. December 1978). Second, we discuss the general tendencies of each incentive type as discussed in policy analysis literature. Third, we describe what policy activitists and policy makers said about the major results of federal energy actions.

For the third task, we rely on four principal sources: The New York Times for 1977 and 1978, testimony from Senate and House Committees in 1977 and 1978, testimony from the House Appropriations Hearings for 1979, and interviews with 
policy activists and policy makers. (a) The New York Times provides expert opinions of those outside government on the results of federal energy actions in FY-1976. The Hearings from the Select Committees and the House Appropriations Committee contain policy activists' and government experts' views of energy actions and effects. These latter sources are particularly useful in assessing qualitative policy effects. Finally, we interviewed the following policy activists and policy makers to determine their views of energy actions and effects:

$\begin{array}{ll}\text { Arie Berrits } & \text { American Public Gas Association } \\ \text { Dr. Loftness } & \text { Electric Power Research Institute } \\ \text { C. Branson Smith } & \begin{array}{l}\text { Department of Energy } \\ \text { Policy Planning }\end{array} \\ \text { Chester Cooper } & \text { Institute for Energy Analys is } \\ \text { J. P. Smith } & \text { Washington Post } \\ \text { Sam Schurr } & \text { Resources for the Future } \\ \text { Paul Turner } & \text { Atomic Industrial Forum } \\ \text { Cathy Abbott } & \text { Department of Energy } \\ \text { Bob Kelly } & \text { Department of Energy } \\ \text { Bob Vines } & \text { Office of Energy Research } \\ \text { Bob Strauss } & \text { Bituminous Coal Operators Association } \\ \text { Sandra Bregman } & \text { U.S. Congress } \\ \text { Harry Havens } & \text { Joint Committee on Taxation } \\ \text { Mel Thomas } & \text { Department of Energy } \\ \text { General Accounting Office } & \text { U.S. Congress } \\ \text { Dick Morgeristern } & \text { Joint Committee on Taxation } \\ \text { John Jamison } & \text { Congressional Budget Office } \\ & \text { Congressional Research Service }\end{array}$

Thus, the views of both governmental and nongovernmental experts are included in our analysis of the results of federal energy actions.

(a) These references are listed separately in Appendix B. 
CHAPTER OUTLINE

The chapter begins with a discussion of the effects that economic theory would predict for each incentive type. It then discusses each incentive type in turn. First, it describes the use of that type in FY-1976 and FY-1977, and then it diagrams the dollars devoted to that incentive type over time. The chapter then discusses the general tendencies of each incentive type and finally, what policy makers and activists have said about the results of that incentive. These expert-opinion observations come from the published sources detailed in Appendix $B$ and from our own interviews of governmental experts. The theoretical predictions are compared to expert-opinion comments to test the congruence of these two different est imation methods. No attribution is provided for comments based on interviews, since we promised respondents complete confidentiality and anonymity.

THE ORETICAL DISCUSSION

This section discusses the effects that economic theory would lead one to expect from the various types of incentives. It focuses on the changes in energy supply curves that one would expect to accompany incentive types, assuming all other things were equal. Of course, all other things are never equal, and these theoretically expected effects give way to actual results when types of incentives interact with each other and with other aspects of any situation. Nonetheless, identifying theoretically expected effects is useful for several reasons. One, the actual results of ten resemble the theoretically expected results because other things do not overcome the economic pressures. Two, the actual results often stem from the expected effects (in second or third rounds of causation). Three, the situations in which the actual results diverge sharply from the expected are particularly interesting because they help reveal the noneconomic factors at work.

For the purposes of this discussion, we have grouped the full range of governmental incentives toward production into five broad categories:

- Coercion (requirements, taxation)

- Market Activity 
- Donation (disbursements, services)

- Exhortation

- Reorganization (creation and prohibition of organizations).

Coercion refers to authoritative action by the government that requires private-sector firms to take certain actions or to abstain from specified activities. Civil and criminal sanctions may be used to enforce compliance with coercive governmental actions. Performance requirements and taxes are examples of governmental coercion.

Market activity by the government involves the purchase and sale of commodities and services. The government is of ten a buyer of goods and services from the private sector, but it also acts as a seller of goods (surplus military equipment) or services (education).

Donation by the government to the private sector refers to the uncompensated transfer of goods or services to the private sector. Money may be donated as in welfare or emergency relief programs. Goods and services, including knowledge, may be donated, as the Agricultural Extension Service donates knowledge. These goods and services often have tangible economic value but are donated by the government because the receiver is especially worthy or needy and has been deemed incapable of procuring the goods or services from the private market due to some form of market imperfection.

A fourth form of governmental incentive toward the private sector is exhortation. Exhortation refers to the government simply talking to the private sector, requesting its compliance with governmental goals, and appealing to $i$ ts self-interest or to its moral, ethical, and patriotic ideals. A familiar term for one form of exhortation is "jawboning." Another familiar form of exhortation is "a campaign for voluntary action" (DOE's "Don't be Fuelish" program). No explicit reward or sanction is involved, distinguishing exhortation from coercion and exchange. No tangible benefits are transferred, distinguishing exhortation from donation. Vague hints of future sanctions, rewards, or governmental market activity may accompany exhortation efforts by governmental officials. But in the classic mode, exhortation is not backed up by any immediate coercion, exchange, or donation. 
A fifth category, reorganization, includes attempts to create or prohibit organizations in both the public and private sectors. It is usually a less direct form of interaction between government and the private sector, especially where public sector organizations are involved. The government may reorganize private-sector production units through antitrust rulings and its powers to approve or veto the securities offerings of merging firms. These actions generally have the goal of making the production sector more competitive, thereby increasing the quantity offered at any given price. The government may also reorganize itself by creating a new agency (the Environmental Protection Agency) or by modifying the mandates and structure of old agencies (the Department of Energy, former ly ERDA). The effects of internal governmental reorganization depend on the types of incentives (coercion, exchange, donation, and exhortation) employed by the reorganized agency.

In this report we are interested in the impacts of governmental actions on the production of energy. In particular, we are interested in the price and quantity impacts of incentives and the product type and technological process changes induced by governmental actions.

Price and quantity impacts are related to each other in economic theory by the notions of supply-and-demand curves. If governmental actions raise the cost of a private-sector good or service, this can be viewed as an upward shift in the supply curve. Consumers are forced to pay more to get any given quantity of the commodity, and they will typically reduce the ir purchases somewhat (unless demand is totally inelastic, in which case no reduction in demand results from the price change). Conversely, if governmental actions lower the cost of a good, the supply curve of the industry may shift downward, offering consumers the opportunity to purchase more at any given price. Aggregate consumption typically increases under these circumstances. (An increase will follow if price effects are stronger than income effects. If income effects dominate, consumers may choose to consume about the same amount of the good at the lower price, thereby freeing up some of their income to be spent on other goods.) 
The price-quantity impacts described above assume constant product type and quality before and after the government takes some action. In fact, products may change because of new government standards or requirements or because entrepreneurs see new opportunities as a result of the government's action and begin to offer a product of different quality. Conceptually, this can be viewed as the introduction of a new good or service into the market place. Supply-and-demand curves for this "new" product determine the quantity of sales. Product changes are difficult to predict if they are of the second entrepreneurially induced variety. Consequently, product change is an impact which the analyst must always keep in mind, but it is not one which can be easily quantified or even qualitatively assessed.

Technological change may also result from government activities. Government-sponsored research may lead to new products or new ways of producing old ones. Requirements programs may explicitly mandate technological change and may specify upper or lower performance limits for the new technology. Plastics from government aerospace programs and the use of catalytic converters to meet recent pollution standards are examples of government-induced technological change.

Establishing a new technology in the private sector takes a long period of time. Once new technology is embodied in industrial processes, or in new or improved products, the forces of supply and demand again determine the quantity and price of the ultimate products. These market forces constrain the direction of impact of government-induced technological change in the private sector. New technology must reduce costs, improve the product, increase the demand for other products, or promise new products in order to find a place in the private sector.

In order to assess the full range of government incentive impacts on production, the four types of government incentives must be considered together with the three categories of impacts. Table 3.1 charts all possible impacts in an incentive-type-by-impact-category matrix. The direction or qualitative type of impact is indicated in the cells of Table 3.1. The direction of impact has been developed from standard economic assumptions which are explained be low. 
The usual economic assumption is that firms want to maximize profits and therefore attempt to minimize costs. This assumption implies the pricequantity effects of Table 3.1. Coercive policies tend to either increase a firms' costs by limiting options, thereby increasing prices and reducing quantity demanded, or they have no effect at all because no viable options are foreclosed. (The now-defunct OSHA standards for size and shape of toilet seat covers may fall into this "no effect" category.) In the exchange category, the direction of impact depends on whether the government is buying or selling. Assuming constant returns to scale, large purchases will drive price up, and quantity in the aggregate (government and private purchases) increases unless many private sector consumers drop out of the market. In some industries, large government purchase programs may permit manufacturers to achieve economies-of-scale in production. In such cases the ability to sell large quantities will drive costs down, and increased private-sector purchases will typically result. Large production and sales by the government have the opposite effects of depressing price and increasing the quantity demanded by consumers. Donations by the government typically reduce costs and thus reduce price and increase the quantity demanded by consumers. Donations may have a very long lag time from donation to private-sector response if the donation is of a service or of knowledge that takes time to be incorporated into production processes. That is, donations often cause technological changes, a separate type of impact discussed below.

Product changes may result from government incentives. Coercive actions by the government may restrict the range of products offered in the market. For example, prescription drugs which promise some therapeutic benefit but pose great risks to patients may not be approved for sale by the Food and Drug Administration. Some consumers might choose to take such risks but are not allowed this option by the government. The government as consumer or producer in the marketplace can affect the product options available to private-sector consumers. Goods built to governmental standards may be offered to consumers by the government or by private-sector firms also producing for sale to the government. Donations by the government can affect the kinds of goods available by taking over part of the market (low cost, low quality housing) or by 


\section{TABLE 3.1. General Tendencies of Incentive Impacts}

\begin{tabular}{|c|c|c|c|}
\hline \multirow[b]{2}{*}{ Type of Incentive (a) } & \multicolumn{3}{|c|}{ Category of Impact } \\
\hline & Price and Quantity & Product Type & Technological Change \\
\hline $\begin{array}{l}\text { Disbursements } \\
\text { Services }\end{array}$ & $\begin{array}{l}\text { Reduces price and } \\
\text { increases quantity. }\end{array}$ & $\begin{array}{l}\text { Changes product } \\
\text { quality resulting } \\
\text { in "new" product. }\end{array}$ & $\begin{array}{l}\text { Reduces price and } \\
\text { increases quantity as } \\
\text { a result of better } \\
\text { processes. Introduces } \\
\text { new products. }\end{array}$ \\
\hline Taxation & $\begin{array}{l}\text { Reduces price and } \\
\text { increases quant ity. }\end{array}$ & $\begin{array}{l}\text { Increases range of } \\
\text { options available. }\end{array}$ & $\begin{array}{l}\text { Increases range of } \\
\text { options available, } \\
\text { encourages capital } \\
\text { investment. }\end{array}$ \\
\hline
\end{tabular}

\begin{tabular}{|c|c|c|c|}
\hline $\begin{array}{l}\text { Government as } \\
\text { consumer }\end{array}$ & $\begin{array}{l}\text { Increases price and } \\
\text { quantity. }\end{array}$ & $\begin{array}{l}\text { May create initial } \\
\text { demand for socially } \\
\text { desirable products. }\end{array}$ & $\begin{array}{l}\text { Government standards } \\
\text { may induce technolog- } \\
\text { ical change. }\end{array}$ \\
\hline $\begin{array}{l}\text { Government as } \\
\text { producer }\end{array}$ & $\begin{array}{l}\text { Reduces price and } \\
\text { increases quantity. }\end{array}$ & $\begin{array}{l}\text { Government sector } \\
\text { may offer different } \\
\text { products. }\end{array}$ & $\begin{array}{l}\text { Government may produce } \\
\text { more advanced produc- } \\
\text { tion or use new pro- } \\
\text { duction methods. }\end{array}$ \\
\hline Requirements & $\begin{array}{l}\text { Increases price; may } \\
\text { increase quantity. }\end{array}$ & $\begin{array}{l}\text { Discourages some new } \\
\text { products or technol- } \\
\text { ogies, encourage } \\
\text { others. }\end{array}$ & $\begin{array}{l}\text { Discourages some new } \\
\text { products or technol- } \\
\text { ogies, encourage } \\
\text { others. }\end{array}$ \\
\hline
\end{tabular}

Reorganization

Private sector

Public sector

Exhortation
Changes structure of private-production sector usually has impacts similar to disbursements and services.

\section{Impacts are generally} long-run and depend on the incentive iypes (disbursements through exhortation) used by the new government agencies.

Impacts usually limited except in emergency situation. Direction of impact variable.
Changes structure of private-production sector usually has impacts similar to disbursements and services.

Impacts are generally long-run and depend on the incentive types (disbursements through exhortation) used by the new government agencies.

Impacts usually limited except in emergency situation. Direction of impact variable.
Changes structure of private-production sector usually has impacts similar to disbursements and services.

Impacts are generally long-run and depend on the incentive types (disbursements through exhortation) used by the new government agencies.

Impacts usually limited except in emergency situation. Direction of impact variable.

(a) This table lists impacts as if the incentive were used positively. The negative use (imposition of a tax, or denial of money) would have the opposite effect. 
performing services that the private sector cannot effectively organize, thereby resulting in product changes (Agricultural Extension Service impacts on agricultural techniques and products). As in the case of price/quantity changes, the impact of donations on production may be mediated by technological change.

Technological-change effects may result from government incentives over a fairly long period of time. Coercive programs may constrain R\&D in certain directions (mileage and emissions standards for automobiles). Tax programs may either facilitate (R\&D credits) or discourage (capital gains taxes) innovative activity. The government-as-buyer can encourage technological change by buying from technologically progressive firms and by building state-of-the-art components into its buildings and machines. The government can also put a significant damper on technological change by continuing to do things as they always have been done, dealing with established suppliers and failing to make an effort to find a better manner of conducting its business. The government's donations of money, services, and knowledge may significantly encourage technological change by disseminating information, directly funding and supporting $R \& D$, and funding innovative private-sector demonstrations of new technology. As noted above, many of the long-run effects of government incentives on the price/quantity and on quality occur through long-run technological change rather than as a direct and immediate consequence of an incentive program.

Exhortation as an incentive category remains to be dealt with. Exhortation does not fit neatly into an economic framework analyzing governmental impacts on the private sector. There is no doubt that in times of crisis such as a war or calamitous natural disaster, government exhortation can appeal to people's senses of morality and patriotism, resulting in more quantity produced at the same dollar cost, dramatic changes in product quality to suit the needs of the crisis, and relatively rapid implementation of technological changes necessary to produce needed materials with available resources. It is not clear how long and under what circumstances such exhortation can maintain the desired results. Coercive, or exchange, incentives are often necessary as backups to exhortation. Exhortation in situations not widely perceived as emergencies is markedly less effective than exhortation in a clear crisis. The 
limited impact of several presidential statements on energy conservation in the years following the 1973 to 1974 energy $\mathrm{cr}$ is is is an example of the ineffectiveness of exhortation in a situation not widely perceived to be an emergency. (For a discussion of cases in which exhortation is effective, see Rothschild 1979).

In the section below, we examine the costs and results of each type of incentive. The costs of each incentive type in one or two recent years are presented, and the costs from 1950 to 1977 are presented in Figures 3.1, 3.2, $3.3,3.4$ and 3.5. Then we discuss the general tendencies of each incentive. Finally, expert-opinion comments on the results of these incentives, based on the opinions summarized in Appendix $B$ and on our interviews of governmental experts (1isted on p. 3.2), are presented and compared to the theoretical predictions discussed above and summarized in Table 3.1.

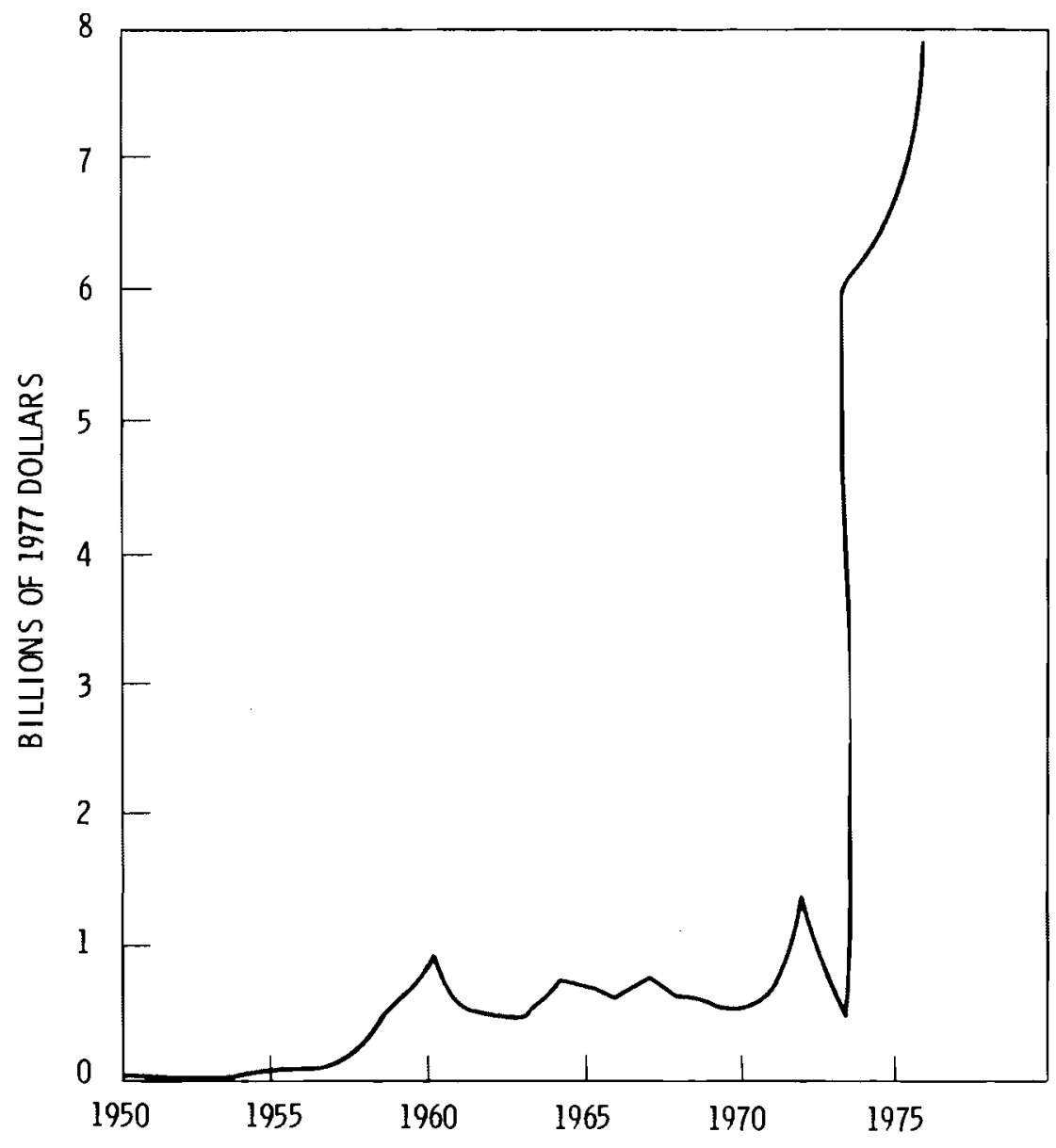

FIGURE 3.1. Costs of Requirements Incentives by Year 


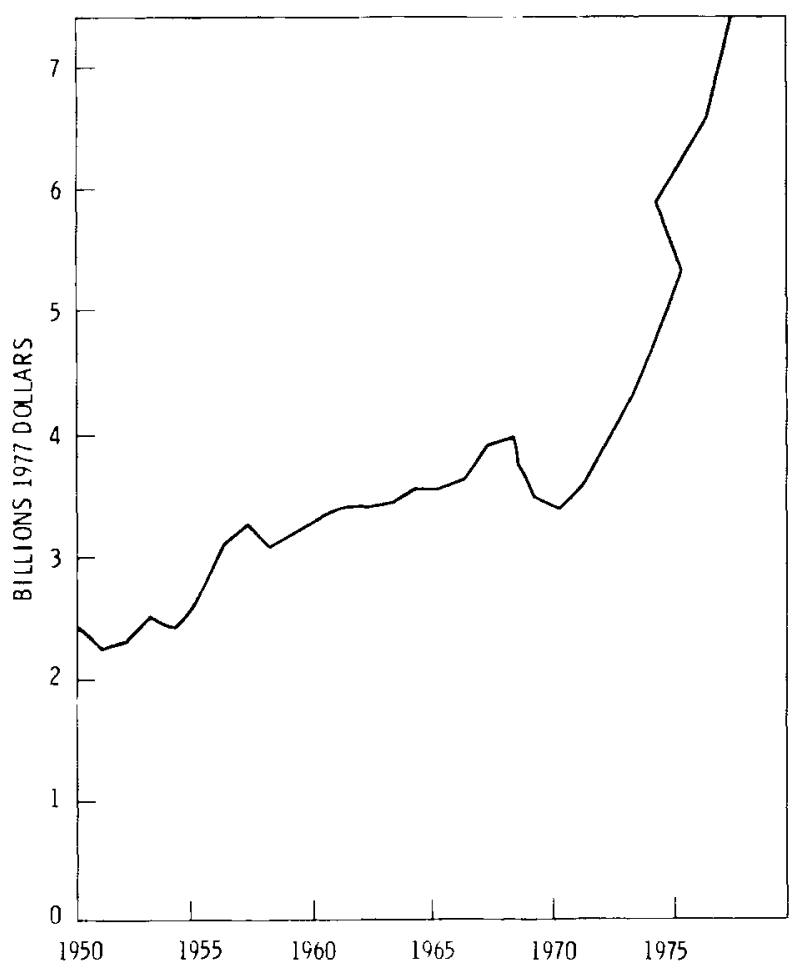

FIGURE 3.2. Cost of Taxation Incentives by Year

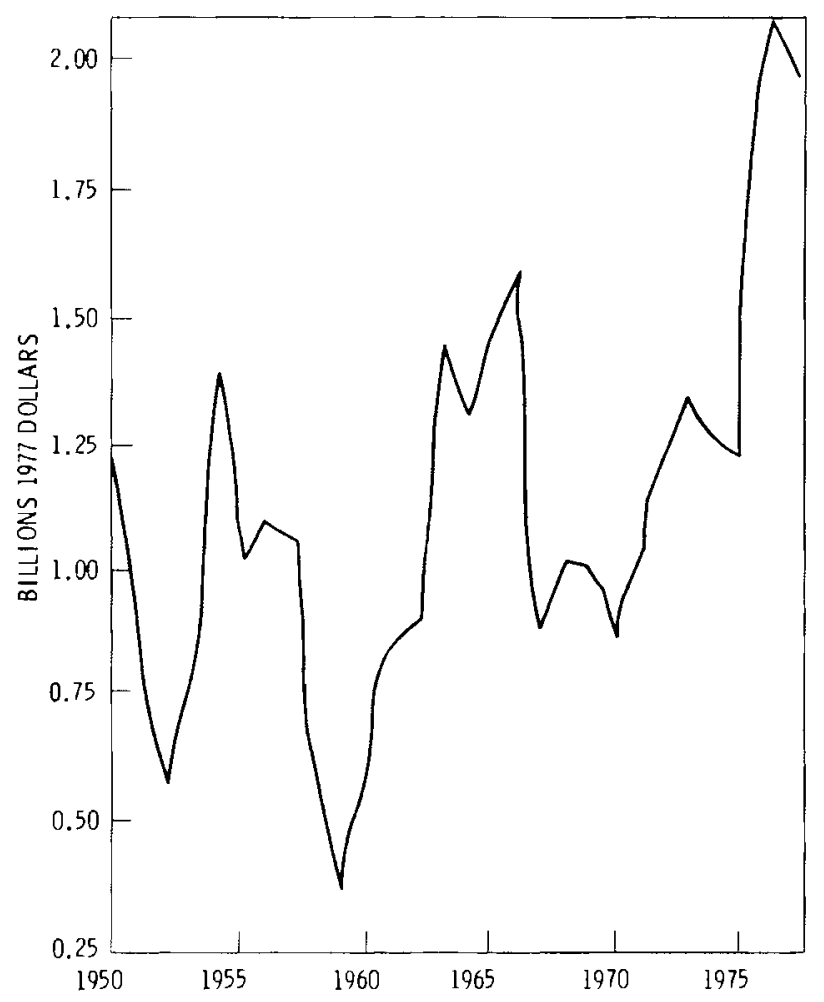

FIGURE 3.3. Cost of Market Activity Incentives by Year 


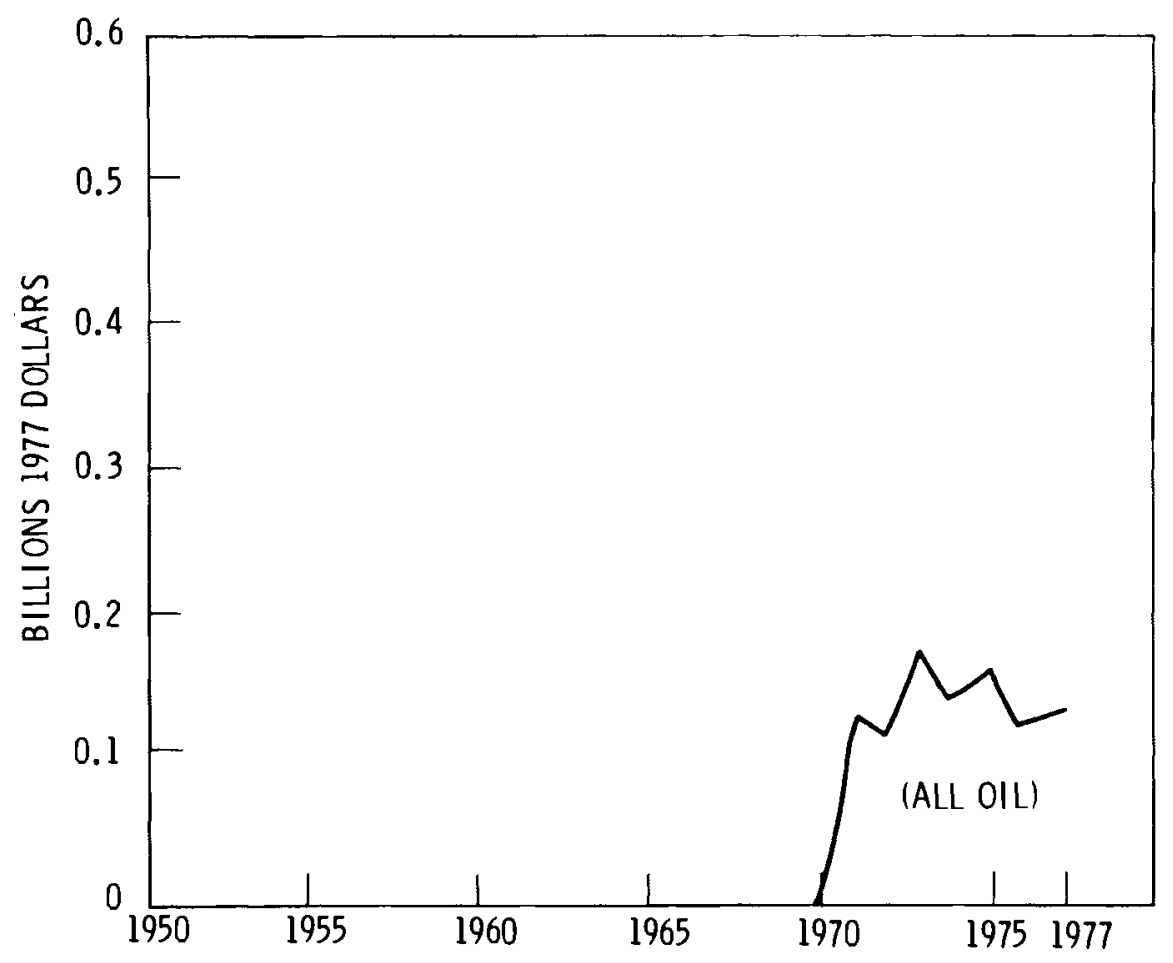

FIGURE 3.4. Cost of Disbursements Incentive by Year

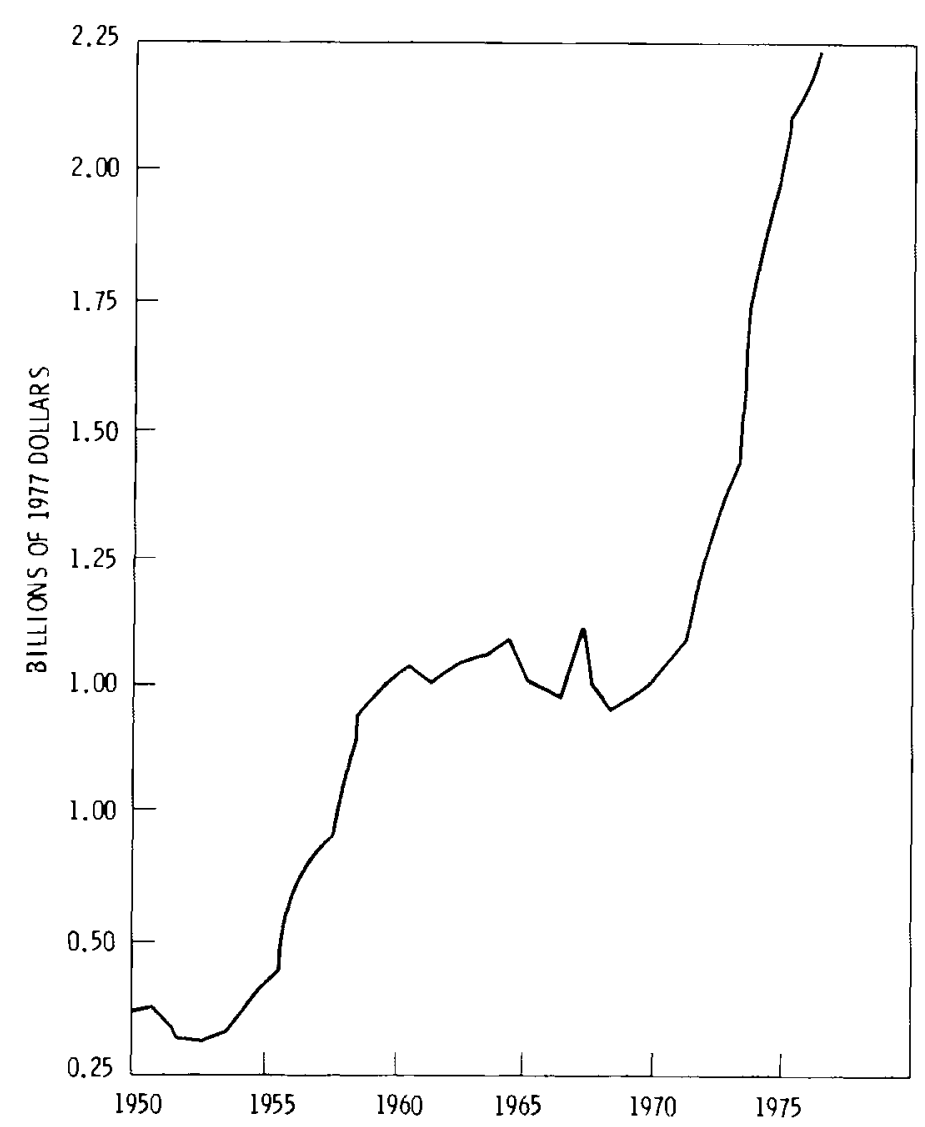

FIGURE 3.5. Cost of Services Incentives by Year 


\section{REQUIREMENTS}

Examples of Incentives

The estimated costs of requirements were $\$ 7,176$ million in 1976 and $\$ 8,128$ million in 1977 . Examples of requirements include: the pricing activities by the Federal Power Commission and the Federal Energy Administration, environmental and health regulation by the EPA, and safety regulation by the OSHA. The costs of requirements from 1950 to 1976 are charted in Figure 3.1. The figure shows a dramatic increase in the use of this incentive in the last three years.

\section{TAXATION}

Examples of Incentives

The estimated costs of taxation were $\$ 6,698$ million in 1976 and these increased to $\$ 7,477$ million in 1977 . Taxation is carried out primarily by the Internal Revenue Service (IRS). Examples of tax incentives include foreign tax credits and the $0 i 1$ depletion allowance. The costs of taxation incentives from 1950 to 1976 are plotted in Figure 3.2. There has been a fairly steady rate of increase in the use of taxation.

\section{MARKET ACTIVITY}

Examples of Incentives

The estimated costs of federal market activity were $\$ 2,210,800,000$ in 1976. The costs were $\$ 2,090$ million in 1977 . This value included expenditures by the Tennessee Valley Authority and the Bonneville, Southwestern, Alaska, and Southeastern Power Administrations whose budgets are financed from operating revenues and not from federal government funds. Examples of incentives include the production, sale, and transmission of electricity by the regional power administrations. Market incentives from 1950 to 1976 are shown in Figure 3.3. While there has been an upward trend in these incentives over time, dramatic variations from year to year are revealed in the figure. (These variations may be due to business cycles.) 


\section{DISBURSEMENTS}

\section{Examples of Incentives}

The estimated costs of disbursements were $\$ 134,600,000$ in 1976 and $\$ 130$ million in 1977. Subsidies to support American shipping by the Maritime Administration are an important example of federal disbursements. These incentives are charted from 1970 and 1977 in Figure 3.4. After an initial sharp increase, the level of incentives appears to be fairly constant from 1972 to 1977. This pattern contrasts with the increasing level of use of all of the other incentive types (except Exhortation whose costs we do not estimate--see below).

\section{SERVICES}

\section{Examples of Incentives}

The estimated costs of services were $\$ 2,125,900,000$ in 1976 and $\$ 2,261,700,000$ in 1977. Research and development by ERDA (nOw DOE) and the Bureau of Mines are important examples of this activity. The cost of service incentives from 1950 to 1977 is shown in Figure 3.5. Two periods of rapid increase in the use of service incentives are shown: 1955 to 1960 and 1970 to the present.

\section{EXHORTATION}

\section{Examples of Incentives}

The costs of exhortation were too small relative to the others mentioned to est imate in both 1976 and 1977. An example of this activity was the commerce Department's voluntary conservation program.

\section{REORGANIZATION}

\section{Examples of Incentives}

The costs of reorganization were too small relative to the others mentioned to estimate in both 1976 and 1977 . Examples of this activity were the 
Coast Guard's assumption of responsibility for service response to oil spills and the Department of Justice's antitrust activities.

RESULTS OTHER THAN THE QUANTITY AND PRICE OF ENERGY

This section discusses the results of federal energy incentives on dimensions other than price, quantity, and technological change. A number of additional result dimensions are suggested in Table 2.1 of Chapter 2 . We used theoretical precepts and accepted results from economics and political science in formulating the following statements about the results of each incentive type on these other results dimensions.

These conclusions should be interpreted as measures of a central tendency, other things being equal. In fact, the actual world is quite complex, with many mediating variables affecting the results of any particular incentive applied in any particular industry. In particular, the variation in results within an incentive type may be as great or greater than the variation across types.

Many variables are involved in explaining the links between incentives and their results. Supply-and-demand conditions, industrial structures, attitudes and beliefs, and institutional processes (legal, organizational, and political) a 11 come into play. Due to the multiple pathways for causation, and the many variables involved in each pathway, we cannot state simple and direct links between a particular incentive and a particular result. Indeed, the ability to predict energy results, the speed with which they occur, and the amount of change they involve are all related to the number of "mediating" variables on these causal pathways. The sensitivity of an incentive type to these "mediating" variables is also important for predictability.

Industrial structure is one of the most important mediating variables. Energy incentives can affect industrial structure, which in turn affects energy prices and quantities, in two ways. First, the particular incentives chosen may have direct effects on industrial structure. Requirements may place disproportionate burdens on certain classes of businesses, for example, small businesses. Tax programs may favor integrated firms over firms engaged in only one stage of production. Research programs may favor smaller and less 
horizontally concentrated firms which would not undertake such research on their own. These effects vary greatly in magnitude and direction depending on other variables. Technological change, the history of the industry and of the technology, and demand conditions must be included in analyses of the effects of incentives on industrial structures.

Second, the physical characteristics of technologies lend themselves to certain kinds of industrial structures. "Soft path" energy technologies are alleged to encourage small-scale production in competitive industries, whereas "hard path" technologies are of ten associated with monopolistic, large-scale industries. Thus, by its choice of which technologies to encourage, the government affects the degree of concentration and vertical integration in various industries, and these changes in structure lead to changes in quantities and prices.

Finally, the pathways of change and the importance of various variables on the paths change over time. A major variable involved in this process is the maturation of the energy technology receiving the incentives. Incentives that have one kind of result when the technology is young may have an entirely different $k$ ind of result as the technology matures. In a dynamically changing world, incentive/result findings that hold today may not be valid tomorrow.

These conclusions appear in Table 3.2. Each entry is explained in the text below.

Taxation, as used in the energy industry, has generally been in the form of exemptions or deductions from the corporate income tax. It is in this sense of a tax cut or tax collections foregone by the federal government that we analyze taxation below. The effects of taxation on competition have been either neutral or offsetting from one action to another. No compelling argument for a pro- or ant $i$-competitive bias in tax programs has emerged. Sectoral impacts have also been neutral; no one sector has been unduly impacted by tax programs. Some sectors have received special treatment by one or more tax actions, e.g., the oil depletion allowance. Hence, the sectoral subsidy effect is positive. Income distribution has probably been made less egalitarian, a negative result, as a result of deductions from a generally progressive tax 
TABLE 3.2. General Characteristics of Incentives

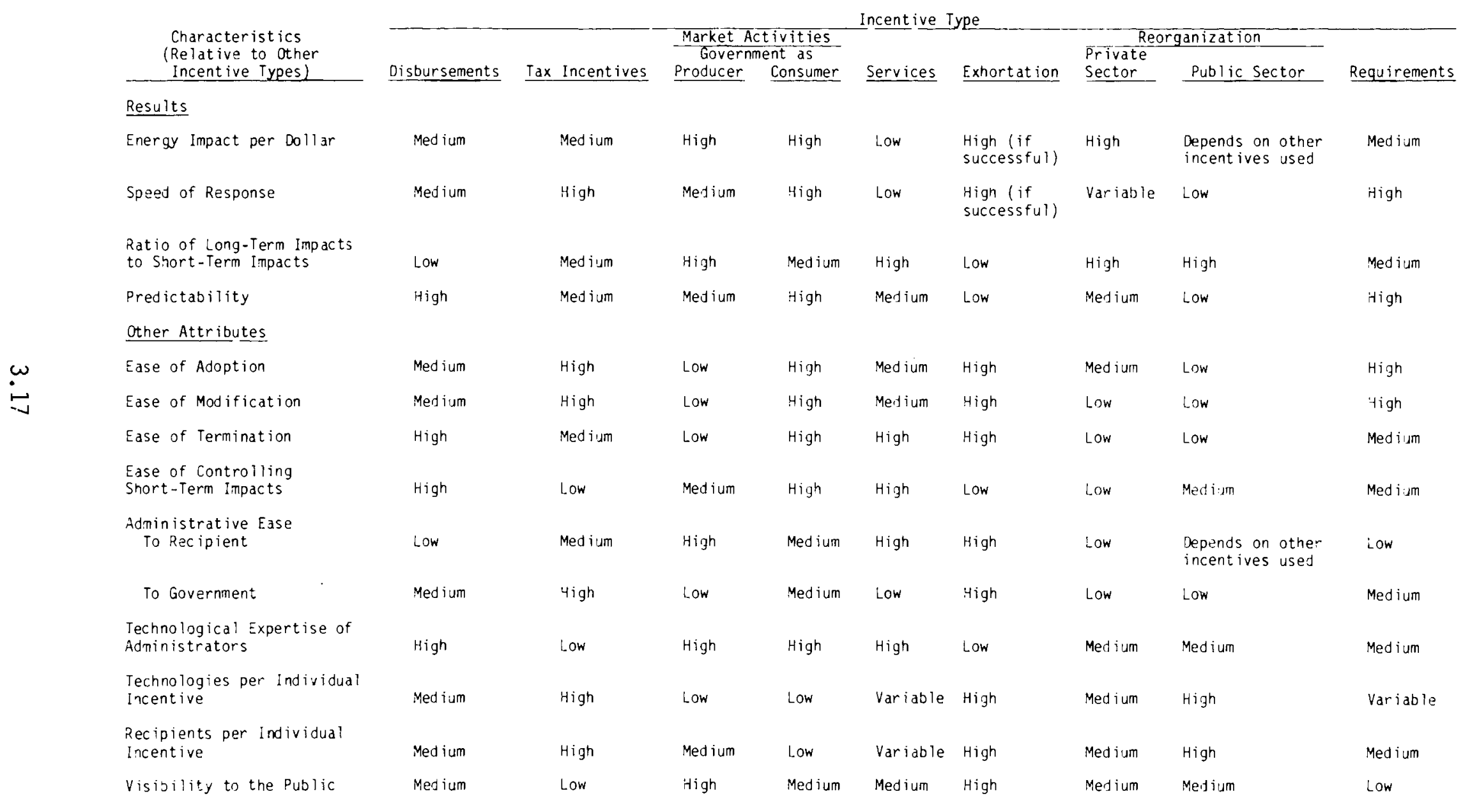


system. Capital formation has been aided by capital gains deductions and other programs. Inflation has been slowed to the extent that tax programs have helped to increase quantities supplied. Employment gains may have been slowed by encouraging more capital-intensive production techniques, but productivity was increased. The balance of payments has been improved by encouraging domestic production, but perhaps worsened by forgiving foreign taxes. Foreign policy/national security effects go both ways as a result of the balance of payment impacts. Societal stability has been increased since many tax actions are explicitly anticyclical in intent. The balance of federal/state relations has been shifted towards more federal involvement, and at the same time the public/private boundary has been shifted in the direction of a larger public role. Preceptions of regulatory burden on the private sector have been increased as a result. Quality of life has presumably benefitted by the provision of more energy products. Taxation has had no obvious results with respect to the distribution of population between urban and rural areas. Energyproducing regions have certainly benefitted from tax programs, however.

By requirements, we refer to any federal requirements except for antitrust actions, which we include under the reorganization category. We distinguish two types of requirement: economic and social. Economic requirements refer to the rate and condition of service regulations, controls over securities issues, and other controls on economic actions. Social requirements refer to health and safety standards and consumer protection laws. Competitive effects of both types of requirements have generally been negative; that is, they have encouraged monopoly or oligopoly rather than competition. Certain sectors of the economy have had higher costs imposed on them. Some sectors have benefitted from economic requirements but few from social requirements. Income distribution has been made less egalitarian, and capital formation has for the most part been discouraged by social requirements. Inflation has been increased by social requirements but perhaps stemmed a bit by economic requirements. Employment and productivity have been negatively impacted by both types of programs, and the balance of payments has been worsened. National security has perhaps been weakened by worsening terms of trade. Social stability has been increased by economic regulation, which tends to keep existing firms 
going in circumstances where a free market would drive some into bankruptcy. Stability has been decreased, however, by social requirements. Such requirements have called for sudden transitions to new sets of social standards, resulting in considerable disruptions. State/federal and public/private boundaries are defined by the requirements programs, with the overall results being greater federal and public roles. Regulatory burden has certainly been increased. Economic requirements have produced offsetting results on the quality of life. Social requirements have gone both ways but have generally had positive results on environmental and quality-of-life matters. Requirements generally have no consistent results on the distribution of the population between rural and urban areas. Regional impacts have occurred from the dislocation of industry resulting from social requirements.

The results of market activities have generally been positive or neutral. Competition has benefitted from such actions as establishing the TVA and using competitive bidding procedures. Although no sectors have been obviously damaged by exchange actions, some have benefitted. Employment levels have increased as a result of government exchange actions. Certain regions have benefitted more than others from government actions. The regions served by the TVA and those served by the power marketing administrations are good examples. Dimensions not mentioned above have had neutral or offsetting results.

Services clearly benefit the sectors that receive them. Capital formation has perhaps been aided by the provision of certain services. Productivity and employment have probably both increased as a result of service actions. The balance of payments has been bettered by export promotion services. Quality of life has surely benefitted, and some regions have probably benefitted more than others. Dimensions not discussed above have had neutral or offsetting results.

Disbursement actions have benefitted certain sectors more than others; the coal and oil sectors were the only ones to receive disbursement dollars in FY-1976. Disbursements have also tended to equalize the income distribution somewhat. Capital formation may have been aided, and thereby, employment and productivity may have increased somewhat. Quality of life has benefitted from such actions as the establishment of a Black Lung trust fund for coal miners. 
Certain regions have certainly received more disbursements than others as a result of the presence of coal and oil industries in those regions.

Few results can be attributed to exhortation. Competition may have benefitted since exhortation is often directed against large firms. The intent of exhortation is often to increase capital formation, reduce inflation, help the balance of payments, and to increase the quality of life. Whether such actions actually produce the desired results is not clear, and in most cases, the results are likely to be short-lived.

Reorganization actions, including antitrust programs, have aided competition and have benefitted certain sectors without obviously damaging any. Income distribution should be more egalitarian as a result of increased competition, and inflation should be reduced. Employment levels should be increased by such actions. Societal stability is perhaps weakened by reorganization. Public/private boundaries are defined and modified by such actions. Regulatory burden is increased. Other results are neutral or offsetting.

\section{CONCLUSIONS ABOUT THE CHARACTERISTICS OF INCENTIVES}

of course, each type of incentive has important attributes other than its results. For instance, disbursements require a great deal of administration in order to select recipients and monitor their use of funds. Tax incentives are administered by an agency generally hostile to such incentives and which lacks technological expertise. Tax incentives place control over the use of the incentive largely in the hands of the recipients, rather than the government. Since tax incentives are largely invisible, they can get out of hand easily and are difficult to end once the need has passed. Market activities require government agencies to engage in activities normally thought to be the province of private organizations, and may place the government in competition with private enterprise in ways that are sometimes good, sometimes bad.

Examination of these incentives also led to predictions about the characteristics of each relative to one another in terms of such attributes as energy impact per dollar, time from adoption to results, and the predictability of the results. The general tendencies of these characteristics are shown in 
Table 3.1. Please keep in mind that these results and characteristics are general tendencies of one type of incentive versus another, and may be different in specific circumstances.

Most of the characteristics in Table 3.2 are fairly self-explanatory. For instance, Energy Impact refers to Btu produced or saved, Speed of Response refers to the time from adoption of the incentive to its energy impact, and the Ratio of Long-Term to Short-Term refers to the multiplier effect of an incentive. Others are less self-explanatory. Technologies per Incentive refers to the ability of a single incentive to encourage many different technologies at once. Ease of Controlling Short-Term Impacts is somewhat the other side of the coin. It refers to the government's ability to control what technologies are encouraged without modifying the incentive itself. Recipients per Incentive refers to the ability of a single incentive to encourage many different users at once.

By size, we mean the amount by which energy prices or quantities change, in either absolute or proportional terms, as a consequence of the incentive. Another way to think of this dimension is as a measure of the resulting energy impact of an incentive dollar. Given a dollar of government funds to spend on energy incentives, which types will produce the most change per dollar, relative to the other types? We divided the dimension into large, medium, and small results.

By timing, we mean the period from the establishment of the incentive to the energy results. This dimension is a measure of the discount rate to be applied to the incentive type, because there is a delay until the incentive takes effect. We divide this dimension into quick, medium, and slow results (here again, relative to other incentive types).

By predictability, we mean the ability to predict the size and timing of results. Obviously, this dimension is a function of the sensitivity of the incentive to all the variables, other than incentive type, on the causal pathway from incentive to results. We divide this dimension into high, medium, and low relative to other incentive types. 
Size of Energy Results

We conclude that the market-type incentives, taxation, exchange, and disbursements, have large effects relative to the other incentive types. The energy industry in the U.S. is a system that, until quite recently, was economically oriented. That is, before the $0 i l$ embargo, production and consumption decisions about energy were remarkably free of noneconomic considerations compared to decisions about matters like education, welfare, or even housing. As a consequence, we would expect economic incentives to be especially effective in the sense of change per dollar of incentive.

We suspect that one incentive type has less capacity to produce change than the others--exhortation. The same reason is at work. Exhortation is most effective when it asks that parties do something they were intending to do anyway and when many intangible values are at stake (e.g., voting in low-level elections). In the past, the energy issue has lacked the intangible values, and people have been asked to go almost directly counter to their inclinations. Recently, energy has been acquiring intangible values related to energy independence and environmental protection. Hence, exhortation may have more capacity to produce change in the future, especially for solar energy technologies.

The other incentives struck us as intermediate on this measure. Requirements can have a large effect when prices and quantities of energy are being directly regulated but probably a smaller effect, on average, in other cases. Services and reorganization are generally too remote from the largely economic decisions surrounding energy to rate more than moderate effectiveness in this sense.

Timing of Energy Results

For much the same reasons, we rated taxation and exchange as relatively quick'to produce changes in energy prices and quantities. Once again, they are direct interventions in the energy market. In addition, our work with the relationships between profit margins and production in the oil industry suggest that the lag time can be as short as one year. When it has any effect, exhortation works quickly. We rated requirements and disbursements as quick when directly concerned with energy, and medium when not. Reorganization, because 
it is so indirect, usually works slowly. We rated services as relatively slow because in the energy field the category includes research more than anything else, and research usually takes a long time to reach any kind of marketplace. Predictability of Energy Results

Once again, the "directness" of the intervention in the energy marketplace was the crucial variable. Exchange is relatively predictable, as are taxation and requirements when they relate directly to energy. Disbursements are medium, as are taxation and requirements when not directly related to energy. Services, exhortation, and reorganization are low because they work through a number of mediating variables that exert major influences on the final results.

CONCLUSIONS

Requirements

\section{Observations by Policy Makers and Activists}

Policy makers and activists reported on the consequences of federal requirements on the price and quantity of energy produced. Several examples of requirements influencing price include: the Federal Energy Administration's increase of stripper oil and Alaskan crude prices to the world price and the Federal Power Commission's increase in allowable rates of return for natural gas companies. Policy activists also criticized the Nuclear Regulatory Commission, the Federal Energy Administration, and the Environmental Protection Agency for their regulatory activities which caused delays and added to costs in the nuclear, coal, and electric power industries. The price increases reported by the experts, and regulatory restrictions noted support the theoretical predictions discussed above (see Table 3.1).

\section{Observations from Energy Form Analysis}

The $0 i l$ and natural gas analyses (Chapters 7 and 8 ) found requirements incentives that did have positive production effects, but generally negative price effects. Requirements incentives increased the production of oil by 2.30 quadrillion Btu (quads) and natural gas by 6.38 quads. This kind of 
incentive decreased the price of natural gas by $\$ 0.125$ per million Btu, but increased the cost of coal by $\$ 0.10$ per million Btu and the cost of oil by $\$ 0.116$ per million Btu.

Taxation

\section{Observations by Policy Makers and Activists}

Policy makers and activists described the consequences of federal taxation on the price and quantity of energy produced. Policy activists identified a number of examples where taxes acted as a disincentive to further production. Policy activists observed that the tax reform of 1976 seemed to have drastically cut capital gains and income, offsetting other incentives. They noted that foreign tax credits were also discontinued in 1976. Others stated that the continuing minimum tax on corporate income acted as a disincentive to the production of coal and petroleum by independent producers. The quantity reductions from removing incentives (imposing taxes) noted confirm the theoretical predictions sumarized in Table 3.1. Other theoretical effects on R\&D were not reported by the experts.

\section{Observations from Energy Form Analys is}

The energy forms analys is found that the taxation incentives existing before the tax reform of 1976 did have significant effects. In oil, 26.62 quads were induced, and in natural gas, 6.60 quads. This kind of incentive lowered the price of hydroenergy by $\$ 0.084$ per million Btu, the price of coal by $\$ 0.013$ per million Btu, the price of oil by $\$ 0.213$ per million Btu, the price of natural gas by $\$ 0.018$ per million Btu, and the price of electricity by $\$ 0.342$ per million Btu.

\section{Market Activity}

Observations by Policy Makers and Activists

Policy makers and activists reported on the consequences of federal market activity on the price and quantity of energy produced. Policy activists noted that the regional power administrations were able to produce and sell electric power more cheaply than private utilities. Policy activists also identified other benefits from federal market activities such as jobs and commerce in the 
rural areas, which can be attributed to Rural Electrification Administration and Bureau of Reclamation programs. Other policy activists described the manner in which Bureau of Land Management leasing policies subsidized western coal producers.

The quantitative and expert-opinion comments deal only with the government qua seller. In this role, the theoretical price/quantity effects are supported, but the product differentiation point is turned on its head. The government, in developing hydroelectric power, differentiated its product from that of the private sector, not the other way around. The government qua buyer was not discussed by the experts. Hence, we offer our own expert opinions based on previous research in the nuclear power industry. The Ohio Valley Electric Cooperative was formed to supply power to Oak Ridge National Laboratory. Several large coal-fired power stations were built by this privatesector utility cooperative to run uranium enrichment and other facilities at Oak Ridge. Competition for available plant sites and, in the current context, competition for limited pollution rights, are implied, supporting the theoretical price/quantity propositions. The naval and strategic petroleum reserves provide another example of the government qua buyer. These reserves involve a distinct product type provided for the government, again supporting the theoretical generalizations.

\section{Observations from Energy Form Analys is}

The energy forms analys is found that market activity incentives induced 12.86 quads of hydro-energy and 4.97 quads of electricity. Such incentives held down the price of hydro and electricity by $\$ 0.292$ and $\$ 1.921$ per million Btu, respectively.

\section{Disbursements}

Observations by Policy Makers and Activists

Policy makers and activists reported on the consequences of federal disbursements on the price and quantity of energy produced. Policy activists noted that subsidies to U.S. shippers lowered the cost of transporting petroleum and may have been a disincentive to domestic production. These reported results are just what theory predicts, as summarized in Table 3.1. 


\section{Observations from Energy Form Analysis}

The only disbursement incentive is support for U.S. shippers of petroleum. This incentive was determined to have a negligible impact on the price and quantity of petroleum.

$\underline{\text { Services }}$

Observations by Policy Makers and Activists

Policy makers and activists described the consequences of federal services on the price and quantity of energy produced. Policy activists observed that federal research and development activities had few short-term impacts. Policy activists concluded that ERDA's research program favored the nuclear industry over the "soft-path" energy technologies and acted as a disincentive to their production. Other activists expressed fears that breeder-reactor development by ERDA and nOw DOE would result in the increased proliferation of nuclear weapons. Other activists feared that greater reliance on coal development would have adverse effects on the environment. The expert-opinion comments support the theoretical proposition that R\&D makes new products available, but a twist is added since some R\&D is alleged to be nonoptimally biased in favor of a particular technology, e.g. nuclear power.

\section{Observations from Energy Form Analys is}

The energy forms analysis found that nontraditional services induced 1.17 quads of nuclear energy and had an indeterminate effect on prices. Exhortation

Observations by Policy Makers and Activists

Policy makers and activists reported on the consequences of federal exhortation on the price and quantity of energy produced. Policy activists observed that federal exhortation and California's resultant changes in its utility rate bases caused losses for utilities and natural gas companies in that state. Policy makers also described the results of the Cormerce Department's voluntary conservation program. They noted large increases in energy efficiency in the petroleum refining, textile, and flat glass industries. 
Expert-opinion comments point to considerably greater effects than theory predicts. However, there is a theoretical problem of other things being equal here; price signals pointed the private sector in the same direction as exhortation and too many of the results may be attributed to exhortation by expert opinion.

\section{Observations from Energy Form Analys is}

The energy forms analyses were much closer to the theoretical predictions. They found no quantifiable effects.

Reorganization

Observations by Policy Makers and Activists

We found very few statements on the consequences of federal reorganization on the price or quantity of energy produced. One policy maker noted that the Coast Guard assumed responsibility for service response to oil spills. Lacking expert-opinion comments, we cannot assess the correctness of the theoretical predictions for the incentive type.

\section{Observations from Energy Form Analys is}

The energy forms analyses found at least two examples of very important, but unquantifiable reorganization incentives. These were the Connally Hot 0il Act and the Price-Anderson Act. Both of these incentives set up schemes under which the private sector could produce oil and nuclear energy, respectively. 
$\checkmark$

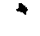


CHAPTER 4

NUCLEAR P OWER

by

Harold Harty, Nuclear Engineer

Paul D. Cohn, Nuclear Engineer 



\section{NUCLEAR POWER}

SUMMARY OF NUCLEAR INCENTIVES

Incentives for commercial nuclear power are estimated to have cost the federal government $\$ 18.0$ billion (1977 $\$$ ) between 1948 and 1977 . This is approximately $8.3 \%$ of the total estimated cost of all incentives used to stimulate energy production (Cone et al. December 1978). Monies for types of incentives and applications are shown in Table 4.1 .

Between 1948 and 1977, the federal government contributed $\$ 15.1$ billion (1977\$) to the development of nuclear power in the area of research and deve1opment (R\&D). This is categorized in Table 4.1 as a nontraditional service. The major program component was the Civilian Reactor Development Program (CRDP). Approximately $62 \%$ of the R\&D funds were spent through CRDP. Developmental fission reactors and the early cooperative power demonstration reactor projects were supported through the CRDP program. More recently, the Liquid Metal Fast Breeder Reactor (LMFBR) program has received most of the funds of

TABLE 4.1. A Sumary of the Cost of Incentives to Stimulate Civilian Nuclear Power Production (in billions of 1977 \$)

(Cone et al. December 1978, p. 141)

$$
\begin{aligned}
& \text { Tradi- Nontradi- } \\
& \text { Taxa- Disburse- Require- tional tional Market } \\
& \text { tion ments ments Services Services Activity }
\end{aligned}
$$

Research and Development

15.1

Liability Insurance

(a)

Uranium Industry

Enrichment Plants

Regul at i on

1.1

Waste Management
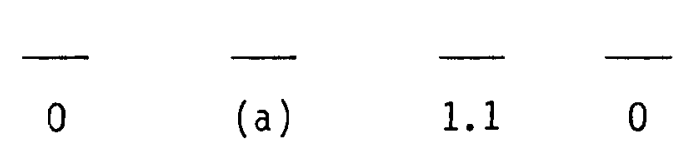

(b)

Total

(a)

1.1

0

15.1

1.8

Total $\$ 18.0$ Billion

(a) Not able to quant ify.

(b) Included in R\&D costs. 
the CRDP. Approximately $\$ 3.1$ billion (1977 \$) had been spent through 1977 on R\&D for the breeder reactor. Other federally-funded R\&D that has contributed to commercial nuclear power include portions of biology and medical research, nuclear submarine propulsion research, education and training programs, and physical research such as high-energy physics.

Another incentive to commercial nuclear power has been federal investment in uranium enrichment facilities. Since 1965, the federal government has supplied utilities with enriched uranium on a cost recovery basis. The existence of these enrichment plants influenced the type of reactor that was commercialized in the U.S. The recent expansion of enrichment services for the commercial nuclear industry is classified in Table 4.1 as a market activity valued at $\$ 1.8$ billion (1977 $\$$ ).

From 1960 to 1977 , the federal government directly spent $\$ 1.1$ billion (1977\$) for regulation of the commercial nuclear power industry. More than half of the total spent for regulatory activities was spent after 1975, reflecting the increase in the number of $p l a n t s$ and the pressure for increased public involvement in nuclear issues. Federal funds spent on regulatory activities have been included as an incentive and are categorized in Table 4.1 as a requirement.

The incentives summarized in Table 4.1 do not consider several nonquantifiable incentives; Legislative actions such as the Price-Anderson Act, which removed the liability roadblock are examples. Several policies (such as longterm uranium procurement) that were initiated for military programs, but indirectly benefited the commercial nuclear power industry, are included. Commercial nuclear power provides an example of a partnership between government and industry aimed at developing an alternative energy source.

\section{NUCLEAR ENERGY PRODUCTION AND FEDERAL INCENTIVES}

Incentives to commercial nuclear power originated with the military applications of nuclear power. Nuclear energy can be considered a special case of electrical power generation development because of the high technology required to develop it. 
Figure 4.1 and Table 4.2 show the cumulative trend of electrical production from nuclear energy and federal financial incentives provided from 1950 to 1977. It can be seen that federal incentives to commercial nuclear power began a dozen or so years before significant amounts of electricity from nuclear energy were produced. The bulk of early incentives (in fact all incentives to nuclear) took the form of federally funded research and development $(R \& D)$. Figure 4.2 and Table 4.2 show the annual levels of production and incentives.

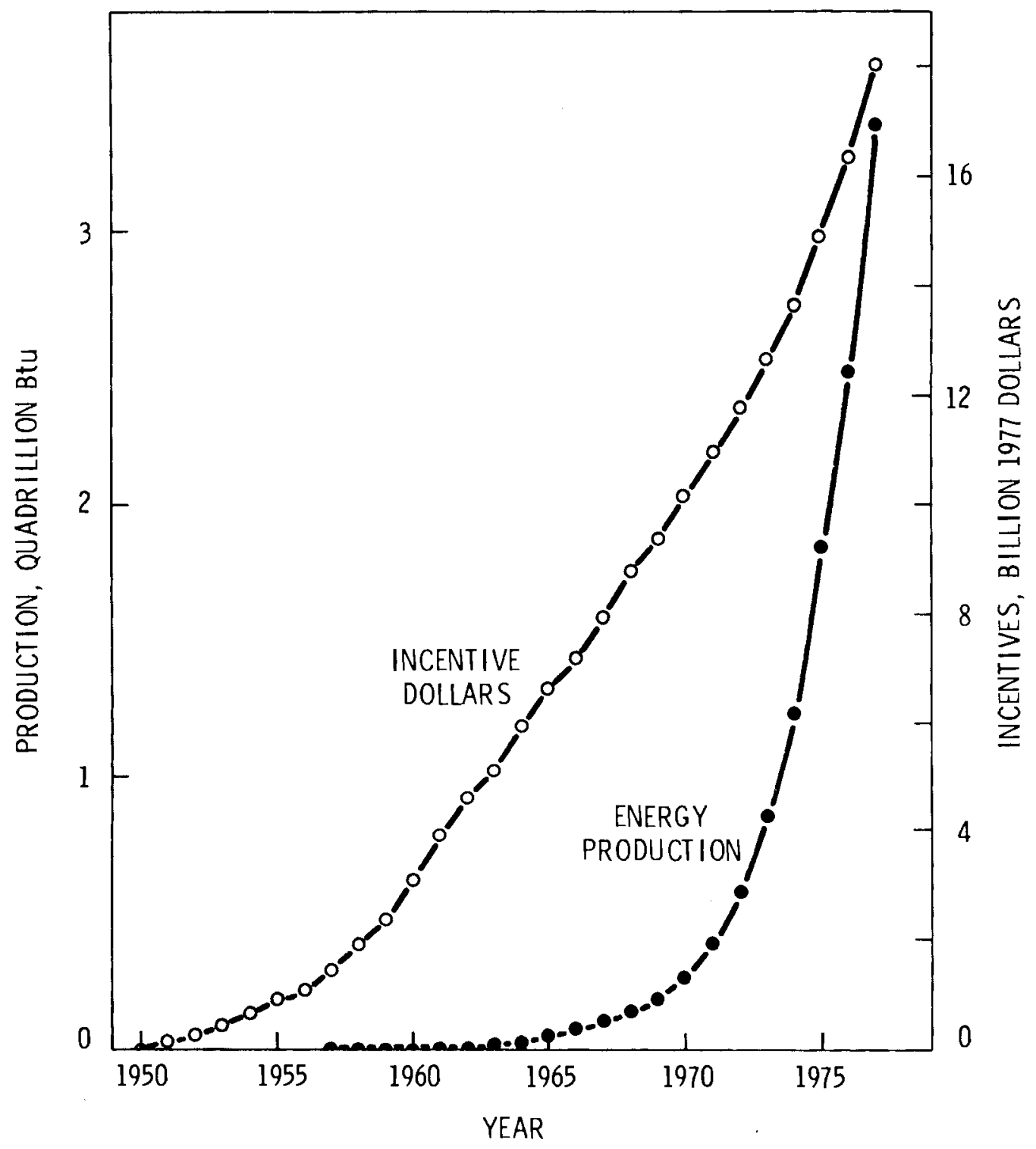

FIGURE 4.1. Nuclear: Cumulative Production and Incentives 
TABLE 4.2. Annual and Cumulative Nuclear Production and Federal Incentives

\begin{tabular}{|c|c|c|c|c|}
\hline Year & $\begin{array}{l}\text { Annual Incentiye } \\
\text { Million } 1977 \$(a)\end{array}$ & $\begin{array}{r}\text { Cumulative } \\
\text { Incent ives } \\
\text { Million } 1977 \$ \\
\end{array}$ & $\begin{array}{c}\text { Annual } \\
\text { Production } \\
\text { Trillion Btu(b,c) } \\
\end{array}$ & $\begin{array}{l}\text { Cumulative } \\
\text { Production } \\
\text { Trillion Btu } \\
\end{array}$ \\
\hline $\begin{array}{l}1950 \\
1951 \\
1952 \\
1953 \\
1954 \\
1955 \\
1956 \\
1957 \\
1958 \\
1959 \\
1960 \\
1961 \\
1962 \\
1963 \\
1964 \\
1965 \\
1966 \\
1967 \\
1968 \\
1969 \\
1970 \\
1971 \\
1972 \\
1973 \\
1974 \\
1975 \\
1976 \\
1977\end{array}$ & $\begin{array}{r}98 \\
114 \\
126 \\
134 \\
167 \\
209 \\
264 \\
373 \\
427 \\
495 \\
767 \\
718 \\
691 \\
689 \\
674 \\
680 \\
661 \\
670 \\
752 \\
711 \\
800 \\
724 \\
767 \\
925 \\
1,032 \\
1,239 \\
1,457 \\
1,636\end{array}$ & $\begin{array}{r}98 \\
212 \\
338 \\
472 \\
639 \\
848 \\
1,112 \\
1,485 \\
1,912 \\
2,407 \\
3,174 \\
3,892 \\
4,583 \\
5,272 \\
5,946 \\
6,626 \\
7,287 \\
7,957 \\
8,709 \\
9,420 \\
10,220 \\
10,944 \\
11,711 \\
12,636 \\
13,668 \\
14,907 \\
16,364 \\
18,000\end{array}$ & $\begin{array}{r}0.03 \\
0.56 \\
0.64 \\
1.77 \\
5.78 \\
7.75 \\
10.96 \\
11.41 \\
12.48 \\
18.84 \\
26.13 \\
42.76 \\
47.54 \\
74.39 \\
130.05 \\
184.61 \\
284.42 \\
389.00 \\
588.76 \\
652.23 \\
856.26\end{array}$ & $\begin{array}{r}0.03 \\
0.59 \\
1.23 \\
3.00 \\
8.78 \\
16.53 \\
27.49 \\
38.90 \\
51.38 \\
70.22 \\
96.35 \\
139.11 \\
186.65 \\
261.04 \\
391.09 \\
575.70 \\
860.12 \\
1,249.12 \\
1,837.88 \\
2,490.11 \\
3,346.37\end{array}$ \\
\hline
\end{tabular}

Sources: (a) Cone et al. (December 1978, Chapter IV).

(b) 1957 to 1970 data from Bureau of the Census (1976a, p. 826); 1971 to 1977 data from Energy Information Administration (August $1978 \mathrm{~b}, \mathrm{p} .33$ ).

(c) Converted from kWh using 3,413 Btu/kWh.

The level of production for the nuclear industry increased very slowly until 1970. Since 1970, nuclear production has been climbing at a rapid rate (see figure 4.2). The cumulative trend in commercial nuclear power production has been of an exponential nature, whereas the cumulative incentive trend has been linear (see Figure 4.1). There is a considerable time lag between the 


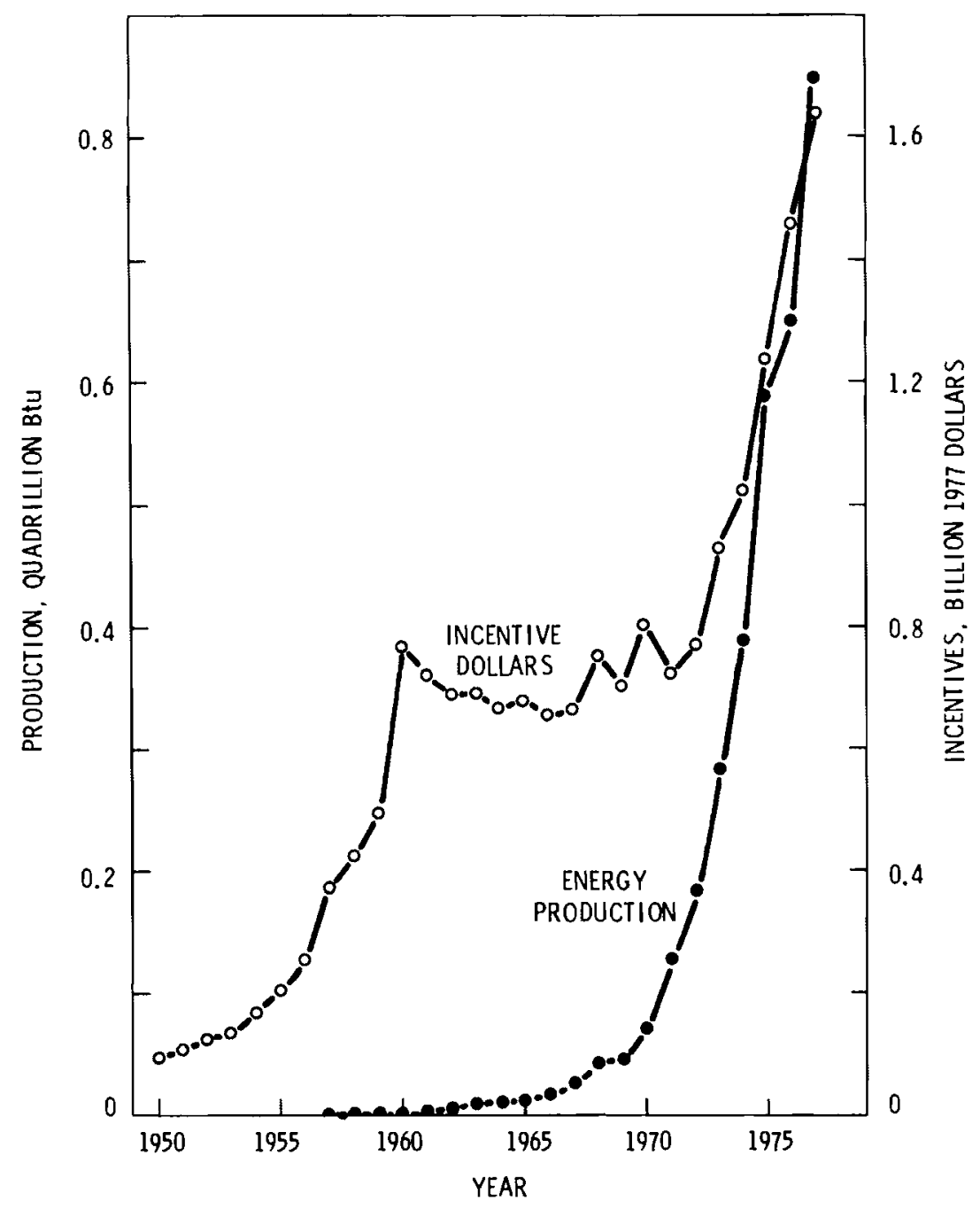

FIGURE 4.2. Nuclear: Annual Production and Incentives

application of an incentive to nuclear power and resulting increase in production. Results of the constant stream of incentives for nuclear have just recently been felt. Growth of nuclear production is expected to continue; nuclear power is projected to provide $59 \%$ of the U.S. generating capacity by the year 2000 (Dupree and Corsentino 1978, p. 36).

NUCLEAR ENERGY PRODUCTION COSTS AND FEDERAL INCENTIVES

Figures 4.3 and 4.4 present the yearly production cost of nuclear power and comparisons with annual and cumulative incentive dollars. The cost of 


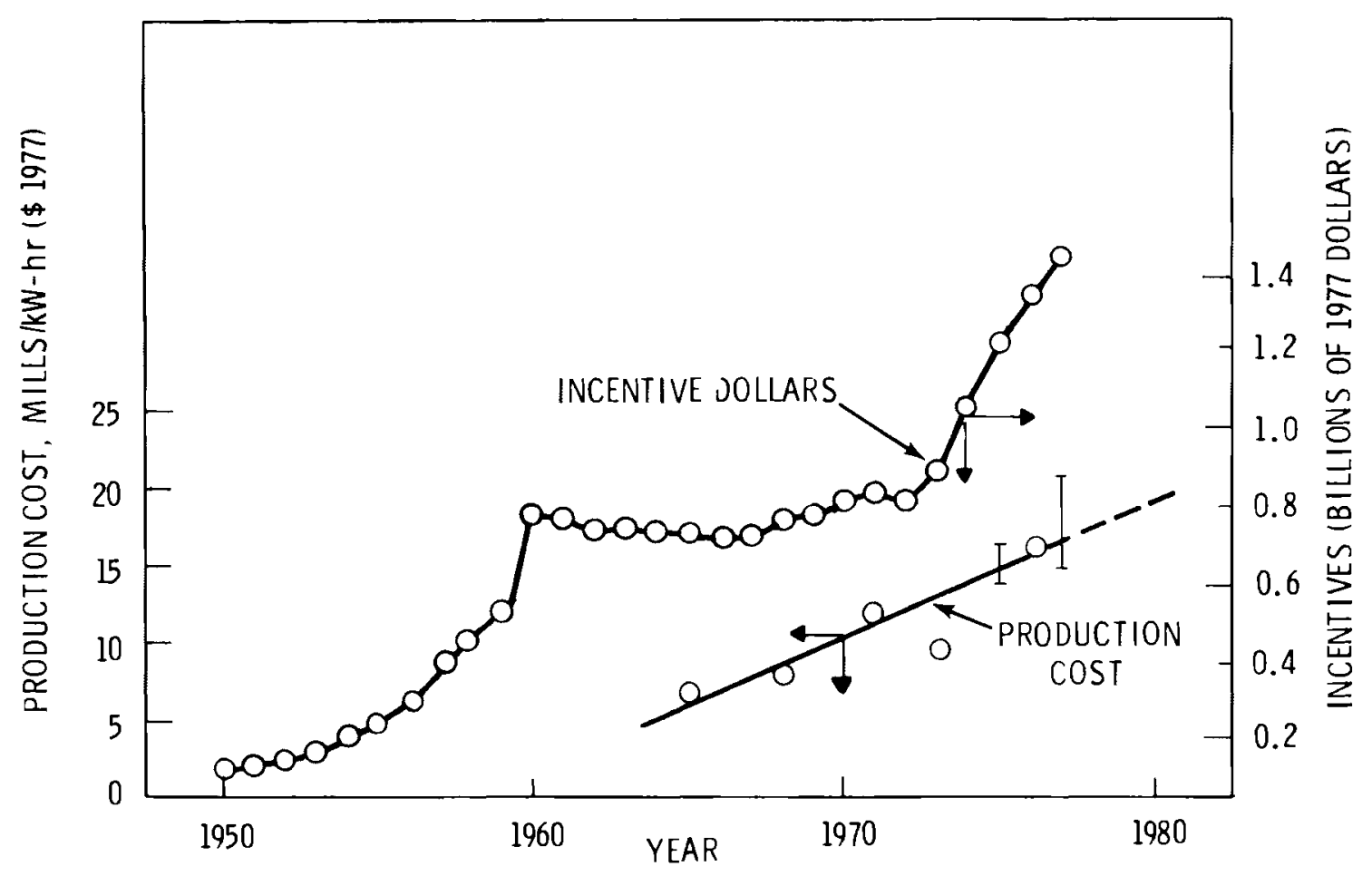

FIGURE 4.3. Annual Production Cost and Annual Incentives

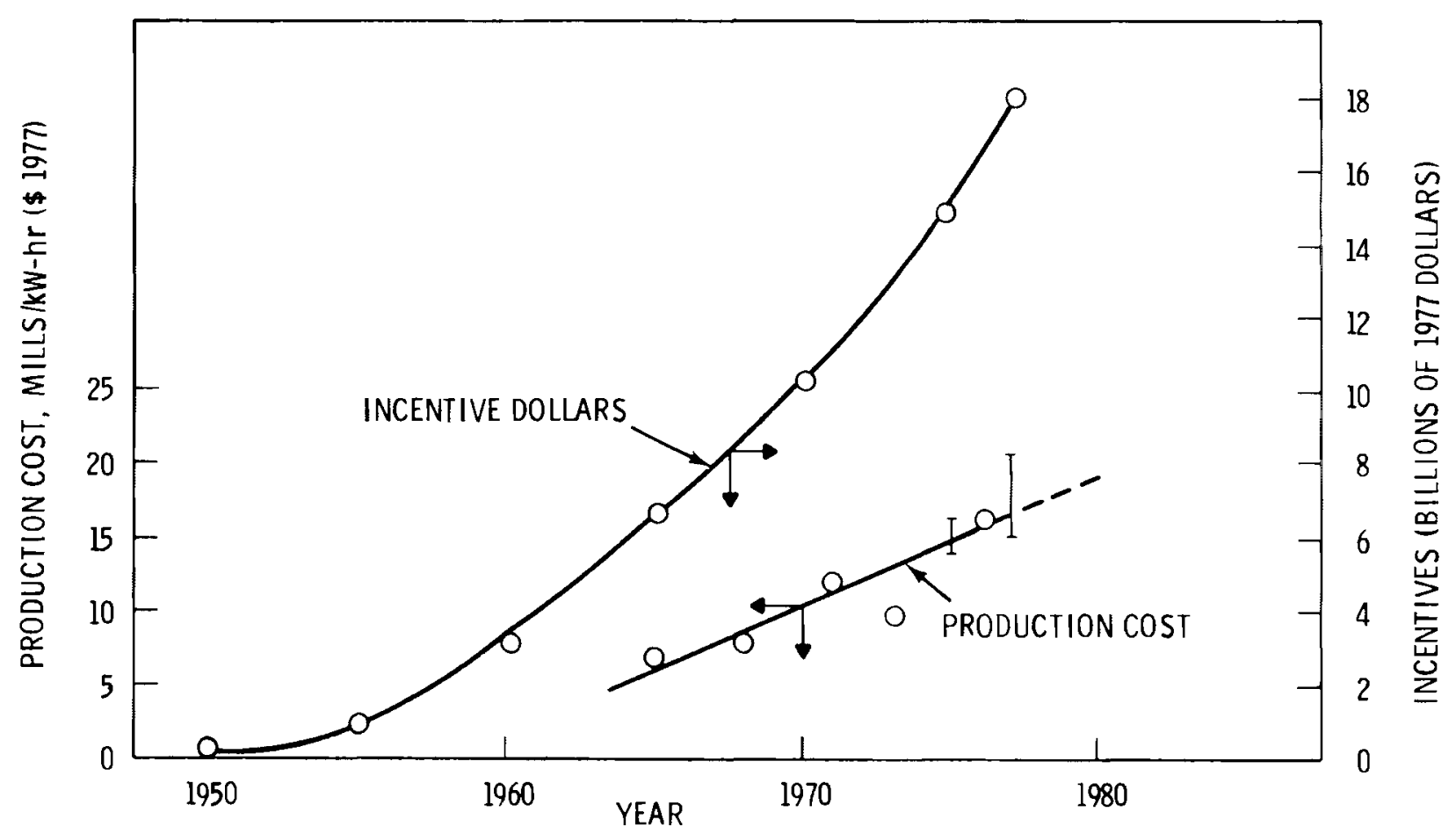

FIGURE 4.4. Annual Production cost and Cumulative Incentives 
nuclear power has not risen as fast as energy from other sources, due primarily to nuclear's isolation from petroleum price effects.

\section{EVALUATING THE EFFECTS OF FEDERAL INCENTIVES}

The U.S. Government has contributed about $\$ 18$ biliion (1977 \$) to the nuclear energy sector. A viable nuclear energy industry has developed in the U.S. which produces energy and manufactures nuclear energy equipment. Is there a cause-and-effect relationship between the government incentives and the nuclear industry? This section describes the results of the Energy Industry Survey which was used to assess the above question.

\section{Energy Industry Survey}

The objective of the Energy Industry Survey was to use expert opinion to est imate the effect of federal R\&D expenditures on the development of commercial nuclear power. Persons known to have been involved in significant positions in the early years of nuclear power development and who have either recently studied the nuclear industry in perspective or been involved in energy policy studies were the primary recipients of the survey. (A copy of the survey is contained in Appendix C.) The survey was sent to 76 individuals; 48 responded.

The survey contained a brief description of the industrial governmental nuclear activities in the early 1950s, together with 1) energy production profiles and projections, 2) four scenarios embracing possible modes of development of the nuclear industry, and 3) a questionnaire which allowed the recipients to estimate how they thought commercial nuclear power would develop in the absence of federal incentives. We asked those receiving the survey to assume that the 1954 amendment to the Atomic Energy Act was approved (permitting industry to build, own, operate, and export reactors) but that no significant federal R\&D in support of commercial nuclear power was funded after 1954. Weapons material production reactors and military reactors would continue to be developed and some of their technology would be available to industry. It was assumed that legislation similar to the Price-Anderson Act would be enacted and that private ownership of nuclear fuel materials would be permitted. The returns were classified in one of four categories: 
1. Those who thought that federal incentives were important to the development of commercial nuclear power. All who estimated that nuclear power would be less than $50 \%$ of that forecast for the year 2000 were included in this category.

2. Those who thought that federal incentives were unimportant or a hindrance to the development of commercial nuclear power. All who estimated that nuclear power would be greater than $50 \%$ of that forecast for the year 2000 were included in this category.

3. Those who have commented but declined to speculate on how the industry might have developed.

4. Those who responded but declined to comment or speculate.

Some responses were received without significant comment, many were received with substantive comments. Those responding with substantive comments appeared to be primarily those who had worked in the nuclear field for some time. The predominance of this group thought that federal incentives were relatively unimportant in the commercialization of light-water reactors. The wide range of estimates received suggests that recycling of opinions (e.g., the Delphi Technique) might be helpful in resolving differences.

The following discussion summarizes the responses for each of the four categories. Sample comments indicative of the general response tone are presented. A more comprehensive listing of response excerpts is presented in Appendix $C$. It is important to note that the sample comments are excerpts from responses, and therefore, may not represent the overall emphasis of the response.

Those who Thought that Federal Incentives were Important to the Development of Commercial Nuclear Power

Fourteen of the responses maintained that commercial nuclear power would account for no more than $50 \%$ of the generation projected for the year 2000 if federal R\&D had been terminated in 1954. Table 4.3 presents the numerical estimates of the 14 responses. 
TABLE 4.3. Response of Those Who Believed that Federal R\&D was of Significant Benefit in the Development of Nuclear Power

\begin{tabular}{cc} 
& $\begin{array}{c}\% \text { of Nuclear Capacity } \\
\text { Achieved by 2000 } \\
\text { Without Federal R\&D }\end{array}$ \\
\hline Response No. & 10 \\
2 & 25 \\
13 & 10 \\
14 & 50 \\
19 & 10 \\
20 & Delayed 15 years \\
21 & 20 \\
22 & 0 \\
23 & 40 \\
24 & 40 \\
27 & 25 \\
41 & 10 \\
42 & 40 \\
45 & Viable, but delayed \\
& more than 5 years
\end{tabular}

Written comments included the following:

"I doubt that the rest of the world would have pursued the development of commercial nuclear power as it has if the U.S. federal government had not provided the 1 arge R\&D funds over the past three decades that it has." (Response No. 2)

"Federal R\&D activities were able to answer a number of questions with authority (for better or worse) that would have been raised in any event by the public and would have led to substantial delays and stoppages. In addition, private enterprise would have been slower in assuming risks." (Response No. 19)

"Industry would not accept the risk without government insurance and front-end risk money." (Response No. 41)

"The Navy program developed pressure vessel, pump, zirconium, heat exchanger, etc., infrastructure that was essential to civilian power.

"So, while nuclear power might have come on its commercial merits, it would have been delayed more than five years.

"The more deliberate pace might have avoided inept consideration of social acceptance." (Response No. 46 -- Comments on Scenario 2) 
Most of those who believed that federal incentives were important did not provide comments to substantiate their positions. The tenor of those who did comment appears to be that federal involvement in R\&D activities provided leadership to private industry and assisted them over hurdles which would have delayed development of the nuclear industry. In one set of comments the opinion was voiced that the private sector might have avoided some of the pitfalls in social acceptance had the pace of commercialization been slower.

None of the responses commented on how much of the federal government's expenditures were required for commercialization of LWRS. Some estimates are made in the summary section which follows the tabulation of responses.

Those who Thought that Federal Incentives Were Unimportant or a Hindrance To The Development of Commercial Nuclear Power

Twent $y$-four of the responses maintained that commercial nuclear power would account for more than $50 \%$ of that projected by the year 2000 if federal $R \& D$ had been terminated in 1954. More than half of those responding thought it would be at least as large an amount as has been recently forecast. Table 4.4 presents the actual quantified responses. The written comments in this category were voluminous.

Some responses cited examples of significant nuclear power activities which proceeded without federal assistance.

"Commonwealth Edison...did go ahead on its own volition to build a water-cooled reactor using uranium fuel. Furthermore, they did this without any government assistance, and the reactor is still working very sat isfactorily." (Response No. 3)

"I find Scenario 3 closest to my views. GE's nuclear power venture (and oyster (reek) were quite independent of direct federal involvement, and in my view GE/Westinghouse would have exploited the field much as they have, without federal R\&D in support of commercial reactor development." (Response No. 4)

"The Shippingport reactor was essentially a submarine-type reactor and cannot be considered as a commercial venture. The first commercial venture by industry in nuclear power was the Dresden \#1 unit, developed in the mid-1950's entirely by private funds and without federal involvement." (Response No. 37) 
TABLE 4.4. Response of Those Who Believed that Federal R\&D Was Not of Sign if icant Benefit in the Development of Nuclear Power

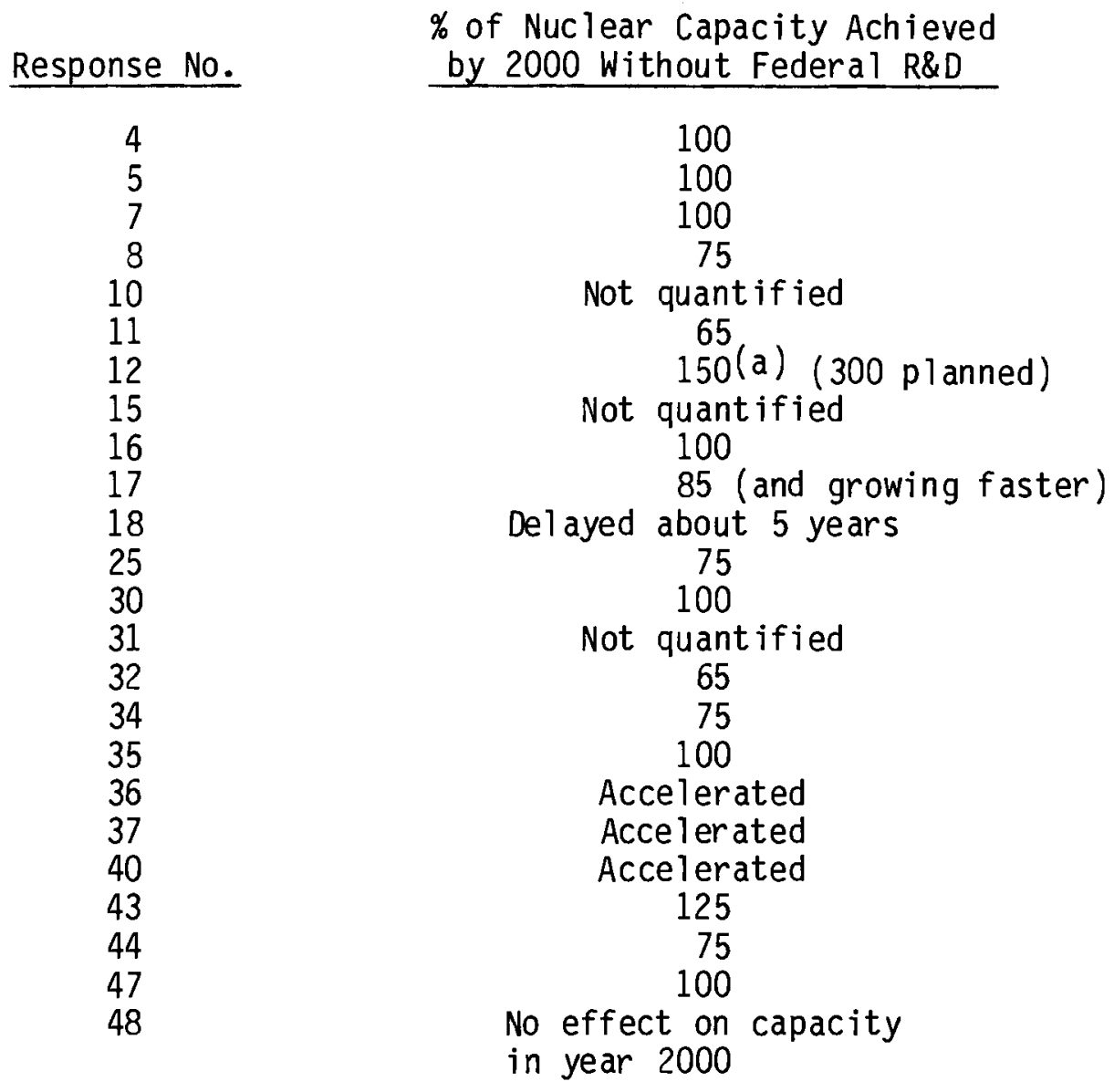

(a) This response had been delegated by the addressee.

The responses made it clear that there was a substantial capability and willingness in industry to attempt to commercialize nuclear power with technology that had been developed by the mid-50s.

A number of responses pointed out that the important factors in commercialization were not related to technology at all.

"Other than basic developments, government activities advanced nuclear power primarily by the act of acceptance of the technology." (Response No. 10) 
"Also important... was the general support of a civilian nuclear program provided by the AEC quite aside from the actual research and development expenditures." (Response No. 15)

"...the federal dollar expenditures were less important than the cl imate created...." (Response No. 30)

"Fortunately, several leaders in the utility industry, fully cognizant of the rapid growth it was, and would be, experiencing in the latter half of the Century and concerned about the air pollution that would develop, had been looking for alternate methods of power generation that would permit the continued use of cheap coal and prevent increased pollution. Their search for cleaner power production methods, coinciding with the politicians' desire for a constructive, peaceful use of the atom, resulted in the intensive educational efforts of power producers and their equipment suppliers, which culminated in the rapid initial acceptance of nuclear power...."

(Response No. 32)

The comments suggested that two factors were much more important than federal expenditures:

1. A positive government attitude

2. Utility desire to have alternative sources for generating electrical energy.

Other factors that are important in business decisions, such as liability limitations, economic considerations, and confidence in the product, were also cited.

A number of responses did cite aspects of federal R\&D programs or facility support that were important to the commercial program.

"...nuclear power would not have developed without the enrichment plants that were built for military purposes." (Response No. 10)

"Federal programs in LWR safety, fuel development, and fuel cycle management continue to be an important--and necessary--part of LWR support even today." (Response No. 11)

"The primary government responsibility with regard to nuclear energy was the issue of health, safety, and security. The technology after the Navy and military developments was quite well established."

(Response No. 16) 
"...the government support through demonstration projects was probably more important that the R\&D technology support." (Response No. 31)

Based on the responses, the important technology developed by the federal government in support of commercial nuclear power appears to include:

1. Proof of principle, both on a fundamental scale and an engineering scale.

2. Underlying technology in basic physics, materials, safety, and nuclear fuel.

3. Development of the fuel cycle.

The enrichment facilities were also cited as an important contribution to nuclear development.

Several of the responses stated that much of the technology developed was for reactor types that never achieved commercial status.

\begin{abstract}
"Much of the AEC R\&D was spent pursuing deadend reactor types. The current LWRS have very little AEC R\&D in their backgrounds, beyond the obvious military." (Response No. 7)

"The simple fact of the matter is that enormous amounts of money were spent on research and development, fuel development, and developing reactor technologies which never got anywhere." (Response No. 15)
\end{abstract}

It is interesting to note that none of the responses acknowledged the desirability of broad-base technology support per se, for the nuclear industry.

Those Who Commented but Declined to Speculate on how the Industry Might have Developed

Two responses were received that did not attempt to quantify how the commercial LWR market would have developed in the absence of federal R\&D expenditures, but these responses did offer comments on the survey.

"The government would not need to interpose itself on the development of nuclear power plants, except in areas where the government obviously has the direct responsibility, such as the furnishing of power plants to naval vessels." (Response No. 3) 
"It would be more interesting to explore how much more quickly the industry might have developed in the absence of controls. Perhaps absence of controls might be viewed as an "incentive", but that was not an incentive offered to the industry." (Response No. 9)

Those Who Responded but Declined to Comment or Speculate

Another group of responses to the Energy Industry Survey were from those who declined to comment about the effect of federal incentives on the nuclear industry.

"In my opinion the study to which you have been assigned cannot contribute to settling how best to apply federal incentives to solar power development, which is a problem so different from that of nuclear development." (Response No. 6)

"Frankly, the approach in your questionnaire assumes there is some parallelism between the technical and economic incentives to utilize solar energy and a corresponding scenario for nuclear power. I disagree with this basic premise. I think a survey taken on this basis is misleading. For this reason I choose not to respond." (Response No. 27)

The major thrust of these comments deal with whether useful information can be obtained from an effort like the Energy Industry Survey. Similar comments appeared in some of the letters which were cited in previous sections.

\section{Summary of Survey Responses}

The responses to the Energy Industry Survey do not permit a simple statistical analysis of the question, "What effect did federal incentives have on the development of the commercial nuclear power industry?" because of the tri-modal distribution. Further, the number of responses is only marginally significant.

The first category of responses (those who thought federal incentives were important to the development of commercial nuclear power) were not given (or did not take) the opportunity to indicate what parts of the incentives were important to the development of commercial nuclear power. Clearly the inclusion of fusion and fast breeder reactor incentives is inappropriate to present LWR technology. Whether non-LWR thermal reactor technology (e.g., gas and 
sodium-cooled reactor technology) should be included probably depends on one's view of the importance to the nuclear industry of a broad technology base. Also, at what point should one consider the LWR to be commercially developed? Certainly the issuance of construction licenses in 1964 for such plants as Connecticut Yankee, Oyster Creek, and San Onofre-1, all large plants, signalled commercialization. The second category of responses (those who thought federal incentives were not important) would probably opt for an earlier commercial readiness date, or maintain that federal incentives after 1954 accelerated commercialization by only a few years, at most. In the subsequent analysis, we have selected 1960 as the date of commercialization, since the large LWR basic designs were essentially fixed after that date.

To arrive at an estimate of federal incentives to commercialize LWRS, we added all R\&D costs prior to 1961, estimated mixed program contributions for that part of the R\&D program, and included all regulatory, reactor safety research, and waste management costs through 1977, plus the enrichment plant expansion costs which were made for the LWR. These incentives were:

- R\&D prior to 1961

(\$ billions)

(a11 reactor systems)

$\$ 2.0$

- Mixed program contributions (including Naval reactor program contribution)

$\$ 0.4$

- Reactor safety research

(through 1977)

$\$ 0.9$

- Waste management

(through 1977)

$\$ 0.1$

- Regulation

(through 1977)

$\$ 1.1$

- Enrichment plant

$\$ 1.8$

The estimated federal incentives to commercialize LWR total $\$ 6.3$ billion, or about one-third of the federal incentives for all aspects of nuclear power which include fusion and fast reactor development, basic research, and other programs not directly related to LWR technology. 
It is likely that many or most of those in the first category of responses would have increased their estimates of the projected role of nuclear by 2000 if they had been told to consider that $\$ 6.3$ billion in federal incentives had been spent. Based on the estimates in Figure 4.5, we can speculate that the present mean of $65 \%$ would be close to $100 \%$. If one can assume that $\$ 6.3$ billion in federal incentives resulted in increasing LWR capacity from $65 \%$ to $100 \%$ by 2000 , then the incentives per kWh of electricity specific to LWR capacity are about $0.09 \mathrm{mi11} / \mathrm{kWh}$. (a) If all $\$ 18$ billion (Table 4.1 ) were assessed to that increase in nuclear generation, the incentives would be three times 1 arger, or about $0.26 \mathrm{mi11} / \mathrm{kWh}$. If on $1 \mathrm{y} \$ 6.3$ billion were needed to commercialize nuclear power to its projected level of $100 \%$ in 2000 , the incentives would be about $0.03 \mathrm{mill} / \mathrm{kWh}$.

From this analysis, we conclude that the federal incentives to commercialize nuclear power probably lie in the range between 0.03 and $0.09 \mathrm{mill} / \mathrm{kWh}$.

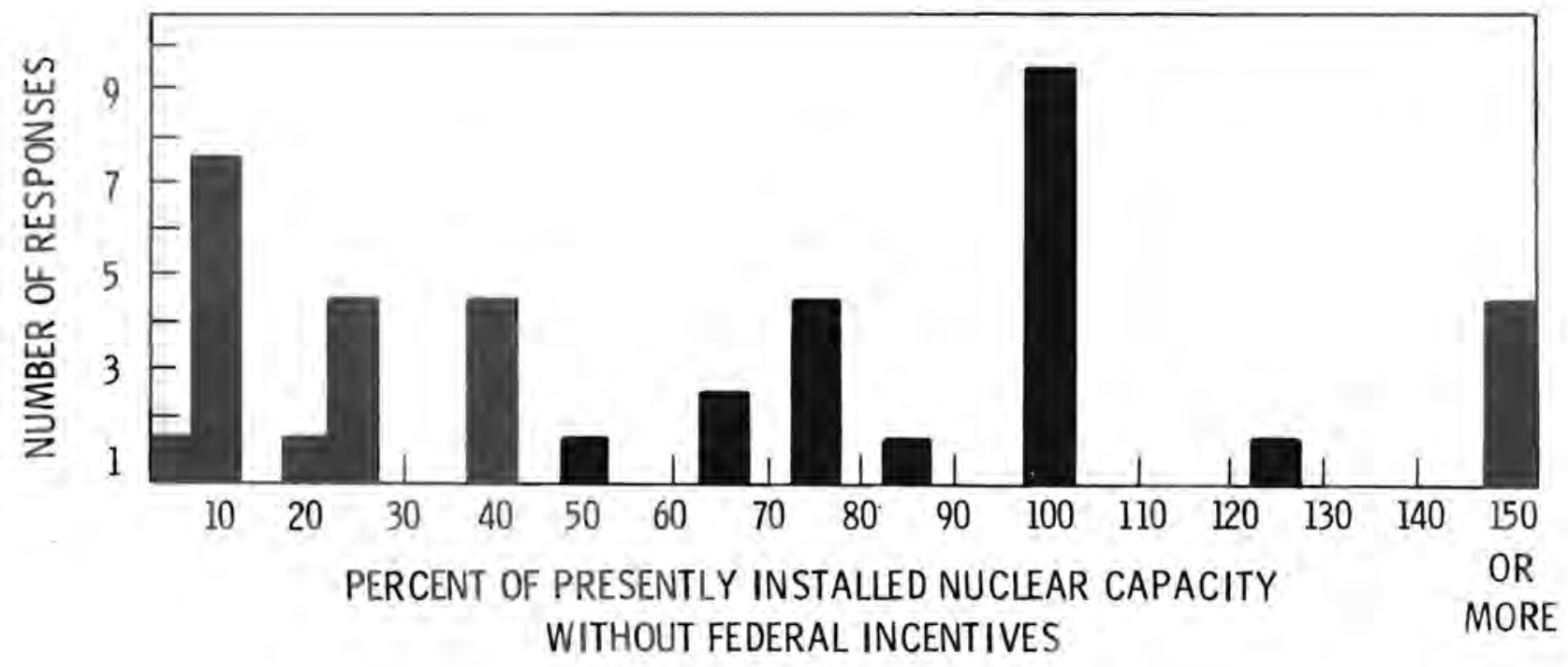

FIGURE 4.5. Tabulation of Responses Estimating Effectiveness of Federal Incentives to Nuclear Power

(a) Based on a projected cumulative 210,000 billion kWh of nuclear electricity generated by the year 2000. 


\section{NONPRICE AND QUANTITY IMPACTS}

In addition to using the Energy Industry Survey to quantify the effects of nuclear incentives, the effects were analyzed with respect to replacement. That is, if the nuclear energy contribution was different than it is now (because federal incentives were or were not applied), and other generating sources were substituted for it in the same generating mix ratio(a) as existed in 1977, and projected to 2000, what would be the economic effects on the foreign trade balance, inflation rate, employment, and industrial growth. The political aspects of foreign policy and national security are considered in a following section.

It is well known that the U.S. foreign trade balance depends heavily on oil imports; since nuclear generation can be substituted for oil generation, and vice versa, it should be possible to relate changes in nuclear generation to foreign trade balance. For example, if nuclear generation was only $65 \%$ (b) of the present $11.8 \%$ and assuming that the nuclear shortfall was distributed among other generating technologies (e.g., coal, oil, hydro, etc.) according to the ir market share, then $0.9 \%(0.17 \times 0.35 \times 0.118) /(1-0.35 \times 0.118)^{(c)}$ more oil would have been required in 1977 for generating electricity.

The effects of nuclear generated electric power on the U.S. economy and its interaction with our international trade conditions are significant and beneficial. Based on 1977 data, nuclear power in that year resulted in the following:

- Generation of 251 billion kWh of electricity (Energy Information Administration August $1978 \mathrm{~b}, p .33$ )

- Reduction of U.S. oil consumption by $103 \mathrm{million}$ bbl/yr or coal by $29 \mathrm{million}$ tons/yr.

(a) Nuclear electric generated $11.8 \%$ of the U.S. electrical production in 1977, oil electric accounted for 17\% (Energy Information Administration, August 1978b, p. 33).

(b) Based on the "mean of Figure 4.5, i.e., 65.3\%.

(c) The denominator is used to adjust the remaining energy sources back to $100 \%$ total. 
- Savings of about $\$ 1.5$ billion in oil import needs (assumes 1977 imported crude oil price of $\$ 14.53 / \mathrm{bb} 7$ ).

The use of petroleum for producing electricity is in a sharp decline. Thus, nuclear energy is, at present, meeting the growing electrical energy needs of the U.S. rather than serving strictly as an alternative to petroleum for supplying electricity needs.

The effects of nuclear power as a replacement to oil for electric generation are shown in Figure 4.6. Data in this figure are given for years 1977 and 2000. Three arbitrary values--22\%, $88 \%$, and $145 \%$--provide a range result from Figure 4.6. The economic conditions for the year 1977 and 2000 lead to the following differences in the curves: by the year 2000, oil prices are projected to have tripled and nuclear energy is projected to increase by a factor of about 4 or 5, and oil-fired electric generation will have declined by a

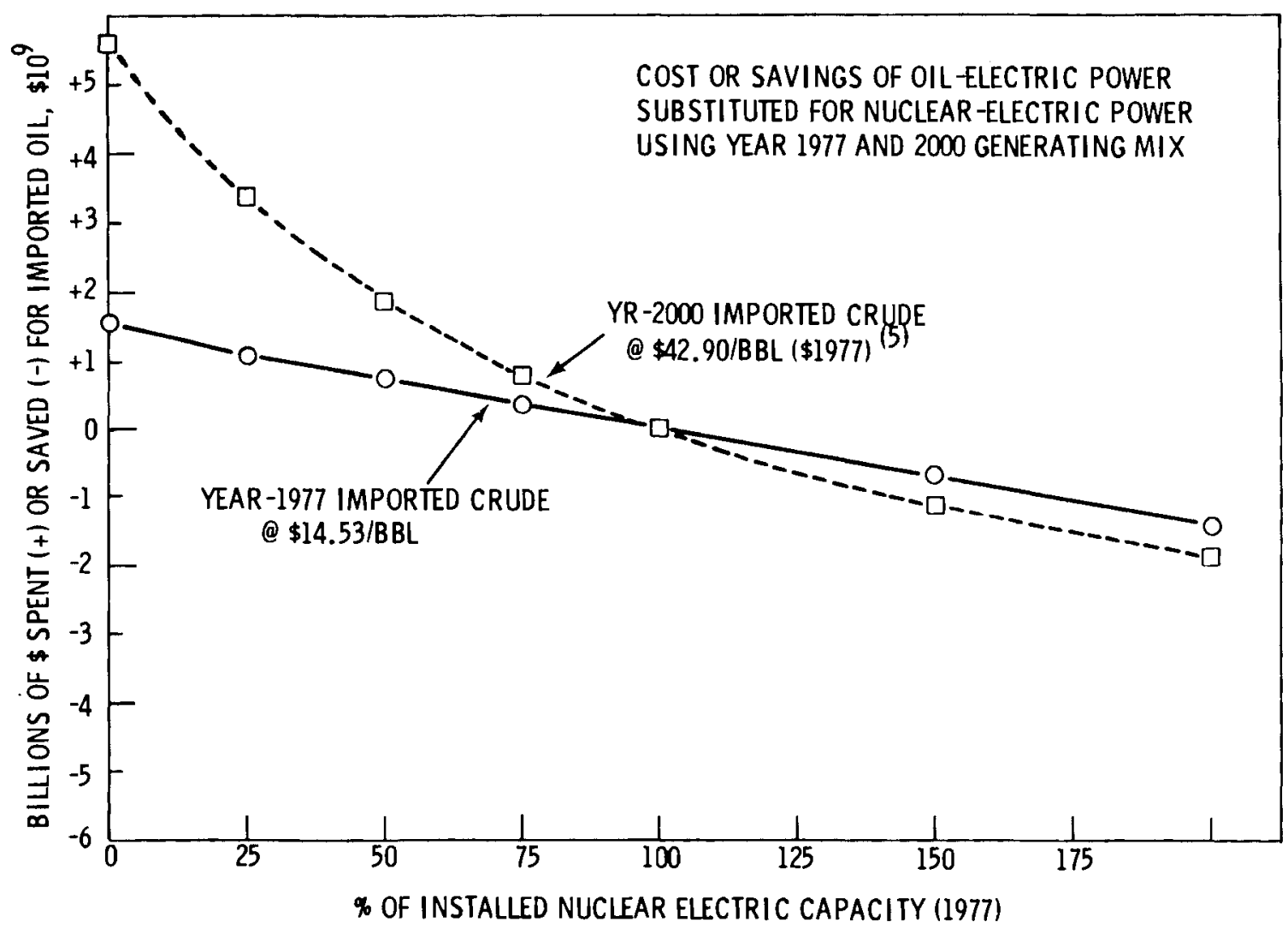

FIGURE 4.6. Monetary Effects of Nuclear Power as a Replacement to 0ilElectric Production 
factor of 5. Thus, while nuclear energy (along with coal) has provided an alternative (and replacement) to $0 i 1$, the price and availability of oil itself are the main forces in the decline of oil-fired electric generation. Table 4.5 summarizes results from Figures 4.6 and 4.7 .

Thus, if one concludes that without incentives the development of nuclear power would be only $22 \%$ of the 1977 and year 2000 values, an additional $\$ 1.1$ to $\$ 3.5$ billion would be spent each year for imported $0 i 1$. If, on the other hand, the conclusion is that without incentives, the nuclear industry would be at $145 \%$ of 1977 and year 2000 levels, then a savings of $\$ 0.7$ to $\$ 1.2$ billion for imported oil would be realized each year. Over the 20-year span, the dollar savings or expenditures for $0 i 1$ compare favorably with the estimated $\$ 6.3$ billion the government has spent on LWR incentives.

The inflationary effects of the oil differentials cited in Table 4.5 were estimated. Two models, described in Deonigi (October 1978) and McNown (1974), were applied to the problem. Both models indicated that the direct inflationary effect would be small. The inflationary effect can be estimated by the following equation:

$$
i=I_{F} \frac{(C I 0-C D O) D I 0}{V I} \times 100
$$

TABLE 4.5. Economic Effects of Nuclear Electric Market Penetrations

$$
\% \text { of }
$$

Nuclear

Capacity

22

88

145

22
88

145
Imported $0 i]$ Cost (+)

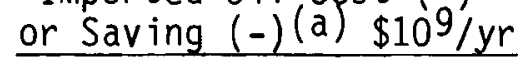

$+1.1$

$+0.3$

$-0.7$

$+3.5$

$+0.4$

$-1.2$
Value of Nuclear Fuel Sold (b) $\$ 10^{9} / \mathrm{yr}$

0.110

0.440

0.730

3.6

14.5

23.9

(a) See Figure 4.6.

(b) See Figure 4.7 . 


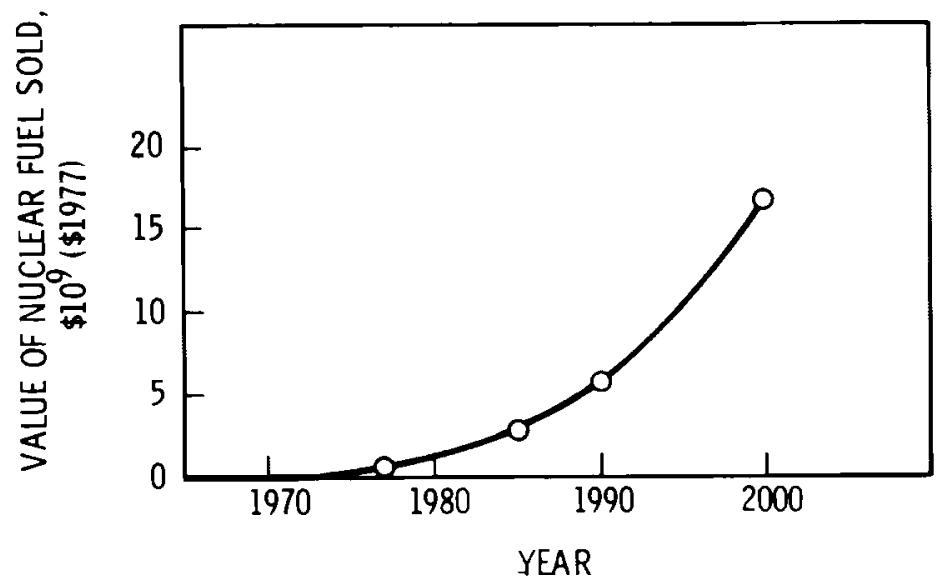

FIGURE 4.7. Value of Nuclear Fuel Sold Per Year From 1970 to 2000.

where

$i=$ differential inflation rate due to increased (oil) imports, $\% / y r$ $I_{F}=$ a coefficient equal to 0.21 (McNown 1974) indicating the domestic price level change resulting from a change in the import price level.

CIO $=\$ /$ bb 1 imported oil $(\$ 14.53 / b b 1)(a)$

$D C O=\$ / b b 1$ domestic oil (composite) $(\$ 11.96 / b b 1)$

DIO = Change in imported $0 i 1, b b 1 / y r$

VI = Value of total U.S. imports, $\$(\$ 147.7$ billion/yr $)$

The direct inflationary rate due to the differential oil imports from nuclear power is less than $0.1 \%$ due to the small difference between the prices for domestic (composite) and imported oil. A truly comprehensive model for the inflationary effect could not be found. The real inflationary effect of energy costs, which is probably significant, is that energy and its price pervades every section of the economy, and oil prices are dictated from outside the U.S. economy. The inflationary pressure from these conditions is significant.

The current and future effects of nuclear power on employment and industrial growth are significant. The differential economic effects of building

(a) 1977 basis data. 
nuclear or coal power plants, for instance, are probably not large, and therefore were not evaluated. However, the growth and characteristics of the nuclear fuel supply industry are significantly different from other fuel supply industries. The nuclear fuel supply business is more intensive from both technical and manufacturing standpoints.

Figure 4.7 shows the dollar value of the nuclear fuel estimated to be supplied to the industry during the period from 1970 to 2000 (Energy Information Administration, April 1978b). Table 4.5, fourth column, shows the growth of this industry for different estimates of installed nuclear capacity. Based on current projections the nuclear fuel industry will become a significant part of the U.S. economy during the next 20 years.

\section{Foreign Policy/National Security}

The fact that the U.S. has a nuclear energy industry provides us with national security and foreign policy advantages that are worthwhile, but not easily quantified. As with most political factors, a strictly monetary evaluation is not adequate.

The availability of an alternative energy source is a significant contribution from nuclear power. This alternative provides a diversity for electrical generation in locales that find other means of generation less attractive or infeasible. The emergence of the nuclear industry has provided a new technical area for employment that the other forms of energy production do not provide. It is recognized that each energy source has some social and environmental penalties. However, for this report, it is assumed that each industry segment has and will manage these problems effectively. Certainly the legislation and public attitudes are in place to assure that these problems are solved. The alternative energy source concept also provides a diversity of choice as the problems of pollution, fuel supply, social interactions, and financing are worked through and solved for the several energy sources.

The contributions of nuclear energy to foreign policy and national security are considerable. Our nuclear industry gives us an international trade contribution in the form of equipment and fuel exports. It provides us with an energy source that is free of foreign oil price pressure and politics. It 
provides us with a technological export capability useful as a bargaining tool in foreign policy with countries interested in purchasing our nuclear equipment. This also provides the U.S. with a method for potentially controlling the spread of nuclear weapons through our export sales policies.

The question is: how has the $\$ 18$ billion spent by the government in behalf of nuclear energy benefited or hindered the contributions described in the preceding paragraphs? Export controls for foreign policy considerations would be applied to the industry regardless of the government incentives. So the question then becomes, again, how has the industry growth level and characteristics been affected by the incentives? Certainly foreign policy would have adapted to the industry characteristics as required. We have not been able to establish a clear relationship between federal incentives and nuclear industry development.

THE IMPACT OF FEDERAL INCENTIVES ON THE PRICE AND OUTPUT OF NUCLEAR POWER

Chapter 2 of this report cites a variety of incentive results; these have been considered in light of the nuclear power incentives. However, only those items cited in Table 4.1 and repeated in Tables 4.6 and 4.7 , and discussed below, are considered significant to nuclear.

The incentive effects on nuclear power production through 1977 are shown in Table 4.6. This table is based on the mean from the industry survey of $65 \%$ of 1977 nuclear-electric capacity without incentives. Thus, (0.35) $x$ (980 billion $\mathrm{kWh})=343$ billion $\mathrm{kWh}$, or 1.17 quadrillion Btu, (quads) may be attributed to the federal incentives. All the generation was assigned to the R\&D category for two reasons: 1) R\&D represents $84 \%$ of all incentive monies, and 2) the contributions of the other categories could not be quantified.

The relationship between incentive dollars and the price of electricity from nuclear plants (15 mills/kWh in 1977) was found to be indeterminant, as shown in Figures 4.3 and 4.4 . Table 4.7 also reflects the indeterminant nature of the incentive effects on price. Certainly, without incentive expenditures by the federal government, nuclear power might have taken a different development route. But, based on the industry survey, the production level would probably not be greatly different from current level. It would be expected 
TABLE 4.6. A Summary of Incentive Effects on Civilian Nuclear Power Productjon (in $10^{15}$ Btue Cumulative Generation Through

\begin{tabular}{ccccc} 
Taxa- Disburse- & $\begin{array}{c}\text { Require } \\
\text { tional } \\
\text { tion }\end{array}$ ments & $\begin{array}{c}\text { Nontradi- } \\
\text { tional }\end{array}$ & $\begin{array}{c}\text { Market } \\
\text { Services }\end{array}$ Services \\
\hline
\end{tabular}

Research and

Deve lopment

1.17

Liability Insurance

(b)

Uranium Industry

(b)

Enrichment Plants

(b)

Regulation

Waste Management

Total

0

(b)

0

1.17

(b)

Total 1.17 quads (increase)

(a) Based on $65 \%$ of current nuclear capacity. See Figure 4.5.

(b) Not able to quant if $y$.

(c) Included in R\&D costs.

TABLE 4.7. A Summary of Incentive Effects on Nuclear Electric Power Price (in $1977 \$ / 10^{6} \mathrm{Btu}$ ) (a)

\begin{tabular}{llll} 
Taxa- Disburse- & $\begin{array}{l}\text { Require- } \\
\text { ments } \\
\text { tion }\end{array}$ - $\begin{array}{c}\text { Tradi- } \\
\text { tional }\end{array}$ & $\begin{array}{c}\text { Nontradi- } \\
\text { tional }\end{array}$ & $\begin{array}{c}\text { Market } \\
\text { Services }\end{array}$ Services \\
\hline
\end{tabular}

Research and

(b)

Liability Insurance

(b)

Uranium Industry

(b)

Enrichment Plants

(b)

Regulation

(b)

Waste Management

Total

0

(b)

(b)

0

(c)

(b)

(b)

(a) Based on 65\% of 1977 nuclear capacity as shown in Figure 4.5, and $4.7 \mathrm{mills} / \mathrm{kWh}$ power costs.

(b) Not able to quantify.

(c) Included in R\&D costs. 
that the price would be competitive with other forms of electrical energy. Thus, incentive monies may have had a small effect on price, but this effect could not be determined.

\section{CONCLUSIONS}

Based on responses from the Energy Industry Survey, perhaps the most important (and most elementary) lesson is that where there are different goals, there will be different views on the efficacy of the means used to reach them. For instance, the federal government had a goal of making thermal nuclear power plants commercially viable. Most reactor vendors has a goal of making some particular model commercially viable. The federal government was interested in avoiding a monopoly in nuclear power. The reactor vendors did not have that as a high priority. The federal government spent large sums on reactor types that never became commercialized. Those whose objectives were to commercialize LWRs might consider such monies wasted.

Survey responses indicate that incentives of money are not the most important factor, by $f a r$, in encouraging comercialization of an energy generating concept. True, the monetary incentives bear out a stated intention. But positive support in the form of legislation, general encouragement, and supportive attitudes are ample incentives where there is a profit potential for private industry.

Our analysis indicates that about one-third of the $\$ 18$ billion in federal incentives for nuclear energy was used to conmercialize the LWR concept. Perhaps a third of the responses to the Energy Industry Survey imply that that amount would be too high. In their eyes, out economic system provides the necessary incentives for industrial growth without being heavily dependent upon federal incentives. The system itself is incentive enough for both direction and growth.

The impacts that nuclear incentives have had on various facets of American life are summarized in Table 4.8. It shows that the research and development incentives had significant effects on a number of areas. By developing both 
TABLE 4.8. Sumary of Impact of Nuclear Incentives

\begin{tabular}{|c|c|c|c|c|c|c|}
\hline \multirow[b]{2}{*}{ Impacts } & \multicolumn{6}{|c|}{ Incentives } \\
\hline & $\begin{array}{l}\text { Research and } \\
\text { Development }\end{array}$ & $\begin{array}{l}\text { Liabili.ty } \\
\text { Insurance } \\
\end{array}$ & $\begin{array}{l}\text { Uranium } \\
\text { Industry }\end{array}$ & $\begin{array}{l}\text { Enrichment } \\
\text { Plants } \\
\end{array}$ & Regulation & $\begin{array}{c}\text { Waste } \\
\text { Management }\end{array}$ \\
\hline \multicolumn{7}{|l|}{ Economic Factors } \\
\hline Competition Versus Monopoly & M & I & I & I & I & I \\
\hline Sectoral Impacts & M & I & $L$ & I & I & I \\
\hline Sectoral Subsidies & M & I & L & I & I & I \\
\hline Income $\mathrm{C} 1$ ass & N & I & I & I & I & I \\
\hline Capital Formation & I & I & I & I & I & I \\
\hline Price/Quantity & M & I & I & I & L & I \\
\hline Inflation & L & I & I & I & M & I \\
\hline Employment/Productivity & I & I & I & I & I & I \\
\hline Balance of Payments & L & I & I & I & I & I \\
\hline \multicolumn{7}{|l|}{ Political Factors } \\
\hline Foreign Policy/National Security & $\mathrm{L}$ & I & I & M & $\mathrm{L}$ & I \\
\hline Stability & L & I & I & I & I & I \\
\hline \multicolumn{7}{|l|}{ Organizational/Legal Factors } \\
\hline State/Federal Regulations & M & I & I & I & $\mathrm{L}$ & M \\
\hline Public/Private & I & M & I & I & L & M \\
\hline Regulatory Burden & I & I & I & I & $L$ & M \\
\hline Quality of Life & I & I & I & I & I & I \\
\hline Demographics & I & I & I & I & I & I \\
\hline $\begin{array}{l}L=L \text { arge effect } \\
M=\text { Moderate effect } \\
I=\text { Indeterminate or no effect } \\
N=\text { Negligible }\end{array}$ & & & & & & \\
\hline
\end{tabular}


boiling water and light water reactors, an added element of competition was possible. Decreasing oil imports has had a large effect on inflation, balance of payments, and political factors.

Provision of liability insurance has had a moderate effect on publicprivate matters. Incentives to the uranium industry helped create a new industry, thus sectoral impacts are large. Expansion of enrichment capacity has affected foreign policy matters moderately. Incentives from regulation are having a large effect at present on numbers of nuclear plants, on foreign policy matters, and on a number of organizational/legal factors. The incentives for waste management are also having moderate effects on a number of organizational/legal factors also.

\section{RECOMMENDATIONS FOR SOLAR POLICY}

A number of comments from the Energy Industry Survey were made about federal involvement in solar activities based on experience in the nuclear field. These comments are also reported in Appendix $C$. These comments helped lead us to the following recommendations.

Utilities are continually exploring alternative power sources for generating electricity. Thus, the federal government can expect them to be receptive to cooperative efforts on solar-electric demonstration plants. The utilities' experience with more traditional generating options, including fossil and nuclear plants, would suggest that, given the choice, they will adopt the new (solar-electric) technology more slowly than many solar-electric vendors and technicians think is warranted. Should it be desirable to accelerate use of solar-electric generation by utilities, it is recomended that a program patterned after the Power Demonstration Reactor Program, adjusted for differences in the two technologies, be instigated. Because of regional and utility differences and the importance of obtaining experience from several utilities to help ensure rapid acceptance by the utility industry, the demonstration program should include several or more installations of each solar technology.

A second recommendation is that an environmental statement or analys is be prepared for utility-type solar-electric technologies to help ensure that social concerns do not develop later. While the public appears to support the 
development of solar-electric technologies, it does not necessarily follow that they support the types of installations that utilities would employ. Informing the public of what accomodations they will have to make to benefit from new energy sources is an important facet of this recommendation.

A third recomendation is that the regulatory or licensing aspects of solar-electric generating stations be investigated in detail to avoid the type of regulatory problems which has afflicted the nuclear industry.

Nuclear power developed a congressional constituency epitomized by the JCAE which helped overcome legislative roadblocks to commercial development. Irrespective of whether solar-electric needs a similar constituency, or whether it already has it, it is sometimes necessary to overcome roadblocks by legislative means. A fourth recommendation is that legislative requirements to facilitate solar adoption be identified so that appropriate solar implementation actions can be instigated in timely fashion.

Low-cost energy storage is an important adjunct to solar. Initial market penetration of solar electric will rely on energy storage systems already in place. As the penetration increases, additional storage will be required. The need for a widespread energy storage industry may be analogous to having a viable uranium industry. A fifth recomendation is that energy storage requirements for various solar market penetrations be investigated to determine whether the industrial infrastructure is likely to be a limiting factor in the adoption of solar. 


\section{CHAPTER 5}

\section{HYDROELECTRICITY}

by

Richard Mazzucchi, Research Engineer Alex Fassbender, Research Engineer 


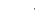




\section{HYDROELECTRICITY}

INTRODUCTION

In 1977 hydroelectric power supplied 10.4\% of the nation's electrical power. The federal government has provided significant incentives to stimulate hydroelectric production. It is presently involved in the planning, construction, operation, regulation and marketing phases. In 1977, 145 federally managed projects accounted for $13 \%$ of the major hydroelectric plants, $43 \%$ of installed generating capacity and $51 \%$ of the net hydroelectric generation. Furthermore, 264 federally subsidized municipal, state, and district cooperative managed facilities produced an additional $24 \%$ of net hydroelectric generation. Most of the remainder is produced by private facilities licensed by the Federal Energy Regulatory Commission. Most of the federal projects are multiuse--constructed to improve navigational facilities, flood control, and management of water resources in addition to the production of electrical power. These provisions have stimulated the economic development of surrounding areas by reclaiming flood plains, providing irrigation water for crops, supplying electrical power for municipal and industrial use, opening up water-bound transportation routes, and creating recreational/tourist areas. Therefore, the analysis of the results of federal incentives to hydroelectric facilities will address the impacts on these and other related concerns.

In Cone et al. (December 1978), we identified incentives and used two methods to estimate the total costs of the incentives. The total federal incentives to stimulate hydroelectric generation were found to be either 8.0 or 15.3 billion $1977 \$$, as shown in Table 5.1. In this chapter, we will identify and describe the results derived from the federal incentives.

There are many ways to consider the effects of the incentives to hydroelectric facilities because of the myriad of related economic and social activity precipitated by hydro development. We shall estimate the impact of federal incentives on the production and price of hydropower by the engineering approach and describe the related benefits of hydro development. The effects are further analyzed, using the inspection approach, by comparing federal with non-federal hydroelectric generation. 
TABLE 5.1. Federal Incentives Used to Stimulate the Development of Hydro-Energy and Electricity Transmission (millions of $1977 \$$ ) (Cone et al. December 1978, p. 158)

Incentive Area

Hydro-energy production

Construction and operation of federal dams

Low-interest loans

federal tax exempt power revenues

Regulation of non-federal dams

Subtotal

Total

Electricity transmission(b)

Construction and operation

of federal transmission systems

Low-interest loans
Market

Activity Taxation Requirements

$$
\begin{array}{r}
13,487.6(1)(a) \\
6,192 \cdot 6(2)(a)
\end{array}
$$

$1,771.7$

$\underline{33.39}$

33.39

(a) Definitions (1) and (2) are mutually exclusive and cannot be added.

(b) Incentives to electricity transmission are included in the total of Chapter 9. They are noted here for completeness.

\section{FEDERAL INVOLVEMENT IN HYDROELECTRIC PRODUCTION}

The federal government has created organizations that design, construct and operate hydroelectric facilities and market the energy they produce. The construction of all federal dams is supervised by the U.S. Army Corps of Engineers (USACE), the Bureau of Reclamation (USBR), or the Tennessee Valley

Authority (TVA). These organizations are involved with site selection and dam design; however, the construction may be performed by subcontractors. Table 5.2 presents the number of projects and generating capacity of facilities assigned to each of these federal agencies and the private sector. 
TABLE 5.2. Electric Utility Hydroelectric Plants in the United States (EIA May 1978b)

\begin{tabular}{|c|c|c|c|c|}
\hline A11 Plants & 1966 & 1970 & 1976 & $\begin{array}{l}\% \text { Change } \\
1966 \text { to } 1976 \\
\end{array}$ \\
\hline \multicolumn{5}{|l|}{ Federal } \\
\hline \multicolumn{5}{|l|}{ TVA } \\
\hline $\begin{array}{l}\text { Number of plants } \\
\text { Installed capacity, MW (a) } \\
\text { Net generation, billion kWh }\end{array}$ & $\begin{array}{r}29 \\
3,076 \\
11.9\end{array}$ & $\begin{array}{r}29 \\
3,119 \\
12.4\end{array}$ & $\begin{array}{r}29 \\
3,231 \\
14.6\end{array}$ & $\begin{array}{r}0 \\
5.0 \\
22.7\end{array}$ \\
\hline \multicolumn{5}{|l|}{ Bureau of Reclamation } \\
\hline $\begin{array}{l}\text { Number of plants } \\
\text { Installed capacity, MW (a) } \\
\text { Net generation, billion kWh }\end{array}$ & $\begin{array}{r}48 \\
6,923 \\
31.2\end{array}$ & $\begin{array}{r}49 \\
7,494 \\
35.8\end{array}$ & $\begin{array}{r}50 \\
9,690 \\
40.2\end{array}$ & $\begin{array}{r}4.2 \\
40.0 \\
28.8\end{array}$ \\
\hline $\begin{array}{l}\text { Corps of Engineers } \\
\text { Number of plants } \\
\text { Installed capacity, MW (a) } \\
\text { Net generation, billion kWh }\end{array}$ & $\begin{array}{r}45 \\
9,490 \\
42.9\end{array}$ & $\begin{array}{r}55 \\
12,032 \\
61.1\end{array}$ & $\begin{array}{r}65 \\
15,962 \\
86.2\end{array}$ & $\begin{array}{r}44.4 \\
68.2 \\
100.1\end{array}$ \\
\hline \multicolumn{5}{|l|}{ Private } \\
\hline $\begin{array}{l}\text { Number of plants } \\
\text { Installed capacity, MW (a) } \\
\text { Net generation, billion kWh }\end{array}$ & $\begin{array}{r}800 \\
16,360 \\
62.8\end{array}$ & $\begin{array}{r}763 \\
18,854 \\
70.5\end{array}$ & $\begin{array}{r}732 \\
23,208 \\
71.1\end{array}$ & $\begin{array}{l}-8.5 \\
41.9 \\
13.2\end{array}$ \\
\hline \multicolumn{5}{|l|}{$\frac{\text { Municipa 1, State, District }}{\text { and Co-ops }}$} \\
\hline $\begin{array}{l}\text { Number of plants } \\
\text { Installed capacity, MW (a) } \\
\text { Net generation, billion kWh }\end{array}$ & $\begin{array}{r}270 \\
9,030 \\
45.5\end{array}$ & $\begin{array}{l}281 \\
12,706 \\
66.1\end{array}$ & $\begin{array}{c}265 \\
15,589 \\
71.5\end{array}$ & $\begin{array}{l}-3.7 \\
72.6 \\
57.1\end{array}$ \\
\hline \multicolumn{5}{|l|}{ TOTAL } \\
\hline $\begin{array}{l}\text { Number of plants } \\
\text { Installed capacity, MW (a) } \\
\text { Net generation, billion kWh }\end{array}$ & $\begin{array}{r}1,200 \\
44,928 \\
194.4\end{array}$ & $\begin{array}{r}1,185 \\
54,524 \\
246.0\end{array}$ & $\begin{array}{l}1,149 \\
67,729 \\
283.7\end{array}$ & $\begin{array}{l}-4.2 \\
50.7 \\
45.9\end{array}$ \\
\hline
\end{tabular}

(a) Pumped-storage capacity included.

The Flood Control Act of 1944 requires the Department of Interior to sell power at reservoir projects operated by the Army Corps of Engineers. To market the energy supplied by USACE and/or USBR projects, five power administrations have been established: Bonneville, Southwestern, Southeastern, Western, and Alaska. These power administrations, combined with the hydroelectric facilities in their regions, are called Federal Power Programs or Federal Power 
Systems. The TVA and USBR have the authority to construct and operate their own power facilities and market the power produced. The generating capacity managed by each power administration and the level of federal investment are listed in Table 5.3. Each agency will be briefly described in the following sections to provide the information necessary to assess the impact of federal incentives.

\section{Army Corps of Engineers}

The Corps of Engineers began its substantial involvement in civilian projects in 1824 when the Congress assigned the Corps the task of clearing snags and sandbars from the Ohio and Mississippi Rivers. In 1909 the federal government acquired a dam on the St. Mary's River in Michigan. Though the acquisition was primarily for navigational purposes, the dam also contained a hydroelectric plant, the Corps' first. Also that year Congress recognized the potential significance of hydroelectricity to a growing nation and directed the Corps to include assessments of water power potential in its periodic surveys of U.S. waterways. At this time, development of hydroelectric facilities was conducted almost entirely by private interests. The Corps began its own hydropower construction in 1916 when it added a turbine unit to the St. Mary's plant.

In 1918 the Corps began building the Wilson Lock and Dam on the Tennessee River in Alabama. Completed seven years later, the hydroelectric generators had a total capacity of $184,000 \mathrm{~kW}$. About that time, the Corps which in 1917 had been charged by Congress with flood control responsibilities, began comprehensive water resource planning. In 1938 the Corps initiated a full fledged hydroelectric program with the construction of a $518,000 \mathrm{~kW} \mathrm{plant}$ at the Bonneville Lock and Dam on the Columbia River. Since the end of World War II, the Corps' role in rydroelectric development has greatly expanded and spread to all regions of the country. Currently, the USACE is the nation's predominant builder and operator of hydroelectric facilities managing a total capacity of over $15.6 \mathrm{million} \mathrm{kW}$ in 65 separate projects. Production from these plants of 86.2 billion $\mathrm{kW} / \mathrm{hr}$ in 1976 constituted over $30 \%$ of total U.S. hydroelectric production. The role of the USACE is continuing its rapid growth with the construction of six new facilities, the addition of generating capacity to 
TABLE 5.3. Marketing of Federal Hydroelectric Production in 1976 (Cone et al. December 1978)

Generating Capacity
$\frac{\text { Billion kW }}{\% \text { of Total }}$

Bonneville Power Administration

Southwestern Power Administration

Southeastern Power Administration

Alaska Power Administration

Western Power Administration (not operational until 1981)

Tennessee Valley Authority

Bureau of Reclamation

TOTAL

$\begin{array}{lr}14.551(7) & 50 . \\ 1.916(8) & 7 . \\ 2.532(9) & 9 . \\ 0.007(10) & 0 .\end{array}$

50.0

7.0

9.0

0.3

$3.231(20)$

11.0

23.0

100.0

31.93
$\%$ of

Federal Investment

(billions 1977 \$)

6.19

1.22

1.68

0.161

1.86

2.36

14

18

13.471 
several existing plants, and the incorporation of pumped storage techniques. These improvements are expected to increase hydroelectric generating capacity of USACE plants by $30 \%$, to 20.2 million $\mathrm{kW}$ in 1985 (USACE July 1976).

Bureau of Reclamation

The federal reclamation program was formally launched with the passage of the Reclamation Act of 1902. Its purpose was to provide people with settlement and economic opportunities by irrigating public lands in the West. The act stipulated that proceeds from the sale of public lands be set aside to finance the construction and maintenance of irrigation works in the arid west and that expenditures from the fund be repaid by the settlers over a 10-yr period. The value of water for power generation was recognized in 1906 in the Town Sites and Power Development Act which permitted the sale of electricity produced in excess of project needs.

Early in the experience of the reclamation program, it became apparent that settlers could not repay project costs in a period as short as 10 years. It also became evident that the reclamation land would not be self-sustaining, as repayments by settlers and proceeds from sales of public lands would be insufficient to finance major irrigation works; consequently, direct appropriation by Congress became necessary. An advance of funds was first sought in 1910 and the repayment period was lengthened to 20 years in 1914 .

As a result of repayment difficulties, the Bureau of Reclamation was incorporated into the Department of Interior in 1923 and more attention was paid to the engineering feasibility of prospective developments. Not until the Boulder Canyon Act of 1928 was there a clear expression of the concept of multiple purpose development of water resources. The concept provides for the evaluation of water projects by synergistically considering the benefits of flood control, navigation, water storage and delivery, recreation, and electricity generation. The Flood Control Act of 1936 contained the genes is of benefit cost analys is by stipulating that the government should consider projects only if the benefits they accrue are in excess of the estimated costs (Coddington et al. December 1972). 
The Great Depression gave much impetus to the reclamation program by justifying large, multiple purpose undertakings such as the Grand Coulee Dam and Power Plant on the Columbia River and the Central Valley Project in California. Between 1935 and 1945, the installed hydroelectric capacity of reclamation projects increased from 35.3 to 2,245.4 MW (Coddington et al. December 1972). These demonstrations of the potential for hydroelectric generation have spurred the construction of 50 hydroelectric facilities by USBR to bring total installed capacity to 9,690 MW in 1976. Yearly generation in 1976 exceeded 40 billion kWh or approximately $14 \%$ of all hydroelectric power generated in that year (EIA May 1978).

\section{The Tennessee Valley Authority (TVA)}

The Tennessee Valley Authority was established by act of Congress in 1933 to help the people of the Tennessee River Basin use natural resources to overcome deep-rooted problems of poverty and inadequate opportunity. In that year the region's income was less than half the national average. Most people in the Tennessee Valley depended on farming for a living, but the need for farm manpower was shrinking as machines began to displace hand labor. Industry was desperately needed to provide jobs and generate related economic activity, but the prospects for industrial growth were slight (Selznick 1966).

Although there were no simple answers for these old and persistent problems, the region's resources offered a base for building a higher standard of living. The TVA was established as an independent government corporation with a regional headquarters. TVA pioneered in building the first system of multiuse dams and reservoirs to control a major river. Construction of the reservoir system began in the 1930s, then was rushed in the 1940s to meet wartime demands for electric power. Since that time, TVA has proceeded with selected water projects at a slower rate, increasing installed hydroelectric generating capacity slightly. The TVA built a system of dams that makes the Tennessee River one of the most useful in the world, controlling its floods and turning its 650-mile main stream into a waterway for large freight. The power harnessed by these dams resulted in an electrical system capable of providing service to over two million homes, farms, businesses, and industries (General Accounting Office November 1978). 
Harnessing the water power from the Tennessee River to generate electricity was more than a challenge for engineers; it was a challenge for the society to use the power to develop the economy. Electricity was expensive in 1933 (see Electricity; Chapter 9). Most of the people lived in rural areas and it was prohibitively costly to build the long lines to serve scattered farms-so only one in 30 had electrical service. The dams TVA built offered a new supply of economical power that was several times the current generating capacity. Financing was made available for farmers to organize cooperative systems to distribute power--a forerunner of the national rural electrification program. TVA power was offered to those cooperatives and to city-owned electric systems at low wholesale rates (preferred customer rates) with the provision that the savings be passed on to the public at a price of about half the former rates.

These local distribution systems became partners with TVA in making low cost electricity a tool in the region's economic development. More and more cooperative systems were organized and, by the end of 1945, they had made TVA the power supplier for nearly all of Tennessee and parts of six adjoining states. Through TVA's first 20 years of operation, essentially all power supply for the region was generated at the dams. By 1950 the region's power requirement was outgrowing the amount that could be supplied from hydroplants, due in large part to the regional development the hydropower precipitated. The TVA then began building steam electric plants to use the abundant coal supplies in the region.

Currently one nuclear facility is in operation and several more are under construction or consideration. In 1977, electricity from 29 TVA hydroelectric facilities supplied 14.3 billion kWh, slightly less than $11 \%$ of TVA's power requirement. This amount constitutes $5.1 \%$ of total hydropower generated in the U.S. for the year (EIA May 1978b).

\section{Private Enterprise}

Production of hydroelectric power by investor-owned utilities constituted $25.1 \%$ of hydroelectric generation in 1976. The 732 privately owned sites provided a total 77.1 billion $\mathrm{kWh}$. The facilities are financed with private 
capital. Power revenues are subject to federal, state and local taxes, and a regulated return on investment (profit) is allowed by state utility commissions. Largely as a result of federal incentives to public hydroelectric developments, the share of generation by IOU's has declined dramatically since 1930. Nonetheless, generation by investor-owned hydroelectric facilities has increased by $41.9 \%$ since 1968 . The privately financed projects are licensed by the Federal Energy Regulatory Commission.

Municipal, State, District, and Cooperative Systems

Publicly-owned hydroelectric facilities operated by municipal, state, district, and cooperative systems supplied $25.2 \%$ of domestic hydroelectric power in 1976. A total of 275 separate projects generated 71.5 billion kWh. Although owned and operated by local governmental bodies or districts, the facilities are financed with tax-free general revenue bonds or low-interest federal loans. Also, the power revenues are exempt from federal taxes, provided the savings are passed on to final consumers. Generation by these systems has increased by $57.1 \%$ between 1966 and 1976 .

\section{Bonneville Power Administration}

The Bonneville Power Administration (BPA) was created in 1937. Through a regional interconnecting transmission system, it markets electric power and energy from federal hydroelectric projects in the Pacific Northwest constructed and operated by the Corps of Engineers or the Bureau of Reclamation (BPA July 1977). Through interregional connections, its sells and exchanges surplus power to other regions.

By an Act of Congress, approved 0ctober 18, 1974, the BPA now has the authority to use its revenues or to sell revenue bonds to the U.S. Treasury in lieu of federal appropriations to build, operate, and maintain its transmission system.

\section{Southwestern Power Administration}

The Southwestern Power Administration (SWPA) was created by the Secretary of the Interior in 1943 (SWPA June 1977). It administers the sale of electric power generated at certain projects constructed and operated by the Army Corps of Engineers in Kansas, Missouri, Oklahoma, Arkansas, Texas, and Louisiana. 


\section{Southeastern Power Administration}

The Southeastern Power Administration (SEPA) was created by the Secretary of the Interior in 1950 to carry out functions assigned to the Secretary by the Flood Control Act of 1944. It administers the sale of electric power from dams operated by the U.S. Army Corps of Engineers in West Virginia, Virginia, North Carolina, South Carolina, Georgia, Florida, Alabama, Mississippi, Tennessee, and Kentucky (SEPA December 1974).

The Western Area Power Administration

The Western Area Power Administration (WAPA) was established on December 21, 1977, to serve the electrical needs of 5 million retail customers in 15 Western states. It will administer the sale and distribution of power produced at existing hydroelectric generation facilities in California, Arizona, Nevada, Montana, North Dakota, South Dakota, Iowa, Colorado, Wyoming, Minnesota, Texas, New Mexico, Utah, and Nebraska. It is anticipated that WAPA will be operational in 1981 (EIA May 1978b).

Alaska Power Administration

The Alaska Power Administration (APA) was created by the Secretary of the Interior in 1967 to carry out functions assigned to the Secretary related to water and power planning and power operations in Alaska, including among others the Eklutna Project Act; the Snettisham Project authorization in the Flood Control Act of 1962, and the power marketing provision of the Flood Control Act of 1944 (APA July 1977).

Federal Energy Regulatory Commission

The Federal Energy Regulatory Commission (FERC) regulates the interstate aspects of the electric power. Formed by the Department of Energy Organization Act of 1977, FERC was assigned the responsibilities previously held by the Federal Power Commission under the Federal Power Act (originally enacted as the Federal Water Power Act of 1920 and subsequently amended by legislation and executive order).

Concerning hydroelectricity, the Federal Energy Regulatory Commission issues permits and licenses for non-federal hydroelectric power projects; 
regulates the rates and other aspects of interstate wholesale transactions in electric power; issues certificates; conducts continuing investigations of the electric power industries and their relationships to national programs and objectives, including conservation and efficient utilization of resources; requires maximum protection of the environment in the construction of new hydroelectric projects and transmission lines consistent with the nation's needs for adequate and reliable electric power; and allocates resources consistent with the public interest under the Federal Power Act. In addition, the FERC prescribes and enforces a uniform system of accounts for regulated electric utilities.

The FERC publishes river basin appraisals for use in licensing projects. It also reviews plans for dams proposed by other federal agencies and makes recommendations concerning facilities for the development of hydroelectric power. The Commission reviews rates for the sale of electric power from certain federal hydroelectric projects. In addition, it participates with other agencies in coordinating development and utilization of the nation's water and related land resources.

\section{FEDERAL INCENTIVES TO HYDROELECTRIC POWER}

Federal incentives to the development of hydroelectric power were discussed in detail in Cone et al. (December 1978). Basically, federal incentives are quantified into three specific categories; 1) taxation, 2) market activity and 3 ) requirements. Annual incentive data are presented in Table 5.4 and plotted in Figure 5.1. Corresponding cumulative information since 1933 can be found in Table 5.5 and Figure 5.2 .

\section{Market Activity}

The amount of incentives provided to the development of hydroelectric facilities by market activity is quantified by two methods. The first method considers the net federal investment in hydrogenerating facilities and the second method considers the savings generated by low-interest federal loans as an incentive. While the following discussion only considers the first definition, it must be remembered that an alternative method does exist. 
TABLE 5.4. Annual Hydroelectric Incentives (millions of $1977 \$$ ) (Cone et a1. December 1978, Chapter V)

\begin{tabular}{|c|c|c|c|c|}
\hline Year & Market Activity & Taxation & Requirements & Total \\
\hline 1977 & 298.72 & 50.97 & 4.57 & 354.26 \\
\hline 1976 & 39.08 & 13.51 & 1.70 & 54.24 \\
\hline 1976 & -209.15 & 61.90 & 4.03 & -143.22 \\
\hline 1975 & 292.57 & 55.27 & 5.10 & 352.94 \\
\hline 1974 & 372.07 & 40.25 & 4.19 & 416.51 \\
\hline 1973 & 363.82 & 52.64 & 4.22 & 420.68 \\
\hline 1972 & 485.74 & 51.05 & 4.95 & 542.76 \\
\hline 1971 & 414.93 & 47.58 & 4.63 & 467.14 \\
\hline 1970 & 149.20 & 49.16 & & 198.36 \\
\hline 1969 & 292.59 & 67.97 & & 360.56 \\
\hline 1968 & 371.48 & 50.61 & & 422.09 \\
\hline 1967 & 342.66 & 75.02 & & 417.68 \\
\hline 1966 & 644.88 & 73.72 & & 718.60 \\
\hline 1965 & 755.53 & 73.90 & & 829.43 \\
\hline 1964 & 450.63 & 71.38 & & 522.01 \\
\hline 196. & 790.19 & 76.51 & & 866.70 \\
\hline 1962 & 376.81 & 75.02 & & 451.83 \\
\hline 1961 & 284.46 & 68.79 & & 284.46 \\
\hline 1960 & 189.02 & 71.83 & & 260.65 \\
\hline 1959 & 59.02 & 50.54 & & 109.56 \\
\hline 1958 & 147.98 & 51.79 & & 199.77 \\
\hline 195 & 413.23 & 48.90 & & 462.13 \\
\hline 195 & 776.82 & 47.92 & & 776.82 \\
\hline 195 & 618.46 & 47.78 & & 666.24 \\
\hline 195 & 910.20 & 41.88 & & 952.06 \\
\hline 1953 & 400.27 & 42.37 & & 442.64 \\
\hline 195 & 163.72 & 47.16 & & 210.68 \\
\hline 195 & 301.78 & 37.65 & & 339.43 \\
\hline 195 & 249.84 & 28.52 & & 278.36 \\
\hline 194 & 239.54 & 21.11 & & 260.65 \\
\hline 1948 & 149.76 & 15.46 & & 165.22 \\
\hline 194 & 152.48 & 16.98 & & 169.46 \\
\hline 194 & 181.54 & 19.28 & & 200.82 \\
\hline 19 & 250.97 & 26.83 & & 277.80 \\
\hline 19 & 301.14 & 25.30 & & 326.44 \\
\hline 194 & 175.44 & 21.14 & & 196.58 \\
\hline 19 & 113.87 & 10.34 & & 124.21 \\
\hline & 162.19 & 21.32 & & 183.51 \\
\hline 194 & 168.40 & 12.28 & & 100.68 \\
\hline 19 & 170.02 & 4.22 & & 174.24 \\
\hline & 167.60 & 4.90 & & 172.50 \\
\hline & 64.48 & & & 164.48 \\
\hline 19 & 83.53 & & & 83.53 \\
\hline & 83.34 & & & 84.34 \\
\hline & 86.45 & & & 86.4 \\
\hline & 89.34 & & & 89 \\
\hline
\end{tabular}


TABLE 5.5. Cumulative Federal Incentives to Stimulate Hydroelectricity (millions of $1977 \$$ ) (Cone et al. December 1978)

\begin{tabular}{|c|c|c|c|c|}
\hline Year & Market Activity & Taxation & Requirements & Total \\
\hline 1977 & $13,487.59$ & 1.771 .75 & 33.39 & $15,292.73$ \\
\hline 1976 & $13,188.87$ & $1,720.78$ & 28.82 & $14,938.47$ \\
\hline 1976 & $13,149.84$ & 1.707 .27 & 27.12 & 14.884 .23 \\
\hline 1975 & $13,358.99$ & $1,645.37$ & 23.09 & $15,027.45$ \\
\hline 1974 & $13,066.42$ & $1,590.10$ & 17.99 & $14,674.51$ \\
\hline 1973 & $13,694.35$ & $1,549.85$ & 13.80 & $14,258.00$ \\
\hline 1972 & $12,330.53$ & $1,497.21$ & 9.58 & $13,837.32$ \\
\hline 1971 & $11,844.79$ & $1,445.16$ & 4.67 & $13,294.58$ \\
\hline 1970 & $11,429.86$ & $1,397.58$ & & $12,827.44$ \\
\hline 1969 & $11,280.66$ & $1,348.42$ & & $12,629.08$ \\
\hline 1968 & $10,988.07$ & $1,208.45$ & & $12,268.52$ \\
\hline 1967 & $10,616.59$ & $1,229.84$ & & 11.846 .43 \\
\hline 1966 & $10,273.93$ & $1,154.82$ & & $11,428.75$ \\
\hline 1965 & $9,629.05$ & $1,081.10$ & & $10,710.15$ \\
\hline 1964 & $8,873.52$ & $1,107.20$ & & $9,880.72$ \\
\hline 1963 & $8,422.89$ & 935.82 & & $9,350.71$ \\
\hline 1962 & $7,632.70$ & 859.31 & & $8,492.01$ \\
\hline 1961 & $7,255.89$ & 784.29 & & $8,040.18$ \\
\hline 1960 & $6,971.43$ & 715.50 & & $7,686.93$ \\
\hline 1959 & $6,782.41$ & 643.67 & & $7,426.08$ \\
\hline 1958 & $6,723.39$ & 593.13 & & $7,316.52$ \\
\hline 1957 & $5,575.41$ & 541.34 & & $7,116.75$ \\
\hline 1956 & $6,162.18$ & 492.44 & & $6,654.62$ \\
\hline 1955 & $5,829.88$ & 444.52 & & $6,654.62$ \\
\hline 1954 & $4,766.90$ & 396.74 & & $5,163.64$ \\
\hline 1953 & $3,856.70$ & 354.86 & & $4,211.56$ \\
\hline 1952 & $3,456.43$ & 312.49 & & $3,768.92$ \\
\hline 1951 & $3,292.71$ & 265.33 & & $3,558.04$ \\
\hline 1950 & $2,990.93$ & 227.68 & & $3,218.61$ \\
\hline 1949 & $2,741.09$ & 199.16 & & $2,940.25$ \\
\hline 1948 & $2,501.55$ & 178.05 & & $2,679.60$ \\
\hline 1947 & $2,351.79$ & 162.59 & & $2,514.38$ \\
\hline 1946 & 2,199.31 & 145.61 & & $2,344.92$ \\
\hline 1945 & $2,017.77$ & 126.33 & & $2,144.10$ \\
\hline 1944 & $1,766.80$ & 99.50 & & $1,866.30$ \\
\hline 1943 & $1,465.66$ & 74.20 & & $1,539.86$ \\
\hline 1942 & $1,290.22$ & 53.06 & & $1,343.28$ \\
\hline 1941 & $1,176.35$ & 42.72 & & $1,219.07$ \\
\hline 1940 & $1,035.56$ & 21.40 & & $1,035.56$ \\
\hline 1939 & 845.76 & 9.12 & & 854.88 \\
\hline 1938 & 675.74 & 4.90 & & 680.64 \\
\hline 1937 & 508.14 & & & 508.14 \\
\hline 1936 & 343.66 & & & 343.66 \\
\hline 1935 & 260.13 & & & 260.13 \\
\hline 1934 & 175.79 & & & 175.79 \\
\hline 1933 & 89.34 & & & 89.34 \\
\hline
\end{tabular}




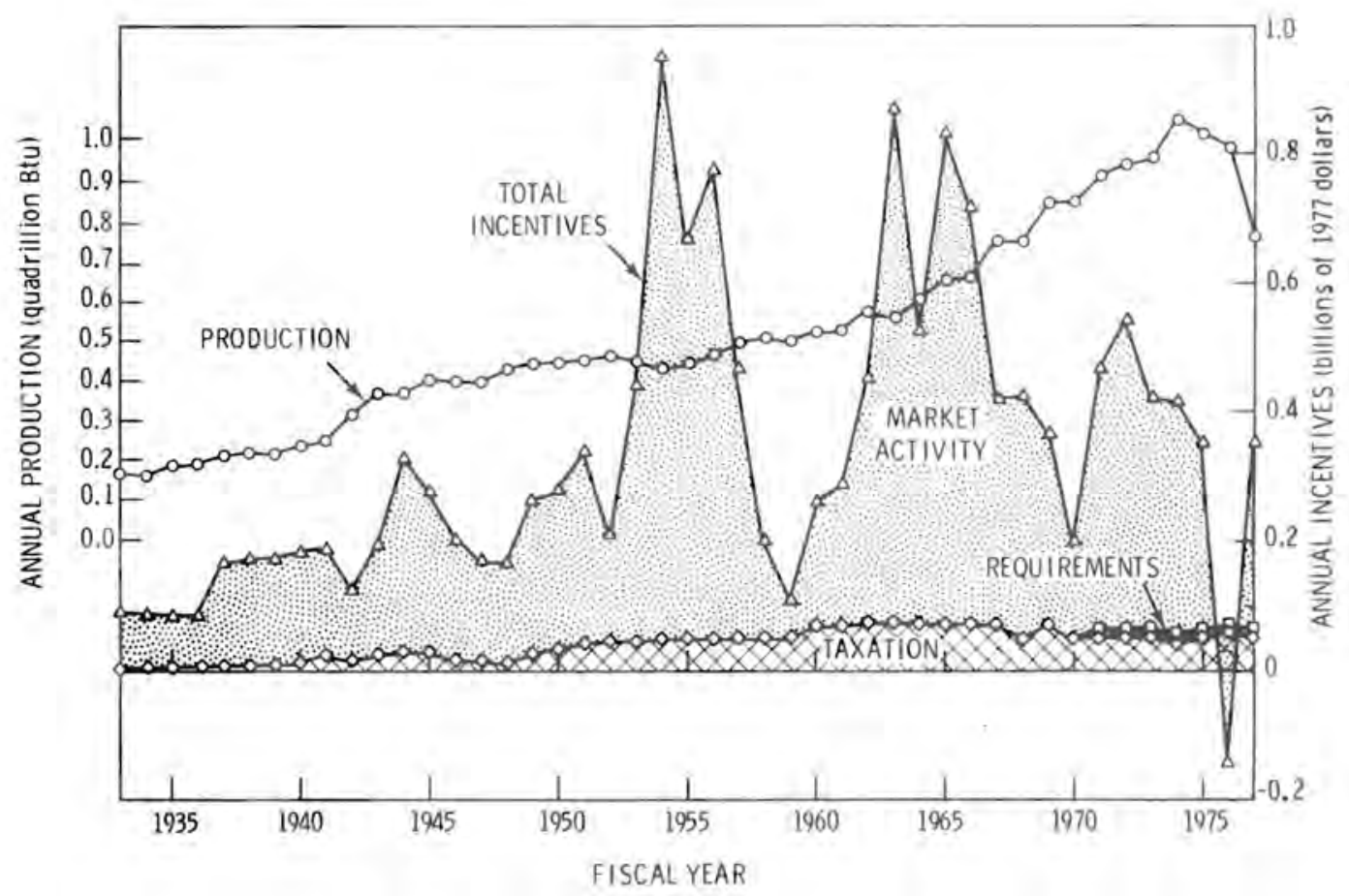

FIGURE 5.1. Annual Production of Hydroelectric Power and Annual Amount of Federal Incentives

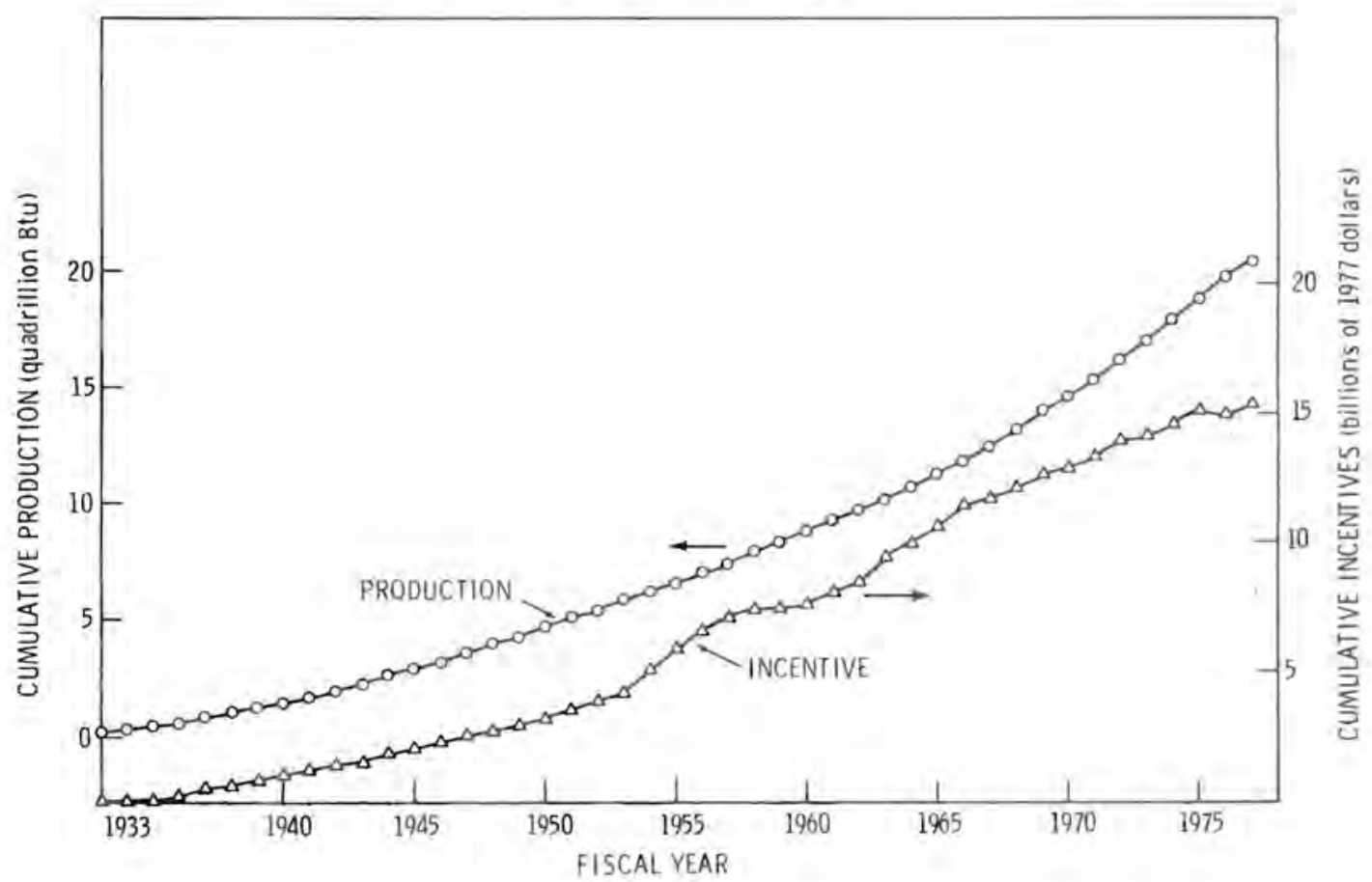

FIGURE 5.2. Cumulative Production of Hydroelectric Power and Cumulative Federal Incentives Since 1933 
When a hydro project is completed, the costs are allocated to the various functions or services provided; flood control, navigation, recreation, irrigation, wildlife management, and power generation. This allocation requires the formation of arbitrary assumptions for individual projects (Cone et al. December 1978). We have used the figures given by project records to calculate the contribution to hydroelectric development (General Accounting office February 1973 ).

The annual incentive data represent additions to federal expenditures for individual years. This figure fluctuates considerably due to the erratic nature of federal appropriations for water projects and the variability in project repayment schedules. Definite trends appear over presidential terms due to the influence of executive leadership on Congressional appropriations. For example, between 1952 and 1956 federal expenditures exceeded \$500 million annually, reaching an all time high of $\$ 910$ million in 1954 . From 1956 to 1960 , expenditures were relatively low, dipping to $\$ 59$ million in 1959 . The 1960 to 1968 period saw improvement and 1968 to 1974 saw moderation. In 1976 federal appropriation was less than loan repayments, yielding a negative figure for that year. As of 1977 , federal investment through market activity to hydropower came to $\$ 13.487$ billion since 1933 constituting $88 \%$ of the total incentives.

\section{Requirements}

The Federal Energy Regulatory Commission regulates the production and marketing of hydroelectric power as part of its duties. The amount attributed to hydroelectric power is approximately $\$ 5$ million annually. Since 1971 , this has supplied an incentive of $\$ 33.3$ million or less than $1 \%$ of total incentives.

\section{Taxation}

Power revenues of public hydroelectric facilities are exempt from federal taxes. This constitutes an incentive to public hydroelectric generation because revenues from private energy sources are taxed. The method used to calculate tax savings accounts for the fact that if taxes were paid the revenues would be larger to accommodate for them. The tax incentive to hydro facilities by exemption from income taxes has gradually increased over the 
years. For the past 20 years, it has contributed approximately $\$ 60$ million annually, and since 1933 tax benefits of $\$ 1.77$ billion have accrued. This constitutes $12 \%$ of the total incentives.

HYDROELECTRICITY PRODUCTION AND FEDERAL INCENTIVES

The production of hydroelectric power is a function of three major factors: 1) the demand for electricity, 2) the availability of water resources to provide motive power, and 3 ) the amount of generating capacity installed. Federal incentives to stimulate hydroelectric production directly impact only the last factor--the amount of generating capacity. Originally, the other parameters were not constraining since ample water resources were available and the demand for additional electric supplies was relatively high. However, as hydroelectric potential is developed, the amount remaining for utilization diminishes and baseload energy demands for particular regions are satisfied.

Since incentives directly affect only the amount of generating capacity installed, an analysis of the effect of incentives on the installation of new hydrogenerating capacities seems to be a more direct method of determining the effect of such incentives. Such an analysis, however, does not reflect the actual production of electrical energy--only the maximum power available. Data regarding the magnitude of generating capacity are shown in Table 5.6 and depicted in Figure 5.3. The amount of electrical power produced is compiled in terms of $\mathrm{kWh}$ and converted to Btu's for comparative analysis. See Appendix $D$ for a discussion of appropriate conversion factors. The actual production of hydroelectric power in terms of quads available to final consumers is supplied in Table 5.7 and plotted in Figure 5.4. The cumulative generation since 1933 has been computed and is presented in Table 5.7 and Figure 5.2.

Federal incentives to hydroelectric power are applied almost exclusively to federal projects; the only exception quantified is the FERC licensing of private power facilities, which represents a negligible fraction of the total incentives. Incentives have caused a steady growth in the proportion of hydroelectric power supplied by federal projects, as shown in Figure 5.4. In 1933 federal projects provided less than $10 \%$ of hydroelectric power supplies, but by 1952 the fraction had grown to 50\% (Edison Electric Institute 1971). 
TABLE 5.6. Generating Capacity of Hydroelectric Facilities (megawatts) (Edison Electric Institute 1971, 1978)

\begin{tabular}{|c|c|c|}
\hline Year & Non-Federal & Total \\
\hline 1977 & 23,158 & 68,334 \\
\hline 1976 & 23,134 & 67,757 \\
\hline 1975 & 23,115 & 65,949 \\
\hline 1974 & 22,737 & 63,560 \\
\hline 1973 & 21,770 & 61,782 \\
\hline 1972 & 19,122 & 56,386 \\
\hline 1971 & 19,076 & 55,912 \\
\hline 1970 & 18,850 & 55,056 \\
\hline 1969 & 18,444 & 52,753 \\
\hline 1968 & 18,337 & 51,168 \\
\hline 1967 & 18,134 & 48,112 \\
\hline 1966 & 16,381 & 44,977 \\
\hline 1965 & 16,096 & 43,782 \\
\hline 1964 & 15,296 & 42,188 \\
\hline 1963 & 14,620 & 40,214 \\
\hline 1962 & 13,629 & 37,342 \\
\hline 1961 & 13,522 & 35,481 \\
\hline 1960 & 13,359 & 32,367 \\
\hline 1959 & 13,110 & 31,074 \\
\hline 1958 & 12,485 & 27,359 \\
\hline 1957 & 11,327 & 27,036 \\
\hline 1956 & 10,948 & 25,654 \\
\hline 1955 & 11,289 & 25,005 \\
\hline 1954 & 10,723 & 23,211 \\
\hline 1953 & 10,527 & 22,045 \\
\hline 1952 & 10,160 & 70,419 \\
\hline 1951 & 9,802 & 18,868 \\
\hline 1950 & 9,663 & 17,675 \\
\hline 1949 & 9,335 & 16,654 \\
\hline 1948 & 9,028 & 15,652 \\
\hline 1947 & 8,866 & 14,971 \\
\hline 1946 & 8,859 & 14,849 \\
\hline 1945 & 8,867 & 14,912 \\
\hline 1944 & 8,747 & 14,568 \\
\hline 1943 & 8,647 & 13,883 \\
\hline 1942 & 8,613 & 12,842 \\
\hline 1941 & 8,492 & 11,817 \\
\hline 1940 & 8,468 & 11,224 \\
\hline 1939 & 8,537 & 11,004 \\
\hline 1938 & 8,584 & 10,675 \\
\hline 1937 & 8,520 & 10,176 \\
\hline 1936 & 8,494 & 10,037 \\
\hline 1935 & 8,437 & 9,399 \\
\hline 1934 & 8,365 & 9,345 \\
\hline 1933 & 8,368 & 9,334 \\
\hline
\end{tabular}


TABLE 5.7. Production of Hydroelectricity (quads)

(Edison Electric Institute 1971, 1978)

Annual

\begin{tabular}{|c|c|c|c|c|}
\hline \multicolumn{5}{|c|}{ Annual } \\
\hline Year & Federal & Non-Federal & Total & $\% \mathrm{Fe}$ \\
\hline 1977 & 0.563 & 0.189 & 0.752 & \\
\hline 1976 & 0.736 & 0.232 & 0.968 & \\
\hline 1975 & 0.746 & 0.278 & 1.024 & \\
\hline 1974 & 0.750 & 0.277 & 1.027 & \\
\hline 1973 & 0.663 & 0.264 & 0.927 & \\
\hline 1972 & 0.663 & 0.264 & 0.927 & \\
\hline 1971 & 0.648 & 0.261 & 0.909 & \\
\hline 1970 & 0.604 & 0.241 & 0.844 & \\
\hline 1969 & 0.598 & 0.255 & 0.854 & \\
\hline 1968 & 0.530 & 0.229 & 0.759 & \\
\hline 1967 & 0.510 & 0.246 & 0.756 & \\
\hline 1966 & 0.450 & 0.215 & 0.665 & \\
\hline 1965 & 0.432 & 0.230 & 0.662 & \\
\hline 1964 & 0.398 & 0.206 & 0.604 & \\
\hline 1963 & 0.363 & 0.202 & 0.565 & \\
\hline 1962 & 0.360 & 0.214 & 0.574 & \\
\hline 1961 & 0.327 & 0.191 & 0.518 & \\
\hline 1960 & 0.290 & 0.206 & 0.497 & \\
\hline 1959 & 0.274 & 0.196 & 0.470 & \\
\hline 1958 & 0.277 & 0.202 & 0.479 & \\
\hline 1957 & 0.263 & 0.181 & 0.444 & \\
\hline 1956 & 0.229 & 0.188 & 0.417 & \\
\hline 1955 & 0.210 & 0.175 & 0.385 & \\
\hline 1954 & 0.187 & 0.178 & 0.365 & \\
\hline 1953 & 0.183 & 0.176 & 0.359 & \\
\hline 1952 & 0.178 & 0.181 & 0.359 & \\
\hline 1951 & 0.164 & 0.176 & 0.340 & \\
\hline 1950 & 0.155 & 0.172 & 0.327 & \\
\hline 1949 & 0.150 & 0.156 & 0.306 & \\
\hline 1948 & 0.133 & 0.147 & 0.281 & \\
\hline 1947 & 0.117 & 0.160 & 0.267 & \\
\hline 1946 & 0.122 & 0.155 & 0.267 & \\
\hline 1945 & 0.111 & 0.162 & 0.273 & \\
\hline 1944 & 0.119 & 0.140 & 0.252 & \\
\hline 1943 & 0.097 & 0.154 & 0.251 & \\
\hline 1942 & 0.070 & 0.148 & 0.218 & \\
\hline 1941 & 0.047 & 0.126 & 0.173 & \\
\hline 1940 & 0.038 & 0.123 & 0.161 & \\
\hline 1939 & 0.028 & 0.120 & 0.148 & \\
\hline 1938 & 0.028 & 0.120 & 0.148 & \\
\hline 1937 & 0.016 & 0.134 & 0.150 & \\
\hline 1936 & 0.013 & 0.120 & 0.133 & \\
\hline 1935 & 0.011 & 0.120 & 0.131 & \\
\hline 1934 & 0.009 & 0.102 & 0.111 & \\
\hline 1933 & 0.010 & 0.104 & 0.114 & \\
\hline
\end{tabular}

Cumulative

\begin{tabular}{|c|c|c|}
\hline Federal & Non-Federal & Total \\
\hline 12.86 & 8.31 & 21.17 \\
\hline 12.29 & 8.12 & 20.40 \\
\hline 11.56 & 7.90 & 19.46 \\
\hline 10.81 & 7.61 & 18.42 \\
\hline 10.06 & 7.33 & 17.39 \\
\hline 9.40 & 7.07 & 16.47 \\
\hline 8.73 & 6.81 & 15.54 \\
\hline 8.08 & 6.54 & 14.63 \\
\hline 7.48 & 6.30 & 13.78 \\
\hline 6.89 & 6.05 & 12.93 \\
\hline 6.36 & 5.82 & 12.18 \\
\hline 5.85 & 5.57 & 11.42 \\
\hline 5.39 & 5.36 & 10.75 \\
\hline 4.96 & 5.13 & 10.09 \\
\hline 4.37 & 4.92 & 9.49 \\
\hline 4.20 & 4.72 & 8.92 \\
\hline 3.84 & 4.51 & 8.35 \\
\hline 3.52 & 4.32 & 7.84 \\
\hline 3.23 & 4.11 & 7.34 \\
\hline 2.95 & 3.91 & 6.86 \\
\hline 2.68 & 3.71 & 6.39 \\
\hline 2.41 & 3.53 & 5.94 \\
\hline 2.18 & 3.34 & 5.52 \\
\hline 1.97 & 3.67 & 5.14 \\
\hline 1.79 & 2.99 & 4.78 \\
\hline 1.60 & 2.81 & 4.42 \\
\hline 1.43 & 2.63 & 4.06 \\
\hline 1.26 & 2.46 & 3.72 \\
\hline 1.10 & 2.28 & 3.38 \\
\hline 0.955 & 2.13 & 3.08 \\
\hline 0.822 & 1.98 & 2.80 \\
\hline 0.705 & 1.83 & 2.53 \\
\hline 0.593 & 1.67 & 2.27 \\
\hline 0.481 & 1.51 & 1.99 \\
\hline 0.369 & 1.37 & 1.741 \\
\hline 0.272 & 1.22 & 1.49 \\
\hline 0.202 & 1.07 & 1.272 \\
\hline 0.155 & 0.943 & 1.09 \\
\hline 0.116 & 0.820 & 0.937 \\
\hline 0.088 & 0.700 & 0.788 \\
\hline 0.060 & 0.580 & 0.640 \\
\hline 0.044 & 0.446 & 0.490 \\
\hline 0. & 0.326 & 0.356 \\
\hline 0.019 & 1.206 & 0.225 \\
\hline 0.010 & 0.104 & 0.114 \\
\hline
\end{tabular}




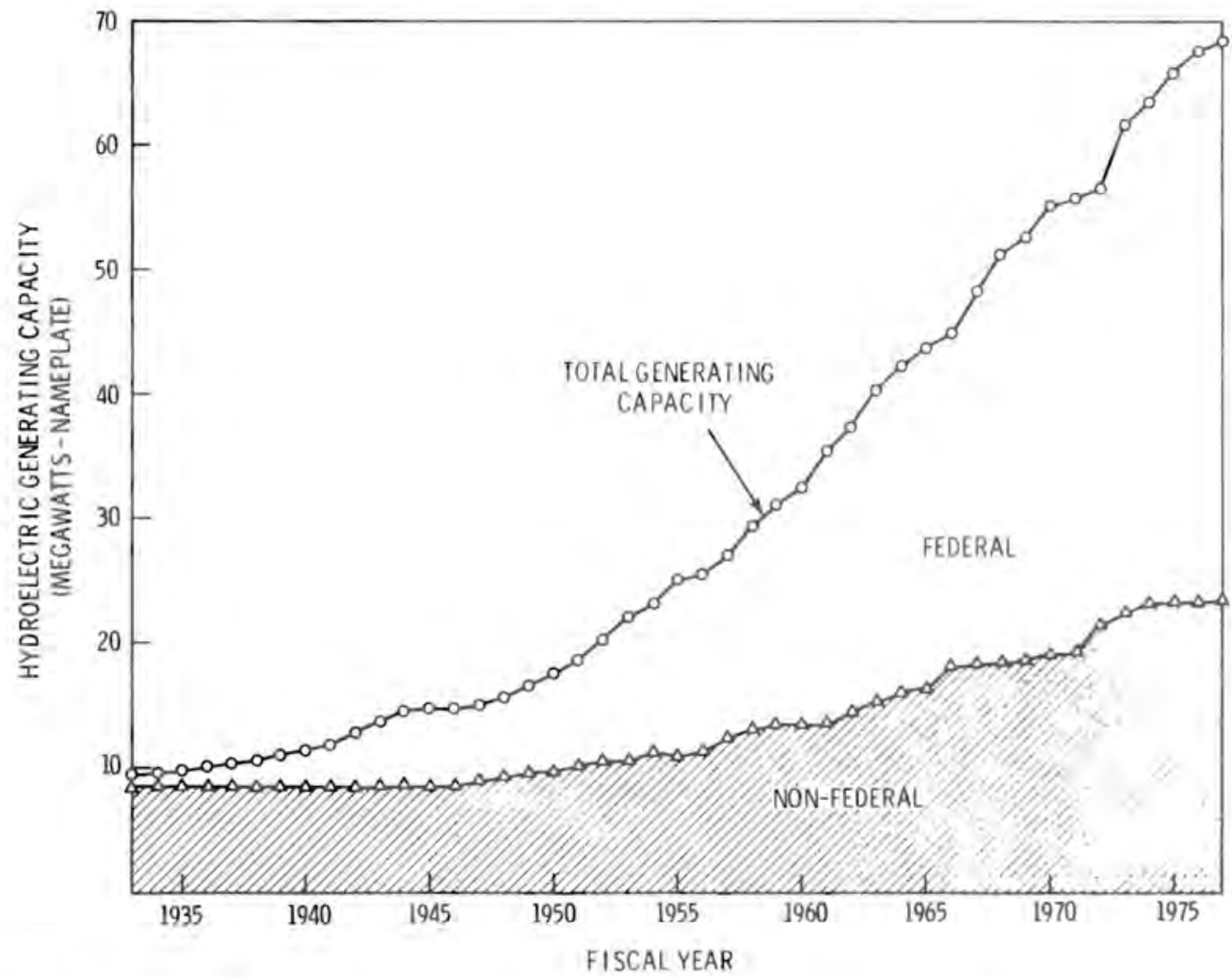

FIGURE 5.3. Generating Capacity of Federal and Non-Federal Facilities

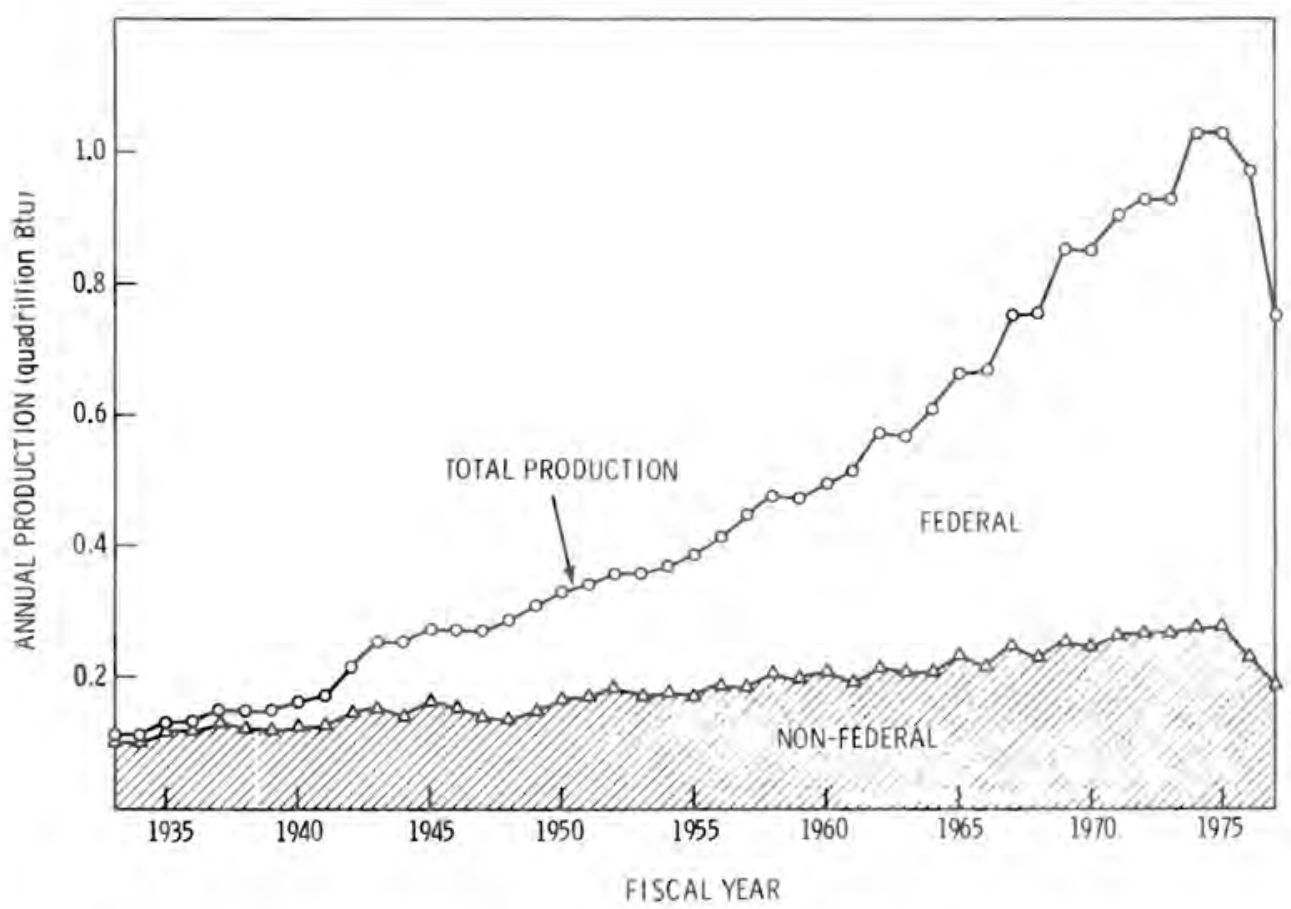

FIGURE 5.4. Annual Production of Hydroelectricity by Federal and Non-Federal Facilities 
Currently, federal facilities generate over 75\% of all hydroelectric power (Edison Electric Institute 1978). Hydroelectric power generation by private projects has grown moderately at a rate of approximately $2 \%$ annually. Meanwhile, the rate of growth of federal projects is approximately $6 \%$ annually.

The level of federal incentive expenditure is plotted in conjunction with the total production of hydroelectric power to reveal any causal relationships. An analysis of Figure 5.1 indicates that the annual perturbation in federal incentives has no obvious reflection in the production curves. This is explained by considering the fact that expenditures for hydroelectric facilities must precede production increases by the time required for construction of additional facilities. For large hydroelectric projects construction has typically required from four to six years. Thus, accelerated increases in generation capacity during the 1956 to 1963 and 1966 to 1970 time frames appear to result from increased incentives during 1954 to 1958 and 1963 to 1966 , respectively.

The reduction in hydroelectric production in 1976 and 1977 is due to the effect of an extended drought in the Pacific Northwest where approximately 50\% of all hydroelectricity originates. The stream flow of the Columbia River in 1977 was 52\% of the 15-yr average and since approximately $80 \%$ of the average streamflow is utilized for power production, energy supplies were reduced by approximately 30\% (Columbia River Water Management Group January 1978). Nonetheless, additional generating capacity is under construction, partially because the drought is not expected to continue indefinitely. The primary reasoning behind the addition, however, is to increase the amount of generating capacity available to supply peak load requirements. Hydroelectric power is particularly suitable for this application because of the relative ease of providing intermittent service.

A comparison of the cumulative amount of incentives made available to hydroelectric development and the levels of production indicates some correlations. The comparative data are plotted in Figure 5.2 since 1933 . Prior to 1940, privately owned facilities generated over $90 \%$ of all hydroelectric power, consequently federal incentives were very low and had little impact on production. As the share of federal generation grew as indicated in Figure 5.4, 
federal incentives accrued at an increasing rate. As a result the federal government came to exercise considerably more influence over the production hydroelectricity. Increasing federal incentives have caused production by federally owned projects to dominate the industry by providing over $75 \%$ of the total hydroelectric power. A drop-off of incentives since 1974 corresponds to a slight decrease in the rate of production growth in 1976. Federal appropriations for hydroelectric development can be expected to diminish since the most promising hydroelectric sites have already been developed. However, existing federal facilities will continue to provide additional power for years to come, resulting in an anticipated departure between the production and incentive curves.

The production curve appears to be insensitive to short-term change in incentive expenditures as demonstrated from 1953 to 1960. No noticeable impact on production resulted from sizeable incentive changes. This is due in part to the large size of the industry where total incentives constituted less than $20 \%$ of revenues. Another significant fact is the inelasticity of demand for energy which indicates that a shift in operating or construction costs can be passed on to the ratepayer without affecting demand significantly. Therefore, one would expect the application of federal incentives to impact electricity prices more directly than electricity production.

The primary effect of federal incentives on the production of hydroelectric power has been to encourage construction of federal generating facilities in preference to non-federal projects. Had federal funding been unavailable, non-federal generating facilities would have been developed at some of the hydro power sites but not at the rate of the federal programs. Furthermore, private enterprise may not have developed the associated non-repayable aspects of multiuse projects.

\section{HYDROELECTRICITY PRICE AND FEDERAL INCENTIVES}

The price of hydroelectric power shows wide variability between projects. Size, age, load factor, and cost allocations have direct bearing on the cost of 
producing hydroelectricity. As previously mentioned, cost allocations for multiuse projects are somewhat arbitrary and inconsistent resulting in wide differences in repayment schedules.

The revenues from hydroelectric power sales must provide for annual operation and maintenance charges (collectively called production expenses) and annual fixed charges. Annual fixed charges include depreciation expenses, taxes, interest on debt, dividends or other return charges, and allocated administrative and general expenses. In 1974, the estimated average production expense of hydroelectric plants was 1.04 mills per kWh of electricity, and the annual fixed charges came to $6.98 \mathrm{mills}$ or $87 \%$ of the total production cost of $8.02 \mathrm{mills}$ per kWh (USACE July 1976).

Annual hydroelectric production expenses for 21 selected non-federal systems ranged from 0.33 to $5.57 \mathrm{mills}$ per $\mathrm{kWh}$ in 1976 . The average was 0.94 mills. The Tennessee Valley Authority costs were approximately $35 \%$ lower at $0.61 \mathrm{mills}$ per $\mathrm{kWh}$ (EIA May 1978b). These production costs are considerably lower than those for steam generation systems which averaged 14.77 mills per $k W h$. The production cost savings are partially offset by the greater construction expense of hydro facilities. Precise comparison at this point becomes difficult due to the subjective allocation of hydro project costs to hydroelectric power.

Because of the wide variation of hydroelectric prices across the nation, calculation of average national hydroelectric prices would be of questionable validity, particularly for historical comparison. Therefore, we will limit our analys is to information supplied by the BPA. The BPA markets power from 33 hydroelectric sites which in 1977 produced 82.21 billion kWh of electricity, some $37 \%$ of the total U.S. hydroelectric generation. The BPA manages the utilization of 13.617 million $\mathrm{kW}$ of hydroelectric generating capacity. Data regarding BPA revenues and annual generation are presented in Table 5.8 as well as the calculated price per $\mathrm{kWh}$. This price is the wholesale price for energy delivered to distribution systems and is plotted in Figure 5.5.

In brief, the repayment policy currently in effect provides that BPA's total revenues from all sources be sufficient to: 
TABLE 5.8. Bonneville Power Administration Prices for Hydroelectric Power (BPA 1940 through 1978)

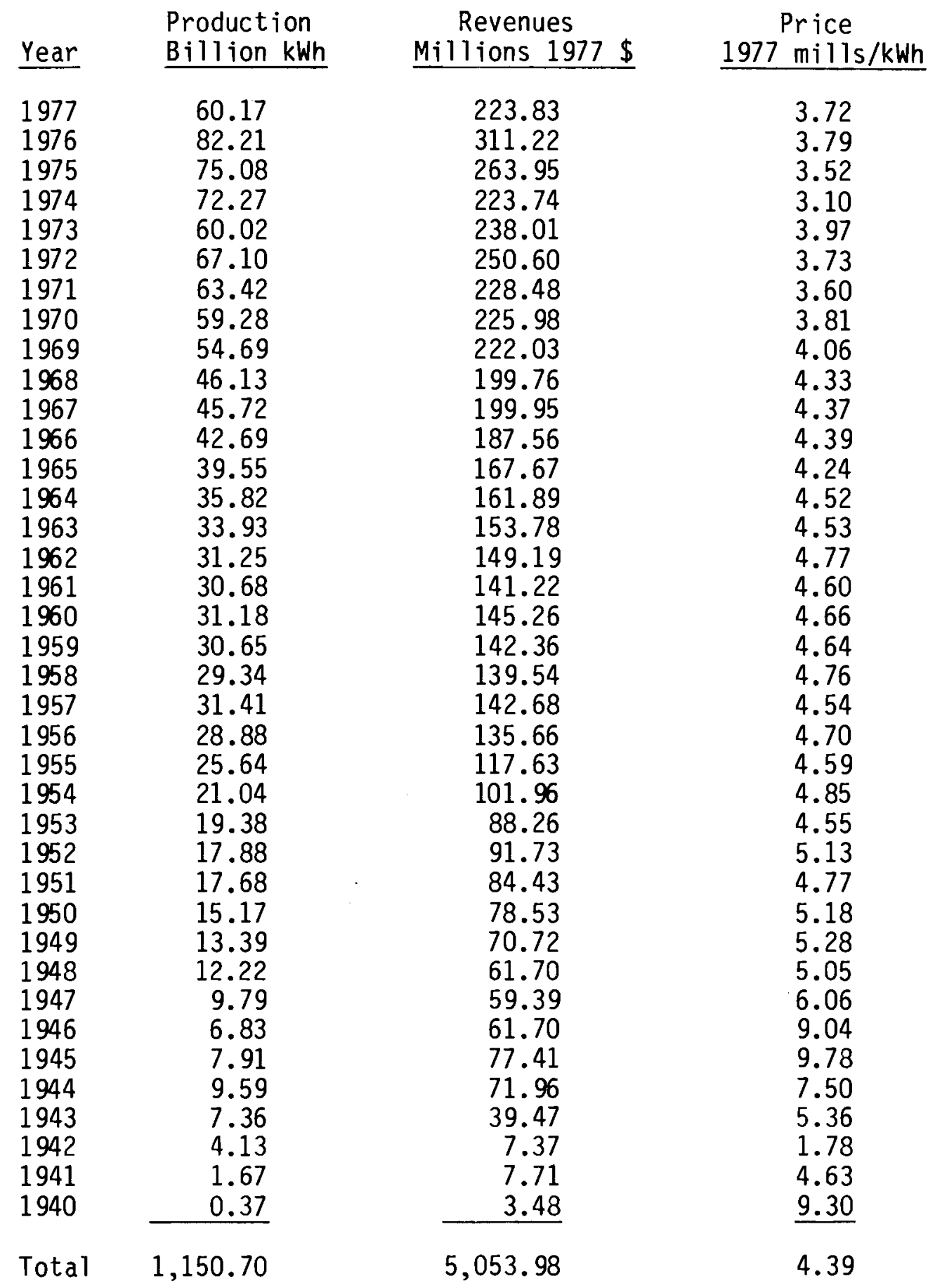




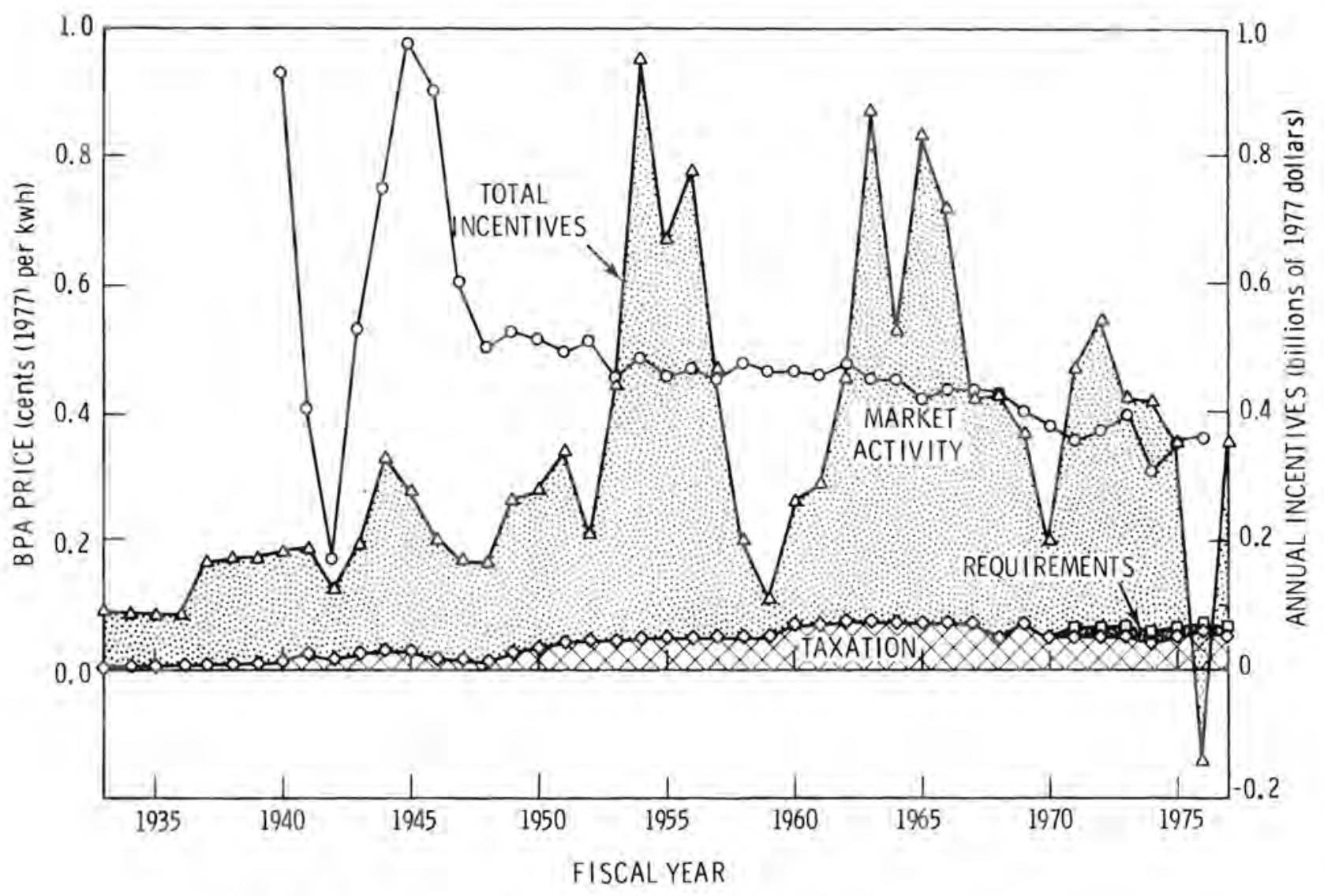

FIGURE 5.5. BPA Hydroelectric Power Price and Annual Amount of Federal Incentives

1. Pay all costs annually of operating and maintaining the Federal Columbia River Power System.

2. Pay the cost each fiscal year of obtaining power through purchase and exchange agreements.

3. Pay, when due, the interest and amortization on outstanding revenue bonds sold to the Treasury.

4. Pay interest each year on the unamortized portion of the commercial power investment financed with appropriated funds at the interest rates established for each generating project and for each annual increment of such investment in the BPA transmission system. 
5. Repay:

a. each dollar of the power investment in the federal generating projects within 50 years after it becomes revenue producing. (Fifty years has been deemed a "reasonable period" as intended by Congress.);

b. each annual increment of transmission investment, previously financed with appropriated funds, within 40 years after it is placed in service. (Forty years is the approximate average depreciation life of the transmission facilities and hence a "reasonable period.");

c. the investment in each replacement of a power generating facility within its service life.

In accomplishing such repayment, the investment bearing the highest interest rate will be amortized first, to the extent possible, while still completing repayment of each increment of investment within its prescribed repayment period.

6. Repay the portion of construction costs at federal reclamation projects which is beyond the repayment ability of the irrigators and which is assigned for repayment from commercial power revenues, within the same overall period available to the irrigation water users for making their payments on construction costs. These repayment periods range from 40 years to 66 years, with 60 years being applicable to most of the irrigation projects. Irrigation costs are repaid without interest.

Public Law 89-448 authorizes the payment of irrigation costs from revenues of the entire power system. This is the so-called "Basin Account" concept. Public Law 89-561, approved on September 7, 1966, amended Public Law 89-448 to provide several limitations on the repayment of irrigation costs from power revenues. These are as follows: 1) the irrigation costs are to be paid from "net revenues" of the power system with net revenues being defined as those revenues over and above the amount needed to cover power costs and previously authorized irrigation repayment; 2) the construction of new federal irrigation projects will be scheduled (deferred, if necessary) so that the repayment of the irrigation costs from power revenues will not require an increase in the BPA power rate level; and 3) the total 
amount of irrigation costs to be repaid from power revenues shall not average more than $\$ 30$ million per year in any period of 20 consecutive years (BPA July 1977).

Fluctuation of BPA prices prior to 1945 were due to varying accounting schedules used during World War II as well as considerable change in the energy requirements of the area. In the years 1945 to 1948, energy prices declined from $0.978 \$ / \mathrm{kWh}$ to $0.505 \$ / \mathrm{kWh}$ due largely to economies of scale. Since 1948 hydroelectric power prices have steadily declined to a low of $0.310 \$ / \mathrm{kWh}$ in 1974. This reduction was due to more efficient use of existing facilities and construction of additional ones. Federal incentives made this growth possible by providing the necessary capital to finance large new projects and additions. Had federal monies been unavailable, it is doubtful that the Columbia River would have been as efficiently developed.

Wholesale rates for federal systems generally resemble the BPA curve, showing moderate yearly declines. However, prices for private hydroelectric production have increased, as shown in Table 5.9. The TVA hydroelectric production expenses are 35\% lower than the average private facilities due mostly to the effect of federal incentives. It has been estimated that the availability of federal loans for hydroelectric projects reduces new facility expenses by $23 \%$ (USACE 1976). This constitutes a substantial incentive to the marketing of federally generated hydroelectric power as opposed to that of investor-owned facilities. The overall effect of federal incentives on hydroelectric power prices has been to reduce the price of federally generated hydroelectric power by approximately 30\%, assuming the resources would otherwise have been developed by private enterprise.

\section{NON-PRICE AND QUANTITY IMPACTS}

Federal incentives to stimulate hydroelectric development impacted factors other than the price and quantity produced. This section assesses incentive impacts on other economic factors as well as political and organizational factors. Estimated impacts will be quantified using the engineering approach where possible; otherwise, qualitative estimates based upon expert opinion and inspection will be provided. 
TABLE 5.9. Private Production Expenses -- 1971 to 1976 (mills per net $\mathrm{kWh}$ ) (EIA May 1978b)

\begin{tabular}{|c|c|c|c|c|c|}
\hline \multirow[b]{2}{*}{ Year } & \multicolumn{5}{|c|}{ Steam-Electric Plants (a) } \\
\hline & Operation & Maintenance & Subtotal & Fuel & Total \\
\hline 1977 & 0.65 & 1.20 & 1.85 & 13.31 & 15.16 \\
\hline 1976 & 0.62 & 1.00 & 1.62 & 11.62 & 13.24 \\
\hline 1975 & 0.70 & 0.90 & 1.60 & 10.79 & 12.39 \\
\hline 1974 & 0.51 & 0.73 & 1.24 & 8.76 & 10.00 \\
\hline 1973 & 0.45 & 0.61 & 1.06 & 4.85 & 5.91 \\
\hline 1972 & 0.42 & 0.57 & 0.99 & 4.06 & 5.05 \\
\hline 1971 & 0.42 & 0.52 & 0.94 & 3.77 & 4.71 \\
\hline
\end{tabular}

Hydroelectric Plants (b)

\begin{tabular}{|c|c|c|}
\hline Year & Operation & Maintenance \\
\hline 1977 & 0.77 & 0.47 \\
\hline 1976 & 0.60 & 0.34 \\
\hline 1975 & 0.46 & 0.31 \\
\hline 1974 & 0.41 & 0.30 \\
\hline 1973 & 0.39 & 0.25 \\
\hline 1972 & 0.37 & 0.24 \\
\hline 1971 & 0.35 & 0.21 \\
\hline
\end{tabular}

(a) Weighted average expenses, steam plant cost book. (b) Selected systems, non-federal hydroelectric plants.

Competition

The massive federal investment in hydroelectric facilities had a moderate effect on competition in the marketplace. Whereas investor-owned utilities would have competed or cooperated to develop hydroelectric resources, the availability of low cost financing and tax exemptions for public utility operations displaced this activity. In the case of the TVA, several investor-owned utility systems were no longer able to operate in the TVA service area. This 
was due to specific language in the TVA Act which gave preference to states, counties, municipalities, and cooperative organizations of citizens and farmers not organized for profit. In 1935, the Act was amended to authorize TVA managers to acquire existing investor-owned facilities used in servicing farms and communities and to help preference customers purchase independent distribution systems. The TVA was also allowed to write contracts for the sale of power which prohibited TVA customers from manufacturing supplemental power or from purchasing power from any other source (TVA 1950). This legislation effectively permitted the TVA a monopoly over the supply of electrical service to the expansive Tennessee Valley region.

In 1977, 160 municipal and cooperative systems and one investor-owned system distributed power to 48 industries and about $2.6 \mathrm{million}$ customers in part of seven states (TVA 1977). The overall impact of such "preference clause" provisions, common to most federally subsidized electrical systems, has been to subsidize publicly-owned and operated systems with tax revenues thus displacing investor-owned competition.

\section{Sectoral Impacts}

The application of federal incentives to stimulate hydroelectric development has resulted in nonhomogeneous sectoral impacts to various regions of the country. Naturally, areas with substantial hydroelectric potential have received a large share of the federal assistance and resulting impacts. The Pacific Northwest and the Tennessee Valley in particular and the western states in general have received large amounts of federal assistance and experienced substantial impacts.

The primary goal of early public water projects was the economic development of frontier or depressed areas. In 1972, the Bureau of Reclamation (USBR) calculated the direct economic benefit of the hydroelectric facilities they managed. For an original investment of approximately $\$ 6$ billion, of which $\$ 1.1$ billion has already been repaid, it is estimated that over $\$ 4$ billion of economic activity takes place annually as shown in Table 5.10 (Coddington et al. December 1972). By assuming that the USBR plants represent average federal 
TABLE 5.10. Economic Activity Resulting from the Reclamation Program, Fiscal Year $1971(a)$ (Miliken et al. January 1972)(b)

Type of Activity

Net Crop Production

Value Added by Livestock Production

Value Added by Food Processing

Retail Value of M\&I Water

Output of Water-Dependent Industries

Retail Value of Hydroelectric Power

Output of Power-Dependent Industrial

Recreation Spending

Capital Investment

USBR Expenditures

Total
Millions of $\$$

$$
\begin{gathered}
\$ 1,035.4 \\
226.0 \\
734.8 \\
86.8 \\
95.7^{(c)} \\
660.1 \\
267.0^{(c)} \\
240.4 \\
534.3 \\
380.0 \\
\hline
\end{gathered}
$$

$\$ 4,260.5$

(a) The economic activity summarized in this table includes the sum of the net dollar value of 1) net direct project output, subtracting output which would exist in the absence of the project; 2) spending required for production inputs (e.g., farmers' purchases of fertilizers and tractors, labor and construction expenditures of $M \&$ * water distribution agencies, services and supplies purchased by firms processing project-grown crops); 3) annual capital investments by power and water distribution agencies, recreation management agencies, etc., to utilize project outputs; 4) first-round spending induced by project outputs (e.g., spending by fishermen and campers at USBR project recreation areas ); and 5) the output of some firms wholly dependent for the ir existence on the supply of project-supplied water or power. The methodology used in arriving at these estimates does not count double.

(b) The proposed methodology is undergoing review and refinement preparatory to implementation.

(c) Incomplete. Includes only some industries $100 \%$ dependent on USBR water or hydroelectric power. 
hydroelectric facility impacts, then, by extrapolation, the first order economic activity precipitated is estimated to be $\$ 9.6$ billion. The output of power dependent industries using Bureau of Reclamation hydroelectric power is a very conservative estimate resulting from consideration on ly of industries $100 \%$ dependent on USBR power. It is clear that public water projects have created significant impacts in terms of economic activity in those areas with hydroelectric resources.

The availability of relatively cheap hydroelectric power creates sectoral impacts by stimulating energy-intensive industries to locate in the proximity of hydroelectric projects. A study by Wilson (1969) analyzed the locational effect of electricity prices. In the TVA operating area, energy-intensive industry accounted for $40.2 \%$ of manufacturing productivity, compared with $29.7 \%$ for the nation as a whole. Five sectors listed in Table 5.11 accounted for $67 \%$ of all new investment in plant and equipment in the area; for the nation as a whole, the group accounted for $37 \%$ of the total. Wilson concluded that since the creation of TVA,

"1) industrial growth in the East South Central states has outpaced the national average; 2) the relatively rapid industrial growth followed in the wake of substantial electricity rate reductions; 3 ) since 1937 , electric power rates have been far below the national average; and 4) those regional industries which have the most impressive growth records consume relatively large amounts of power. From these observations we conclude that electric power rates have been a significant and important determinant of both the rate and pattern of industrial development in the East South Central states."

Wilson's conclusions regarding the TVA area, with the exception of the aluminum industry, cannot be applied to the Pacific Northwest based on historical evidence. Of Wilson's five industries, only paper and primary metals are significantly concentrated in the Pacific Northwest, and the former is a resource-based industry. The primary reason for the concentration of aluminum plants in the Northwest was the availability of scarce electric power supplies during World War II. However, it is true that the presence of cheap power has encouraged aluminum operations to remain and expand. For most of industry other location factors dominate, such as proximity to raw material or markets, availability of skilled and unskilled labor, and political considerations. 
TABLE 5.11. Growth in Value Added by Manufacturing in Industries with Electricity-Intensive Production Techniques (1947-1963) (Bureau of Census, 1963)

All Manufacturing

Chemicals

Primary Metals

Paper

Textiles

Stone, Clay, and Glass $\frac{\text { Increase from } 1947 \text { to } 1963(\%)}{\text { East }}$

South

U.S. Central Tennessee
345

507

179

422

155

536
258

328

265

257

115

350

326

487

348

350

129

433

$28.43 \quad 39.23$

Percent of Growth Accounted For by the top six (included petroleum and coal products)

But if the savings from utilization of cheap hydroelectric power increase due to rapidly growing fuel costs, these other location parameters will carry relatively less weight (BPA July 1977).

Sectoral Subsidies

The impacts associated with the availability of cheap hydroelectric power, which is treated here as a subsidy to the industrial sector, are revealed by an analysis of BPA's direct service customers. An industry is a collection of individual plants which produce a similar product. An industry's total production cost is determined by aggregating the production cost of each plant in the industry. Thus an industry's total production cost can be lowered if the production cost of some of the industry's individual plants can be lowered.

BPA's direct-service customers purchase electricity which is a mix of that generated by federally-owned hydroelectric dams and from non-federal sources of thermal energy. The cost of hydroelectric generation is relatively low; and even when higher priced thermal energy is included, BPA's direct-service customers pay less for electricity than owners of most plants without access to 
federal energy. The average cost of BPA's direct-service industrial electricity in 1975 was $3.02 \mathrm{mills} / \mathrm{kWh}$ (BPA July 1977). (However, purchase of Industrial Replacement Energy (IRE) raised the average price of all electricity purchased by these industries to approximately 3.8 mills.) Industrial plants without access to federal energy generally paid prices which ranged from 6 to $12 \mathrm{mills} / \mathrm{kWh}$ (EIA May 1978b).

The BPA, therefore, has the effect of lowering an industry's total production costs by providing its direct-service customers with electricity at a lower cost than that paid by other plants in the industry. The approximate amount of production cost savings can be calculated by subtracting the price of electricity available to BPA's direct-service customers from the most likely alternate price if BPA electricity were not available. This difference can then be multiplied by the amount of electricity consumed by BPA's directservice customers to yield the production cost savings.

This technique was used to calculate production cost savings of BPA direct-service customers for Calendar Year 1975. The most likely alternate price was estimated in a study prepared by Ernst \& Ernst (June 1976) to be in the $r$ ange of 10 to $12 \mathrm{mill} / \mathrm{s} / \mathrm{kWh}$. Assuming the use of $17 \mathrm{kWh} / 1 \mathrm{~b}$ of aluminum and $12 \mathrm{mills} / \mathrm{kWh}$ in other regions, the Pacific Northwest's advantage on the bas is of power alone is $5.7 \$$ per pound, which compares with the recent market price of aluminum ingot of approximately $42 \$$ per pound. (Ernst \& Ernst also report that a Figure of 18 to $19 \mathrm{kWh} / \mathrm{lb}$ might be more accurate, and this would increase the advantage to between $6-1 / 2 \phi$ and $7-1 / 2 \$$ per pound.)

This conclusion is subject to the same qualification as the conclusion regarding BPA's effect on industry location decision. The savings are in production costs only. The Ernst \& Ernst (June 1976) study indicated that BPA's direct-service customers pay greater transportation costs than customers of other plants in the nation. The higher transportation costs reduce the production cost savings by about $28 \%$. Therefore, when transportation costs are included, the net savings are approximately $4.1 \$$ per pound of aluminum. (As was noted above, these savings were calculated for 1975, a year in which water for generation was plentiful. Had there been a shortage of water, the savings could have been much less.) 
Because cheap hydroelectric power makes the aluminum industry profitable in the Pacific Northwest, many regional benefits have been realized. Direct service customers account directly for 15,000 jobs and secondarily for about 42,000 jobs (BPA 1973). These jobs account for approximately $\$ 800$ million of income and some $\$ 16$ million in various state and local taxes (BPA July 1977).

This multiplying effect of benefits from hydroelectric development is not peculiar to the Pacific Northwest but is typical of most hydroelectric projects. By subsidizing the development of hydroelectric facilities, the government is also indirectly subsidizing energy-intensive industry and regional economic development.

\section{Capital Formation}

The impact of federal hydroelectric incentives on the level of capital formation has been substantial. Initially, each of the hydro facilities constructed by the government represented an increase in the capital stock. Second, the availability of power from these facilities enticed industry into the area, which contributed to additional increases in capital formation and stimulated economic growth further. From Table 5.10 it can be seen that an estimated $\$ 534$ million worth of capital investment resulted annually from the Bureau of Reclamation program. This is a significant increase.

\section{Employment/Productivity}

During the depression years, federal hydroelectric incentives provided funds that were used to put thousands of unemployed workers to work, both directly and indirectly. Today, many jobs are made available by industries benefitting from inexpensive federal hydroelectric power. In those areas where hydroelectricity is available, there has been an improvement in worker productivity. With the availability of less expensive power, industry increased it's use of labor saving electric power devices which increased the output per unit of labor input. Thus, the quantity of labor employed and the degree of labor productivity have both been enhanced by the application of federal hydroelectric incentives. 


\section{Balance of Payments}

The balance of payments effect resulting from the stimulation of hydroelectric energy is of particular importance. Had federal funds not been made available for hydroelectric development, it is doubtful that investor-owned utilities could have or would have developed hydroelectric facilities as rapidly. Certainly, some hydroelectric development would have occurred; yet, because of the historic availability of cheap oil and gas supplies, interest in relatively expensive hydroelectric facilities would have been slight. In today's world, the availability of a domestic energy supply reduces the demand for imported energy which improves our international trade balance. Had the U.S. substituted oil to produce the power generated by hydroelectric plants in 1977, an additional 20 billion gallons of $0 i 1$ would have been needed at a cost of approximately $\$ 6$ billion. Since approximately half of the oil used in the U.S. is imported, the use of hydroelectric power creates substantial balance of payments benefits. At 1977 efficiencies and prices, hydroelectric power has conserved the equivalent of 437 billion gallons of oil worth approximately $\$ 150$ billion.

\section{Public/Private Relations}

The federal hydroelectric power programs have had a significant effect on public versus private relations. The preference clause, included in the pro$v$ isions for the distribution of power from federally subsidized facilities, clearly encourages public ownership of electric utility systems at the expense of private interests. Investor-owned utilities express concern about the fact that a portion of the federal taxes they pay is used to subsidize hydroelectric facilities to which they have limited access.

\section{Regulatory Burden}

The overall regulatory burden due to federal hydroelectric power involvement is considered to be moderate. The federal government has established power administrations whose functions are to market most of the power produced at federal hydroelectric sites. Therefore, the burden of regulating the marketing aspects of hydroelectric power is retained by the federal government. However, by creating the dual nature of private and public utility systems, a 
considerable amount of complexity has been added to the regulation of electric utility systems. Sorting through this complexity does create a burden.

\section{Quality of Life}

Federal incentives to develop hydroelectric power have enhanced the quality of life by providing improved public safety through flood control, increasing public transportation through navigation, enhancing public recreation through development of outdoor facilities and lakes, increasing productivity of farm lands through irrigation, and providing for additional municipal water supplies. Some adverse impacts have been felt by fish and wildlife interests, by the loss of lands impounded by reservoirs (which often times were areas of cultural value to Indian tribes), and some reduction in the natural beauty of the landscape. However, an argument can be made that the benefits have outweighed the costs and that revenues generated by the plants have provided millions of dollars for fish and wildlife research and facilities, reparation to affected landowners and Indian tribes, and construction of new public recreation areas.

Because hydroelectric power is essentially pollution free, the nation has also benefitted from reduced levels of emissions from alternate electrical generation facilities. Approximately 130 million tons of coal would have been burned to supply electricity equivalent to that generated by hydroelectric facilities in 1977, with the associated mining and air pollution impacts. A study of the effect of the importation of BPA hydroelectric power into California on the state's air quality, revealed that by supplying $12 \%$ of California's electricity demand, the emission of sulfur oxides, nitrogen oxides, and particulates within the state were reduced by $13 \%, 3 \%$, and $1 \%$, respectively, from 1973 average yearly levels (California Energy Resources Conservation and Development Commission 1975).

\section{Demographics}

The demographic effects resulting from federal hydroelectric power development have been significant. By promoting the development of underdeveloped regions, the federal government stimulated large population movements into 
these areas. Initially, people were employed on the construction sites. As more industry moved in, people came to the areas in the hopes of finding employment. All of these shifts have been important.

THE IMPACT OF FEDERAL INCENTIVES ON THE PRICE AND OUTPUT OF HYDROELECTRICITY

The most significant impact in terms of quantity came from the application of approximately $\$ 13.49$ billion of federal incentives to hydroelectric power through market activities. While these activities did not serve as a hindrance to hydroelectric development by investor-owned utilities, it did reduce the demand for additional private generating facilities and the availability of suitable hydroelectric sites. Due to the multi-use provisions, however, most federal hydroelectric projects were of a scale and complexity beyond the capability of private utilities. These projects were also located in underdeveloped areas which were not of current interest to private investors. Undoubtedly, some of the sites developed by public programs eventually would have been developed by private concerns but at a rate dictated by economic advantage instead of national development. Assuming that the loss of potential hydroelectric sites was offset by hydroelectric technology advances and regional economic development stimulated by federal incentives, the total production of power at federal facilities can be attributed to market activity incentives. Thus, we conclude that federal incentives by market activity have provided for the production of 12.86 quads since 1933 , as shown in Table 5.12 .

Concerning taxation incentives, the provision of $\$ 1.77$ billion worth of incentives through the exemption of federal power revenues from taxes serves primarily as a price subsidy rather than an incentive to production. Certainly, any action reducing the price of federal power stimulates production indirectly, but the amount cannot be accurately quantified. Consequently, as a first approximation, it is assumed that tax policies only impact prices, and no effect on production is noted in Table 5.9 .

The impact of requirements by the Federal Energy Regulatory Commission (FERC) on hydroelectric production is negligible due to its relatively minor expense of $\$ 0.033$ billion and its posture of monitoring hydro development rather 
than stimulating it. Action by the FERC impacts energy prices more directly than production, but the impact is negligible in both cases. (See Tables 5.12 and 5.13.)

Regarding the price of federal hydroelectric power, the benefits from taxfree revenues are direct. This impact, however, is difficult to quantify relative to private hydroelectric power, due to the complex tax policies of investor-owned utilities (see Chapter 9, Electricity). The impacts on the price of hydroelectric power are calculated as national average impacts which in fact vary widely by region.

If we assume that taxes which increase the revenue requirements are fully recovered from the consumer in the form of higher prices, then a tax reduction lowers the revenue requirements and, consequently, the price by an amount equivalent to the tax reduction. Since tax reductions affected only federally generated hydroelectric power, an average price reduction of $13.8 \$$ per million Btu can be calculated by dividing the total amount of the tax incentive ( $\$ 1.772$ bil$1 \mathrm{ion}$ ) by the amount of federally generated hydroelectric power (12.86 quads). This price reduction does not pass on fully to the consumer because federally generated hydroelectric power is combined in the power grid with non-federal sources resulting in a smaller overall price reduction. An average overall price reduction of $8.4 \$$ per million Btu is derived by dividing the tax incentive ( $\$ 1.772$ billion) by the total amount of hydroenergy produced (21.17 quads). This value is presented in Table 5.13 and is understood to represent an average hydroelectric price reduction over the entire country. The impact on actual electricity prices will vary within particular areas depending upon the proportion of power supplied by federal or non-federal hydro-electric facilities and other electricity sources.

Market activity which measured the net amount of money that the federal government has spent developing hydroelectric power, is considered to primarily impact the production of hydroelectric power, as previously indicated. It is important to note that reductions in construction capital expenses from this incentive probably affect the price of hydroenergy. It is virtually impossible, however, to estimate this impact with any degree of certainty. 
TABLE 5.12. An Estimate of the Results of Incentives Used to St imulate Hydroenergy Production (in quads)

\begin{tabular}{|c|c|}
\hline Incentive Area & Production Impac \\
\hline Taxation & 0 \\
\hline Market Activity & 12.86 (increase) \\
\hline Requirements & Negligible \\
\hline
\end{tabular}

TABLE 5.13. An Est imate of the Results of Incentives Used to St imulate Hydroenergy Production In Terms of Price (\$ per million Btu)

\begin{tabular}{|c|c|}
\hline Incentive Area & Production Impact \\
\hline Taxation & 0.084 (reduction) \\
\hline Market Activity & 0.292 (reduction) \\
\hline Requirements & Negligible \\
\hline
\end{tabular}

Since market activity quantifies the savings to federal hydroelectric facilities through the availability of low-interest loans, it is possible to determine the approximate subsidy provided to hydroelectric power. Again assuming that any cost savings are fully reflected in a lower price, a price reduction of $48 \$$ per million Btu can be determined by dividing the savings due to low-interest loans ( $\$ 6.193 \mathrm{billion}$ ) by the amount of federally generated hydroelectric power (12.86 quads). Because federal and non-federal hydroenergy is combined, an average overall price reduction of $29.2 \$$ per million Btu is found by dividing the cost savings ( $\$ 6.193$ billion) by the total amount of hydroenergy produced (21.17 quads). Once again the final savings depend on the mix of electricity supplies for a particular location. This is a high estimate because some of these benefits accrue to other attributes of multi-use projects which are neglected here.

\section{CONCLUSIONS}

Federal incentives have stimulated the construction of hydroelectric facilities and the development of public utility systems to transmit and 
distribute the electricity produced. It is not known to what extent or at what rate investor-owned utilities would have constructed similar facilities in the absence of federal incentives. However, it is certain that the hydroelectric dams built had a beneficial effect on the economic and resource development of depressed and frontier areas. Whether this stimulus outweighs the adverse impacts on investor-owned interests is open to debate.

It is doubtful though, that in the absence of federal incentives to hydropower, the West and the Tennessee Valley would have developed at a comparable rate. Government initiatives were necessary to plant the seeds of regional development by controlling floodwaters, to provide year round water supplies to agricultural and municipal users, by opening up inland navigational routes, and by providing dependable and affordable electrical energy. As a result of these initiatives, the federal government has been repaid several times over from tax revenues resulting from the increased economic activity in addition to the revenues from the sale of electricity.

Table 5.14 presents a qualitative summary of the estimated impacts of federal hydroelectric incentives. The largest impacts came in the form of sectoral subsidies, increased capital formation, modification of public/private relations, demographic factors, increased employment and productivity, and definite hydroelectricity quantity and price impacts. More moderate impacts occurred for such factors as the competitive structure of the industry, the balance of payments, the regulatory burden, the quality of life, and sectoral changes. The effects upon income class, inflation, foreign policy/national security, political stability, and state/federal relations were found to be indeterminate.

\section{RECOMME NDATIONS FOR SOLAR POLICY}

Hydroelectric power is essentially a product of solar energy. The sun evaporates water from land and sea, and this moisture collects in the atmosphere to later return as rain or snow. Much of the water falls on high lands and drains back to the sea. This flow, together with the difference in elevation can be harnessed by a hydroelectric project to produce electricity. 
TABLE 5.14. Summary of Impact of Hydroelectricity Incentives

Incent ives

\begin{tabular}{|c|c|c|c|}
\hline \multirow[b]{2}{*}{$\begin{array}{l}\text { Dam Construction } \\
\text { and Operation }\end{array}$} & \multicolumn{2}{|c|}{ Incent ives } & \\
\hline & $\begin{array}{l}\text { Low-Interest } \\
\text { Loans }\end{array}$ & $\begin{array}{l}\text { Federal Tax } \\
\text { Exemptions }\end{array}$ & Regulations \\
\hline
\end{tabular}

Economic Factors

Competition Versus Monopoly

Sectoral Impacts

Sectoral Subsidies

Income Class

Capital Formation

Price/Quantity

Inflation

Employment/Productivity

Balance of Payments

$\underset{0}{*}$ Political Factors

Foreign Policy/National Security

Stability

M

$M$

L

Organizational/Legal Factors

State/Federal Relations

Public/Private

Regulatory Burden

Quality of Life

Demographics

$L=$ Large effect

$M=$ Moderate effect

$I=$ Indeterminate or no effect

$\mathrm{N}=$ Negligible effect 
The impact of federal involvement has been to supply tremendous amounts of capital at very low interest rates for dam construction and to exempt revenues of the dams from income taxes. In this way the government expedited the development of hydroelectric potential and, simultaneously, provided for improved flood control, navigation, irrigation, and economic development.

Due to the centralized nature of hydroelectric power facilities, we must restrict an analogy to solar power development to centralized systems. The federal government could stimulate the centralized production of solar energy by proceeding along the same lines as its hydroelectric power development: first, locate promising sites where solar potential is highest and economic development is necessary; carry out detailed economic analys is to determine the long range return on such an investment; and finance construction. Since no fuel costs are incurred, only operation, maintenance and fixed annual expenditures need be paid. To accelerate repayment, the revenues from such a facility should not be taxed.

Means of deriving associated benefits from solar production facilities should be investigated--perhaps for provision for irrigation pumping, recreational development by shading desert areas, and improved land navigation by road construction. Because of the anticipated relatively low output of solar power facilities, emphasis should be placed on development of low-energyintensive industry surrounding the plant.

Primary applications for such solar power facilities include isolated Indian villages, military posts, or penal colonies that desire or need to be removed from the main power grid. Should the centralized production of solar electricity become marginally competitive, large public works programs similar in scale to the construction of Bonneville or Grand Coulee dams could be carried out, financed by federal monies subject to repayment over a "reasonable" period.

A solar application particularly amenable to hydroelectric facilities is the possible use of the temperature variation present in a water storage reservoir. Studies underway at the Jet Propulsion Laboratory and other research institutes indicates that, with emerging ocean thermal energy conversion (OTEC) 
technology, it may be possible to generate more power from the thermal gradient in a hydroelectric reservoir than is generated by the existing hydroelectric turbines. Since the transmission systems are already in place, such a hybrid application may significantly improve system performance.

At the present time, the Department of Energy is constructing wind turbines along the Columbia Gorge on the border of Washington and Oregon, to extract the solar power of the winds. Tying these plants in with the existing hydroelectric facilities offers another significant solar resource to utilize in conjunction with the existing hydroelectric production and transmission systems.

The reduction in hydroelectric power costs precipitated by federal involvement in facility construction and operation effectively serves as a disincentive to all alternate energy sources. This creates an unfair market for new technologies. Since it has been concluded that federal incentives have reduced hydroelectric prices by approximately $30 \%$, a subsidy of a similar amount to new technologies would correct for the distortion in hydroelectric prices. Until such time that solar technologies are assisted by federal programs to the same extent that hydroelectric power experienced, we can not expect to witness a similar growth in the quantity of energy supplied. 
CHAPTER 6

COAL

William J. Sheppard, Fuels Analyst

David E. Lenerz, Energy Economist 
$\underline{\text { COAL }}$

INTRODUCTION

A variety of coal production incentives have been provided by the federal government. These have been enumerated in a previous study (Cone et al. December 1978, Chapter VI). The purpose of this analysis is to determine the impact of these incentives on production levels and other economic, political, environmental, and social factors. This chapter will proceed from a general discussion of the incentives to the specific impacts which have been discovered.

U.S. coal production has been generally increasing in both relative and absolute terms since 1961 . By 1977 coal accounted for $26.5 \%$ of total U.S. energy output, with the most rapid growth coming in recent years. This is in contrast to oil and natural gas production which have been declining during this decade.

Domestic coal consumption has followed the same trend as coal production. In 1977, consumption reached 14.1 quadrillion Btu (quads), up $42.4 \%$ from its modern day low of 9.9 quads in 1961. Also in contrast to oil and gas, production has consistently outpaced consumption, resulting in a net balance of trade surplus. In 1977 this amounted to 1.4 quads and was worth $\$ 2.7$ billion.

The coal industry has expanded in recent years without the huge government incentives provided to other energy sectors. Coal has received a smaller total amount of incentives than any other energy source examined in this study. The total since 1950 amounts to $\$ 9.7$ billion (1977 $\$$ ), only $4.5 \%$ of total federal energy incentives. The subsidy since 1950 averages just $2.6 \$$ per million Btu. Furthermore, a large portion of this total has been expended since 1974 so it has not yet had a great impact. A summary of coal incentives is provided in Table 6.1.

The largest single incentive ( $\$ 4.0$ billion) has been preferential tax treatment in the form of a percentage depletion allowance. This may be compared to depreciation of capital investments, but it is calculated on the bas is of production value, not cost. Although not comparable to the sums received by the gas and oil industry, the value of the coal depletion allowance 
TABLE 6.1. Summary of Incentives to Coal by Type (in Millions of $1977 \$$ )

(Cone et al. December 1978, p. 190)

\begin{tabular}{|c|c|c|c|c|c|c|c|}
\hline Incentive Area & Taxation & $\begin{array}{c}\text { Disburse- } \\
\text { ment }\end{array}$ & $\begin{array}{c}\text { Require- } \\
\text { ments }\end{array}$ & $\begin{array}{c}\text { Traditional } \\
\text { Services }\end{array}$ & $\begin{array}{l}\text { Nontrad. } \\
\text { Services }\end{array}$ & $\begin{array}{c}\text { Market } \\
\text { Activity } \\
\end{array}$ & Total \\
\hline Research and Development & & & & & 2,508 & & \\
\hline $\begin{array}{l}\text { Exploration } \\
\text { Geological Survey } \\
\text { Bureau of Land Managemen }\end{array}$ & & & & & 128 & 18 & \\
\hline $\begin{array}{l}\text { Mining } \\
\text { Depletion Allowance } \\
\text { Mine Health and Safety } \\
\text { Bureau of Mines Data }\end{array}$ & 4,026 & & 670 & & 49 & & \\
\hline $\begin{array}{l}\text { Transportation, } \\
\text { Ports and Waterways }\end{array}$ & & & & 2,308 & & & \\
\hline TOTAL & 4,026 & & 670 & 2,308 & 2,685 & 18 & 9,707 \\
\hline
\end{tabular}


has climbed substantially in recent years. The next largest incentive category (\$2.5 billion) is nontraditional services, primarily in the form of research and development. These expenditures have rapidly accelerated since the Arab oil embargo. Included are R\&D on mining methods and systems, mechanization, coal cleaning processes, mine health and safety, coal utilization, and pollution control. The last major incentive ( $\$ 2.3$ billion) is federal support of ports and waterways, a traditional service which has not shown any increasing or decreasing trend.

Each of the incentives provided by the federal government has had a somewhat different impact. This is the subject of the sections to follow. Before a detailed analysis is presented, the overall relationship between the magnitude of the incentives and the price and output of coal production will be discussed.

\section{COAL PRODUCTION AND FEDERAL INCENTIVES}

The value of annual coal production incentives remained stable from 1950 to 1969, increased modestly for a few years and then began a dramatic expansion in 1974. The recent increases are primarily due to increased research and development expenditures and larger amounts of tax preferences. Government R\&D programs have been aimed at finding new ways to utilize coal without environmental damage and to transform coal to gaseous and liquid forms. These efforts have been undertaken to reduce the nation's dependence on foreign energy sources. Tax preferences for the coal industry are in the form of a percentage depletion allowance. The increase in this incentive is due to a combination of higher coal prices and greater output.

Over the 1950 to 1977 period, coal production has followed a different and irregular trend. Annual output declined from 1950 to 1961 at which point it began a slow, unsteady recovery. During this time, coal use was almost completely phased out in the transportation and commercial/residential sectors but experienced rapid growth in the electric utility market.

Coal production and incentive trends are displayed in Figure 6.1 and Table 6.2. As can be seen, no simple correlation exists between the value of 


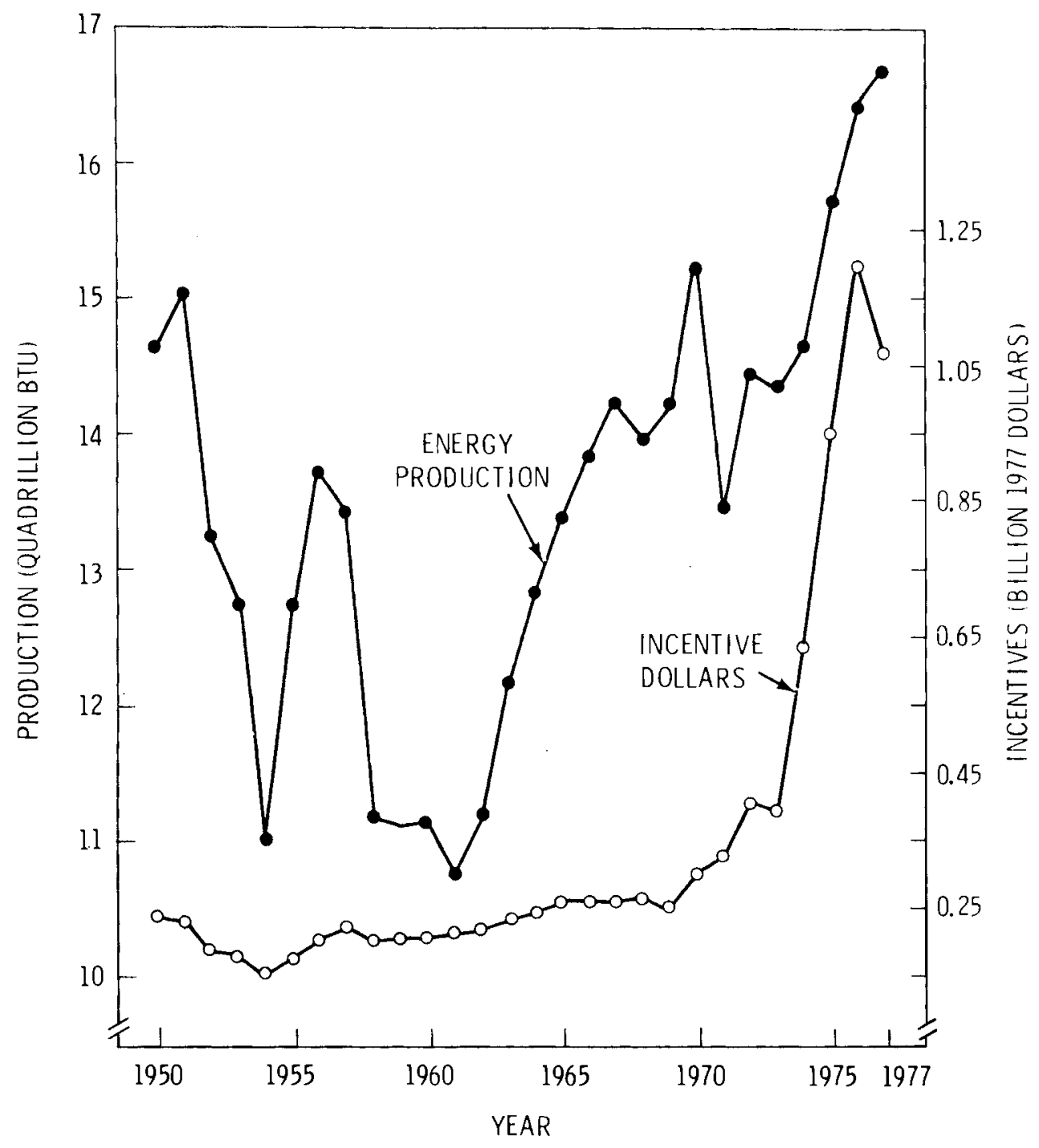

FIGURE 6.1. Coa 1: Annual Production and Incentives

annual incentives and production levels. Many other factors have influenced coal output and could easily outweigh the effect of government incentives. Furthermore, the impact of most incentives (e.g., R\&D) are felt over a period of years, not immediately. This lag effect can be investigated by comparing cumulative production and incentive figures. This is shown in Figure 6.2 and Table 6.3. 
TABLE 6.2. Annual Coal Production and Federal Incentives

\begin{tabular}{lcc} 
Year & $\begin{array}{c}\text { Production(a) } \\
\left(10^{12} \text { Btu }\right)\end{array}$ & $\begin{array}{c}\text { Incentives (b) } \\
\left(10^{6} 1977 \$\right)\end{array}$ \\
\cline { 2 - 3 } 1977 & 15,926 & 1,069 \\
1976 & 15,870 & $1,155(\mathrm{c})$ \\
1975 & 15,201 & 950 \\
1974 & 14,487 & 637 \\
1973 & 14,381 & 394 \\
1972 & 14,500 & 407 \\
1971 & 13,607 & 327 \\
1970 & 15,248 & 303 \\
1969 & 14,223 & 250 \\
1968 & 13,955 & 266 \\
1967 & 14,215 & 262 \\
1966 & 13,836 & 262 \\
1965 & 13,395 & 262 \\
1964 & 12,854 & 242 \\
1963 & 12,176 & 236 \\
1962 & 11,211 & 217 \\
1961 & 10,751 & 214 \\
1960 & 11,140 & 207 \\
1959 & 11,105 & 206 \\
1958 & 11,171 & 202 \\
1957 & 13,444 & 226 \\
1956 & 13,747 & 205 \\
1955 & 12,745 & 173 \\
1954 & 11,001 & 151 \\
1953 & 12,767 & 182 \\
1952 & 13,262 & 188 \\
1951 & 15,066 & 231 \\
1950 & 14,647 & 240 \\
& &
\end{tabular}

\footnotetext{
(a) The 1950 to 1971 production is from EIA (May 1978a, p. 3) while the 1972 to 1977 production is from EIA (January 1979 , p. 4).

(b) Incentives are from Cone et al. (December 1978, Ch. VI).

(c) Excludes direct government expenditures for transition quarter 1976 (\$46 million)
}

The results of this comparison are not much more satisfying. There is a definite positive correlation as expected; however, output has increased in a linear manner while incentives increased exponentially. It obviously requires a more sophisticated analys is to elicit the true relationship between the two variables. The impact of incentives must be isolated from all of the other factors which influence production. The latter include a wide range of things 


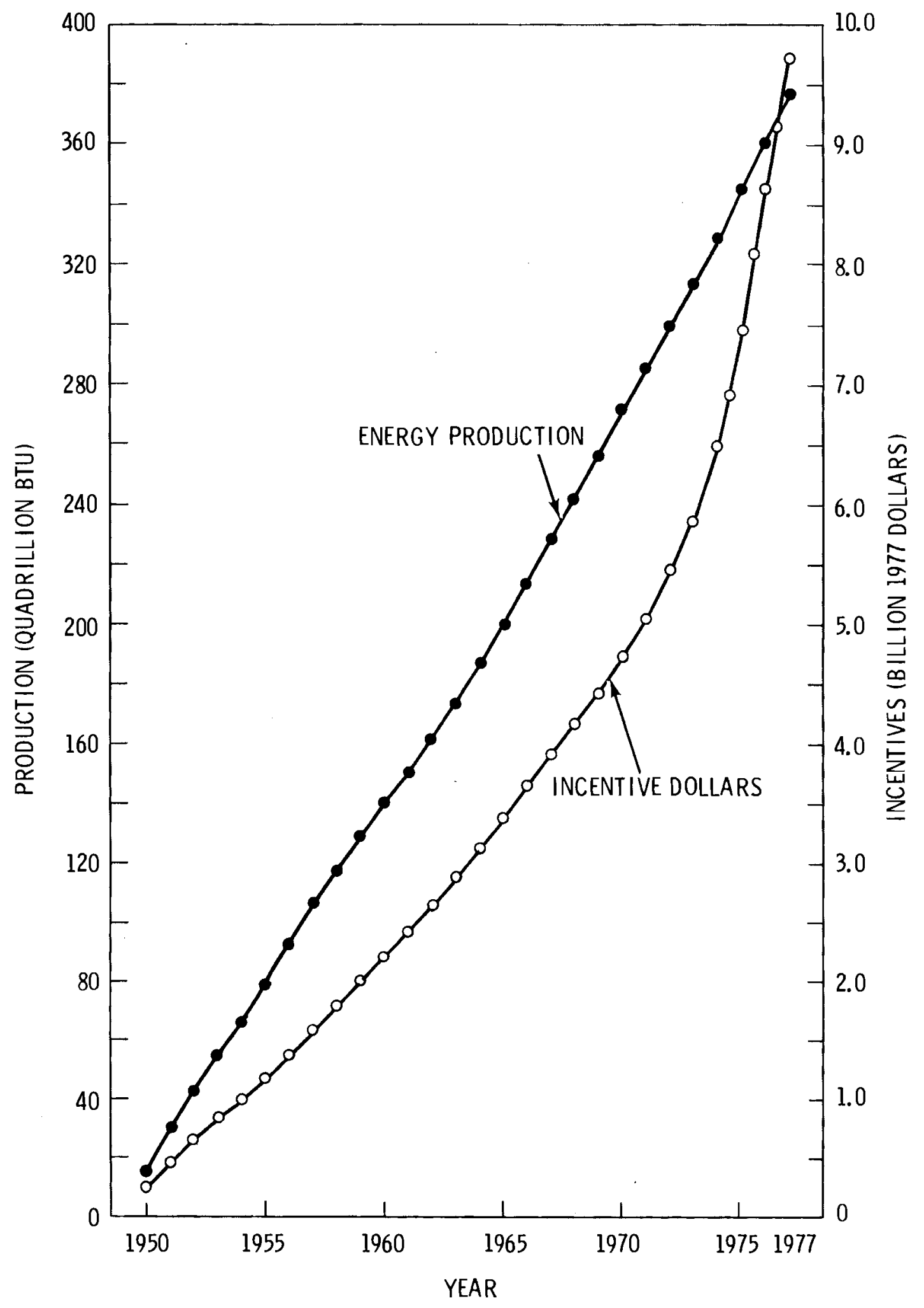

FIGURE 6.2. Coal: Cumulative Production and Incentives 
TABLE 6.3. Cumulative Coal Production and Federal Incentives(a)

\begin{tabular}{lcc} 
Year & $\begin{array}{c}\text { Production } \\
\left(10^{12} \text { Btu }\right)\end{array}$ & $\begin{array}{c}\text { Incent ives } \\
\left(10^{6} 1977 \$\right)\end{array}$ \\
\cline { 3 - 3 } 1977 & & \\
1976 & 375,932 & 9,664 \\
1975 & 360,006 & 8,595 \\
1974 & 344,136 & 7,440 \\
1973 & 328,935 & 6,490 \\
1972 & 314,447 & 5,853 \\
1971 & 300,066 & 5,459 \\
1970 & 285,566 & 5,052 \\
1969 & 271,959 & 4,725 \\
1968 & 256,711 & 4,422 \\
1967 & 242,488 & 4,172 \\
1966 & 228,533 & 3,906 \\
1965 & 214,318 & 3,644 \\
1964 & 200,482 & 3,382 \\
1963 & 187,087 & 3,120 \\
1962 & 174,233 & 2,878 \\
1961 & 162,057 & 2,642 \\
1960 & 150,846 & 2,425 \\
1959 & 140,095 & 2,211 \\
1958 & 128,955 & 2,004 \\
1957 & 117,850 & 1,798 \\
1956 & 106,679 & 1,596 \\
1955 & 93,235 & 1,370 \\
1954 & 79,488 & 1,165 \\
1953 & 66,743 & 992 \\
1952 & 55,742 & 841 \\
1951 & 42,975 & 659 \\
1950 & 29,713 & 471 \\
& 14,647 & 240 \\
& &
\end{tabular}

(a) Calculated from Table 6.2.

from consumer demand to labor strikes. A methodology is required to extract the precise relationship between output and incentives from the multitude of interrelationships which exist. This is the topic of a later section. We next turn to a comparison of incentives and price levels.

COAL PRICE AND FEDERAL INCENTIVES

Federal incentives act to increase coal output by reducing production costs. To the extent that this action is successful, a comparable impact on price will also occur assuming that we are dealing with a competitive worker. 
TABLE 6.4. Coal Prices and Federal Incentives

\begin{tabular}{|c|c|c|c|}
\hline Year & $\begin{array}{c}\text { Price (a) } \\
\left(1977 \notin / 10^{6} \mathrm{Btu}\right) \\
\end{array}$ & $\begin{array}{c}\text { Annual } \\
\text { Incentives (b) } \\
\left(10^{6} 1977 \text { \$) }\right.\end{array}$ & $\begin{array}{c}\text { Cumulative } \\
\text { Incentives(b) } \\
\left(10^{6} 1977 \$\right) \\
\end{array}$ \\
\hline 1977 & 92.6 & 1,069 & 9,664 \\
\hline 1976 & 90.0 & 1,155 & 8,595 \\
\hline 1975 & 87.6 & 950 & 7,440 \\
\hline 1974 & 80.9 & 637 & 6,490 \\
\hline 1973 & 48.7 & 394 & 5,853 \\
\hline 1972 & 46.5 & 407 & 5,459 \\
\hline 1971 & 44.0 & 327 & 5,052 \\
\hline 1970 & 37.8 & 303 & 4,725 \\
\hline 1969 & 32.1 & 250 & 4,422 \\
\hline 1968 & 31.5 & 266 & 4,172 \\
\hline 1967 & 32.5 & 262 & 3,906 \\
\hline 1966 & 33.9 & 262 & 3,644 \\
\hline 1965 & 33.4 & 262 & 3,382 \\
\hline 1964 & 34.4 & 242 & 3,120 \\
\hline 1963 & 34.4 & 236 & 2,878 \\
\hline 1962 & 35.5 & 217 & 2,642 \\
\hline 1961 & 36.7 & 214 & 2,425 \\
\hline 1960 & 37.9 & 207 & 2,211 \\
\hline 1959 & 39.3 & 206 & 2,004 \\
\hline 1958 & 40.7 & 202 & 1,798 \\
\hline 1957 & 43.5 & 226 & 1,596 \\
\hline 1956 & 42.6 & 205 & 1,370 \\
\hline 1955 & 40.3 & 173 & 1,165 \\
\hline 1954 & 41.5 & 151 & 992 \\
\hline 195 & 47.1 & 182 & 841 \\
\hline 195 & 45.9 & 188 & 659 \\
\hline 195 & 46.9 & 231 & 471 \\
\hline 19 & 49.8 & 240 & 240 \\
\hline
\end{tabular}

(a) Figures calculated using data from EIA (May 1978a, pp. 19,77,85) and
the 1977 price data is from EIA (January 1979). (b) From Tables 6.2 and 6.3 .

As listed in Table 6.4, the real price of coal declined gradually from 1950, reaching a low point in 1968. From then, it began a steady climb, climaxed by a huge jump in 1974. By 1977, the price had nearly tripled from its level of nine years earlier.

A comparison of coal price and annual incentives (Figure 6.3 ) does not reveal a simple relationship. While production incentives were fairly stable 


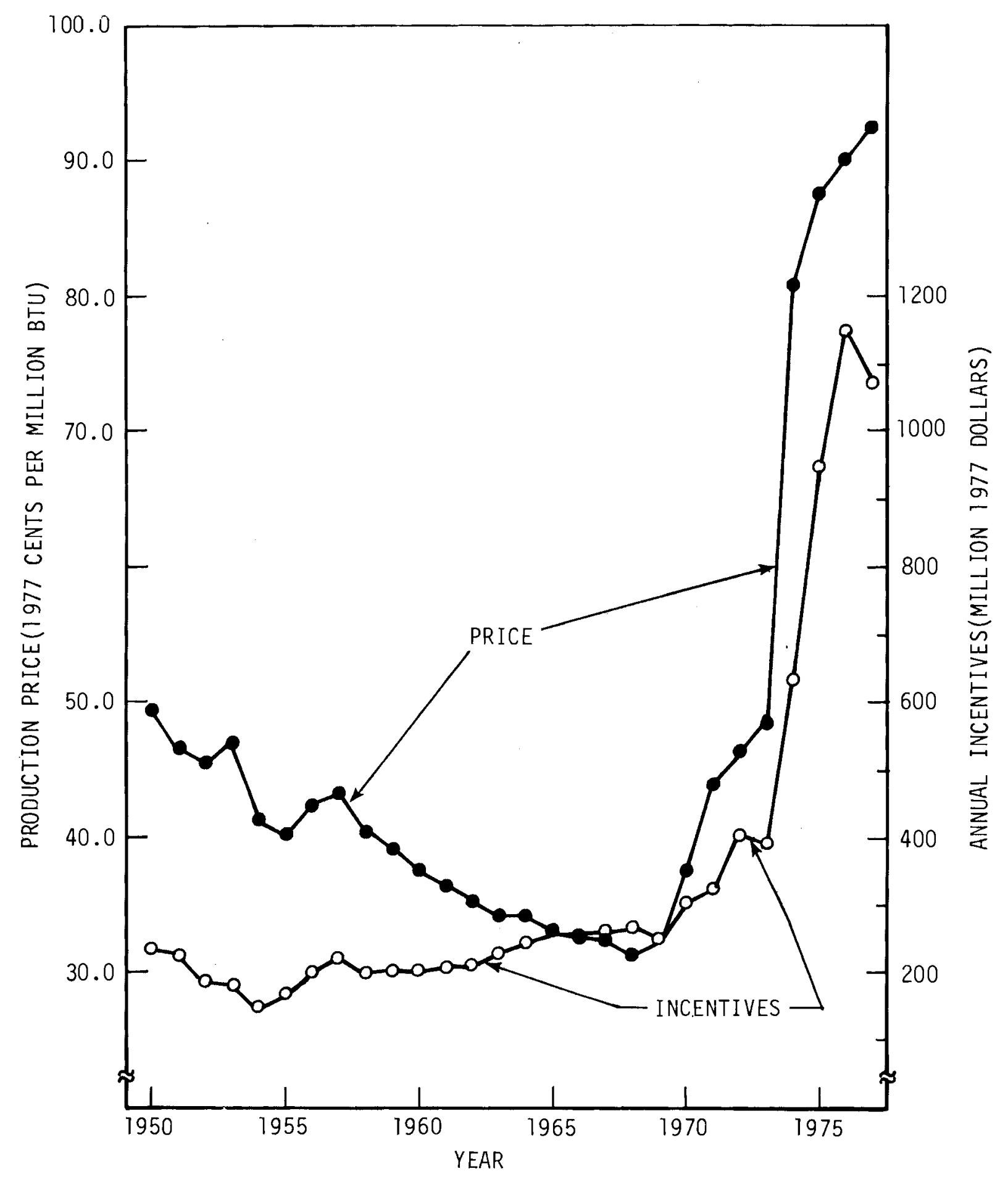

FIGURE 6.3. Coal Prices and Annual Incentives 
during the first segment of this period, coal price was declining. Over the past decade, both have been rising tremendously.

Although the incentives presumably helped keep down the price of coal, that cannot be demonstrated by this simple diagram. It is apparent that other factors have had a more dominant impact over this period of time. For example the huge increase in mining costs since 1970 are of a far greater magnitude than were the value of federal incentives. Price has also climbed because of increases in demand, largely as a result of the high prices and questionable availability of substitute fuels.

Another reason for the lack of a simple correlation is that many incentives take years to have an impact. Research and development is an obvious example. This implies that the impact of accumulated incentives on price ought to be analyzed. The time trends for these two variables are depicted in Figure 6.4. From 1950 to 1968, there was a generally inverse relationship however this does not hold over the current decade for the reasons stated above.

It is apparent that the impact of federal production incentives on both coal quantity and price cannot be demonstrated by a simple approach. It will be necessary to develop a more sophisticated methodology to determine precise relationships. Possible approaches to this task are discussed in the next section.

\section{EVALUATING THE EFFECTS OF FEDERAL INCENTIVES}

It was initially thought that one or more large energy-economic models would be utilized to determine the effect of incentive policies for coal as well as petroleum and natural gas. No suitable model to analyze the effect of incentives over a long historical period was found, however. This conclusion is supported by a study by Paul Sommers (November 1978). This led to a decision to use existing published studies as a basis for our estimates.

Most of the important incentives have received a great deal of attention from analysts. This provided a starting point from which necessary modifications could be made. It is felt that this produced good estimates of the relative impact of various incentives but that the quantitative results must 


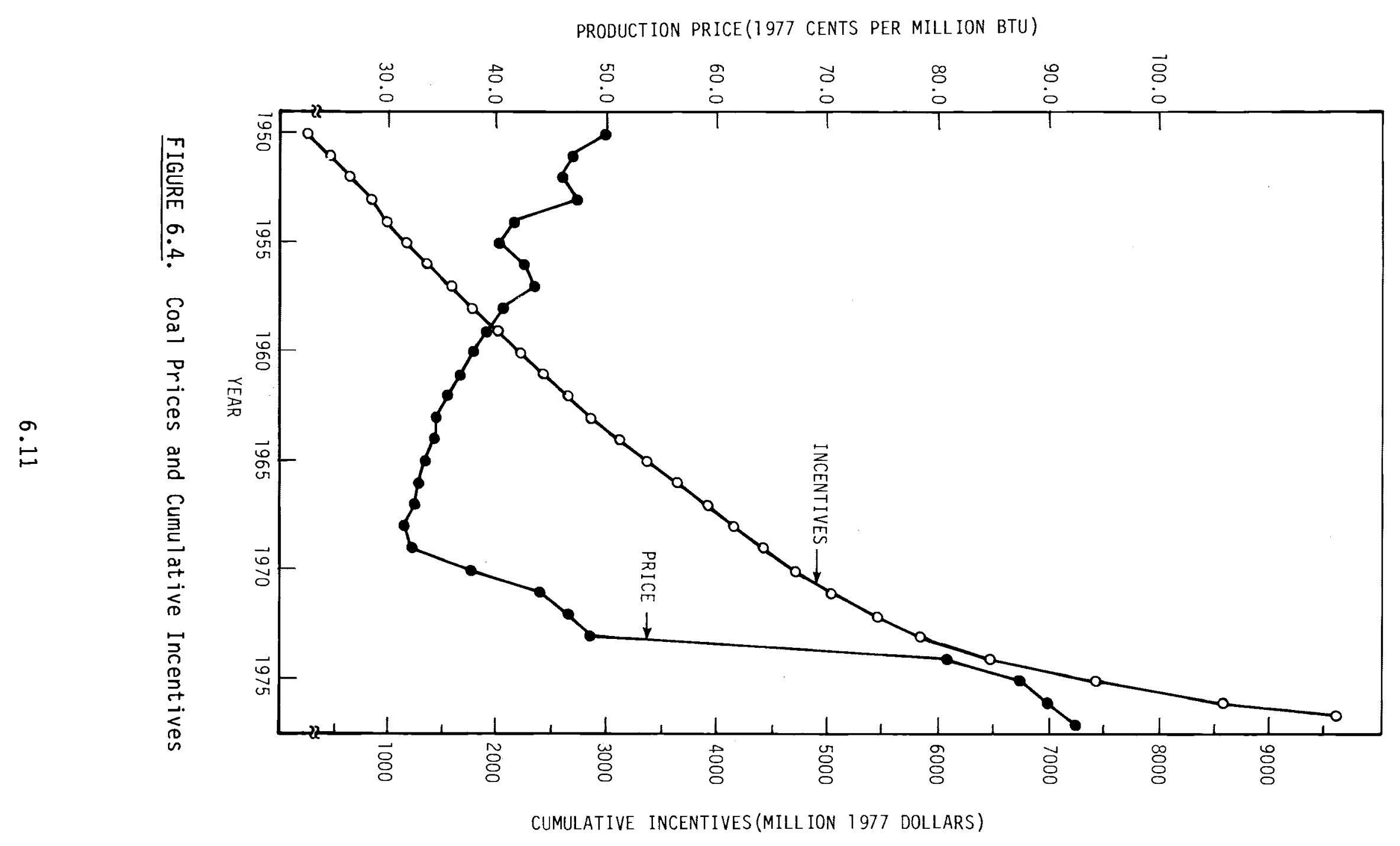


be used with caution. Because the figures were pieced together from various sources and calculations, some overlap and duplication exists and, thus, the figures are not generally additive. This is a drawback if one wants to determine the comprehensive impact of the incentives but is not particularly harmful if one wishes to assess the merit of alternative incentive policies. This study is aimed toward the latter purpose and these results, if properly utilized, are felt to make a useful contribution.

Federal incentives for coal have been much smaller than for other energy forms. Under $\$ 10$ billion was provided from 1950 through 1977 . The impact of these incentives on coal price and output has generally been minor, although this may change in future years.

The Mine Health and Safety Act of 1969 , although not intended as an incentive, has had a substantial negative impact on productivity and therefore has been analyzed. From 1960 to 1969, productivity in underground mines grew at a simple annual rate of between 4\% and 5\%. Although from 1969 to 1977 productivity in underground mines declined by $5.5 \%$ per year, it may not be valid to attribute this entire change to health and safety requirements. During this period many new mines were opened and new, untrained employees hired. Numerous wildcat strikes and a major recession interrupted mining operations. These factors had a depressing effect on productivity. However, the partial replacement of cutting machines with more productive continuous mining equipment and longwall operations have largely balanced this effect. Attributing recent productivity losses entirely to health and safety measures, therefore, is probably fairly accurate, although it may be considered the maximum impact case.

To calculate the effect on coal price, the drop in productivity was measured and transformed into cost per ton. The productivity decline was measured as the difference between actual 1977 productivity and what would have occurred had the previous trend continued. This difference was multiplied by the average worker salary in 1977 to arrive at the change in cost per ton. It is assumed that the mine operators have had the ability to pass on the increased costs to consumers, due to the extreme rise in the prices of competing fuels. The effect upon output is not readily measured. Primary substitutes, such as nuclear fuel, oil, and gas have experienced rapid price rises and questionable 
availability while coal has maintained or improved its competitiveness, as demonstrated by continued growth. It is quite possible that growth would have been even greater had productivity increased and costs been held down, but this is uncertain. (For example, without improved mining conditions, it would have been more difficult to recruit the additional miners necessary to increase output.) In addition, coal was being stockpiled throughout the summer and fall of 1977 in anticipation of the United Mine Workers strike that occurred in December of that year. These and other factors have so complicated the picture that no estimate of a change in production due to the incentives could be made.

Improvements to domestic ports and waterways were another incentive which has had an impact on the price and quantity of coal. Approximately $11 \%$ of coal output is loaded at the mine for shipment by water. One-third of all coal production is transported by water at some point from the mine to the consumer. This includes virtually all coal exports. The use of federally improved ports and waterways has generally been free of charge. (a) Coal's share of total federal expenditures is taken as the ratio of coal tonnage shipments to total waterborne commerce. This amounted to $\$ 2.3$ billion over the 1950 to 1977 period.

In recent years, roughly $70 \%$ of waterborne coal shipments have been domestic and the remainder foreign trade, predominantly exports of metallurgical coal. Most domestic coal shipments are carried by barge. The free use of improved waterways has reduced the total cost of coal. The incidence of this incentive must be known to determine its impact. The direct beneficiaries are the barge operators. If a competitive mode of transportation exists, however, some of the benefit will be passed to consumers or back to mine owners. For example, where there is direct competition between rail and barge, the railroads have often established a special low rate to remain competitive. This implies that the barge operator is not able to retain the full benefit of free waterway utilization but, rather, is forced by competition to lower his price.

(a) A recently enacted waterway use tax will take effect in 1980. For coal transportation, the cost will amount to approximately $16 \phi /$ ton, rising to $40 \$ /$ ton by 1985 . 
The indirect beneficiaries are the mine owners and coal customers. The ultimate distribution of the benefit will depend upon the competitive conditions and institutional factors, such as contractual arrangements, which apply to each particular situation. This makes it difficult to generalize about the effect of this incentive. The largest possible impact upon the minemouth price of coal would occur if all the benefit were passed back to the mine owners, an unlikely situation. For those mines served by barge, this would have amounted to approximately $39 \$ /$ ton in 1977 . To the extent that the cost saving was passed on to consumers, a slight increase in the quantity demanded would result. However, this impact is considered slight and is taken to be zero as a best estimate.

Two other federal incentives have had a minimal impact on coal price and output. Government leasing of western coal land has as yet had no measurable impact. Even though huge tracts have been kept unavailable for mining, enough private and state owned land has been made available so that no constraint on production is evident. For example, coal production west of the Mississippi more than doubled from 1973 to 1977. In recent years, about $40 \%$ of this was from federal and Indian lands. (a) At the same time, a large amount of excess mine capacity exists. It is therefore concluded that federal leasing policy has not yet had much impact upon the price or amount of coal production. (In the absence of an acceptable environmental impact statement, federal leasing in the northern Great Plains area has been minimal in recent years).

Federal coal research and development has been a relatively large incentive, with over $\$ 2.5$ billion spent since 1950 . A wide range of projects have been funded including mine safety, pollution control, mining technology, strip mine reclamation and coal utilization (e.g. gasification and liquefaction). Most of this research has been done in recent years and has not yet had much impact. For example, there have been virtually no commercial operations resulting from coal utilization $R \& D$, by far the largest expenditure category. For the period covered by this study, it is concluded that there has been no measurable impact on price or output.

(a) In 1975, 43.6 million tons of coal were mined on federal and Indian lands compared to 110.9 million tons mined west of the Mississippi. See Dupree et al. (1975). 
The percentage depletion allowance is the last significant coal incentive to be considered. It is the largest single incentive in terms of federal expenditures, or in this case, reduction in federal revenue. This amounted to approximately $\$ 4$ billion over the 1950 to 1977 period.

Compared to oil and gas, the depletion allowance for coal is quite small. The rate has been set at $10 \%$ versus $22 \%$ (formerly $27.5 \%$ ) for the other fuels. Even this lower rate has not been attained due to a limitation equal to $50 \%$ of net income. Until this decade, the industry was depressed and prices and profits were low. This caused an estimated reduction in the effective depletion rate to $4 \%$. This has since risen to $5 \%$ or $6 \%$ as the market for coal has become stronger (Brannon 1975).

As expected, the effect of this incentive has been quite minor. Brannon (1975) has estimated it to be equal to a $4.4 \%$ rise in price. Not all of the benefit will be retained by the mine operator, however. Some will be passed back to landowners in the form of higher lease payments and some will be received by customers in the form of lower prices. This disperses the already small benefit to such an extent that its impact becomes negligible.

NONPRICE AND QUANTITY IMPACTS

A number of federal incentives have had significant impacts in addition to changes in production quantities and price. A review of the more substantial impacts follows.

\section{Competition}

The structure of the coal industry is characterized by a large number of relatively small firms. According to the Census of Mineral Industries (Bureau of the Census 1976b, pp. 1-96), there were 3,365 bituminous and lignite mining establishments (SIC 12) in 1972. Two-thirds of these had fewer than 20 employees and, altogether, accounted for $9.6 \%$ of total industry value added. Only 36 establishments had over 500 employees. The 50 largest mines accounted for $25.1 \%$ of total production in 1975. These mines were owned by 26 different firms (National Coal Association 1979, p. II-7). 
Coal mining is conducted by a variety of firms including electric utilities, stee 1 companies, and oil companies as well as firms primarily engaged in mining. The entry of non-coal companies into mining has increased both the vertical and horizontal integration of the industry. For example, in the steel industry over one-half of the coal delivered to coke plants is captive. In electricity generation, less than $20 \%$ of purchases are made on the spot market and the remainder are made on long-term (up to 30 to 35 years) contracts (National Coal Data 1979, pp. II-53 and II-55). These figures demonstrate that the unconcentrated nature of the coal industry described above is somewhat misleading. Concentration ratios alone are not an accurate indicator of market performance.

Most federal incentives have been essentially neutral in their impact upon competition in the coal industry. An exception is government construction, operation, and maintenance of ports and waterways. These activities have fostered competition among mining companies located in diverse geographic regions by opening up mining areas which were previously economically inaccessible. The relatively high cost of transporting coal has made this incentive especially valuable.

Balance of Payments

The United States has historically run a balance of trade surplus for coal. In 1977, a net 1,351 trillion Btu of coal was exported at a value of $\$ 2,615$ million. In 1974 , the trade balance increased substantially, primarily due to a large increase in the unit value of coal.

The exportation of U.S. coal has been assisted by the development of domestic ports and waterways. Coastal ports have provided the necessary facilities for shipping the product abroad. Internal waterways have played a role in transporting coal from the interior areas where it is mined to consumption points on rivers, seacoasts, and for export. Federal subsidies for water transportation have thus been an important, although relatively minor, incentive for increased coal exports.

\section{Capital Formation}

The coal industry benefits from a percentage depletion allowance similar to that in the $0 i 1$ and gas sector. However, the rate has been set at $10 \%$, 
substantially less than the $22 \%$ (formerly 27.5\%) for $0 i 1$ and gas. Only in recent years, with the great increase in coal prices, has the percentage depletion allowance been a substantial incentive. By increasing the cash flow into the industry, it has improved the ability of coal companies to attract new capital.

Government coal research and development has also increased capital formation to a moderate degree. The promise of new technology to spur the use of coal has encouraged investment in the industry. The impact is expected to become much greater when this technology is successfully developed and demonstrated on a commercial scale.

\section{Employment/Productivity}

The Federal Mine Health and Safety Act of 1969 has had the largest impact of any factor on recent coal mine employment and productivity trends. From 1969 to 1977 , coal mining productivity fell from 19.90 tons/man/day to 14.74 tons/ man/day. Productivity fell particularly steeply in underground mining from 15.61 tons/man/day to 8.70 tons/man/day. This was a period of modest growth for the coal industry. Thus, the number of miners employed had to grow substantially (62.4\%) to compensate for the decline in productivity. One response to these trends is a switch from underground mining to surface mining where productivity is greater (almost 3 times in 1976). This has led to a drop in underground production $(-18.9 \%)$ and a $r$ ise in surface production $(+94.8 \%)$ over the 1969 to 1977 time period. Employment in surface mining has consequently experienced substantially greater growth, $177.8 \%$ versus $37.2 \%$, calcu- lated from National Coal Association (1973 and 1979) data.

These trends cannot be attributed entirely to health and safety regulations. Other factors have also played a role. A rough estimate of the effect of the Mine Health and Safety Act may be developed by comparing the trends prior to the Act to actual results. If output per employee had grown as it had prior to 1969 , it would have stood at 157.4 in $1975(1967=100)$ rather than the actual 70.9. Total coal mining employment would have dropped to $45 \%$ of its actual figure (Denison January 1978, p. 34). While these figures probably overstate the true impact, they do support the contention that the Mine Health and Safety Act has had a tremendous effect on coal mining employment and productivity. 
$\underline{\text { Income Class }}$

The 1969 Mine Health and Safety Act has led to a huge increase in the total income paid to miners. As mentioned above, mine employment has increased tremendous $1 y$, by $62.4 \%$ from 1969 to 1976. Average weekly earnings rose from $\$ 169$ to $\$ 355$ over the same period (National Coal Association 1973, 1979). As a class, therefore, miners have experienced a huge income gain, much of which can be attributed to employment increases made necessary by productivity decreases.

Regu latory Burden

In addition to the direct capital and operating costs of complying with the 1969 Mine Health and Safety Act, comprehensive reporting requirements have been placed on the coal industry. Total costs have been substantial and have been reflected in the rapid rise in the price of coal. The average price of coal rose over 70\% in current dollars from 1969 to 1973, even before the effect of the Arab 0il Embargo was felt. This compares to a $5 \%$ increase over the preceding 10 years (National Coal Association 1973, 1979).

Coal operators also must report coal production and reserve data to the federal government. These reporting requirements are substantially less burdensome than those for health and safety but should be included in considering the total impact upon industry.

Quality of Life

A substantial improvement in the quality of miners' lives has resulted from the Mine Health and Safety Act. The Act formulated new standards which were stricter than most existing state and federal regulations. All aspects of mine operations were covered, including equipment specifications, lighting and ventilation improvements, roof support rules, and an increased level of worker training.

Enforcement levels al so were substantially increased. A special agency, the Mine Enforcement and Safety Administration (MESA) was created in 1973. Originally part of the Department of Interior, MESA was transferred to the 
Department of Labor in 1977 and renamed the Mine Safety and Health Administration by the Federal Safety and Health Amendments Act of 1977. The result of strict standards and enforcement has been a significant reduction in mining accidents. For example, fatal injuries have dropped from an average of 1.06 per million man-hours in the five years before the Act, to 0.41 over the most recent five years for which data are available. If just underground mines are considered, the improvement is even greater, decreasing from 1.23 to 0.48 fatal injuries per million man-hours. It is fair to say that this can be almost entirely attributed to the Health and Safety Act.

\section{THE IMPACT OF FEDERAL INCENTIVES ON THE PRICE AND OUTPUT OF COAL}

As measured by the impact upon the price and output of coal, there have been five federal incentives which can be considered relatively major. They have been more significant than other coal incentives, but still are quite small in comparison to incentives for other energy forms.

Table 6.5 indicates that the impact of federal incentives on coal production has been minor with one possible exception, the Mine Health and Safety Act. The increase in coal prices resulting from the Act's implementation reduces the quantity of coal demanded by users. During the period of price increases, however, the price of substitute fuel increased just as rapidly. This has largely counteracted the effect of coal price increases on the demand for coal. Other nonprice factors have also affected the demand for coal. These include pollution control regulations, restrictions on the use of alternatives, and a major recession. On the supply side, it may be argued that without improvements in mine working conditions, output may have been restricted due to labor recruitment problems. Alternatively, labor may have become available only at much higher wages, thus tending to offset "savings" obtained by not making improvements. The net effect of these various factors is not known which makes it impossible to determine the precise impact of health and safety regulations on coal production.

Federal incentives have had a more noticeable effect upon the price of coal as indicated in Table 6.6. The Mine Health and Safety Act has had the 
TABLE 6.5. An Estimate of the Results of Incentives Used to Stimulate Coal Production (in quads)

\begin{tabular}{|c|c|}
\hline Incentive Area & Production Impact \\
\hline Taxation & Negligible \\
\hline Requirements & Indeterminate \\
\hline Traditional Services & Negligible \\
\hline Nontraditional Services & Negligible \\
\hline Market Activity & Negligible \\
\hline
\end{tabular}

TABLE 6.6. An Estimate of the Results of Incentives Used to Stimulate Coal Production in Terms of Price (dollars per million Btu)

\begin{tabular}{lll}
\multicolumn{1}{c}{ Incentive Area } & & \multicolumn{1}{c}{ Price Impact } \\
\cline { 1 - 1 } Taxation & & 0.013 (reduction) \\
Requirements & & 0.100 (increase) \\
Traditional Services & & 0.006 (reduction) \\
Nontraditional Services & Negligible \\
Market Activity & Negligible
\end{tabular}

estimated $\$ 5.73 /$ ton. This large increase is to be considered as a maximum impact. When averaged over the total volume of coal production, the price increase comes to approximately $\$ 2.26 /$ ton or $\$ 0.10 / \mathrm{million}$ Btu.

Other incentives have had a much smaller impact on the price of coal. Transportation incentives have caused an estimated maximum $\$ 0.39 /$ ton price reduction for coal carried by water. This would be reduced to $\$ 0.13 /$ ton or less if averaged over all production. In terms of Btu's, this reduction in price amounts to less than $\$ 0.01 / \mathrm{million}$ Btu. The percentage depletion allowance has had a comparable effect on the price of coal. It is estimated that the impact on the 1977 price of coal ranges from $\$ 0.20$ to $\$ 0.40 /$ ton with the impact being much smaller in earlier years. Using a simple average value of $\$ 0.30 /$ ton, the coal depletion allowance has reduced coal price by $1.3 \$ / \mathrm{mi} 11$ ion Btu. The other incentives considered -- research and development, and leasing of federal lands -- have as yet caused no measurable change in coal price. 


\section{CONCLUSIONS}

The relatively small amount of incentives that the federal government has provided the coal industry did not create a significant set of impacts. Table 6.7 presents a summary of the coal incentive impacts based on the typology of incentive impacts identified in Table 2.1.

Of the incentives listed, the mine health and safety regulations had the largest impact, yet they were estimated to have cost the government only $\$ 670$ million. These regulations were determined to have increased the price of coal while having an indeterminate effect on coal output. Significant increases in coal mining employment, total income paid to miners, improvements in the quality of miner's lives, increased regulatory burden, and declining productivity are impacts that can all be attributed to the health and safety regulations.

The remaining incentives have had a significantly smaller impact. The coal percentage depletion allowance accounts for the largest federal coal incentive expenditure ( $\$ 4$ billion). This incentive, however, had a negligible impact on the output of coal, created a moderate reduction in coal price, and a moderate stimulation of the level of capital formation. Government construction, operation, and maintenance of ports and waterways cost $\$ 2.3$ billion and moderately enhanced the competitive structure of the industry, created a small reduction in coal price, had a negligible impact on output, and a positive balance of payments effect. The $\$ 2.5$ billion spent by the federal government on research and development activities has had only moderate benefits for the level of capital formation. These activities, however, have a potential for substantial impacts on the coal industry over the long term. Data gathering activities moderately increased the regulatory burden and federal coal leasing policies have not yet created a significant impact. 
TABLE 6.7. Summary of Impact of Coal Incentives

\begin{tabular}{|c|c|c|c|c|c|c|}
\hline \multirow[b]{2}{*}{ Impacts } & \multicolumn{6}{|c|}{ Incent ives } \\
\hline & $\begin{array}{l}\text { Depletion } \\
\text { Allowance }\end{array}$ & $\begin{array}{l}\text { Ports and } \\
\text { Waterways }\end{array}$ & $\begin{array}{c}\text { Research } \\
\text { and } \\
\text { Development }\end{array}$ & $\begin{array}{l}\text { Mine } \\
\text { Health and } \\
\text { Safety } \\
\end{array}$ & $\begin{array}{c}\text { Data } \\
\text { Gathering }\end{array}$ & $\begin{array}{l}\text { Coal } \\
\text { Leasing } \\
\text { Policy } \\
\end{array}$ \\
\hline \multicolumn{7}{|l|}{ Economic Factors } \\
\hline Competition Versus Monopoly & I & M & I & I & I & I \\
\hline Sectoral Impacts & I & I & I & I & I & I \\
\hline Sectoral Subsidies & I & I & I & I & I & I \\
\hline Income Class & I & $\mathrm{I}$ & I & $\mathrm{L}$ & I & I \\
\hline Capital Formation & M & I & M & I & I & I \\
\hline Price/ Quantity & M & M & $\mathrm{N}$ & L & $\mathrm{N}$ & $\mathrm{N}$ \\
\hline Inflation & I & I & I & I & I & I \\
\hline Employment/Productivity & I & I & I & L & I & I \\
\hline Balance of Payments & I & M & I & I & I & I \\
\hline \multicolumn{7}{|l|}{ Political Factors } \\
\hline Foreign Policy/National Security & I & I & I & I & I & I \\
\hline Stability & I & I & I & I & I & I \\
\hline \multicolumn{7}{|l|}{ Organizational/Legal Factors } \\
\hline State/Federal Relations & I & I & I & I & I & I \\
\hline Public/Private & I & I & I & I & I & I \\
\hline Regulatory Burden & I & I & I & $\mathrm{L}$ & M & I \\
\hline Quality of Life & I & I & I & L & I & I \\
\hline Demographics & I & I & I & I & I & I \\
\hline
\end{tabular}




\section{RECOMMENDATIONS FOR SOLAR POLICY}

The single largest federal incentive for coal production has been the percentage depletion allowance; however, it has had a negligible impact upon output. This is due in part to the limitation of the deduction to $50 \%$ of net income. In times when the industry was depressed and net income was very low, the full amount of the depletion allowance could not be utilized. Therefore, part of the potential impact of this incentive was lost.

If an extraordinary tax deduction is provided to the solar industry, it may result in a similar consequence. The beginning years of a business or industry are likely to be the least profitable. Therefore, a tax deduction may be worth little during the period when an incentive would be most useful. This points to the superiority of a tax credit, which is independent of income, over a tax deduction. A credit may be structured to allow for a refund if the tax liability is negative.

Another major incentive for coal has been federally sponsored R\&D. The impact upon production has been minimal thus far due to the long lead time between the research expenditures and a change in production. Federal R\&D efforts are expected to eventually lead to new ways of utilizing coal, however. The absolute abundance of coal by itself has not been enough to assure its widespread adoption. Solar energy is in a similar position. Continued research to improve technology will reduce costs, improve reliability, and increase the ways in which solar energy can be used. If the experience with coal is an appropriate example, substantial R\&D expenditures for solar energy are necessary to assure widespread use in the long run.

The coal industry has also received incentives through subsidies to the transportation sector. This does not correspond to solar energy since production and consumption are of ten simultaneous. For some types of solar energy such as biomass, however, the analogy does apply. This form of solar energy requires an entire chain of production and marketing functions as does coal. If any element in the chain is inadequate, the whole process will be hindered. Therefore, to promote biomass or a similar form of solar energy, incentives are likely to be the most beneficial if directed toward the weakest element in the production-marketing chain. 
Another incentive provided to coal production has been federal data collection and dissemination. Although the impact of this incentive on coal production is difficult to discern, a similar incentive for solar energy is likely to be useful. In particular, the development of data on solar radiation and wind levels would be helpful to potential investors. Such a data collection activity is an appropriate govermental function and, due to the nature of the data, could be done best at the federal level. 
CHAPTER 7

$\underline{\text { OIL }}$

by

William J. Sheppard, Fuels Analyst

David E. Lenerz, Energy Economist 
INTRODUCTION

Petroleum is the nation's largest source of energy, accounting for nearly one-half (48.7\%) of total energy consumption in 1977. Domestic oil production of 17.4 quadrillion Btu (quads) provided only slightly over $50 \%$ of total oil consumption. This gap between domestic petroleum production and consumption has widened over the past decades as production leveled off and then declined while consumption continued to grow. In 1950, petroleum passed coal as the most used energy form and it has continued to dominate. Petroleum production, however, was the largest domestically produced energy source for only an 11 year period, from 1952 through 1962. As a result of declining production, the U.S. has become increasingly dependent upon foreign sources of oil.

For many decades, the federal government has provided incentives to encourage petroleum production. The major ones are listed in Table 7.1. Over $\$ 100$ billion worth of incentives have been directed toward increasing production (Cone et al. December 1978, Chapter VII). Petroleum has received by far the largest amount of incentives, four times the combined total of natural gas ( $\$ 16$ billion) and coal ( $\$ 10$ billion), or $47 \%$ of all incentives studied.

A wide range of federal actions have benefited the oil industry. The largest, in terms of value, are preferential taxation and special price control regulations ("requirements"). Preferential taxation consisted of permitting firms to expense intangible drilling costs and to receive percentage depletion allowance. Together, these have accounted for approximately one-half ( $\$ 50.4$ billion) of all incentives. The requirements category contains four individual items, the largest being stripper well and new oil pricing. These two categories of $0 i 1$ were wholly or partially exempted from the price controls placed on oil in 1974. This has been worth a total of $\$ 36.1$ billion to the oil industry over the 1974 to 1977 period. Other large incentives are the high return formerly allowed on pipeline investments, charge-free maintenance of ports and waterways, oil tanker subsidies, and government-sponsored R\&D programs. Most of these incentives were underwritten by the government, while others were paid for directly by consumers. 
TABLE 7.1. Summary of $0 i 1$ Incentiyes by Type (in millions of 1977 \$)

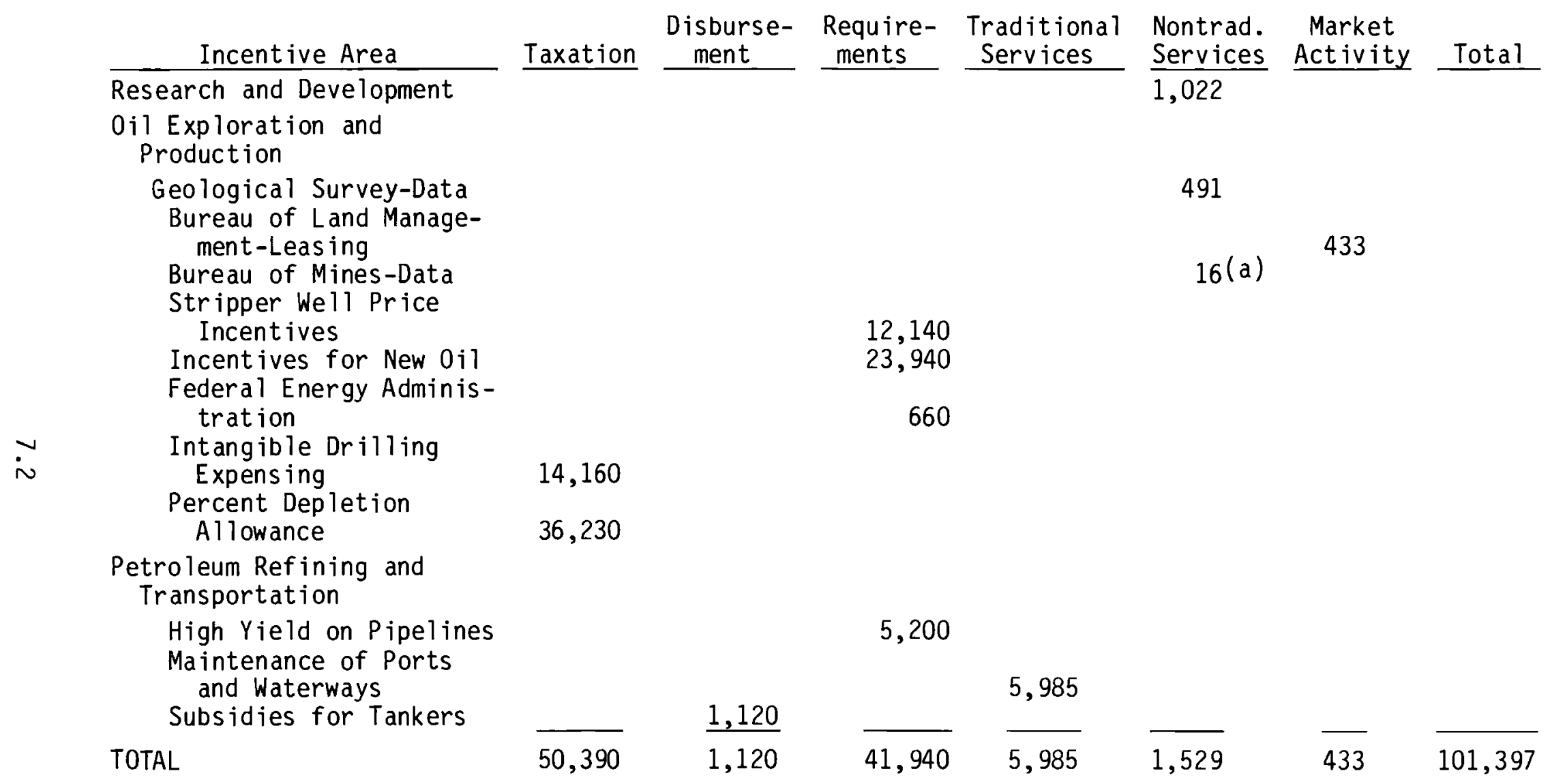

(a) 1964 to 1977 only. 
The composition of the incentives package has changed significantly in recent years. Starting in 1975, the oil depletion allowance began to be reduced. At about the same time, however, another huge incentive took effect. Stripper and new oil were exempted from the price controls which were imposed in 1974. The size of this exemption (which has been modified somewhat since then) has been large enough to overcome reduction of the depletion allowance for the industry as a whole. As a result, since 1974 the total value of government production incentives has increased substantially while at the same time the nature of the incentives has changed. This will be discussed in more detail in the following sections.

\section{PETROLEUM PRODUCTION AND FEDERAL INCENTIVES}

Historically, petroleum production climbed quite steadily, reaching a peak in 1970. In this decade, however, domestic production from the 48 contiguous states has been declining. This has resulted primarily from the (previous) availability of inexpensive foreign oil and the consequent decline in domestic exploration. Production incentives over the same period have followed a different pattern. Through 1973, the value of government incentives remained very level, averaging $\$ 2.14$ billion per year. In 1974, the annual total leaped to $\$ 10$ billion and has remained at or above that figure ever since. These trends are displayed in Figure 7.1 and Table 7.2.

It is difficult to detect correlation between annual production incentives and output for a number of reasons. First (as mentioned above), during the time period under consideration, there was very little change in the annual incentive level until 1974. Because of this, it is virtually impossible to determine what impact it may have had. A longer time frame over which to examine movements in the two variables is needed before meaningful conclusions about their relationship can be made.

Secondly, at any given time, the output response to a change in a casual variable is limited by current production capacity. Output beyond this amount requires development of additional capacity. Thus, there is a lag between the 


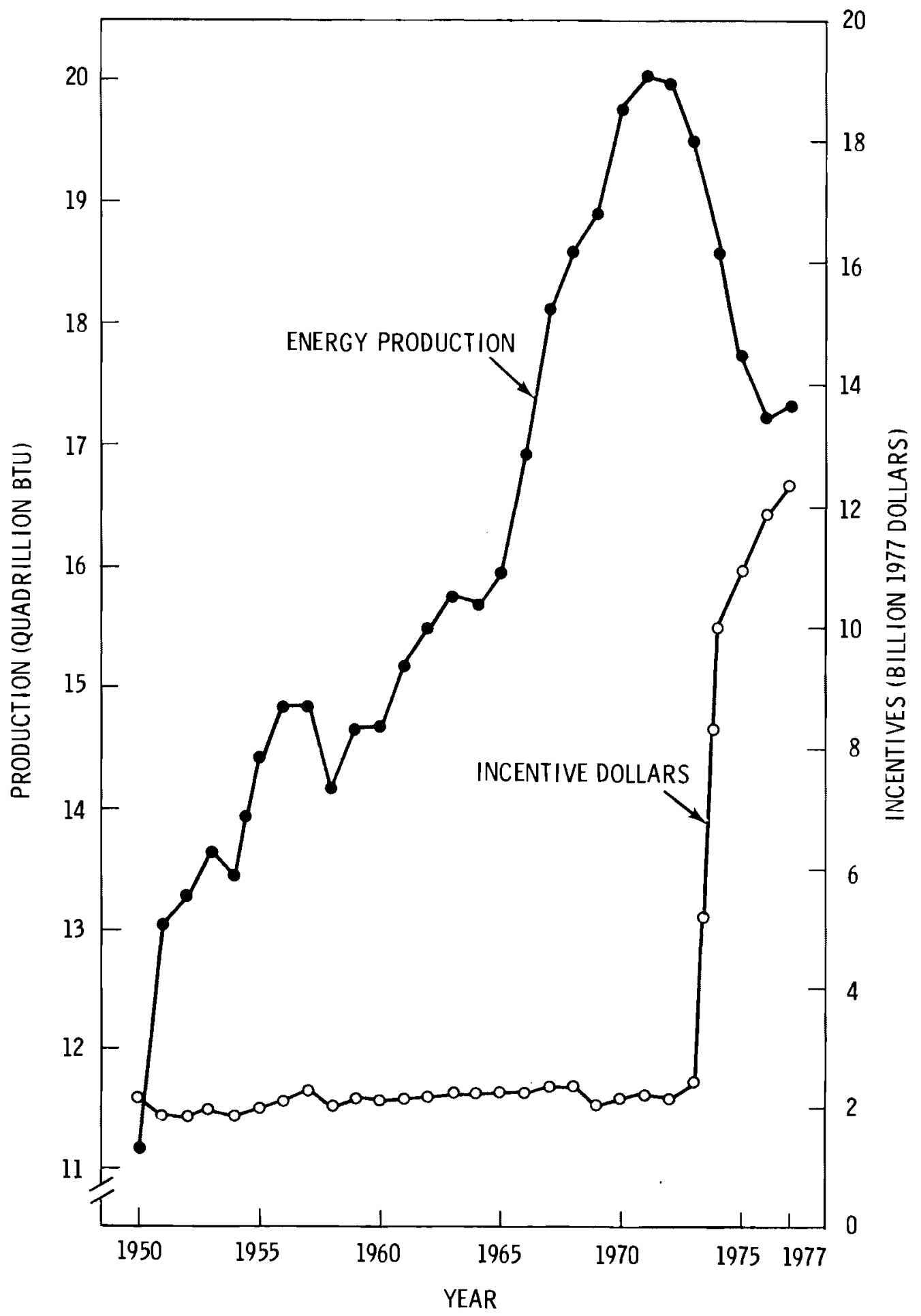

FIGURE 7.1. Annual Production and Incentives for $0 \mathrm{il}$ 
TABLE 7.2. Annual $0 i 1$ Production and Federal Incentives

\begin{tabular}{|c|c|c|}
\hline Year & $\begin{array}{c}\text { Production(a) } \\
\left(10^{12} \mathrm{Btu}\right) \\
\end{array}$ & $\begin{array}{l}\text { Incentives (b) } \\
\left(10^{6} 1977 \$\right)\end{array}$ \\
\hline 1977 & 17,315 & 12,362 \\
\hline 1976 & 17,262 & 11,832 \\
\hline 1975 & 17,729 & 10,891 \\
\hline 1974 & 18,575 & 10,006 \\
\hline 1973 & 19,493 & 2,414 \\
\hline 1972 & 20,041 & 2,163 \\
\hline 1971 & 20,031 & 2,213 \\
\hline 1970 & 20,402 & 2,137 \\
\hline 1969 & 19,558 & 2,008 \\
\hline 1968 & 19,308 & 2,382 \\
\hline 1967 & 18,653 & 2,360 \\
\hline 1966 & 17,562 & 2,289 \\
\hline 1965 & 16,524 & 2,277 \\
\hline 1964 & 16,165 & 2,262 \\
\hline 1963 & 15,967 & 2,218 \\
\hline 1962 & 15,521 & 2,178 \\
\hline 1961 & 15,208 & 2,148 \\
\hline 1960 & 14,935 & 2,110 \\
\hline 1959 & 14,935 & 2,157 \\
\hline 1958 & 14,204 & 2,016 \\
\hline 1957 & 15,179 & 2,278 \\
\hline 1956 & 15,179 & 2,094 \\
\hline 1955 & 14,407 & 1,985 \\
\hline 1954 & 13,427 & 1,850 \\
\hline 1953 & 13,671 & 1,975 \\
\hline 1952 & 13,282 & 1,836 \\
\hline 1951 & 13,037 & 1,904 \\
\hline 1950 & 11,449 & 2,170 \\
\hline
\end{tabular}

(a) 1950 to 1971 production data is from EIA (May $1978 b$, p. 3).

(b) This data is from Cone et. al. (December 1978, Chapter VII).

time of the incentive and the time of the resulting production increase. For example, the bulk of Alaskan North Slope $0 i 1$ was added to known proved reserves in 1970 , but the production did not begin until 1977.

Recognizing that at least a portion of the output response to increased incentives will be lagged, it is appropriate to consider the cumulative effect 
of incentives upon production. This is depicted in Figure 7.2 and Table 7.3. There appears to be a more consistent relationship between the two variables when expressed in this manner.

The apparent inverse relationship between annual incentives and production levels which was observed in recent years can be explained by another factor. Although total annual incentives increased tremendously in 1974, the nature of the incentives changed very radically. A strong incentive, the percentage depletion allowance, was substantially reduced in 1975 . While this was happening, wellhead price controls were established in 1974. Stripper well production and new $0 i 1$, however, were exempted from these controls. This has been defined as an incentive for production, even though the overall impact of price controls is to discourage the development of new supplies and, in some cases, to encourage premature abandonment of old wells. A result of this is the seemingly contradictory relationship between incentives and production which has occurred over the past few years.

Finally, several other variables have a substantial impact upon domestic petroleum production. Costs of exploration and development, consumer demand, and the relative attractiveness of foreign crude have all been important. The latter in turn was significantly influenced by foreign tax credits and quotas on foreign imports. Thus, one cannot expect to find a simple correlation between the value of government production incentives and output levels. Before the complexity of this relationship is explored, the general effect of incentives on price will be discussed.

\section{PETROLEUM PRICE AND FEDERAL INCENTIVES}

Because there are many factors which complicate the relationship between incentives and production, we would not expect to find a simple correlation between incentives and price since price and quantity are codetermined. This is borne out by Figure 7.3 and Table 7.4 which displays the annual price and incentives trends and values. Through 1973, no consistent relationship is apparent. Starting in 1974, the two variables show strong movement in the same direction, just the opposite of what one would expect. The reasons for this are well-known and were presented in the previous section. 


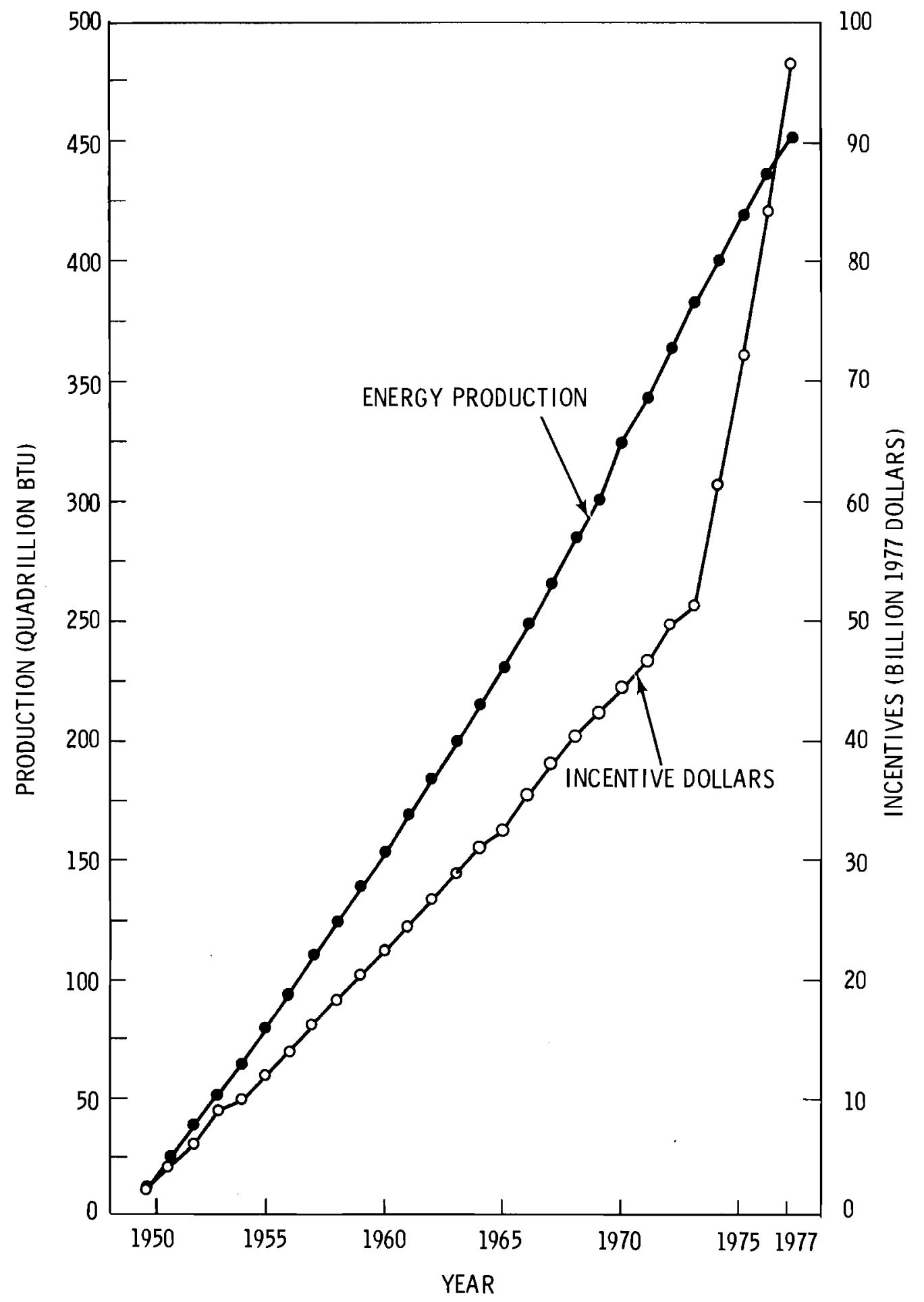

FIGURE 7.2. Cumulative Production and Incentives for $0 \mathrm{il}$ 
TABLE 7.3. Cumulative $0 i 1$ Production and Federal Incentives(a)

\begin{tabular}{lcc} 
Year & $\begin{array}{c}\text { Production } \\
\left(10^{12} \text { Btu }\right)\end{array}$ & $\begin{array}{c}\text { Incentives } \\
\left(10^{6} 1977 \$\right)\end{array}$ \\
\cline { 3 - 3 } 1977 & 459,019 & 96,439 \\
1976 & 441,704 & 84,077 \\
1975 & 424,442 & 72,245 \\
1974 & 406,713 & 61,354 \\
1973 & 388,138 & 51,348 \\
1972 & 368,645 & 48,934 \\
1971 & 348,604 & 46,771 \\
1970 & 328,573 & 44,634 \\
1969 & 308,171 & 42,497 \\
1968 & 288,613 & 40,489 \\
1967 & 269,305 & 38,107 \\
1966 & 250,652 & 35,747 \\
1965 & 233,090 & 33,458 \\
1964 & 216,566 & 31,181 \\
1963 & 200,401 & 28,919 \\
1962 & 184,434 & 26,701 \\
1961 & 168,913 & 24,523 \\
1960 & 153,705 & 22,375 \\
1959 & 138,770 & 20,265 \\
1958 & 123,835 & 18,108 \\
1957 & 109,631 & 16,092 \\
1956 & 94,452 & 13,814 \\
1955 & 79,273 & 11,720 \\
1954 & 64,866 & 9,735 \\
1953 & 51,439 & 7,885 \\
1952 & 37,768 & 5,910 \\
1951 & 24,486 & 4,074 \\
1950 & 11,449 & 2,170 \\
& &
\end{tabular}

(a) Calculated from Table 7.2.

Matching the price trend with cumulative incentives provides a somewhat different picture (Figure 7.4). In the pre-price control years, a generally inverse relationship between price and incentive is demonstrated. This supports the theory that incentives have had a negative impact on price, as would be expected. However, the precise relationship is not as simple as depicted in these figures.

EVALUATING THE EFFECTS OF FEDERAL INCENTIVES

Federal incentives have had a substantial impact upon domestic oil production and price. This impact has varied over time as the magnitude of the 


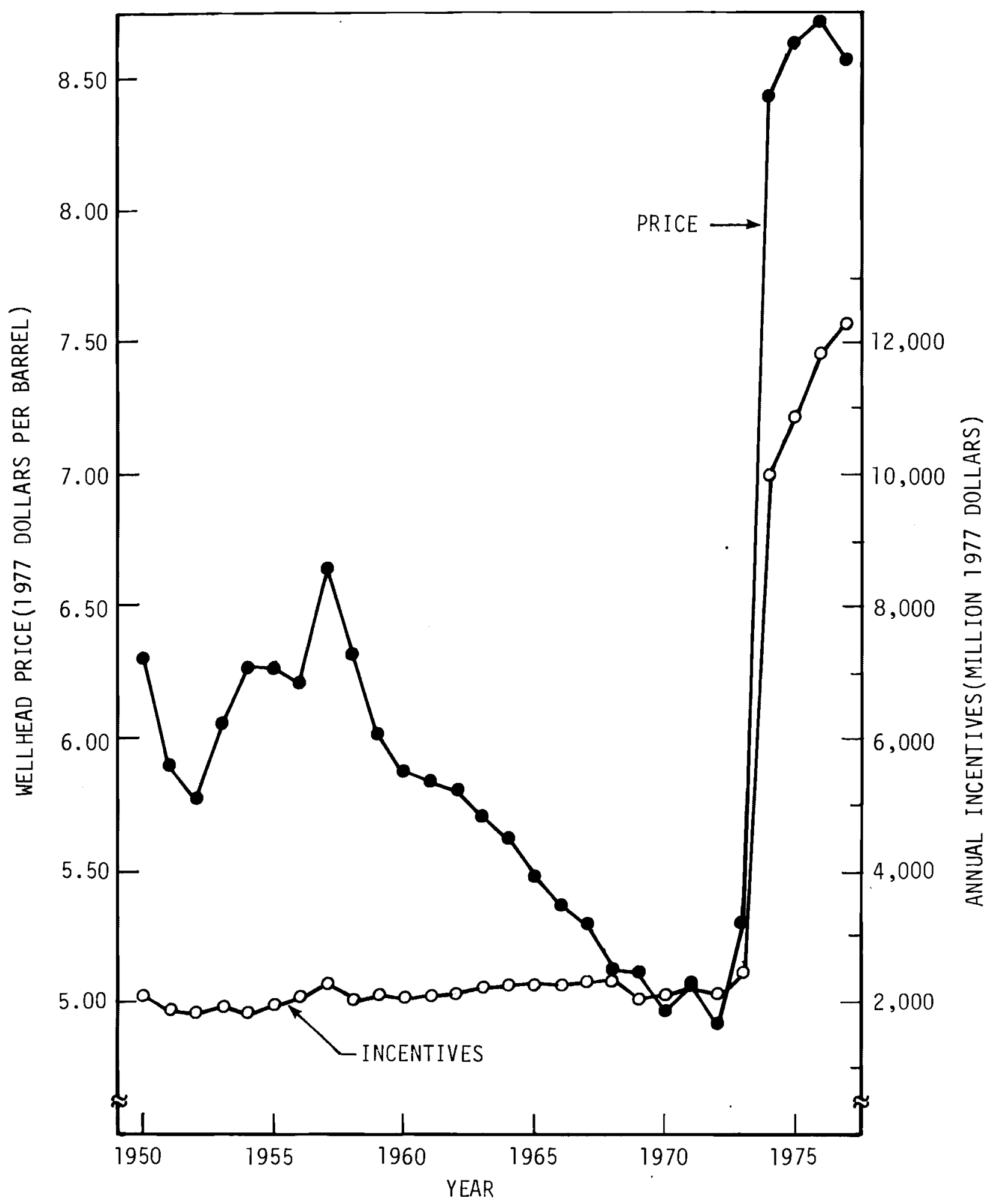

FIGURE 7.3. 0 il Prices and Annual Incentives 
TABLE 7.4. $0 i 1$ Prices and Federal Incentives

\begin{tabular}{|c|c|c|c|}
\hline Year & $\begin{array}{c}\text { Price(a) } \\
(1977 \$ / \text { barrel) } \\
\end{array}$ & $\begin{array}{l}\text { Annual Incentives(b) } \\
\left(10^{6} 1977 \$\right)\end{array}$ & $\begin{array}{c}\text { Cumulative Incentives(b) } \\
\left(10^{6} 1977 \$\right)\end{array}$ \\
\hline 1977 & 8.57 & 12,362 & 96,439 \\
\hline 1976 & 8.72 & 11,832 & 84,077 \\
\hline 1975 & 8.64 & 10,891 & 72,245 \\
\hline 1974 & 8.44 & 10,006 & 61,354 \\
\hline 1973 & 5.30 & 2,414 & 51,348 \\
\hline 1972 & 4.91 & 2,163 & 48,934 \\
\hline 1971 & 5.07 & 2,213 & 46,771 \\
\hline 1970 & 4.96 & 2,137 & 44,634 \\
\hline 1969 & 5.11 & 2,008 & 42,497 \\
\hline 1968 & 5.12 & 2,382 & 40,489 \\
\hline 1967 & 5.30 & 2,360 & 38,107 \\
\hline 1966 & 5.38 & 2,289 & 35,747 \\
\hline 1965 & 5.49 & 2,277 & 33,458 \\
\hline 1964 & 5.63 & 2,262 & 31,181 \\
\hline 1963 & 5.72 & 2,218 & 28,919 \\
\hline 1962 & 5.81 & 2,178 & 26,701 \\
\hline 1961 & 5.85 & 2,148 & 24,523 \\
\hline 1960 & 5.89 & 2,110 & 22,375 \\
\hline 1959 & 6.03 & 2,157 & 20,265 \\
\hline 1958 & 6.31 & 2,016 & 18,108 \\
\hline 1957 & 6.65 & 2,278 & 16,092 \\
\hline 195 & 6.22 & 2,094 & 13,814 \\
\hline 195 & 6.27 & 1,985 & 11,720 \\
\hline 195 & 6.27 & 1,850 & 9,735 \\
\hline 19 & 6.07 & 1,975 & 7,885 \\
\hline 19 & 5.78 & 1,836 & 5,910 \\
\hline 19 & 5.90 & 1,904 & 4,074 \\
\hline & 6.3 & 2,170 & 2,170 \\
\hline
\end{tabular}

(a) Figures calculated using data from EIA (May 1978a, p. 39).

(b) From Tables 7.2 and 7.3.

incentives changed and other factors have come into play. The interrelationships among the various incentives, other causal variables, and price and quantity are extremely complex. To determine the individual impact of each incentive, therefore, is virtually impossible.

of the numerous incentives provided to the oil industry, approximately $86 \%$ of their total value is accounted for by tax preference items and exemption from price controls. The remainder is spread over all the other incentive categories, none of which received more than $6 \%$ of the total over the $28-y \mathrm{r}$ 


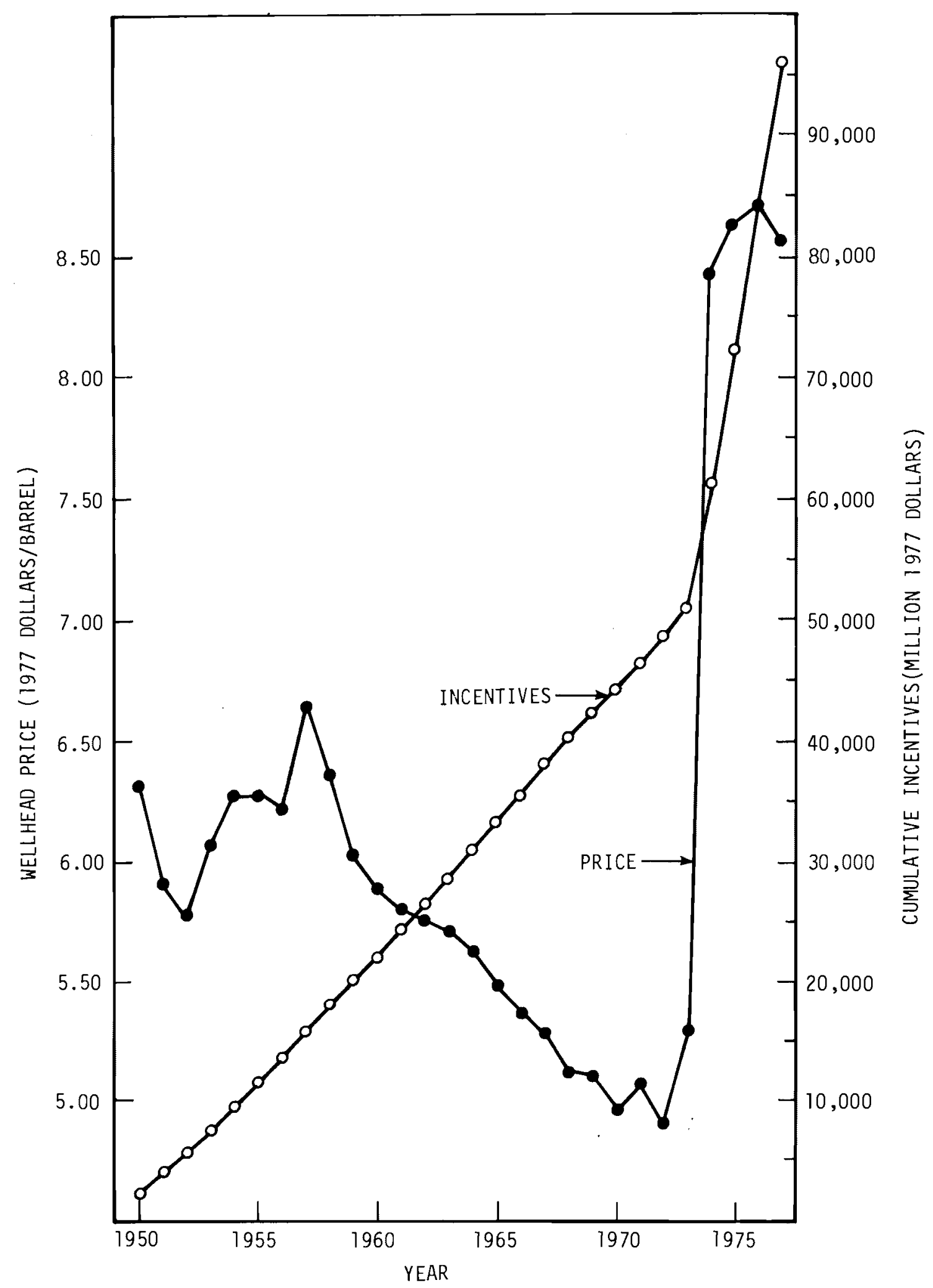

FIGURE 7.4. $0 i 1$ Prices and Cumulative Incentives 
period under study. It has been determined that the price/quantity impacts of these small incentives are relatively insubstantial and can be eliminated from consideration. Estimates of price/quantity impacts will be confined to tax preference items and price control exemptions.

The largest federal incentives to the petroleum industry are the percentage depletion allowance and the expensing of intangible drilling costs. To estimate their impact, it is necessary to determine what price/quantity relationships would have existed had the incentives not been available. Because percentage depletion was instituted in 1926 and some expensing of intangible drilling costs was allowed as early as 1917, there is virtually no historical experience without tax preferences upon which to rely. Therefore any models or constructs which attempt to isolate the impact of the two tax preferences cannot be tested against actual historical data. This has lead to a wide range of estimated impacts, with no general agreement among the experts.

Brannon (1974) has estimated that the percentage depletion allowance (22\% rate) and current deduction of intangible drilling costs together have caused a price decrease of $10 \%$, a production increase of $3 \%$, and an increase in reserves of $3 \%$ as compared to the no tax preference case. These figures are based upon an estimate that industry tax benefits are equivalent to about $20 \%$ of the wellhead price of crude oil. Brannon does not provide the detailed methodology upon which these figures are based.

The relatively small impact upon production and reserves claimed by Brannon generally supports a study done by CONSAD Research Corporation (1968). The CONSAD study found that eliminating percentage depletion would reduce reserves by $3 \%$ and eliminating the expensing provisions would cause a $1.9 \%$ to 4.0\% decline. This is based upon the questionable assumption that a tax change would be totally absorbed by producers.

Other studies have found that tax preferences have had a much greater impact. Spann, Erickson, and Millsaps (1973) estimated that elimination of percentage depletion (22\% rate) and current deduction of intangible drilling costs would result in the following changes: 


\begin{tabular}{|c|c|c|c|}
\hline & Crude $0 i l$ Price & Production & Reserves \\
\hline Depletion & $+9.8 \%$ & $-4.3 \%$ & $-11.2 \%$ \\
\hline Intangible Costs & $+14.0 \%$ & $-6.2 \%$ & $-15.1 \%$ \\
\hline Both & $+24.5 \%$ & $-10.5 \%$ & $-24.4 \%$ \\
\hline
\end{tabular}

These figures represent long-run changes after all adjustments have taken place.

McDonald (May 1974) has taken another approach to determine the impact of percentage depletion. He analyzed the impact of the percentage reduction from $27.5 \%$ to $22 \%$ and found that the price would rise $5.2 \%$ in the long-run. He does not say whether elimination of the $22 \%$ depletion allowance would have a proportional impact. If so, a further price increase of $20.8 \%$ would be predicted.

About the only conclusion that can be drawn from these studies is that widespread disagreement exists regarding the impact of the tax preference items, even though all but one of the studies had the benefit of observing the results of the 1970 reduction in percentage depletion from $27.5 \%$ to $22 \%$. $\mathrm{A}$ comparison of the 1967 to 1969 period with the 1970 to 1972 period reveals the following: annual domestic production increased $5.1 \%$ from an average of 3,306 million barrels to 3,475 million (EIA May 1978a, p. 3); the average wellhead price rose from $\$ 2.98 /$ barrel to $\$ 3.32 /$ barrel, a $9.0 \%$ increase (EIA May 1978a, p. 39); and, exploratory and development drilling expenditures declined $12.9 \%$ from $\$ 5.43$ billion to $\$ 4.73$ billion (U.S. Senate Finance Committee, Hearings, June 1974). While these data do not clarify the precise impact of the reduction in percentage depletion, they do indicate a significant impact upon drilling activity, which was followed in the mid-70's by production declines. It is not known, however, to what extent this was the result of decreased incentives since other factors such as price controls also had a large effect. Therefore, a range rather than a single value was chosen to represent the impact of the $27.5 \%$ depletion allowance and current expensing of intangible drilling costs. A price reduction of from $10 \%$ to $25 \%$ is estimated together with a $3 \%$ to $10 \%$ increase in production.

The other major category of petroleum incentives consists of stripper well and new oil pricing. Since 1974, when price controls were placed on domestic crude oil, production from stripper wells (wells producing 10 or less 
barrels/day) and new oil production have been exempted from federal price regulations or have been allowed higher prices than old oil. Stripper well pricing is aimed at maintaining production from marginal properties, where the average production per well is less than 10 barrels per day. The pricing scheme for new oil was established to encourage exploration for and development of additional domestic reserves.

The measured impact of federal price incentives depends upon the assumed base price. Normally this would be the price established by the market in the absence of government action. The concept of market price loses its meaning, however, in the case of oil. This is so because any semblance of a free market has been replaced by the workings of a cartel. The world price of oil, therefore, is just as arbitrary as a price established for domestic oil by the federal government. Without a free market price system, and the resultant efficiency of resource allocation that implies, the choice of a base price scenario from which to measure the effect of government action becomes quite judgemental.

The decision to use the regulated price for old oil as the base price is based on the fact that the government considers prices above this to be incentive prices. Thus, the intent, rather than the result, of this action has been taken into consideration. This is consistent with the definition of an incentive used in Cone et al. (December 1978, Chapter VII).

As a consequence of this choice of base price, stripper well and new oil pricing became incentives resulting in increases in production. If, on the other hand, the world oil price had been taken as the base, federal price controls on net would be considered a disincentive resulting in a decrease in production. The choice of the former was made for the reasons stated previously. In either case, the impact on quantity results from a movement along the supply curve, not a shifi in the supply curve, since the fundamental supply function is not affected by a change in the price ceiling.

From 1974 through 1977, stripper well incentives totaled over \$12 billion. New oil incentives amounted to almost $\$ 24$ billion over the same time period. 
(Both are measured in $1977 \$$ ). While these are substantial sums, their value as incentives must be considered in the context of other government actions during the same period.

First, had price controls not been placed on crude oil production, the market price of stripper $0 i 1$, new $0 i 1$, and old oil as well would have risen substantially. Oniy by considering government controls, rather than the market, as the base pricing mechanism can the treatment of stripper and new oil be identified as incentives.

Using supply and demand analysis, the effects of price controls can be identified. In Figure 7.5, a market price, $P_{m}$, and Quantity, $Q_{m}$, would result without government price controls. (In the case of oil, $P_{m}$ is highly inflated due to the action of the OPEC cartel.) If the government controlled the price at Level $P_{C}$, firms would be willing to supply only $Q_{S}$ at that price and Quantity $Q_{d}$ would be demanded. Thus, the imposition of price controls creates a supply shortage of $Q_{d}-Q_{s}$ which must be overcome by either non-price rationing of the good or an increase in non-domestic supply. Raising the controlled price to $P_{c}{ }^{\prime}$ increases the amount firms are willing to supply to $Q_{S}{ }^{\prime}$ and lowers the amount demanded to $Q_{d}{ }^{\prime}$, thus, reducing the shortage to $Q_{d}{ }^{\prime}-Q_{s}{ }^{\prime}$. If one takes the original controlled price, $P_{C}$, as a base, then any price allowed which is above $P_{c}$ increases the amount firms are willing to supply. When the controlled price is used as a base, pricing allowances for stripper well and new oil production have been considered as incentives for production.

Other government actions also played an important role in determining price and output. For example, the percentage depletion allowance was eliminated for large producers in 1975. Other government actions, as well as nongovernment events, also significantly affected crude $0 i 1$ prices and output.

One other complication should also be mentioned. In the four years being considered, the federal government changed the definitions and interpretations of crude oil classes on several occasions. For example, a February 1976 change in the method of calculating the amount of new oil from an existing well substantially increased the amount of $0 i 1$ in that category. An attempt will be made to measure the impact of each incentive, as it was defined at each point in time. 


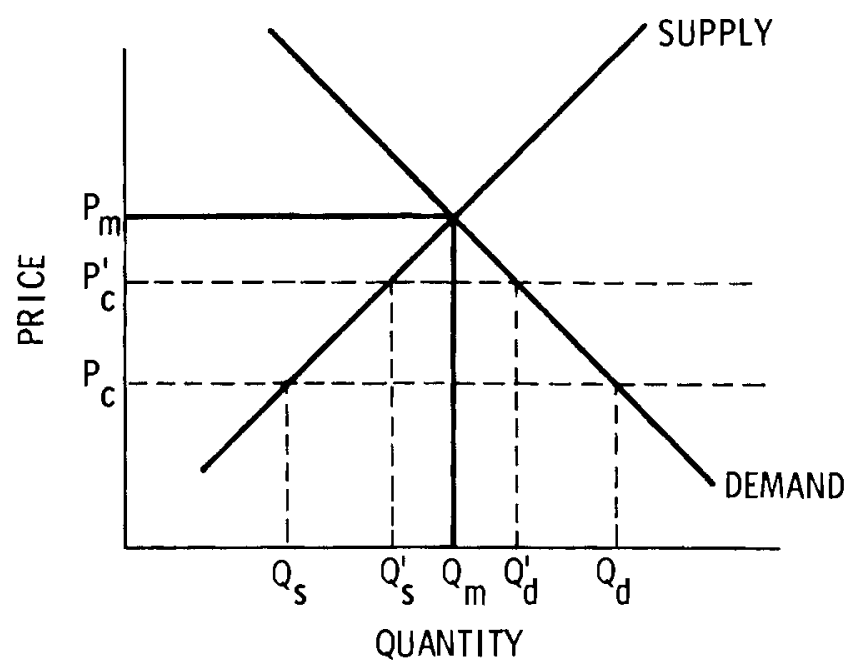

FIGURE 7.5. The Effects of Price Controls

It has been estimated (a) that $20 \%$ of all stripper wells have been saved from premature abandonment by market pricing as opposed to using the controlled price for old oil. A range from 15\% to $25 \%$ will be used for this study. (b) Production from stripper wells responds very rapidly to a change in price because only small amounts of additional capital, if any, are required to alter production. Therefore, it is assumed that output from stripper wells increases in the same year as the price rise to which it responds.

The impact of incentive pricing for new oil is more complex because new oil includes increased production from an existing property as well as production resulting from exploration and development of new properties. Thus, varying amounts of capital investment and time lags are involved in the response of production to a change in price.

(a) Estimates are from a study by Keplinger and Associates quoted in "Freed Prices Hike Stripper Output, Save Wells" (May 29, 1978).

(b) It is assumed that an " $X$ " percent change in the number of wells due to a price change results in an " $X$ " percent change in production. This assumption is equivalent to saying the probability of abandonment is independent of the average production rate of stripper wells on a given property. This was assumed because oil-to-water ratio rather than production rate is the most important factor in determining the marginal cost of production. 
It is assumed that 1) "revisions and extensions"(a) of petroleum reserves have not been affected by new oil pricing, and 2) a lag of two years exists between the time of a "discovery" addition to reserves and the start of production. In a typical field, production will start slowly and expand as the extent of reserves is more precisely delineated. Revisions and extensions will be made to the original reserve estimates as field development proceeds. The amount of ultimate production from a field, therefore, cannot accurately be determined at the time of original discovery. It is necessary to assume a typical field history in order to estimate production changes which will result from changes in new discoveries. A figure of first year production equal to about $3.65 \%$ of the original reserve estimate, and a doubling of that in the second year will be used (Davis August 1974).

To determine the impact of the incentives on the price of $0 i 1$, it is assumed that consumption is not affected by changes in domestic production. Therefore, a reduction in domestic production would be made up by imports at the higher import price. It was also assumed that the differential between the domestic wellhead price and refiner acquisition cost would not be affected.

The measured price change, therefore, will represent the change in refiner acquisition cost and will be the result of lower domestic output at a lower price and a compensating increase in crude imports at the higher world price. The results of these calculations are presented in a subsequent section.

\section{NON-PRICE AND QUANTITY IMPACTS}

Government incentives have had additional impacts, many of which are not readily quantifiable. This section will present a discussion of the degree to which incentives have impacted various economic, political, social and environmental factors. The impacts will generally be presented in qualitative terms, although quantitative estimates will be provided where possible.

(a) The data on these changes are taken from American Petroleum Institute American Gas Association, and Canadian Petroleum Association, (June 1978). 


\section{Competition}

An impact on competition is taken to mean an appreciable change in the competitive performance or structure of the petroleum industry. Examples are market concentration, vertical or horizontal integration, pricing behavior, barriers to entry, and degree of innovation. Several federal incentives have had an effect upon one or more of these factors.

The structure of the petroleum industry is characterized by a large number of firms at all levels of activity. At the extraction stage, the $0 i l$ and gas industries are virtually identical. There are thousands of firms engaged in drilling and production of $0 i l$ and/or gas. Over $80 \%$ are quite small, with fewer than 20 employees. These firms account for only $15 \%$ of the industry's total value added. There are few firms with over 500 employees $(0.4 \%)$, but they account for approximately $28 \%$ of value added. (These figures are provided in Table 7.5). By any standard, this is not a concentrated industry.

TABLE 7.5. $0 i 1$ and Gas Extraction (SIC 13) Number of Employees and Value Added, 1972 (Bureau of Census 1976b)

\begin{tabular}{|c|c|c|c|c|}
\hline \multirow{2}{*}{$\begin{array}{l}\text { Number of } \\
\text { Emp loyees }\end{array}$} & \multicolumn{2}{|c|}{ Establishments } & \multicolumn{2}{|c|}{ Value Added } \\
\hline & Number & $\%$ & Million \$ & $\%$ \\
\hline 0 to 4 & $14,084^{(a)}$ & 70.9 & $1,161.7^{(a)}$ & 6.5 \\
\hline 5 to 9 & 1,797 & 9.0 & 721.4 & 4.0 \\
\hline 10 to 19 & 1,583 & 8.0 & $1,010.1$ & 5.7 \\
\hline 20 to 49 & 1,476 & 7.3 & $2,222.1$ & 12.4 \\
\hline 50 to 99 & 514 & 2.6 & $2,158.7$ & 12.1 \\
\hline 100 to 249 & 255 & 1.3 & $2,434.6$ & 13.6 \\
\hline 250 to 499 & 101 & 0.5 & $3,200.5$ & 17.9 \\
\hline 500 to 999 & 37 & 0.2 & & \\
\hline 1,000 to 2,499 & 8 & - & $4,948.6$ & 27.7 \\
\hline 2,500 and above & 2 & - & & \\
\hline Total & 19,857 & 100 & $17,857.6$ & 100 \\
\hline
\end{tabular}

(a) Includes firms whose data were estimated from administrative records supplied to other agencies of the federal government-generally less than five employees. 
Domestic petroleum is transported primarily by pipeline (87\%), although tankers and barges (11\%) and truck and rail (2\%) are also used (Bureau of Competition May 1978, p. 17). The first stage of transportation is the gathering line. Except for the largest fields, normally only one gathering system exists for a field. These systems are usually common carriers and, thus, must serve anyone who purchases the oil in the field being served.

The gathering lines feed into trunk lines which are also normally regulated as common carriers by either a state or federal agency. These lines are required to carry all oil meeting specified standards. Thus, even where monopoly situations may occur, it is expected (at least in theory) that monopoly power is controlled by regulation. In this environment, industry structure is not a good indicator of market performance.

The refining sector contained 274 plants operated by 148 companies as of January 1, 1977. Many of these companies were quite small; only 22 owned more than 175,000 barrels per day capacity. Concentration levels, moreover, appear to be getting smaller. The percent of capacity controlled by the top 16 firms dropped from $79.8 \%$ in 1970 to $71.4 \%$ in 1977 (a) This can be partially attributed to the preference given small refiners by the entitlements program.

At the retail end of the petroleum industry, low concentration levels are the rule. Markets are local and can differ considerably from one location to another. Overall concentration levels are, therefore, quite meaningless. The existence of thousands of independent retail gasoline firms is evidence of a high level of competition.

Despite the apparent lack of substantial market concentration at each level of the petroleum industry, a substantial degree of vertical integration must be acknowledged. The major oil companies are all totally integrated and have market power beyond what the above discussion may imply. Furthermore, each of the major companies is a giant corporation when measured by absolute

(a) The figures are from Gordian Associates (January 1978, p. 32) while the data is from U.S. Bureau of Mines (1977 Annual Refinery Survey). 
size. Recent data ("The 500 Largest Industrial Corporations" May 7, 1979) place four petroleum firms among the largest six industrial companies, while 16 were in the top 50 .

Of all the incentives which have influenced the competitive structure or behavior of the petroleum industry, efforts to promote orderly markets have probably had the greatest impact. The Connally Hot $0 i 1$ Act and the Interstate $0 i 1$ Compact Commission together permitted state government control over all production, whether for intrastate or interstate sales in the name of preventing physical waste. (This also prevented economic waste.)

Prior to this, the market for crude oil was very volatile. Discovery of a new field would cause prices to drop precipitously. Competition became destructive as firms attempted to extract the oil as quickly as possible and this caused considerable physical waste. It also resulted in a high failure rate for oil producers.

These conditions were substantially changed by the conservation rules of the producing states. Stable prices were maintained by controlling output to match demand. In this way, market performance was altered without affecting the basic structure or competitive nature of the industry.

Other government actions have also had noticeable impacts. One is the current policy for leasing federal land. Sizeable advance bonus royalty payments are required. This increases the already high cost of exploratory drilling, especially offshore and, thus, favors large companies at the expense of smaller ones. Over a period of time, this would tend to increase concentration levels in the industry.

The Deepwater Ports Act provided funds for assisting the development of deepwater ports. Because only the large companies are petroleum importers, they receive the benefits from this incentive and thus have some competitive advantage.

There are two incentives which have probably provided marginally greater benefits to small firms. The first is the data collection and dissemination activities of the federal government. Smaller companies must place greater 
reliance upon free published data than large companies which can afford to conduct their own independent data collection. The availability of data puts all firms on a more equal basis in the quest for new discoveries.

The other incentive which may give somewhat greater benefit to small producers is stripper well pricing. This enables small wells to be operated profitably rather than to be shut down. Because small companies are likely to obtain a greater percentage of their production from strippers, this provides them with some competition advantage. It also provides an opportunity for producers who cannot afford off-shore or foreign operations.

Balance of Payments

The U.S. balance of payments deficit has increased tremendously in recent years. In 1977 , U.S. exports amounted to $\$ 120,576$ million, while imports totaled $\$ 151,706$ million for a net trade deficit of $\$ 31,130 \mathrm{million}$ (Council of Economic Advisors January 1979, p. 36). While there is no single cause for this imbalance, petroleum accounts for a large share of total imports. In 1977, crude oil and refined products together accounted for a net deficit of $\$ 40,443$ million (EIA May 1978a, p. 17). Given the magnitude of this figure, the importance of analyzing the influences that government incentives have upon the balance of payments is obvious.

The two incentives which have had the greatest impact are stripper well pricing and new oil pricing. Stripper wells have been essentially free of price controls while new oil has either been controlled at a much higher price then old oil or not at all. These measures have increased the benefits of producing these categories of domestic oil over what would exist if they were restricted to lower prices. This has increased domestic production and, thus, has had a favorable impact upon the balance of trade.

A significant portion of domestic production is from stripper wells (12\% to $15 \%$ ). If this oil were priced at the old oil level, a large share would be uneconomical to produce because of high operating costs. Most of this would be replaced by imports. 
New oil pricing encourages exploration to find additional reserves. Ultimately, this leads to greater production. The magnitude of this impact is impossible to determine with precision, largely due to complications introduced by the entitlements program. Because this program subsidizes the use of foreign oil by refiners at the expense of those refining domestic oil, the new oil incentive is partially negated. Drilling activity has nonetheless increased substantially with the increase in new oil prices. The number of exploratory wells drilled in the U.S. increased from 7,466 in 1973 to 9,961 in 1977 (EIA May 1978a, p. 71). Thus far, however, this has not lead to production increases, although output decreases have been ameliorated. This in turn has moderated imports and improved the balance of payments.

On the other hand, the low average price for oil in the U.S. due to price controls has made feedstock for petrochemicals cheaper than in Europe. This has improved the U.S. position with respect to exports of petrochemicals which have a higher value added than fuels, thus reducing the balance of payments problem. However, this has only partially compensated for America's larger fuel bill due to more expensive crude oil and product imports.

\section{Capital Formation}

A number of incentives have had a significant impact upon capital formation. This includes improved ability to obtain financing as well as actual changes in capital investment. Increases in capital formation ultimately lead to greater production as additional reserves are discovered.

The two tax preference items, percentage depletion allowance and expensing of intangible drilling costs, have had the greatest impact on capital formation. Percentage depletion allows deduction of a fixed percentage of revenues, normally an amount greater than actual costs. (a) This reduces the tax liability of oil producers and thus increases cash flow. This provides a substantial potential source of funds for investment in exploration and development. (b)

(a) It has been estimated that $87 \%$ of gross percentage depletion allowance deductions were (at $27.5 \%$ rate) in excess of the amount that would have been allowed under cost depletion (CONSAD Research Corporation 1968, pp. $5,11-13$ ).

(b) It has been estimated that the $27.5 \%$ depletion allowance is equivalent to a $33 \%$ investment tax credit (Brannon 1975, p. 11). 
Income Class

In some instances, incentives aimed at increasing production have had an especially noticeable impact upon a particular income class, for example, land owners. The petroleum incentives which have had such an effect are the percentage depletion allowance and expensing of intangible drilling costs.

The above tax preference items have provided additional cash flow to oil drillers as an incentive to increase exploration and production. This has had a beneficial effect upon the owners of land leased by the oil companies. Land owners benefit through increased royalty and related payments as leases are bid up by companies competing for potential reserves. It has been estimated that $40 \%$ of the value of petroleum tax benefits has been passed back to 1 and owners, which includes the federal government (Brannon 1974, p. 41). Stability

Extreme, abrupt changes in petroleum prices and/or outputs have occurred at times in history. These have caused similar changes in resource allocation often resulting in temporary (but substantial) waste and inefficiency. Several federal incentives have ameliorated this problem by controlling price and output levels within certain bounds.

In the 1920's and early 1930's, the petroleum industry was characterized by "boom or bust" conditions. Discovery of a large new field would be followed by rapid, haphazard development. Each firm owning lease rights would produce as much $0 i l$ as possible before the field was exhausted, usually resulting in plunging prices. This destructive type of competition led to high failure rates for small oil companies, and more importantly, a substantial amount of physical and economic waste.

To rectify this situation, several related measures were taken. Most producing states passed laws to establish and enforce petroleum conservation. To provide and encourage conservation through established state agencies, the Interstate $0 i 1$ Compact Commission was formed. Rules were established by the various producing states to control output which also had the effect of promoting stability. 
The actual impact upon investment in capital and additional lease holdings is the subject of much debate. Certainly, some of the benefits will be dissipated as higher royalty payments, lower crude prices, and higher company dividend payments.

Expensing intangible drilling costs in the year they are incurred, rather than being charged as acquisition costs of discovered reserves and recovered through depletion or depreciation, amounts to a tax-free loan from the government. This may also be compared to an investment tax credit. (a) The resulting increase in cash flow provides additional funds for acquisition of reserves in a manner similar to the percentage depletion allowance.

The combined impact of these two tax incentives has been described as follows. The higher after-tax return will encourage additional investment in reserves. Increased demand for leases will cause them to be bid up, with land holders consequently receiving larger royalties, which are estimated at $40 \%$ of the initial tax benefit. 0 il companies can increase their profits by $10 \%$ of the incentive because a superior bargaining position allows them to capture part of the rents which would otherwise accrue to the landowner. Finally, the remaining $50 \%$ of the incentive goes to crude $0 i 1$ price reductions, encouraging consumers to use more. It has been estimated that the tax incentives are equivalent to $20 \%$ of the price of crude $0 i 1$. This implies a $10 \%(0.20 \times 0.50)$ reduction in wellhead prices and a $3 \%$ increase in output (Brannon 1974, pp. 39-41). An equivalent impact upon drilling is expected.

Other incentives have caused an increase in the price of $0 i 1$ and therefore increased the flow of capital funds into the industry. Included are new oil pricing, promotion of orderly markets (Connally Hot 0 il Act and Interstate $0 i 1$ Compact Commission) and rate-of-return incentives for pipelines. To the extent that capital funds become more readily available, a commensurate increase in real capital investment also occurred.

(a) Expensing of intangible drilling costs has been estimated to be equivalent to a $13 \%$ investment tax credit (Brannon 1975, p. 11). 
Enforcement of conservation rules proved difficult due to the huge number of wells in production and the fact that production in violation of state regulations was often shipped across state borders and thus out of state jurisdiction. To control this practice, the federal government passed the Connally Hot 0 il Act in 1935. This effectively stopped interstate shipment of illegally produced oil and thus permitted the states to maintain effective controls.

To enable the states to set reasonable limits on output per well; reliable, accurate production and price data were required. The Bureau of Mines was instructed to gather and disseminate these data. It has been used by the states to set the allowable rate of production to match demand.

The immediate effect of conservation regulations was an increase in petroleum prices and a decrease in output. In the long run, however, just the opposite would be expected. By eliminating waste and extending the productive life of most of the wells, the total amount of output was raised and prices were kept down to some extent. For example, the price per barrel of crude 011 rose from $\$ 0.97$ in 1935 to $\$ 1.18$ by 1937 . The price then leveled off so that in 1941 it stood at $\$ 1.14$. Production from typical uncontrolled fields dropped to less than $10 \%$ of peak in less than 10 years, whereas most controlled fields averaged over $50 \%$ of peak 20 years after discovery.

In addition, the prospect of long-term stability at a reasonable price encouraged exploration efforts in new areas. This increased activity, after a time lag of several years to a decade, added to reserves and ultimately added to production.

After the early 1930's the U.S. did not again experience wide price fluctuations until the 1973 Arab oil embargo and its aftermath. To keep consumer prices from rising too rapidly, the price of domestic oil products and domestic crude oil production were placed under controls in 1972 during a period of rapid inflation. These were still in place when the OPEC price rise came. While preventing the general level of oil prices from rising quite as fast as import prices, the basic controls had the potential of causing some instability. With the rapidly rising costs of the mid-1970's, stripper well production would 
quickly become uneconomical at controlled prices. To prevent widespread abandonment of this capacity, stripper wells were exempted from the price controls placed on other old oil. To encourage exploration, new oil was allowed a higher price than old oil.

Another potential source of instability resulting from price controls is differential access by refiners to price-controlled old oil. If not rectified, refiners dependent on imported crude $0 i 1$ and the customers they served would have been at a severe cost disadvantage. The potential for disruption was removed by the Federal Energy Administration (FEA) entitlements program which largely equalized the cost of crude oil to refiners. This program particularly favored consumers in New England and the middle Atlantic states. Foreign Policy/National Security

The interrelationship between energy policy and foreign policy has become quite evident in recent years. A number of government actions directed toward the energy industry have had (or were intended to have) a noticeable impact upon foreign relations or national security. The more important ones are discussed below.

U.S. petroleum imports are currently approaching $50 \%$ of total domestic consumption. This dependency on foreign oil, especially from the Mideast, has significantly reduced national security, and this in turn has affected U.S. foreign policy. Government programs and actions to increase domestic oil production and thus lessen dependency upon imports are one result of this situation.

The two government programs which in recent years have had the greatest impact upon domestic oil production are stripper well pricing and new oil pricing. $0 i 1$ from stripper wells provides $12 \%$ to $15 \%$ of total U.S. production. Most of this would be uneconomical to produce at controlled old oil prices. By allowing the price of stripper oil to sell at the world market level, the need for additional imports is removed.

The price of new oil is also allowed to rise above the controlled old oil level. This is an incentive for exploration and development of new supplies. 
Without this incentive, domestic exploration would be substantially reduced. This would lead to even greater reliance upon foreign oil, with an obviously detrimental effect upon U.S. security.

The federal government has provided a number of incentives which have impacted the transportation of oil. These have influenced national security by strengthening domestic transportation capability. Included in this category are the following: 1) above the normal rate of return allowed (1921 to 1951) on pipeline investments to encourage expansion of the system, 2) U.S. Army Corps of Engineers construction and maintenance of inland waterways, 3) the Trans-Alaska Pipeline Authorization Act which speeded up construction of the Alaskan Pipeline, and 4) the Merchant Marine Act of 1970, which provided subsidies for the construction and operation of U.S. flagships engaged in international trade. By increasing U.S. petroleum transportation capability and flexibility, these measures have improved national security. An obvious example is the performance of the "Big Inch" and "Little Big Inch" pipelines constructed during World War II to carry crude oil from the Southwest to the East Coast.

A final incentive which needs to be mentioned in the context of foreign policy is the data collection activity of the U.S. Geological Survey. Knowledge of the nature of domestic resources is necessary to permit the government to deal effectively with internally and externally generated energy problems. It is impossible, however, to determine exactly how this knowledge has been utilized by energy and foreign policy makers.

\section{State/Federal Relations}

Some federal incentives have had an impact upon the jurisdiction or role of the federal government vis-a-vis the states. In a few cases this was intended while in others it was incidental. The more significant examples are described in this section.

Federal regulation of interstate petroleum pipelines was intended, in part, to reduce the multiplicity of local regulations which the companies had to follow. The Interstate Commerce Commission was given the role of issuing certificates which eliminated the need for state and local permits. This 
authority was transferred to the Department of Energy in 1977. The intended and actual result of federal control was to spur the development of the interstate petroleum pipeline system.

An area of contention between the federal government and the states has been off-shore leasing. In the early 1950's the federal government's title to off-shore oil out to the historic boundary was relinquished to the states. Although this was not intended as an incentive for production, it may have accelerated development, particularly off the Louisiana coast.

Previous sections have described federal involvement in petroleum pricing and output. In the 1930 's, federal actions exemplified by the Connally Act were aimed at assisting the states maintain effective conservation regulations. The cooperative nature of the state/federal regulations lasted until the 1970's. At that time, the FEA, followed by DOE, undertook to control prices and outputs as part of a national energy policy. As a result, much state control was preempted or became moot.

\section{Regulatory Burden}

The point at which compliance with government regulations becomes burdensome is largely a subjective judgement. It is evident, however, that the cost of complying with federal regulations has risen enormously in recent years. This higher cost of doing business is factored into the ultimate prices consumers are charged for petroleum products.

Recent federal regulation has almost exclusively been of an economic nature. Successive government agencies have developed a massive catalogue of rules and procedures, primarily aimed at keeping down the price of oil, and additional rules to counteract the negative effects of the initial rules. Numerous cases of noncompliance have been filed against oil companies. While no estimate of total compliance cost is available, it would have to be quite large, given the complex and changing nature of recent regulations. Quality of Life

Of all the federal petroleum incentives studied, leasing policy alone has been concerned with quality of life considerations. (Pollution controls on 
drilling, production, and refining the low polluting products and devices mandated have not been considered as incentives although they have had an inhibitory effect on investment for production and have required the use of extra processing energy.) Numerous environmental impact assessments have preceded leasing of additional government controlled property. This has been especially evident in the case of leasing on the outer continental shelf. The federal government has been extremely careful to protect these areas from possible environmental damage. In the case of the Alaska oil pipeline, environmental concerns delayed construction for about five years and increased transportion costs substantially.

THE IMPACT OF FEDERAL INCENTIVES ON THE PRICE AND OUTPUT OF OIL

The impacts of federal incentives upon domestic oil production and price are listed in Tables 7.6 and 7.7, respectively. The figures are not necessarily additive because combinations of incentives may either reinforce or counterbalance one another. The figures listed in the price category refer to 1977 composite (domestic and imported) refiner acquisition costs. Output represents cumulative (1950 to 1977) domestic crude production.

The incentive category with the largest impact upon the production of oil is taxation (see Table 7.6). The taxation category includes the impact of both the percentage depletion allowance and current deductibility of intangible

TABLE 7.6. An Estimate of the Results of Incentives Used to Stimulate 0 il Production (in quadrillion Btu)

\begin{tabular}{l} 
Incentive Area \\
\hline Taxation \\
Disbursements \\
Requirements \\
Traditional services \\
Nontraditional services \\
Market activity
\end{tabular}

Production Impact

26.62 (increase)

Negligible

2.30 (increase)

Negligible

Negligible

Negligible 
TABLE 7.7. An Estimate of the Results of Incentives Used to Stimulate 0il Production in Terms of Price (dollars per million Btu)

\begin{tabular}{lll}
\multicolumn{1}{c}{ Incentive Area } & & Price Impact \\
\cline { 1 - 1 } Taxation & & 0.213 (reduction) \\
Disbursements & & Negligible \\
Requirements & & 0.116 (increase) \\
Traditional services & Negligible \\
Nontraditional services & Negligible \\
Market activity & Negligible
\end{tabular}

drilling costs. The percentage impact of these tax preference items, as determined in the earlier section, was applied to cumulative domestic oil production during the 1950 to 1974 period when these tax items were in effect. The resulting figure was then compared to 1950 to 1977 cumulative production to determine the impact over the entire study period. A $2.7 \%$ to $8.9 \%$ or a 12.4 to 40.8 quad increase in domestic oil production was calculated. Taking a simple average of the impact range yields approximately 26.6 quads of production which can be attributed to petroleum taxation incentives.

The second incentive category with a significant impact upon the production of oil consists of stripper well and new oil pricing requirements. These incentives were in effect for only the last four years of the study period, yet they had a significant impact. If oil produced from stripper wells had been priced at the old oil price, a $15 \%$ to $25 \%$ decline in production would have resulted because of the high costs of stripper production. The new oil pricing provision directly impacts exploration and discovery of new reserves and consequently has a lagged impact on production. This incentive was initiated in 1974 and little effect on production was noticeable by 1977. Applying the combined effect of these incentives over the entire 1950 to 1977 period yields an estimated $0.4 \%$ to $0.6 \%$ or 1.8 to 2.8 quads increase in domestic oil production. On the average then, approximately 2.3 quads of oil production can be attributed to these incentives.

The same incentive categories that significantly affected output (taxation and requirements) also affected price. The estimates of the price effects of 
the percentage depletion allowance and current deductibility of intangible drilling costs taken from the earlier section were applied to the 1977 domestic refiner acquisition cost and then combined with the cost of imported oil to determine the overall impact. Because tax preferences were eliminated for large producers in 1975, the estimated impact represents what would have occurred had the incentives remained in effect. The calculated reduction in price of between $5.6 \%$ and $13.9 \%$ is based on the estimated free market price, not the controlled price which existed in 1977. Thus, taxation incentives have prompted an average price reduction of $21.3 \phi$ per million Btu.

Requirements, the incentive category consisting of stripper well and new oil pricing, had a positive impact on production by providing for higher prices. However, higher prices for crude oil means higher acquisition costs for the refiners. It is estimated that refiner acquisition costs in 1977 would have been $5.0 \%$ to $5.7 \%$ lower had stripper well and new oil prices been controlled. Hence, the impact of stripper well and new oil pricing provisions was to increase price by an average of $11.6 \notin$ per million Btu.

All other federal oil incentives have had a negligible effect on the price and output of petroleum. These incentives include disbursements such as tanker subsidies, traditional services such as port and waterway maintenance, nontraditional services such as research and development, and market activities such as land leasing.

\section{CONCLUSIONS}

Incentives provided by the federal government to stimulate the production of oil have amounted to over $\$ 100$ billion and created a significant impact on several factors. A summary of the impact of federal oil incentives based on the typology of incentive impacts identified in Chapter 2 is presented in Table 7.8.

Of the 10 incentive types listed, stripper well and new oil pricing provisions affected the largest number of items. These two incentives stimulated the output of oil while prompting the price of oil to rise. They also enhanced the stability of the industry and, by promoting increased domestic production, 
TABLE 7.8. Summary of Impact of $0 i 1$ Incentives

\begin{tabular}{|c|c|c|c|c|c|c|c|c|c|c|}
\hline Impacts & $\begin{array}{l}\text { Stripper } \\
\text { We11 } 0 i 1 \\
\text { Pricing } \\
\end{array}$ & $\begin{array}{l}\text { Depletion } \\
\text { Allowance }\end{array}$ & $\begin{array}{l}\text { New } 0 i 1 \\
\text { Pricing }\end{array}$ & $\begin{array}{l}\text { Intangible } \\
\text { Orilling } \\
\text { Costs } \\
\end{array}$ & $\begin{array}{l}\text { Transportation } \\
\text { Incentives }\end{array}$ & $\begin{array}{c}\begin{array}{c}\text { Research } \\
\text { and } \\
\text { Development }\end{array} \\
\text {. }\end{array}$ & $\begin{array}{l}\text { Leasing } \\
\text { Policy }\end{array}$ & $\begin{array}{c}\text { Data } \\
\text { Gathering }\end{array}$ & $\begin{array}{c}\text { FEA } \\
\text { (nOW DOE) }\end{array}$ & $\begin{array}{l}\text { Promotion } \\
\text { of Orderly } \\
\text { Markets }\end{array}$ \\
\hline \multicolumn{11}{|l|}{ Economic Factors } \\
\hline $\begin{array}{l}\text { Compet it ion versus } \\
\text { monopoly }\end{array}$ & M & $\mathrm{I}$ & $\mathrm{I}$ & I & M & I & M & M & I & $L$ \\
\hline Sectoral impacts & I & I & I & I & I & I & I & I & I & I \\
\hline Sectorial subsidies & I & I & I & I & I & I & I & I & I & I \\
\hline Income class & I & $\mathrm{L}$ & I & L & I & I & I & I & I & I \\
\hline Capital formation & I & L & L & $L$ & L & I & I & I & I & L \\
\hline Price/Quantity & $\mathrm{L}$ & $\mathrm{L}$ & L & L & N & N & N & N & N & I \\
\hline Inflation & I & I & I & I & I & I & I & I & I & I \\
\hline $\begin{array}{l}\text { Employment/ } \\
\text { Productivity }\end{array}$ & I & I & I & I & I & I & I & I & I & I \\
\hline $\begin{array}{l}\text { Ba lance of } \\
\text { payments }\end{array}$ & L & I & L & I & I & I & I & 1 & I & I \\
\hline \multicolumn{11}{|l|}{ Political Factors } \\
\hline $\begin{array}{l}\text { Foreign policy/ } \\
\text { Nat. Security }\end{array}$ & $\mathrm{L}$ & I & L & I & M & I & I & y & I & I \\
\hline Stability & $L$ & I & $L$ & 1 & ! & I & I & M & $\mathrm{L}$ & L \\
\hline \multicolumn{11}{|l|}{$\begin{array}{l}\text { Organ ization/Lega } 1 \\
\text { Factors }\end{array}$} \\
\hline $\begin{array}{l}\text { State/Federal } \\
\text { relations }\end{array}$ & I & I & I & I & M & I & M & I & M & L \\
\hline Public/Private & I & I & I & I & I & I & 1 & I & I & I \\
\hline Regulatory burden & I & I & [ & I & I & I & I & I & M & I \\
\hline Quality of Life & I & I & I & I & I & I & M & I & I & I \\
\hline Demographics & I & I & I & I & I & I & I & I & I & I \\
\hline
\end{tabular}


had a favorable balance of payments and foreign policy/national security effects. Allowing a higher price for stripper well output enabled these wells to stay in production, thus enhancing the competitive structure of the industry. New oil pricing provisions also stimulated the search for new oil which resulted in a favorable impact on the level of capital formation.

Taxation incentives, the percentage depletion allowance and deductibility of intangible drilling costs, had significant effects also. These incentives stimulated a large increase in output and had a depressing effect on the price of oil. By lowering the tax liability of oil producers, these incentives increased the cash flow which in turn provides additional funds for capital formation. A large impact on income distribution is also noted because a portion of the tax preference benefits were estimated to be passed back to resource owners in the form of higher royalty payments.

The remaining incentive with a large set of impacts concerns activities aimed at promoting orderly markets. The Interstate 011 Compact Commission and the Connally Hot $0 \mathrm{il}$ Act are included in this category. These incentives had a major positive impact on the stability and competitive structure of the petroleum industry which consequently increased the level of capital formation. These activities also enhanced the cooperative nature of state/federal relations.

Impacts associated with the remaining incentives have been somewhat smaller. Transportation incentives were determined to have negligible impacts on the output and price of oil. These incentives did, however, adversely impact the competitive characteristics, stimulate capital formation, and improve foreign policy/national security considerations as well as enhancing state/federal relations. The Federal Energy Administration (now the Department of Energy) had negligible effects on price and output. The FEA improved stability, modified state/federal relations, and increased the regulatory burden. Data gathering activities have had negligible effects on price and quantity, have enhanced the competitive structure and stability of the industry, and have affected foreign policy/national security factors. Federal leasing policies 
have negligibly affected price and quantity, have adversely affected the competitive structure, and have improved the quality of life concerns and state/ federal relations. Federal research and development activities have as yet made no significant impact.

\section{RECOMMENDATIONS FOR SOLAR POLICY}

Before one can determine whether incentives used to stimulate oil production are applicable in the area of solar energy, it is necessary to be fully aware of the differences between the two energy forms. Solar energy is a renewable resource, whereas the use of oil depletes the stock. The vast amount of oil is found in relatively concentrated areas, often at great distances from its point of consumption. Solar energy is dispersed and is plentiful in most areas. The production of oil requires a huge capital investment. Solar energy can be utilized with a relatively small investment in equipment. The development of oil resources has been undertaken almost entirely by private industry. Initial solar developments have received primary impetus from government programs.

Because of these and other differences between oil and solar energy, a particular incentive is unlikely to produce precisely the same result in each area; however, some general principles can be discovered and then applied to solar energy. The largest and most significant incentives for the oil industry have been the percentage depletion allowance and the expensing of intangible drilling costs. These incentives increased the expected after-tax return to the oil investor and made the oil business more attractive. The improved profitability which resulted from these tax incentives provided a boost to further exploration and, ultimately, production.

Tax incentives can also be applied to solar energy. The federal government currently provides credits for the installation of solar equipment. Special investment tax credits on capital intensive processes, such as ocean thermal energy conversion (OTEC), would provide an incentive similar to those in the oil industry. Special tax treatment for both the manufacturer of solar equipment and the purchaser/consumer would be appropriate. Tax incentives can serve to increase the potential return on both the use and sale of solar equipment in order to overcome the apparent risk and uncertainty of solar investments. 


\section{CHAPTER 8}

NATURAL GAS

William J. Sheppard, Fuels Analyst David E. Lenerz, Energy Economist 


\section{NATURAL GAS}

INTRODUCTION

In 1977, over 19.6 quadrillion Btu (quads) of natural gas was consumed in the United States, second only to petroleum in total consumption. Natural gas (including liquids) was the largest single source of domestically produced energy, accounting for approximately 21.8 quads, slightly over one third of the nation's total energy production (EIA May 1978a, p.3). The role of gas has expanded substantially over the past three decades, as both consumption and production quadrupled. Part of this increase can be attributed to production incentives provided by several federal government actions.

A previous study (Cone et al. December 1978) has catalogued and tabulated these incentives. A sumary is provided in Table 8.1. The total value (1977\$) of the incentives provided for natural gas production over the 1950 to 1977 period is $\$ 16.5$ billion or $7.6 \%$ of the total incentives provided to the major energy forms. This amounts to a subsidy of $3.5 \$$ per million Btu.

Nearly the total amount (97\%) of these incentives have been provided in the form of tax preferences--expensing intangible drilling costs and the percentage depletion allowance. During the 1950 to 1977 period, this amounted to a $\$ 16$ billion revenue equivalent. These benefits have of ten been shared with petroleum since the two products are frequently jointly developed and produced.

Other incentives include data collection and dissemination by the Bureau of Mines and Geological Survey and Bureau of Land Management leasing activities. These services have been relatively minor sources of incentives, totaling $\$ 0.4$ billion over the study period.

The Federal Power Commission (now the Federal Economic Regulatory Commission) has also been a source of incentives. It has provided services, such as pipeline regulation, which have assisted the development of natural gas. One FPC action, however, has in recent years become a net disincentive. Well-head price controls have kept prices substantially below unregulated intrastate prices. This has caused a reduction in the supply of gas and therefore is listed as a negative incentive (disincentive). The net value of this incentive amounts to negative $\$ 170$ million. 
TABLE 8.1. Summary of Natural Gas Incentives by Type (in Millions of $1977 \$$ ) (Cone et al. December 1978, p. 241)

Incentive frea From 0 il Chapter

Geological Survey-data

Bureau of Land Managementleasing

Bureau of Mines-data

Intangible drilling

expensing

Percentage depletion allowance

Well-head Price Control

Federal Power Commission Regulation

Subtotal

TOTAL $=6,503$
Traditional Taxation Disbursement Requirements

Services

Nontrad.

Services Activity

$$
4,066
$$$$
11,980
$$

$-170$

288

16,046

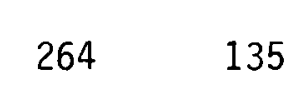


Whether measured as a total figure or on a per Btu basis, the amount of incentives provided for natural gas production is relatively small compared to petroleum incentives, although it is somewhat larger than coal incentives. The removal of well-head price controls will eliminate a major disincentive which currently exists, the net effect of which cannot yet be estimated.

Having made dollar estimates of historical natural gas incentives, an analys is of their effect is required. The following sections will discuss the impacts of federal incentives upon price and quantity of production as well as a number of other less quantifiable factors. The first section contains a discussion of the relationship between the historical value of incentives and the quantity of natural gas production.

\section{NATURAL GAS PRODUCTION AND FEDERAL INCENTIVES}

Each type of federal incentive has impacted natural gas production in a somewhat different manner. Some incentives, such as the depletion allowance, have acted directly to increase production. The impacts of others, such as data collection and dissemination, have worked in a more roundabout way. Moreover, the composition of total natural gas incentives has changed as some federal programs have been enlarged while others have been phased out over time. As a result of these and other complications, an analys is of the effect of the total amount of incentives over time is not likely to disclose true casual relationships. Nevertheless, the trends in natural gas production and federal incentives do provide an interesting comparison.

Annual incentives and production levels are displayed in Figure 8.1 and Table 8.2. As can be seen, annual natural gas production increased rather un iformly from 1950 until it reached a peak in 1971. From that point it started to decline so that by 1977 it had fallen $11.7 \%$ from its high point six years earlier. Some of the decline can be attributed to a reduction in $0 i l$ production since frequently the two products are jointly explored for and produced. Thus, the decline in domestic oil exploration has had an indirect effect of reducing gas discoveries.

Over the same time period, federal incentives followed a somewhat similar pattern. The value of incentives steadily increased from 1950 to 1961. Except 


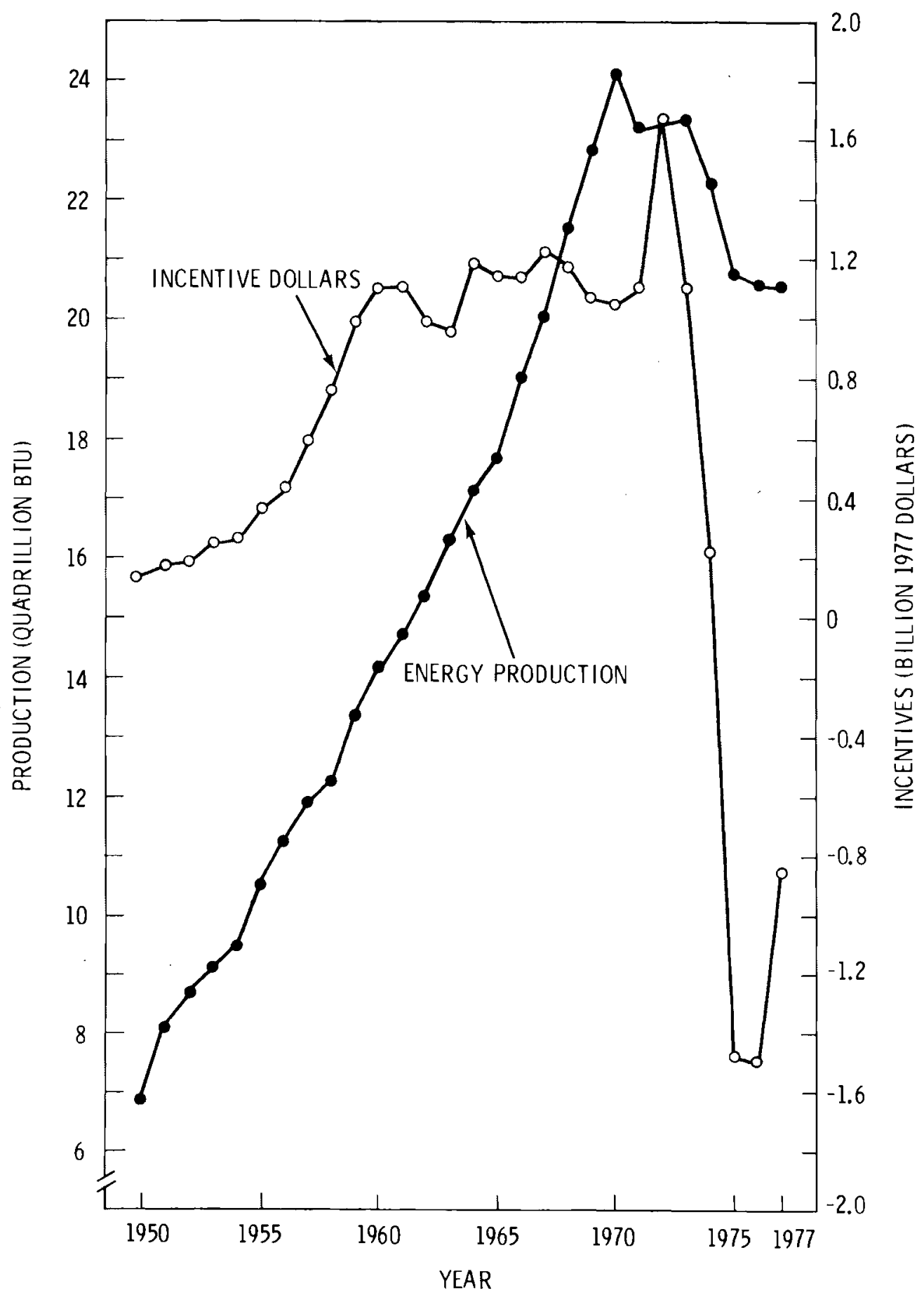

FIGURE 8.1. Natural Gas: Annual Production and Incentives 
TABLE 8.2. Annual Natural Gas Production and Federal Incentives

\begin{tabular}{|c|c|c|}
\hline Year & $\begin{array}{c}\text { Production (a) } \\
(1012 \mathrm{Btu}) \\
\end{array}$ & $\begin{array}{l}\text { Incentives (b) } \\
\left(10^{6} 1977 \$\right)\end{array}$ \\
\hline 1977 & 21,907 & $-(857)$ \\
\hline 1976 & 21,827 & $-(1,499)$ \\
\hline 1975 & 22,019 & $-(1,481)$ \\
\hline 1974 & 23,696 & $-(426)$ \\
\hline 1973 & 24,754 & 1,103 \\
\hline 1972 & 24,785 & 1,674 \\
\hline 1971 & 24,805 & 1,109 \\
\hline 1970 & 24,154 & 1,055 \\
\hline 1969 & 22,838 & 1,076 \\
\hline 1968 & 21,548 & 1,181 \\
\hline 1967 & 20,087 & 1,233 \\
\hline 1966 & 18,984 & 1,149 \\
\hline 1965 & 17,652 & 1,152 \\
\hline 1964 & 17,138 & 1,188 \\
\hline 1963 & 16,271 & 953 \\
\hline 1962 & 15,365 & 983 \\
\hline 1961 & 14,691 & 1,014 \\
\hline 1960 & 14,135 & 1,109 \\
\hline 1959 & 13,361 & 985 \\
\hline 1958 & 12,244 & 761 \\
\hline 1957 & 11,885 & 584 \\
\hline 1956 & 11,252 & 436 \\
\hline 1955 & 10,532 & 362 \\
\hline 1954 & 9,488 & 247 \\
\hline 1953 & 9,116 & 236 \\
\hline 1952 & 8,705 & 193 \\
\hline 1951 & 8,106 & 172 \\
\hline 1950 & 6,841 & 141 \\
\hline
\end{tabular}
(a) The 1950 to 1971 production is from EIA (May 1978a, p. 3), and the 1972 to 1977 production is EIA (January 1979, p. 4).
(b) Incentives are from Cone et al. (December 1978, Chapter VIII).

for 1972, the annual total fluctuated around the 1961 level for the next 12 years. This was followed by a plunge in 1974 which has resulted in total incentives taking on negative values for the past few years. 
There is no simple relationship between these two time series. The annual incentives value has been dominated by two components: we11-head price controls and tax benefits. The latter has increased rather steadily throughout this period. The former has actually become a net disincentive over the past few years. This undoubtedly contributed significantly to the downward trend in domestic natural gas production. A comparison of the trends is depicted in Figure 8.1. The precise relationship however, is much more complex and is influenced by many other variables.

Because the response to many incentives may lag behind the time when they are received, a one-to-one correspondence between annual incentives and production does not exist. This aspect of the relationship may be brought out by a display of cumulative production and incentives. This has been done in Figure 8.2 and Table 8.3. The correspondence between the two variables is again demonstrated, although in a somewhat different manner. A precise causal relationship, however, is still yet to be identified.

\section{NATURAL GAS PRICE AND FEDERAL INCENTIVES}

Incentives aimed at increasing domestic gas production are likely to have additional impacts, some intended, some coincidental. A major impact upon the price of natural gas is to be expected; indeed, it is the primary objective of one major federal action, well-head price controls. To the extent that the various incentives have been successful in increasing production, a commensurate impact on price will occur.

The comparison between the average well-head price of natural gas and annual and cumulative incentives are displayed in Figures 8.3 and 8.4 and Table 8.4. It is difficult to discern a consistent relationship between the two variables thrcughout the entire period. As opposed to 0i1, most natural gas is sold via long-term contract and, therefore, is not available to the current market. Thus, at any given point in time, the average price of gas will be below the current price, perhaps substantially. The last few years do demonstrate an inverse relationship between price and production incentives. Given the fact that the sharp downward swing in incentives was due to well-head 


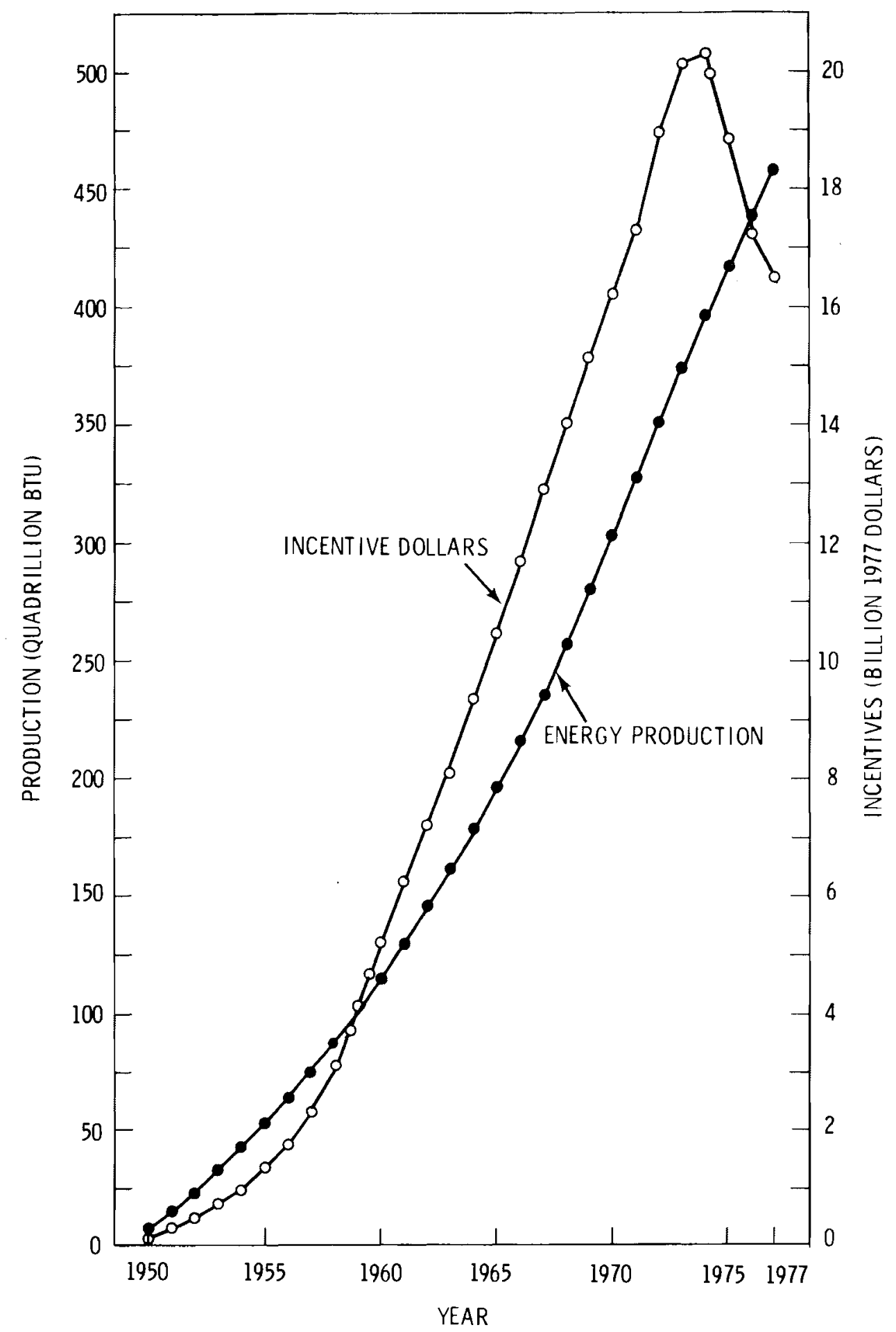

FIGURE 8.2. Natural Gas: Cumulative Production and Incentives 
TABLE 8.3. Cumulative Natural Gas Production and Federal Incentives (a)

\begin{tabular}{|c|c|c|}
\hline Year & $\begin{array}{l}\text { Production } \\
\left(10^{12} \mathrm{Btu}\right)\end{array}$ & $\begin{array}{l}\text { Incentives } \\
(106 \quad 1977 \$) \\
\end{array}$ \\
\hline 1977 & 468,186 & 15,833 \\
\hline 1976 & 446,279 & 16,690 \\
\hline 1975 & 424,452 & 18,189 \\
\hline 1974 & 402,433 & 19,670 \\
\hline 1973 & 378,737 & 20,096 \\
\hline 1972 & 353,983 & 18,993 \\
\hline 1971 & 329,198 & 17,319 \\
\hline 1970 & 304,393 & 16,210 \\
\hline 1969 & 280,239 & 15,155 \\
\hline 1968 & 257,401 & 14,079 \\
\hline 1967 & 235,853 & 12,898 \\
\hline 1966 & 215,766 & 11,665 \\
\hline 1965 & 196,782 & 10,516 \\
\hline 1964 & 179,130 & 9,364 \\
\hline 1963 & 161,992 & 8,176 \\
\hline 1962 & 145,721 & 7,223 \\
\hline 1961 & 130,356 & 6,240 \\
\hline 1960 & 115,665 & 5,226 \\
\hline 1959 & 101,530 & 4,117 \\
\hline 1958 & 88,169 & 3,132 \\
\hline 1957 & 75,925 & 2,371 \\
\hline 1956 & 64,040 & 1,787 \\
\hline $\begin{array}{l}1955 \\
1954\end{array}$ & 52,788 & 1,351 \\
\hline $\begin{array}{l}19 \\
19\end{array}$ & $\begin{array}{l}42,256 \\
32,768\end{array}$ & 989 \\
\hline $\begin{array}{l}195 \\
195\end{array}$ & $\begin{array}{l}32,768 \\
23,65 ?\end{array}$ & $\begin{array}{l}742 \\
506\end{array}$ \\
\hline 19 & $\begin{array}{l}23,652 \\
14,947\end{array}$ & $\begin{array}{l}506 \\
313\end{array}$ \\
\hline 195 & 6,841 & 141 \\
\hline
\end{tabular}

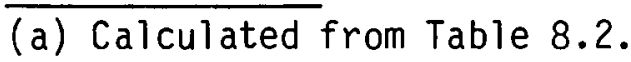

price controls, however, this may seem somewhat contradictory. The price has been free to rise rapidly, though, because not all production is subject to price controls. Notably, intrastate sales have been exempt. This has encouraged more and more producers to sell in intrastate markets rather than in the price controlled interstate market. Interstate sales have fallen from a high of $63.8 \%$ of the total market in 1969 to $59.0 \%$ in 1973, the last year average interstate prices exceeded the intrastate figure. The percentage has continued to fall, reaching 54.8\% in 1977. During the same 1969 to 1977 time period, 


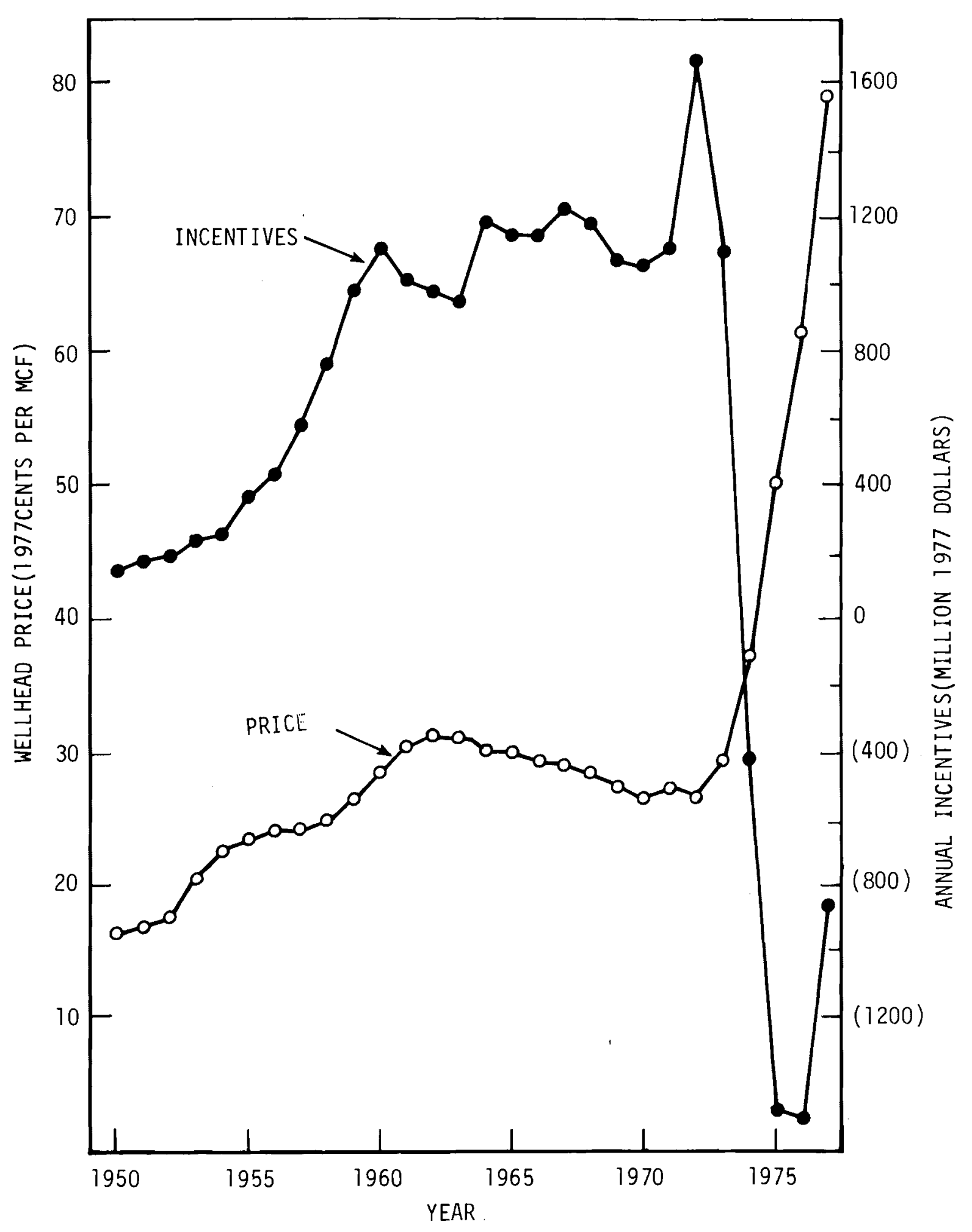

FIGURE 8.3. Natural Gas Prices and Annual Incentives 


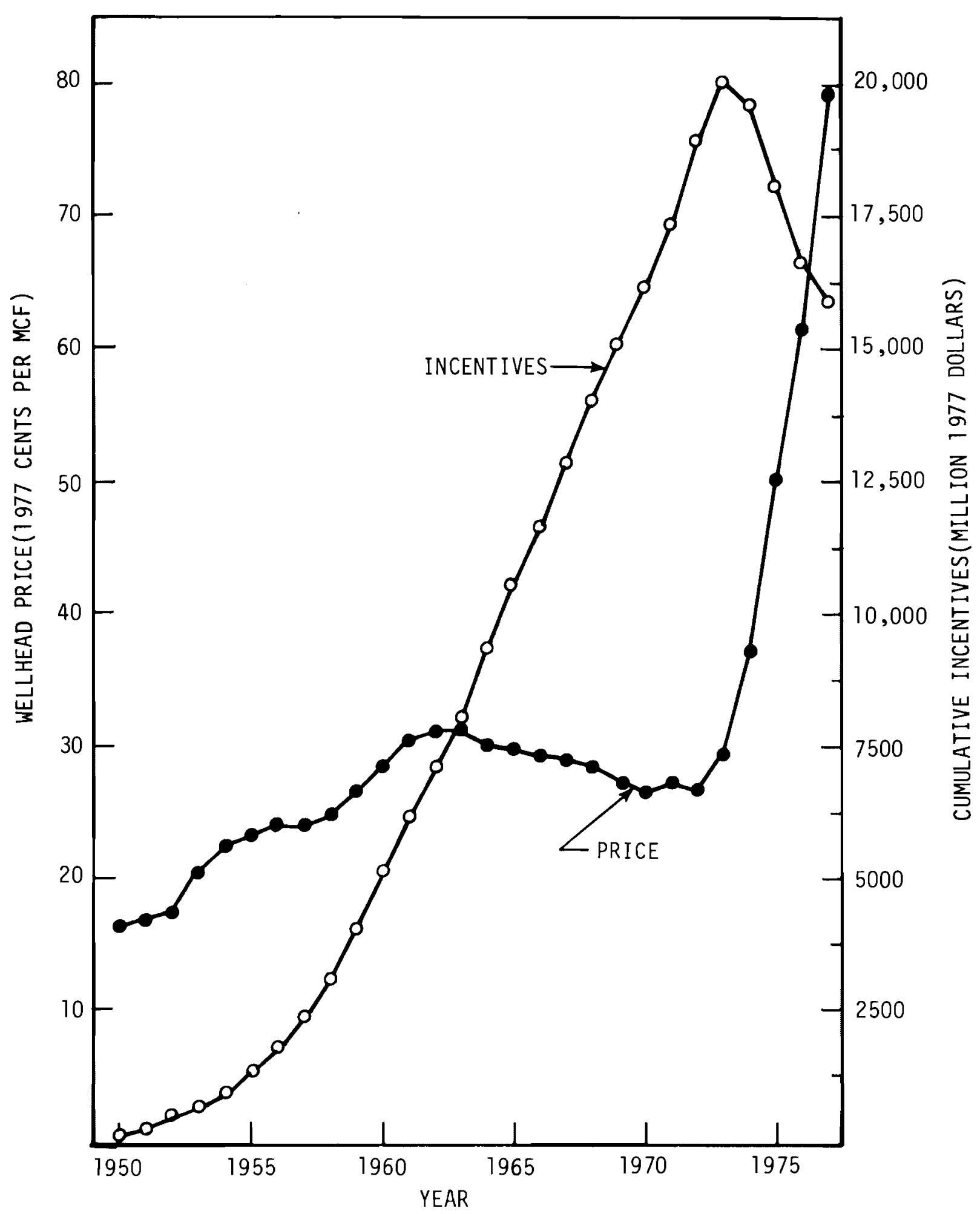

FIGURE 8.4. Natural Gas Prices and Cumulative Incentives 
TABLE 8.4. Natural Gas Price and Federal Incentives

\begin{tabular}{|c|c|c|c|}
\hline Year & $\begin{array}{l}\text { Well-head Price(a) } \\
(1977 \$ / M C F) \\
\end{array}$ & $\begin{array}{c}\text { Annual } \\
\text { Incent ives (b) } \\
\left(10^{6} 1977 \$\right) \\
\end{array}$ & $\begin{array}{l}\text { Cumulative } \\
\text { Incentives (b) } \\
\left(10^{6} 1977 \$\right) \\
\end{array}$ \\
\hline 1977 & 79.1 & $-(857)$ & 15.833 \\
\hline $\begin{array}{l}1976 \\
\end{array}$ & 61.4 & $-(1,499)$ & 16,690 \\
\hline 1975 & 50.1 & $-(1,481)$ & 18,189 \\
\hline 1974 & 34.4 & $\begin{array}{l}-(426) \\
-\end{array}$ & 19,670 \\
\hline 1973 & 29.5 & 1,103 & 20,096 \\
\hline 1972 & 26.9 & 1,674 & 18,993 \\
\hline 1971 & 27.2 & 1,109 & 17,319 \\
\hline 1970 & 26.7 & 1,055 & 16,210 \\
\hline 1969 & 27.6 & 1,076 & 15,155 \\
\hline 1968 & 28.6 & 1,181 & 14,079 \\
\hline 1967 & 29.0 & 1,233 & 12,898 \\
\hline 1966 & 29.3 & 1,149 & 11,665 \\
\hline 1965 & 30.0 & 1,152 & 10,516 \\
\hline 1964 & 30.1 & 1,188 & 9,364 \\
\hline 1963 & 31.3 & 953 & 8,176 \\
\hline 1962 & 31.1 & 983 & 7,223 \\
\hline 196 & 30.6 & 1,014 & 6,240 \\
\hline 1960 & 28.6 & 1,109 & 5,226 \\
\hline 195 & 26.8 & 985 & 4,117 \\
\hline 195 & 24.9 & 761 & 3,132 \\
\hline 195 & 24.3 & 584 & 2,371 \\
\hline 19 & 24.1 & 436 & 1,787 \\
\hline & 23.5 & 362 & 1,351 \\
\hline & 22.8 & 247 & 989 \\
\hline & 20.6 & 236 & 742 \\
\hline & 17.8 & 193 & 506 \\
\hline 10 & 17.0 & 172 & 313 \\
\hline 195 & 16.4 & 141 & 141 \\
\hline
\end{tabular}

(a) Figures were calculated using data from EIA (May 1978a, p. 59) and 1977 price data from EIA (January 1979).

(b) From Table 8.2 and Table 8.3.

the price of intrastate gas went from $2.2 \$$ per thousand cubic feet (MCF) below interstate price to $23.24 / \mathrm{MCF}$ above it. Thus, even though the price ceiling has been raised significantly, it has not kept pace with the market price. (The Natural Gas Policy of 1978 will change these relationships in the future.) In addition to the impact of federal incentives, the price of natural gas depends upon many other variables. On the supply side, exploration, development, and production costs are the primary determinants. These have all 
increased tremendously over the past few years. Looking at demand, a multitude of factors are important. Notably, in recent years, the rapid increase in the prices of substitutes, primarily oil and electricity, has kept the relative price of natural gas attractive to consumers. In addition, the lack of sulfur oxide pollution from gas use has made it more attractive relative to high sulfur residual fuel oil and coal. These factors have tended to increase demand. All other variables have also been changing and thus exerting varying degrees of influence over the price. Therefore one should not expect a simple relationship between prices and federal incentives. Approaches to isolate the impact of incentives on both price and quality are discussed in the next section.

\section{EVALUATING THE EFFECTS OF FEDERAL INCENTIVES}

The total amount of federal natural gas incentives over the 1950 to 1977 period was $\$ 16.5$ billion measured in $1977 \$$. Almost all of this $(\$ 16.0$ billion) was in the form of the percentage depletion allowance and current expensing of intangible drilling costs. The impact of these tax preferences on gas production and price would have been practically the same as their effect on oil, other things being equal. Other things were not equal, however, in that well-head price controls were placed on gas production starting about 1960 (following the 1954 Supreme Court decision). The impact of tax preference items has been substantial and has at least partially negated the effect of the price controls. Other federal incentives have also played a role, but their impact is considered too small to be measured.

Tax preferences increase the cash flow available to gas producers for future investment. This ultimately leads to an increase in gas production and a reduction in price. The existence of price controls, however, tends to counteract these impacts. If the price is set too low, the incentive for additional investment will be removed altogether.

Most studies have determined that the absence of a free market has actually eliminated most, if not all, of the potential impact of natural gas 
tax preferences. An example is the FEA Project Independence Blueprint, (a) which concluded that an increase or decrease in percentage depletion of $3 \%$ from then existing $22 \%$ rate would cause virtually no change in reserves. A relatively minor price change of $2 \$ / M C F$ would occur. This assumes continued price controls. These figures are used to estimate the impact of tax preferences in a price control situation.

The impact of price control itself can be estimated by comparing the interstate controlled price with the intrastate market price. It is the price of new gas, or the marginal price, which is the relevant variable. Data limitations, however, restricted the comparison to average annual prices. The point in time (1974) when the average intrastate price first exceeded the average interstate price occurred after the time when the respective marginal prices crossed. This lag, however, is roughly matched by the lag between a well-head price change and a change in output. This can be demonstrated by observing that the impact of price controls on reserves occurred much sooner than the impact on gas production. (Domestic natural gas reserves peaked in 1967 while production continued to climb until 1971 to 1973). Thus, the use of average price rather than marginal price to estimate output changes is considered to be acceptable.

In keeping with previous conclusions, a controlled interstate price above the intrastate price is considered an incentive for additional production in the year under consideration while the opposite is considered a disincentive. A calculation was made to determine the responsiveness of a change in the average well-head price to a change in total production. (b) The resulting factor was applied to the annual price differential between controlled and uncontrolled gas prices to determine each year's potential change in output. A range of values was established to cover uncertainties in the calculations. The results are provided in a subsequent section.

(a) These results are summarized in Mathematica, Inc. (February 1977, pp. III 47-86).

(b) Estimated from data provided in American Gas Association (May 27, 1977) and EIA (April 1978b, pp. 155-175). 
NONPRICE AND QUANTITY IMPACTS

In addition to price and quantity impacts, federal natural gas incentives have had several other significant effects. The more important ones will be reviewed in this section.

\section{Competition}

At the extraction stage, the gas and oil industries overlap to a great extent. The structure of the $0 i 1$ and gas extraction industry (SIC 13) is characterized by thousands of very small firms and a few 1 arge ones. In 1972, over $80 \%$ of the 19,857 establishments covered by the Federal Census had fewer than 20 employees (Bureau of the Census 1976b, pp. 1-96). Only the 47 largest establishments, accounting for $28 \%$ of the total industry value added, had more than 500 employees. This is not considered to be a highly concentrated industry.

A comprehensive study of the total gas industry, from production to consumption, has been made by the Federal Power Commission (FPC 1973a). Over 100 interstate pipeline transmission companies and 1,600 distribution companies are involved in gas transportation. Some vertical integration does exist, but it is not the dominant pattern. Horizontal integration at both the production stage (primarily oil) and at the distribution stage (primarily electricity) are common. Over the past few years, integration of the vertical type has increased. This has primarily consisted of the entry of pipeline companies, and even some distribution companies, into exploration and development as a response to curtailment by their normal suppliers. Although, it has been stated that "there do not appear to be any substantial economies of scale associated with exploring for or producing natural gas (FPC 1973c, p. 58), the ability of a firm to withstand risk and the absolute cost of doing business can be barriers to entry. This is especially evident for offshore exploration. Small firms normally cannot compete for offshore leases because of federal leasing policy. The large advance bonus royalty payments normally required increase the cost and the risk of offshore drilling. This tends to preempt small companies from this growing segment of the business. (To counteract this, some of the gas companies have participated in consortiums with big oil companies that bid jointly for leases.) 
Another government action which has historically had a large impact upon industry competitiveness is FPC regulation of interstate pipelines. Prior to regulation, development of natural gas pipeline systems was sluggish. Small producers were unsure of a market for the gas, and thus it often went unused. By assuring access to markets at a regulated transportation cost, the FPC was able to reduce risk for producers. This contributed substantially to the development of the natural gas industry and helped put all gas producers on an even competitive footing. It also made financing easier, an important factor for pipeline companies.

Two other federal incentives have had a small impact and will be briefly mentioned. The data gathering activities of the U.S. Geological Survey have tended to give somewhat greater benefit to small producers who may rely on published data to a greater extent than large companies. Well-head price controls have probably worked in the opposite direction, toward reducing the number of companies in the business. Price controls have substantually reduced the incentive to explore for new gas reserves. Because, the most risky segment of the industry is wildcat drilling, it has been most adversely affected. This has had the greatest impact upon the smaller companies, which do a disproportionate share of wildcat drilling.

\section{Balance of Payments}

In 1977, the United States imported a net 959 trillion Btu of natural gas (EIA May 1978a, p. 9). This contributed $\$ 1,825$ million (EIA May 1978a, p. 17) to the nation's balance of payments deficit, a relatively small amount (4.6\%) of the total energy trade deficit. While the quantity of gas imports has not changed much in recent years, the value has increased substantially as unit costs have soared.

Government incentives which have strongly affected domestic production also have tended to influence gas imports and exports. The impact has not been very large, however, since there are close energy substitutes for most uses of natural gas. This partially accounts for the lack of increased gas imports even though large shortages have occurred in recent years. (Delay in regulatory approvals has also helped to keep imports down.) 
The major natural gas production incentives, percentage depletion and expensing of intangible drilling costs, have had a positive effect upon the U.S. balance of payments. It is not possible to quantify this impact, however, since it has been quite minor.

Contributing to a reduction in domestic gas production and therefore an increase in imports have been well-head price controls and federal leasing policy. Due to the long lead times involved in establishing liquid natural gas facilities, the increase in imports is just beginning to be felt. In addition, imports have been restricted by Department of Energy policies and ratemaking decisions.

Capital Formation

Capital formation is defined to include not only impacts on investment in physical capital but also factors which improve the industry's ability to obtain capital financing. The incentives having the greatest impact are the tax preference items. They have increased after-tax cash flow to the gas producing companies to provide a source of investment funds.

The percentage depletion allowance and expensing of intangible drilling costs are virtually identical to the same incentives applied to the oil industry. These incentives are described in Chapter 7 on oil. Because of well-head price controls for natural gas, however, the impact of these incentives is not the same. Price controls have limited the return on investment in gas wells and thus counteracted the tax preference incentives. This effect is reflected in the general decrease in wildcat drilling which has been reversed only in the past few years.

\section{Sectoral Impacts}

Sectoral impacts refer to the effects of energy incentives on certain classes of suppliers or consumers. Well-head price controls have had this type of impact. Although all classes of customers have been hurt by the shortages of natural gas brought on by price controls, the industrial sector has been hardest hit. Gas curtailments and unreliable supplies have forced many industrial customers to switch to alternative fuels. Between 1972 and 1975, the nationwide total of industrial natural gas customers fell by $17.2 \%$ (American 
Gas Association 1978, p. 71). Firms, such as those in the chemical industry, which must rely heavily on natural gas as a raw material have located new plants in producing states in order to avoid supply interruptions.

Another government action which has had an unusual impact upon a particular sector is offshore leasing policies. Delays due to environmental regulations and other requirements have kept the available supply of offshore leases well below the demand. This has indirectly hurt the offshore drilling rig and platform producers since the demand for their products has been reduced.

\section{Income Class}

The impact of percentage depletion and current deductability of intangible drilling costs upon landowners has been described in Chapter 7. There, it was estimated that $40 \%$ of the benefits of these tax preferences are passed back to landowners in the form of higher royalties. The impact upon owners of natural gas producing property is be very similar.

\section{Demographic Factors}

An impact upon a specific geographic region or a differential urban/rural impact is included in this category. By contributing to a reduction in the interstate supplies of natural gas, well-head price controls have affected regional development. Gas-dependent industries have been encouraged to locate new plants in gas producing states to avoid federally mandated curtailment schedules. This behavior is typified by the movement of the chemical industry to Texas and Louisiana.

Stability

The Natural Gas Act of 1938 placed the interstate gas industry under the jurisdiction of the Federal Power Commission. Among the reasons given for the passage of the act were the need for conservation of gas, the inability of some communities to obtain secure supplies even though sufficient gas was available, and hardships of independent producers in securing interstate markets (FPC 1973b, p. 538). Regulation of interstate transmission of natural gas gave assurance of fair treatment to producers and consumers. It also greatly improved the ability of the pipeline companies to obtain financing for construction. This had a stabilizing influence on the industry and contributed to its rapid development. 
Foreign Policy/National Security

United States foreign policy and energy policy have become complexly interrelated as the nation attempts to obtain sufficient, reliable energy supplies. This has been reflected in a goal of energy self-sufficiency. Government actions which contribute toward this goal include incentives for domestic energy production.

The primary gas production incentives have been the percentage depletion allowance and expensing provisions for intangible drilling costs. To the extent that domestic production has increased, reliance on foreign sources has been diminished and national security improved. Ironically, these incentives were removed for 1 arger producers starting in 1975 at about the same time that the magnitude of U.S. energy imports became a major concern.

\section{State/Federal Relations}

The Natural Gas Act of 1938 gave jurisdiction over the interstate transmission of natural gas to the Federal Power Commission. The FPC power preempted many of the state and local laws which were in effect at that time. With the 1954 U.S. Supreme Court decision, FPC jurisdiction was extended to the well-head prices of gas production which was to be shipped interstate. FPC authority and duties were transferred to the Federal Energy Regulatory Commission (which is now part of the Department of Energy) in 1977.

Regu latory Burden

The cost to industry of complying with the requirements of some federal incentives can be burdensome. The gas industry is obligated to provide various reports and informational records to the FERC (formerly FPC). Additional data must be provided to the Geological Survey. The total of these requirements is considered to be moderately burdensome to the industry.

Quality of Life

The federal natural gas leasing policy has had environmental protection as a primary consideration. Environmental impact studies are required prior to the leasing of federal 1 and. The requirements have been especially strict for offshore leases. Environmental damage has been quite minimal because the regulations have been strong. 
THE IMPACT OF FEDERAL INCENTIVES ON THE PRICE AND OUTPUT OF NATURAL GAS

A summary of the quantitative impacts of federal incentives on the production and price of natural gas is provided in Tables 8.5 and 8.6 , respectively. The production figures specify the increase in cumulative production which has occurred over the 1950 through 1977 period. The figures in the price category represent the decrease in 1977 well-head price of natural gas resulting from each incentive category. The figures are not additive because the assumptions underlying the various calculations differ somewhat.

The taxation category consists of the percentage depletion allowance and current deductibility of intangible drilling costs. To determine the effect of taxation incentives on the output of natural gas, one must consider the impact of well-head price controls at the same time. Well-head price controls became generally effective about 1960 and from that time on largely negated the potential impact of preferential tax treatment. The positive production impacts of the tax benefits which occurred prior to that time have been estimated and then averaged over the entire 1950 to 1977 period. The estimated

TABLE 8.5. An Estimate of the Results of Incentives Used to Stimulate Natural Gas Production (In Quadrillion Btu)

Incentive Area

Taxation

Requirements

Nontraditional Services

Market Activity
Production Impact

6.60 (increase)

6.38 (increase)

Negligible

Negligible

TABLE 8.6. An Estimate of the Results of Incentives Used to Stimulate Natural Gas Production in Terms of Price ( $\$$ per Million Btu)

Incentive Area

Taxation

Price Impact

Requirements

Nontraditional Services

Market Activity 
production impact using this procedure is approximately $0.7 \%$ to $2.2 \%$ or 3.0 to 10.2 quads. Using a simple average, it is estimated that approximately 6.6 quads of natural gas production can be attributed to the application of taxation incentives.

The overall direct impact of controls on cumulative 1950 through 1977 production is fairly small, in the range of $1.0 \%$ to $2.0 \%$. This result is comprised of two portions. The period prior to 1974 was one of positive price incentives on the order of 3.0\%. In 1974, however, the average intrastate price first exceeded the interstate price and became a net production disincentive. Over the 1974 to 1977 period, this caused about a 5.0\% to 6.0\% decline in natural gas production. By considering the total 1950 to 1977 period, we arrive at the relatively small net production impact of approximately 4.3 to 8.5 quads of natural gas. On the average then, about 6.4 quads of natural gas production can be attributed to incentives in the requirements category.

Incentives in the taxation category also had an impact on the price of natural gas. Although the percentage depletion allowance was eliminated for large firms in 1975, the 1977 price impact is based upon the assumed existence of a $22 \%$ depletion rate for all natural gas producers. A $10 \%$ to $20 \%$ price impact is estimated. Based on the actual 1977 average well-head price of $79 \$ / M C F$, this amounts to from $7.9 \$$ to $15.8 \$ / M C F$. Again, taking a simple average of the price impact range and converting to Btu's, an approximate reduction in the natural gas price of $10.8 \$$ per million Btu can be assigned to taxation incentives.

To determine the impact of well-head price controls on the price of natural gas, it is assumed that the intrastate price is a valid representation of the market price which would exist in the absence of controls. The price effect of controls, therefore, is the difference between the actual average well-head price and the intrastate price. In 1977, the differential was 13.7\$/MCF. Thus, the impact due to incentives of the requirements category has been a reduction in the price of natural gas of some $12.5 \$$ per million Btu. (The heating value of "wet" natural gas is taken as 1,095 Btu/CF and that of natural gas after removal of natural gas liquids is $1,020 \mathrm{Btu} / \mathrm{CF}$ ). 
Incentives in the nontraditional service and market activity categories, namely, Geological Survey and Bureau of Mines data, and Bureau of Land Management leasing programs, were determined to have had a negligible impact on the price and output of natural gas.

\section{CONCLUSIONS}

The total value of federal incentives provided for natural gas production over the 1950 to 1977 period is some $\$ 16.5$ billion (1977 \$). This expenditure has affected a significant number of items. A summary of the impact of federal natural gas incentives based on the typology of incentive impacts as identified in Chapter 2, is presented in Table 8.7 .

Of the six incentive types listed, the incentive with the greatest number of large impacts is the regulatory activities of the Federal Power Commission (FPC), now the Federal Energy Regulatory Commission (FERC). FPC regulation of interstate pipelines enhanced the competitive structure and stability of the industry as well as stimulating the level of capital formation and affecting state/federal relations. FPC requirements did, however, moderately increase the regulatory burden of the industry.

Taxation incentives in the form of the percentage depletion allowance and deductibility of intangible drilling expenses had large impacts on the price and output of natural gas. These incentives also helped to increase the level of capital formation and created moderate positive effects on the U.S. balance of payments and consequently foreign policy/national security factors. A portion of the tax preference benefit was felt to create a moderate impact on income distribution.

Well-head price controls also had a large positive impact on the price and output of natural gas over the entire 1950 to 1977 period. These controls did, however, adversely affect the competitive structure of the industry. Since 1974, price controls have contributed to a reduction in domestic gas production, thus increasing the demand for imported gas which resulted in adverse balance of payments effects. Price controls have limited the return on investment in gas wells, which affects capital formation and controls produced moderate impacts on demographic and sectoral factors. 
TABLE 8.7. Summary of Impacts of Natural Gas Incentives

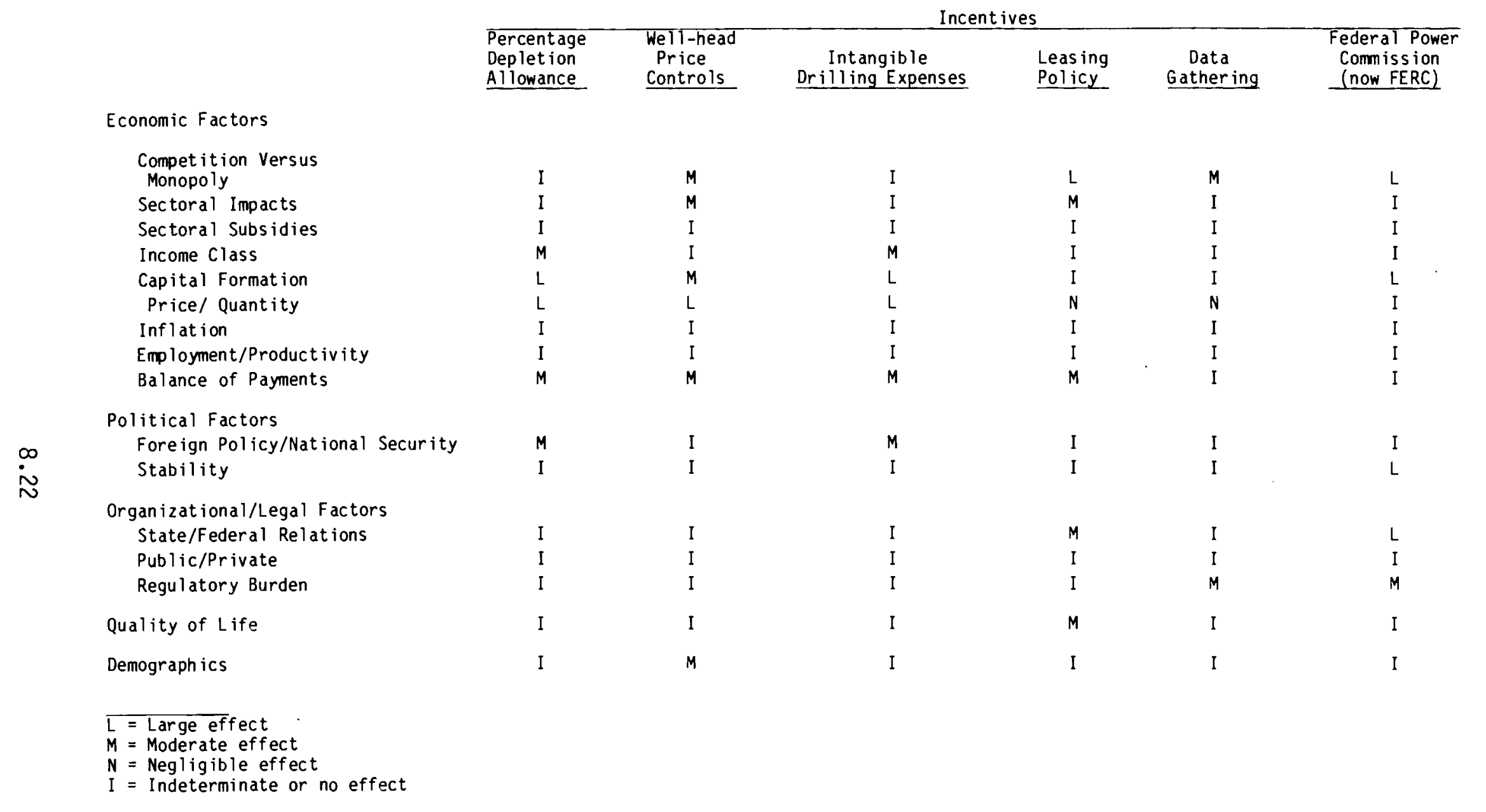


Federal leasing policies and data gathering activities have also had noticeable effects. Leasing policies have had a negative impact on the competitive structure and the balance of payments. Leasing policies have also created moderate sectoral impacts and have affected state/federal relations. Environmental aspects of leasing policies have positively affected the quality of life. Data gathering activities have enhanced the industry's competitive structure and moderately increased the regulatory burden.

\section{RECOMMENDATIONS FOR SOLAR POLICY}

The percentage depletion allowance and current deductibility of intangible drilling costs have been by far the largest incentives provided to the natural gas industry. The impact on production has been similar to that for petroleum, although limited somewhat by well-head price controls. A discussion of the applicability of tax incentives such as these is provided in Chapter 7 and will not be repeated here.

Another important incentive provided for natural gas is government regulation of interstate pipelines. This regulation was important in two ways. First, it provided protection to consumers and led to greater acceptance of natural gas. Second, regulation was beneficial to gas suppliers since it reduced the uncertainty of prices and markets, thus, encouraging production.

Regulation or licensing, may be applied to some solar energy participants. For a consumer unfamiliar with solar equipment and unable to discern familiar brand names, a government seal of approval may remove some of the hesitancy to purchasing solar equipment. Government involvement may include such things as certification of solar architects and designers, licensing of installers, and inspection of equipment. Such regulations by the government may provide reassurance to a public generally unfamiliar with solar technology.

It will take a careful appraisal of such government involvement to determine whether the impact will, in fact, be beneficial. Perhaps such interference would discourage some individuals and businesses from entering the solar market. A voluntary rather than a mandatory program may be more suitable. It may also be appropriate only until the solar industry becomes established and accepted by the public. 


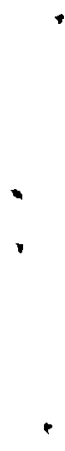


CHAPTER 9

ELECTRICITY

by

Alex Fassbender, Research Engineer Richard Mazzucchi, Research Engineer John Nassikas, Lawyer 


\section{$\underline{\text { ELECTRICITY }}$}

\section{INTRODUCTION}

The business of selling electricity to the public began in 1879 , and by 1900, there were 3,620 electric utility systems. The majority of these, 2,805, were investor-owned utilities (IOUs) ("The Utility Industry" June 1, 1974). The federal government entered the power business in 1906 with the Reclamation Act and began marketing electricity under the Boulder Canyon Act of 1928. The Tennessee Valley Authority (TVA) was established in 1933 as a social experiment, involving the government in the total economic development of an entire region primarily through the generation of electrical power. In the early $30^{\prime} \mathrm{s}$ about two thirds of the population was served by electricity. However, only $10 \%$ of the farms were served due to the high cost of transmission and distribution lines in low density areas. On the average, rates for electricity were 3 times what they are today and use per customer was less than $1 / 8$ of what it is today. Many rural areas had no hope of receiving electric service until the Rural Electrification Act of 1938 established government programs to produce and distribute electrical energy. The structure of the electric utility industry has changed over the years. Investor-Owned Utilities have become larger and fewer in number. Today there are 212 IOUs. The Rural Electrification Administration Cooperatives (REA-Co-Ops) have flourished since 1938 and they currently number 980. There are currently about 511 municipal utilities (MUs) and 74 federal utilities in operation in the U.S. The long-term rate of growth has been quite steady at approximately 7\% annually, except for 1973 and 1974, when the impact of the OPEC oil embargo stunned the country.

\section{Utility Structures}

There are currently three basic structural types of domestic electric utilities. They are as follows:

1. Investor-Owned Electric Utilities

2. Government-Owned Electric Utilities: 
- Federal Agencies

- Municipal Systems

- Public Power Districts and State Projects

3. REA Financed, Cooperatively-Owned Electric Utilities.

One measure of the relative size or market share of these utilities is their total net generation. This measure is presented in Table 9.1 (EIA April 1978a). Energy generated by the federal sector has increased in magnitude but has decreased as a percent of total generation. This low growth rate is largely due to the previous completion of massive hydro projects. The most telling statistic from Table 9.1 is the dramatic growth of the REA Co-ops. The basic incentive structure and financing mechanisms of REA Co-ops are covered in a later section.

The total investment in generation facilities averages less than half of the total investment in an electric plant. This holds true for public as well as private power facilities. The breakdown of the investment in electric plants for Investor-Owned and Cooperatively-Owned Utilities is shown in Table 9.2. Note that the two types of utilities should not be compared using Table 9.2 because the data are on different bases.

We have gone through a brief description of the electric utility industry looking at the principal actors, their market share, and the relative size of the components of the industry. The rest of this chapter focuses on how federal involvement has shaped the industry.

\section{FEDERAL INCENTIVES TO ELECTRICITY PRODUCTION}

Thirteen major federal energy-related organizations have some involvement with the distribution of electricity as an energy form. Major energy-related actions toward electricity are conducted by the following 12 organizations. Department of Agriculture (DOA)

- Rural Electrification Administration (REA)

Department of Energy (DOE) 
TABLE 9.1. Electric Utility Net Generation, United States 1967 to 1976(a) (Millions of kWh) (EIA April 1978a)

Privately, Publicly and Cooperatively owned(b)

\begin{tabular}{|c|c|c|c|c|c|c|c|}
\hline ear & Total (c) & $\begin{array}{c}\text { Privately }(d) \\
\text { Owned } \\
\end{array}$ & Subtotal & Munic ipal & $\begin{array}{c}\text { State } \\
\text { Projects }\end{array}$ & Federal & Cooperatives \\
\hline $\begin{array}{l}1967 \\
1968 \\
1969 \\
1970 \\
1971 \\
1972 \\
1973 \\
1974 \\
1975 \\
1976\end{array}$ & $\begin{array}{l}1,217,349 \\
1,332,131 \\
1,445,282 \\
1,532,796 \\
1,613,936 \\
1,747,323 \\
1,856,216 \\
1,864,961 \\
1,917,638 \\
2,037,482\end{array}$ & $\begin{array}{r}931,423 \\
1,011,000 \\
1,105,262 \\
1,186,069 \\
1,250,005 \\
1,356,677 \\
1,448,860 \\
1,441,014 \\
1,486,821 \\
1,582,011\end{array}$ & $\begin{array}{l}285,926 \\
310,131 \\
340,020 \\
346,727 \\
363,931 \\
390,646 \\
407,356 \\
423,948 \\
430,817 \\
455,471\end{array}$ & $\begin{array}{l}57,789 \\
63,804 \\
69,614 \\
71,490 \\
72,535 \\
78,922 \\
80,872 \\
78,500 \\
81,541 \\
78,120\end{array}$ & $\begin{array}{r}53,350 \\
61,352 \\
69,648 \\
66,023 \\
69,678 \\
73,378 \\
79,642 \\
91,981 \\
92,699 \\
100,317\end{array}$ & $\begin{array}{l}162,399 \\
170,834 \\
183,245 \\
185,755 \\
194,490 \\
206,736 \\
211,817 \\
219,622 \\
221,223 \\
235,904\end{array}$ & $\begin{array}{l}12,388 \\
14,141 \\
17,513 \\
23,459 \\
27,288 \\
31,610 \\
35,126 \\
33,845 \\
35,354 \\
41,230\end{array}$ \\
\hline
\end{tabular}

Percent of Total

Privately, Publicly and Cooperatively Owned(b)

$\begin{array}{llllllll}1967 & 100.0 & 76.5 & 23.5 & 4.8 & 4.4 & 13.3 & 1.0 \\ 1968 & 100.0 & 76.7 & 23.3 & 4.8 & 4.6 & 12.8 & 1.1 \\ 1969 & 100.0 & 76.5 & 23.5 & 4.8 & 4.8 & 12.7 & 1.2 \\ 1970 & 100.0 & 77.4 & 22.6 & 4.7 & 4.3 & 12.1 & 1.5 \\ 1971 & 100.0 & 77.4 & 22.6 & 4.5 & 4.3 & 12.1 & 1.7 \\ 1972 & 100.0 & 77.6 & 22.4 & 4.5 & 4.2 & 11.9 & 1.8 \\ 1973 & 100.0 & 78.1 & 21.9 & 4.3 & 4.3 & 11.4 & 1.9 \\ 1974 & 100.0 & 77.3 & 22.7 & 4.2 & 4.9 & 11.8 & 1.8 \\ 1975 & 100.0 & 77.5 & 22.5 & 4.3 & 4.8 & 11.5 & 1.9 \\ 1976 & 100.0 & 77.6 & 22.4 & 3.8 & 4.9 & 11.6 & 2.0\end{array}$

(a) Exclusive of energy used for pumped storage.

(b) Revised 1973 to separate Power Districts and State Projects from Municipals and Cooper at ives.

(c) Does not include industrial plants net generation.

(d) Includes the generation of numerous small utilities accounting for less than $2 \%$ of the privately owned division of the industry. 
TABLE 9.2. Percent Breakdown of Investment in Total Electric Plant. for Investor-Owned and Cooperatively-Owned Utilities (EIA April 1978a, Cone et al. December 1978)

Type of Electric Plant

Generation

Transmission

Distribution

Other
Classes $A$ and $B$ Investor-Owned Electric Utilities-Percent of Plant in Service(a)

\section{5}

17.7

33.2

2.6
Cooperatively-Owned

Electric Utilities-Percent of Loans for Electric Plant $(b, c)$

45.9

75.2

15.0

10.4

38.9

14.4

0.2

0.0

\footnotetext{
(a) Total In Service

(b) Cumulative

(c) 1977
}

- Alaska Power Administration (APA)

- Bonneville Power Administration (BPA)

- Southeastern Power Administration (SEPA)

- Southwestern Power Administration (SWPA)

- Western Area Power Administration (WAPA)

- Economic Regulatory Administration (ERA)

- Federal Energy Regulatory Commission (FERC)

- Energy Information Administration (EIA)

Department of the Treasury (DotT)

- Internal Revenue Service (IRS)

Independent Organizations

- Securities and Exchange Commission (SEC)

- Tennessee Valley Authority (TVA)

The organizations that have had the largest direct impact on the dollar incentive figures presented in this chapter are the REA, TVA, BPA, SWPA, and FERC. The actions of the SEC and IRS in administering tax and investment incentives constitute the largest indirect impacts. 
The directly quantifiable federal incentives to electricity distribution, transmission and generation (excluding incentives already identified for hydro and nuclear energy) were found to be 57.9 or 47.2 billion 1977 (Cone et al. December 1978). The incentive types and values are summarized in Table 9.3. The two costs represent two different viewpoints on how an incentive is defined. The incentive definition designated as Number 1 includes the net federal investment in the production and transmission of electricity plus the value of special tax policies to the industry. The second definition considers both the effect of low interest rates on reimbursable federal appropriations and the special tax policies as incentives. Since either of these figures represent a conservative

TABLE 9.3. Federal Incentives Used to Stimulate the Development of Electric Energy. (Millions of $1977 \$$ ) (Cone et al. December 1978, p. 263)

Incentive Area

Investor-Owned Utilities:

- Investment Tax Credits

- Liberalized Depreciation

Public Utilities:

- Electricity Transmission

- Tax Exemption:

Federal Power

Authorities

State Power Author-

ities and Municipal

Utilities

REA Cooperatives

- Tax-Free Bonds

- REA Bonds

- REA Administration

Subtotal

TOTAL 57,912.4[1] or

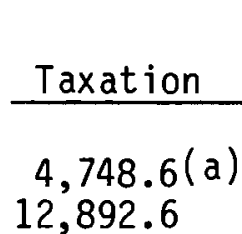

$12,892.6$

\section{Traditional \\ Services}

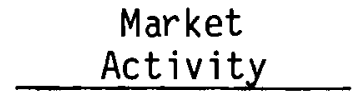

$5,636.1[1](b, c)$ $2,319.3[2]$ $1,766.1^{(d)}$

$1,386.9$

$7,547.6$

$5,154.9$

$3,112.3$

$\frac{476.5}{44,842.9}$

$47,184.2^{[2]}$ $16,956.9[1](c)$

$9,545.5[2]$

$22,593.0[1]$

(a) Current dollars.

(b) Definitions [1] and [2] represent different viewpoints and do not add or indicate a range.

(c) Transferred from Chapter 5.

(d) Included in Chapter 5 total and shown here only for completeness. 
minimum estimate of the incentives to electricity, the discussion will deal with definition Number 1 while keeping in mind that an alternative definition exists. Most of the quantifiable incentives identified constitute market activity and taxation actions by the federal government. Annual incentive data since 1933 is presented in Table 9.4 by incentive type and the corresponding cumulative figures since 1933 are presented in Table 9.5.

The incentives are grouped into three fundamental categories: 1) taxation, which includes all tax breaks and exemptions to the electric utility industry, 2) traditional services, which considers the costs of regulating the industry, and 3) market activity, which includes all savings perpetuated by federal capital sharing programs.

The proportional share that each incentive type contributes to the total is presented graphically in Figure 9.1. The cumulative incentives since 1933 are shown in Figure 9.2.

Tax incentives have contributed a total of $\$ 34.8$ billion to the electric industry since 1933. This constitutes over $58 \%$ of all of the incentives to electricity recognized in this study. In recent years the tax share of incentives has grown to constitute approximately $80 \%$ of electricity incentives. The exemption of government and cooperatively owned utilities from federal income tax payments are responsible for all of the tax savings prior to 1954 and $40 \%$ of the total tax incentives from 1933 to 1977. The doubling of tax incentives in 1955 is attributed to policies that allowed liberalized depreciation of privately owned electric generation facilities. Through 1976, liberalized depreciations have added nearly $\$ 13$ billion in incentives, or $37 \%$ of all tax incentives. Commencing in 1964, government-sponsored utilities were permitted to float tax-free bonds, thus the bonds could be offered for sale at a lower interest rate than a taxable IOU bond. This action provided a savings of $\$ 3.11$ billion overall, about $9 \%$ of tax breaks. The investment tax credits extended to investor-owned utilities intermittently since 1962 have added $\$ 4.74$ billion to the tax incentives package, contributing $14 \%$ overall.

The distribution of tax incentives between government-sponsored utilities (GSU) and investor-owned utilities has changed over the years. Prior to 1954 
TABLE 9.4. Annual Electricity Incentives (Millions of 1977 \$ Per Year) (Cone et al. December 1978)

\begin{tabular}{|c|c|c|c|c|}
\hline Year & Taxation & $\begin{array}{c}\text { Traditional } \\
\text { Services } \\
\end{array}$ & $\begin{array}{c}\text { Market } \\
\text { Activity }\end{array}$ & Total \\
\hline 1977 & $3,903.66$ & 11.28 & 754.93 & $4,669.87$ \\
\hline $1976 \mathrm{TQ}$ & 923.99 & 2.93 & 189.59 & $1,116.51$ \\
\hline 1976 & $3,660.80$ & 11.56 & 763.30 & $4,435.66$ \\
\hline 1975 & $2,630.23$ & 11.08 & 781.30 & $3,422.61$ \\
\hline 1974 & $1,926.07$ & 10.82 & 782.88 & $2,719.77$ \\
\hline 1973 & $1,612.34$ & 10.65 & 856.45 & $2,479.44$ \\
\hline 1972 & $1,411.16$ & 12.62 & 643.88 & $2,067.66$ \\
\hline 1971 & $1,067.64$ & 12.23 & 524.94 & $1,604.81$ \\
\hline 1970 & 903.48 & 12.32 & 526.17 & $1,441.97$ \\
\hline 1969 & $1,140.04$ & 12.34 & 593.75 & $1,746.13$ \\
\hline 1968 & $1,179.66$ & 12.24 & 606.05 & $1,797.95$ \\
\hline 1967 & $1,101.50$ & 12.06 & 440.63 & $1,554.19$ \\
\hline 1966 & 955.55 & 11.98 & 917.72 & $1,885.25$ \\
\hline 1965 & 940.96 & 12.20 & 627.20 & $1,580.36$ \\
\hline 1964 & 995.12 & 11.57 & 757.87 & $1,764.56$ \\
\hline 1963 & 898.59 & 10.96 & 566.29 & $1,475.84$ \\
\hline 1962 & 931.55 & 10.66 & 416.02 & $1,358.23$ \\
\hline 1961 & 930.65 & 10.01 & 458.24 & $1,398.90$ \\
\hline 1960 & 917.98 & 9.66 & 279.26 & $1,206.90$ \\
\hline 1959 & 863.21 & 9.88 & 304.03 & $1,177.12$ \\
\hline 1958 & 801.42 & 9.52 & 451.89 & $1,262.83$ \\
\hline 1957 & 773.85 & 9.20 & 660.72 & $1,443.77$ \\
\hline 1956 & 759.87 & 9.70 & 325.86 & $1,095.43$ \\
\hline 1955 & 364.02 & 9.60 & 429.51 & 803.13 \\
\hline 1954 & 306.66 & 10.16 & 385.28 & 702.10 \\
\hline 1953 & 282.80 & 12.97 & 511.00 & 806.77 \\
\hline 1952 & 240.84 & 15.15 & 424.71 & 680.70 \\
\hline 1951 & 205.08 & 16.48 & 542.77 & 764.33 \\
\hline 1950 & 157.58 & 16.84 & 960.92 & $1,135.34$ \\
\hline 1949 & 118.48 & 15.04 & $1,180.05$ & $1,313.57$ \\
\hline 1948 & 95.54 & 12.14 & 780.93 & 888.61 \\
\hline 1947 & 189.81 & 12.49 & 681.19 & 883.49 \\
\hline 1946 & 209.15 & 13.88 & 762.44 & 985.47 \\
\hline 1945 & 209.04 & 11.79 & 238.77 & 459.60 \\
\hline 1944 & 211.67 & 8.78 & 101.53 & 321.98 \\
\hline 1943 & 216.10 & 11.22 & 41.84 & 269.16 \\
\hline 1942 & 198.45 & 14.33 & 381.64 & 594.42 \\
\hline 1941 & 194.13 & 13.18 & 444.67 & 651.98 \\
\hline 1940 & 121.06 & 11.72 & 229.69 & 362.47 \\
\hline 1939 & 104.64 & 9.72 & 668.78 & 783.14 \\
\hline 1938 & 101.11 & 6.34 & 186.33 & 293.78 \\
\hline 1937 & 88.30 & 4.22 & 249.46 & 341.98 \\
\hline 1936 & 0 & 2.93 & 85.58 & 88.51 \\
\hline 1935 & 0 & 0 & 24.96 & 24.96 \\
\hline 1934 & 0 & 0 & 25.58 & 25.58 \\
\hline 1933 & 0 & 0 & 26.44 & 26.44 \\
\hline
\end{tabular}


TABLE 9.5. Cumulative Electricity Incentives (Millions of $1977 \$$ ) (Cone et al. December 1978)

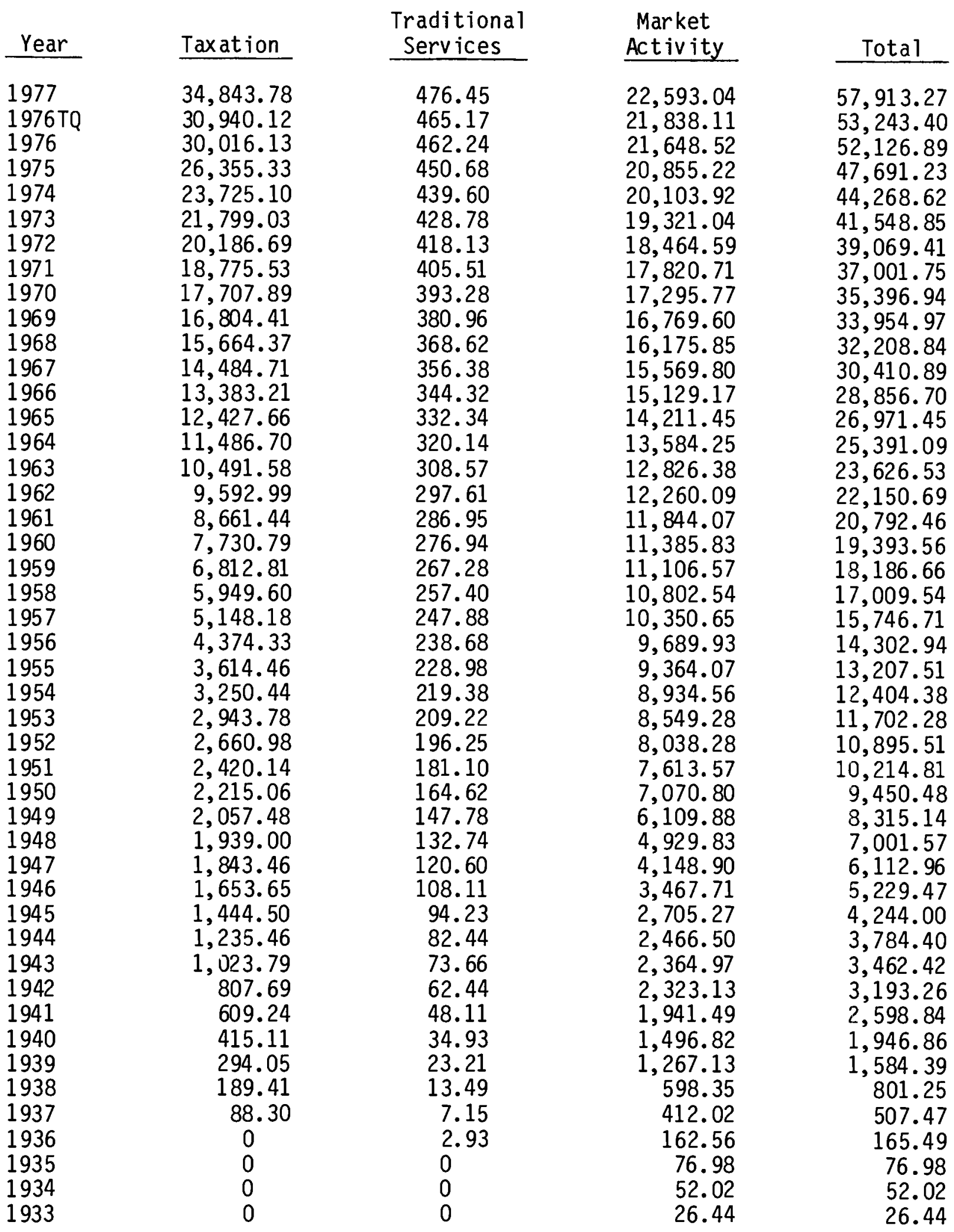




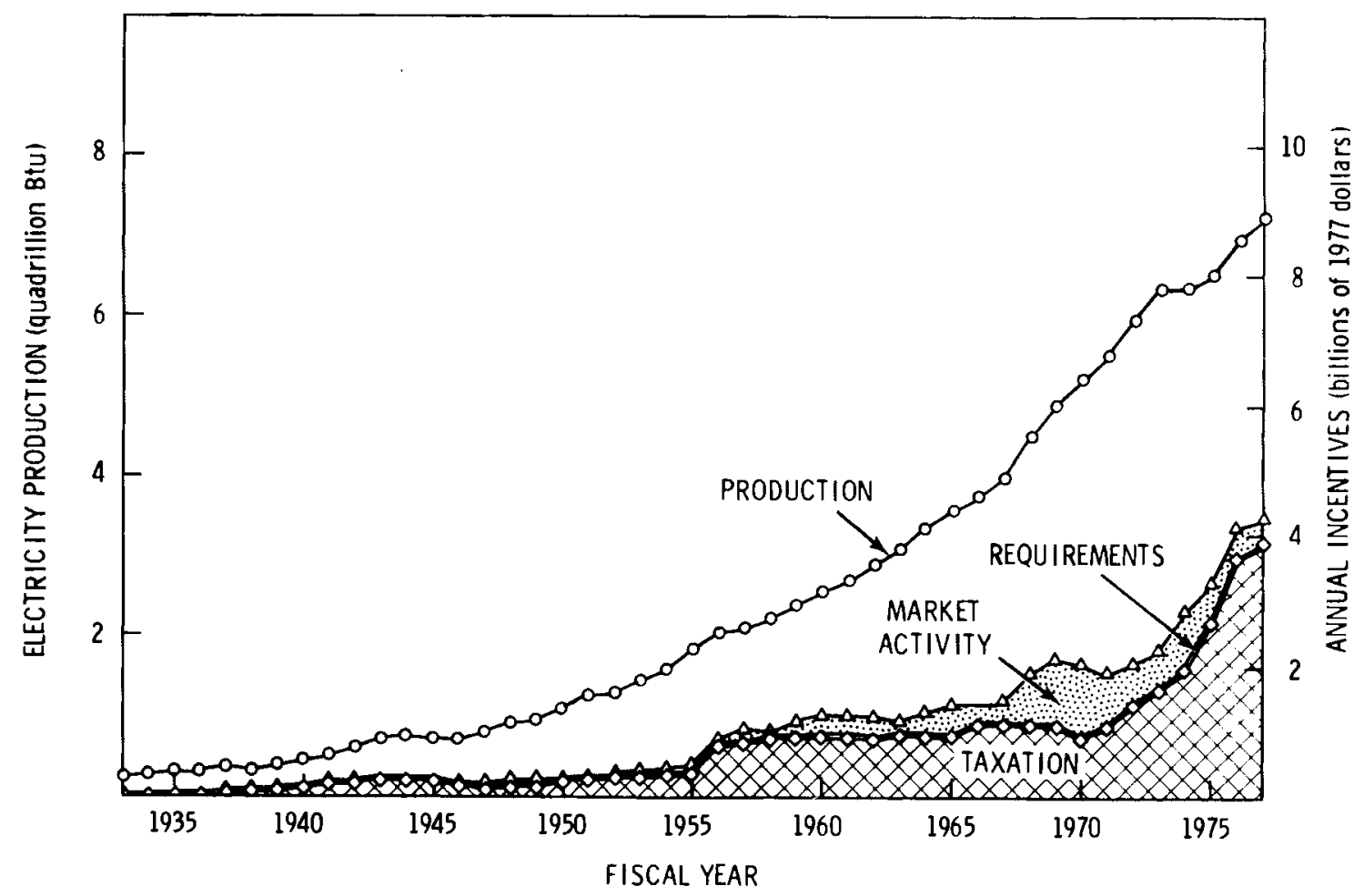

FIGURE 9.1. Annual Electricity Production and Incentives

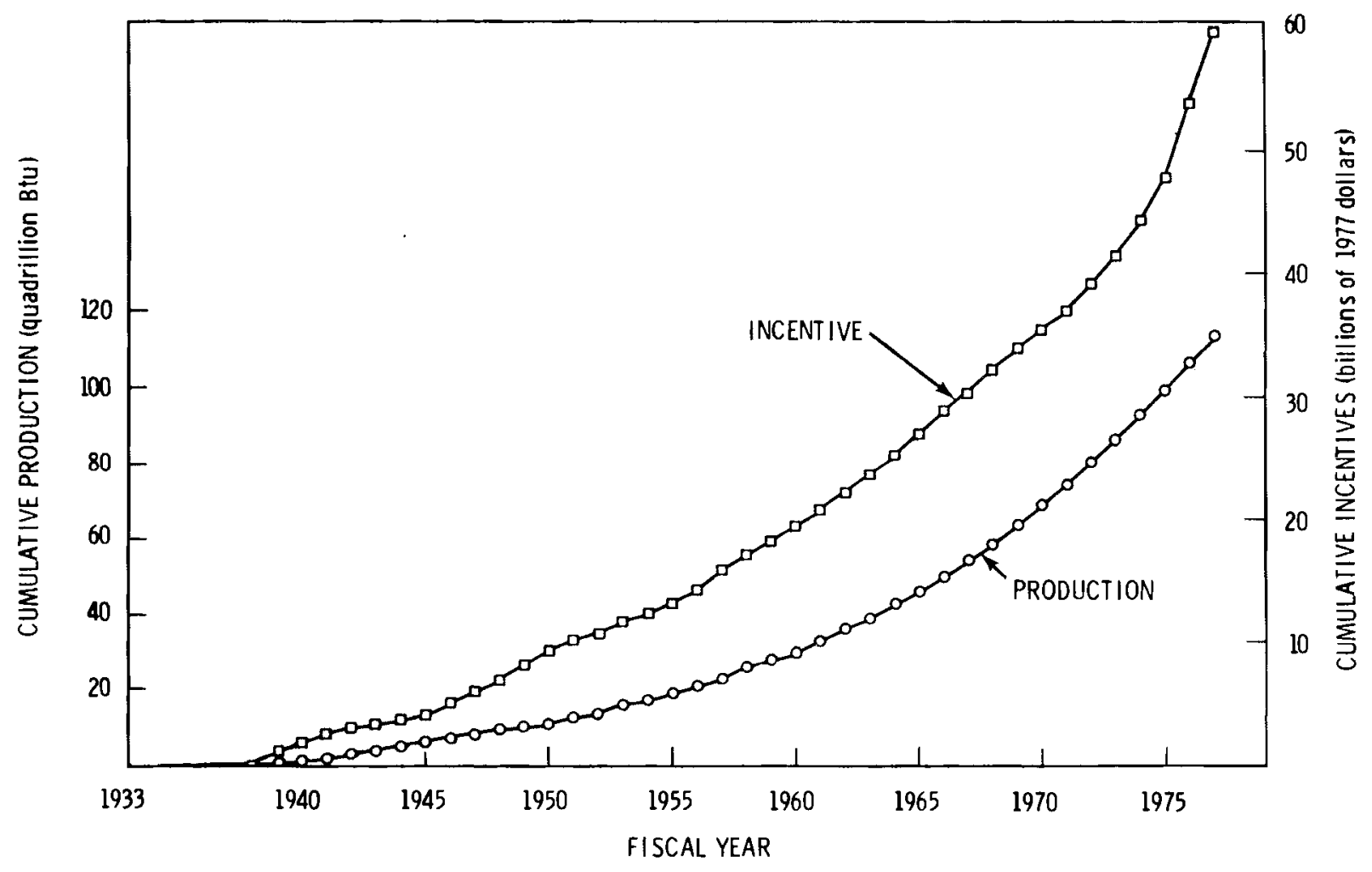

FIGURE 9.2. Cumulative Electricity Incentives and Production 
all tax incentives were given to the GSUs; however, since that time, an increasing proportion has been allotted to IOUs. In 1976, IOUs received approximately $\$ 3.1$ billion on tax breaks compared with $\$ 0.8$ billion to GSUs. If the trend initiated in 1970 continues, tax incentives to electric utilities can be expected to increase at an annual rate of $12 \%$.

Traditional services rendered to the electric power industry by the Federal Energy Regulatory Commission (formerly the Federal Power Commission) have contributed $\$ 0.475$ billion, or less than $1 \%$ of the total federal involvement. The operating budget of the regulatory agency that can be attributed to electrical power is approximately $\$ 11$ million annually.

The federal government constructs, operates, and maintains electricity transmission systems and provides loans and loan guarantees for electricity generation, transmission, and distribution systems. The net federal capital outlay comes to a value of $\$ 24.6$ billion and this is classed as a market activity incentive. This annual outlay fluctuates considerably due to the variability of new facility construction and repayment schedules. A high of $\$ 2.2$ billion of federal financing occurred in 1976. Overall market activity has constituted $41 \%$ of all federal incentives to the industry.

\section{ELECTRICITY PRODUCTION AND FEDERAL INCENTIVES}

Federal incentives are just one factor which influences the production of electrical energy. In order to assess the effects of federal programs, it is necessary to have a general understanding of the other parameters influencing the growth of the industry.

The dramatic growth in the generation and transmission of electrical energy in the past century is due to the movement of society into the technological age. Use of all sources of energy was on the rise as machine power displaced man or animal power. Electricity, because of its ability to provide clean, continuous, and easily utilized energy to consumers, has been in great demand ever since it was first demonstrated.

The business of selling electricity to the public began in 1879, and less than 10 years later, over 3,600 privately owned electric utility systems were 
in operation. The federal government entered the electric power industry in 1906 under the Reclamation Act. Substantial involvement began in 1933 with the establishment of the Tennessee Valley Authority, which called for the total economic development of a region primarily through the generation of electricity. Data regarding the magnitude of electrical energy produced since that date is presented in Table 9.6 and plotted in Figure 9.1. Electricity production by type of utility is presented in Table 9.7.

In the early 30 's about two-thirds of the population was served by electrical service, but less than $10 \%$ of the farms because of the prohibitively high price of supplying energy to low density areas. Many rural areas had no hope of receiving electrical power, causing a migration of citizens from farms to the cities. The Rural Electrification Act of 1936 stemmed the tide by providing low cost federal funds to produce and distribute electricity to areas not served by privately owned utilities. Most of the electricity transmitted through REA transmission lines was generated by the neighboring privately owned utilities. Thus, the act benefited both the public and private electricity industries. Without the development of the program it is doubtful whether a significant number of Americans would have access to affordable electrical power.

The effect of federal expenditures on the production or distribution of electricity is difficult to ascertain for individual years because of the time required to construct additional power facilities. In 1972, for instance, the time between funding for generation facilities and initiation of generation exceeded 5 years in many instances. Because of the tremendous size of the electrical industry, the impacts of federal programs on an annual basis are slight.

A comparison of the total cumulative amount of electricity generated with the cumulative value of federal incentives since 1933 helps illustrate interrelationships by exposing long-term developments. Figure 9.2 shows the cumulative production of electricity since 1933 with the cumulative incentive level. The plot shows a strong correlation as the slopes of the curves are equivalent until recent years. The departure is most likely due to rapid increases in generating costs resulting from rising fuel costs and environmental concerns. 
TABLE 9.6. Production and Price of Electric Energy

(Edison Electric Institute 1963, October 1978)

\begin{tabular}{|c|c|c|}
\hline \multirow[b]{2}{*}{ Year } & \multicolumn{2}{|c|}{$\left(10^{15} \mathrm{Btu}\right)$} \\
\hline & Annual & Cumu lat ive \\
\hline$\overline{1977}$ & 7.247 & 113.561 \\
\hline 1976 & 6.952 & 106.314 \\
\hline 1975 & 6.542 & 99.361 \\
\hline 1974 & 6.368 & 92.818 \\
\hline 1973 & 6.333 & 86.450 \\
\hline 1972 & 5.969 & 80.117 \\
\hline 1971 & 5.502 & 74.147 \\
\hline 1970 & 5.225 & 68.645 \\
\hline 1969 & 4.920 & 63.419 \\
\hline 1968 & 4.536 & 58.498 \\
\hline 1967 & 4.143 & 53.962 \\
\hline 1966 & 3.904 & 49.819 \\
\hline 1965 & 3.600 & 45.914 \\
\hline 1964 & 3.357 & 42.314 \\
\hline 1963 & 3.128 & 38.956 \\
\hline 1962 & 2.916 & 35.828 \\
\hline 1961 & 2.710 & 32.912 \\
\hline 1960 & 2.570 & 30.202 \\
\hline 1959 & 2.422 & 27.631 \\
\hline 1958 & 2.201 & 25.209 \\
\hline 1957 & 2.154 & 23.008 \\
\hline 1956 & 2.049 & 20.853 \\
\hline 1955 & 1.866 & 18.804 \\
\hline 1954 & 1.609 & 16.937 \\
\hline 1953 & 1.510 & 15.328 \\
\hline 1952 & 1.362 & 13.817 \\
\hline 1951 & 1.264 & 12.455 \\
\hline 1950 & 1.123 & 11.190 \\
\hline 1949 & 0.993 & 10.067 \\
\hline 1948 & 0.964 & 9.074 \\
\hline 1947 & 0.872 & 8.110 \\
\hline 1946 & 0.761 & 7.237 \\
\hline 1945 & 0.759 & 6.475 \\
\hline 1944 & 0.778 & 5.716 \\
\hline 1943 & 0.742 & 4.938 \\
\hline 1942 & 0.634 & 4.195 \\
\hline 1941 & 0.572 & 3.560 \\
\hline 1940 & 0.483 & 2.988 \\
\hline 1939 & 0.435 & 2.504 \\
\hline & 0.388 & 2.068 \\
\hline & 0.405 & 1.680 \\
\hline & 0.372 & 1.274 \\
\hline & 0.325 & 0.901 \\
\hline & & 0.576 \\
\hline & 0.279 & 0.279 \\
\hline
\end{tabular}

Revenues

(Billions

Current \$)

62.610

53.462

46.853

39.126

31.662

27.921

24.725

22.066

20.139

18.579

17.223

16.196

15.158

14.408

13.697

13.025

12.169

11.515

10.572

9.733

9.289

8.698

8.020

7.277

6.793

6.137

5.647

5.086

4. 614

4.313

3.853

3.459

3.341

3.277

3.078

2.855

2.665

2.440

2.289

2.156

2.160

2.045

1.912

1.831

1.754
$(1977 \& / \mathrm{kWh})$

3.296

3.078

3.044

2.827

2.535

2.564

2.522

2.475

2.405

2.692

2.823

2. 910

3.054

3.162

3.262

3.361

3.420

3.448

3.507

3.584

3.584

3.658

3.774

3.993

4.006

4.090

4. 141

4.563

4. 719

4.509

4.803

5.626

5.812

5.694

5.801

6.678

7.831

8.873

9.447

9.896

9.179

9.929

10.812

11.664

12.452 
TABLE 9.7. Electricity Production by Utility Type During the Period the Quantified Federal Incentives Were in Effect (Millions of kWh) (Edison Electric Institute 1963, October 1978)

\begin{tabular}{lr} 
Year & $\begin{array}{c}\text { Owned } \\
\text { ut i ities }\end{array}$ \\
1977 & $1,683,794$ \\
1976 & $1,582,029$ \\
1975 & $1,486,844$ \\
1974 & $1,442,114$ \\
1973 & $1,448,860$ \\
1972 & $1,358,929$ \\
1971 & $1,248,596$ \\
1970 & $1,183,190$ \\
1969 & $1,102,162$ \\
1968 & $1,019,313$ \\
1967 & 928,439 \\
1966 & 880,837 \\
1965 & 809,474 \\
1964 & 756,183 \\
1963 & 701,253 \\
1962 & 651,016 \\
1961 & 604,883 \\
1960 & 578,600 \\
1959 & 544,234 \\
1958 & 490,402 \\
1957 & 480,943 \\
1956 & 459,015 \\
1955 & 420,869 \\
1954 & 370,970 \\
1953 & 354,272 \\
1952 & \\
1951 & \\
1950 & \\
1949 & \\
1948 & \\
1947 & \\
1946 & \\
1945 & \\
1944 & \\
1943 & \\
1942 & \\
1941 & \\
1940 & \\
1939 & \\
1938 & \\
1937 & \\
TotAL & \\
& \\
\hline
\end{tabular}

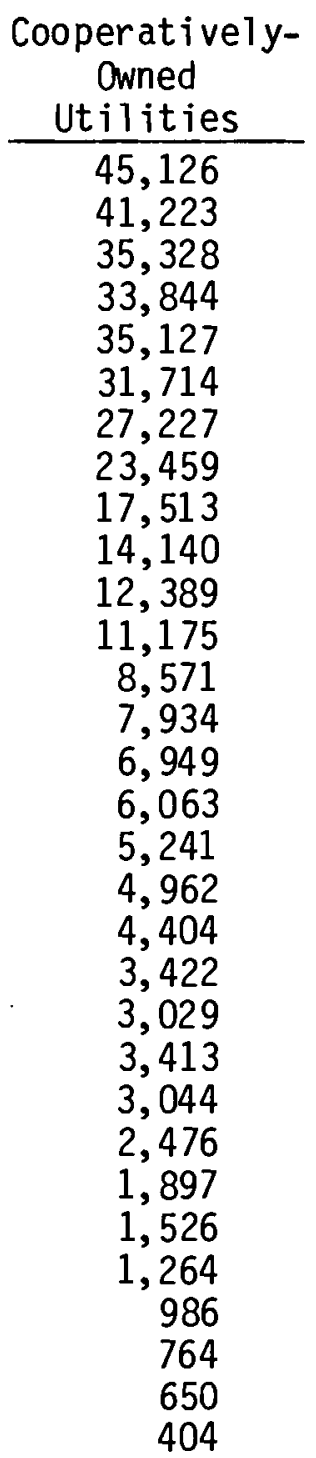

Included with Government-

Owned

Utilities

Prior to 1947
Government-

Owned

Utilities

395,106

414,422

395,447

390,478

372,229

358,994

336,766

324,960

322,507

295,990

273,537

252,338

237,207

219,873

208, 591

195,235

181,915

169,788

161,368

151,274

147,535

138,240

123,125

98,240

86,496

75,572

67,564

61,295

57,224

53,817

47,229

42,158

41,560

42,339

37,511

27,927

20,499

16,426

12,564

9,722

8,449

395,264

$6,873,517$ 
Since total federal incentives constitute less than $8 \%$ of total electric industry revenues, it is not surprising that no direct correlation between such expenditures and production of electricity is apparent. The fact that utilities provide a commodity with relatively inelastic demand further obscures the effect of incentives on production because additional costs can be passed on to the rate payer with little impact on the demand for electricity. Therefore, one would expect the application of federal incentives to influence price more than production. Considerable increases in the amount of incentives provided by investment tax credits and liberalized depreciation since 1970 have helped to offset rising production costs and stimulate the construction of additional generating capacity.

\section{ELECTRICITY PRICE AND FEDERAL INCENTIVES}

The effect of federal incentives on the price of electricity is analyzed in this section. Prices are regulated by individual state power commissions so as to allow electric utilities to pay for the costs of production and distribution of electricity and make a moderate profit in the case of investorowned utilities.

The price of electricity to the final consumer varies widely across the country due to the variability in the costs of electricity production and distribution. For example, in 1977 the lowest bill for $500 \mathrm{kWh}$ was $\$ 5.42$ in Seattle, Washington, and the highest bill for the same amount of energy was $\$ 40.15$ in New York, New York (Edison Electric Institute October 1978). These are the extremes with the bill for $500 \mathrm{KWh}$ coming to $\$ 20.86$ on a national average. Even within a particular region, the unit price paid is a function of the amount of energy consumed. Large industrial users are allowed cheaper rates due to the continuous nature of the load and because high price peak saving generation equipment is necessary only to supply the intermittent service required almost exclusively by residential consumers. Thus, the average charge for a large industrial user per kWh came to $4.11 \phi$, whereas the small residential consumer paid $6.54 \$--$ a difference of $46 \%$. Because of the wide variability in price, an average price per unit of energy produced on a national level was computed by dividing the net operating revenues of the 
electric power industry by the total energy delivered to all consumers. In 1977 the figure came to $3.30 \$$ per $\mathrm{kWh}$ as compared to a national low of $1.08 \$$ and a high of 8.03\%. The average price from 1933 to 1977 is presented in Table 9.6 and adjusted to constant 1977 \$. This data is plotted with the incentives data from Table 9.4 and is presented in Figure 9.3. Since constant $1977 \$$ are used, the effects of inflation are removed.

Electricity prices have declined substantially from the levels during the infancy of the industry. Operational experience in conjunction with increased production by more efficient generating systems brought prices from 12.45 per kWh in 1933 to $3.77 \$$ per $\mathrm{kWh}$ in 1955 (Edison Electric Institute 1963). Since that time, electricity prices have remained relatively stable, dipping to a minimum of $2.40 \$ / \mathrm{kWh}$ in 1970 . After 1970 , prices have slowly escalated to a 1977 level of $3.30 \$ / \mathrm{kWh}$. Projections indicate that the prices of electricity will continue to moderately increase.

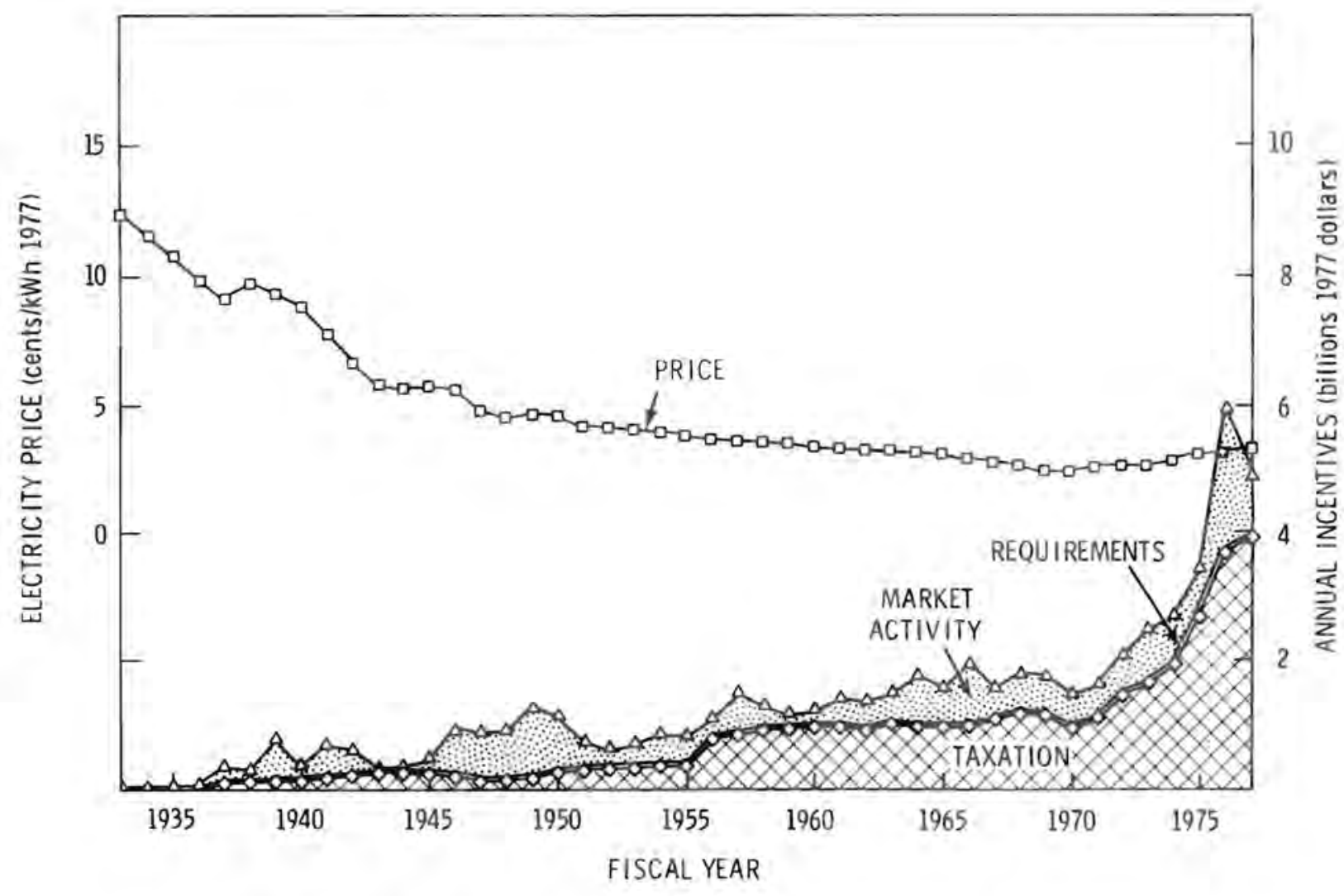

FIGURE 9.3. Annual Electricity Prices and Incentives 
In order to determine the impact of federal expenditures on the price of electricity, it is necessary to understand the factors that influence electricity production costs. The disposition of the "average" private electric utilities revenues in 1974 is presented in Table 9.8. Production expenses account for $58 \%$ of total expenses with the remainder of expenses for capital related activities. Expenses in both categories have increased dramatically since 1970 .

Fue 1 costs accounted for over $80 \%$ of the total production expenses or approximately $35 \%$ of total electric utility expenses. Until 1969, fuel costs showed stable declines of approximately $2 \%$ annually. Since that time, fuel prices have increased markedly, as shown in Table 9.9. Fuel prices in 1976 were over 2.5 times those of 1970, causing an increase in production expenses of $150 \%$. Consequently, the proportion of total revenues earmarked for fuel purchasing has climbed from $72 \%$ in 1970 to $81 \%$ presently. Fuel purchasing increases since 1970 have caused the revenue requirement for the electric industry to increase by approximately $50 \%$.

Another major factor contributing to electricity prices is the expense of constructing additional or replacement generating capacity. In Table 9.10 the cost per kWh from steam electric plants in excess of 300 MWe is presented for the years 1967 to 1976. Prior to 1967, the average price decreased slightly every year, but commencing in 1967, the costs have risen at an increasing $r a t e$. In 1976 , additional generating capacity cost $\$ 320 / \mathrm{kW}$ compared to $\$ 206 / \mathrm{kW}$ in 1969 -- an increase of 55\%. These increases were precipitated by more stringent environmental control and regulation procedures and a concomitant jump in the allowance for funds during construction of new facilities.

The costs incurred raising capital to finance electric utility projects have risen substantially from earlier levels. In 1976, newly issued domestic electric and gas bonds yielded $8.92 \%$ as compared to $7.50 \%$ in 1972 and longterm financing by REA changed from $2.00 \%$ in 1970 to over $7 \%$ in 1976.

In spite of all of the aforementioned increases in electric utility expenses since 1970, the prices charged to the rate payer have increased by an average of only 28\%. During the same period federal incentives have increased 
TABLE 9.8. Disposition of One Revenue Dollar By Investor-Owned Electric Utilities (EIA April 1978a)

Disposition

Fossil-Fuel Expense

Nuclear-Fuel Expense

Purchased Power

Other Operations Expense

Maintenance Expense

Depreciation

Taxes Other than Income

Income Taxes - Net

Interest Charges

Other Deductions and Extraordinary Charges

Preferred Dividends

Common Dividends

Retained in Business

TOTAL
$\%$ of Total

26.5

0.5

6.1

19.0

5.5

8.2

8.3

3.7

10.1

0.1

2.2

6.9

$\frac{2.9}{100.0}$

TABLE 9.9. Fuel Costs of Electricity Generation (1977 \$/Million Btu) (EIA August 1978a)

$\begin{array}{lrrrrr}\frac{\text { Year }}{1976} & \frac{\text { Coal }}{90.31} & \frac{\text { Gas }}{110.33} & \frac{0 i 1}{211.83} & \frac{\begin{array}{c}\text { Weighted } \\ \text { Average }\end{array}}{119.71} & \frac{\text { \% Change }}{+1.44} \\ 1975 & 91.77 & 83.55 & 227.90 & 118.00 & +5.75 \\ 1974 & 87.26 & 58.87 & 236.21 & 111.59 & +72.24 \\ 1973 & 55.24 & 46.10 & 109.35 & 64.79 & +12.06 \\ 1972 & 55.21 & 43.90 & 85.20 & 57.82 & +6.17 \\ 1971 & 53.86 & 41.89 & 77.04 & 54.45 & +13.64 \\ 1970 & 48.55 & 42.15 & 57.13 & 47.92 & +7.76 \\ 1969 & 43.97 & 41.99 & 52.73 & 44.47 & -2.20 \\ 1968 & 44.42 & 43.72 & 57.14 & 45.47 & -2.53 \\ 1967 & 45.74 & 44.83 & 58.44 & 46.65 & -1.62 \\ 1966 & 46.15 & 46.67 & 60.49 & 47.42 & \end{array}$




\section{TABLE 9.10. Cost of Additional Generating Capacity}

(EIA August 1978a)

\begin{tabular}{|c|c|c|c|c|}
\hline Year & $\begin{array}{l}\text { Installed } \\
\text { Capacity } \\
\end{array}$ & $\begin{array}{l}\text { Plant Investment } \\
\text { (Million of } 1977 \$) \\
\end{array}$ & $(\$ / \mathrm{kW})$ & $\%$ Change \\
\hline $\begin{array}{l}\overline{1976} \\
1975 \\
1974 \\
1973 \\
1972 \\
1971 \\
1970 \\
1969 \\
1968 \\
1967\end{array}$ & $\begin{array}{l}5,242 \\
6,970 \\
9,816 \\
3,735 \\
5,347 \\
9,067 \\
4,863 \\
2,483 \\
5,115 \\
4,165\end{array}$ & $\begin{array}{r}1787.04 \\
1793.25 \\
2334.89 \\
969.28 \\
1159.90 \\
1854.21 \\
1238.32 \\
512.44 \\
1092.03 \\
831.15\end{array}$ & $\begin{array}{l}340.80 \\
256.73 \\
238.43 \\
259.16 \\
217.35 \\
204.96 \\
254.44 \\
206.63 \\
214.27 \\
197.84\end{array}$ & $\begin{array}{l}+32.75 \\
+7.68 \\
-8.0 \\
+19.24 \\
+6.05 \\
-19.45 \\
+23.14 \\
-3.57 \\
+8.31\end{array}$ \\
\hline
\end{tabular}

by over 150\%. It appears that additional incentives have offset the cost increases to maintain electricity prices at a relatively constant level.

A steady decline in prices prior to 1955 was not precipitated by increasing incentives, as prices dropped by $70 \%$ while incentives showed only moderate increases. The reduction in price was due to technological advances in production and transmission of electricity and economics of scale. The substantial increases in federal incentives since 1970 have helped to mitigate the effect of increased production expenses on electricity prices. It appears that continuing increases in federal incentives will be required to maintain the rate of electricity price escalation to socially acceptable levels.

\section{FEDERAL INCENTIVES AND ELECTRIC UTILITIES}

Federal incentives to the electric utility industry have not been applied equally among the various types of electric utilities. In this section, the three major types of electric utilities (investor-owned, government-owned, and cooperatively-owned) and the incentives applicable to each will be discussed. Considerations concerning differences in capital raising mechanisms, financing and interest cost differences, and antitrust regulations will also be identified in the attempt to clarify the impact of federal electricity production incentives. 


\section{Investor-Owned Electric Utilities}

Investor-owned electric utilities (IOUs) are privately held corporations. They are subject to regulations from both state and federal agencies. The federal agencies directly involved with IOU regulation are the Securities and Exchange Commission (SEC) and the Federal Energy Regulatory Commission (FERC). The following cases illustrate specific actions by the SEC and FERC that have impacted the investor-owned utility industry.

Accelerated Depreciation

In 1953, IOUs were permitted to use accelerated depreciation schedules for tax purposes. However, for reporting purposes straight line depreciation must be used. The difference between the taxes actually paid using accelerated depreciation and the taxes that would have been paid using straight line depreciation is called "Deferred Income Tax." For reporting purposes, deferred income tax is credited to a liabilities account when accelerated depreciation is greater than straight line depreciation. When the size of an IOU is stable or growing, the accelerated depreciation will be greater than straight line depreciation; so the deferred income tax represents a permanent tax savings. At one point in the late 1950's the IOUs were making a charge to an expense account for deferred taxes for rate making purposes but had been retaining the deferred tax account in an "earned surplus" account to avoid any diminution of net worth for borrowing purposes. In 1958 the American Institute of Certified Public Accountants (AICPA) backed by the SEC issued a bulletin stating that "Deferred Income Taxes" must be credited to a liability account and not to earned surplus. This bulletin and the subsequent SEC ruling was bitterly contested by the American Electric Power Company, a large investor-owned utility, and three of the AEPs subsidiaries filed suit against the AICPA (Fiflis and Kripke 1971). The reason behind the suit is that the IOUs did not want their borrowing power diminished because equity capital is more costly than debt capital. The suit failed but the pressure from the IOUs was intense and the resolution as described by $F$ iflis and Kripke (1971) was as follows: 
"The formidable contestants were the SEC itself and the powerful public utility group headed by a former chairman of the SEC. The end result was in substance a victory for the utility company and a retreat by the SEC. It adhered to its principle that the Deferred Tax account could not be designated part of Shareholder's Equity, but permitted the Deferred Tax account to be designated by the non-classifying title, 'Accumulated Amount Invested in the Business Equivalent to Reductions in Federal Income Taxes Resulting from Accelerated Amortization and Liberalized Depreciation, Which Is Recorded as Earned Surplus Restricted, or as a Reserve for Future Income Taxes, in Accounts Maintained Pursuant to State Regulatory Requirements.' Then the Commission authorized for the American Electric Power system a lower ratio of Shareholder's Equity than it customarily required, so long as the system had ample supplies of the account mentioned."

Depending on the state in which the IOU is operating, it can account for the accelerated depreciation by the 'flow-through' or the 'normalization' method. With the flow-through method, the IOU passes its tax savings on to its rate payers. With the normalization method the I OU continues to make a charge to an expense account for rate making purposes for taxes that it has not yet paid. In essence, the normalization method allows an IOU to charge rate payers now for taxes that are deferred for the IOU. The net effect is that the rate payers are forced to give the IOU an interest-free loan. There is currently $\$ 10.6$ billion worth of deferred taxes due to accelerated depreciation. A part of this amount has been passed on to consumers but the majority represents an interest-free loan to the IOUs. Currently, 35 states allow the use of the normalization method of accounting for IOUs using accelerated depreciation (Morgan December 1976).

\section{Investment Tax Credits}

The investment tax credit has been an intermittent incentive. There has been much controversy over whether it is needed in the utility industry. The 1 aw requires IOUs to make the investments necessary to provide the public with adequate electric power. In addition, the IOUs are guaranteed a fair rate of return on these investments. 
The effects of the investment tax credit are hard to measure because it has not been applied on a consistant basis for any length of time. When originally enacted in 1962 the investment tax credit for IOUs was set at 3\%. The credit was repealed in 1969 but reinstated in 1971 at a 4\% rate. In 1975 the rate was increased to $10 \%$ and in 1976 it was increased again to $11.5 \%$ for certain categories of IOUs effective in 1977 (Morgan December 1976). The investment tax credits given to IOUs amounts to a minimum of $\$ 4.4$ billion (see Table 9.11). Again there are two ways that an IOU can account for investment tax credits. Under the flow through method, the IOU passes the tax savings on to the rate payers in the period that the credit is received. Under the normalization method, the IOU amortizes the credits over the life of the asset for which the IOU received the credit. Under normalization, the IOU incorporates the reported taxes minus the amount of the tax credit amortized during that period into the rate base. The net effect of the normalization method is that rate payers are forced to give IOUs an interest-free loan with a term equal to the 1 ife of the asset. In the case of new power plants, this term can be as long as 35 years. The decision on whether an IOU may use a flow through or a normalization method in accounting for investment tax credits for the purpose

TABLE 9.11. Investment Tax Credits Provided to Investor-Owned Electric Utilities (EIA April 1978a)

\begin{tabular}{ll} 
Year & \\
\cline { 1 - 1 } 1977 & \\
1976 & TQ \\
1976 & \\
1975 & \\
1974 & \\
1973 & \\
1972 & \\
1971 & \\
1970 & \\
1969 & \\
1968 & \\
1967 &
\end{tabular}

\section{Millions of $1977 \$$}

$1,300.00(a)$
$375.00(a)$
$1,215.08$
603.40
197.17
269.24
251.30
129.56
40.54
105.41
131.55
130.37

(a) Estimates 
of incorporating costs into the rate base is made by the Public Utility Commission of each state. A discussion of impacts of the normalization method on consumers follows in the next section.

"Phantom Taxes"

The normalization method of accounting for investment tax credits and accelerated depreciation permits IOUs to charge rate payers for taxes that the IOUs have not actually paid. If an IOU grows fast enough and can make use of the normalization method of accounting, it can generate large amounts of income that is beyond the reach of the tax collector. For reporting to the stockholders, the IOU must use straight line depreciation and can charge taxes that have actually been deferred as an expense. Thus reported taxes appear higher than they actually were and reported income appears less than it actually was. If the IOU then distributes dividends that are in excess of its reported income, the Internal Revenue Service classifies the dividends as a return of assets rather than a distribution of profits. This makes the dividends tax exempt! In 1974 at least $\$ 796$ million (1977 \$) in cormon stock dividends paid out by IOUs were tax exempt ("Congress, PUCs Tackle Phantom Taxes" October 1977). The supporting data presented in Table 9.12 was developed by Senator Lee Metcalf (D-Montana).

The 1 aws and regulations surrounding utility regulation are very complex and the current efforts to change them are summed up in the following excerpt from The Power Line ("Congress, PUCs Tackle Phantom Taxes" October 1977).

"A new bill introduced by Senator Lee Metcalf (D-Mont.) and Rep. Fortney (Pete) Stark (D-Calif.) would do away with the phantom tax problem. The legislation absolves the nation's electric utilities from all federal income tax liability. In its $\mathrm{place}$, the $\mathrm{plan}$ substitutes a kilowatt-hour usage tax designed to generate the same amount of revenue that the U.S. Treasury normally collects from the utilities for income taxes - about $\$ 700$ million annually...

The utilities are not so enthused about losing their federal tax liability. 'We should pay taxes like any other business,' says Robert Dolan of the National Association of Electric Companies (NAEC), the power industry's lobbying arm. Edward Frye of the Edison Electric Institute (EEI), the electric utility trade association, adds, 'We're as patriotic as anyone else'." 
TABLE 9.12. Representative Investor-0wned Electric Utilities Distributing Tax-Free Dividends in 1974 (1974 \$) ("Congress, PUCs Tackle Phantom Taxes" October 1977)

\begin{tabular}{|c|c|c|c|}
\hline & $\begin{array}{l}\quad \% \text { of } \\
\text { per share } \\
\text { dividend } \\
\text { tax free } \\
\end{array}$ & $\begin{array}{c}\text { Total } \\
\text { dividends } \\
\text { paid } \\
\end{array}$ & $\begin{array}{c}\text { Total } \\
\text { tax free } \\
\text { dividends } \\
\end{array}$ \\
\hline $\begin{array}{l}\text { Arizona Public Service Co. } \\
\text { Atlantic City Electric Co. } \\
\text { Boston Edison Co. } \\
\text { Carolina Power \& Light Co. } \\
\text { Central Hudson Gas \& Electric Co. } \\
\text { Central Louisiana Electric Co. } \\
\text { Central Vermont Public Service Corp. } \\
\text { Columbus \& Southern Electric Co. } \\
\text { Concord Electric Co. } \\
\text { Delmarva Power \& Light Co. } \\
\text { Detroit Edison Co. } \\
\text { Duke Power Co. } \\
\text { Duquesne Light Co. } \\
\text { Exeter \& Hampton Electric Co. } \\
\text { Fitchburg Gas \& Electric Light Co. } \\
\text { Green Mountain Power Co. }\end{array}$ & $\begin{array}{r}24 \\
62 \\
100 \\
100 \\
91 \\
17 \\
44 \\
49 \\
1 \\
38 \\
51 \\
100 \\
47 \\
35 \\
100 \\
100\end{array}$ & $\begin{array}{r}17,680,000 \\
13,530,313 \\
23,264,180 \\
37,374,994 \\
7,327,842 \\
8,361,403 \\
2,960,379 \\
15,092,000 \\
152,000 \\
17,995,232 \\
65,249,245 \\
59,263,350 \\
36,378,004 \\
296,400 \\
594,000 \\
690,566\end{array}$ & $\begin{array}{r}4,243,200 \\
8,388,794 \\
23,264,180 \\
37,374,994 \\
6,645,620 \\
1,404,716 \\
1,302,566 \\
7,373,951 \\
841 \\
6,820,193 \\
33,277,115 \\
59,263,350 \\
16,915,772 \\
103,651 \\
594,000 \\
690,566\end{array}$ \\
\hline
\end{tabular}

It appears that the tax advantages are very attractive to the IOU industry.

The IOUs maintain two entirely separate sets of books: one set of books is for reporting to the stockholders and one set is for the IRS. The books kept for the stockholders usually use straight-line depreciation schedules for investments in plants and facilities. The books kept for the IRS use accelerated depreciation and normalization where possible. The amount of depreciation over the life of the asset is the same under both methods. It is the timing of the depreciation for tax purposes that makes the difference. On a $\$ 1$ billion $\mathrm{plant}$ with a service 1 ife of 30 years with no salvage value, an IOU with a $48 \%$ tax rate and an $8.25 \%$ cost of capital would, under accelerated depreciation have a tax schedule with a $\$ 60$ million present value savings. An example is detailed in Appendix E.

Construction Work in Progress and Allowance for Funds Used During Construction

The state and federal regulatory policies on construction work in progress (CWIP) and allowance for funds used during construction (AFDC) have a tremendous 
impact on IOUS. Except for pollution control equipment and fuel conversion facilities, the current federal regulations do not allow the costs of CWIP to be put into the rate base. The reason for this dates back to the original Federal Power Act which stipulated that the utility plant had to be "used and useful" in order to be included in the rate base. Capital costs of new electric plants, construction times, and interest rates increased, and these pressures lead to the creation of AFDC. The creation of AFDC recognized that the IOUs needed to pay a return (or interest) on invested (or borrowed) capital used to construct new facilities. How "Allowance for Funds Used During Construction" (AFDC) works and what it is, is described by the following excerpt from the 1977 Portland General Electric Co. Annual Report (Portland General Electric Co., Inc. 1978):

"Allowance for Funds Used During Construction (AFDC) - AFDC represents the net cost for the period of construction of borrowed funds used for construction purposes and a reasonable rate on other funds when so used. AFDC is capitalized as part of the cost of utility plant and is credited to income but does not represent cash earnings. Effective January 1, 1977 the Federal Energy Regulatory Commission (FERC) ordered that the allowance for borrowed funds used during construction be credited to interest charges and that the allowance for other (equity) funds used during construction be credited to income. For comparative purposes, AFDC has been reclassified in the 1973 through 1976 consolidated statements of income and changes in financial position. The amount of AFDC capitalized has varied from year to year, depending principally upon the amount of construction program expenditures. The allowance for borrowed funds used during construction is calculated on a pre-tax basis. AFDC is not capitalized for income tax purposes. A $7 \%$ rate is used on other construction costs, except nuclear fuel for the Trojan nuclear plant which is capitalized at the actual interest rate of the nuclear core notes. Effective November 15, 1977 a 9.32\% rate, the maximum rate under the FERC order, was adopted for construction expenditures relating to the Pebble Springs, Skagit and Colstrip projects."

The AFDC is eventually added to the total depreciable plant for rate making purposes (though not for tax purposes) and the IOU recovers the AFDC from the rate payers. During a time of high interest rates and rising prices, the present value of the eventual 'AFDC' cash inflows recovered from rate payers is small compared to the present value of the actual interest payments made. This 
is especially the case for construction efforts taking 8 to 10 years. In 1976 the IO industry recorded $\$ 1.86$ billion of AFDC as income. The effect of this FPC ruling is significant.

If all CWIP costs were allowed in the rate base there would be no AFDC. In this case, the rate payers would provide a return on the net investment in existing plant and the new investment in CWIP. The IOU would receive an immediate return on new construction investment instead of having to wait until the plant is in service. Like the accelerated depreciation case, the issue is more the timing of dollar flows and not the total dollar amount. Many industry experts believe that CWIP in the rate base will be essential for continued growth of the industry.

\section{Government Competition}

Competition has been the most important indirect federal action that has stimulated the I $\boldsymbol{O}$ industry. The battle of public versus private power has raged for decades. When the U.S. Supreme Court upheld the constitutionality of the TVA power sales from Wilson Dam in the 1936 "Ashwander Case," investorowned utilities realized that if they did not amply satisfy the demand for electric power the federal government would. Federal government ownership and operation of electric utilities is a direct competitive threat to the IOU industry and has stimulated the production of electricity by the IOU industry. The IOUs have held the ir own in the last decade as evidenced by Table 9.1. However, for reasons discussed later in the section on the Quest for Capital, this may not continue.

Government-Owned Electric Utilities

Government-owned electric utilities (GOUs) include municipal utilities (MUs), federal agencies, state projects and public power districts (PPDs). The GOUs do not pay federal tax and are not-for-profit entities whose purpose is to supply electric energy to their customers at the lowest possible rates consistent with sound business practices. Each of the sub-types of GOUs has a different scope of operations and a different structure. 


\section{Federal Agencies}

Federal agencies like the BPA and TVA are very large, in fact, regional in scope. When they were initially created in the 1930's, they received funds from the U.S. Treasury for the construction and operation of their power projects. Today they are independent corporations wholly owned by the U.S. Government. The responsibilities of these agencies goes beyond producing and marketing power. The TVA is charged with the social and economic well being of the entire area in which it operates. In the use of water power, the power requirements of the BPA are secondary to the water requirements of the Bureau of Reclamation. Thus, these organizations are broad in a social, as well as geographic, scope.

The federal agencies market excess power from federal hydroelectric projects and maintain extensive transmission systems by which to market the power. The customers for these agencies in order of preference are:

- Public Utilities and Cooperatives

- Direct Service Industries

- Investor-Owned Utilities.

The federal agencies do not maintain distribution systems whereas distribution systems are the mainstay of the other GOUs.

\section{Municipal Utilities}

Municipal utilities (MUs) are not-for-profit municipal corporations and are generally an integral part of local government. They are primarily involved with the distribution of electricity, al though some municipal utilities own and operate generation and transmission facililities. The policymaking body is usually the city council. The responsibilities of a municipal utility are summarized well in the following passage from City of Seattle, Ordinance 107787 .

"Under the direction of the Mayor, the duties of the Superintendent of City Light include:

(a) Managing, controlling, operating and maintaining the municipal light and power system and related facilities. 
(b) Enforcing and implementing City ordinances, contracts, and rules which related to the City Light Department.

(c) Appointing, supervising and controlling all officers and employees of the City Light Department, subject to personnel ordinances and rules of the City.

(d) Making maps, surveys, profiles, plans, specifications, estimates and reports in connection with the City Light Department as directed by the City.

(e) Laying out, directing, constructing and supervising all public works of the City Light Department.

(f) Performing other duties as directed by the City."

Municipal utilities raise capital by issuing tax-exempt bonds. The size of the utility is usually confined to the limits of the local governing body.

Public Power Districts

Public power districts (PPDs) are not-for-profit municipal corporations. A PPD is formed by a majority vote of the people in its service area for the purpose of providing electric service in a prescribed area on a cost-of-service basis. A PPD is a separate and distinct public agency which has its own separate policy board elected by the local voters. A PPD is not owned by nor a branch of a city or state government. Some of the fundamentals of the laws concerning PPDs are (Washington Public Utility Districts Association June 1, 1978):

- The right of eminent domain whereby the will of the majority may be exercised.

- The right to finance by revenue bonds.

- The right to establish rates and services.

- The right to cooperate jointly with other PPDs.

The key points about PPDs are that they can set their own rates, exercise the right of eminent domain, and issue tax-exempt securities.

The State of Washington has a long history of public power. The Public Utility Districts (PUDs) of Washington State have cooperated to create a Joint 
Operating Agency (JOA) called the Washington Public Power Supply System (WPPSS). WPPSS is currently embarking on a massive construction program that will make it the largest single non-federal public utility in the United States. It is able to do this because of its structure and the net billing agreements (a) it has with the BPA. In the past, small public utilities bought small portions of capacity from new electric plants built by investor-owned utilities. Today, the creation of organizations like WPPSS has reversed that situation. Several IOUs have bought small portions of the generating plants WPPSS is building.

REA-Financed, Cooperatively-Owned Electric Utilities

REA-financed, cooperatively-owned utilities (REA Co-ops) are not-forprofit corporations created by the members of the corporation for the purpose of providing electricity to the members. Any person, corporation, or other entity in the service area of the utility may become a member for a nominal fee. The members elect the directors who run the corporation. REA Co-ops, like government-owned utilities, can debt finance $100 \%$ of their plant and construction costs. REA Co-ops can raise capital in a variety of ways. First, they can apply for low interest loans from the Rural Electrification Administration. Second, they can apply for loans from the National Rural Utilities Cooperative Finance Corporation (CFC). Third, they can apply for REA or CFC loan guarantees for loans from private lending institutions. Fourth, al though it is seldom done, REA Co-ops can issue their own debt securities. Bonds issued by REA Co-ops are not tax-exempt.

REA electric loans are made to non-profit and cooperative associations, public bodies, and other electric utilities. These loans finance the construction and operation of distribution lines or systems, generating plants and transmission lines to provide initial and continued adequate electric service to persons in rural areas. About $99 \%$ of the REA-financed electric systems are cooperatives, owned and controlled by their consumer-members.

REA-financed distribution systems typically buy their power wholesale from existing suppliers and deliver it at retail to their consumers. REA generation

(a) Described in section on the Quest for Capital. 
and transmission loans are made only where no adequate or dependable source of power is available or where the rates offered by existing power sources would result in a significantly higher cost of power to the consumers than the cost from facilities to be financed by REA.

Most REA loans bear interest at the standard rate of $5 \%$. A special $2 \%$ rate is available for electric and telephone borrowers that have experienced extenuating circumstances or extreme hardship or that meet criteria set forth in the $1 \mathrm{aw}$. These include electric systems with an average consumer density of two or fewer per mile or an adjusted plant revenue ratio of 9.0 or more and telephone systems with an average subscriber density of three or fewer per mile. The plant revenue ratio is the total of distribution and general plant cost divided by the annual gross revenue after excluding the cost of power (REA 1974).

The National Rural Utilities Cooperative Finance Corporation (CFC) is a non-profit financing cooperative, organized by rural electric systems throughout the U.S. to provide themselves with an independent source of loan funds. Incorporated in April 1969, CFC's membership includes 840 cooperatively owned rural electric distribution and power supply systems and 48 statewide, regional, and national organizations whose membership consists of rural electric distribution and power supply systems. CFC's distribution system members provide electrical service to approximately 26 million consumers located in rural areas and small towns in 46 states. CFC makes available five types of loan programs to its member systems; long-term secured loans, intermediate-term loans, lines of credit, "weatherization" loans, and guarantees of pollution control financing (National Rural Utilities 1975).

As a cooperative organization, CFC charges its member-systems the lowest possible loan interest rates commensurate with prudent financial management. Loan interest rates are based upon CFC's cost of funds to support its loan programs, plus administrative costs. Currently, the interest rate for CFC long-term loans is fixed for the first seven years of the loan. After that time, another interest rate will be fixed for an additional period of time or to the maturity of the 1oan. This rate will reflect CFC's cost of funds to support the program at that time. 
CFC's intermediate-term rate is the lowest bank prime rate (as published in The New York Times on the last day of the prior month) plus 1\%; the 1 ine of credit rate is the lowest bank prime rate, plus 1/2\%; and the weatherization loan rate is based on CFC's cost of funds to support the program, plus $1 / 2 \%$ for administrative expenses.

Short-term funds are raised through the sale of CFC commercial paper in the money market by CFC's commercial paper dealer; the direct sale of commercial paper to member-systems; and the issuance of bank "master notes" (sixmonth, floating-rate notes) to bank trust departments. The CFC's commercial paper is rated "A-1, Prime-1." The sale of commercial paper and master notes is supported by lines of credit with major commercial banks throughout the country.

The REA guarantees loans to facilitate the obtaining of financing for 1 arge-scale electric facilities from non-REA sources. Guarantees are considered if such loans could have been made by REA under the Act and may be made concurrently with an REA loan. Guaranteed loans bear interest at a rate agreed upon by the borrower and the lender and may be obtained from any legally organized lending agency qualified to make, hold, and service the loan.

In 1974, REA entered into an agreement with the Federal Financing Bank (FFB), whereby FFB agreed to purchase obligations guaranteed by the REA Administrator. Interest rates on FFB loans are determined at the time each advance of funds is made and are based upon the cost of money to the FFB. REA acts as an agent for the FFB and performs all loan servicing functions as authorized by the act creating FFB. Borrowers' dealings are with REA and all policies and procedures of REA are applicable to a guaranteed loan.

In the 53-yr period from 1882, when the first central generating system went into service, to 1935, when REA was created, only $10.9 \%$ of all farms in the United States had obtained electric service. Today, $98.6 \%$ of the $2.8 \mathrm{mil}$ lion U.S. farms are electrified, and REA-financed systems serve about half of these farms.

REA has made about $93 \%$ of its electric loans to cooperatives organized under state laws by rural people. These organizations are local, independent 
private enterprises. About 50\% of the electric loans thus far approved by REA have been for distribution facilities, $49 \%$ for generating and transmission facilities, and 1\% for financing of farmstead wiring, plumbing, electrical equipment, and irrigation facilities.

Consumers on REA-financed lines have nearly doubled their use of electricity every seven years (see Table 9.13). Average monthly consumption per residential consumer increased from $479 \mathrm{kWh}$ in 1965 , to $840 \mathrm{kWh}$ in 1975 . The REA-financed, cooperatively owned electric utility concept has gained recognition throughout the world for its success in bringing low cost power to rural people. The key ingredients to this success have been the cooperative structure and the access to low cost financing.

The Quest for Capital

The electric utility industry is the most capital intensive of all major industries. In 1976 investor-owned utilities received $\$ 1.00$ of net operating

TABLE 9.13. Total Sales of Electricity by REA Borrowers (Edison Electric Institute 1971, 1978)

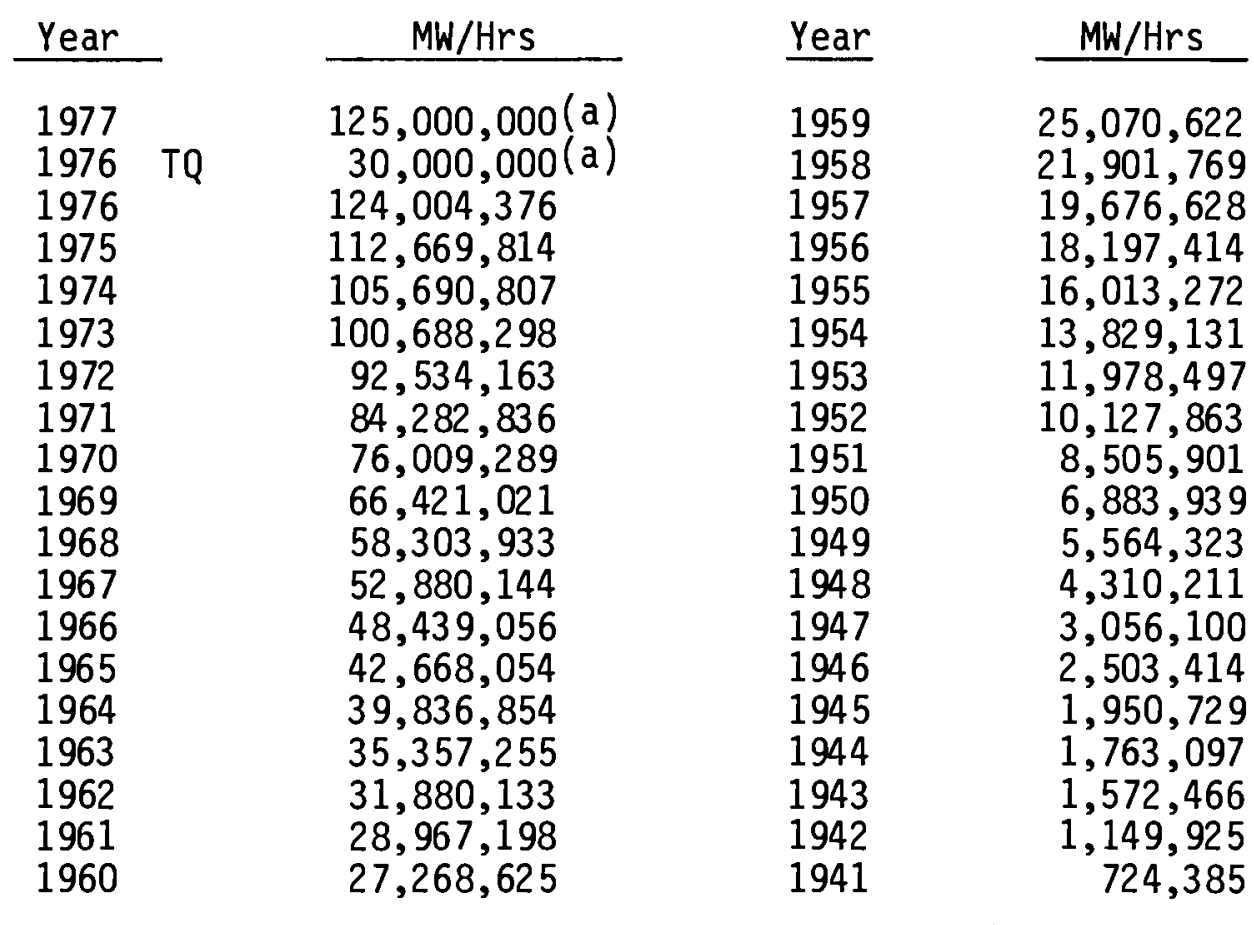

(a) Estimate 
income for every $\$ 16.00$ of net investment in utility plants. They received only $\$ 1.00$ of gross operating revenue for every $\$ 3.75$ of gross utility plants. The projected capital expenditures of electric utilities for the near future is presented in Table 9.14 .

Each of the utility types have their own mechanisms to raise capital. However, the ease of raising capital and the price (not necessarily interest alone) that must be paid for the use of that capital differs substantially among utility types. The basic capital raising mechanisms of the utility types are presented in Table 9.15. It is interesting to note that IOUs are the only utility type that cannot debt finance $100 \%$ of the cost of new plant construction. Except for a limited number of pollution control bonds, the mortgage bonds of an IOU are taxable bonds. That is, the bond holder must pay income tax on the periodic interest income he receives. All other utility types can debt finance $100 \%$ of new plant and equipment and most can use taxexempt bonds with a lower interest rate. This is an important distinction because debt payments are fixed payments and payments for equity capital (dividends) are not fixed. Utilities generally retain a portion of their earnings and therefore stockholders expect the utility and their future dividends to grow. The argument that common stock dividends do not have to be paid does not apply to the electric utility industry. In the investor-owned electric utility industry payment of dividends is, in reality, mandatory although it may not be required by $1 \mathrm{aw}$. In the past 20 years only two IOUs, Potomac Electric and Consolidated Edison of N.Y., have omitted or reduced dividends. This action had such a negative impact on their ability to raise capital that the two utilities have since restored or increased their dividend.

The difference between the ability of investor-owned electric utilities and government and cooperatively owned electric utilities to raise capital at

TABLE 9.14. Projected Capital Expenditures of Electric Utilities ("Utility Programs Adequate for Power Demands" September 15, 1972)

$\frac{\text { Period }}{1976 \text { to } 1980}$

Projected Expenditures (Billions of $\$$ )

$$
\begin{aligned}
& 112.7 \\
& 139.0
\end{aligned}
$$


TABLE 9.15. Capital Raising Mechanisms of Different Electric Utility Types.

\begin{tabular}{|c|c|c|c|c|c|}
\hline Utility Type & $\begin{array}{l}\text { Equity or } \\
\text { Non-Debt } \\
\text { Financing }\end{array}$ & $\begin{array}{l}\text { Debt } \\
\text { Financing }\end{array}$ & $\begin{array}{c}\text { Maximum } \% \\
\text { Debt Financing }\end{array}$ & $\begin{array}{l}\text { Principal Sources } \\
\text { of Borrowed Capital }\end{array}$ & Financial Backing \\
\hline Investor-0wned & $\begin{array}{l}\text { Common \& } \\
\text { Preferred } \\
\text { Stock }\end{array}$ & $\begin{array}{l}\text { First Mortgage } \\
\text { Bonds }\end{array}$ & $60 \%$ & Commercial Money Market & $\begin{array}{l}\text { Debt is backed by } \\
\text { Equity Capital and/or } \\
\text { Net Billing Agreements }\end{array}$ \\
\hline $\begin{array}{l}\text { Government-Owned } \\
\text { Federal Agencies }\end{array}$ & & $\begin{array}{l}\text { Tax-Exempt Bonds } \\
\text { Notes }\end{array}$ & $100 \%$ & $\begin{array}{l}\text { U.S. Treasury Federal } \\
\text { Financing Bank } \\
\text { Commercial Money } \\
\text { Market }\end{array}$ & $\begin{array}{l}\text { Debt is backed by the } \\
\text { Federal Financing Bank }\end{array}$ \\
\hline $\begin{array}{l}\text { Public Power Districts/ } \\
\text { Joint Operating } \\
\text { Agencies }\end{array}$ & $\begin{array}{l}\text { Taxes can be } \\
\text { levied }\end{array}$ & $\begin{array}{l}\text { Tax-Exempt Revenue } \\
\text { Bonds } \\
\text { Long-Term Low } \\
\text { Interest Loans } \\
\text { Notes }\end{array}$ & $100 \%$ & $\begin{array}{l}\text { Commercial Money } \\
\text { Market } \\
\text { Rural Electrification } \\
\text { Administration }\end{array}$ & $\begin{array}{l}\text { Debt is backed by } \\
\text { Future Revenue and/or } \\
\text { Net Billing Agreements }\end{array}$ \\
\hline Municipal Utilities & $\begin{array}{l}\text { Taxes can be } \\
\text { levied }\end{array}$ & Tax-Exempt Bonds & $100 \%$ & $\begin{array}{l}\text { Commercial Money } \\
\text { Market }\end{array}$ & $\begin{array}{l}\text { Debt is backed by } \\
\text { Future Revenues and/or } \\
\text { Net Billing Agreements }\end{array}$ \\
\hline & & $\begin{array}{l}\text { Short-Term Loans } \\
\text { Mortgage Bonds } \\
\text { (seldom issued) }\end{array}$ & & $\begin{array}{l}\text { Rural Electric } \\
\text { Utilities Cooperative } \\
\text { Finance Corporation } \\
\text { Commercial Money } \\
\text { Market }\end{array}$ & \\
\hline
\end{tabular}


low cost is tremendous. Government and cooperatively owned utilities have lower cost capital than investor-owned utilities. Financial analyst T. P. Friery recently conducted a private study comparing the ultimate cost of a new electric plant for an IOU and a joint operating agency (JOA). The hypothes is and conclusions are presented below with the assumptions and calculations in Appendix $F$. The analysis shows that a JOA's financial structure is such that it can finance a large generating plant for a lower total cost than an IOU. However, the analysis says nothing about managerial ability or the effect of "phantom taxes."

Financing and Interest Cost Comparisons for JOAs and IOUs

The legal structure of a JOA which permits the financing of $100 \%$ of projects with municipal revenue bonds and disregards concern for profit from the operating facility and the commitment of capital, results in substantially less financing and interest costs than an IOU utility for an identical operating facility. Two conclusions can be drawn from the calculations in Appendix F:

- The net financing and interest costs for financing an assumed $\$ 1$ billion plant will be $\$ 924,641,000$ less for JOAs than IOUs during a 5-yr construction and 30-yr operation phase. This represents an overall conservative cost reduction of $24 \%$ during the cycle for financing and interest costs and disregards consideration of fuel, manpower, and maintenance.

- The net financing and interest costs for financing an assumed $\$ 1$ billion plant could be as much as $\$ 1,367,497,000$ less for JOAs than IOUs during a 5-yr construction and 30-yr operation phase. This represents a cost reduction of $39 \%$ during the cycle if JOA bonds are sold at $6.25 \%$ as opposed to $7.25 \%$ in the above statement.

\section{Construction Phase}

JOA - Net financing and interest costs during an assumed 5-yr construction period, making level construction payments, including capitalizing interest from bond sales for 2 years from date of sale or estimated date of commercial operation, whichever is shorter for a $\$ 1$ billion plant for a JOA, results in total costs of $\$ 185,751 \mathrm{million}$. 
IOU - Net financing and interest costs during an assumed 5-yr construction period, including AFDC at an $8 \%$ rate for a $\$ 1$ billion plant for an investorowned utility would result in total net costs of $\$ 542,169$ million.

\section{Operation Phase}

JOA - Net financing and interest costs during an assumed 30-yr operating period including $\$ 300$ million in bonds sold to capitalized interest during the construction period, including interest income that will be earned from investment of reserves and interest payments on bonds for a JOA results in total net cost of $\$ 2,491,647,000$. Included would be the availability of an estimated $\$ 63,125$ million in reserves from bond proceeds.

IOU - Financing and interest costs during an assumed 30-yr operating period for an investor-owned utility results in total gross costs of $\$ 3,296,700,000$. No funds are available for decommissioning, and the $\$ 150,000,000$ in preferred stock and $\$ 350,000,000$ in common stock are assumed as part of the financing and interest costs.

\section{Decommissioning Phase}

$J O A$ - Net financing and interest costs, including construction costs and retirement of bonds issued and deduction of funds available for decommissioning costs results in total plant costs of $\$ 3,914,173,000$ for a J0A. Additionally, $\$ 130,000,000$ provided by the participants could be returned or used to pay decommissioning costs but are not considered as a reduction of net costs.

IOU - Net financing and interest costs, including the common and preferred stock sales used to finance construction, results in total plant costs of $\$ 4,838,914$ for IOUs. It should be noted that the $\$ 500$ million in cormon and preferred stock sales would not be retired and would have dividend requirements as long as they were outstanding. However, for purposes of comparability to a JOA they are assumed to be retired.

The Current Trends of Private Power

Investor-owned utilities have kept up with rapid growth in the past 10 years but whether they can continue to do so is uncertain. Federal and other taxes paid by IOUs are a much smaller percentage of operating income 
today than in 1967. The number of times long-term debt interest is earned has declined and is approaching the default limit. Part of the reason for this is the increase in the cost of long-term debt. These income account relationships are shown in Table 9.16 (EIA Apri1 1978a).

One of the ways IOUs have used to get access to lower cost capital has been to purchase power from new plants built by municipal utilities. There have been instances where a MU would build a plant for the purpose of selling a large block of firm power to an IOU. To curtail this practice, the Treasury Department recently promulgated regulations that would deny tax-free status to the interest on the municipal bonds if more than $25 \%$ of the projects power output is sold to systems which are not authorized to issue tax-exempt bonds.

Net Billing Agreements

The BPA has entered into agreements with both an IOU and a JOA to support the construction of thermal power plants under what is called a "net billing agreement." What this agreement is and the level of BPA's involvement is summarized in Note 5 of the 1977 BPA Annual Report presented below (BPA 1978).

"Note 5. Commitments to Exchange Power and Acquire Project Capability: Existing net billing and exchange agreements provide that BPA will acquire all or part of the generating capability of the nuclear power plants listed in the table below. BPA is obligated to make payments exchange power, or apply credits (net billings) to participating customers equal to the customers' portions of the annual project costs, including annual debt service requirements, whether or not the projects are completed operable, or operated. The "Present Termination Commitment" represents the outstanding debt issued to finance the projects (without credit for salvage of assets or unspent construction funds) which would be payable over the varied financing repayment periods if the projects were terminated as of September 30, 1977.

BPA's commitment period under the net billing agreements extends for the life of the projects, except that the terms of the Trojan Nuclear Project net billing agreements under which Eugene Water \& Electric Board (Eugene) assigned its $30 \%$ share of the project output to BPA and other participants, contain a provision allowing Eugene to withdraw the project capability for use in its own system beginning in 1984. Eugene has until July 1, 1978 (under an agreement granting a one-year extension from the original July 1 , 1977 not ification date) to give BPA notification of its intention to withdraw 
TABLE 9.16. Selected Income Relationships of Investor-Owned Class A \& B

Electric Utilities, 1967 to 1976 (EIA April 1978a)

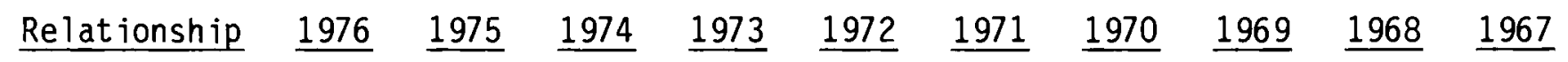

\begin{tabular}{|c|c|c|c|c|c|c|c|c|c|c|c|}
\hline \multirow[t]{2}{*}{$\begin{array}{l}\text { Percent of } \\
\text { Electric } \\
\text { Operating } \\
\text { Revenues }\end{array}$} & $\begin{array}{l}\text { Income } \\
\text { Taxes } \\
\text { Electric }\end{array}$ & 1.0 & 1.8 & 1.4 & 2.9 & 3.5 & 4.3 & 5.6 & 8.0 & 9.2 & 9.0 \\
\hline & $\begin{array}{l}\text { Other } \\
\text { Taxes } \\
\text { Electric }\end{array}$ & 8.6 & 8.8 & 9.2 & 10.4 & 10.9 & 11.0 & 11.2 & 11.0 & 10.9 & 10.8 \\
\hline \multirow{3}{*}{$\begin{array}{l}\text { Interest on } \\
\text { Long Term } \\
\text { Debt }\end{array}$} & $\begin{array}{l}\text { Percent of } \\
\text { Operating } \\
\text { Revenues }\end{array}$ & 8.9 & 9.0 & 9.1 & 9.6 & 9.6 & 9.3 & 8.6 & 7.7 & 7.0 & 6.5 \\
\hline & $\begin{array}{l}\text { Average } \\
\text { Interest } \\
\text { Rate }\end{array}$ & 7. & 6.8 & 6.3 & 5.9 & 5.7 & 5.5 & 5.1 & 4.6 & 4.3 & 4.0 \\
\hline & $\begin{array}{l}\text { Times } \\
\text { Earned }\end{array}$ & 2.4 & 2.4 & 2.4 & 2.6 & 2.6 & 2.6 & 2.7 & 3.0 & 3.2 & 3.5 \\
\hline
\end{tabular}


project capability. Eugene has notified BPA that, in the event the extension is determined to be invalid for any reason, it will withdraw substantially all of such capability in increments from 1984 through 1997. The net billing agreements provide for the repayment by Eugene to BPA of the net billing advances existing at the dates related capability is withdrawn. No such withdrawal options exist for the WPPSS projects. See Note 1 for information concerning net billing advances and amortization thereof."

The demonstrated ability of the BPA to pay the debt service on net billed plants when commercial operation is delayed reduces the construction risk for the bondholder. Also, the BPA has the ability to market power both within and outside the Northwest once the plants are operating. Thus, not only does the JOA, in this case WPPSS, have the ability to issue tax-exempt bonds, but the bonds are backed by agreements with one of the largest federal power marketing agencies. This greatly reduces the cost of capital for the JOA.

The Preference Clause

The preference clause is one of the cornerstones of public power. It was first approved by Congress in 1902 and has since been reaffirmed by Congressional enactments 31 times. The preference clause as it appears in one part of the Bonneville Project Act is as follows:

"832c. Distribution of electricity; preference to public bodies and cooperatives - General Provisions

(a) In order to insure that the facilities for the generation of electric energy at the Bonneville project shall be operated for the benefit of the general public, and particularly of domestic and rural consumers, the administrator shall at all times, in disposing of electric energy generated at said project, give preference and priority to public bodies and cooperatives."

The preference clause is currently under severe attack by IOUs in the Pacific Northwest. The BPA has not renewed contracts with IOUs for firm power due to the increased demand from public power and cooperative organizations. This has resulted in a large price differential between public and private power consumers, as shown in Figure 9.4. In some areas, a neighbor across the 
street may pay almost twice as much for electricity. Lawsuits filed by Portland General Electric Co. and others are currently pending against the BPA to essentially abolish the preference clause. The arguments for abolishing the preference clause range from rate disparities to conservation efforts to environmental considerations. The basic argument for retaining the preference clause was summed up recently by Alex Radin, Executive Director of the American Public Power Association in the following passage.

"The preference clause embodies a fundamental public policy namely that the people, through their own non-profit institutions, shall have first right in obtaining property disposed of by the federal government. The preference clause also has provided antimonopoly protection for consumers by assisting competitive systems which establish a yardstick against which one can compare utilities. It has also supported the opportunity for local control over electric service.

In times past, many smaller municipal electric systems and rural electric cooperatives - struggling to compete against large private power companies, and often denied access to wholesale power at a reasonable price or under equitable conditions - could not have survived if they had not had access to federal power on a preference basis."

The argument also states that if equalization of rate disparities were taken to its ultimate extreme, rates would have to be equalized nationally. Some rate disparities will tend to diminish due to increasing demand and higher cost new sources power for all utilities.

\section{Antitrust Regulation of Regulated Utilities}

"Competition is our fundamental national policy" (U.S. versus Philadelphia National Bank, 374 U.S. 321, 1963). This principle may not be applicable to regulated utilities like the electric utility industry where Congress ostensibly has decided that the public interest is best served, not by free competition but rather by direct and uniform regulation of interstate operations. Even though a regulated monopoly may promote the public interest by preventing waste, nevertheless, established court and Congressional precedents now impose the obligation upon regulatory agencies to enforce antitrust laws by determining whether anticompetitive policy of regulation are outweighed by the public 

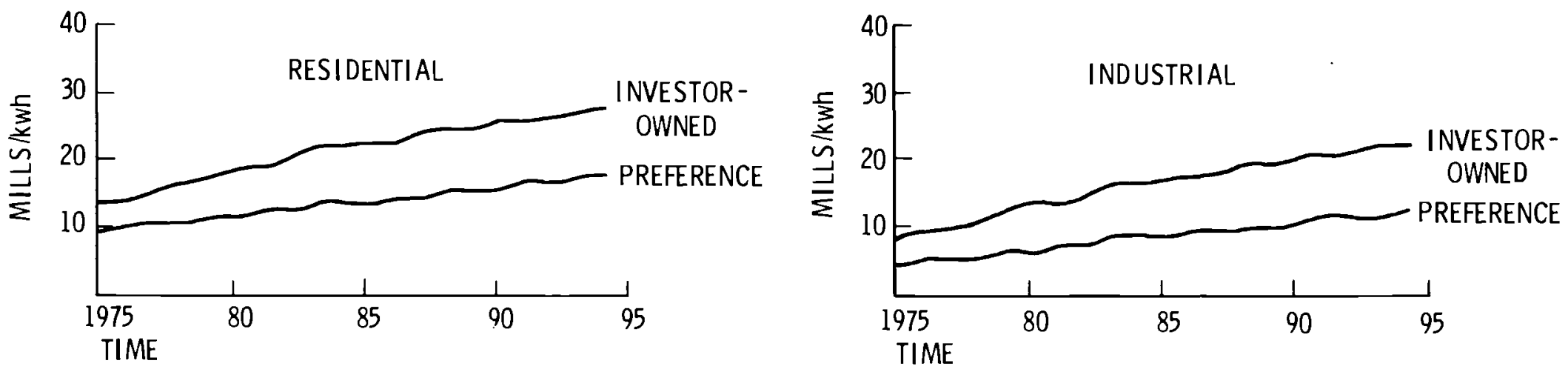

$\stackrel{0}{0}$
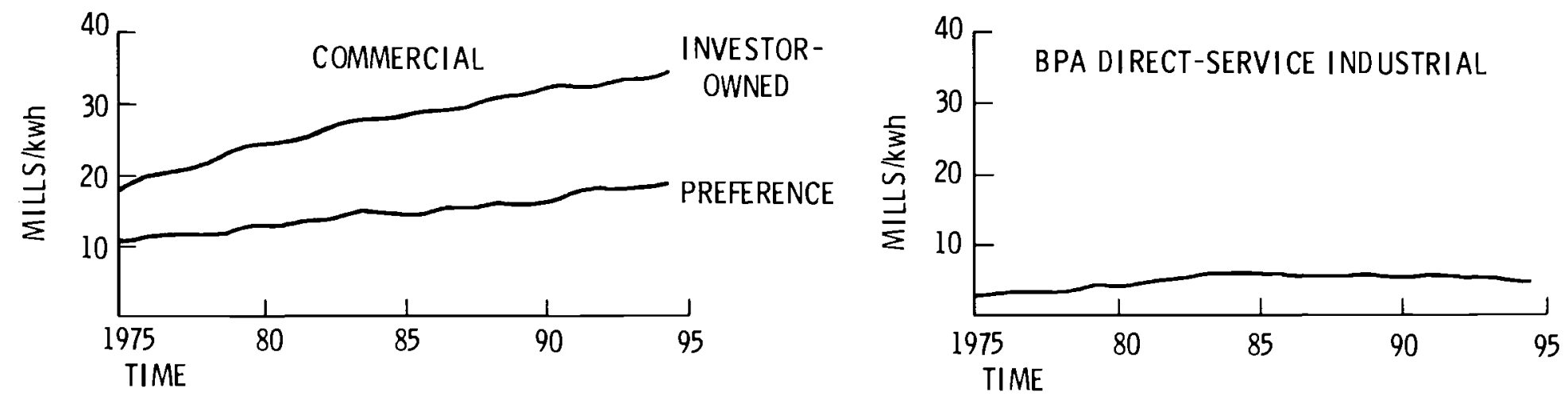

FIGURE 9.4. Bonneville Power Administration Base Alternative Electric Energy Prices (1944 to 1975) (In 1974 \$) (BPA July 22, 1977) 
benefits of regulated monopoly. In Northern Natural Gas Co. versus Federal Power Commission (399 F.2d 958, 959, 971, D.C. Cir. 1968), the court observed:

\begin{abstract}
". . it appears that the basic goal of direct governmental regulation through administrative bodies and the goal of indirect governmental regulation in the form of antitrust law is the same--to achieve the most efficient allocation of resources possible... This analys is suggests that the two forms of economic regulation complement each other."
\end{abstract}

"Unless the Commission finds that other important considerations militate in favor of the joint venture and that these considerations are more beneficial to the public than additional competition, the antitrust policies should be respected. . . ."

The evolution of judicial precedent directing the FPC to consider in its analys is of public policy the balance between anticompetitive impact and regulated monopoly illustrates the pervasiveness of competition as the linchpin of our economic system. In Otter Tail Power Co. versus United States (410 U.S. $366,1973)$, the U.S. Supreme Court held that strategic dominance in the transmission of power prevented potential entrants into the retail distribution business from obtaining electric power from other sources of supply and, therefore, Otter Tail Power Co. violated Sec. 2 of the Sherman Act by attempting to monopolize the retail distribution and sale of power to towns in its service area. Further, Otter Tail must "wheel" electric power from other bulk power suppliers to municipal systems.

In the Cantor versus Detroit Edison Co. (428 U.S. 591, 1976) case the U.S. Supreme Court held that Detroit Edison's electric light bulb exchange program compelled conformity to the antitrust laws in the same manner as unregulated business. Just as an electric utility regulated by the state must observe antitrust laws, utility operations by a state or a municipal subdivision are also subject to antitrust laws enjoining competitive behavior (City of Lafayette, Louisiana, versus Louisiana Power and Light Company, 532 F. 2d 431, CA 5th, 1976). 
In Gulf States Utilities Co. versus Federal Power Commission (411 U.S. 747 , 1973) the U.S. Supreme Court held that anticompetitive aspects of a jurisdictional security issue must be evaluated by the Commission in determining whether to authorize its issuance.

In Conway Corp. versus Federal Power Commission (426 U.S. 271, 1976), the U.S. Supreme Court held that the Commission must consider whether undue intervention would result from the disparity between wholesale and retail rates. The Commission's General Policy and Interpretations enumerates the recommended minimum showing necessary to demonstrate a prima facie case of "price squeeze."

1. Specification of retail rate schedules with which a wholesale customer is unable to compete due to purchase power costs;

2. A showing that the wholesale customer competes in the same market as the filing utility;

3. A showing that retail rates are more than the wholesale rates for comparable service;

4. An indication in the reduction of the wholesale rate necessary to eliminate the "price squeeze."

The Conway Corp. versus Federal Power Commission decision compels consideration of the anticompetitive impact of bulk wholesale rates in virtually all rate proceedings before the FERC. The doctrine of this case may be the basis for a substantially improved competitive position for public power at the expense of investor-owned utilities and their customers.

Antitrust review by the NRC is required by the 1970 amendments to Sec. 105 of the Atomic Energy Act of 1954 compelling the NRC, prior to issuance of construction or operating licenses for nuclear plants, to determine "whether the activities under license would create or maintain a situation inconsistent with the antitrust laws." Antitrust review by the Justice Department in coordination with the NRC normally results in negotiated settlements adopting procompetitive license conditions. If a negotiated settlement cannot be reached, the Justice Department litigates anticompetitive issues before the NRC. 
It is questionable whether the end result of judicial precedents and Congressional legislation extending the application of the antitrust laws to regulated utilities will result in allocating electric resources at reasonable costs to consumers as efficiently as a regulatory process guided by public interest standards without antitrust intervention.

\section{THE IMPACT OF FEDERAL INCENTIVES ON THE PRICE AND OUTPUT OF ELECTRICITY}

Of the various federal incentives to the generation and transmission of electricity, those provided by the Rural Electrification Administration have been the most significant. In Tables 9.17 and 9.18, estimates of the impacts that federal incentives have had on electric energy production and price are presented.

Table 9.17 indicates that market activity incentives provided by REA loans increased electrical energy production by 4.97 quadrillion (quads) Btu $e^{\text {. }}$ This represents the full amount of electricity sold by facilities borrowing from the REA. This figure is based on the assumption that rural electrification would not have been accomplished through the normal course of business due to the high cost of supplying electricity to sparsely populated rural areas. As a first approximation, it is assumed that cost reductions that can be attributed to the low interest aspect of REA loans are fully reflected in lower prices to the consumer. Thus, a price reduction of $\$ 1.92$ per million Btue can be determined by dividing the savings due to low interest loans $(\$ 9,545$ million) by the total amount of REA related production $\left(4.97\right.$ quads $\left._{e}\right)$. This value is presented in Table 9.18.

Traditional services provided by the REA in the area of administration were felt to have a negligible impact on electricity price and quantity of production. This estimate is noted in Tables 9.17 and 9.18.

The tax exemption of power revenues and the tax-exempt status of Municipal Utility and Public Power District revenue bonds are incentives to public power rather than incentives to electricity production. The ability of MUs and PPDs to debt finance $100 \%$ of new plants at interest rates lower than IOUs can obtain 
TABLE 9.17. An Estimate of the Results of Incentives Used to Stimulate Electricity Production (in Quad Btue)

Incentive Area

Taxation

Traditional Services

REA Administration

Market Activity

REA Loans
Energy Production

0

negligible

4.97 (increase)

TABLE 9.18. An Estimate of the Results of Incentives Used to Stimulate Electricity Production in Terms of Price (in $\$$ per million Btue)

Incentive Area

Taxation

Traditional Services

REA Admin istration

Market Activity

REA Loans

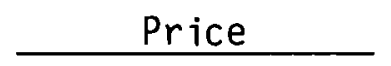

0.342 (reduction)

negligible

1.921 (reduction)

is a definite advantage for MUs and PPDs. However, since most MUs and PPDs serve high-density areas that would be served in the normal course of private business, these tax breaks should be considered price subsidies.

An estimate of the average electricity price reduction resulting from taxation incentives is provided in Table 9.18. On the average, the value of the tax incentive was distributed over the entire amount of electricity produced by utilities. Thus, the $\$ 0.342$ per million Btue price reduction is calculated by dividing the value of taxation incentives $(\$ 34,843$ million) by the total electricity produced by utilities (101.9 quads). 


\section{CONCLUSIONS}

The expenditure of over $\$ 50$ billion on incentives to electricity generation and transmission has significantly affected the industry. A qualitative summary of these impacts on a number of factors is presented in Table 9.19.

The Rural Electrification Act and subsequently the implementing of regulations and administration constitute the most important incentive to electricity production of all of the federal actions examined in this chapter. The basic rationale for this statement are:

- Rural electrification would not have been accomplished through the normal course of business as it existed prior to the Act.

- The funding was adequate and consistent except during World War II.

- The administration was consistent and applied on both national and local levels.

- The federal funds used attained very high leverage especially with the use of loan guarantees.

- Many REA Co-ops are reaching self-sufficiency via independent financing through CFC.

From Table 9.19 it can be seen that the REA impacted the competitive structure of the industry through the establishment of the REA cooperatives. As indicated in Table 9.1, these co-ops are the fastest growing segment of the electric energy market. REA loans created large impacts on the level of capital formation in the industry and helped to promote increased electricity production at a lower price. By providing public funds to private organizations, the REA impacted public/private relationships. Other impacts resulting from the provision of electricity to rural areas fell on employment/productivity, quality of life, and demographic factors.

The impacts of the various types of taxation incentives fell into primarily two categories: investment tax credits and liberalized depreciation allowances, both of which created significant effects on the level of capital formation. These incentives were also found to have affected the price of electricity to a moderate extent. Capital formation and price were also 
TABLE 9.19. Summary of Impact of Electricity Incentives

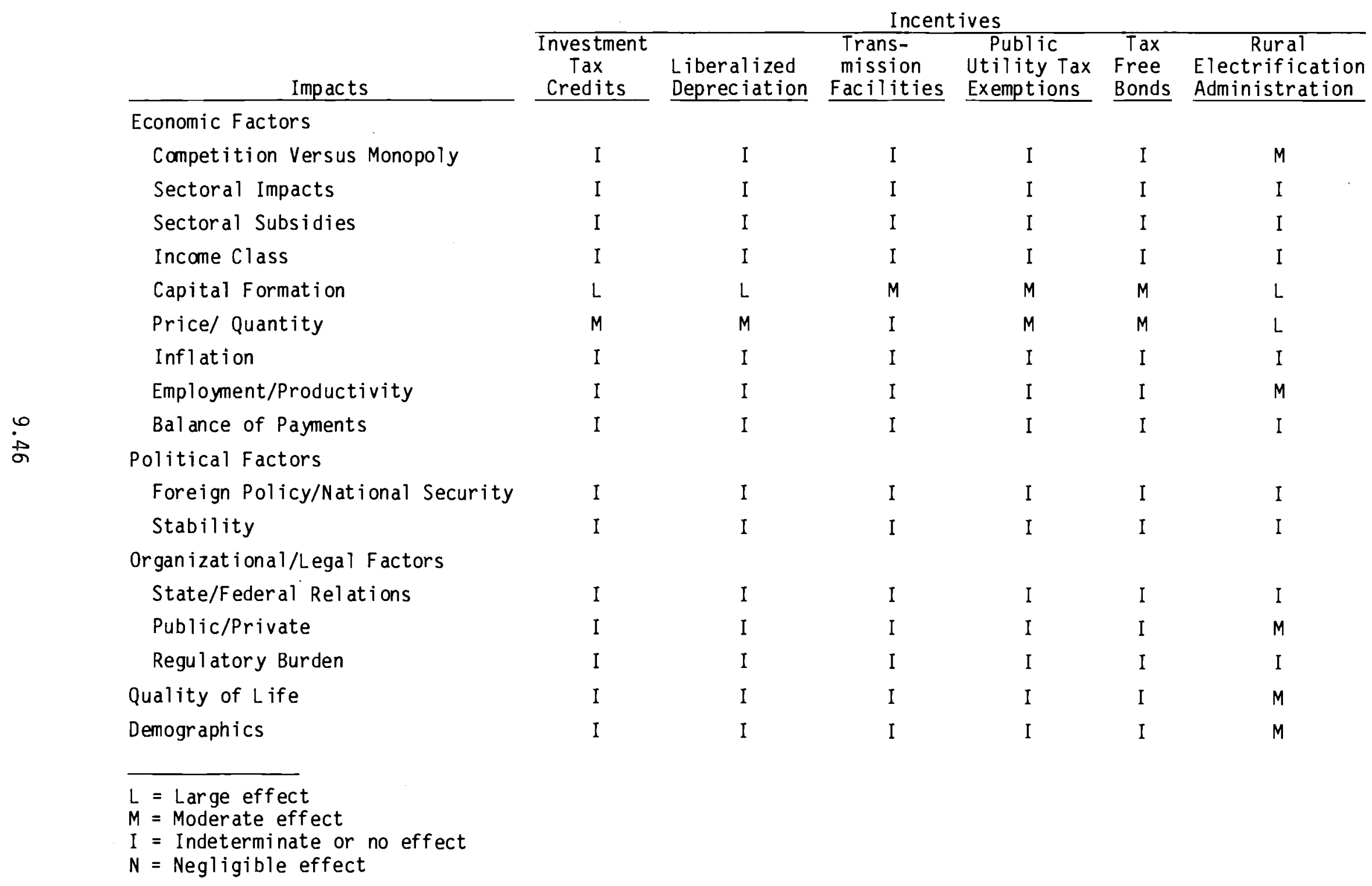


impacted through the tax exemptions and tax-free bonds allowed the public utilities. Electricity transmission incentives also stimulated capital formation.

\section{RECOMMENDATIONS FOR SOLAR POLICY}

What policy makers can learn from this chapter is that subtle accounting changes allowed by the IRS, SEC, and FERC, can make substantial changes in the energy market. If commercial firms were allowed to expense purchases of solar equipment in the period they were purchased, the impact on the solar energy market would likely exceed the impact of all other current federal solar programs. Financing is another area of prime concern. Providing low interest, long-term financing to home-owners would reduce the ir first cost problems. Banks or other institutions (utilities) could be allowed to sell tax-free bonds in order to provide these long-term loans to homeowners. These are significant institutional changes but there are precedents for them.

Redirection of the REA could provide an exceptional incentive to some forms of solar energy. Rural applications of biomass technology fit well with the REA co-op framework. The conversion of biomass from crop residues into usable energy favors small facilities to a few large ones due to transportation costs. Each of these "small" facilities may require the crop residues of about 100 square miles of cropland. The REA has experience in organizing rural citizens into cooperative ventures. The REA also has the ability to provide technical and financial backing.

REA co-ops are often able to reduce the capital costs of new power lines by actually providing the labor and some of the machinery required to set the poles and string the lines. Today's farmer is in a position to similarly assist the development of solar energy in rural areas. The modern farmer has far more technical and managerial expertise than his counterparts of the 1930s. While many farmers may not fully understand the chemical engineering aspects of methanol or ammonia manufacture, they would certainly know how to build a biomass receiving and storage facility. Since the farmers themselves would be the most probable users of the biomass facilities products, there are many synergisms in this scheme. 
The REA itself would also benefit from this type of redirection. The task the REA was created for has largely been completed. Today the REA is a large organization with great depth of managerial and financial skills. The redirection would give the REA a new challenge and a new purpose. The application of the REA's skills could rapidly accelerate the production of solar energy in rural areas. 
CHAPTER 10

THE RESULTS OF INCENTIVES

by

Bruce W. Cone, Economist

William J. Sheppard, Fuels Analyst

Roland J. Cole, Policy Analyst and Lawyer John Emery, Economist 


\section{THE RESULTS OF INCENTIVES}

This study estimates that 61 quadrillion Btu's (quads) of increased energy production is attributable to the $\$ 217$ billion of federal energy incentives. This is 280,000 Btu's per dollar of federal expenditure and foregone revenue or $\$ 3.57$ per million Btu's. Table 10.1 provides more detailed estimates of the energy production resulting from federal incentives. The largest production increase occurred in the oil industry with approximately 29 quads or $48 \%$ of the total production increase. Natural gas and hydroenergy production each increased by approximately 13 quads or $21 \%$ of the total increase. Electricity production from fossil fuels increased by about 5 quads and nuclear power production increased by 1.17 quads. The impact of federal incentives on coal production was indeterminate.

The rows of Table 10.1 indicate the production impact of federal incentives by incentive type. The largest impact came from incentives categorized as the action of levying a tax or the exemption or reduction of an existing one. Approximately 33 quadrillion Btu or $55 \%$ of the production increase resulted from taxation incentives with the bulk of this increase occurring in the petroleum sector. Market activity incentives stimulated the second largest increase in energy production. These incentives stimulated electricity and hydroenergy production by a total of almost 18 quads Btu which accounted for $29 \%$ of the total production increase. Incentives classified as requirements promoted $14.3 \%$ of the total or approximately 9 quads of increased production in the petroleum and natural gas industries. Nontraditional services such as research and development activities were found to have significantly affected only the nuclear power industry with an increase in production of 1.17 quads. The production impact of incentives classified as disbursements and traditional services was found to be indeterminate and negligible, respectively.

Table 10.2 presents the estimated impacts of federal incentives on the price of energy. The largest price impact occurred in the electricity sector. The Rural Electrification Administration's low interest loans for rural electrification projects kept the price of rural electricity down by $\$ 1.92$ per million Btu. The taxation incentives provided to the various utilities 
TABLE 10.1 An Estimate of the Production Results of Incentives Used to Stimulate Energy Production (Quadrillion Btu)

\begin{tabular}{|c|c|c|c|c|c|c|c|c|}
\hline & Nuclear $(a)$ & Hydro (a) & Coal & $0 i 1$ & Gas & Electricity (a) & Total & \% of Total \\
\hline Taxation & - & 0 & (b) & 26.62 & 6.60 & 0 & 33.22 & $54.5 \%$ \\
\hline Disbursements & (c) & - & - & (b) & - & - & (c) & - \\
\hline Requirements & (c) & (b) & (c) & 2.30 & 6.38 & - & 8.68 & $14.3 \%$ \\
\hline $\begin{array}{l}\text { Traditional } \\
\text { Services }\end{array}$ & - & - & (b) & (b) & - & (b) & (b) & - \\
\hline $\begin{array}{l}\text { Nontraditional } \\
\text { Services }\end{array}$ & 1.17 & - & (b) & (b) & (b) & - & 1.17 & $1.9 \%$ \\
\hline Market Activity & (c) & $\underline{12.86}$ & (b) & (b) & (b) & $\underline{4.97}$ & $\underline{17.83}$ & $29.3 \%$ \\
\hline $\begin{array}{l}\text { Totals } \\
\% \text { of Total }\end{array}$ & $\begin{array}{l}1.17 \\
1.9 \%\end{array}$ & $\begin{array}{l}12.86 \\
21.1 \%\end{array}$ & (c) & $\begin{array}{l}28.92 \\
47.5 \%\end{array}$ & $\begin{array}{l}12.98 \\
21.3 \%\end{array}$ & $\begin{array}{l}4.97 \\
8.2 \%\end{array}$ & 60.90 & $100 \%$ \\
\hline $\begin{array}{l}\text { (a) } 3413 \mathrm{Btu} / \mathrm{kWh} \\
\text { (b) Negligible } \\
\text { (c) Indeterminate }\end{array}$ & & & & & & & & \\
\hline
\end{tabular}


TABLE 10.2 An Estimate of the Price Impacts of Incentives Used to Stimulate Energy Production (Dollars per million Btu)

\begin{tabular}{|c|c|c|c|c|c|c|}
\hline & Nuclear (a) & Hydro (a) & Coal & $0 i 1$ & Gas & Electricity $(a)$ \\
\hline Taxation & - & 0.084 & 0.013 & 0.213 & 0.108 & 0.342 \\
\hline Disbursements & (b) & - & - & (c) & - & - \\
\hline Requirements & (b) & (c) & 0.100 & 0.116 & 0.125 & - \\
\hline $\begin{array}{l}\text { Traditional } \\
\text { Services }\end{array}$ & - & - & 0.006 & (c) & - & (c) \\
\hline $\begin{array}{l}\text { Nontraditional } \\
\text { Services }\end{array}$ & (b) & - & (c) & (c) & (c) & - \\
\hline Market Activity & (b) & 0.292 & (c) & (c) & (c) & 1.921 \\
\hline $\begin{array}{l}\text { (a) } 3413 \text { Btu/kWh } \\
\text { (b) Indeterminate } \\
\text { (c) Negligible }\end{array}$ & & & & & & \\
\hline
\end{tabular}

lowered costs and consequently the price for electricity by $34 \$$ per million Btu. The price for hydroenergy was reduced some $29 \$$ per million Btu because of the impact of federal market activity incentives, while federal tax exemptions lowered the price of hydroenergy by $8.4 \$$ per million Btu. The impact of federal nuclear incentives on the price of nuclear power was found to be indeterminate.

For the coal, oil, and natural gas industries, taxation incentives held the price per million Btu down by an estimated $1.3 \phi, 21.3 \phi$, and $10.8 \$$, respectively. Incentives categorized as requirements increased the price of coal by $10 \$$ per million Btu and put upward pressure, totalling $11.6 \$$ per million Btu on the price of oil. Requirements did, however, hold the price of natural gas down by $12.5 \$$ per million Btu. Traditional service activities helped to lower the price of coal by $0.6 \notin$ per million Btu. The remaining fossil fuel incentives were found to have had a negligible impact on the price of coal, oil, and natural gas. 
$\underline{\text { NUCLEAR }}$

Eighty-four percent of the $\$ 18$ billion (1977\$) federal expenditure to stimulate commercial nuclear power was for research and development. In response to a survey of expert opinion, it was estimated that the commercial nuclear power industry would have attained approximately $65 \%$ of its current generating capacity without federal R\&D expenditures. Thus federal R\&D incentives resulted in an additional 1.17 quads of nuclear energy production.

HYDRO

Eighty-eight percent of the federal expenditure to stimulate hydroelectricity generation was market activity in which the federal government controlled the factors of production and marketed the power. The government spent approximately $\$ 13.5$ billion for the construction and operation of federal dams. Due to the scale and complexity of most federal hydro projects, it was assumed that private utilities would not have undertaken the necessary investment. Hence, 12.9 quads were attributed to these incentives. Without the provision of low interest loans, the price of hydroenergy would have been higher by approximately $29 \$$ per million Btu. Without tax exemptions, the price would have been higher by about $8.4 \$$ per million Btu.

$\underline{\text { COAL }}$

Federal incentives for coal amounted to about $\$ 10$ billion. It was estimated that the Mine Health and Safety Act of 1969 resulted in a $10 \$$ per million Btu increase in price and had a negative impact on productivity. The coal depletion allowance has a negligible impact on coal output yet, without it, the price of coal would be approximately $1.3 \notin$ per million Btu higher. Government construction, operation, and maintenance of ports and waterways helped lower the market price of coal by less than $1 \$$ per million Btu while having a negligible impact on coal output. Government research and development activities, data gathering activities, and federal coal leasing policies have not yet had a significant impact on the price and output of coal. 
$\underline{O I L}$

Federal incentives to stimulate oil production have amounted to over $\$ 100$ billion. It is estimated that 26.6 quads of increased production resulted from the expensing of intangible drilling costs and the depletion allowance. These taxation incentives held the price of $0 i 1$ down by $21.3 \notin$ per million Btu. Stripper well and new oil pricing allowances accounted for almost $\$ 42$ billion of the incentives and stimulated approximately 2.3 quads of increased production. The higher price for new and stripper well oil did, however, cause refiner acquisition costs to increase by approximately $11.6 \$$ per million Btu.

$0 i 1$ transportation incentives, data gathering, federal leasing policies, and federal research and development activities were determined to have created negligible impacts on price and output. The impacts on price and output of the promotion of orderly oil markets through the Interstate $0 i 1$ Compact Commission and the Connaly Hot $0 i l$ Act were found to be unquantifiable but highly significant.

NATURAL GAS

The total value of federal incentives provided for natural gas production is $\$ 16.5$ billion. The depletion allowance and expensing of intangible drilling costs stimulated an increase in output of 6.6 quads and held the price down by $10.8 \$$ per million Btu. Natural gas wellhead price controls have promoted an estimated 6.4 quads of production and kept the price down by $12.5 \notin$ per million Btu. (As natural gas supply changed from surplus to shortage, wellhead price controls began to decrease production.)

Data gathering activities and federal leasing policies have had negligible impacts on natural gas price and output. Regulatory activities of the Federal Power Commission (FPC), now the Federal Energy Regulatory Commission (FERC), other than welihead price controls, had an indeterminate effect on the price and output of natural gas. 


\section{ELECTRICITY}

The federal incentives to electricity distribution, transmission, and generation were about $\$ 57.9$ billion. About one third of this went to the Rural Electrification Administration. The Rural Electrification Administration (REA) loans increased electrical energy production by 4.97 quads. The cost savings attributable to REA low interest loans promoted a $\$ 1.92$ per million Btu reduction in the price of electricity. Traditional services had a negligible impact on electricity price and production. Taxation incentives in the form of investment tax credits, liberalized depreciation, and tax exemptions for public utility power revenues were estimated to have held down the price of electricity by approximately $34 \$$ per million Btu.

\section{INCENTIVE COST PER UNIT OF INDUCED PRODUCTION}

Choosing among incentives to stimulate solar energy production requires some information on the cost of a given incentive per unit of production the incentive induces. In this section, we interpret the results presented in terms of the historical incentive cost per unit of induced production. The differences in the costs for various incentive types and different energy forms will be discussed.

To calculate the incentive cost per unit of induced production presented in Table 10.3, data on the cost of the federal incentives (Table 1.1) were divided by their respective production impacts (Table 10.1). In the following discussion of these estimates, those incentive impacts which could not be included in the estimate of the costs are identified in an attempt to assess the overall effects of energy production incentives. The discussion below is organized by energy form as shown in the columns of Table 10.3.

The increase in nuclear energy generation attributable to research and development activities (nontraditional services) cost approximately $\$ 13 / \mathrm{mil}$ lion Btu of induced production. If the other incentive types provided to the nuclear industry are taken into account, the cost is increased to $\$ 15 / \mathrm{million}$ Btu. These relatively high costs are partially related to the sophisticated technology characteristic of the industry and to the fact that the results of research and development activities are not felt immediately. 
TABLE 10.3. The Cost of Federal Energy Incentives Per Unit of Induced Production (Dollars per Million Btu)

\begin{tabular}{|c|c|c|c|c|c|c|c|}
\hline & Nuclear (a) & Hydro(a) & Coal & $0 i 1$ & Gas & Electricity (a) & $\begin{array}{l}\text { Overall } \\
\text { Result }\end{array}$ \\
\hline Taxation & - & (b) & (b) & 1.89 & 2.43 & (b) & 3.12 \\
\hline Disbursements & (b) & - & - & (b) & - & - & (b) \\
\hline Requirements & (b) & (b) & (b) & 18.22 & 0.04 & - & 5.04 \\
\hline $\begin{array}{c}\text { Traditional } \\
\text { Services }\end{array}$ & - & - & (b) & (b) & - & (b) & (b) \\
\hline $\begin{array}{l}\text { Nontraditional } \\
\text { Services }\end{array}$ & $\begin{array}{l}12.91 \\
(2.91)(c)\end{array}$ & - & (b) & (b) & (b) & - & 16.74 \\
\hline Market Activity & (b) & $\underline{1.05}$ & (b) & (b) & (b) & 4.98 & 2.27 \\
\hline Overall Result & $\begin{array}{l}15.38 \\
(5.38)(c)\end{array}$ & 1.19 & (b) & 3.50 & 1.27 & 11.38 & 3.57 \\
\hline
\end{tabular}

(a) 3413 Btu/kWh.

(b) Indeterminate.

(c) These estimates based on revised cost of incentives to commercialize nuclear power of $\$ 3.4$ billion for nontraditional services and $\$ 6.3$ billion overall. 
In addition, a good deal of the R\&D in a pioneering field, such as nuclear power during the 1950s, is inevitably directed at technologies which ultimately prove to be dead ends. Such wide-ranging R\&D (homogeneous reactors, early breeder concepts, and so forth) is necessary because the best options cannot be predicted a priori. However, if one counts only the costs of R\&D on nuclear technologies which ultimately proved successful (i.e., light water reactor programs), the total incentive cost estimate falls from $\$ 18$ billion to $\$ 6.3$ billion, of which $\$ 3.4$ billion is for R\&D.

One nuclear incentive whose effects could not be quantified is the PriceAnderson Act. The Price-Anderson Act was designed to protect energy consumers and the nuclear industry against the excessive financial risks associated with the use of nuclear power. Federal acceptance of the nuclear liability problem removed a crucial stumbling block to development of the industry. This program may have been a necessary condition for the development of commercial nuclear power. This action also indicated a supportive federal attitude toward nuclear power which was noted by some survey respondents as being an important incentive in its own right.

There were several other important impacts of nuclear incentives which were not quantified. Federal nuclear incentives stimulated the growth of the nuclear power industry, which concomitantly stimulated national employment and affected the industrial structure of the economy. Promoting the growth of an energy form which is an alternative to imported conventional fuel sources affects the balance of payments, which may in turn affect the level of inflation. The impacts of nuclear power, both on the cultural and social aspects of the economy and on the environment, are also of significance. While these impacts are very complex and not readily quantifiable, they are nonetheless very significant.

Hydroelectric energy production resulting from federal investment in the construction and operation of dams (market activity) cost $\$ 1.05 / \mathrm{million}$ Btu. Adding together all of the incentives applied to the hydroelectric power sector increases the cost to $\$ 1.19 / m i l l i o n$ Btu. While the capital cost of federal hydroelectric facilities is high, the resulting production increase is sufficiently large to yield a relatively low cost. 
Additional incentives were provided through the exemption of federal power revenues from taxes and the provision of loans for dam construction at interest rates substantially below market rates. The effects of these incentives depend on suppliers' responses to lower production costs and consumers' responses to lower offered prices. These effects are beyond the scope of this study. Thus the amount of increased hydroelectric energy demand and the amount of increased dam construction due to these incentives were not quantified.

The cost for the federal incentives used to stimulate coal production is listed in Tables 10.3 as being indeterminate because the production impact of federal coal incentives was negligible or unquantifiable. The incentives provided to this energy form include the percentage depletion allowance, research and development activities, data gathering activities, coal leasing policies, and the construction, operation, and maintenance of ports and waterways. These incentives have all had negligible impacts on coal production due to lack of demand for coal. The effect of coal requirements, such as pollution and safety regulations, was unquantifiable for the same reason.

A significant number of nonquantifiable effects, which are important to consider, resulted from incentives provided the coal industry. The Mine Health and Safety Act (requirements) may have had a substantial negative impact on worker productivity, thereby increasing the price of coal and contributing to the regulatory burden on the industry. On the positive side, health and safety regulations may have increased mine safety, employment, and the total income paid to miners. The depletion allowance may have stimulated a reduction in coal price and a growth in the level of capital formation in the industry. Federal port and waterway funding promoted a lower coal price and may have had a positive impact on the competitive structure of the industry and on the balance of payments. Research and development activities have provided the industry with new mining technologies while government data gathering activities moderately increased the regulatory burden.

For the oil industry, the incentive cost was $\$ 3.50 / \mathrm{milli}$ ion Btu of increased production. Taxation incentives stimulated increased petroleum production at an incentive cost of $\$ 1.89 / \mathrm{million}$ Btu while requirement incentives, principally stripper well and new oil pricing allowances, were more expensive at $\$ 18.22 / \mathrm{million}$ Btu. 
A number of other impacts resulted from federal petroleum incentives but are not included in the cost estimates. Besides stimulating production, taxation incentives promoted a reduction in the price of oil. By increasing the cash flow, which in turn provided more funds for investment in exploration and development, taxation incentives significantly increased the level of capital formation in the oil industry. A large portion (40\%) of the tax preference benefit was estimated to be passed back to resource owners in the form of higher royalty payments, thereby creating income distribution impacts. Pricing allowances for new and stripper oil caused refiner acquisition costs to increase, stimulated capital formation, enhanced the industry's stability, and helped to maintain the industry's competitive structure by enabling the high-cost stripper well operations to remain in production. By stimulating increased domestic oil production, these incentives had balance of payments benefits in terms of reducing the need for imported oil.

Federal promotion of orderly petroleum markets through the Interstate $0 \mathrm{il}$ Compact Commission and the Connally Hot 0 il Act had significant impacts on the petroleum industry. By controlling the output and stabilizing the price, these actions created a feeling of stability for an industry which had been characterized during the 1920s and 1930s by boom and bust conditions. The prospect of long-term stability in the petroleum market stimulated the level of capital formation and exploration which added to reserves and ultimately increased production. These actions also had a substantial impact on the competitive structure of the industry and modified state/federal relations. While the cost of these actions was small, the results have been substantial.

Still other incentives to oil production were estimated to have had indeterminate or negligible impacts on the production and price of petroleum. Federal transportation programs (traditional services) supported the competitive structure of the industry and stimulated the level of capital formation. Activities by the Federal Energy Administration(a) (requirements) were intended to promote industry stability but increased the regulatory burden as

(a) Many of these activities have continued under the aegis of the Department of Energy, the agency which assumed the FEA's responsibilities. 
wel1. Data gathering activities (nontraditional services) may have promoted industry stability and competitiveness while federal leasing policies (market activity) have impacted state/federal relations and the competitive structure of the industry. Research and development activities by the federal government are relatively recent in this industry and have not yet resulted in any impacts.

The overall incentive cost for natural gas production increases which can be attributed to federal natural gas incentives is $\$ 1.27 / \mathrm{million}$ Btu. Production increases resulting from taxation incentives cost approximately $\$ 2.43 / \mathrm{mil}$ lion Btu while requirements incentives have stimulated natural gas production at a cost of $\$ 0.04 / \mathrm{million}$ Btu of additional production. Both the overall and the requirements measures of cost are biased downward. Starting in 1974, the value of the wellhead price controls became negative, constituting a disincentive to production. The disincentive during each of the 1974 to 1977 years was enough to make the cumulative incentive value for wellhead price controls negative. This negative value reduces the cumulative cost for requirements incentives which affects the overall incentive value, concomitantly lowering the value in Table 10.3.

The nonquantifiable impacts of gas incentives are apparent in both the taxation and requirements categories. Taxation incentives promoted a reduction in the price of gas, and price controls were successful in keeping down the price of interstate gas. Taxes or tax exemptions for natural gas production have stimulated capital formation and impacted income distribution in the same manner as petroleum taxation incentives, due to the basic similarity between gas and oil exploration. Price controls have changed the competitive structure of the industry by substantially reducing the incentive to explore for new gas. Since 1974, price controls have contributed to a reduction in domestic gas production. This reduced domestic production contributed to an increased demand for gas imports. Price controls have limited the return on investment in gas wells which has reduced capital formation. By contributing to reduced supplies of interstate natural gas, price controls have encouraged gas-dependent industries to locate new plants in gas producing states creating demographic and sectoral impacts. 
The regulatory activities of the Federal Power Commission (FPC), now the Federal Energy Regulatory Commission (FERC), have also had significant impacts. FPC regulation of interstate pipelines contributed substantially to the development of the natural gas industry and greatiy enhanced the competitive structure and stability of the industry. These regulations also increased the capital formation, modified state/federal relations, and increased the regulatory burden. The effect of these regulations on the price and output of natural gas was found to be indeterminate. Data gathering activities supported the competitive structure of the industry and moderately increased the regulatory burden. Federal gas leasing policies have impacted competition, the balance of payments, state/federal relations, and created sectoral impacts.

A cost for generation, distribution, and transmission of electricity is also presented in Table 10.3. Market activity incentives in the form of loans made by the Rural Electrification Administration (REA) cost $\$ 4.98 / \mathrm{million}$ Btu of increased production. Adding in the cost of other incentives yields an overall cost of $\$ 11.38 / \mathrm{milli}$ ion Btu.

These estimates also need to be qualified by a discussion of nonquantifiable impacts. One of the reasons behind the REA's efforts to promote rural electrification was that the high cost of this service made it uneconomical for private business to undertake the investment. Thus, the cost is expected to be high. The early electrification of rural areas through REA programs stimulated worker productivity and substantially improved the quality of life in these areas. This program also promoted economic growth and increased capital formation. These impacts have not been quantified, which biases the cost upwards. The overall cost value is high because the value of taxation incentives, whose impact on production was not determined is included, as well as the cost of traditional services which had a negligible production impact. All of these factors bias the cost upward.

In the last columns of Table 10.3 the overall cost per unit of induced production for the various incentive types is shown. These values indicate that market activity incentives were the least costly at $\$ 2.27 / \mathrm{million}$ Btu of increased production. Nontraditional service incentives were the most costly 
at $\$ 16.74 / m i l l i o n$ Btu of additional energy. Taxation incentives stimulated energy production at a cost of $\$ 3.12 / \mathrm{million}$ Btu while requirements had a cost of $\$ 5.04 / \mathrm{milli}$ ion Btu of induced production. Considering the total incentive cost of $\$ 217$ billion and the production impact of 61 quadrillion Btu's (quads) yields an estimated overall cost of $\$ 3.57 / \mathrm{million}$ Btu of induced production. 


\section{CHAPTER 11}

PARITY BETWEEN SOLAR ENERGY AND

TRADITIONAL ENERGY SOURCES

by

Bruce W. Cone, Economist

William J. Sheppard, Fuels Analyst

Rol and J. Cole, Policy Analyst and Lawyer

John C. Emery, Economist 


\section{PARITY BETWEEN SOLAR ENERGY AND TRADITIONAL ENERGY SOURCES}

An initial criterion in developing elements of a strategy for solar policy is parity with other energy forms. How much should the federal government plan to expend to stimulate solar energy production in order to give solar energy an overall incentive equivalent to those given to other energy forms? The purpose of this chapter is to construct a parity index based on the incentive results presented earlier in this report.

Parity is defined as an equivalence between federal incentives to solar and federal incentives to traditional energy sources. Federal incentives for traditional energy sources are translated into a parity index of dollars per million Btu's of sustained incentives desirable for the solar energy industry. All figures are in dollars per million Btu's of total production. Dollars per million Btu's of induced production were discussed in Chapter 10.

If incentives which no longer affect the selling price of other energy forms do not enter into the determination of an equitable level of solar subsidy, an ad hoc decision is made to reject some portion of the energy incentive expenditure. The approach taken here is to include all of the incentives which have affected the national energy budget.

The formula used to translate the incentive data into a parity index is:

$$
P=\sum_{i=1}^{5}\left[\frac{\frac{E_{i, D}}{q_{i, D}}+\frac{E_{i, 77}}{q_{i, 77}}}{2}\right]\left[\frac{\frac{q_{i, D}}{Q_{D}}+\frac{q_{i, 77}}{Q_{77}}}{2}\right]
$$

where:

i describes the specific primary energy source, 1 through 5, i.e., nuclear, hydro, coal, oil, and gas;

$$
\begin{aligned}
& E_{i, D} \begin{array}{l}
\text { describes the expenditures for incentives to a specific energy } \\
\text { industry during the designated period of stability; }
\end{array} \\
& E_{i, 77} \begin{array}{l}
\text { describes the expenditures for incentives to a specific energy } \\
\text { industry during } 1977 ;
\end{array}
\end{aligned}
$$




$$
\begin{gathered}
q_{i, D} \begin{array}{l}
\text { describes the quantity of energy produced by the specific energy } \\
\text { industry over its designated period of stability; }
\end{array} \\
q_{i, 77} \begin{array}{l}
\text { describes the quantity of energy produced by the specific energy } \\
\text { industry during } 1977 \text {; }
\end{array} \\
Q_{D} \quad \begin{array}{l}
\text { describes the total quantity of energy produced by all energy } \\
\text { industries over their designated periods of stability; }
\end{array} \\
Q_{77} \begin{array}{l}
\text { describes the total quantity of energy produced by all energy } \\
\text { industries during } 1977 \text {; }
\end{array} \\
P \quad \begin{array}{l}
\text { represents the parity index expressed in federal incentive dol- } \\
\text { lars per million Btu of production. }
\end{array}
\end{gathered}
$$

The first term of equation (11-1) averages the dollars expended on incentives per million Btu of energy production over the designated period of stability plus the incentive dollars per million Btu of energy production during 1977. The justification for this average is that current incentives for energy production have a greater relative impact on current production than past incentives. The second term in Equation (11-1) weights the average dollar expenditure per million Btu of energy production by the average of the particular energy industry's share of total production over the designated time period of stability plus its share of total 1977 production. Index values for particular energy forms can be computed by eliminating the summation-acrossforms step in Equation (11-1).

Data on energy production and incentives by primary energy form over the designated period of stability are listed in Table 11.1. (a) The period of stability for coal, oil, gas, and nuclear energy is 1950 to 1977 . Incentive data for these energy forms prior to 1950 is not complete and inclusion of

(a) Since electricity production is generated in hydroelectric, coal, oil, gas, and nuclear plants, adding electricity production to Tables 11.1 and 11.2 would have resulted in double counting. However, electricity has received specific incentives whose costs must be included in the parity index. To account for this, annual electricity incentives were apportioned to the primary energy forms on the bas is of their respective percentage contribution to annual electricity generation. Therefore, the incentive figure for each primary energy form listed in Tables 11.1 and 11.2 includes a portion of federal electricity incentives. 
TABLE 11.1. Energy Production and Incentives by Energy Form

(1)

\section{Designated}

\begin{tabular}{l}
$\begin{array}{c}\text { Energy } \\
\text { Form }\end{array}$ of Stability \\
\hline
\end{tabular}

Hydro 1933 to 1977

Coal $\quad 1950$ to 1977

$0 i 1$

Gas

Nuc lear 1950 to 1977

Total
(2)

Incent ives

(millions of $\$$ )

26,850

34,665

102,179

25,355

$\underline{20,016}$

209,065
(3)

(4)

Incent ive Value (\$ per million Btu)

(2) $/(3)$

(trillion Btu)

\begin{tabular}{c}
$23,760(a)$ \\
375,932 \\
459,019 \\
468,186 \\
3,346 (a) \\
\hline $1,330,243$
\end{tabular}

1.130

0.092

0.223

0.054

$\underline{5.982}$

0.157

(a) Converted from kWh using $3413 \mathrm{Btu} / \mathrm{kWh}$. See Appendix D.

TABLE 11.2. Energy Production and Incentives by Energy Form During 1977

(1)

\begin{tabular}{l} 
Energy \\
Form \\
\hline
\end{tabular}

Hydro

Coal

$0 i 1$

Gas

Nuc lear

Total
Incent ives (millions of \$)

999

3,710

$$
13,322
$$$$
-39
$$

$\underline{2,094}$

20,086
(2)

Production (trillion Btu) $799(a)$ 15,926

17,315

21,907

$856(a)$

56,783
(3) Incent ive Value (\$per million Btu) $(1) /(2)$
1.282

0.233

0.769

$-0.002$

2.446

0.354

(a) Converted from kWh using $3413 \mathrm{Btu} / \mathrm{kWh}$. See Appendix D. 
pre-1950 production data would underestimate the incentive cost per million Btu. The period of stability for hydroelectric power is 1933 to 1977.

Table 11.1 shows the incentive value per million Btu of total production for each energy form. These figures range from a high of $\$ 5.98$ per million Btu for nuclear to $\$ 0.054$ per million Btu for natural gas. The total level of incentives for all energy forms over their designated period of stability was over \$209 billion (1977\$). This amount differs from the figure of $\$ 217$ billion in Chapter 1 because some pre-1950 incentives are not included for $0 i 1$, gas, and coal. Dividing the $\$ 209$ billion (1977 $\$$ ) worth of incentives by the 1,330 quadrillion Btu (quads) of energy production yields an overall incentive value of $\$ 0.157$ per million Btu.

Energy production and incentive data for 1977 by energy form are listed in Table 11.2. The 1977 incentive value ranged from a high of $\$ 2.45$ for nuclear to a disincentive of $\$ 0.002$ for natural gas. The disincentive to natural gas production results from the wellhead price controls which held the price of interstate gas below the price of intrastate gas. This difference in price is proving to be a disincentive to gas production. However, even with this disincentive, natural gas energy production was larger than any other energy form. The large incentive to oil production is due primarily to stripper well and new oil pricing policies. Dividing the $\$ 20$ billion (1977\$) energy incentive by the 56.8 quads of energy production yields a 1977 incentive value of $\$ 0.354$ per million Btu.

Using the data contained in Tables 11.1 and 11.2 and the parity index formula, Equation (11-1), the index values shown in Table 11.3 were calculated. The parity index for oil is the highest of all the energy forms and the incentive for natural gas is the lowest. The value of the parity incentive should fall between the average long-run efficiency index value of $\$ 0.157$ per million Btu (Table 11.1) and the 1977 efficiency index value of $\$ 0.354$ per million Btu (Table 11.2), yet closer to the 1977 value because of the weight given to 1977 incentives in Equation (11-1). Looking at Table 11.3, this expectation is confirmed by the long-run parity index value of $\$ 0.273$ per million Btu. 
TABLE 11.3. Parity Index for Energy Form and Total

\begin{tabular}{lc} 
Energy Form & $\begin{array}{c}\text { Parity Index } \\
(\$ / \mathrm{mi} i 1 i \text { Btu })\end{array}$ \\
\cline { 2 - 2 } Hydro & 0.019 \\
Coal & 0.046 \\
$0 i 1$ & 0.161 \\
Gas & 0.010 \\
Nuclear & $\underline{0.037}$ \\
Total & 0.273
\end{tabular}

Based on the analysis of federal incentives to energy production and the use of the parity index developed above, it has been estimated that a long-run incentive of $27 \$$ per million Btu applied to solar energy will provide parity with other subsidized energy forms.

SPECIFYING A NATIONAL COMMITMENT

The level of federal funding or foregone revenue to induce President Carter's goal of 18 quads of new renewable energy production in 2000 is established on the basis of parity with the historic incentives to traditional energy production.

Calculating the level of national commitment requires an assumption about the growth of the renewable energy industry. Calculating the level of national commitment requires on assumption about the growth of the renewable energy industry. The s-shaped curve depicted in Figure 11.1 is indicated by Burns (1934), Kuznets (1930), and Gaston (1961) as a general pattern of industrial growth. This growth curve has become widely used in studies on market penetration and diffusion of new technologies (see for example Peterka November 1977; Packard 1973; and Jeckovich 1973). The curve'in Figure 11.1 depicts a growth pattern with a period of slow growth (I) followed by a period of accelerating growth (II), and then slower more stable growth (III). 


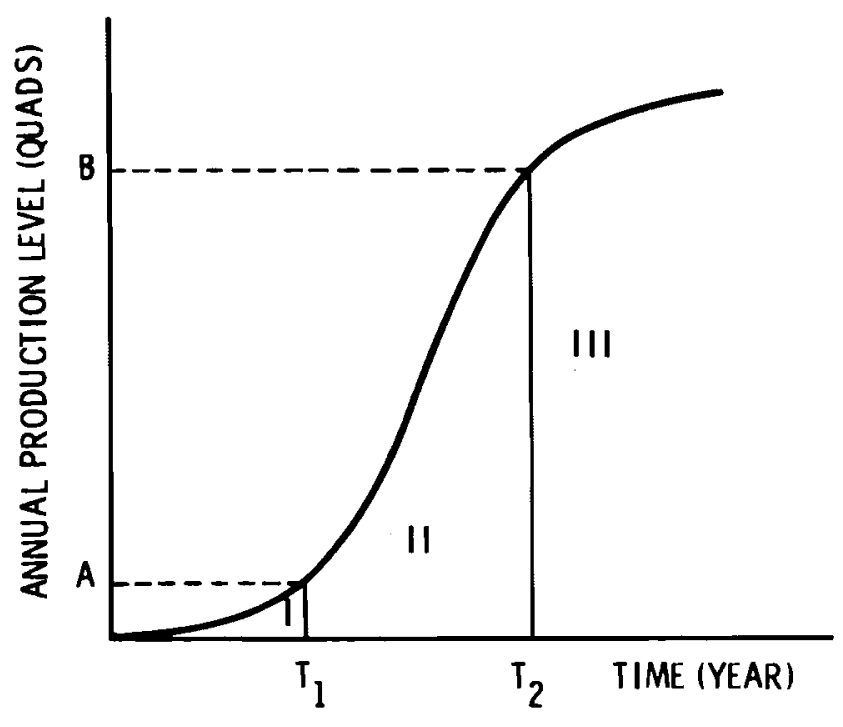

FIGURE 11.1 The S-Shaped Industrial Growth Curve

Currently, the renewable resource industry is experiencing its period of slow growth which relates to the first one-third of its s-curve. It is assumed that the renewable resource industry should move through the first two-thirds of its s-curve if new annual production is expected to be 18 quad by the year 2000. In terms of Figure 11.1, this implies that federal incentives from $T_{1}$ (1980) to $T_{2}(2000)$ should stimulate the renewable resource industry from a current production of point $A$ to an annual production at point $B$ which is 18 quad greater than $A$.

Drawing on the analysis of historic incentives to traditional energy forms it was found that the natural gas industry provided an example of an industry moving through the period of accelerating growth. During the 1950 to 1970 period, the production of natural gas increased by 17 quad annually. Cumulating the annual production levels above the 1950 production level yields a total production increase of 144 quad during the 20-year period. In terms of Figure 11.1, between periods $T_{1}(1950)$ and $T_{2}(1970)$, the annual production of natural gas at point $B$ was 17 quad greater than production point A. Cumulating, between $T_{1}$ and $T_{2}$, the annual production of natural gas above production level A yields a total production increase of 144 quad. This cumulative measure indicates a discrete estimate of the area under the s-curve between points $T_{1}, T_{2}$, $A$ and $B$. 
This analysis assumes that the 20 year growth curve for the renewable resource industry will be similar to that of the natural gas industry. Adjusting the cumulative natural gas production increase to a production level $B$ of 18 quad instead of 17 quad yields a total production increase for the renewable resource industry of 152 quad by 2000 . At a rate of 27 cents per million Btu, the total incentives budget to induce the 18 quad increase in annual production of renewable energy by 2000 would be a 20 year total of $\$ 41$ billion (1977\$).

This parity concept compares incentive spending to total production not to induced production. Chapter 10 showed that federal spending per induced production was $\$ 3.57$. Historically, identifiable induced production was about $5 \%$ of total production, although much higher for some forms of energy. In the line of argument that we are pursuing, the necessary incentive spending assuming the future will be somewhat like the past depends on how much of the renewable energy necessary to reach the 18 quad goal would be forthcoming without incentives. If you assume that less than $95 \%$ would be forthcoming without incentives, then the $\$ 41$ billion figure needs to be adjusted upwards. If you assume none would be forthcoming, the adjustment goes all the way to at least $\$ 3.57$ per million Btu or a 20 -year total of $\$ 555$ billion, more than twice what we have spent in the last 27 years. 
-
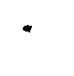

: 


\section{CHAPTER 12 \\ THE HISTORY OF TRADITIONAL ENERGY INCENTIVES AS A GUIDE \\ TO SOLAR ENERGY INCENTIVES}

by

Bruce W. Cone, Econom ist

Roland J. Cole, Policy Analyst and Lawyer John C. Emery, Econom ist

William J. Sheppard, Fuels Analyst 


\section{THE HISTORY OF TRADITIONAL ENERGY INCENTIVES AS A GUIDE}

\section{TO SOLAR ENERGY INCENTIVES}

On June 20, 1979, President Carter called for "a national mobilization in our country toward the time when our major source of energy will be derived from the sun" (DOE 1979, p. 2). In line with the Results of the Domestic Policy Review of Solar Energy, the Administration recommended taking steps to increase solar and renewable energy use to the point where they would be providing $20 \%$ of the Nation's energy by the year 2000 (DOE 1979, p. 2).

The goal of $20 \%$ is estimated to be 18 quadrillion Btu (quad) of energy in the year 2000 (Bennington et al. June 1979, p. 26). The purpose of this chapter is to draw on the research presented in this report to determine the types of incentives needed, the level of federal funding or foregone revenue necessary, and the appropriate distribution of incentives and dollars over time.

The use of past policies to achieve future goals may or may not prove to be successful. There is no guarantee that the future application of historical policies will impact future decisions in the same manner as they did in the past. Nevertheless, past actions do set precedents and their estimated results provide useful input for the determination of future policies. Currently, federal renewable energy incentives are heavily based upon historical energy incentives. Consequently, specification of a 20 year solar incentive stragegy using history as a guide will provide valuable information for solar policy makers.

This chapter is divided into four sections. The first section summarizes the findings concerning identifiable results to establish a base distribution among incentives. The second section estimates the financial comitment that could be required to bring solar and renewable energy to parity with other subsidized energy forms. The third section applies the distribution of incentive spending by incentive type and by time during the 1950 to 1970 period to the 1980 to 2000 period. The application provides a basis for development of a long range incentives program. The chapter concludes by postulating a point of departure for further analys is of incentives to stimulate the production and use of energy from renewable resources. 


\section{DISTRIBUTION AMONG INCENTIVES}

Approximately 33 quad or $55 \%$ of the production increase resulted from taxation incentives. Market activity incentives resulted in a total of almost 18 quad or $29 \%$ of the total production increase. Requirements incentives induced approximately 9 quad of increased production or $14.3 \%$ of the total. Nontraditional services such as research and development activities were found to increase production by about 1.17 quad. The production impacts of disbursements incentives were found to be indeterminate and the production impacts of traditional services were found to be negligible.

Assuming that incentive types are equal in energy impact per dollar, the est imated results of historic incentives to traditional energy production would suggest that $55 \%$ of the federal investment to stimulate renewable energy production would be in the form of taxation incentives; $29 \%$ of the federal investment would be in the form of market activities; $14 \%$ would be in the form of requirements; $2 \%$ would be for research and development.

The largest price impact resulted from market activity and occurred in the electricity sector. The Rural Electrification Administration's low interest loans for rural electrification projects kept the price of rural electricity down by $\$ 1.92$ per million Btu. The taxation incentives provided to the various utilities lowered costs and consequently the price for electricity by $34 \$$ per million Btu. The price for hydroenergy was reduced some $29 \$$ per million Btu because of the impact of federal market activity incentives while federal tax exemptions lowered the price of hydroenergy by $8.4 \$$ per million Btu.

Taxation incentives held the price per million Btu down by an estimated 1.3\$, 21.3\$, and 10.8\$ for the coal, oil, and natural gas industries. Incentives categorized as requirements increased the price of coal by $10 \$$ per million Btu and put upward pressure, totaling $11.6 \$$ per million Btu, on the price of oil. Requirements did, however, hold the price of natural gas down by $12.5 \$$ per million Btu. Traditional service activities helped to lower the price of coal by $0.6 \$$ per million Btu. 
The price results of alternative incentives does not suggest any changes in the distribution of incentives suggested above because those incentives with the largest production impacts also had the most significant price impacts. Taxation incentives generally had the most downward pressure on energy prices. Although the downward pressure on prices that resulted from market activity was limited to hydroenergy and electricity, they were the two largest values of the eleven estimates. Requirements had both positive and negative pressure on energy prices.

\section{LEVEL OF NATIONAL COMMITMENT}

The level of federal funding or foregone revenue to induce 18 quad of new renewable energy production in 2000 is established on the basis of parity with the historic incentives to traditional energy production. Based on the analy$s$ is of federal incentives to energy production and the use of an appropriate index measure, it was estimated that a long-run incentive of $27 \not$ per million Btu of total production applied to solar energy will provide parity with other subsidized traditional energy forms.

Calculating the level of national comitment requires an assumption about the growth of the renewable energy industry. As explained in Chapter 11, industrial production is generally assumed to grow in an "s-shaped" pattern indicating an early period of slow growth followed by accelerating growth and then slower more stable growth. Currently, the renewable resource industry is experiencing its period of slow growth which relates to the first one-third of its "s" curve. It is assumed that the renewable resource industry should move through the first two-thirds of its "s" curve to the period of stable growth if annual production is expected to reach 18 quad by the year 2000 . This implies that federal incentives should stimulate the renewable resource industry through the period of accelerating growth.

Drawing on the analys is of historic incentives to traditional energy forms it was found that during the 1950 to 1970 period the natural gas industry provided an example of an industry moving through the period of accelerating growth. During this 20-year period, the production of natural gas increased 
to where the 1970 production level was 17 quad greater than the 1950 production level. Cumulating the annual production levels above the 1950 production level yields a total production increase of 144 quad during the 20-year period. Assuming a 20-year growth curve of the renewable energy industry like that of the natural gas industry, a total increase in production of 152 quad would be necessary to achieve an annual production level of 18 quad by the year 2000 . At a rate of $27 \$$ per million $B t u$, the total incentives budget to induce the production of renewable energy would be a 20-year total of $\$ 41$ billion $(1977 \$)$.

Based on the historical distribution calculated in the previous section: $55 \%$ of the incentives budget or $\$ 22.6$ billion would be allocated to taxation incentives during the next 20 years; $29 \%$ or $\$ 11.9$ billion for market activities; $14 \%$ or $\$ 5.7$ billion would be spent for requirements; and, $2 \%$ or $\$ 0.8$ billion for nontraditional services such as research and development.

\section{DYNAMICS OF THE INCENTIVES STRATEGY}

The analysis of historical incentives provides information that can be used to determine how the estimated renewable energy incentive budget may be allocated over the next 20 years. The assumption is made that the historical incentive spending pattern can be used as a reference case for allocating future renewable resource incentives. Since the assumed growth curve for the renewable energy industry is based on the 1950 to 1970 period, the incentive spending pattern during that period is used to allocate the future incentive budget.

The annual incentive spending pattern by incentive type is presented in Chapter 3. This data is used to determine what proportion of the estimated incentive funding for taxation, requirements, nontraditional services, and market activity incentives should be allocated to each of the four 5-year periods from 1980 to 2000. During the 1950 through 1969 period, $\$ 102.5$ billion was allocated to these four incentive types. From 1950 through 1954, 19\% of the total was expended; from 1955 through 1959, 23\% was expended; from 1960 through 1964, 28\% was expended; and from 1965 through 1969, 30\% of the 20-year total 
was expended. Applying this pattern to the 1980 through 1999 period indicates the dynamics of the incentive strategy based on historical considerations.

\section{CONCLUSIONS}

A point of departure for federal incentives to renewable energy based on historic incentives to traditional sources of energy is presented in Table 12.1. The overall incentive value of $\$ 41$ billion (1977 \$) is based on the parity principle and an assumed growth curve for renewable energy production similar to the historic growth of the natural gas industry. This value is distributed among incentives by their relative historic production impacts. The $\$ 41$ bi1lion is distributed over time based on the precedent set by historic incentive spending patterns.

The table is based on precedent and presents a point of departure for the specification of an incentive strategy. The application of precedent to current conditions is useful because many organizational activities persist in the face of radically different conditions. The procedures, resources, and thoughts of the past and present frame the problem and shape the alternatives available in the future. Current activities for stimulating solar and renewable energy sources are similar to incentives used in the past to stimulate

TABLE 12.1. A Point of Departure for Federal Incentives to Solar Energy Based on Historic Incentives to Traditional Sources of Energy (Billions of $1977 \$$ )

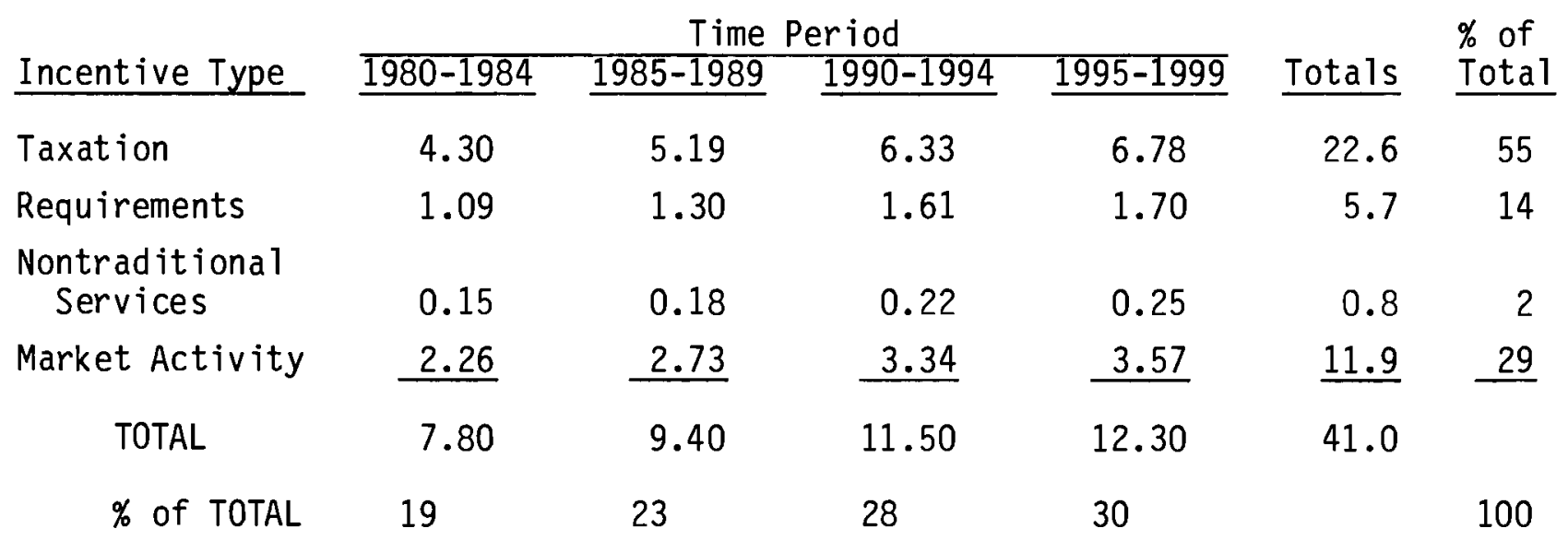


conventional energy forms. Historically, the federal government has favored tax incentives over all others. Currently, the principal actions in support of renewable energy are tax incentives.

These conclusions are intended as a device for framing the policy questions about what incentives are necessary to stimulate desired levels of energy development. The table suggests the financial resources that could be necessary to achieve 18 quad per year from renewable resources by 2000 . The analysis presented in this report shows that smaller scale programs are unlikely to reach this goal. The table also suggests many of the questions that have to be asked. Decisions about incentives are not only about dollars, but also about types of incentives, particular technologies, and the stages at which the government will provide incentives. This table, and the historical information that was used for allocation, can be a guide in choosing the particular incentives that deserve careful consideration in the years ahead. It is therefore intended as a point of departure in the process of achieving a national goal through the interaction of scientific inquiry and public debate. 


\section{APPENDIX A}

MACROECONOMIC MODELS OF THE U.S. 
APPENDIX A

\section{MACROECONOMIC MODELS OF THE U.S.}

The more well-known of these models are the ones developed by Data Resources Incorporated (DRI), the Wharton School, Chase Econometrics Incorporated and Brookings-MIT. Although these models differ in the way they specify the interrelationships in the economy, they have a number of elements in common. Each views the economy as composed of producers and consumers and balances the associated supplies of and demands for goods and services through some equilibrating mechanism. The production sector is generally modeled by means of an input-output structure; energy is regarded as an intermediate good used in the manufacture of other goods. The models differ in the level of aggregation in the production sector (from none to more than 50 industrial sectors); in the extent of substitution of input sectors of production (all of the models allow some flexibility in the substitution of one energy source for another, e.g., gas or coal for oil, but some also allow other nonenergy factors to be substituted for energy in the production process); the underlying dynamic structure (in some models decisions are determined solely by the current values of variables while in others they are determined by all the present and even future values of variables); in some models adjustments to change occur instantaneously while in others they occur gradually as capital stocks are altered; and in how they handle trend elements (changes in technology and growth of the population or the labor force are the major homogenous variables treated as simple trends in all the models). Similar model differences occur in the consumption sector. The level of aggregation generally matches that of the production sector, but further separation into different consumption, investment, government, and types of net expenditures also occurs; in some models demands are estimated econometrically while in others they are derived from engineering end-use requirements. The extent of substitution in consumption varies widely from little or none so that a change in the consumption of all other goods to such extensive substitution that a change in the consumption of one good does not affect consumption of other goods. The dynamics of the consumption sector 
match those of the production sector. Trends in the consumption sector are considered exogenous to all the models; in connection with energy it is generally assumed that mandatory conservation measures will reduce energy consumption by $10 \%$.

The balancing of mechanisms differ considerably. In some models consumers who maximize utility and producers who maximize profits come together in perfectly competitive markets where relative prices provide all the information needed by participants to make decisions and where balance is achieved when the quantities demanded by consumers equal the quantities supplied by producers and the prices consumers are willing to pay for those quantities equal the prices the suppliers will accept for them. In other models, some objective function is to be optimized, such as maximizing the cumulative consumption possible from the production sector, by cooperative efforts on the part of consumers and producers and balance is achieved when the flow of goods is at that optimum; markets and market equilibria are not a part of these models.

For a discussion of the macroeconomic models, their energy components and their implications, see especially Hogan and Parikh (February 1977). Also see, Searl (1974); Benenson et al., (June 1974); Khazzoom (January 1976); Cohen and Costello (June 1975); Hudson and Jorgenson (1974, pp. 461-514); Carter (1974, pp. 578-594); MIT Energy Laboratory Policy Study Group (1974); Stanford Energy Institute (July 1976). 


\section{APPENDIX B}

\section{STATEMENTS ON THE RESULTS OF}

FEDERAL ENERGY ACTIONS 
APPENDIX B

STATEMENTS ON THE RESULTS OF

FEDERAL ENERGY ACTIONS

The major results of governmental energy-related actions are described in this appendix. The data summarized in Table B.1 form the basis for the expert-opinion statements in Chapter 3.

AGENCY NAME (COLUMN 1)

In FY-1976, there were 58 major energy actions conducted by the federal government. This column identifies the agency (executive or congressional) which had primary responsibility for carrying out the major energy action.

MAJOR ENERGY-RELATED ACTIVITIES (COLUMN 2)

All major energy actions were implemented under the guidance of statutory authority. This column describes the initial legal basis for an agency to conduct the energy actions assigned to it. This description stems from a shortened version of the purposes listed in the authorizing legislation for the actions.

INTENDED EFFECTS OR OBSERVED RESULTS (COLUMNS 3, 4, AND 5)

Entries listed as "intended effects" refer to the objectives or purposes of energy actions. Our sources identified numerous objectives of federal energy actions. We listed these intended effects in Columns 3, 4, and 5 of Table B.1.

As mentioned before, entries listed as "results" refer to the consequences of energy actions. Our sources identified consequences in a number of cases. We also listed these observed results in Columns 3,4 , and 5 .

We are using a form of content analysis relying on three principal sources: the New York Times for 1977 and 1978, the Congressional hearings for 1977 and 1978, and the House Appropriation hearings for 1979. 
This table covers federal energy actions in FY-1976 and the effects to the present. This includes analyzing effects and results of actions undertaken and legislation passed in FY-1976. When actions occur over a number of years and continue into 1976, they are also included. 
TABLE B.1. Reports on Energy Actions by Policy Makers and Activists

\begin{tabular}{|c|c|c|c|c|}
\hline $\begin{array}{c}\text { Agency Name } \\
1\end{array}$ & $\begin{array}{c}\text { Major Energy-Related } \\
\text { Activities } \\
2\end{array}$ & 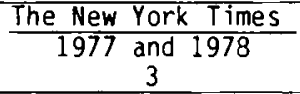 & $\begin{array}{c}\text { Senate or House } \\
\text { Committees, } 1977 / 78 \\
4\end{array}$ & $\begin{array}{c}\text { House Appropriations } \\
1979 \\
5\end{array}$ \\
\hline
\end{tabular}

REQUIREMENTS

Federal Energy Administration

w

\section{Statistical and} economic and social impact of nationa energy policies; audits and enforcements to assure compliance with regulations; conservation and economic policy analysis of national energy goals: policies and programs; to increase domestic energy production; IEA participation; strategic petroleum reserve maintenance.

Federal Power Cormission

Regulatory authority analytical studies of

ness and increases

over rates in inter-

state wholesale elec-

tric power cert if i-

cates for interstate

gas sales and pipeline

construction; investi-

gates private-public

agreement in electric

and gas national

development; regulates

mergers, consolida-

tions, and acquisi-

tions of electric

utilities and finance.

Delivery of Alaska

natural gas to the

continental U.S.

Est imates crude oil

production costs.
Intended effects:

1) eased price

controls on oil from

Alaska's North Slope

2) proposed manda-

tory conservation

program by public

utilities. Result:

FEA oil price

equalization scheme

keeps inefficient

refineries in busi-

costs of petroleum

refining.

Intended effects:

1) proposed deregula-

$t i o n$ of natural gas.

Results: 1) increased

reliance on coal

(mandatory conversion

program for coal);

2) increase in the use

of nuclear power;

coal conversion

legislation that par-

ticularly impacts the

following industries:

paper chemicals, pet-

rochemicals, and steel.

Result: Federal

pricing of interstate

natural gas has been

a disincentive to

production.

Results: 1) regulations lead to higher costs and prevent

capital from being

provided; 2) certain

high energy consuming

high energy consuming

adversely affected by

changes in the utili-

ties' rate structures.
Results: 1) increas-

ed emphas is on

a) ternative (sof $t$

path) energy research;

2) increased prices

for North Slope and

stripper oil;3) the

two tier price system

on oil encouraged the

importation of foreign

oil; (4) coal legisla-

tion resulted in 34

utilities at 43 sites

and covered 92 power

plants that are convert

ing to coal.

Results: 1) increase in the rates of return to

investor-owned utility

stockholders; 2)

increase in the rates

of-return for natural

gas pipeline companies;

3) increase in stock

prices for utilities

and gas pipeline

companies. 


\section{TABLE B.1. (contd)}

\begin{tabular}{|c|c|c|c|c|}
\hline $\begin{array}{c}\text { Agency Name } \\
1\end{array}$ & $\begin{array}{c}\text { Major Energy-Related } \\
\text { Activities } \\
2 \\
\end{array}$ & $\begin{array}{c}\text { The New York Times } \\
1977 \text { and } 1978 \\
3 \\
\end{array}$ & $\begin{array}{c}\text { Senate or House } \\
\text { Committees, } 1977 / 78 \\
4\end{array}$ & $\begin{array}{c}\text { House Appropriations } \\
1979 \\
5 \\
\end{array}$ \\
\hline $\begin{array}{l}\text { Nuclear Regulatory } \\
\text { Commission }\end{array}$ & $\begin{array}{l}\text { Licensing and regula- } \\
\text { tory functions, includ- } \\
\text { ing antitrust, of } \\
\text { primarily electric } \\
\text { power generation } \\
\text { nuclear facilities. }\end{array}$ & $\begin{array}{l}\text { Result: NRC safety } \\
\text { regulations take } \\
\text { precedence over } \\
\text { economic considera- } \\
\text { tions. }\end{array}$ & $\begin{array}{l}\text { Intended effect: } \\
\text { reduction in length } \\
\text { of licensing process, } \\
\text { sound waste manage- } \\
\text { ment program, improv- } \\
\text { ed safeguards. }\end{array}$ & $\begin{array}{l}\text { Results: regulations } \\
\text { have slowed nuclear } \\
\text { development and in- } \\
\text { creased costs for power. }\end{array}$ \\
\hline $\begin{array}{l}\text { Environmental } \\
\text { Protection Agency }\end{array}$ & $\begin{array}{l}\text { Protection against } \\
\text { radiation pollution } \\
\text { and energy-related } \\
\text { environmental } \\
\text { programs. }\end{array}$ & $\begin{array}{l}\text { Results: 1) pro- } \\
\text { posed strip mining } \\
\text { bill, 2) amendments } \\
\text { of the } 1977 \text { Clean } \\
\text { Air Act discouraged } \\
\text { western coal produc- } \\
\text { tion. }\end{array}$ & $\begin{array}{l}\text { Intended effect: } \\
\text { proposed that all } \\
\text { coal-burning power } \\
\text { plants will use the } \\
\text { best available con- } \\
\text { trol technology. } \\
\text { Result: Using the } \\
\text { best available con- } \\
\text { trol technology } \\
\text { increases the capi- } \\
\text { tal requirements of } \\
\text { the utility industry. }\end{array}$ & $\begin{array}{l}\text { Results: 1) as much as } \\
18 \text { billion tons of coal } \\
\text { are being held up by } \\
\text { NEPA requirements; } 2 \text { ) } \\
\text { improvements in air } \\
\text { quality except for } \\
\text { emissions produced by } \\
\text { coal; } 3 \text { ) estimated cost } \\
\text { of federal and state } \\
\text { environmental regula- } \\
\text { tions on the petroleum } \\
\text { industry was \$6 billion } \\
\text { in } 1976 \text {; } 4 \text { ) Historic } \\
\text { Site Preservation and } \\
\text { the Endangered Species } \\
\text { Acts add } 3 \text { years to the } \\
\text { construction time for } \\
\text { coal-fired electric } \\
\text { plants; } 5 \text { ) environmen- } \\
\text { tal litigation is a } \\
\text { major problem facing } \\
\text { the utility industry; } \\
\text { (6) environmental } \\
\text { permits have held up } \\
\text { the Coal Loan Program. }\end{array}$ \\
\hline
\end{tabular}


TABLE B.1. (contd)

\begin{tabular}{|c|c|c|c|c|}
\hline $\begin{array}{c}\text { Agency Name } \\
1\end{array}$ & $\begin{array}{c}\text { Major Energy-Related } \\
\text { Activities } \\
2 \\
\end{array}$ & $\begin{array}{c}\text { The New York Times } \\
1977 \text { and } 1978 \\
3\end{array}$ & $\begin{array}{c}\text { Senate or House } \\
\text { Committees, } 1977 / 78 \\
4\end{array}$ & $\begin{array}{c}\text { House Appropriations } \\
1979 \\
5 \\
\end{array}$ \\
\hline $\begin{array}{l}\text { Geological Survey, } \\
\text { Interior Department }\end{array}$ & $\begin{array}{l}\text { 1) Provides basic sci- } \\
\text { entific data concerning } \\
\text { water, land, and min- } \\
\text { eral resources; and 2) } \\
\text { supervises the pros- } \\
\text { pecting, development, } \\
\text { and production of } \\
\text { minerals and mineral } \\
\text { fuels on leased fed- } \\
\text { eral, Indian, and OCS } \\
\text { land. }\end{array}$ & $\begin{array}{l}\text { Result: Decrease } \\
\text { in production which } \\
\text { correlates with } \\
\text { implementation of } \\
\text { mine health and } \\
\text { safety inspections. }\end{array}$ & $\begin{array}{l}\text { Result: Environmental } \\
\text { litigation has held } \\
\text { up coal development. }\end{array}$ & \\
\hline $\begin{array}{l}\text { Bureau of Mines, } \\
\text { Interior Department }\end{array}$ & $\begin{array}{l}\text { Research and fact } \\
\text { finding to stimulate } \\
\text { private interest and } \\
\text { technology use in } \\
\text { extracting, process- } \\
\text { ing, use, and recycl- } \\
\text { ing of national } \\
\text { mineral resources. }\end{array}$ & $\begin{array}{l}\text { Results: Decrease } \\
\text { in production which } \\
\text { correlates with the } \\
\text { implementation of } \\
\text { mine health and } \\
\text { safety inspections. }\end{array}$ & $\begin{array}{l}\text { Result: Environ- } \\
\text { mental litigation has } \\
\text { held up coal develop- } \\
\text { ment. }\end{array}$ & \\
\hline $\begin{array}{l}\text { Bureau of Indian } \\
\text { Affairs, Interior } \\
\text { Department }\end{array}$ & $\begin{array}{l}\text { Energy leasing, gen- } \\
\text { eration, and power. }\end{array}$ & & & \\
\hline $\begin{array}{l}\text { Mining Enf orcement } \\
\text { and Safety Adminis- } \\
\text { tration, Interior } \\
\text { Department }\end{array}$ & $\begin{array}{l}\text { 1) Coal mine and metal } \\
\text { and nonmetal mine } \\
\text { heal th and safety } \\
\text { inspections; and } 2 \text { ) } \\
\text { education and train- } \\
\text { ing programs in safety } \\
\text { motivation constitute } \\
\text { the major thrusts in } \\
\text { activities. }\end{array}$ & $\begin{array}{l}\text { Intended Effect: } \\
\text { Monitors compliance } \\
\text { with the Surface } \\
\text { Mining Control and } \\
\text { Reclamation Act. }\end{array}$ & $\begin{array}{l}\text { Results: 1) strict } \\
\text { enforcement of regu- } \\
\text { lation may explain } \\
\text { greater mine safety; } \\
\text { and 2) requirements of } \\
\text { Mine and Safety Act } \\
\text { (1969) raise costs for } \\
\text { coal producers. }\end{array}$ & \\
\hline
\end{tabular}


TABLE B.1. (contd)

\begin{tabular}{|c|c|c|c|c|}
\hline Agency Name & $\begin{array}{c}\text { Major Energy-Related } \\
\text { Activities } \\
2 \\
\end{array}$ & $\begin{array}{c}\text { The New York Times } \\
1977 \text { and } 1978 \\
3\end{array}$ & $\begin{array}{r}\text { Senate or House } \\
\text { Committees, } 1977 / 78 \\
4\end{array}$ & $\begin{array}{c}\text { House Appropriations } \\
1979 \\
5 \\
\end{array}$ \\
\hline $\begin{array}{l}\text { Federal Trade } \\
\text { Commission }\end{array}$ & $\begin{array}{l}\text { In } 1978 \text {, the Commission } \\
\text { will focus principal } \\
\text { antitrust attention on } \\
\text { the energy, food, health } \\
\text { care, transportation, } \\
\text { and chemical industries. }\end{array}$ & $\begin{array}{l}\text { Result: FTC recomended } \\
\text { that the Justice Dept. } \\
\text { take steps to force the } \\
\text { oil companies to sell up } \\
\text { to } \$ 108 \text { billion in oil } \\
\text { and gas properties. }\end{array}$ & $\begin{array}{l}\text { Results: 1) proposed FTC } \\
\text { regulations in regard to } \\
\text { retrofit, insulation, } \\
\text { and solar technical may } \\
\text { increase short-run costs } \\
\text { of alternate technologies; } \\
\text { 2) regulations for the } \\
\text { labeling of heating units. }\end{array}$ & $\begin{array}{l}\text { Result: Insulation man- } \\
\text { ufacturers revised } \\
\text { claims. }\end{array}$ \\
\hline
\end{tabular}

ஜ்
Department of Enforcement of anti-

Justice, Antitrust trust.

Division
Results: 1) increased

emphas is on oil pro-

ducers (also their con-

trol of uranium sup-

plies); 2) federal grand

plies); 2) federal grand
jury investigation into

uranium pricing; 3 )

decision not to force

the major oil companies

to get out of the coal

industry.

Housing and Implementation of

Community Research, Solar Heating and

Department of Cooling Demonstra-

Housing and Urban tion Act of 1974,

Development conservation

research, and
development of

more efficient

energy and utility

systems.
Results: 1) HUD regula- Results: 1) HUD regulations in regard to solar tions enable the FHA and equipment drive up the VA to make solar loans; industry's costs and $\quad 2$ ) solar industry guideretard its development; lines were devised with 2) HUD devised regula- the Solar Industry tions in regard to energy standards for building and construction (may change the shape of office buildings and houses, etc.

in the future). 
TABLE B.1. (contd)

\begin{tabular}{|c|c|c|c|c|}
\hline $\begin{array}{c}\text { Agency Name } \\
1 \\
\end{array}$ & $\begin{array}{c}\text { Major Energy-Related } \\
\text { Activities } \\
2 \\
\end{array}$ & $\begin{array}{c}\text { The New York Times } \\
1977 \text { and } 1978 \\
3\end{array}$ & $\begin{array}{cc}\text { Senate or House } \\
\text { Committees, } & 1977 / 78 \\
4 & \\
\end{array}$ & $\begin{array}{c}\text { House Appropriations } \\
1979 \\
5 \\
\end{array}$ \\
\hline $\begin{array}{l}\text { Occupational Safety } \\
\text { and Health Admini- } \\
\text { strat ion (OSHA), } \\
\text { Labor Department }\end{array}$ & $\begin{array}{l}\text { Promulgates occupa- } \\
\text { tional safety and } \\
\text { health standards; } \\
\text { establishes regula- } \\
\text { tions; enforces } \\
\text { compliance with } \\
\text { standards and } \\
\text { regulations. }\end{array}$ & & $\begin{array}{l}\text { Intended effect: } \\
\text { Elimination and/or } \\
\text { simplification of } \\
\text { standards. }\end{array}$ & \\
\hline $\begin{array}{l}\text { Highway Systems: } \\
\text { (Passenger cars, } \\
\text { trucks and busses), } \\
\text { Transportation } \\
\text { Department }\end{array}$ & $\begin{array}{l}\text { R\&D has advanced } \\
\text { automotive engine } \\
\text { systems, heat engines, } \\
\text { and turbo-fitting to } \\
\text { increase fuel economy } \\
\text { and fuel baseline } \\
\text { monitoring. }\end{array}$ & & $\begin{array}{l}\text { Result: Mandatory } \\
\text { fuel economy program } \\
\text { (MHTSA) has increased } \\
\text { fuel efficiency in } \\
\text { automobiles. }\end{array}$ & \\
\hline $\begin{array}{l}\text { Nat ional Bureau } \\
\text { of Standards, } \\
\text { Commerce } \\
\text { Department }\end{array}$ & $\begin{array}{l}\text { Energy conservation } \\
\text { and efficiency } \\
\text { standards, energy } \\
\text { conversion-materials } \\
\text { reliability, energy } \\
\text { storage systems, } \\
\text { nuclear-standards } \\
\text { for fission power } \\
\text { and thermonuclear } \\
\text { reactions. }\end{array}$ & & $\begin{array}{l}\text { Results: 1) safety } \\
\text { standards for home } \\
\text { furnaces may hinder } \\
\text { conservation efforts, } \\
\text { 2) energy conserva- } \\
\text { tion standards for } \\
\text { building codes. }\end{array}$ & \\
\hline $\begin{array}{l}\text { National Oceanic } \\
\text { and Atmospheric } \\
\text { Administration, } \\
\text { Comerce } \\
\text { Department }\end{array}$ & $\begin{array}{l}\text { Coastal zone } \\
\text { management, energy } \\
\text { impact formula } \\
\text { grants, coastal } \\
\text { energy impact fund. }\end{array}$ & & & $\begin{array}{l}\text { Intended effect: } \\
\text { Reduced environmental } \\
\text { impact of off shore } \\
\text { energy development. }\end{array}$ \\
\hline
\end{tabular}


TABLE B.1. (contd)

\begin{tabular}{ll}
\hline \multicolumn{1}{c}{ Agency Name } & \multicolumn{1}{c}{$\begin{array}{c}\text { Major Energy-Related } \\
\text { Activities } \\
2\end{array}$} \\
\hline $\begin{array}{l}\text { General Services } \\
\text { Administration }\end{array}$ & $\begin{array}{l}\text { Energy conservation } \\
\text { programs in feder- } \\
\text { ally owned or } \\
\text { occupied buildings. }\end{array}$ \\
$\begin{array}{l}\text { Federal Metal and } \\
\text { Nonnetallic Mine } \\
\text { Safety Board of } \\
\text { Review }\end{array}$ & $\begin{array}{l}\text { Board was abolished in } \\
\text { are now its functions } \\
\text { the Interior Secretary. }\end{array}$
\end{tabular}

\section{TAXATION}

Internal Revenue Service (IRS),

Treasury

Monitoring revenue

Department

policy vis-a-vis

energy companies.
The New York Times

1977 and 1978
House Appropriations $\begin{array}{rr}\text { Senate or House } & \text { House Approp } \\ \text { Committees, } 1977 / 78 & 1979\end{array}$
Results: Increased regulation caused an increase in mine safety.

Result: Tax reform has drastically cut capital gains and income which are of $f$ setting incentives. (Flow of private venture capital has dried up.)
Result: Minimum tax on corporate income acts as a disincentive to both cod and petroleum production by independent producers.
Results:

) Tax Reform Act of 1976 discontinues the foreign tax credits; 2) recent tax law discourages using cheaper resources because it provides that, for any end product, the tax burden will be lower the more the the more the contributed by the the resources used up producing it; 3 ) publicly owned utilities reduces electricity prices and increases resource use. 
TABLE B.1. (contd)

\begin{tabular}{|c|c|c|c|c|}
\hline $\begin{array}{c}\text { Agency Name } \\
1\end{array}$ & $\begin{array}{c}\text { Major Energy-Related } \\
\text { Activities } \\
2\end{array}$ & $\begin{array}{c}\text { The New York Times } \\
1977 \text { and } 1978 \\
3\end{array}$ & $\begin{array}{c}\text { Senate or House } \\
\text { Committees, } 1977 / 78 \\
4\end{array}$ & $\begin{array}{c}\text { House Appropriations } \\
1979 \\
5\end{array}$ \\
\hline
\end{tabular}

MARKET ACTIVITY

Bureau of Reclamation, Hydroelectric power

Interior Department generation and transmission.

Bonneville Powe Administration, Interior Department

Constructs, operates and maintains facilities to market electric power from 29 federal hydroelectric generating plants.

Southeastern Power Administration,

Interior Department Administration, Interior Department
The administration markets power gener ated at Corps of

Engineers hydro-

electric plants in a

10 -state area of the

Southeast.

Maintains transmission,

sub-station and switch-

ing facilities to

transmit power gener-

ated at Corps of

Engineers hydro-

electric projects

in Southwest.
Results: 1) 60.9

billion kWh hours of

electricity was gener-

ated for sale in 1976;

2) economic or business

activity attributable

tion totaled \$12.1 bil-

tion totaled
lion in 1976.

Intended effect:

Carry out activities

mandated by Federal

Columbia River Trans-

mission System Act

(1974).

Results: A BPA

report showed that

the costs of nuclear

plants planned and

under construction

in the region have

escalated rapidly as

a result of extended

a result of extended

permit and licens-

ing delays, environ-

inental opposition, and inflation and interest during construction.

Result: Unable to meet increased demand

for federal power

(increased litigation

over power allocation).
Result: Has produced and allocated powe to consumers in the Southwest region. 


\section{TABLE B.1. (contd)}

\begin{tabular}{ll}
\hline \multicolumn{1}{c}{ Agency Name } & $\begin{array}{c}\text { Major Energy-Related } \\
\text { Activities } \\
2\end{array}$ \\
\hline $\begin{array}{l}\text { Federal Energy } \\
\text { Administration } \\
\text { (Now part of DOE) }\end{array}$ & \\
Bureau of Land & \\
Management, Interior & $\begin{array}{l}\text { Energy and minerals } \\
\text { mepartment }\end{array}$ \\
& $\begin{array}{l}\text { leasing and manage- } \\
\text { ment of energy min- } \\
\text { erals for both on- } \\
\text { shore and nonenergy } \\
\text { minerals. }\end{array}$
\end{tabular}

\begin{tabular}{|c|c|c|}
\hline $\begin{array}{c}\text { The New York Times } \\
1977 \text { and I978 } \\
3\end{array}$ & $\begin{array}{c}\text { Senate or House } \\
\text { Committees, } 1977 / 78 \\
4\end{array}$ & $\begin{array}{c}\text { House Appropriations } \\
1979 \\
5 \\
\end{array}$ \\
\hline & & $\begin{array}{l}\text { Results: 1) produced } \\
\text { enriched uranium for } \\
\text { government contracts, } \\
\text { 2) weatherization } \\
\text { programs by utilities } \\
\text { may lead to an insula- } \\
\text { tion monopoly. }\end{array}$ \\
\hline
\end{tabular}

\section{SERVICES}

Energy Research and Development (Now part of DOE)
Directs and conducts

R\&D on domestic

energy sources;

carries out nuclear

energy functions

related to national

defense and fuel

production; and

production; and

research in the

physical, biomedical.

and environmental

sciences.
Result: Breeder

reactor development

has resulted in the

increased proliferation

of nuclear weapons.
Intended effects:

1) increased coal

production, 2)

greater reliance on

nuclear power.
Intended effects:

1) increased coal

production, 2)

greater reliance on

nuclear power.

Results: 1) inflationary impact of rising energy prices, 2) very results from R\&D. 
TABLE B.1. (contd)

\begin{tabular}{|c|c|c|c|c|}
\hline $\begin{array}{c}\text { Agency Name } \\
1 \\
\end{array}$ & $\begin{array}{c}\text { Major Energy-Related } \\
\text { Activities } \\
2 \\
\end{array}$ & $\begin{array}{c}\text { The New York Times } \\
1977 \text { and } 1978 \\
3\end{array}$ & $\begin{array}{c}\text { Senate or House } \\
\text { Committees, } 1977 / 78 \\
4 \\
\end{array}$ & $\begin{array}{c}\text { House Appropriations } \\
1979 \\
5 \\
\end{array}$ \\
\hline $\begin{array}{l}\text { Appalachian Regional } \\
\text { Development Program }\end{array}$ & $\begin{array}{l}\text { Limited programs of } \\
\text { grants to stimulate } \\
\text { energy-related enter- } \\
\text { prise and grants for } \\
\text { the sealing and filling } \\
\text { of voids in abandoned } \\
\text { coal mines. }\end{array}$ & & & $\begin{array}{l}\text { Intended ef fect: } \\
\text { Restoration of } \\
\text { abandoned mines. }\end{array}$ \\
\hline $\begin{array}{l}\text { Corps of Engineers, } \\
\text { Defense Department }\end{array}$ & $\begin{array}{l}\text { Major dam and } \\
\text { reservoir construc- } \\
\text { tion, hydroelectric } \\
\text { power generation, and } \\
\text { deep water port } \\
\text { construction. }\end{array}$ & & & $\begin{array}{l}\text { Results: 1) decrease } \\
\text { in consumption of } \\
\text { energy by military, } \\
\text { (2) increase in danl } \\
\text { construction. }\end{array}$ \\
\hline $\begin{array}{l}\text { Naval and Strategic } \\
\text { Petroleum Reserve, } \\
\text { Defense Department }\end{array}$ & $\begin{array}{l}\text { Administration of all } \\
\text { production reserves } \\
\text { and advising on crude } \\
\text { and oil shaie } \\
\text { development. }\end{array}$ & & & $\begin{array}{l}\text { Result: A supply of } \\
\text { petroleu'n in case of } \\
\text { a future embargo. }\end{array}$ \\
\hline $\begin{array}{l}\text { Tennessee Valley } \\
\text { Authority }\end{array}$ & $\begin{array}{l}\text { Government-owned } \\
\text { corporation acting } \\
\text { as wholesale } \\
\text { supplier for } 160 \\
\text { local, mun icipal, and } \\
\text { cooperative } \\
\text { electrical systems. }\end{array}$ & & & $\begin{array}{l}\text { Results: 1) inter- } \\
\text { est-free loans to } \\
\text { ut ility rate payers } \\
\text { for insulation, } 2 \text { ) } \\
\text { demonstration project } \\
\text { for fluidized bed com- } \\
\text { bustion. }\end{array}$ \\
\hline
\end{tabular}


TABLE B.1. (contd)

\begin{tabular}{|c|c|c|c|c|}
\hline $\begin{array}{c}\text { Agency Name } \\
1 \\
\end{array}$ & $\begin{array}{c}\text { Major Energy-Related } \\
\text { Activities } \\
2 \\
\end{array}$ & $\begin{array}{c}\text { The New York Times } \\
1977 \text { and } 1978 \\
3\end{array}$ & $\begin{array}{c}\text { Senate or House } \\
\text { Committees, } 1977 / 78 \\
4\end{array}$ & $\begin{array}{c}\text { House Appropriations } \\
1979 \\
5 \\
\end{array}$ \\
\hline $\begin{array}{l}\text { The Joint Federal } \\
\text { and State Use and } \\
\text { Planning Commission } \\
\text { for Alaska }\end{array}$ & $\begin{array}{l}\text { Created in } 1971 \text { and } \\
\text { terminating in } 1979 ; \\
\text { resolves land-use } \\
\text { matters between } \\
\text { federal, state, and } \\
\text { local (tribal) } \\
\text { jurisdictions. }\end{array}$ & & & \\
\hline $\begin{array}{l}\text { Office of Technology } \\
\text { Assessment }\end{array}$ & $\begin{array}{l}\text { Impact assessments } \\
\text { of energy production } \\
\text { technologies. }\end{array}$ & & & $\begin{array}{l}\text { Result: Reports on } \\
\text { energy impacts. }\end{array}$ \\
\hline $\begin{array}{l}\text { Congressional } \\
\text { Budget Office }\end{array}$ & $\begin{array}{l}\text { Budget priorities } \\
\text { for energy. }\end{array}$ & & & $\begin{array}{l}\text { Result: Work on the } \\
\text { modeling of energy. }\end{array}$ \\
\hline $\begin{array}{l}\text { General Accounting } \\
\text { Office }\end{array}$ & $\begin{array}{l}\text { In 1976, through the } \\
\text { office of Special } \\
\text { Programs, the GAO } \\
\text { conducted Energy } \\
\text { Policy Conservation } \\
\text { Act verification } \\
\text { examinations of } \\
\text { energy-related inform- } \\
\text { ation developed by } \\
\text { private business } \\
\text { concerns under } \\
\text { circumstances of the } \\
\text { Act. }\end{array}$ & & $\begin{array}{l}\text { Results: 1) a } \\
\text { study showed that } \\
\text { nuclear licensing } \\
\text { delays may not be } \\
\text { able to be el iminated } \\
\text { (increased cost of } \\
\text { nuclear power); } 2 \text { ) } \\
\text { another study showed } \\
\text { that licensed material } \\
\text { was missing at several } \\
\text { nuclear plants. }\end{array}$ & $\begin{array}{l}\text { Results: 1) audited new } \\
\text { programs set up by EPCA } \\
\text { and ECPA, 2) evaluated } \\
\text { programs under the } \\
\text { Nuclear Export Act. }\end{array}$ \\
\hline $\begin{array}{l}\text { Non-Highway Systems, } \\
\text { Transportation } \\
\text { Department }\end{array}$ & $\begin{array}{l}\text { Air, rail, marine, } \\
\text { and pipel ine trans- } \\
\text { port. }\end{array}$ & $\begin{array}{l}\text { Intended effects: } \\
\text { proposed that any } \\
\text { new energy taxes be } \\
\text { rebated in the form } \\
\text { of a more flexible } \\
\text { subsidized public } \\
\text { transit system. }\end{array}$ & $\begin{array}{l}\text { Intended effect: } \\
\text { Proposed improvements of } \\
\text { high-speed rail ser- } \\
\text { vice in the North- } \\
\text { east. }\end{array}$ & \\
\hline
\end{tabular}


TABLE B.1. (contd)

\begin{tabular}{|c|c|c|c|c|}
\hline $\begin{array}{r}\text { Agency Name } \\
1\end{array}$ & $\begin{array}{c}\text { Major Energy-Related } \\
\text { Activities } \\
2 \\
\end{array}$ & $\begin{array}{c}\text { The New York Times } \\
1977 \text { and } 1978 \\
3\end{array}$ & $\begin{array}{c}\text { Senate or House } \\
\text { Committees, } 1977 / 78 \\
4\end{array}$ & $\begin{array}{c}\text { House Appropriations } \\
1979 \\
5 \\
\end{array}$ \\
\hline $\begin{array}{l}\text { National Science } \\
\text { Foundation }\end{array}$ & $\begin{array}{l}\text { Basic energy- } \\
\text { related general } \\
\text { research; RANN } \\
\text { studies on renew- } \\
\text { able and non- } \\
\text { renewable resources; } \\
\text { Ocean Sediment Coring } \\
\text { Program. }\end{array}$ & & $\begin{array}{l}\text { Result: Energy- } \\
\text { related academic } \\
\text { research has negligible } \\
\text { short term results. }\end{array}$ & \\
\hline $\begin{array}{l}\text { Smithsonian Institute, } \\
\text { Science Inf onmation } \\
\text { Exchange }\end{array}$ & $\begin{array}{l}\text { SSIE plays an increas- } \\
\text { ing role in support of } \\
\text { a number of programs } \\
\text { of national interest, } \\
\text { such as energy, cancer } \\
\text { and pesticides research. }\end{array}$ & & $\begin{array}{l}\text { Result: Energy- } \\
\text { related academic } \\
\text { research has negligible } \\
\text { short-term results }\end{array}$ & \\
\hline
\end{tabular}

\section{EXHORTATION}

Federal Power

Commission

(NOw part of DOE)

Result: Federal exhorta-

tion to change the struc

ture of utility rates

results in lost revenues to

utilities and natural gas

companies in the State

of Cal ifornia.

Federal Energy

Administration

(Now part of DOE)

Result: Exhortation to

to change the structure

of utility rates. 
TABLE B.1. (contd)

\begin{tabular}{|c|c|c|c|c|}
\hline $\begin{array}{c}\text { Agency Name } \\
1\end{array}$ & $\begin{array}{c}\text { Major Energy-Related } \\
\text { Activities } \\
2 \\
\end{array}$ & $\begin{array}{c}\text { The New York Times } \\
1977 \text { and } 1978 \\
3\end{array}$ & $\begin{array}{c}\text { Senate or House } \\
\text { Committees, } 1977 / 78 \\
4\end{array}$ & $\begin{array}{c}\text { House Appropriations } \\
1979 \\
5 \\
\end{array}$ \\
\hline $\begin{array}{l}\text { Domestic and Inter- } \\
\text { national Business, } \\
\text { Commerce Department }\end{array}$ & $\begin{array}{l}\text { Coordinating and formu- } \\
\text { lating Department of } \\
\text { Energy policy, conser- } \\
\text { vation programs, energy- } \\
\text { related analytical } \\
\text { activities, and opti- } \\
\text { mum fuel utilization } \\
\text { in business and indus- } \\
\text { trial reactors. }\end{array}$ & & $\begin{array}{l}\text { Results: Voluntary } \\
\text { industrial energy con- } \\
\text { servation program involv- } \\
\text { ing } 39 \text { trade associations } \\
\text { and } 1500 \text { companies with a } \\
10.7 \% \text { increase in energy } \\
\text { efficiency for petroleum } \\
\text { refining; } 11.8 \% \text { increase } \\
\text { in energy efficiency for } \\
\text { textile manufacture; } 19.8 \% \\
\text { increase in energy effi- } \\
\text { ciency for flat glass. }\end{array}$ & \\
\hline
\end{tabular}

DISBURSEMENTS

Maritime Adminis- Construction and

tration, Commerce operating subsidies

Department for U.S. ships and

waterborne transpor-

waterborne transpor
tation systems.

Result: Subsidies to

U.S. shippers lowered

the cost of transporting

petroleum.

\section{REORGANIZATION}

$\begin{array}{ll}\text { Fish and Wildife } & \text { Environmental } \\ \text { Service, Interior } & \text { monitoring of energy } \\ \text { Department } & \text { impacts under habi- } \\ & \text { tat preservation }\end{array}$

Result: Assumed responsibilty for the coordi-

nation of the Service's

guidel ines.

response to oil spills. 


\section{REFERENCES APPENDIX B}

\section{Column 3}

These references were used to obtain the information in Column 3 . They appear in the order in which they were used.

Clymer, Adam. July 23, 1977. "President Thwarted on Authority to Set Natural Gas Prices." New York Times, p. 9, col. 1.

Mower, Charles. February 28, 1978. "Governors Urge Carter to Facilitate Nuclear Power." New York Times, p. 16, col. 1.

Sharecoff, Phillip. January 3, 1978. "Carter Record Mixed on the Environment." New York Times, p. 21, col. 1.

Cowen, Edward. March 31, 1978. "Antitrust Aides See No Need to Split Up $0 i 1$ and Coal Sector." New York Times, p. 1, col. 3.

"Be11 Says Antitrust Enforcement Will Top His List of Priorities." May 12, 1977. New York Times, Section IV, p. 7, col. 1.

Cowen, Edward. May 23, 1977. "Price Rise in Steel Under Study in U.S. on Antitrust Basis." New York Times, p. 41, col. 6.

Ratner, Steven. March 15, 1978. "Jackson Criticizes Carter Moves on Foreign and Domestic Moves." New York Times, p. 8, col. 3 .

"Brown Warns on Reactor." June 14, 1977. New York Times, p. 25, col. 1.

Holsendolph, Ernest. April 20, 1977. "Energy Plan Said to Lack Public Transport Aspect." New York Times, p. 18, col. 1.

Ratner, Steven. February 25, 1978. "U.S. Drafts Plans to Put Emphasis on Alternative Sources of Energy." New York Times, p. 1, col. 4.

Hill, Gladwin. March 1, 1978. "Environmental Unit Urges Merger of Opposing Strategies on Energy." New York Times, p. 14, col. 4.

Wicker, Tom. April 30, 1978. "The Future is Now." New York Times, Section IV, p. 19, col. 2 .

Haitch, Richard. June 5, 1977. "The President's Solar Advocate." New York Times, Section XI, p. 1, col. 1 .

Charlton, Linda. April 15, 1977. "Grass Roots Energy Advice for Carter." New York Times, Section II, p. 6, col. 5.

Farnsworth, Clyde H. January 29, 1977. "Leading Indicators for Economy Surge." New York Times, p. 1, col. 3. 
"Aiding Energy Saving Inventions." February 17, 1977. New York Times, p. $57, \mathrm{col} .4$.

Parisi, Anthony J. February 23, 1977. "Can We Have Our Energy and Burn It Too?" New York Times, p. 1, col. 5.

Lyons, Richard D. January 1, 1978. "Mapping Rocks and Rills, 011 , and Gas." New York Times, Section III, p. 3, col. 1.

\section{Column 4}

These references were used to obtain the information in Column 4. They appear in the order in which they were used.

U.S. Senate, Committee on Energy and Natural Resources. 1977. "Hearings on Natural Gas Pricing Proposals of President Carter's Energy Program," June $7,13,14$, and 17, 1977. Hearings. 95th Congress, 1st sess. U.S. Government Printing Office, Washington, D.C.

U.S. Senate, Committee on the Judiciary, Subcommittee on Antitrust and Monopoly. 1977. "Hearings on the Public Impact of Natural Gas Price Deregulations." Hearings. 95th Congress, 1st sess. U.S. Government Printing office, Washington, D. C.

U.S. Senate, Committee on Energy and Natural Resources. 1977. "Hearings on the Economic Impact of President Carter's Energy Plan," May 3, 1977, pp. 51-52, 116-118. Hearings. 95th Congress, 1st sess. U.S. Government Printing Office, Washington, D.C.

U.S. Senate, Committee on Energy and Natural Resources. 1977. "Hearing: Congressional Budget Office Analys is of the President's Energy Proposals," May 19, 1977, pp. 11-19. Hearings. 95th Congress, 1st sess. U.S. Government Printing Office, Washington, D.C.

U.S. Congress, House Committee on Interior and Insular Affairs. 1977. "Test imony of Monte Caufield," June 13, 1977. Hearings. 95th Congress, 1st sess. U.S. Government Printing Office, Washington, D.C.

U.S. Congress, Committee on Interstate and Foreign Commerce, Subcommittee on Transportation. 1977. (Hearings April 26, May 18 and 19, 1977.) Hearings. 95th Congress, 1st sess. U.S. Government Printing Office, Washington, D.C.

U.S. Congress, Committee on Interstate and Foreign Commerce, Subcommittee on Energy and Power. 1977. "Hearings on MRC and ERDA Nuclear MUF Data," August 8, 1977. Hearings. 95th Congress, 1st sess. U.S. Government Printing office, Washington, D.C.

U.S. House of Representatives, Committee on Interstate and Foreign Commerce. 1977. "Hearing: MRC and ERDA Nuclear MUF Data," August 8, 1977. Hearings. 95th Congress, 1st sess. U.S. Government Printing Office, Washington, D.C. 
U.S. Senate, Committee on Energy and Natural Resources, Subcommittee on Energy Conservation and Regulation. 1977. "Hearings on Federal Energy Administration Pricing Policies for Alaskan 0il," May 9, 1977. Hearings. 95 th Congress, 1st sess. U.S. Government Printing Office, Washington, D.C.

U.S. Senate, Committee on Finance, Subcommittee on Energy and Foundations. 1977. "Hearings on Incentives for Developing New Energy Sources," June 20-21, 1977. Hearings. 95th Congress, 1st sess. U.S. Government Printing office, Washington , D.C.

U.S. Senate, Committee on Energy and Natural Resources. 1977. "Hearings on Coal Conversion Legislation, Part II," June 24, 1977. Hearings.

95 th Congress, 1st sess. U.S. Government Printing Office, Washington, D.C.

U.S. Congress, Committee on Science and Technology, Subcommittee on Energy Research and Development. 1976. "Hearings on an Energy Standard of Value," June 1976, pp. 35-39. Hearings. 94th Congress, 2nd sess. U.S. Government Printing Office, Washington, D.C.

U.S. Senate, Committee on Energy and Natural Resources, Subcommittee on Energy Conservation and Regulation. 1977. "Hearings on the Status of Federal Energy Programs," April 6, 1977. Hearings. 95th Congress, 1st sess. U.S. Government Printing Office, Washington, D.C.

U.S. Congress, Committee on Agriculture, Subcommittee on Family Farms. 1977. "Hearings on Present and Future Energy Needs on Family Farms," May 17, 18, 19, 24, 1977. Hearings. 95th Congress, 1st sess. U.S. Government Printing Office, Washington, D.C.

U.S. Senate, Committee on Energy and Natural Resources, Subcommittee on Energy Conservation and Regulation. 1977. "Hearings on Energy Conservation Provisions of President Carter's Energy Program," June 21-22, 1977. Hearings. 95th Congress, 1st sess. U.S. Government Printing Office, Washington, D.C.

U.S. House of Representatives, Committee on Science and Technology, Subcommittee on Domestic and International Scientific Planning and Analysis. 1976. "Hearings on Review of Federal Research and Development Expenditures and the United States Economy," December 1976. Hearings. 94th Congress, 2nd sess. U.S. Government Printing Office, Washington, D.C.

U.S. Senate, Committee on Energy and Natural Resources, Subcommittee on Parks and Recreation. 1977. "Hearings on the Montana Wilderness," April 6, 1977. Hearings. 95th Congress, 1st sess. U.S. Government Printing Office, Washington D.C.

U.S. Senate, Committee on Energy and Natural Resources. 1977. "Report on Alaska 0il Price Policy," April 1977. Hearings. 95th Congress, 1st sess. U.S. Government Printing Office, Washington, D.C. 
U.S. House of Representatives, Committee on Small Business, Subcommittee on Energy, Environment, Safety, and Research. 1977. "Report on the Small Business Energy Conservation and Commercialization Amendments," September 14, 1977. Hearings. 95th Congress, 1st sess. U.S. Government Printing Office, Washington, D.C.

U.S. House of Representatives, Committee on Interstate and Foreign Commerce, Subcommittee on Transportation and Commerce. 1977. "Hearings: Implementation of the Resource Conservation and Recovery Act of 1976," April 26, May 18 and 19, 1977. Hearings. 95th Congress, 1st sess. U.S. Government Printing Office, Washington, D.C.

U.S. House of Representatives, Committee on Interstate and Foreign Commerce, Subcommittee on Oversight and Investigations. 1977. "Hearings: Adverse Personnel Actions Against Professional Staff Members at the Federal Power Commission," April 28, and May 5, 1977. Hearings. 95th Congress, 1st sess. U.S. Government Printing Office, Washington, D.C.

U.S. House of Representatives, Committee on Interstate and Foreign Commerce, Subcommittee on Energy and Power. 1977. "Hearing: Strategic Petroleum Reserve," February 16, 1977. Hearing. 95th Congress, 1st sess. U.S. Government Printing Office, Washington, D.C.

U.S. Congress, Joint Committee on Defense Production. 1977. "Hearings: Emergency Preparedness in the Electric Power Industry," August 10-11, 1977. Hearings. 95th Congress, 1st sess. U.S. Government Printing Office, Washington, D.C.

U.S. Senate, Committee on Energy and Natural Resources. 1977. "Hearing: Department of Energy Nominations," October 7, 1977. Hearings. 95 th Congress, 1st sess. U.S. Government Printing Office, Washington, D.C.

U.S. House of Representatives, Committee on Small Business, Subcommittee on Energy, Environment, Safety, and Research. 1977. "Hearing: Impact of the President's Energy Proposal on Small Business," May 19, 1977. Hearings. 95 th Congress, 1st sess. U.S. Government Printing Office, Washington, D.C.

U.S. Senate, Committee on Environment and Public Works. 1977. "Hearing: Urban Transportation and Energy: The Potential Savings of Different Modes," October 5, 1977. Hearings. 95th Congress, 1st sess. U.S. Government Printing Office, washington, D.C.

U.S. Congress, Joint Economic Committee, Subcommittee on Energy. 1977. "The Impact of the President's Energy Plan on the Northeast," May 13, 1977. Hearings. 95th Congress, 1st sess. U.S. Government Printing Office, Washington D.C. 
$\underline{\text { Column } 5}$

These references were used to obtain the information in Column 5. They appear in the order in which they were used.

U.S. Congress, House Appropriations Committee. 1978. "The Department of Energy Appropriations for 1979," pp. 250-325. Hearings. 95th Congress, 2nd sess. U.S. Government Printing office, Washington, D.C.

U.S. Congress, House Appropriations Committee. 1978. "The Department of Labor: OSHA Appropriations for 1979," pp. 628-629. Hearings. 95th Congress, 2nd sess. U.S. Government Printing Office, Washington, D.C.

U.S. Congress, House Appropriations Committee. 1978. "Public Works for Water and Power Development and the Energy Research Appropriation Bi11, Part 6; The Federal Regulatory Commission," pp. 874-877. Hearings. 95th Congress, 2nd sess. U.S. Government Printing Office, Washington, D.C.

U.S. Congress, House Appropriations Committee. 1978. "Public Works for Water and Power Development and the Energy Research Appropriation Bill, 1979, Part 4; The Nuclear Regulatory Commission." Hearings. 95th Congress, 2nd sess. U.S. Government Printing Office, washington, D.C.

U.S. Congress, House Appropriations Committee. 1978. "Department of Housing and Urban Development--Independent Agencies Appropriations for 1979; The Environmental Protection Agency." Hearings. 95th Congress, 2nd sess. U.S. Government Printing Office, Washington, D.C.

U.S. Congress, House Appropriations Committee. 1978. "Military Construction Appropriations for 1979," pp. 64-75. Hearings. 95th Congress, 2nd sess. U.S. Government Printing Office, Washington, D.C.

U.S. Congress, House Appropriations Committee. 1978. "Hearings on the Departments of State, Justice, and Commerce, Appropriations for 1979; The Federal Trade Commission," pp. 976-985. Hearings. 95th Congress, 2nd sess. U.S. Government Printing Office, Washington, D.C.

U.S. Congress, House Appropriations Committee. 1978. "Agriculture, Rural Development and Related Appropriations for 1979; The Rural Electrification Administration." Hearings. 95th Congress, 2nd sess. U.S. Government Printing Office, washington, D.C.

U.S. Congress, House Appropriations Committee. 1978. "Bureau of Land Management Appropriations for 1979." Hearings. 95th Congress, 2nd sess. U.S. Government Printing Office, Washington, D.C.

U.S. Congress, House Appropriations Committee. 1978. "Public Works for Water and Power Development and Energy Research Appropriation Bill, Part 5; The Strategic Petroleum Reserve," pp. 13-17. Hearings. 95th Congress, 2nd sess. U.S. Government Printing Office, Washington, D.C. 
U.S. Congress, House Appropriations Committee. 1978. "Public Works for Water and Power Development and Energy Research Appropriation Bi11, 1979, Part 6; The Energy Research and Development Administration," pp. 1-315. Hearings. 95 th Congress, 2nd sess. U.S. Government Printing Office, Washington, D.C.

U.S. Congress, House Appropriations Committee. 1978. "Publ ic Works for Water and Power Development and Energy Research Appropriation Bi11, 1979, Part 3; Water Resources Council." Hearings. 95th Congress, 2nd sess. U.S. Government Printing Office, Washington, D.C.

U.S. Congress, House Appropriations Committee. 1978. "National Oceanic and Atmospheric Administration Appropriations for 1979." Hearings. 95th Congress, 2nd sess. U.S. Government Printing Office, Washington, D.C.

U.S. Congress, House Appropriations Committee. 1978. "Geological Survey Appropriations for 1979." Hearings. 95th Congress, 2nd sess. U.S. Government Printing Office, Washington, D.C.

U.S. Congress, House Appropriations Committee. 1978. "Maritime Administration Appropriations for 1979," pp. 824-826. Hearings. 95th Congress, 2nd sess. U.S. Government Printing Office, Washington, D.C.

U.S. Congress, House Appropriations Committee. 1978. "Fish and Wildlife Service Appropriations for 1979." Hearings. 95th Congress, 2nd sess. U.S. Government Printing Office, Washington, D.C.

U.S. Congress, House Appropriations Committee. 1978. "Small Business Administration Appropriations for 1979." Hearings. 95th Congress, 2nd sess. U.S. Government Printing Office, Washington, D.C.

U.S. Congress, House Appropriations Committee. 1978. "Mining Enforcement and Safety Administration Appropriations for 1979." Hearings. 95th Congress, 2nd sess. U.S. Government Printing Office, Washington, D.C. 
APPENDIX C

ENERGY INDUSTRY SURVEY 
APPENDIX C

\section{ENERGY INDUSTRY SURVEY}

This appendix presents a copy of the survey used to determine the impact of federal incentives on the nuclear power industry. Excerpts from the survey responses are presented to indicate the general tone of the responses.

\section{INDUSTRY SURVEY ON FEDERAL INCENTIVES TO NUCLEAR POWER}

We are attempting to estimate the effect of federal R\&D expenditures on the development of the commercial nuclear power industry. The information obtained will be part of an evaluation of how best to apply federal incentives to the development of solar energy.

The approach we have selected is to assume that the 1954 amendment to the Atomic Energy Act was approved (permitting industry to build, own, operate, and export reactors) but that no significant federal R\&D in support of commercial nuclear power was funded after 1954. Weapons material production reactors and military reactors would continue to be developed and some of their technology would be available to industry. It has been assumed that legislation similar to the Price-Anderson Act would be enacted and that private ownership of nuclear fuel materials would be permitted.

Based on these assumptions four scenarios were developed to represent possible ways in which commercial nuclear power might have developed had major federal involvement not materialized after 1954:

- Commercial nuclear power would never have become viable.

- Commercial nuclear power would never have been delayed about five years.

- Commercial nuclear power would have developed much as it has.

- Commercial nuclear power would have been accelerated. We would like you to read the four scenarios that follow and select one that you think would most likely have occurred (if any). Then fill out the 
questionnaire at the end. A profile of U.S. Energy Production, Past and Projected, is shown in Figure C.1. We suggest that nuclear power would replace or be replaced by the same source mix as shown in the figure.

Based on the responses we receive, we will attempt to estimate the effects of federal R\&D expenditures on nuclear power development, i.e., what the federal funds accomplished in furthering commercial nuclear power development.

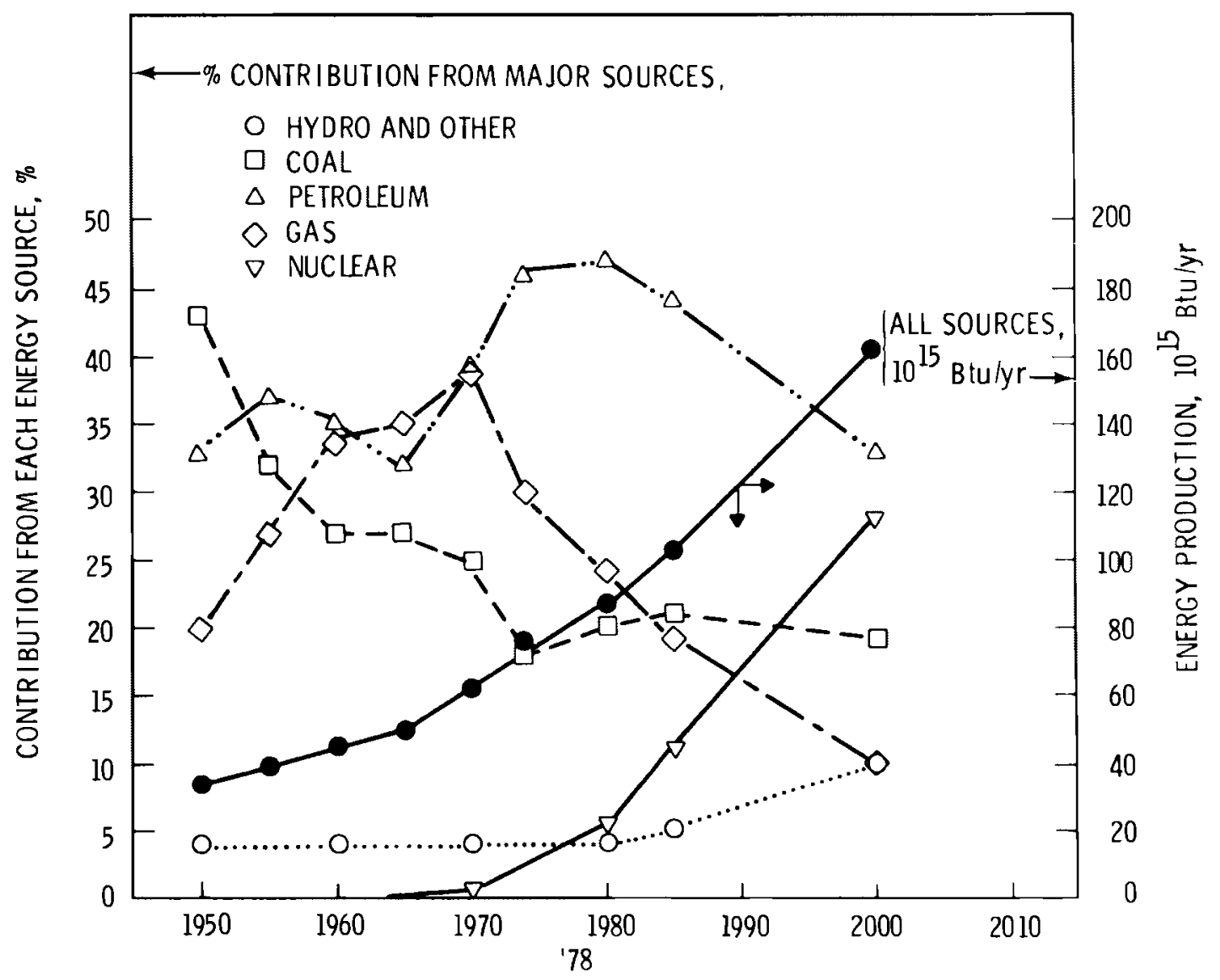

FIGURE C.1. U.S. Energy Production versus Year, 1950 to 2000 
NUCLEAR POWER - THE SETTING IN 1953-54

In August of 1954 an amendment was made to the Atomic Energy Act (AEA) to permit industry to build, own, operate, and export reactors.

During 1953-54 industry had become convinced that dual purpose reactors (power and plutonium for weapons use) were inappropriate for electric power generation. It was recognized that initially nuclear power was likely to cost $20 \%$ to $25 \%$ more than power from coal plants. While the electric power industry was termed "disunited and nonpurposeful" in its approach to nuclear power, there was still significant activity in nuclear electric generation:

- Detroit Edison was deeply involved in a fast breeder reactor program.

- The Shippingport reactor program was initiated.

- Several utility/industrial firms were studying reactor types.

- In 1953 Commonwealth Edison had requested AEC authorization to build a water-cooled reactor but subsequently had withdrawn its application.

On the foreign scene the United Kingdom had started construction of Calder Hall in 1953.

In noncommercial nuclear power the following were occurring.

- The prototype submarine test reactor had been producing power for over a year.

- 32 reactors had been built since 1942 .

- The APPR (Army Package Power Reactor) was being bid on a fixed-cost basis.

- General Electric proposed building an AEC-financed dual purpose reactor at Hanford, probably using zirconium tubes and on-line fuel handling.

- The reactor safety picture "brightened" as a result of NRTS tests. Forecasts were being made:

- 500 MWe of nuclear ( 1 to 2 plants) would be operational by 1960; 210,000 MWe by 2000 . 
- AEC projects 4 to $7 \mathrm{mill}$ power for nuclear plants.

- There is no urgent need for low cost nuclear power.

- Dow/Detroit Edison will invest their own money in a reactor plant if the AEA is amended.

- One of the AEC commissioners (Dean) projected 10 years to the first full-scale nuclear power plant; 3 to 4 years less if the AEA is amended.

- If the AEC does not support a program to complement one in industry, the U.S. may lose five years or more in commercial development.

The Atomic Industrial Forum was formed in 1953; the ACRS was formed in 1953; the USSR exploded a thermonuclear weapon.

The Joint Committee on Atomic Energy hearings in 1953 concluded the following about commercial nuclear power:

- National security is of paramount importance in any commercial nuclear program.

- The federal government should control safety, health, and security aspects of nuclear power.

- Nuclear power will be economically competitive.

- Delaying amendments to the AEA will have no particular effect on the development of commercial nuclear power.

- No company indicated that it was ready to make a substantial investment in commercial nuclear power.

Commercial Nuclear Power Would Never Have Become Viable

Industry would not invest the requisite R\&D and front-end funds, in light of major unknowns, to create a viable commercial nuclear power industry. A few commercial ventures would be attempted, but lack of an adequate knowledge base, coupled with poor performance (such as with the Fermi reactor), would result in the industry languishing. Some U.S. firms would be licensed by foreign countries (such as the United Kingdom) and a few reactors would be built, but the lack of industrial base, the noncompetitive nature of the import 
compared to non-nuclear alternatives, and the lack of support for such an import policy would cause this option to languish also. A number of dual purpose reactors built by federal funds would be operational-- the reactors would produce heat, isotopes, weapons material, etc., as well as power. Further, reactors for military and other special purposes would be built in significant numbers. While the utilities would operate many of the nuclear power plants (or the steam-related portions) the federal government would own them (or the nuclear steam supply system), and the initiative to build additional nuclear plants would rest with the government. Politics would render this option ineffective.

In sumary, we suggest about $10 \%$ to $20 \%$ of the actual capacity (MWe) being installed today or planned to the year 2000 would be installed under this option.

Commercial Nuclear Power Would Have Been Delayed About Five Years

The lack of significant federal involvement in commercial reactor R\&D and the secrecy surrounding military and weapons production reactors would have caused the power generation industry to delay initiation of programs for about five years. Some utilities and reactor vendors would have built small prototype plants to establish proof-of-principle and to gain operating, economic, and design experience. The lack of safety research would contribute to the delay. Overall, the commitment to large plants and the subsequent generations of plant sizes would have been delayed about five years. This delay would have permitted the emergence of other reactor types which are not presently available to utilities; the U.S. licensing of foreign reactor types would also be a viable option for utilities.

Commitment to the larger reactor sizes would have occurred at the onset of the environmental awareness era. The major effect of this would be twofold: 1) increased support for the more (thermally) efficient reactor types, and 2) substantially increased involvement of federal agencies in licensing and regulation. Initially, the lack of federal involvement in R\&D would also result in decreased federal involvement in licensing and regulation. 
In summary, we suggest about $75 \%$ of the actual capacity (MWe) being installed today or $\mathrm{planned}$ to the year 2000 would be installed under this option. The major $\mathrm{plant}$ type would still be the present light water reactors. Commercial Nuclear Power Would Have Developed As It Was

The lack of significant federal involvement in commercial reactor R\&D would have slowed the development of the industry initially, but later, partly due to decreased licensing and regulatory activities, the rate of installing nuclear plants would increase to its present level. The initial slowdown would result from industry's need to build prototype plants and gain experience with them before committing to larger plants sited closer to population centers. Plants would generally be built farther from population centers than they are today. The large amount of funds required to develop the nuclear power option and the substantial risk involved would limit the vendors and reactor types to those in the industry today. Enriched uranium from the diffusion cascades would have become available much as it has to date. However, commercial enrichment would be a competing source today due to limited diffusion cascade capacity and uncertainty of supply.

Commercial Nuclear Power Would Have Been Accelerated

The competitive nature of U.S. industry driving to recoup its larger investment in nuclear power would have resulted in an accelerated development of the commercial nuclear power industry. The smaller federal licensing and regulatory effort would have permitted commercial nuclear power to maintain a larger margin of competitiveness compared to coal. Industry development of enrichment technology, with major investments that would follow, would further drive the commercialization of nuclear power. Initial reactor plants would be smaller and more isolated until adequate experience was obtained. The greater market penetration would result in more competitors offering a wider range of reactor types. The export market would be larger. Industry would be playing a larger role in all aspects of the back end of the fuel cycle, and greater progress would be noted today.

In summary, we suggest about $150 \%$ to $200 \%$ of the actual capacity (MWe) being installed today or planned to the year 2000 would be installed under this option. 


\section{EXHIBIT C.1. QUESTIONNAIRE}

The scenario of nuclear power growth which seems most likely under the assumptions set forth, and the percentage of (installed and planned) for the one scenario selected would be:

Option Selected

Commercial nuclear power would never have become viable.

Something between the preceding and following cases.

Commercial nuclear power would have been delayed about five years.

Something between the preceding and following cases.

Commercial nuclear power would have developed much as it has.

Something between the preceding and following cases.

Commercial nuclear power would have been accelerated.

Other (please describe) and Comments. Also, please provide a brief characterization of your industry position in 1954 .

Return to Mr. Harty, Battelle Northwest (ROB), Box 999, Richland, WA 99352 


\section{SURVEY RESPONSES}

In this section, sample comments indicative of the general response tone are presented. It is important to note that the sample comments are excerpts from responses and, therefore, may not represent the overall emphasis of the response. The comments are listed according to the four categories identified in Chapter 4 with a final section listing comments concerning solar development.

Those Who Thought that Federal Incentives were Important to the Development of Commercial Nuclear Power

"My own belief is that a proper economic view of the very low price of $0 i l$ and gas at the time nuclear power was getting started (together with a realistic assessment of the cost of a full-scale nuclear system) would have eliminated nuclear power as a commercially viable alternative." (Response No. 21)

"The dual power-weapons grade plutonium reactors would have been very limited. Low burnup for weapons grade plutonium makes them costly unless, as at the ' $N$ ' reactor, a heat exchanger was required to limit reactivity in cooling water and was not charged to power production (steam-free).

"Isotope reactors would have been limited too. Not many needed with plucking of weapons waste streams.

"Heat reactors would not emerge for commercial use. Steel processing still seems far off. Low temperature heat would have been ruled out (district heating or desalting) by close-in reactor siting to limit transport burdens. Chemical heat pipes would have represented a double development and cost deterrent." (Response No. 46 -- Comments on Scenario 1)

"Delays would result from absence of the Argonne Lab reactor program plus Shippingport plus availability of enriched uranium from the gaseous diffusion plants plus structure of regulation.

"Incentive for private industry would have been less (gap to commercial power bigger, threat of all-public-power not existent, and development cost for industry greater without rounds 1, 2, and 3)." (Response No. 46 -- Comments on Scenario 2)

"Early reactors were not held up by licensing (construction permits). The fault was postponements and escalating licensing requirements that delayed plants, required retrofits, and greatly increased costs. 
"If the U.S. tried the Magnox reactors, they would have had the same results as Italy and Japan if the Candu or LWR (PWR/BWR) came along. So then we might be licensing Candu, unless the availability of enrichment permitted LWR. If it did, diffusion capacity would be as adequate as at present with the same military cutback, and commercial enrichment would probably have been delayed, as it was by the AEC and State Department, for proliferation reasons.

"Vendors would certainly not be more numerous - quite likely would have been but two or three." (Response No. 46 -- Comments on Scenario 3)

"Very unlikely (i.e., scenario 4). Long time scale for development would limit commercial resources that could be allocated. Resolution of enriched material ownership, licensing procedures, and state versus federal jurisdiction would have added delay.

"It is not clear the private sector would have sensed the social acceptability question better than government and, with reduced pace and communication, would have enhanced acceptance (which, with political ramifications, has now served to essentially halt further development of nuclear power).

"It is unlikely the private sector could have resolved, by itself, the back end of the fuel cycle. Industry recognized the need, but government prevented/ignored waste disposal and management, of crucial concern to society today." (Response No. 46 -- Comments on Scenario 4)

Those Who Thought that Federal Incentives were Unimportant or a Hindrance to the Development of Commercial Nuclear Power

"Development of the basic physics, accomplished in the military programs, was essentially the only requirement needed to proceed with commercial nuclear power. Material programs greatly reduced the problems encountered and therefore accelerated the advent of viable systems. We didn't seek government funding in 1954." (Response No. 10)

"In 1954, General Electric was an active contractor in three government managed nuclear programs: Knolls Atomic Power Laboratory, Aircraft Nuclear Power Program, and Hanford. Through this participation, General Electric had developed the technical capability to design and manufacture a nuclear power plant for commercial utility service. General Electric subsequently chose to develop the BWR as a proprietary product, with minimal external funding. However, AEC program funding was important in advancing LWR technology, particularly PWR technology, and developing utility interest in nuclear power." (Response No. 11) 
"Government R\&D in support of LWR has only been token for over $11 / 2$ decades." (Response No. 12)

"... when the power reactor demonstration program was started in 1955, two of those utilities making proposals (for Dresden and Indian Point) decided to proceed without any government support whatever. As you will recall, for those reactor projects (such as Yankee Rowe) where government research and development funding was provided, this support was limited to research and development as well as some waivers of 'fuel use charges'.

"Also of importance is the EBWR, an experimental boiling water reactor, which was originally planned in 1954 along with the aqueous homogeneous reactor experiment, the sodium graphite reactor experiment, and the organic reactor. While most of these concepts did not turn out to be very useful, the EBWR clearly was a useful experimental device and demonstrated much of the boiling water technology; however, it must be kept in mind that GE started their Vallecitos boiling water reactor before EBWR was in operation, and, in fact, had proceeded quite far on the Dresden reactor plans." (Response No. 15)

"I might note that the first commercial BWR, Dresden-I, was initiated in 1955 with no federal funds involved. Further, in my view, the maturation of the nuclear industry occurred largely because of the Turnkey project commitments by GE and Westinghouse in the early 60's without a full realization on their part of the economic costs involved." (Response No. 31)

"Two most important things needed then were (a) utility conf idence that nuclear power would be technically and economically successful; and (b) liability limitations." (Response No. 8)

"I think the subject of technology development with and without government incentives is an important one. It is so important that it is essential that assessments recognize the difference between federal involvement that encourages and federal involvement that discourages and the difference between federal involvement as regulation or policy as opposed to R\&D support. A very difficult factor to assess is the effect of government spending on the perception of government objectives and policy. Government spending may accelerate a program even if not one dime of such spending is directly supportive or relevant (just because people feel the government is behind the program). The converse is, of course, also true; the government can continue spending, but the program can be halted by policy statements that are in conflict with the spending.

"The largest single boost for nuclear power was the formation of OPEC, and the largest setback has been government policy. The U.S. 
export business has gone from a thriving one to zero on government policy -- this may or may not be desirable, but it is clear that the government is entirely responsible." (Response No. 12)

"...you have to define very carefully what you mean by Federal Government research and development and identify whether, specifically, the actions that you are assuming were or were not carried out. Secondly, I believe that it is important to also specify a good deal more about the general political climate in addition to simply the monetary expenditures for research and development.

"...it would have been completely impossible for the reactor development program to emerge as it did with or without government research and development support under the present policies and practices of the DOE and the Federal Government." (Response No. 15)

"Where there is a public demand, an economic and profit potential, and no major institutional restriction, development... can be expected.

"Inducements were being given for the development of demonstration plants but the only real inducement the utilities had at that time seemed to be a forecast of eventually cheaper energy from the nuclear source than they were getting from oil, coal, and gas. However, these latter sources were adequate and were coming down in cost so only those utilities with a farsighted outlook seemed to be particularly interested in exploring the nuclear route." (Response No. 16)

"...since the Congress operates on a series of two-year cycles, Congress seemed to want rapid acceptance by the utilities. Since the utilities live for 30 years with the results of their decisions, they seemed to want reassurance that the product first of all would work well, and secondly that it would be cost effective. The Federal Government took the quick route of paying a part of the uneconomic costs through R\&D at National Laboratories and major NSSS designers, and through the various Demonstration Rounds." (Response No. 30)

"I believe that government actions on nuclear power in the 1954 period and following helped the early establishment of the nuclear industry. On the other hand, I'm not sure I could easily differentiate between the effects of the very positive government attitude on nuclear power and its funding of R\&D activities. Indeed, it is not clear in your questionnaire how R\&D is defined. For example, does R\&D include the financial support of nuclear projects in the various rounds of demonstration programs or does R\&D refer strictly to technology development programs? My general feeling is that the government support through demonstration projects was probably more important than the R\&D technology support. 
"...it is doubtful that the Turnkey plants would have been committed if there was not a positive government attitude towards nuclear power.

"If there had been no government support of nuclear energy and a benign or negative attitude, I believe that nuclear power would not have developed in this country, or at least its commercialization would have been delayed for a couple of decades or more pending results from abroad. On the other hand, I believe that nuclear power would have developed along its present lines if the positive attitude by the government had prevailed and with substantially less R\&D support." (Response No. 31)

"Nuclear power became possible only because of the gargantuan effort to develop the nuclear bomb which brought the war in the Pacific to an abrupt end. Recognizing that fear alone would not provide an acceptable reason for continued development and production of nuclear weapons, Congress, following the lead of the Military Services, started to promote and develop nuclear power without reducing nuclear weapons development and production." (Response No. 32)

"...the actual research and development effort contributed less to the overall incentive than other fortuitous factors and deliberate incent ives." (Response No. 34)

"Impossible to factor out hindsight--but reasonable people could have foreseen OPEC which could have made nuclear very attractive at a given time." (Response No. 43)

"While Shippingport was not a demonstration reactor or a prototype, it did lead to the development of many of the key features of the light water reactor. Without this reactor and access to the information, it seems doubtful that the nuclear program would have proceeded, at least for some time.

"The most profitable expenditures are really those which were made by the Naval Reactors Program which, although it was a part of the Division of Reactor Development, was operated quite separately." (Response No. 15)

"... it was necessary that a great deal of Government attention be given to the matters of public health and safety and special nuclear material security. Had not the extens ive work been done on safety and security, ...commercial nuclear power development would have been considerably delayed, but probably mainly because of unknown and speculative safety requirements." (Response No. 16)

"...it would require operation of large prototypes before [utility] desired to replace the better known 'old standards' with entirely new systems." (Response No. 30) 
"Basically, the existence of a substantive research and development (R\&D) effort by AEC on nuclear power concepts and the ex-reactor components of the fuel cycle provided the psychological security that the utilities and manufacturers probably needed to make the commitments for Dresden 1, Yankee, Oyster Creek, Browns Ferry, and the other early plants. Actually, we do not believe the AEC's R\&D effort itself contributed that much. The General Electric Company and the Westinghouse Electric Corporation ident if ied what was needed. Sp inoff from the nuclear submarine effort (in spite of tight secrecy) probably contributed more than AEC's civilian nuclear power program did because it was directed or focused and was a substantial effort.

"The weapons program, for the same reasons, also made the same type of contributions to Savannah River and Hanford fuel reprocessing; to the availability of enrichment capability; to uranium ore reserve, mining, and milling; and to conversion technology." (Response No. 34 )

"...the issues of engineering feasibility and safety were paramount in the early development. The major contribution of the AEC was primarily focused on these two issues and also represented its major contribution to commercial development.

"While the government did make marginal contributions to the nuclear fuel programs for both the PWRs and the BWRs, these represented only a very small part of the total government program. Many of the AEC's efforts were devoted to alternative reactor types, which have never been made commercial, and to the scientific and long-range concepts in the national laboratories.

"These [Shippingport (PWR) and Borax (BWR)] proved the engineering principle of the two types." (Response No. 40)

"I believe that a very large part of federal R\&D after 1954 has been on options which have not come into use for civilian power. The answer 'much as it has'(a) could apply, but this conceals the irrelevance of the assumed role of federal R\&D implied in the question." (Response No. 5)

"Government R\&D results generally not available to industry.

1. Shippingport data still not available.

2. All LMFBR information only available to government contractors--not available to utilities or anyone else in the public sector." (Response No. 12)

"Had not the extensive work been done on safety and security, I feel that commercial nuclear power development would have been considerably delayed, but probably mainly because of unknown and speculative

(a) Quoted from the Energy Industry Survey 
safety requirements. Enough work had been done in the development of Naval reactors and in the Army Package Power Reactor development to demonstrate the technology and potential costs of commercial development and the operating characteristics. It is my feeling that the electric utilities and nuclear equipment suppliers would have taken it from there and developed commercial nuclear power much as has occurred without further Government hardware and nuclear research and development.

"As a comparative example, the coal-fired electric power development industry made tremendous strides over several decades without any appreciable Government research and development assistance, al though massive independent R\&D on materials and equipment was required." (Response No. 16)

"Without government R\&D including subsidy to early demonstration plants, initial commercialization would have been slower to start. Similarly, I feel the lower profile government participation and lesser involvement of government agencies would have been accompanied by a much slower growth in burdensome regulation, the net effect of which would have been a slower start but a faster current rate of growth." (Response No. 17)

"...nuclear power would have developed along its present lines if the positive attitude by the government had prevailed and with substantially less R\&D support." (Response No. 31)

"Perhaps, it can be stated that early federal involvement accelerated nuclear power's development in the early years by 2 to 5 years. By 1960 , the industry may have been 2 years ahead on this basis. But, obviously, what has transpired since in the federal sector has enormously delayed nuclear power's development.

"Government seed-money is no guarantee for a technology's development. Better, most often, to let the free market-place decide these issues." (Response No. 37).

"By direct subsidy the government can shape the direction and timing of marginally commercial activities...." (Response No. 40)

Those Who Commented but Declined to Speculate on How the Industry Might Have

\section{Developed}

"One of the things that has been wrong with the atomic energy program is the stance of the regulatory agencies of the government. There are two aspects of this regulatory function; one for the Federal Power Commission stance which has put restrictions on the revenues utilities could require. This has the result of preventing the utility from investing large sums of money on ventures such as a nuclear power plant. Were this restriction removed, it should be possible 
for the utility to issue bonds in a sufficient quantity to finance the construction of such a power plant, placing the burden where it belongs--on the public (since the public is the beneficiary).

"Another point to keep in mind is that manufacturing companies that sell turbogenerators are placed in a position that forces them to develop the technology of nuclear equipment. The reason for this pressure is that the entire industry has been forced to make its improvements very cautiously, but they have been very successful knowing that the boilers, pipes, valves, and other equipment could be furnished to meet the particular requirements of the turbine generators they propose to sell.

"When a nuclear plant is being built, however, it is the reactor design that determines the steam conditions--in the turbine. Consequently, a manufacturer who doesn't design and build a reactor becomes subject to the specifications of the reactor designer and builder. In other words, the turbine manufacturer has lost the initiative. It was this kind of pressure that forced GE and Westinghouse to enter the nuclear business.

"Another major deterrent of the business has been the mismanagement of the government (the Congress particularly) in failing to treat reactor licensing using the same methods used by the Federal Aviation Authority regarding the licensing of aircraft. In other words, reactors should be licensed solely on the bas is of reliability and safety of a given design. Designs, in other words, should be such that manufacturers could continue to use or sell a licensed design without further hearings and disputes. Hearings would be reserved for site approval only.

"There are two kinds of assistance provided by the government if Congress thinks it is appropriate. In a case where no one knows whether it will really work and be economical, the manufacturer would expect to share the risk somehow. Unfortunately, antitrust laws of ten prohibit the sharing of risks and profits--so the practical course to follow is to seek a contract on some portion of the technology with other contractors doing likewise with different aspects of the plant. This is a form of government assistance.

"The second kind of assistance from the government occurs when the cost of initial plants may be so heavy that the chance of recovering the excess outlay is practically nonexistent, since stockholders will not be satisfied if they cannot have their investment returned in a reasonable period (such as ten years). The government can, however, put in 20 to $40 \%$ of the excess cash on the bas is of the national need to launch a successful business. This was typical in the government's role in promoting airline service." (Response No. 3) 
"Obviously, when the government controls an industry almost completely, it is not going to develop unless the government puts money into it. In 1954 many aspects of nuclear power were still subject to government control and secrecy regulations. The companies mining uranium ore could sell only to one mill, at a government-controlled price. The only buyer of uranium "yellow-cake" was the government, at a controlled price, and enriched uranium could be acquired, under very stringent controls, only from the government. Government controls also impinged on the industry in various other ways. Under such circumstances, the flow of private capital into the industry could scarcely be expected to be very great, and unless the government put money into it, it would not develop. (Response No. 9)

Those Who Responded but Declined to Comment or Speculate

"I was not involved in nuclear power in the beginning of its development. Indeed, I have had little contact with it at any time." (Response No. 1)

"Sorry, but I decided I would not respond." (Response No. 28)

"I must apologize for having been unable to respond to the questionnaire you sent me. This has been an exceedingly busy time, and I just do not know when I will get a chance to spend any time on it. Please excuse me." (Response No. 33)

"The three scripts you chose to send seemed to me to be completely unrealistic, so I chose not to reply... I do not believe the chosen assumptions can possibly produce worthwhile information." (Response No. 29)

\section{Comments Concerning Solar Energy Development Based on the Nuclear Experience}

"The situation with solar is quite different... I would urge, however, an early environmental impact analys is, even though the public seems to favor solar energy, to be sure social concerns do not develop later that have not been adequately dealt with in communications." (Response No. 46)

"In translating this to solar, it should be recognized the public already seems to favor solar. It should also be recognized solar is less susceptible to technology advance but is similarly dependent on volume for cost reduction and infrastructure, and on escalation of alternative energy costs for economic viability. Overdone, premature promotion with uneconomic or unavailable installation, could cause a back lash." (Response No. 46) 
"I personally feel that we cannot rationally compare the development of nuclear energy with the development of solar energy as implied in the first paragraph of Attachment $A$. The primary government responsibility with regard to nuclear energy was the issue of health, safety, and security. The technology after the Naval and military developments was quite well established. In the case of solar, there are essentially no health, safety, or security matters to be considered and the electrical industry should be fully as capable of carrying out the necessary technical developments in this field as they were in expanding nuclear power developments from units having sizes of a few 10's of megawatts to those having capabilities of over 1,000 megawatts. However, assistance with demonstration solar units is fully just if ied." (Response No. 16)

"With respect to the application of the nuclear example to solar, I believe you should carefully consider some 'externalities.' For example, it should be well known that the total cost of nuclear electricity in New England is less than the fuel cost only of electricity from 0 il. That this is true even for the pioneering Yankee Rowe plant is due more to the oil price rise than to the nuclear cost being low.

"Perhaps the key consideration for electric utilities occurred about 1971, when the Federal Power Commission and State Rate Commissions began to allow R\&D projects to be placed into the rate base. Before that time, the higher price of initial new equipment purchased was the primary means of paying for a supplier's R\&D. A utility could put R\&D into the rate base as R\&D only if it were unsuccessful R\&D-the case of Northern States Power Company's PATHFINDER nuclear superheat unit is an example.

"Other considerations are the OPEC price rise and the resultant actions taken by Rate Commissions to keep electricity costs down (which work against high-capital-cost technology such as solar); the NEPA process and the environmental movement. Currently, we appear to be well into a period of government 'austerity' and a recognition of the effects of over-regulation. Perhaps the environmental regulations of the past will be balanced in the future with a more pragmat ic cost/benefit consideration." (Response No. 30)

"I believe that it is a mistake to try and draw parallels between early nuclear development and solar development since the times are quite different. Although I indicated that with a positive government attitude and substantially lower R\&D funding nuclear power may have progressed as well in the $50^{\prime} \mathrm{s}$ and $60^{\prime} \mathrm{s}$, I bel ieve that the breeder reactor, fusion, and indeed nuclear power if it had to start over today would not progress without substantial government support. This is because it has become clear that the government is intimately involved in these activities in any event, and thus the rewards for industrial investment are determined as much by government actions 
and regulations as by technological success. Thus, the large investments required are hard to come by when the rewards are determined by future government actions which are, at best, uncertain.

"This heavy government involvement may not be present in some solar activities. This together with the smaller scale of some solar technologies may make it easier to obtain industrial investment. However, the economics are still so uncertain that government R\&D funding can hasten solar development. In particular, it seems to me that government funding may be necessary to fulfill the role of the Turnkeys in nuclear power. To develop economic solar systems one must first develop the technology which in large-scale usage will produce economic benefits and secondly, one must obtain the largescale usage so the economics can be obtained. It is in this transitional period that government support can be productive. I question whether the present large federal outlays for solar R\&D will be productively utilized." (Response No. 31)

"...solar power has no destructive weapon characteristics... The Military Services have no desire for solar energy development. The Members of Congress have many more pressing problems than energy--if the difficulties experienced by President Carter's Energy Bill were real and not contrived. The common people could care less about the source of their low-cost energy; they just enjoy it and hope it will continue to be available, at prices they can afford. The environmentalists and intervenors are looking feverishly for features of Solar Power they can object to, violently and vehemently, to maintain the dominant position they have learned to enjoy with the media and the governmental regulatory groups.

"Comparisons of nuclear and solar power development are as absurd as comparing apples and oranges; each has its place and we should learn to employ both for maximum benefits and enjoyment." (Response No. 32)

"Since the purpose of your study is to investigate development of solar energy, I doubt the full applicability of the nuclear experience. The major distinction is the secrecy which, of necessity, surrounded nuclear's early development. This does not apply to solar.

"Furthermore, it is not at all clear to me that federal involvement is necessarily a good thing. What would happen if the Federal Government initially encourages solar's development and then later smothers it with constricting regulations such as have occurred in nuclear power? It is not at all inconceivable that land use and environmentally-oriented regulations will not ultimately constrain the application of solar energy. Government seed-money is no guarantee for a technology's development. Better, most often, to let the free market-place decide these issues." (Response No. 37) 
"...the nuclear power experience to solar energy development is extremely questionable. In the case of nuclear power, the issues of engineering feasibility and safety were paramount in the early development. The major contribution of the AEC was primarily focused on these two issues and also represented its major contribution to commercial development.

"In the case of solar energy, neither of the two above issues is paramount. The primary questions are those of engineering economics, and it is very questionable whether any amount of government incentive or participation will contribute to the solution of this issue. What is clearly needed in the solar field is the stimulation of new scientific and engineering concepts which can alter the economics performance by at least a factor of 10. As yet, no such new ideas have been suggested.

"By direct subsidy the government can shape the direction and timing of marginally commercial activities, but except for the direct use of solar heat, the government is likely to make little contribution to a commercial industry." (Response No. 40)

"I hope that the government does not so encumber solar power with regulations that it develops as slowly as has nuclear power." (Response No. 9) 
APPENDIX D

FUEL CONVERSION FACTORS 


\section{APPENDIX D}

\section{FUEL CONVERSION FACTORS}

In the development of energy production tables for comparative purposes it is necessary to convert production statistics into consistent units. For purposes of this report, British Thermal Units (Btu) were selected. A Btu represents the amount of energy required to raise the temperature of one pound of water by one degree Fahrenheit.

Due to inefficiencies in any energy production process, data must be specified as either primary resource energy consumed (which is the quantity of fuels consumed in the overall production process) or building boundary energy produced (the net production of useful transmitted energy). Since the efficiencies of most energy conversion processes increase with time, the conversion factors from primary units to useful energy units are subject to change. The conversion factors for coal, 0il, and gas energy sources since 1947 are presented in Table D.1.

So as to permit comparison with other fuel types, electricity data usually presented in terms of kilowatt-hours, has been converted to Btu's using the thermodynamic relation of 3,413 Btu/kWh. By definition, using a kilowatt-hour of electrical power in a $100 \%$ efficient system (resistance heating for example) produces 3,413 Btu of available energy. Use of this conversion factor yields the maximum amount of useful energy produced and neglects the variable efficiencies of energy production systems. The thermodynamic conversion factor was used for the conversion of the nuclear, hydroenergy, and electricity data presented in this report. 
TABLE D.1. Btu Conversion Factors (EIA May 1978a, p. 145)

\begin{tabular}{|c|c|c|c|c|c|c|c|}
\hline Year & $\begin{array}{l}\text { Bituminous } \\
\text { Production } \\
\text { Million Btu } \\
\text { per Short } \\
\text { Ton } \\
\end{array}$ & $\begin{array}{c}\text { Coal } \\
\text { L Lignite } \\
\text { Consumption } \\
\text { Million Btu } \\
\text { per Short } \\
\text { Ton } \\
\end{array}$ & $\begin{array}{c}\text { Anthracite } \\
\text { MiTlion Btu } \\
\text { per Short } \\
\text { Ton } \\
\end{array}$ & $\begin{array}{l}\text { Crude } \\
\text { Petroleum } \\
\text { Production } \\
\text { Thousand Btu } \\
\text { per Barrel } \\
\end{array}$ & $\begin{array}{l}\text { Petroleum } \\
\text { Product } \\
\text { Consumption } \\
\text { Average } \\
\text { Thous and Btu } \\
\text { per Barrel } \\
\end{array}$ & $\begin{array}{c}\text { Natural } \\
\text { Gas, (Wet) } \\
\text { Product jon } \\
\text { Btu/ft } 3 \\
\end{array}$ & $\begin{array}{c}\text { Natural } \\
\text { Gas, (Wet/ } \\
\text { Consumption } \\
\text { Btu/ft } 3 \\
\end{array}$ \\
\hline 1947 & 26.200 & 26.200 & 25.400 & 5,800 & $5,713.00$ & 1,120 & 1,035 \\
\hline 1948 & 26.200 & 26.200 & 25.400 & 5,800 & $5,923.50$ & 1,118 & 1,035 \\
\hline 1949 & 26.200 & 26.200 & 25.400 & 5,800 & $5,695.50$ & 1,120 & 1,035 \\
\hline 1950 & 26.200 & 26.200 & 25.400 & 5,800 & $5,679.30$ & 1,119 & 1,035 \\
\hline 1951 & 26.200 & 26.200 & 25.400 & 5,800 & $5,745.60$ & 1,114 & 1,035 \\
\hline 1952 & 26.200 & 26.200 & 25.400 & 5,800 & $5,741.00$ & 1,115 & 1,035 \\
\hline 1953 & 26.200 & 26.200 & 25.400 & 5,800 & $5,800.00$ & 1,116 & 1,036 \\
\hline 1954 & 26.200 & 26.200 & 25.400 & 5,800 & $5,662.34$ & 1,115 & 1,035 \\
\hline 1955 & 25.900 & 25.840 & 25.400 & 5,800 & $5,653.00$ & 1,120 & 1,035 \\
\hline 1956 & 25.980 & 25.740 & 25.400 & 5,800 & $5,761.00$ & 1,116 & 1,035 \\
\hline 1957 & 25.980 & 25.720 & 25.400 & 5,800 & $5,742.50$ & 1,113 & 1,035 \\
\hline 1958 & 25.980 & 25.540 & 25.400 & 5,800 & $5,700.00$ & 1,110 & 1,035 \\
\hline 1959 & 25.680 & 25.480 & 25.400 & 5,800 & $5,672.50$ & 1,109 & 1,035 \\
\hline 1960 & 25.660 & 25.480 & 25.400 & 5,800 & $5,557.00$ & 1,107 & 1,035 \\
\hline 1961 & 25.680 & 25.380 & 25.400 & 5,800 & $5,626.00$ & 1,108 & 1,037 \\
\hline 1962 & 25.580 & 25.340 & 25.400 & 5,800 & $5,602.50$ & 1,107 & 1,037 \\
\hline 1963 & 25.520 & 25.300 & 25.400 & 5,800 & $5,593.00$ & 1,103 & 1,035 \\
\hline 1964 & 25.500 & 25.280 & 25.400 & 5,800 & $5,549.00$ & 1,102 & 1,035 \\
\hline 1965 & 25.420 & 25.220 & 25.400 & 5,800 & $5,531.00$ & 1,101 & 1,032 \\
\hline 1966 & 25.300 & 25.100 & 25.400 & 5,800 & $5,933.83$ & 1,103 & 1,032 \\
\hline 1967 & 25.160 & 24.940 & 25.400 & 5,800 & $5,526.20$ & 1,105 & 1,032 \\
\hline 1968 & 25.060 & 24.860 & 25.400 & 5,800 & $5,519.00$ & 1,115 & 1,032 \\
\hline 1969 & 24.900 & 24.660 & 25.400 & 5,800 & $5,508.10$ & 1,103 & 1,031 \\
\hline 1970 & 24.900 & 24.220 & 25.400 & 5,800 & $5,506.00$ & 1,102 & 1,031 \\
\hline 1971 & 24.240 & 23.960 & 25.400 & 5,800 & $5,505.60$ & 1,103 & 1,031 \\
\hline 1972 & 24.050 & 23.750 & 25.400 & 5,800 & $5,503.20$ & 1,100 & 1,027 \\
\hline 1973 & 24.010 & 23.650 & 25.400 & 5,800 & $5,517.00$ & 1,093 & 1,021 \\
\hline 1974 & 23.730 & 23.070 & 25.400 & 5,800 & $5,506.10$ & 1,097 & 1,024 \\
\hline 1975 & 23.200 & 22.800 & 25.400 & 5,800 & $5,495.90$ & 1,095 & 1,021 \\
\hline $1976^{\text {(a) }}$ & 23.150 & 22.750 & 25.400 & 5,800 & $5,495.90$ & 1,094 & 1,020 \\
\hline $1977^{(a)}$ & 22.900 & 22.565 & 25.400 & 5,800 & $5,495.90$ & 1,094 & 1,020 \\
\hline
\end{tabular}

(a) Preliminary. 
APPENDIX E

ANALYSIS OF PHANTOM TAXES 
APPENDIX E

\section{ANALYSIS OF PHANTOM TAXES}

The investor-owned utilities (IOUs) maintain two entirely separate sets of books. One set of books is for the stockholders and the other is for the Internal Revenue Service (IRS). The books kept for stockholders usually use straight line depreciation for investments in plant and facilities whereas the books kept for the IRS use accelerated depreciation where possible. The effects of the normalization method of accounting for accelerated depreciation and investment tax credits are traced for each set of books in the following example:

EXAMPLE A. Calculation of the present value of the difference in cash flows using accelerated depreciation instead of straight line depreciation .

Assumptions:

Starting book value or initial cost of plant: \$1 billion

Expected life of plant: 30 years

Salvage value at 30 years: $\$ 0.00$

Federal income tax rate: $48 \%$

Discount rate or cost of capital: $8.25 \%$

Calculation Procedures and Nomenclature

SBV: Starting book value

LIFE: Expected life of the plant

SV: Salvage value

IV: Discount rate

TX: Tax rate

Yi: $\quad$ Year $i$ (starts at 1.0 and goes to LIFE)

DDBi: Double declining balance depreciation taken in Year $i$ 
SOYDi: Sum-of-the-years digits depreciation taken in Year i

SLi: $\quad$ Straight line depreciation taken in Year $i$

$$
\begin{aligned}
& S L i=\frac{S B V}{L I F E} \\
& \text { SOYD } i=\left[\frac{31-Y}{30} \sum_{i=1} Y_{i}\right] \quad[S B V] \\
& D_{i=B}=\left[\frac{2\left(S L_{i}\right)}{S B V}\right]\left[S B V-\sum_{i=1}^{i-1} D_{i}\right]
\end{aligned}
$$

Depreciation Differences

$D S i=S O Y D-S L i$

$D D i=D D B-S L i$

After Tax Cash Flows Due to Depreciation Differences

$$
\begin{aligned}
& \text { CFS } i=\text { DS }(1-T X) \\
& \text { CFDi }=\text { DD }(1-T X)
\end{aligned}
$$

Present Value of Cash Flows

Total present value of the sum-of-the-years depreciation method:

$$
\operatorname{PV}(\text { CFS } i)=\sum_{i=1}^{30} \operatorname{CFS}\left[\frac{1}{(1+I)^{i}}\right]
$$

Total present value of the double declining balance depreciation method:

$$
\operatorname{PV}(C F D i)=\sum_{i=1}^{30} \operatorname{CFD}_{i}\left[\frac{1}{(1+I)^{i}}\right]
$$




\section{Calculation Results}

The cash flow differences due to accelerated depreciation are presented in Table E.1. The after tax present value of these cash flows are as follows:

- Present value for sum-of-the-years digits depreciation: $\$ 59,081,000$

- Present value for double declining balance depreciation: $\$ 45,146,000$

TABLE E.1. Present Value of Accelerated Depreciation Schedules

Income Between Sum-of-the

Years Depreciation and

Year Straight Line Depreciation
1

2

3

4

5

6

7

8

9

10

11

12

13

14

15

16

17

18

19

20

21

22

23

24

25

26

27

28

29

30

$\$ 16,215,054$

$15,096,774$

$13,978,495$

$12,860,215$

$11,741,935$

$10,623,656$

$9,505,376$

$8,387,097$

$7,268,817$

$6,170,538$

$5,032,258$

$3,913,978$

2, 795, 699

$1,677,419$

559,140

$-559,140$

$-1,677,419$

$-2,795,699$

$-3,913,978$

$-5,032,258$

$-6,150,538$

$-7,268,817$

$-8,387,097$

$-9,505,376$

$-10,623,656$

$-11,741,935$

$-12,860,215$

$-13,978,495$

$-15,096,774$

$-16,215,054$

Present value

at $8.25 \%$
Income Difference Between

Declining Balance Depreciation

and Straight Line Depreciation

$\$ 17,335,333$

$15,022,222$

$12,865,185$

$10,851,951$

$8,972,932$

$7,219,181$

$5,582,346$

$4,054,634$

$2,628,770$

$1,297,963$

55,877

$-1,103,404$

$-2,185,399$

$-3,195,262$

$-4,137,800$

$-5,017,502$

$-5,838,557$

$-6,604,876$

$-7,320,106$

$-7,987,655$

$-8,610,700$

$-9,192,209$

$-9,734,951$

$-10,241,509$

$-10,714,298$

$-11,155,567$

$-11,567,418$

$-11,951,812$

$-12,312,580$

$\underline{52,985,210}$

$\$ 45,146,000$ 
, 


\section{APPENDIX $F$}

FINANCING AND INTEREST COST COMPARISONS

FOR A JOINT OPERATING AGENCY (JOA)

AND AN INVESTOR-OWNED UTILITY (IOU) 


\section{APPENDIX $F$}

$\frac{\text { FINANC ING AND INTEREST COST COMPARISONS }}{\text { FOR A JOINT OPERATING AGENCY (JOA) }}$
AND AN INVESTOR-OWNED UTILITY (IOU)

This appendix provides the supporting analysis for the conclusions made in Chapter 9. This analysis was conducted by Mr. Thomas P. Friery. Until recent 1y, Mr. Friery was the Assistant Treasurer for Investments at a large Joint Operating Agency $(J O A)$. Mr. Friery is now the Treasurer of the City of Sacramento in California.

FINANCING AND INTEREST COST

COMPARISONS FOR WPPSS AND IOUS

\section{HYPOTHESIS}

The legal structure of a J0A which permits the financing of $100 \%$ of projects with municipal revenue bonds and disregards concern for profit from the operating facility and the commitment of capital results in substantially less financing and interest costs than an IOU utility for an identical operating facility.

\section{ASSUMPTIONS}

1. For comparability purposes, a common plant, construction cost, and completion time will be established. It is recognized that in actual circumstances the costs, construction expenditure curve and lead time will be different from the assumption. However, the assumption presented becomes a mathematical progression and therefore is a valid tool to measure differences in financing and interest costs.

$$
\begin{array}{ll}
\text { Estimated Cost of Plant } & \$ 1,000,000,000 \\
\text { Estimated Lead Time } & 5 \text { years } \\
\text { Annual Construction Payments } & \$ 200,000,000
\end{array}
$$


2. For a JOA, it is assumed that the funds raised, investment income earned, and reserves, whether capitalized from bond proceeds or provided by participants during the operating period, will be similar to the requirements of WPPSS Nos. 4/5 Bond Resolution. Further, reserves which are funded by bond proceeds are considered available for decommissioning costs or reduction of the original financing and interest costs. The Extraordinary Reserve Fund which is provided by the participants will produce interest income during the retention period to offset financing and interest costs but the corpus will be available to the participants for disposition and not considered a reduction of financing and interest costs.

- Bonds sold to finance construction $\$ 1,000,000,000$

- Bonds sold to capitalize interest during construction period

$\$ 300,000,000$

- Bond Borrowing Rate

- Working Capital Reserve

- Bond Fund Reserve 1/2 maximum payment

- Reserve \& Contingency Fund (1\%, maximum $\$ 10$ million)

$$
\begin{array}{cr} 
& 7.25 \% \\
\$ & 6,000,000 \\
\$ & 47,125,000 \\
\$ & 10,000,000 \\
\$ & 130,000,000 \\
\$ & 7,854,166.67
\end{array}
$$

- Extraordinary Reserve (10\% of Bonds)

- Bond Interest Account Monthly Deposits DCO to maturity date of bonds

The net financing and interest costs of a JOA during construction, operation, and bond retirement phases are as follows:

Construction Phase (see Table F.1)

Operation Phase (see Table F.2)

Bond Retirement (see Tables F.3 and F.4)

Funds provided by the bond proceeds available which may be used for decommissioning costs (see Tables F.3 and F.4)

Total financing and interest costs (see Tables F.3 and F.4)
$\$ 185,751,000$

$\$ 2,491,647,000$

$\$ 1,300,000,000$

$\$(63,125,000)$

$\$ 3,914,272,875$ 
TABLE F.1. Construction Phase: JOA Estimated Financing Costs (Millions of Dollars)

\begin{tabular}{|c|c|c|c|c|c|c|c|}
\hline & 1st Year & 2nd Year & 3rd Year & 4th Year & 5 th Year & \multicolumn{2}{|c|}{$\begin{array}{c}\text { Total for } \\
5-Y \text { ear Period } \\
\end{array}$} \\
\hline $\begin{array}{l}\text { Bonds Outstanding: } \\
\text { Beginning of year }\end{array}$ & $\$$ & 230 & 475 & 735 & 1,010 & & \\
\hline $\begin{array}{l}\text { Sales in Year: } \\
\text { For Construction } \\
\text { For Capitalized Interest (a) } \\
\text { End of Year }\end{array}$ & $\begin{array}{lr}\$ & 200 \\
\$ & 30 \\
\$ & 230 \\
\end{array}$ & $\begin{array}{r}200 \\
45 \\
475 \\
\end{array}$ & $\begin{array}{r}200 \\
60 \\
735 \\
\end{array}$ & $\begin{array}{lr}\$ & 200 \\
\$ & 75 \\
\$ & 1,010 \\
\end{array}$ & $\begin{array}{rr}\$ & 200 \\
\$ & 90 \\
\$ & 1,300 \\
\end{array}$ & $\$$ & $\frac{1,000}{300}$ \\
\hline $\begin{array}{l}\text { Avg. Out. Per Year (b) } \\
\text { Est. Borrowing Cost } \\
\text { Interest Paid(c) }\end{array}$ & $\begin{array}{l}\$ \quad 115 \\
7.25 \% \\
\$ \quad 8.338 \\
\end{array}$ & $\begin{array}{r}\$ \quad 352.5 \\
7.25 \% \\
\$ 25.556 \\
\end{array}$ & $\begin{array}{rr}\$ \quad 605 \\
7.25 \% \\
\$ 43.863 \\
\end{array}$ & $\begin{array}{r}\$ 872.5 \\
7.25 \% \\
63.256 \\
\end{array}$ & $\begin{array}{r}\$ 1,155 \\
7.25 \% \\
83.738 \\
\end{array}$ & $\$$ & 224.751 \\
\hline $\begin{array}{l}\text { Deduct: } \\
\text { Interest Income Earned(d) } \\
\text { Net Capitalized Interest } \\
\text { During Construction }\end{array}$ & & & & & & $\$$ & $\frac{39.000}{185.751}$ \\
\hline
\end{tabular}

(a) Interest capitalized for 2 years or until estimated date of operation (5th year) from time of sale.

(b) Beginning of Year + End of Year

(c) Avg. Out. Per Year x Est. Borrowing Cost

(d) Assume $\$ 130$ million invested per year at $\$ 6 \%(\$ 130 \mathrm{million} \times 6 \% \times 5$ years $+\$ 39$ million $)$. 
TABLE F.2. Operation Phase: JOA Estimated Financing and Interest Costs

Bonds Outstanding at Completion of Construction

$\$ 1,300,000,000$

Borrowing Rate

$7.25 \%$

Annual Interest Expense

Gross Interest Cost for 30 years $(\$ 1.3$ billion $\times 7.25 \% \times 30$ years)

$94,250,000$

$2,827,500,000$

Deduct: Interest Income from Investments of Reserves:

Working Capital ( $\$ 6$ million $\times 5 \%$ x 30 Years)

Bond Fund Reserve ( $\$ 47.125$ million $\times 7.25 \% \times 30$ years)

Reserve \& Contingency ( $\$ 10$ million $\times 7.25 \% \times 30$ years)

Extraordinary Reserve ( $\$ 130$ million $\times 7.25 \% \times 19$ years)

Bond Interest Account (monthly deposit $\times 4 \% \times$ months

invested $\times 30$ years)

Total Interest Income

Net Interest Cost During Operation Phase
$\$ 9,000,000$

$102,496,875$

$21,750,000$

$179,075,000$

$23,531,250$
$\$ 335,853,125$

$\$ 2,491,646,875$ 
TABLE F.3. Decommissioning Phase: JOA Estimated Financing and Interest Costs(a)

Construction Phase (see Table F.1)

Operation Phase (see Table F.2)

Decommissioning Phase - Bonds to be Retired

Deduct: Balances in:

Working Capital Fund

Bond Fund Reserve

Reserve \& Contingency Fund

Estimated Financing and Interest Costs
$\$ 185,751,000$

$2,491,646,875$

$1,300,000,000$

$(6,000,000)$

$(47,125,000)$

$(10,000,000)$

$\$ 3,914,272,875$

(a) $\$ 130$ million dollars would be in the Extraordinary Reserve Fund.

TABLE F.4. Estimated Financing and Interest Costs if JOA Bonds are Sold at $6.25 \%$ Instead of $7.25 \%$

$\%$ differential between $7.25 \%$ and $6.25 \%=13.79 \%$

Reduction in Financing Cost in Construction Phase

$13.79 \% \times \$ 185,751,000=$ savings

$\$ 25,615,000$

Reduction in Bonds Issues

save $\$ 25.615$ million present value in

capitalized interest

$25,615,000$

Reduction in Financing cost in Operation Phase

$13.79 \% \times \$ 2,491,646,875=$ savings

$343,598,000$

Reduction in Interest charges during operation as

a result of selling $\$ 25,615$ million less in bonds

$\$ 25,615$ million $\times 6.25 \% \times 30$ years

$48,028,000$

Total Reduction

$\$ 442,856,000$

Estimated Financing and Interest cost on

Assumption of $6.25 \%$ Sale

$\$ 3,471,416,875$ 
3. For an IOU it is assumed that its capitalization structure is $35 \%$ common stock, $15 \%$ preferred stock, and $50 \%$ debt. As a rule, covenents contained in 1st mortgage bond indentures limit the maximum amount of debt to be raised on the value of plant and property to $60 \%$. Further, pre-tax and after-tax interest coverages are generally 3 times and 2.3 times, respectively. Therefore, failure of an IOU to keep bonds less than $60 \%$ of the finished project and or the failure to earn from the operations all of the interest expense on bonds 3 times before taxes and 2.3 times after taxes from rate payers would result in a default on the bonds.

The consequences to an IOU therefore requires the commitment of capital (common stock) prior to initiating a construction program as effectively, they would be restricted from starting such a program.

Common stock and preferred stock dividends by definition are not the same as interest charges since they are not required to be paid. However, in the last 20 years only two IOUs have omitted or reduced dividends and the action impacted negatively on their ability to raise funds in the market. The two utilities are Potomac Electric and Consolidated Edison of New York who have since restored or increased their dividend. In an 8-yr period ending in Calendar Year 1976, 75 major IOUs increased their annual dividend by $3.3 \%$ compounded. Fifteen of these companies annual compounded dividend increase was as high as $4.7 \%$ while another 15 were as low as 2.3\%. Only 2 of the 75 companies did not raise their dividend during this period.

Therefore common stock dividends as well as the compounded growth of these dividends are considered a cost of constructing plants and are properly includable for compatability purposes to a JOA.

Further, IOUs use an accounting term "Allowance for Funds used During Construction" (AFDC) which is no more than management's estimate of the Rate of Return that the construction program would have contributed to earnings if the plant under construction were operating. In other words, AFDC is an accounting procedure whereby the net composite interest and equity costs of capital funds used to finance construction are transferred from the income statement to construction work in progress on the balance sheet 
and, accordingly, are capitalized in the same manner as construction labor and material costs. This item is recognized as a cost of "Electric Plant" with an offsetting credit to "Other Income" because, under established regulatory rate practices, a utility is permitted to include a fair return on, and the recovery of, these capital costs through their inclusion in the rate base and in the provision for depreciation and therefore properly a cost of IOU financing for comparability with a JOA.

The net financing and interest costs for IOUs during the construction operation and decomissioning phase are as follows:

Construction Phase (see Table F.5) $\$ 542,169,000$

Operations Phase (see Table F.11) $\$ 3,296,745,000$

Funds used to finance construction (see Tables F.11 and F.6)

$\$ 1,000,000,000$

All bonds sold are term bonds and the original sale has a 35-year maturity. Subsequent sales mature on this common anniversary date. As of the retirement of the bonds, an additional $\$ 130,000,000$ will be available in the Extraordinary Fund Reserve for the participants in compliance with the Bond Fund Indenture. These funds have not been considered in cost reduction.

TABLE F.5. Construction Phase: IOU Estimated Financing and Interest costs Preferred Stock Dividends (see Table F.7) $\$ 30,000,000$ Bond Interest (see Table F.8) $103,124,000$ Common Stock Dividends (see Table F.9) $153,195,000$ AFDC (see Table F.11) $219,850,000$ Loan Interest Expense (see Table F.10) $36,000,000$ $\$ 542,169,000$ 
TABLE F.6. Investor-Owned Utility - Financing Costs (Millions of Dollars)

Preliminary Assumptions: Estimated plant cost $\$ 1$ billion. Company has $\$ 350$ million in common stock, current dividend $8 \%$. Plant will ultimately be financed $35 \%$ equity, dividend $8 \%, 15 \%$ preferred stock $88 \%$, and $50 \%$ first mortgage bonds at $8.25 \%$.

Financing Program starts with $\$ 350$ million in bank as a result of common stock sales which were required because of covenant restrictions on sale of bonds on property.

Capitalization at completion of Construction Program would be:

\begin{tabular}{lrr} 
Common Stock & $\$ 350,000,000$ & $35 \%$ \\
Preferred Stock & $150,000,000$ & $15 \%$ \\
1st MTG Bonds & $500,000,000$ & $50 \%$ \\
\cline { 2 - 3 } & $\$ 1,000,000,000$ & $100 \%$
\end{tabular}

TABLE F.7. IOU Estimated Financing Schedule - Preferred Stock Sales

\section{1st Year 2nd Year 3rd Year 4th Year 5th Year 5-Year Period}

Preferred Stock Outstanding:

Beginning of Year

Sales in Year

End of Year

Average Per Year (a)

Est. Borrowing Cost

Dividends Paid(b)

$\begin{array}{r}\$ \quad 0 \\ \quad 30 \\ \$ \quad 30 \\ \hline \$ 15 \\ \hline 8 \%\end{array}$

$\begin{array}{r}\$ \quad 30 \\ \quad 30 \\ \$ \quad 60 \\ \hline \$ \quad 45 \\ \hline 8 \%\end{array}$

$\begin{array}{r}\$ \quad 60 \\ \quad 30 \\ \$ \quad 90 \\ \hline \$ 75 \\ \hline 8 \%\end{array}$
$\$ 90$
30
120
$\$ 105$

$\$ 120$

$\$ 1.2$

$\$ 3.6$

$\$ 8.4$

$\frac{30}{150}$
$\frac{135}{8 \%}$

$\$ 150$

(a) Beg. of Year + End of Year

(b) Average Per Year $x$ Borrowing Cost 
TABLE F.8. IOU Estimated Financing Schedule - First Mortgage Bond Sales (Millions of Dollars)

Total for

1st Year 2nd Year 3rd Year 4th Year 5th Year 5-Year Period

1st Mortgage Bonds Outstanding:

Beginning of Year

Sales in Year

End of Year

Average Per Year(a)

Est. Borrowing Cost

Interest Paid(b)

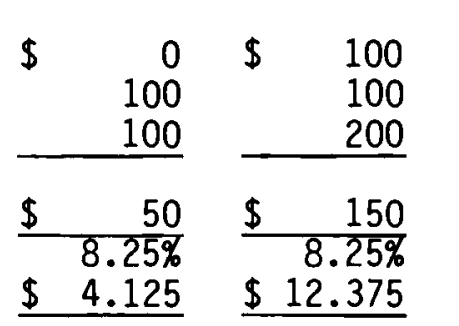

$\begin{array}{r}\$ \quad 200 \\ 100 \\ 300 \\ \hline \$ \quad 250 \\ \hline 8.25 \% \\ \$ 20.625 \\ \hline\end{array}$

\begin{tabular}{|c|c|c|c|}
\hline$\$$ & $\begin{array}{l}300 \\
100 \\
400\end{array}$ & $\$$ & $\begin{array}{l}400 \\
100 \\
500\end{array}$ \\
\hline$\$$ & $\begin{array}{r}350 \\
.25 \% \\
.875\end{array}$ & $\$$ & $\begin{array}{r}450 \\
.25 \% \\
.125\end{array}$ \\
\hline
\end{tabular}

$\$ 500$

(a) Beg. of Year + End of Year

(b) Avg. Per Year $x$ Borrowing Cost

TABLE F.9. IOU Estimated Growth of Common Stock Dividends (Millions of Dollars)

1st Year 2nd Year 3rd Year 4th Year 5th Year 5-Year Period

Common Stock Outstanding: Beginning of Year

Sales in Year

End of Year

Average Per Year (a)

Est. Dividend (b)

Dividends Paid(c)

\begin{tabular}{|c|c|}
\hline $\begin{array}{r}350 \\
0\end{array}$ & $\$ \quad 350$ \\
\hline$\$ \quad 350$ & $\$ \quad 350$ \\
\hline$\frac{\$ 350}{82 \%}$ & $\begin{array}{r}\$ 350 \\
8.36 \% \\
\$ 29.260\end{array}$ \\
\hline
\end{tabular}

$\begin{array}{r}\$ \quad 350 \\ \$ \quad 350 \\ \$ \quad 350 \\ \hline \$ \quad 8.74 \% \\ \$ 30.590 \\ \hline\end{array}$

\begin{tabular}{|c|c|}
\hline $\begin{array}{r}\$ \quad 350 \\
0 \\
\$ \quad 350 \\
\end{array}$ & $\begin{array}{r}350 \\
0 \\
350 \\
\end{array}$ \\
\hline $\begin{array}{l}\$ \quad 350 \\
9.13 \% \\
\$ 31.955\end{array}$ & $\begin{array}{r}\$ \quad 350 \\
9.54 \% \\
\$ 33.390\end{array}$ \\
\hline
\end{tabular}

$\$ 0$

$\$ 103.124$

\footnotetext{
(a) Beg. of Year + End of Year

(b) Avg. Per Year $\times$ Borrowing Cost

(c) Est. to Increase 4.5\% Annually
} 
TABLE F.10. Investor-Owned Utility - Estimated Flow of Funds (Millions of Dollars)

\begin{tabular}{|c|c|c|c|c|c|c|c|}
\hline Cash Account & $\$ 350$ & $\$ 265$ & $\$ 162$ & $\$ 40.7$ & $\$ 41.9$ & & \\
\hline $\begin{array}{l}\text { Deduct: } \\
\text { Dividends Paid(a) } \\
\text { Bond Int. Exp. (b) } \\
\text { Loan Int. Exp. (c) } \\
\text { Construction Pay }\end{array}$ & $\begin{array}{l}(29.9) \\
(4.125) \\
0 \\
(200.0)\end{array}$ & $\begin{array}{l}(32.860) \\
(12.365 \\
0 \\
(200.0)\end{array}$ & $\begin{array}{c}(36.590) \\
(20.625) \\
0 \\
(200.0)\end{array}$ & $\begin{array}{l}(40.355) \\
(28.875) \\
(12.0) \\
(200.0)\end{array}$ & $\begin{array}{l}(44.190) \\
(37.125) \\
(24.0) \\
(200.0)\end{array}$ & & $\begin{array}{c}183.195 \\
103.124 \\
36.0 \\
, 000.0 \\
\end{array}$ \\
\hline $\begin{aligned} \text { Add: } & \\
& \text { Financings }(d) \\
& \text { Bank Loans }(c) \\
& \text { Int. Inc. Earned }(e)\end{aligned}$ & $\begin{array}{r}130 \\
0 \\
17.9 \\
\end{array}$ & $\begin{array}{r}130 \\
0 \\
12.445 \\
\end{array}$ & $\begin{array}{r}130 \\
0 \\
5.9 \\
\end{array}$ & $\begin{array}{r}130 \\
150 \\
2.4 \\
\end{array}$ & $\begin{array}{r}130 \\
150 \\
2.5 \\
\end{array}$ & $\$$ & $\begin{array}{c}650.0 \\
300.0 \\
41.145 \\
\end{array}$ \\
\hline Cash End of Year & $\$ 264.575$ & $\$ 162.210$ & $\$ 40.685$ & $\$ 41.870$ & $\$ 19.085$ & & \\
\hline \multicolumn{8}{|c|}{$\begin{array}{l}\text { (a) Sum of common and preferred stock dividend (Sum of totals from Tables } F .7 \text { and F.9). } \\
\text { (b) See Table F.8. } \\
\text { (c) Assumed } \$ 150 \text { million borrowed in } 4 \text { th and } 5 \text { th year in cash flow and retired with financings in } 6 \text { th year. } \\
\text { (d) Preferred stock and } 1 \text { st mortgage bond sales. } \\
\text { (e) Average amount in cash account beginning and end of year, invested at } 6 \% \text {. }\end{array}$} \\
\hline
\end{tabular}

TABLE F.11. Investor-Owned Utility - Estimated AFDC (Millions of Dollars)

Construction Account

\begin{tabular}{|c|c|c|c|c|c|c|}
\hline $\begin{array}{l}\text { Beginning of Year } \\
\text { Additions } \\
\text { End of Year } \\
\text { Average per Year } \\
\text { AFDC Rate } \\
\text { AFDC Cost }\end{array}$ & $\begin{array}{r}\$ 0 \\
200 \\
200 \\
\$ 100 \\
8 \% \\
\$ 8\end{array}$ & $\begin{array}{c}\$ 208 \\
200 \\
408 \\
\$ 304 \\
8 \% \\
\$ 24.320\end{array}$ & $\begin{array}{l}\$ 432.320 \\
200 \\
\frac{632.320}{\$ 532.320} \\
\frac{8 \%}{\$ 42.586}\end{array}$ & $\begin{array}{l}\$ 674.906 \\
200 \\
874.906 \\
\frac{\$ 774.906}{8 \%} \\
\$ 61.992\end{array}$ & $\begin{array}{l}\$ 936.898 \\
200 \\
1,136.898 \\
\$ 1,036.898 \\
8 \% \\
82.952 \\
\end{array}$ & $\$ 219.850$ \\
\hline
\end{tabular}


NET FINANCING AND INTEREST COSTS - JOA VERSUS IOUS IF JOA BONDS ARE SOLD AT $6.25 \%$ AS OPPOSED TO $7.25 \%$ IN ASSUMPTION 1

To demonstrate the conservative bias in calculating the difference between JOAs and IOUS, an assumed borrowing cost of $7.25 \%$ for JOA Municipal Revenue Bonds was used and $8.25 \%$ for IOUs 1st Mortgage Bonds in Assumption 1 . However, for the 3-yr period ending February 1977, the Bond Buyer 20 Bond Index averaged 1.35\% greater than Federal Funds. During this same period, "AA", 20-yr Utility Bonds averaged 3.99\% greater than Federal Funds and $2.64 \%$ greater than the Bond Buyer 20-Bond Index. Therefore, based on current market conditions and relative spread values, JOA bonds could sell at $6.25 \%$ while IOU bonds could sell at $8.25 \%$, or $2 \%$ less than IOUs.

The $1 \%$ reduction in interest rates to a $J 0 A$ is equivalent to reducing bonds sold to capitalize interest and interest expense to be incurred $13.79 \%$ less than in Assumption 1. Tables F.3 and F.4 show this reduction as having the effect of decreasing financing and interest costs an additional $\$ 442,856,000$ from Assumption 1 . 
TABLE F.12. IOU Estimated Financing and Interest Cost

\section{Operation Phase}

Preferred Stock Dividends $\$ 150 \mathrm{million} \times 8 \% \times 30$ years

Bond Interest Expense $\$ 500 \mathrm{milli}$ ion $\times 81 / 4 \% \times 30$ years

Common Stock Dividends $\$ 33.390$ million $\times 33 / 4 \%$ compounded annually 29 years

$\$ 360,000,000$

$\$ 1,237,500,000$

$\$ 1,699,244,813$

$\$ 3,296,744,813$

\section{Decommissioning Phase}

Funds Raised for Construction

Bonds

Pref erred Stock

Funds Available to Start Construction

Common Stock

Amount of Financing Allocated for Construction

Decommissioning Funds Available

Construction Phase Costs

Operation Phase Costs

Total Financing and Interest costs

$\$ 500,000,000$ $150,000,000$

$350,000,000$

$\$ 1,000,000,000$ 0

$542,169,000$

$\frac{3,296,744,813}{\$ 4,838,913,813}$ 


\section{APPENDIX G}

SUBSIDY VALUE OF TWO SOLAR ENERGY INCENTIVES 


\section{APPENDIX G}

\section{SUBSIDY VALUE OF TWO SOLAR ENERGY INCENTIVES}

The Energy Tax Act of 1978 established a federal tax credit for investments in solar, wind, and other renewable sources of energy for both new and existing residences through 1985 . The credit is valued at $30 \%$ of the first $\$ 2,000$ and $20 \%$ of the next $\$ 8,000$ spent, for a maximum of $\$ 2,200$. The Act also established an exemption through 1984 from the $4 \$ /$ gal federal excise tax on gasoline for fuels containing a mixture of at least $10 \%$ alcohol produced from agricultural products or waste. This appendix presents examples of the subsidy value of these two incentives in terms of dollars per million Btu.

The subsidy value for the tax credit to homeowners is analyzed for solar collectors used for hot water or space heating purposes. For the first example, it is assumed that a residential solar collector is installed in Columbus, Ohio, for the purpose of supplying hot water. At this location, which is not ideal by any means, the available sunlight captured per year is $600 \mathrm{kWh} / \mathrm{m}^{2}$ of collector, approximately $190,000 \mathrm{Btu} / \mathrm{ft}^{2}$. Assume that a $50 \mathrm{ft}^{2}$-system is installed at a cost of $\$ 40 / \mathrm{ft}^{2}$. This comes to a total cost of $\$ 2,000$ for a system with an assumed rate of 20 years. The tax credit avaialble for this system is $\$ 600$ or $\$ 12 / \mathrm{ft}^{2}$. The yearly subsidy is the annualized value of $\$ 12 / \mathrm{ft}^{2}$ using an annuity (or capital recovery) factor. Assuming a yield on an alternative investment of $10 \%$, inflation of $7 \%$, and an effective marginal income tax rate of $29 \%$, the real after-tax return on the alternative investment is $2 \%$. The capital recovery factor for $2 \%$ and 20 years is 0.0612 . (This means $\$ 1$ invested at $2 \%$ will yield $\$ 0.0612$ per year for 20 years; some of the payment each year is interest and some of it is part of the original dollar.) Thus, the annualized value of the subsidy is $\$ 0.734 / \mathrm{ft}^{2}$ or $\$ 3.86 / \mathrm{milli}$ ion Btu. The subsidy for the tax credit would vary with solar insolation. In a location like Phoenix that has much more sunshine, the subsidy would be about half this.

For another example, residential solar collectors are assumed to be installed in Columbus, Ohio, for the purpose of supplying space heat (ignoring 
hot water during the off-season). The sunshine captured in Columbus during a winter season is $150 \mathrm{kWh} / \mathrm{m}^{2}$ or $47,500 \mathrm{Btu} / \mathrm{ft}^{2}$ collector. A $500-\mathrm{ft}^{2}$ system is installed at a cost of $\$ 40 / \mathrm{ft}^{2}$. The total cost is $\$ 20,000$ for a $20-y$ r life system. The value of the tax credit is at its maximum of $\$ 2,200$ or $\$ 4.40 / \mathrm{ft}^{2}$ of collector. The annualized value of $\$ 4.40 / \mathrm{ft}^{2}$ at $2 \%$ over 20 years is $\$ 0.269 / \mathrm{ft}^{2}$. This yields an annualized subsidy of $\$ 5.66 / \mathrm{million}$ Btu. Of course, there will be a considerable variation in other locations, depending on winter insolation and heating load.

Exemption from federal gasoline tax of $4 \$ /$ gal for gasohol can be converted into a subsidy of $\$ /$ million Btu. Gasohol is made from one volume of ethyl alcohol which contains $84,100 \mathrm{Btu} / \mathrm{gal}$ and nine volumes of gasoline which contains $125,000 \mathrm{Btu} / \mathrm{gal}$. The volume change when mixing the two is less than $0.3 \%$ and can be ignored. Therefore, gasohol contains 121,000 Btu/gal. A tax exemption of $4 \$ / \mathrm{gal}$ is equivalent to a subsidy of $\$ 4.76$ for each million Btu of alcohol. (Note that one Btu of alcohol in gasohol may be $5 \%$ to $10 \%$ more efficient in a car than one Btu of gasoline.) In addition the producer can obtain an "entitlement" of $7.5 \$$ per gallon. This is a fee that a refiner with access to more than the average fraction of low-cost, price-controlled crude oil must pay to those with a larger than average fraction of imported oil (with extra amounts to small refiners). The aim is to equalize the acquisition costs, but it also serves to provide a subsidy of $\$ 0.89$ per million Btu of ethanol. The combined subsidy for ethanol is $\$ 5.65 / \mathrm{million}$ Btu. 


\section{REFERENCES}

Acar, William. 1976. "An Integrated Approach to Multidimensional Evaluation and Cost-Effectiveness Analysis." Public Finance 3(1):58-72.

Acharya, Shankar M. 1972. "Public Enterprise Pricing and Social Benefit Cost Analysis." Oxford Economic Papers 24(1):36-53.

Alaska Power Administration. July 1977. Alaska Power Administration 1976 Annual Report. Department of the Interior, Washington, DC 20240.

Altman, S. M. 1976. "Teaching Data Analysis to Individuals Entering Public Service." Journal of Urban Analysis 3(2):211-237.

American Gas Association. May 27, 1977. A Comparison of Estimates of Additional Natural Gas Production from Deregulation of New Gas Prices. American Gas Association, New York, N.Y.

American Gas Association. 1978. 1978 Gas Facts. American Gas Association, New York, N.Y.

American Petroleum Institute, American Gas Association, and Canadian Petroleum Association. June 1978. Reserves of Crude 0il, Natural Gas Liquids, and Natural Gas in the United States and Canada as of December 31, 1977. American Petroleum Institute, Washington, D.C.

Bardach, Eugene. 1977. The Implementation Game: What Happens after a Bi11 Becomes Law. Massechusetts Institute of Technology Press, Cambridge, Mass.

Baughman, M. L., and P. L. Joskow, and D. P. Kamat. September 1977 . Electric Power in the United States: Models and Policy Analysis. Draft manuscript, Massachusetts Institute of Technology, Cambridge, Mass.

Benenson, P., H. Ruderman, D. Merri11, and J. Sathaye (eds.). June 1974. Proceedings of the Conference on Energy Modeling and Forecasting. Lawrence Berkeley Laboratory and the National Science Foundation, Berkeley, Cal if.

Bennington, $G$. et al. June 1979. Toward A National Plan for the Commercialization of Solar Energy. Vol. 1 of The Implications of a National Commitment, Prepared by the MITRE Corporation, McLean, Va., for the Department of Energy, Conservation and Solar Applications, Washington, D.C.

Bishop, A. B. 1972. "An Approach to Evaluating Environmental, Social and Economic Factors in Water Resource Planning." Water Resources Bulletin $8(4): 724-734$.

Bonneville Power Administration. 1941 Through 1978. Annual Report 1940 through 1977. Bonneville Power Administration, Port Tand, Ore. 
Bonneville Power Administration. 1973. Population, Employment, and Housing Unit Projected to 1990. Bonneville Power Administration, Portland, Ore.

Bonneville Power Administration. July 1977. The Role of the Bonneville Power Administration in the Pacific Northwest Power Supply System. Published Draft, Department of the Interior, Portland, OR 97208.

Bonneville Power Administration. July 22, 1977. "Appendix C BPA Power Marketing. "In The Role of the Bonneville Power Administration in the Pacific Northwest Power Supply System. Published Draft, Bonnevilie Power Administration, Portland, Ore.

Bonneville Power Administration. 1978. Fiscal Year 1977 Financial and Statistical Summary. Bonneville Power Administration, U.S. Department of Energy, Port land, Ore.

Brannon, G. M. 1974. Energy Taxes and Subsidies. Ballinger Publishing Company, Cambridge, Mass.

Brannon, G. M. 1975. "Existing Tax Differentials and Subsidies Relating to the Energy Industries." In Studies in Energy Tax Policy, G. M. Brannon (ed.). Ballinger Publishing Company, Cambridge, Mass.

Bureau of Census, U.S. Department of Cormerce. 1968. 1963 Census of Manufacturers. U.S. Government Printing Office, Washington, D.C.

Bureau of the Census, U.S. Department of Commerce. 1976a. Historical Statistics of the United States: Colonial Times to 1970, Part 2. U.S. Government Printing office, Washington, D.C.

Bureau of the Census, U.S. Department of Commerce. 1976b. 1972 Census of Mineral (Industries, Industry Statistics). U.S. Department of Commerce, U.S. Government Printing office, Washington, D.C.

Bureau of Census, U.S. Department of Commerce. 1978. Statistical Abstract of the United States: 1978. U.S. Government Printing office, Washington, D.C.

Bureau of Competition. May 1978. Entitlement, The Reseller Rule and the Supplier/Purchaser Rule. Federal Trade Commission for the Economic Regulatory Administration of the Department of Energy, Washington, D.C.

Bureau of Mines, li.S. Department of Interior. 1968. Minerals Yearbook, Vol. I. Washington, D.C.

Bureau of Mines, U.S. Department of Interior. 1978. 1977 Annual Refinery Survey (Revised). National Technical Information Service, Arlington, Va.

Burns, A. F. 1934. Production Trends in the United States Since 1870. National Bureau of Economic Research, New York, N.Y. 
Cain, G. C., and R. G. Hollister. 1972. "The Methodology of Evaluating Social Action Programs." In Evaluating Social Programs: Theory, Practice and Politics, Peter H. Rossi and Walter Williams (eds.). Academic Press, New Tork, N.Y.

California Energy Commission Staff. September 1975. An Independent Staff Analysis of the California Public Utilities Commission's Report on Ten-Year Forecasts of Electric Utilities; Loads and Resources. California Energy Commission, Sacramento, Calif.

California Energy Commission Staff. November 1976. Decision Analysis Framework for Future Electrical Planning. California Energy Commission, Sacramento, Calif.

California Energy Resources Conservation and Development Commission. 1975. Quarterly Fuel and Energy Summary. California Energy Resources Conservation and Development Commission, Sacramento, Calif.

Cantor vs. Detroit Edison Co. 428 U.S. 591. (1976).

Carter, A. P. 1974. "Energy, Environment, and Economic Growth." Bell Journal of Economics $5(2): 578-594$.

Chase Manhattan Bank. October 1977. 1976 Financial Analysis of a Group of Petroleum Companies. Energy Economic Division, Chase Manhattan Bank, New York, N.Y.

Cho, Yong Hyo. 1972. "A Multiple Regression Model for the Measurement of the Public Policy Impact on Big City Crime." Policy Sciences 3(4):435-455.

City of Lafayette, Louisiana, vs. Louisiana Power \& Light Co. 532 F.2d 431. (CA 5th 1976).

Clawson, Marion. February 1959. Methods of Measuring the Demand and the Value of Outdoor Recreation. (Reprint No. 10), Resources for the Future, Washington, D.C.

Coddington, D. C., et a1. December 1972. The Federal Reclamation Program: Its Impacts, Issues and Future Considerations. Bickert, Browne, Coddington and Associates, Inc., Denver, CO 80209.

Cohen, A. S., and K. W. Coste110. June 1975. Regional Energy Modeling: An Evaluation of Alternative Approaches. Argonne National Laboratory, Argonne, I11.

Columbia River Water Management Group. January 1978. Columbia River Water Management Report for Water Year 1972. Columbia River Water Management Group, PortTand, Ore. 
Cone, Bruce W. et al. March 1978. Analysis of Federal Incentives Used to Stimulate Energy Production, 1st Edition. PNL-2410, Pacific Northwest Laboratory, Richland, Wash.

Cone, Bruce W. et al. December 1978. Analysis of Federal Incentives Used to Stimulate Energy Production, 2nd Edition. PNL-2410, Pacific Northwest Laboratory, Richland, Wash.

"Congress, PUCs Tack le Phantom Taxes." October 1977. The Power Line, $3(3): 4$ sic.

CONSAD Research Corporation. 1968. "The Economic Factors Affecting the Level of Domestic Petroleum Reserves." In Part 4 of Tax Reform Studies and Proposals. U.S. Treasury Department, U.S. Government Printing Office, Washington, D.C.

Conway Corp. vs. Federal Power Commission. 426 U.S. 271 . (1976).

Cook, Thomas J., and Frank P. Scioli. 1972. "A Research Strategy for Analyzing the Impacts of Public Policy." Administrative Science Quarterly $17(3): 328-339$.

Council of Economic Advisors. January 1979. Economic Indicators. U.S. Government Printing Office, Washington, D.C.

Council on Environmental Quality. December 1975. Environmental Quality--the Sixth Annual Report of the Council on Environmental QuaTity. U.S. Government Printing Office, Washington, D.C.

Curry, Martha, et al. January 1977. State and Local Planning Procedures Dealing with Social and Economic Impacts from Nuclear Power Plants. Battelle, Human Affairs Research Centers, Seattle, Wash.

Dalky, Norman. 1969. The Delphi Method: An Experimental Study of Group Opinion. RM-5888-PR, The Rand Corporation, Santa Monica, Calif.

Davis, Warren B. August 1964. "The Enigma of $0 i 1$ and Gas Economics." Petroleum Management 36(9):53-60.

Dechesneau, T. D. 1975. Competition in the United States Energy Industry. Ballinger Publishing Company, Cambridge, Mass.

Defina, Robert. November 1977. Public and Private Expenditures for Federal Regulation of Business. Working Paper Number 22, Center for the Study of American Business, Washington University, St. Louis, Mo.

Denison, E. F. January 1978. "Effects of Selected Changes in the Institutional and Human Environment Upon Output per Unit of Input." Survey of Current Business 58(1):21-44. 
Deonigi, D. E. October 1978. "A World Trade Mode1." In Proceedings of the Workshop on World $0 i 1$ Supply-Demand Analysis. BNL-50782. Brookhaven National Laboratory, Upton, N.Y.

Department of Energy. 1979. The Energy Consumer 1(4):2.

Derthrick, Martha. 1972. New Towns in Town: Why a Federal Program Failed. The Urban Institute, Washington, D.C.

Dickinson, J. R. 1975. "Federal Evaluation Policy--Analyzing Effects of Public Programs." American Political Science Review 64(4):460-462.

Dolbeare, Kenneth M., and Phillip E. Hammond. 1971. School Prayer Decisions: From Court Policy to Local Practice. The University of Chicago Press, Chicago, I11.

Dorfman, Robert. 1968. Measuring Benefits of Government Investments. The Brookings Institution, Washington, D.C.

Dunlop, D. W. 1975. "Benefit-Cost Analysis - Review of Its Applicability in Policy Analysis for Delivering Health Services." Social Science and Medicine $9(3): 133-139$.

Dupree, W. G., Jr. and J. S. Corsentino. 1978. United States Energy through the Year 2000 (Revised). Bureau of Mines, U.S. Department of the Interior.

Dupree, W., H. Enzer, S. Miller, and D. Hillier. 1975. Energy Perspectives 2. U.S. Department of the Interior.

Eckbo, P. L., H. D. Jacoby, and J. L. Smith. 1978. "0il Supply Forecasting: A Disaggregated Process Approach." Bell Journal of Economics 9(1):218-235.

Economic Sciences Corporation. October 1975. A Methodology for California Electric Energy Forecasting. Economic Sciences Corporation, San Fransisco, Calif.

Edison Electric Institute. 1963. Historial Statistics of the Electric Utility Industry. Edison Electric Institute, New York, N.Y.

Edison Electric Institute. 1971. Historical Statistics of the Electric Utility Industry Through 1970. Edison Electric Institute, New York, $N Y$ 10016 .

Edison Electric Institute. 1978. Statistical Yearbook of the Electric Utility Industry for 1977. Edison Electric Institute, New York, NY 10016.

Edison Electric Institute. October 1978. Statistical Yearbook of the Electric Utility Industry. Edison Electric Institute, New York, NY 10016. 
Electric Power Research Institute. February 1977. Comparative State-of-theArt Assessment of Gas Supply Modeling. Electric Power Research Institute, Palo Alto, Calif.

Energy Information Administration, U.S. Department of Energy. February 1978. Annual Report to Congress-1977, Vol. I. U.S. Government Printing Office, Washington, D.C.

Energy Information Administration, U.S. Department of Energy. April 1978a. Statistics of Privately-Owned Electric Utilities in the United States Classes $A$ and B Companies. DOE/EIA-0044, U.S. Government Printing Office, Washington, D.C.

Energy Information Administration, U.S. Department of Energy. Apri1 1978 b. Projections of Energy Supply and Demand and Their Impacts. Volume II of Annual Report to Congress - 1977. DOE/EIA-0036/2, U.S. Government Printing Office, Washington D.C.

Energy Information Administration, U.S. Department of Energy. May 1978a. Annual Report to Congress-1977, Vo1. III. U.S. Government Printing Office, Washington, D.C.

Energy Information Administration, U.S. Department of Energy. May 1978b. Hydroelectric Plant Construction Cost and Annual Production Expenses 1976. DOE/EIA-0006/20, U.S. Government Printing Office, Washington, D.C.

Energy Information Administration, U.S. Department of Energy. August 1978a. Steam-E Tectric Plant Construction Costs and Annual Production Expenses 1976. DOE/E IA-0033/2, U.S. Government Printing Office, Washington, D.C.

Energy Information Administration, U.S. Department of Energy. August $1978 b$. Monthly Energy Review. DOE/EIA-0035/8, U.S. Government Printing Office, Washington D.C.

Energy Information Administration, U.S. Department of Energy. January 1979. Monthly Energy Review. U.S. Government Printing Office, Washington, D.C.

Environmental Protection Agency, Office of Planning and Evaluation. September 1973. The Electroplating Industry: Economic Analysis of Proposed Guidelines. U.S. Government Printing Office, Washington, D.C.

Environmental Protection Agency, Office of Planning and Evaluation. December 1973. Economic Analys is of Proposed Guidelines for the Pulp, Paper, and Paperboard Industry. U.S. Government Printing Office, Washington, D.C.

Environmental Protection Agency, Office of Planning and Evaluation. October 1974. Analysis of Proposed Effluent Guidelines for the Wooden Furniture and Fixture Manufacturing Segment of Timber Products Processing Industry, Phase II. U.S. Government Printing office, Washington, D.C. 
Environmental Protection Agency, Office of Planning and Evaluation. February 1975. Economic Analysis of Interim Final Effluent Guidelines for Seafood Processing Industry. U.S. Government Printing Office, Washington, D.C.

Erickson, E. W., and R. M. Spann. 1971. "Supply Response in a Regulated Industry: The Case of Natural Gas." Bell Journal of Economics 2(1):94-121.

Ernst and Ernst. June 1976. The Energy-Economy Relationship. Prepared for the Bonneville Power Administration, Washington, D.C.

Federal Energy Administration. November 1974. "Appendix AIV: Project Independence Evaluation System." In Project Independence Report. U.S. Government Printing office, Washington D.C.

Federal Power Commission. 1973. National Gas Survey. U.S. Government Printing Office, Washington, D.C.

Federal Power Commission. National Gas Survey, Vol. II. U.S. Government Printing Office, Washingtion, D.C.

Federal Power Commission. March 1968. Hydroelectric Power Evaluation. FPC-P-35, Federal Power Commission, Washington, D.C.

Fiflis, T. J., and H. Kripke. 1971. Accounting for Business Lawyers. West Publishing Co., St. Paul, Minn.

Ford Foundation Energy Policy Project. 1975. A Time to Choose. Ballinger, Cambridge, Mass.

Franklin Institute for Local Self-Reliance. October 1978. The Great Adventure, A Report of the 10 Regional Public Hearings for the Domestic Policy Review. Prepared for the Office of Consumer Affairs, U.S. Department of Energy, Washington D.C.

"Freed Prices Hike Stripper Output, Save Wells." May 29, 1978. 0il and Gas Journal 76(22):40.

Freeman, Nyrick, and Robert Havemen. 1972. "Clean Rhetoric and Dirty Water." The Public Interest 28:51-65.

Gaston, J. F. 1961. Growth Patterns in Industry: A Reexamination. The Conference Board, New York, N.Y.

General Accounting Office. June 3, 1977. Government Regulatory Activity: Justifications Processes, Impacts, and Alternatives. U.S. Government Printing Office, Washington, D.C.

General Accounting Office, U.S. Comptroller General. February 1973. Revenues and Costs Allocated to Power Operations of Multi-Purpose Projects in the Southwestern Federal Power System. U.S. Government Printing Office, Washington, D.C. 
General Accounting Office, U.S. Comptroller General. November 1978. Electric Energy Options Hold Great Promise for the Tennessee Valley Authority. EMD 78-91, U.S. Government Printing Office, Washington, D.C.

Glennan, T. K., Jr. 1972. "Evaluating Federal Manpower Programs." In Evaluating Social Programs: Theory, Practice, Politics, Peter H. Rossi and Watter Williams (eds.). Seminar Press, New York, N.Y.

Goldfarb, R. S. 1975. "Learning in Government Programs and the Usefulness of Cost-Benefit Analysis." Policy Sciences 6(3):281-299.

Gordian Associates. January 1978. Small Refiner Bias Analysis. NTIS-No. $\mathrm{HCP} / \mathrm{B} / 70258-01$, U.S. Department of Energy, Washington, D.C.

Griffin, J. M. 1974. "The Effects of Higher Prices on Electricity Consumption." Bell Journal of Economics 5(2):515-539.

Gulf $0 i 1$ Corporation. January 1977. The Gulf Energy Model: An Overview. Management Sciences Group, Gulf $0 i l$ Corporation, Pittsburgh, Penn.

Gulf $0 i 1$ Corporation. April 13, 1977. Gulf Energy Model: Base Case. U.S. Energy Analysis Task Group, Gulf 0il Corporation, Pittsburgh, Penn.

Gulf States Utilities Co. vs. Federal Power Commission. 411 U.S. 747. (1973).

Guttenberg, Marcia. 1971. "Models and Methods in Evaluating Research." Journal of Theory and Social Behavior 10:75-95.

Harrar, William S., and D. Lee Bawden. 1972. "The Use of Experimentation in Policy Formulation and Evaluation." Urban Affairs Quarterly $7(4): 419-430$.

Haveman, Robert H., and Burton A. Weisbrod. 1970. "Defining Benefits of Public Programs: Some Guidance for Policy Analyst." In Public Expenditure and Policy Analysis, 2nd Edition, Robert H. Haveman and Julius Margolis (eds.). Rand McNaT1y, Chicago, I11.

Helms, R. B. 1974. Natural Gas Regulation. American Enterprise Institute for Public Policy Research, Washington, D.C.

Hoffman, K. C., and D. W. Jorgenson. 1977. "Economics and Technological Models for Evaluation of Energy Policy." The Bell Journal of Economics $8(2): 444-466$.

Hogan, N. W., and S. C. Parikh. February 1977. Comparision of Models of Energy and the Economy. Working Paper 1.4, Energy Modeling Forum, Stanford University, Stanford, Calif.

Houston, Tom R., Jr. 1972. "The Behavioral Sciences Impact--Effectiveness Model." In Evaluating Social Programs: Theory, Practice, and Politics, Peter H. Rossi and Walter Williams (eds.). Academic Press, New York, N.Y. 
Hudson, E. A., and D. W. Jorgenson. 1974. "U.S. Energy Policy and Economic Growth, 1975-2000." Bell Journal of Economics 5(2):461-514.

Hudson, E. A., and D. W. Jorgenson. 1976. "Tax Policy and Energy Conservation." In Econometric Studies of U.S. Policy, D. W. Jorgenson (ed.), North Holland, Amsterdam, Nether lands.

Huey, John. July 7, 1978. "Antitrust Investigation Could Reshape Makers of Offshore-0il Gear." Wall Street Journal. p. 1.

Humpherey, Hubert H. 1975. "Planning Economic Policy," Challenge 18(1):22.

ICF, Inc. October 1976. The National Coal Model: Description and Documentation, NTIS: PB-263 334, Prepared for the Federal Energy Administration, Washington, D.C.

Jacob, Herbert. 1972. "Contact with Government Agencies: A Preliminary Analysis of the Distribution of Government Services." Midwest Journal of Political Science 16(1):123-146

Jeckovich, Stephen. 1973. "Managerial Planning Beyond Statistical Forecasting." In A Guide to Practical Technological Forecasting, eds. James R. Bright and Milton E. F. Schoeman, pp. 13-25. Prentice-HalT Inc., Englewood Cliffs, N.J.

Johnston, J. 1972. Econometric Methods, 2nd Edition. McGraw-Hi11, New York, N.Y.

Jones, Bryan. 1977. "Distributional Considerations in Models of Government Service Provision." Urban Affairs Quarterly 12(3):291-312.

Joskow, P. L., and M. L. Baughman. 1976. "The Future of the U.S. Nuclear Industry." Bell Journal of Economics 7(1):3-32.

Kamrany, N. M. 1974. "Technology - Measuring Socioeconomic Impact of Manufacturing Automation." Socio-Economic Planning Sciences 8(5):281-292.

Kennedy, M. 1974. "An Economic Model of the Wor ld 0il Market." Bell Journal of Economics $5(2): 540-577$.

Khazzoom, J. D. 1971. "The FPC Staff's Econometric Model of Natural Gas Supply in the United States. "Bell Journal of Economics 2(1):51-93.

Khazzoom, J. D. (ed.). January 1976. Proceedings of the Workshop on Modeling the Interrelationship Between the Energy Sector and the General Economy. Electric Power Research Institute, Palo Alto, Calif.

Klarman, Herbert E. 1965. "Syphilis Control Programs." In Measuring Benefits of Government Investments, Robert Dorfman (ed.). The Brookings Institution, Washington, D.C. 
Kraenze1, C. F. 1957. "The Social Consequences of River Basin Development." Law and Contemporary Social Problems 22(2):221-236.

Kuburski, A. A. 1974. "Evaluating Economic Impact of Government Expenditures by Department, An Application of Input - Output Analysis." Socio-Economic Planning Sciences 8(2):101-108.

Kuznets, Simon S. 1930. Secular Movements on Production and Prices. Houghton Mifflin, New York, N.Y.

Kvasha, I. 1975. "Measuring Effectiveness of Social Production." Problems of Economics $17(11): 79-99$.

Lehne, R., and D. M. Fisk. 1974. "Impact of Urban Policy Analysis." Urban Affairs Quarterly 10(2):115.

Lucas, William A. 1974. The Case Survey: Aggregating Cast Experience. R1515-RC, The Rand Corporation, Santa Monica, Calif.

Luft, Harold S. 1976. "Benefit Cost Analysis and Public Policy Implementation: From Normative to Positive Analysis." Public Policy 24(4):437-462.

MacAvoy, Paul. 1970. "The Effectiveness of the Federal Power Commission." Bell Journal of Economics 1(2):271-303.

MacAvoy, P. W., and R. S. Pindyck. 1975. The Economics of the Natural Gas Shortage (1960-1980). North Holland, Amsterdam, Netherlands.

Mack, Ruth P., and Sumner Myers. 1965. "Outdoor Recreation." In Measuring Benefits of Government Investment, Robert Dorfman (ed.). The Brookings Institution, Washington, D.C.

Manne, A. S. 1976. "ETA: A Model for Energy Technology Assessment." Bell Journal of Economics $7(2): 379-406$.

Manne, A. S. December 1977. ETA-MACRO: A Growth Model of Energy-Economic Interactions. Prepared by the Department of Operations Research, Stanford University, Stanford, Calif., for the Electric Power Research Institute, Palo Alto, Calif.

Margolis, Julius, (ed.). 1970. The Analys is of Policy Output. Columbia University Press, New York, N.Y.

Mathematica, Inc. February 1977. A Comparative State-of-the-Art Assessment of Gas Supply Modeling. Prepared for the Electric Power Research Institute, Palo Alto, Calif.

Mathematical Sciences Northwest, Inc. 1977. Energy Demand Modeling and Forecasting. Northwest Energy Policy Project, Bellevue, Wash. 
Maurizi, Alex R. November 30, 1978. A Suggested Method for Estimating Past and Future Effects of Future Energy Incentives. BatteTTe, Human Affairs Research Centers, Seattle, wash.

McDonald, S. L. May 1974. "Incentives Policy and Supplies of Energy Sources." American Journal of Agricultural Economics 56(22):397.

McNown, Robert. 1974. "The Impact of Currency Depreciation and International Markets on U.S. Inflation." Quarterly Review of Economics and Business $15(4): 7-14$.

Miliken, J. Gordon, Dean C. Coddington, Reuben A. Zubrow, and Lucy B. Creighton. January 1972. Design of a Method for Estimating Federal Internal Revenues Generated by Economic Impact of Reclamation Projects. Prepared by the University of Denver Research Institute for the U.S. Bureau of Reclamation.

Mintz, Ilse. 1973. U.S. Import Quotas: Costs and Consequences. American Enterprise Institute, Washington, D.C.

Mitche11, R. B. 1977. "Scenario Generation--Limitations and Development in Cross-Impact Analysis." Futures 9(3):205-215.

MIT Energy Laboratory Policy Study Group. 1974. Energy Self-Sufficiency: An Economic Evaluation. Prepared for the American Enterprise Institute for Public Policy Research, Washington, D.C.

Morgan, R. December 1976. Phantom Taxes in Your Electric Bill. The Environmental Action Foundation, Washington, D.C.

Mosteller, Fredrick. 1977. "Assessing Unknown Numbers: Order of Magnitude Estimation." In Statistics and Public Policy, William B. Fairley and Frederick Mosteller (eds.). Addison-Wesley, Reading, Mass.

Mount, T. D., L. D. Chapman, and T. J. Ture11. June 1973. Electicity Demand in the United States. Oak Ridge National Laboratory, Oak Ridge, Tenn.

Murphy, Jerome. 1971. "Title I of ESEA: The Politics of Implementing Educational Reform." Harvard Educational Review 41(1):35-63.

Nash, C., D. Pearce, and J. Stanley. 1975. "Evaluation of Cost-Benefit Analysis Criteria." Scottish Journal Of Political Economy 22(2):121-134.

National Coal Association. 1973. Bituminous Coal Data 1972. National Coal Association, Washington, D.C.

National Coal Association. 1979. Coal Data 1977. National Coal Association, Washington, D.C. 
National Rural Utilities. 1975. Supplemental Financing for Rural Electrification. National Rural Utilities Cooperative Finance Corporation, Washington, D.C.

National Research Counci1. 1977. Implications of Environmental Regulations for Energy Production and Consumption, Volume VI. National Academy of Sciences, Washington D.C.

Newhauser, Duncan. 1971. "Elective Inguinal Herniorrhaphy versus Truss in the Elderly." In Costs, Benefits, and Risks of Surgery, Barnes B. Bunker and F. Mosteller (eds.). Oxford University Press, Oxford.

Northern Natural Gas Co. vs. Federal Power Commission. 399 F. 2nd, 959, D.C. Cir. (1968)

Oppenheimer, Bruce I. 1974. $0 i 1$ and the Congressional Process. Lexington Books, Lexington, Mass.

Otter Tail Power Co. vs. United States. 410 U.S. 366. (1973).

Packard, Karle S. 1973. "Impact of an Emerging Technology on Company Operations." In A Guide to Practical Technological Forecasting, eds. James R. Bright and Mitton E. F. Schoeman, pp. 301-314. Prentice-Hal1, Inc., Englewood Cliffs, N.J.

Peltzman, S. 1973. "An Evaluation of Consumer Protection Legis lation-1962 Drug Amendments." Journal of Political Economy 81(5):1049

Peterka, V. November 1977. Macrodynamics of Technological Change: Market Penetration by New Technologies. RR-77-22 International Institute for Applied Systems Analysis, Laxenburg, Austria.

Pi11, J. 1971. "The Delphi Method: Substance, Content, a Critique and An Annotated Bibiliography." Socio-Economic Planning Sciences 5(1):57-71.

Pindyck, R. S. 1978. "Higher Energy Prices and the Supply of Natural Gas." Energy System and Policy 2(2):177-209.

Portland General Electric, Co., Inc. 1978. 1977 Portland General Electric Company Annual Report. Portland General Electric Co., Inc., Portland, Ore.

Pressman, Jeffrey L., and Aaron Wi11davasky. 1973. Implementation. University of California Press, Berkeley, Calif.

Pri11, E. L. 1975. "Benefit Cost and Policy Analysis." Annals of Regional Science $9(3): 150-151$.

Rigby, Paul H. 1976. "Measuring Program Output." California Management Review 19(1):58-67. 
Rossi, Peter H. 1972. "Testing Success and Failure in Social Action." In Evaluating Social Programs: Theory, Practice, and Politics, Peter H. Rossi and Walter Williams, (eds.). Seminar Press, New York, N.Y.

Rothenberg, Jerome. 1965. "Urban Renewal Programs." In Measuring Benefits of Government Investments, Robert Dorfman (ed.). The Brookings Institution, Washington, D.C.

Rothschild, Michael L. 1979. "Marketing Communications in Nonbusiness Situations or Why It's so Hard to Sell Brotherhood Like Soap." Journal of Marketing 43(2):11-20.

Rural Electrification Administration, U.S. Department of Agriculture. 1974. REA Loans and Loan Guarantees for Rural Electric and Telephone Service. U.S. Government Printing Office, Washington, D.C.

Schwartz, Seymour J. 1975. "Distributional Impacts of Automotive Pollution Control Programs: A Model for Evaluation." Journal of Environmental Systems 5(3):185-200.

Sear 1, M. F. (ed.). 1974. Energy Modeling: Art, Science, Practice. John Hopkins University Press, Baltimore, Md.

Selznick, P. 1966. TVA and the Grass Roots. University of California Press, Berkeley, Calif.

Shields, M. A. 1975. "Social Impact Studies - Expository Analysis." Environment and Behavior 7(3):265-284.

Simon, William E. 1978. A Time for Truth. McGraw-Hill Book Company, Chicago, I11.

Singer, Max. 1971. "The Vitality of Mythical Numbers." The Public Interest (23):3-9, Spring 1971.

Smith, J. S. September 1976. "The Equal Credit Opportunity Act of 1974: A Cost-Benefit Analysis." Paper presented at the Annual Meeting of the American Finance Association.

Sommers, Pau1. November 1978. Using Large Scale Energy Models to Estimate the Effects of Federal Energy Policies: A Survey of Model Capabilities. Battelle Human Affairs Research Centers, Seatt Te, Wash.

Sorensen, J. E., and H. D. Grove. 1977. "Cost Outcome and Cost/Effectiveness Analysis - Emerging Nonprofit Performance Evaluation Techniques." Accounting Review 52(3):658-675.

Southeastern Power Administration. December 1974. Southeastern Power Administration 1974 Annual Report. Department of the Interior, Washington, DC 20240. 
Southwestern Power Administration. June 1977. Southwestern Power Administration 1976 Annual Report. Department of the Interior, Tu1sa, OK 74101.

Spann, R. M., E. W. Erickson, and S. Millsaps. 1973. "Percentage Depletion and the Price and Output of Domestic Crude 0il." In Panel Discussion on General Tax Reform, U.S. Congress, House Committee on Ways and Means, 93rd Congress, U.S. Government Printing Office, Washington, D.C.

Stanford Energy Institute. July 1976. Stanford EPRI Workshop for Considering a Forum for the Analys is of Energy Options Through the Use of Models. Electric Power Research Institute, Palo ATto, Calif.

Strom, Gerald S. 1975. "Congressional Policy Making: A Test of Theory." Journal of Politics 37(3):711-735.

Suchman, Edward. 1967. Evaluative Research. Russell Sage, New York, N.Y.

Taylor, L. D. 1975. "The Demand for Electricity: A Survey." Bell Journal of Economics 6(1):74-110.

Tennessee Valley Authority. 1977. Annual Report 1977. Tennessee Valley Authority, Knoxville, Tenn.

Tennessee Valley Authority. 1950. "Power Contract between TVA and the City of Columbia, May 15, 1949." In Annual Report of the Tennessee Valley Authority, 1950. Tennessee Valley Authority, Knoxville, Tenn.

"The 500 Largest Industrial Corporations." May 7, 1979. Fortune, p. 270.

Thei1, H. 1971. Principles of Econometrics. John Wiley, New York, N.Y.

"The Utility Industry." June 1, 1974. Electrical World 181(11):44-48.

Turfte, Edward R., (ed.). 1970. The Quantitative Analys is of Social Problems. Addison-Wesley, New York, N.Y.

Tybout, R. A. 1958. Atomic Power and Energy Resource Planning. Monograph No. 94, Bureau of Business Research, Ohio State University, Columbus, Ohio.

U.S. Army Corps of Engineers. 1976. Pumped Storage in the Pacific Northwest. Report \#26. North Pacific Division, U. S. Army Corps of Engineers.

U.S. Army Corps of Engineers. July 1976. Hydropower: The Role of The Corps. EP 1165-2-3. U.S. Army Corps of Engineers Civil Works Directorate. Washington, DC 20006.

U.S. Congress, Joint Committee on Atomic Energy on Government Indemnity for Private Licenses and AEC Contractors Against Reactor Hazards. 1956. Hearings. 84 th Congress, Second Session, U.S. Government Printing Office. Washington, D.C. 
U.S. Congress, Joint Committee on Atomic Energy on Governmental Indemnity and Reactor Safety. 1957. Hearings. 85th Congress, First Session, U.S. Government Printing Office, Washington, D.C.

U.S. Senate, Commerce Committee. June 29, 1974. "FPC Oversight--Natural Gas Curtailment Priorities." Hearings. U.S. Government Printing Office, Washington, D.C.

U.S. Senate, Finance Committee. June 1974. Hearings.

U.S. vs. Philadelphia National Bank. 374 U.S. 321. (1963)

"Utility Programs Adequate for Power Demands. September 15, 1972. Electrical Wor 1d 178(6):65.

Washington Public Utility Districts Association. June 1, 1978. Laws of the Public Utility Districts State of Washington. Washington Public Utility Districts Association, Seattle, Wash.

Weisbrod, Burton A. 1965. "Preventing High School Dropouts." In Measuring Benefits of Government Investments, Robert Dorfman (ed.). The Brookings Institution, Washington, D.C.

Whelan, J. M. 1976. "Project Profile Reports Measure R\&D Effectiveness." Research Management 9(5):14-16.

Wholey, Joseph. 1972. "What Can We Actually Get From Program Evaluation." Policy Sciences 3(3):361-369.

Williams, J. A. 1969. "The Effects of Urban Renewal Upon a Black Community." Social Science Quarterly 50(3):703-712.

Williams, Larry J. March 1976. A Preliminary Forecast of Energy Consumption Through 1985. Electric Power Research Institute, Palo Alto, Calif.

Wilson, J. W. 1969. Residential and Industrial Demand for Electricity: An Empirical Analysis. Dissertation, Cornell University, University Microfilms, Ann Arbor, Mich.

Wilson, J. W., and Associates. February 1977. Elasticity of Demand: Topic 2. Electric Power Research Institute, Palo Alto, Calif.

Wolf, C. P. 1974. "Social Impact Assessment: The State of Art." In Social Impact Assessment, C.P. Wolf (ed.). Volume 2 of Man-Environment Interactions, Evaluations, and Applications Series. Environmental Design Research Association, Inc., Milwaukee, Wis.

Wonnacott, R. J., and T. H. Wonnacott. 1970. Econometrics. John Wiley, New York, N.Y. 
Yang, Y. Y. October 1976. "Temporal Stability of Residential Electricity Demand in the U.S." In Southern Economic Forecasting and Planning Report. California Energy Commission, Sacramento, Calif.

Yin, Robert K. 1975. "Using the Case Survey Method to Analyze Policy Studies." Administrative Science Quarterly 20(3):360-381.

Zimmerman, M. B. 1977. "Modeling Depletion in a Mineral Industry: The Case of Coal." Bell Journal of Economics 8(1):41-65. 


\section{DISTRIBUTION}

No. of

Copies

OFFSITE

A. A. Churm

DOE Chicago Patent Group

Department of Energy

Argonne, IL 60439

25 Roger Bezdek, Chief

Division of Conservation and

Solar Applications

Department of Energy

20 Massachusetts Avenue, NW

Washington, DC 20545

27 DOE Technical Information Center

Dr. Seymour Abrahamson

Professor of Genetics

University of Wisconsin

Madison, WI 53706

Raymond Anderson

Deputy Director

Office of Energy Management

and Conservation

Washington State Energy Office

1000 South Cherry Street

Olympia, WA 98504

Mr. Philip M. Arnold

P.0. Box 1457

Bartlesville, OK 74003

Dr. William Howard Arnold, Jr.

General Manager

Pressurized Water Reactor

Systems Division

Westinghouse Electric Corp.

Nuclear Center

P.0. Box 355

Pittsburgh, PA 15230
No. of

Copies

Dr. E. R. Ast ley

Exxon Nuclear Company, Inc.

777-106th Avenue NE (C-00777)

Bellevue, WA 98009

Mr. Charles F. Avila

Corporate Director

Retired Chairman of the Board

Boston Edison Company

272 Atlantic Avenue

Swampscott, MA 01907

Dr. Dale F. Babcock

711 River Road

Wilmington, DE 19809

Mr. William H. Babcock

Director of Policy and Economic Analysis for PRC Energy

Analysis Company

7600 01d Springhouse Road

McLean, VA 22101

Mr. Eugene C. Bailey

Dolio and Metz, Ltd.

208 South LaSalle Street

Chicago, IL 60604

$\mathrm{Mr}$. Robert A. Baker, Sr.

285 Clinton Place

Hackensack, N.J. 07601

Dr. Thomas D. Barrow

Director and Senior VicePresident

Exxon Corporation

1251 Avenue of the Americas

New York, N.Y. 10020 
No. of

Copies

Dr. Roy H. Beaton

Vice President

Nuclear Energy Systems Division

General Electric Company

185 Curtner Avenue

San Jose, CA 95125

Mr. Stephen D. Bechte I, Jr. 50 Beale Street

P.0. Box 3965

San Francisco, CA 94119

Dr. Manson Benedict

Institute Professor Emeritus

Massachusetts Institute of

Technology

Room 24-109

Cambridge, MA 02139

Mr. Jack Benveniste

Senior Staff Scientist

The Aerospace Corporation

P.0. Box 92957

Los Angeles, CA 90009

Mr. Richard N. Bergstrom

Partner, Sargent \& Lundy

55 East Monroe

Chicago, IL 60603

Mr. Willi am D. Beverly

17778-41st Avenue, South

Seattle, WA 98124

Mr. Thomas E. Biery

Director Policy Analysis

Independent Petroleum Assn. of America

1101 16th Street, NW

Washington, DC, 20036

Mr. John E. Bigger

Solar Energy Program

Electric Power Research

Institute

3412 Hillview Avenue

Palo Alto, CA 94303
No. of

Copies

Mr. Douglas R. Boleyn, P.E.

Energy Management Consultant

17610 Springhill Place

Gladstone, OR 97027

Mr. Ken Bostock

Washington Energy Office

1000 South Cherry Street

Olympia, WA 98504

Mr. Harry E. Bovay

Bovay Engineers, Inc.

5009 Caroline

Houston, TX 77004

Professor Gerard M. Brannonall

Georgetown University

$140037 \mathrm{th}$, NW

Washington, DC 20057

Dr. Harvey Brooks

Harvard University

Aiken Computation Lab. 226

Cambridge, MA 02138

Dr. Allan Brosz

Science \& Public Policy Program

University of $\mathrm{Ok} 1$ ahoma

Norman, OK 73019

Mr. G. W. Brown

Solar Thermal Branch

Department of Energy

Washington, DC 20545

Mr. Howard Bucknell, III

P.0. Box 1508

East Hampton, NY 11937

Dr. L. P. Bupp

Vice-President, Research \& Technology

Exxon Nuclear Company, Inc. 777-106 th Avenue NE (C-00777) Bellevue, WA 98009 
No. of

Copies

Dr. David Bushne 11

9620 Hawick Lane

Kensington, MD 20795

Mr. Sheldon Butt

Solar Energy Industry Assn.

1001 Connecticut Ave., NW

Suite 800

Washington, DC 20036

Mr. Chris Byal

Public Interest Economics

1095 Market Street Suite 604

San Francisco, CA 94103

Mr. Jack Cadogan

Department of Energy (ETS)

600 E Street, NW

Washington, DC 20545

Dr. Albert Carnesale

Associate Director

Program for Science and

International Affairs

Harvard University

Cambridge, MA 02138

Dr. Meir Carraso, Manager

Energy Systems Integration

California Energy Resources

Conservation and Development

Commission

111 Howe Avenue

Sacramento, CA 95825

Ms. Esther Cassidy

Office of Congressional Affairs

12 th and Pennsylvania, NW

Washington, DC 20461

Dr. Duane Chapman

Department of Agricultural Economics

New York State College of

Agriculture \& Life Sciences

304 Warren Hall

Cornell University

Ithaca, N.Y. 14853
No. of

Copies

Dr. Abram Chayes

Harvard Law School

Cambridge, MA 02138

Mr. Walker L. Cisler, President

Overseas Advisory Assoc., Inc. 1300 Washington Boulevard Bldg. Detroit, MI 48226

Mr. Wilson Clark

Assistant to the Governor for Issues and Planning

California State Governor's Office

140010 th Street

Sacramento, CA 95814

Dr. Dayton H. Clewe 11

Senior Vice-President

Mobil 0 il Corporation

150 East 42nd Street

New York, NY 10017

Mr. V. R. Cooper

Electric Power Research Institute

$412 \mathrm{Hillview} \mathrm{Avenue}$

Palo Alto, CA 94304

Mr. Dennis R. Coste 110

Solar Energy Research Institute

1536 Cole Blvd.

Golden, CO 80401

Mr. Herbert Costner

Division of Social Sciences

National Science Foundation

1800 G Street, NW

Washington, DC 20006

Mr. Kenny Cousins

c/o Senator Paul Tsongas

Senate Office Building

Washington, DC 20515 
No. of

Copies

Dr. Floyd Culler, President

Electric Power Research Institute

412 Hillview Avenue

Palo Alto, CA 94304

Mr. Dick D'Amato

U.S. Congress

429 Cannon Office Building

Washington, DC 20515

Mr. W. Kenneth Davis

Vice-President

Bechtel Power Corporation

50 Beale Street P.0. Box 3965

San Francisco, CA 94119

Mr. Vincent DiCara

Office of Energy Resources

55 Capitol Street

Augusta, ME 04330

Mr. Raymond L. Dickeman

Battelle-Seatt le Research

Center (HARC)

4000 N.E. 41 st Street

Seatt le, WA 95105

Mr. Ronald Doctor, Commissioner

California Energy Resources

Development Commission

1111 Howe Avenue

Sacramento, CA 95825

Mr. Patrick Donnelly

Office of Public Affairs

Department of Energy

12 th and Pennsylvania Avenue

Washington, DC 20461

Dr. Paul Doty, Director

Program for Science and

International Affairs

Harvard University

Cambridge, MA 02138
No. of

Copies

Mr. Daniel Drayfus

Committee on Energy and National Resources

U.S. Senate

Dirkson Office Building

Washington, DC 20510

Dr. Thomas D. Duchesneau

University of Maine at Orono

Orono, ME 04473

Mr. James Easterling

Division of Conservation and

Solar Applications

Department of Energy

20 Massachusetts Avenue, NW

Washington, DC 20545

Dr. Merril Eisenbud

Institute of Environmental Medicine

New York University Medical

Centre

New York, NY 10016

$\mathrm{Mr}$. Harold Etherington

84 Lighthouse Drive

Jupiter, FL 33458

Dr. Barbara C. Farhar

Solar Energy Research Institute

1536 Cole Boulevard

Golden, CO 80401

Dr. Philip Farley

The Brookings Institution

1775 Massachusetts Avenue NW

Washington, DC 20036

Mr. John Fattorini

House Republican Caucus

Legislative Building

Olympia, WA 98504 
No. of

Copies

William Fenzel

U.S. General Accounting Office

Room A2-2200

Century 21 Building

Department of Energy

Washington, DC 20545

Dr. Harry Finger

General Electric Company

3135 Easton Turnpike

Fairfield, CT 06431

Dr. Silvio J. Flaim

Solar Energy Research Institute

1536 Cole Boulevard

Golden, CO 80401

Dr. Richard L. Garwin

IBM Corporation P.0. Box 218

Thomas J. Watson Research Center

Yorktown Heights, NY 10598

Mr. Michael W. Grainey, Esq.

Special Assistant to the

Director

Department of Energy

Salem, OR 97310

Ms. Jane Gravelle

Economic Division

Congressional Research Service

Library of Congress Main Building

lst Floor, West Side, Room 103

Washington, DC 20540

Dr. 0. H. Greager

2363 Harris Avenue

Richland, WA 99352

Dr. Harold P. Green

Professor of Law

The National Law Center

The George Washington University

720-20th Street, NW

Washington, DC 20006
No. of

Copies

Mr. Max Goldman

Texaco Inc. Suite 500

1050 17th Street, NW

Washington, DC 20036

Dr. Marvin Goldberger

Princeton University

Princeton, NJ 08540

Mr. William R. Gould

Executive Vice President

Southern California Edison Co.

2244 Walnut Grove Avenue

Rosemead, CA 91770

Mr. David Gushee

Congressional Research Service

Library of Congress

Washington, DC 20540

Mr. Martin Gutsten

Solar-Thermal Systems R\&D

Department of Energy

Washington, DC 20545

Mr. Michael L. Haider

Retired Chairman of the Board

Exxon Corporation, Room 1250

One Rockefeller Plaza

New York, NY 10020

Dr. Bruce Hannon

Associate Professor

Director, Energy Research Group

University of Illinois at Urbana-Champaign

Center for Advanced Computation

Urbana, IL 61801

Mr. James Hardcastle

Energy Research Digest

Dulles International Airport

P.0. Box 17162

Washington, DC 20005 
No. of

Copies

Mr. Harvey A. Harris

Attorney at Law

Stolar, Heitzmann \& Eder

515 Olive Street, Room 1700

St. Louis, M0 63101

Mr. Charles R. Hauer, Consultant

Planning Research Corp.

7600 01d Springhouse Road

McLean, VA 22101

Mr. George Hinman, Director

Environmental Research Center

Washington State University

Pullman, WA 99164

Mr. Allen Hirshberg

Booze-Allen-Hamilton Mgmt. Consultants

1025 Connecticut Ave., NW

Bethesda, MD 20014

Dr. Thomas F. Hogarty

Department of Economics

Virginia Polytechnic Institute and State University

Blacksburg, WA 24060

Dr. Barry Hyman

Program in Social Management of Technology

University of Washington, FS-15

Seattle, WA 98195

Mr. Robert T. Jaske

Nuclear Regulatory Commission

Office of State Programs

Washington, DC 20555

Ms. Lois M. Baird

Jet Propulsion Laboratory

California Institute of Technology

4800 0ak Grove Drive

Pasadena, CA 91103

ATTN: Library Tech. Operations \#1680
No. of

Copies

Mr. Terry Johnson

c/o Senator Hart

254 Russell Office Building

Washington, DC 20510

Mr. Wilfrid E. Johnson

P.0. Box 963

Richland, WA 99352

Mr. Robert Kalisch

Amer ican Gas Association

1515 Wilson Boulevard

Arlington, VA 22209

Mr. George Kaplan

Department of Energy

Solar-Central Receiver Branch

Washington, DC 20545

Mr. Elliott Katz

Aerospace Corporation

P.0. Box 92957

Los Angeles, CA 90009

Mr. Myron B. Katz

Northwest Energy Policy Project

Pacific Northwest Regional Commiss ion

1097 Lloyd Building

700 NE Multnomah Street

Portland, OR 97232

Dr. Carl Kaysen

School of Humanities and Social Sciences

Massachusetts Institute of Technology

Cambridge, MA 02139

Mr. Spurgeon M. Keeny, Jr. Director, Policy \& Program Development

The MITRE Corporation

1820 Dolly Madison Boulevard

McLean, VA 22101 
No. of

Copies

Mr. Frederick Koomanoff, Chief Environmental \& Resource Studies Branch

Department of Energy

Washington, DC 20545

Mr. Andrew Krantz

Division of Solar Energy

Department of Energy

Washington, DC 20545

Jan G. Laitos

Assistant Professor of Law University of Denver College of Law

200 W. 14th Avenue

Denver, CO 80204

Mr. James M. Landis 2701 Golden Rain Road, No. 5 Walnut Creek, CA 94595

Dr. Hans H. Landsberg, Co-Director Energy and Materials Division Resources for the Future 1755 Massachusetts Avenue NW Washington, DC 20036

Mr. Stephan Lanes

House Science Committee B-374 Rayburn Building

Washington, DC 20515

Ms. Susannah Lawrence

Non-Congressional Coordinator of Solar Thermal Branch

317 Pennsylvania Avenue SE

Washington, DC 20003

Dr. Steven Lawroski

Senior Chemical Engineer

Argonne National Laboratory

9700 South Cass Avenue

Argonne, IL 60439
No. of

Copies

Mr. William S. Lee

President \& Chief Operating Officer

Duke Power Company

P.0. Box 2178

Charlotte, NC 28242

Dr. Leon Lindberg, Professor

Department of Political Science

University of Wisconsin-Madison

1050 Bascom Hall

Madison, WI 53706

$\mathrm{Mr}$. Clarence $\mathrm{H}$. Linder

(winter) Lake House South

875 E. Camino Real

Boca Raton, FL 33432

(summer) Northwest Bay-Lake George Lakeshore Drive

Route 9N

Bolton Landing, NY 12814

Mr. John H. Lixhtblau

Petroleum Industry Research Foundation

122 E. 42nd Street

New York, NY 10017

Randi Lornel1

Solar Energy Research Institute

1536 Cole Boulevard

Golden, CO 80401

Dr. Gordon J. MacDonald

Dartmouth College

Hanover, NH 03755

Dr. Paul MacMurray

Exxon Nuclear Company, Inc.

777-106th Avenue NE (C-00777)

Bellevue, WA 98009

Mr. Bruce Macphee, Economist

Tennessee Valley Author ity

1340 Commerce Union Bank Bldg.

Chattanooga, TN 37401 
No. of

Copies

Dr. Edwin Mansfield

Wharton School

University of Pennsylvania

Philadelphia, PA 19174

Mr. Paul Maycock

Division of Solar Energy

Department of Energy

Washington, DC 20545

Mr. Mike McCabe

Environmental Study Conference

3334 House Annex 2

Congress of the United States

Washington, DC 20515

Mr. W. R. McCluney

Program Director

Florida Solar Energy Center

300 State Road 401

Cape Canaveral, FL 32920

Mr. Franc is K. McCune

1564 Danny Drive

Sarasota, FL 53580

Mr. Louis L. Meier, Jr.

American Society for

Chemical Engineers

1625 I Street, NW

Washington, DC 20006

Mr. Otto N. Miller

Standard 0 il Co. of California

555 Market Street, Suite 1624

San Francisco, CA 94105

Mr. John Mitchner

Mail Stop 4723

Sandia Laboratories

P.0. Box 5800

Alburquerque, NM 87185
No. of

Copies

Dr. Dade W. Moeller

Head, Department of Environmental Health Sciences

School of Public Health

Harvard University

Cambridge, MA 02115

Dr. Thomas Gail Moore

Department of Economy

Michigan State University

East Lansing, MI 48823

Dr. Earl Finbar Murphy

Ohio State University

College of Law

1659 North High Street

Columbus, $\mathrm{OH} 43210$

Mr. Theodore J. Nagel

Senior Executive Vice-President, System Planning

American Electric Power Service Corporation

2 Broadway

New York, NY 10004

Mr. John Nassikas, Attorney

Cox, Langford \& Brown

21 Dupont Circle, NW

Washington, DC 20035

Dr. Joseph S. Nye, Jr.

Professor of Government

Center for International Affairs

Harvard University

Cambridge, MA 02138

Dr. E. E. O'Rourke

Atomic Power Division

General Electric Company

175 Curtner Avenue

San Jose, CA 95125 
No. of

Copies

Dr. Wolfgang K. H. Panofsky

Director

Stanford Linear Accelerator

Center

Palo Alto, CA 94305

Mr. George Patton

American Petroleum Institute

21 st and L Street

Washington, DC 20036

Mr. George R. Perrine

Legal Consultant

Tenneco Incorporated

Suite 4300-1100 Milan Bldg.

P.0. Box 2511

Houston, TX 77001

Mr. Robert Perry, Directore Systems Acquisition Management 1700 Main Street

Santa Monica, CA 90406

Mr. 0. P. Pitts

Tennessee Valley Authority

815 Power Building

Chattanooga, TN 37401

Ms. Penny Plamann

$K$ ansas Energy Office

503 Kansas Avenue

Topeka, KA 66603

Mr. Ron Quist

Senior Research Analyst

Second Floor

House Office Building

Olympia, WA 98504

Dr. Howard Raiffa

John F. Kennedy School of Government

Harvard University

Cambridge, MA 02138
No. of

Copies

Dr. George Rathjens

Professor of Political Science

Massachusetts Institute of

Technology

Cambridge, MA 02139

Dr. Don P. Reynolds

American Society of Chemical

Engineers

345 East 47 th Street

New York, NY 10017

Dr. Robert B. Richards

General Manager

Fast Breeder Reactor Department

General Electric Company

310 De Guigne Drive

Sunnyvale, CA 94086

Iraida B. Rickling, Librarian

Florida Solar Energy Center

300 State Road 401

Cape Canavera1, FL 32920

$\mathrm{Mr}$. Louis H. Roddis, Jr.

110 Broad Street

Charleston, SC 29401

Mr. Wade Rose

Governor's Office

1400 10th Street Room 108

Sacramento, CA 95814

Mr. Philip N. Ross

Genera 1 Delivery

Irvington, VA 22480

Mr. Paul Rothberg

Library of Congress

1st and Independence Ave., SE

Washington, DC 20540

Mr. Will H. Rowand

Babcock \& Wilcox Co. P.0. Box 6485

Litchfield Park, AR 85340 
Dr. Lester M. Salamon

Asst. Prof. of Political Science Duke University

Durham, NC 27706

Mr. Gerald Savitsky, Editor

Energy User News

7 East 12th Street

New York, NY 10003

Dr. John C. Sawhill, President

New York University

New York, NY 10003

Mr. Thomas Scanton

Rural Electrification Admin. Department of Agriculture 14th St. \& Independence Ave., SW Washington, DC 20250

Dr. Robert Scot

Campus Box 1126

Washington University

St. Louis, MO 63130

Ms. Meg Schachter

National Center for Economic Alternatives

2000 P Street, NW Suite 515

Washington, DC 20510

R. Scheidigar

NM Solar Energy Institute

Las Cruces, NM 88003

Dr. Thomas C. Schelling

Professor of Political

Economy

Harvard University

Cambridge, MA 02138

Dr. William D. Schulze

Department of Economics

New Mexico University

Albuquerque, NM 87185
Dr. Glenn Seaborg, Professor

University of California

Berkeley, CA 94704

Dr. John L. Siegfried

Assistant Professor, Economics

Vanderbilt University

Nashville, TN 37240

Mr. Calvin C. SiTverstein

Westinghouse Electric Corp. P.0. Box 10864

Pittsburgh, PA 15236

Mr. Michael Silverstein

President

Energy Marketing Associates

c/o Energy User News

7 East 12 th Street

New York, NY 10003

Dr. Jules M. Simmons

10 Radburn Court

Rockville, MD 20850

Mr. Gary D. Simon

California Energy Commission

1111 Howe Avenue

Sacramento, CA 95825

Mr. John W. Simpson

2055 Outlook Drive

Pittsburgh, PA 15241

Mr. Joey Skaff

Department of Energy Library Room 1223

20 Massachusetts Avenue, NW

Washington, DC 20545

Mr. Daniel L. Skoler

Program Development Counsel

American Bar Association

1800 M Street, NW

Washington, DC 20036 
No. of

Copies

Dr. Thomas Sparrow

Purdue University

West Lafayette, IN 41906

Mr. Robert Spongberg

Solar Energy Research Institute

1536 Cole Boulevard

Golden, CO 80303

Dr. Lombard Squires

939 Nelsons Walk

Naples, FL 33940

Mr. Alan Starr

Economics Regulatory Admin. Office of Utilities Systems

U.S. Department of Energy

20 Massachusetts Avenue NW

Washington, DC 20545

Mr. Eugene Starr

Bonneville Power Administration

P. 0. Box 3621

Portland, OR 97208

Mr. Bob Stewart

Department of Energy

Richland, WA 99352

Mr. John E. Swearingen

Chairman of the Board

Standard $0 i 1$ Company

200 East Randolph Drive

Chicago, IL 60601

Mr. Ronald W. Szwajkowski

Mayer, Brown and Platt

231 South LaSalle Street

Chicago, IL 60604

Mr. William A. Thomas

American Bar Foundation

1155 East 60th Street

Chicago, Il 60637
No. of

Copies

Chand ler Thompson

New Mexico Solar Energy Institute

P.0. Box 3 SOL

Las Cruces, NM 88003

Dr. Arthur Upton

Professor of Pathology

State University of New York

Stony Brook, NY 11790

Mr. Jon Veigel

Solar Energy Research Institute 1536 Cole Boulevard

Golden, CO 80303

A. Verrips

American Public Gas Assn.

301 Maple Ave., West

Section 4, Suite $G$

Vienna, VA 22180

Mr. Robert L. Vines

Bituminous Coal Operators

Association, Inc.

World Center Building

Washington, DC 20036

Mr. Aubrey J. Wagner

Chairman, Board of Directors

Tennessee Valley Authority

E12A7 East Tower Commercial

Realty Management Building

Knoxville, TN 37902

Dr. Haskell P. Wald

Chief Economist

Federal Power Commission

Washington, DC 20426

Mr. Edward W. Ware III

American Gas Association

1515 Wilson Boulevard

Arlington, VA 22209 
No. of

Copies

Dr. Richard $H$. Watson

Social Management of Technology

University of Washington FS-15

Seattle, WA 98195

Professor G. W. Watt

University of Texas

Austin, TX 78705

Dr. Alvin M. Weinberg, Director Institute of Energy/Analysis P.0. Box 117

Oak Ridge, TN 37830

Mr. G. 0. Wessenauer

2931 Nurich Drive

Chattanooga, TN 37415

Professor Gary Widman

Hastings College of Law

198 McAllister St.

San Francisco, CA 94102

Senator Al Williams

4801 Fremont, North

Seattle, WA 98103

Mr. Rocky Wilson, Co-Editor

The Times Journal

P.0. Box 746

Condon, OR 97823

Dr. Bertram Wolfe

Atomic Power Division

General Electric Company

175 Curtner Avenue

San Jose, CA 95125

Dr. James F. Young, Vice President

Technical Resources

General Electric Company

3135 Easton Turnpike

Fairfield, CT 06431
No. of

Copies

\author{
Dr. E. L. Zebroski \\ Department Director \\ Electric Power Research \\ Institute \\ 412 Hillview Avenue \\ Palo Alto, CA 94304 \\ Dr. Walter H. Zinn \\ 2940 Bay Meadow Court \\ Clearwater, FL 33519
}

\section{FOREIGN}

Mr. Roger W. Gryenton

956 East 16th Avenue

Vancouver, BC V5T2V9

CANADA

Dr. Monroe E. Spaght, Director Royal Dutch/She 11 Companies

She 11 Centre

London, SEI 7NA

ENGLAND

ONSITE

DOE Richland Operations office Programs Division

H. E. Ransom

127 Pacific Northwest Laboratory

F. Albaugh

D. Brenchley

R. Cole (HARC) (20)

B. Cone (50)

D. Deonigi

K. Drumhe 11er (5)

J. Emery (10)

A. Fassbender (10)

J. Fox

J. Goodnight (HARC)

H. Harty (10)

D. Lenerz (Columbus) (5)

A. Marcus (HARC)

J. Maxwe 11 (HARC) 
No. of

Copies

R. Mazzucchi (5)

H. Parker

W. Sheppard (Columbus) (20)

P. Sommers (HARC)

R. Watts

L. Williams

Economics Library (3)

Technical Information (5)

Publishing Coordination RO (3)

Distr-13 
